\title{
Ibn Battûta
}

\section{Voyages}

\section{De La Mecque aux steppes russes}

\author{
Traduction de l'arabe de C. Defremery \\ et B.R. Sanguinetti (1858)
}

Introduction et notes de Stéphane Yérasimos

François Maspero, Paris 1982

Collection FM/La Découverte

Un document produit en version numérique par Jean-Marc Simonet, bénévole, professeur retraité de l'enseignement de l'Université de Paris XI-Orsay Courriel: jmsimonet@wanadoo.fr

Dans le cadre de la collection: "Les classiques des sciences sociales" Site web: http://classiques.uqac.ca/

Une collection développée en collaboration avec la Bibliothèque Paul-Émile-Boulet de l'Université du Québec à Chicoutimi

Site web: http://bibliotheque.uqac.ca/ 
Cette édition électronique a été réalisée par Jean-Marc Simonet, ancien professeur des Universités, bénévole.

Courriel: jmsimonet@wanadoo.fr

À partir du livre de

\begin{tabular}{|c|c|}
\hline Ibn Battûta \\
Voyages \\
II. De La Mecque aux steppes russes \\
Ibn Battûta \\
Voyages \\
II. De La Mecque aux steppes russes \\
Traduction de l'arabe de C. Defremery et \\
B.R. Sanguinetti (1858) \\
Introduction et notes \\
de Stéphane Yerasimos \\
Cartes de Catherine Barthel \\
Collection FM/La Découverte \\
Librairie François Maspero, Paris, 1982, \\
480 pages.
\end{tabular}

Polices de caractères utilisées :

Pour le texte: Times New Roman, 14 et 12 points.

Pour les notes de bas de page : Times New Roman, 10 points.

Édition électronique réalisée avec le traitement de textes Microsoft Word 2004 pour Macintosh.

Mise en page sur papier format : LETTRE (US letter), 8.5'” x 11')

Édition numérique réalisée le 12 février 2008 à Chicoutimi, Ville de Saguenay, province de Québec, Canada.

\section{Fait avec}




\section{Table des matières}

Volume II. — De La Mecque aux steppes russes et à l'Inde

Introduction

L’océan Indien et le golfe Persique ; — L’Asie Mineure ; - La Russie mé$\underline{\text { ridionale et Constantinople ; - L'Asie centrale ; - L'Inde (première }}$ partie).

1. L'océan Indien et le golfe Persique

2. L'Asie Mineure

3. La Russie méridionale

4. L'Asie centrale

$\underline{5 .}$ Le voyage à Dihli

6. L'histoire du sultanat de Dihli

$\underline{\text { 7. Le bon et le mauvais gouvernement de Muhammad bin Tughluk }}$

Bibliographie 


\section{Introduction}

Retour à la Table des Matières

Le premier volume des Voyages d'Ibn Battûta dans cette édition correspond à la partie du récit traitant des terres centrales de l'islam avec pour objectif et aboutissement le pèlerinage à La Mecque ; ce volume possède ainsi une autonomie relative. Par contre, les deux volumes qui suivent ne seront qu'artificiellement séparés, puisqu'ils concernent l'un et l'autre le domaine islamique périphérique, avec seulement quelques excursions notables au-delà. De même, une introduction générale étant présentée au début du premier volume, les introductions aux deuxième et troisième volumes tenteront uniquement de compléter les informations données dans les notes et d'aborder un certain nombre de problèmes soulevés par le texte.

\section{L’OCÉAN INDIEN ET LE GOLFE PERSIQUE}

Retour à la Table des Matières

Quand Ibn Battûta quitte La Mecque en septembre 1330 pour descendre vers le sud, il se trouve, en quelque sorte, au milieu de son parcours. Il a accompli son voyage initiatique et sanctificateur, mais il n'a pas encore entrepris celui qui lui permettra de cueillir les fruits de cette sanctification. Aussi les raisons de ce circuit intermédiaire, qui sera encore bouclé sur La Mecque par le pèlerinage de 1332, restent obscures. Ce n'est pas un itinéraire parsemé de visites de saints p005 personnages, morts ou vivants, ni de rencontres de souverains avides de nouvelles, profanes ou sacrées, sortant de la bouche d'un saint pèlerin. Il s'agit de rivages, directs ou indirects, de l'océan Indien avec leur grand commerce d'or, d'ivoire et d'esclaves. Or, bien que ne dédaignant pas les biens de ce monde, notre voyageur ne semble pas avoir exercé d'activité commerciale, et son horreur de la mer transparaît à chaque occasion. Ce serait donc un parcours où la passion du 
voyage se manifeste à l'état pur ? Et pourquoi pas ? Ainsi Ibn Battûta n'annonce pas ses intentions au début de cet itinéraire. Il semble se laisser aller au fil du hasard et des moussons.

La mer Rouge, trait d'union, à l'époque, entre le commerce méditerranéen et celui de l'océan Indien, est contrôlée par les mameluks d'Égypte, mais ces derniers semblent déléguer, de gré ou de force, leur pouvoir à la famille des émirs de La Mecque, lesquels maintiennent à leur tour l'équilibre entre les maîtres de l'Égypte et ceux du Yémen, les Rasulides. Ibn Battûta rencontre ainsi un fils d'Abu Numayy, le Mecquois, établi à Sawakin, sur le littoral soudanais et va, par la suite, faire sa cour chez le sultan du Yémen.

Le Yémen, par sa situation géopolitique — refuges des hauts plateaux face aux plaines périodiquement envahies des tribus du Sud réfractaires à un islam mecquois et médinois —, fut mêlé à une bonne partie des péripéties sociopolitiques de l'islam. Un imamat zaydite (pour l'ensemble des références religieuses, se reporter à l'introduction du premier volume) se retranche solidement sur les plateaux, tandis que, dans la plaine, des sunnites, des shi'ites, des karmates ou des kharidjites se succèdent jusqu'à ce que Saladin, glaive de l'orthodoxie musulmane, entreprenne de rétablir le sunnisme dans les terres hérétiques de l'islam. Comme, en même temps, un empire syroégyptien a besoin de contrôler le Yémen, la mise au pas politicoreligieuse s'étend, avec l'arrivée ${ }_{\text {p006 }}$ d'une armée ayyubide sous la direction de Turanshah, frère de Saladin, également à cette province — du moins à ses plaines. Parmi les dignitaires de cette armée figure un Turkmène nommé Muhammad bin Hasan, originaire de l'Asie Mineure et utilisé par le calife abbasside al-Mustenfid (1160-1170) dans un certain nombre de missions d'où il tirera le surnom aussi vague que ronflant de Rasul (Envoyé). Au cours du demi-siècle de règne de la branche ayyubide du Yémen, les descendants du Rasul s'y implantèrent fortement, jusqu'à ce qu'un de ses petits-fils, Nur al-din Omar, proclame son indépendance vers l'année 1230. Lui et ses descendants auront à lutter contre les imams zaydites des hauts plateaux, contre les tribus, les contingents mameluks locaux et aussi contre les prétendants de la famille. Ainsi, lorsque le cinquième souverain de la dynastie et arrière petit-fils de Nur al-din Omar, Mudjahid Nur al-din, arrive au pouvoir en 1321, il devient pratiquement roi sans royaume.Les membres de la famille déclarent leur indépendance un peu partout, les ma- 
meluks se révoltent, l'imam zaydite attaque et l'Égypte, profitant de tout cela, envoie des troupes de conquête. La situation est loin d'être calmée lorsque Ibn Battûta traverse, en deux mois, novembredécembre 1330, le Yémen du nord au sud, en faisant une longue et rapide excursion à San'a, sur les hauts plateaux, avant d'aboutir à Aden vers le début du mois de janvier 1331. Dans cette partie du récit, l'image de l'unité idyllique de l'islam semble encore prévaloir sur les réalités. Mais il est bien possible aussi que les séries d'événements violents et remarquables qui remplissent les chroniques, compte tenu du fait que les chroniques n’ont pour objet que de répertorier ces événements, soient loin d'épuiser le calme et la continuité de la vie quotidienne qui constituent l'immense océan paisible dans la vie d'un peuple agité périodiquement d'orages passagers ; et c'est cette mer que notre voyageur traverse en recevant seulement quelques échos des troubles passés ou à venir et qu'il ne juge pas toujours dignes d'être mentionnés dans un récit ${ }_{p 007}$ de voyage. Il faut également signaler que dans cet itinéraire l'excursion de San'a, bien que matériellement possible, peut paraître suspecte par la pauvreté de l'information que renferme le récit.

Aden, le verrou méridional de la mer Rouge, reste un port aussi riche que convoité sur le chemin du grand commerce oriental. Les Portugais s'y intéresseront vivement dès le début du XVI ${ }^{e}$ siècle, et avant les Ottomans et les Anglais. C'est ainsi qu'on possède une description portugaise de la ville, écrite avant 1515 par Tomé Pirès, premier ambassadeur européen en Chine, qui fixe, par son récit, les points d'intérêt de l'expansion portugaise.

Le pendant d'Aden sur la côte africaine est Zaïla, port de transit mais aussi débouché de l'arrière-pays éthiopien, aussi bien chrétien que musulman ; d'où une certaine imprécision dans les textes concernant son aire de mouvance politique. Les plateaux éthiopiens, traditionnellement chrétiens, voient émerger vers la fin du XIII ${ }^{\mathrm{e}}$ siècle une nouvelle dynastie, dite salomonienne, qui va consolider l'empire éthiopien pour les siècles à venir. Les basses terres, situées entre les plateaux et la mer, sont par contre des aires de pénétration musulmane où plusieurs unités évoluent lentement du statut de la fédération tribale vers celui de la royauté. Parmi celles-ci, le royaume d'Ifat émerge vers la fin du $\mathrm{XIII}^{\mathrm{e}}$ siècle comme rempart face à l'expansionnisme éthiopien. Un choc majeur se produit entre Amda 
Sion (1314-1344), le salomonien, et Hak al-din I ${ }^{\mathrm{er}}$ d'Ifat, et aboutit à la défaite et la mort de ce dernier. Ifat devient vassal des Éthiopiens et en 1332 une grande révolte est matée. A celle-ci participent d'autres petites formations musulmanes dont Adal, située plus près de la côte qui est souvent présentée comme contrôlant directement Zaïla. Le roi d'Adal est tué dans cette révolte de 1332 et ce n'est que plus tard, dans la deuxième moitié du XIV ${ }^{\mathrm{e}}$ siècle, qu'Adal remplace Ifat comme entité dominante de l'Éthiopie musulmane. Jusqu'à cette période, p008 Zaïla, forte de sa puissance économique, semble vivre politiquement en marge, sous la forme d'une fédération tribale. L'historien du XIV siècle Mufazzal raconte que le souverain du Yémen — probablement un Rasulide - , ayant voulu construire une mosquée à Zaïla pour faire dire la prière du vendredi en son nom, transporta en cette ville du matériel pour la construction et que les habitants le jetèrent à la mer, ce qui amena le souverain à décréter l'embargo sur les navires de Zaïla. Cette anecdote démontre l'indépendance, même relative, de Zaïla et son souci de la conserver. Par conséquent, on peut reconstituer la situation lors du passage d'Ibn Battûta de la façon suivante: à l'extrémité d'un arrière-pays soumis aux Éthiopiens où la révolte gronde, Zaïla conserve ses débouchés économiques et son indépendance politique. Toutefois, notre voyageur, qui ne débarque même pas, ne nous donne pas cette fois-ci d'indications sur le statut de la ville.

Le même système de fédération tribale régissait, jusqu'à la fin du XIII ${ }^{\mathrm{e}}$ siècle, la ville de Mogadiscio, comptoir fondé vers le $\mathrm{X}^{\mathrm{e}}$ siècle par les Arabes et étape suivante d'Ibn Battûta. L'évolution de la structure du pouvoir dans l'actuelle capitale de la Somalie est caractéristique de la colonisation arabe dans l'océan Indien. Au début, les clans des tribus ayant participé à la colonisation fondent une fédération. Par la suite, la fonction du cadi, dont la prééminence se trouve à la base de la loi islamique, se détache. Parallèlement se concentrent entre les mains d'un clan fortune et puissance. La fonction du cadi finit ainsi par devenir héréditaire au sein d'un clan et une première cristallisation de pouvoir s’opère. C'est le cas de la tribu des Muqri à Mogadiscio. Enfin, dans des conditions mal connues pour cette ville, un personnage, ici Abu Bakr bin Fakhr al-Din, établit une dynastie. Ce fut vers la fin du XIII siècle, à l'issue d'un compromis avec les Muqri, qui gardèrent la fonction de cadi pour leur descendance. Les choses se p009 $_{\text {trouvent }}$ 
dans cet état lors du passage d'Ibn Battûta et le resteront probablement jusqu'au XVI ${ }^{\mathrm{e}}$ siècle.

Mogadiscio est le plus septentrional des grands comptoirs islamiques situés sous la corne d'Afrique. Plus loin, il y a Mombasa, Kilwa et Sofala, pour ne citer que les plus importants. Ils ont la même origine, un peu brouillée par la légende, et par le manque de sources. Ce sont des comptoirs fondés vers le $\mathrm{X}^{\mathrm{e}}$ siècle par des Arabes de l'Arabie du Sud ou des Iraniens du golfe Persique, souvent des hérétiques fuyant les persécutions, comme les zaydites. Ils constituent le départ d'un grand arc de cercle, qui va de Madagascar à Ceylan en longeant les côtes de l'Afrique, l'Arabie du Sud, le Makran, le Sind, le Gudjarat et la côte du Malabar. Les comptoirs de l'Afrique fournissent surtout de l'or, de l'ivoire et des esclaves, auxquels viennent s'ajouter l'ambre, l'encens et les chevaux de l'Arabie du Sud. Certaines de ces marchandises, notamment les esclaves et une partie de l'or, bifurquent, à partir de Zaïla ou de Qalhat, vers la mer Rouge ou le golfe Persique, à destination du Moyen-Orient. Le reste, notamment l'ivoire, continue vers l'Inde où il s'échange contre les épices et les étoffes qui remontent ainsi vers le nord, tandis que des vivres s'acheminent pour l'approvisionnement des comptoirs africains. Enfin, ces comptoirs connaîtront le même sort, balayés ou réduits à l’impuissance par la pénétration portugaise au début du XVI ${ }^{\mathrm{e}}$ siècle.

Les centres les plus importants sur le continent africain sont à l'époque Mogadiscio et Kilwa, et c'est là qu'Ibn Battûta s'arrête le plus longtemps. Les origines de Kilwa se perdent dans la légende, mais on peut parler d'une royauté beaucoup plus précoce que celle de Mogadiscio, appuyée peut-être sur une richesse plus importante, celle de l'or, et fondée par une dynastie shirazienne. Elle est remplacée par le clan des Mahduli, originaire du sud-ouest du Yémen et déjà installé sur place, dans la personne de Hasan bin Talut, qui p010 accéda au pouvoir vers 1227. Son petit-fils, Hasan bin Suleyman, est connu sous le nom d'Abu'l Mawahib, le Père des dons, pour la part qu'il réservait aux émirs de La Mecque sur le commerce des esclaves noirs, capturés par ses soins. Il régnait lors du passage d'Ibn Battûta et mourut peu après, en 1332. C'est son frère, Da'ud, auparavant gouverneur de Sofala, qui lui succéda. 
Avec Kilwa, notre auteur achève le tour de ce qui constituait l'Afrique orientale aux yeux du monde musulman de l'époque : une série d'îlots vivant de l'exploitation des richesses d'un continent hostile et inconnu. C'est ainsi que, pour les géographes arabes, les points extrêmes connus, au Soudan, en Éthiopie ou au Mozambique, semblent communiquer à travers des terres inconnues dont ils n'imaginent pas l'étendue. Pour Ibn Battûta, l'arrière-pays de Sofala et celui du Mali sont presque limitrophes, et on verra souvent cette conception se perpétuer chez les Européens, et jusqu’au XVIIe siècle.

Les moussons, soufflant vers le nord, ramènent Ibn Battûta vers les rivages de l'Arabie au printemps 1331. A cette époque, deux villes de sa côte méridionale participent au grand commerce : al-Shihr dans le Hadramawt, sur le territoire de l'actuelle République du Sud-Yémen, et Zhafar, aujourd'hui disparue, dans la province de Dhofar, au sudouest de l'actuel sultanat d'Oman. Marco Polo, bien que ne les ayant pas visitées, les mentionne toutes les deux, et qualifie al-Shihr de " grandissime cité ». Ibn Battûta ne visite toutefois que Zhafar, directement située sur l'arc de cercle de la navigation indo-africaine.

Un établissement commercial fut créé en cet endroit, probablement par des Persans qui se sont dispersés vers les mers, ouvertes après le déclin du golfe Persique. On signale, en 1145, un souverain d'une dynastie d'origine persane, établie à Mirbat, ville qui existe encore 011 aujourd'hui à proximité du site de Zhafar. Le pouvoir passe vers 1220 à une dynastie arabe originaire du Hadramawt, les Habudi. On ne connaît que le nom du premier souverain, Ahmad al-Habudi, qui détruisit Mirbat pour bâtir Zhafar, et celui du dernier, Salim bin Idris, qui fut dépossédé par les Rasulides du Yémen. A partir de cette époque, et jusqu'à la fin du $\mathrm{XIV}^{\mathrm{e}}$ siècle, la ville est gouvernée par une branche de la famille régnante yéménite.

La ville exporte, de l'encens et des chevaux, produits tous deux de l'arrière-pays. Ibn Battûta détaille ici les productions locales. Même s'il arrive encore à dénicher quelques tombeaux, comme celui du prophète coranique Hud dont il n'avait pas manqué de signaler une autre sépulture à Damas, il commence à s’intéresser de plus en plus aux biens de ce monde et même, au-delà de Zhafar, il fait place dans son récit à l'aventure, en nous contant les péripéties maritimes et terrestres de son trajet pour l'Oman. 
En contournant le Ras al-Hadd, la pointe la plus orientale de l'Arabie, notre voyageur pénètre dans l'aire du golfe Persique et, par là, dans le domaine du royaume d'Hormuz.

Après l'abandon du golfe Persique comme lieu de passage privilégié du commerce d'Orient et le déclin du califat abbasside, le littoral tombe aux mains des puissances voisines ou locales qui se partagent un commerce certes amenuisé, mais point négligeable. Le recul du grand commerce entraîne une série de conséquences et principalement le déclin des centres commerciaux de l'époque classique, notamment le quasi-abandon de Basra et la ruine progressive de Siraf après sa première destruction par un séisme, en 977. Les commerçants arabes et surtout persans se dispersent alors, soit dans d'autres points du Golfe, vers l'île de Qaïs ou Qatif sur le littoral arabe, soit sur le pourtour de la péninsule arabe jusqu'à Djedda et sur la côte de l'Est africain 012 y compris même jusqu'à Madagascar. L'affaiblissement de la police du Golfe entraîne la floraison des États dissidents sur la côte arabe : les karmates à Bahrein, les kharidjites ibadites à Oman qui s'adonnent très vite à la piraterie et portent ainsi un coup supplémentaire au commerce.

Ce vide, ainsi créé, va être occupé, dans un premier temps, par des puissances continentales qui s'avancent vers le Golfe. Une dynastie de Turcs Kara-Khitaï établie au Kirman et des vassaux des Grands Seldjukides, les atabeks Salghurides du Fars contrôlent respectivement le golfe d'Oman et le golfe Persique à l'est et à l'ouest du détroit d'Hormuz au début du XIII ${ }^{\mathrm{e}}$ siècle. Mais c'est précisément au centre, à Hormuz même, qu'une nouvelle puissance locale va naître. Au XIII siècle, les souverains d'Hormuz sont établis à l'emplacement de l'actuel Minab, sur le littoral persan, en face du détroit. Ils sont soumis au sultan de Kirman mais cette vassalité, ainsi qu'en témoigne Marco Polo, est toute relative : "Quand le sultan de Kirman veut imposer au melic de Curmos [Hormuz] des taxes extraordinaires, celui-ci prend la mer et empêche les marins des Indes de pénétrer dans le Golfe. Le sultan de Kirman en éprouve beaucoup de pertes ; les revenus de ses douanes diminuent, de sorte qu'il doit faire la paix sans exiger autant qu’il avait réclamé. »

L'arrivée des Mongols et l'établissement de l'empire ilkhanide en Iran profite doublement à Hormuz. D'une part, aussi bien les Salghu- 
rides que les Kara-Khitaï s’affaiblissent pour disparaître vers la fin du siècle ; d'autre part, la pax mongolica s'étend sur les mers et, après la conquête définitive de l'empire des Song par les Mongols de la Chine en 1279, des contacts par mer deviennent possibles ; or ceux-ci aboutissent au golfe Persique.

Le royaume d'Hormuz devait contrôler, dès ses p013 débuts, une partie de la côte arabe du golfe d'Oman, et notamment Qalhat, à l'entrée de ce golfe. C'est de là que viendra le fondateur d'une nouvelle dynastie, Mahmud Qalhati (1243-1277), auparavant gouverneur de cette ville. Celui-ci cherche à étendre son contrôle sur les cités du Golfe et des environs, et c'est de son époque que date une expédition sur Zhafar (1262), mentionnée par Ibn Battûta, mais aussi par les chroniques d'Oman.

La montée d'une nouvelle puissance dans le Golfe inquiète les grands des familles marchandes lesquelles établies à Shiraz ou dans l'île de Qaïs, avaient profité du vide politique pour s'enrichir. Parmi ces grands se distingue, vers la fin du XIII ${ }^{\mathrm{e}}$ siècle, Djamal al-din Ibrahim, dit al-Sawamili, qui obtient le quasi monopole du commerce avec la Chine. Après avoir réussi à nommer son frère vizir d'un souverain de l'Inde méridionale où les cargaisons des jonques chinoises étaient transbordées dans les navires arabes, il avait affermé aux Ilkhans l'ensemble des revenus du Fars. Ce personnage, qui finira par acheter l'île de Qaïs pour 200000 dinars or pour y fonder une dynastie éphémère de princes marchands, était naturellement opposé à l'extension du pouvoir d'Hormuz qui taxait les navires au passage. Ainsi, quand Saif al-din Nusrat, fils et successeur de Mahmud Qalhati, est assassiné en 1290 par son frère Rukn al-din Mas'ud, l'occasion d'un coup se présente. Un esclave turc affranchi, Baha al-din Ayaz, à l'époque gouverneur de Qalhat, est alors aidé par al-Sawamili dans son ascension au trône d'Hormuz. Ayaz conquiert ainsi le pouvoir en 1291, pour se brouiller rapidement, comme on pouvait s'y attendre, avec son protecteur qui se tourne cette fois-ci vers Rukn al-din Mas'ud, mais en vain. C'est à cette époque qu'Ayaz juge plus prudent de transférer sa capitale sur l'île d'Hormuz, endroit plus conforme à la vocation maritime du royaume.

Ayaz étant mort, ou disparu de la scène politique, en 1311, sa femme Bibi Maryam, que mentionne Ibn ${ }_{\text {p014 }}$ Battûta, se retire à Qal- 
hat où elle exerce le pouvoir au moins jusqu'en 1320, tandis que le royaume d'Hormuz retourne à la famille de Mahmud Qalhati en la personne d'Izz al-din Kurdanshah, fils de Rukn al-din Mas'ud. Celuici aura à lutter contre le fils d'al-Sawamili qui contrôle économiquement ou politiquement Qaïs, Bahrein, Qatif et Basra, et assiège Hormuz pendant trois ans. Comme la guerre porte préjudice au commerce, les marchands interviennent pour chercher un compromis, et la paix se fait, jusqu'à ce que la mort de Kurdanshah en 1317 brouille une nouvelle fois les cartes. Un fils, Burhan al-din, est écarté l'année suivante par un usurpateur, Shihab al-din Yusuf. C'est de nouveau à partir de Qalhat que la situation sera rétablie. Bibi Maryam aide deux autres fils de Kurdanshah, Nizam al-din Kayqubad et Qutb al-din Tehemten, à conquérir le pouvoir. C'est ce dernier qui monte sur le trône et règne jusqu'à sa mort en 1347. Allié au nouvel homme fort de Shiraz, Mahmud Shah Indju (voir préface du tome I), il étend sa puissance sur l'ensemble du golfe Persique en occupant Qaïs, Qatif et les côtes de Bahrein. Ibn Battûta le visite deux fois : en 1331 et en 1347, juste avant sa mort. C'est à son deuxième voyage qu'il apprend la révolte de son frère et de ses neveux, mais, ainsi qu'il nous a toujours habitués, il fournit toutes ses informations concernant Hormuz dans le récit de son premier voyage. Nizam al-din Kayqubad saisit Hormuz en 1344, mais il meurt l'année suivante, tandis que ses fils, soutenus par Abu Ishaq de Shiraz, continuent la lutte à partir de Qaïs. Ce n'est qu'après 1347 que le fils et successeur de Tehemten, Turanshah recouvre le domaine de son père en payant, au début, tribut à Abu Ishaq, puis, après la disparition de celui-ci, aux Muzaffarides. Ainsi, de suzerain en suzerain, le royaume d'Hormuz subsiste jusqu'à l'arrivée des Portugais. C'est Albuquerque qui mettra fin au royaume en amenant les deux derniers princes captifs à Lisbonne en 1507. p015

A l'époque du passage d'Ibn Battûta, Hormuz contrôle donc le littoral d'Oman, tandis que l'intérieur est soumis à une dynastie locale celle des Banu Nabhan, sur laquelle on ne connaît quasiment rien. L'Oman, place forte du kharidjisme ibadite, possédait, depuis le milieu du VIII siècle, une lignée d’imams électifs interrompue, à la fin du $\mathrm{IX}^{\mathrm{e}}$ siècle-début du $\mathrm{X}^{\mathrm{e}}$ siècle, par les Buwaihides, tuteurs du califat abbasside, soucieux de remettre de l'ordre dans le Golfe. Les Banu Nabhan apparaissent alors comme alliés locaux des buwaihides. Mais le pouvoir des imams reprendra et ne sera interrompu qu'en 1162 avec 
la prise du pouvoir par les Nabhan dans l'Oman continental. La lignée des imams reprend progressivement à partir du $\mathrm{XV}^{\mathrm{e}}$ siècle, et l'ère nabhanide sera considérée comme une parenthèse impie, malgré le fait que ces derniers étaient aussi kharidjites. Mais comment un imamat kharidjite pourrait être héréditaire ? Ainsi les chroniques d'Oman gomment soigneusement trois siècles d'histoire jusqu'à n'en laisser que deux ou trois souvenirs, dont le passage de Mahmud Qalhati, en 1262, en route pour l'expédition de Zhafar, et sa demande d'aide aux nabhanides, et une autre invasion en 1276. Par conséquent, les témoignages d'Ibn Battûta sont aussi uniques qu'incontrôlables.

Après Hormuz, Ibn Battûta passe en Perse pour visiter la région de Lar. Là, pour la première fois dans cet itinéraire depuis La Mecque, une préoccupation religieuse semble le guider la visite d'un saint personnage, parfaitement inconnu par ailleurs. Le nom de la ville et de la région de Lar est inconnu des géographes antérieurs à Ibn Battûta, mais une dynastie locale paraît se perpétuer depuis les temps préislamiques jusqu'à l'avènement des Safavides au $\mathrm{XVI}^{\mathrm{e}}$ siècle. On ne peut que constater que le nom du souverain cité par Ibn Battûta ne correspond pas à celui donné par les chroniques locales. D'ailleurs, à partir de cet endroit, le récit de notre voyageur se brouille au point que certains commentateurs (Hrbek) ont pensé qu'il s'agissait d'un itinéraire ${ }_{016}$ factice, composé de deux trajectoires différentes : celle de 1331-1332, allant directement de l'Oman au Bahrein, par voie de terre, à travers le littoral arabe, et celle de 1347, de Hormuz à Shiraz, en traversant le Lar. Effectivement, ce sont les traversées du Golfe qui posent le plus de problèmes. Ibn Battûta confond Siraf, détruite en 977 et abandonnée depuis, avec l'île de Qaïs, fief d'al-Sawamili et de ses descendants, conquise en 1331 par Tehemten. La description qu'il en donne convient aussi difficilement à l'un qu'à l'autre. Le récit de la pêche des perles, dont la période ne correspond pas à celle du passage d'Ibn Battûta, et dont la localisation se révèle impossible, semble être de seconde main et contient des passages fantastiques. La ville de Bahrein n'existe sans doute pas et les rochers de Kusair et d'Uwair ne sont pas des montagnes mais apparemment deux îlots dans le détroit d'Hormuz. Mais «Dieu seul sait!", comme disent les auteurs de l'époque.

Pour le reste, on a droit à quelques renseignements sur la côte de Bahrein et sur la ville de Qatif, traditionnellement shi'ite, sinon kar- 
mate, mais qui devait se trouver, à l'époque, sous la suzeraineté de Hormuz. Notre auteur arrivera, à travers l'Arabie, assez tôt à La Mecque pour participer au pèlerinage de 1332 avec station le $1^{\mathrm{er}}$ septembre à Arafat.

\section{L’ASIE Mineure}

Retour à la Table des Matières

Après avoir accompli, selon ses dires, ce sixième pèlerinage, Ibn Battûta annonce son intention de partir pour les Indes. Quelle est la raison de cette décision et, celle-ci ne pouvant se réaliser dans l'immédiat, pourquoi se retrouve-t-il en Asie Mineure ? On n'en sait rien, sauf que, peut-être fort de ses acquis religieux et savants, il semble se décider à s'aventurer plus loin, vers les nouvelles terres de l'islam afin de tenter sa chance. p017

Son départ de La Mecque nous introduit en même temps dans le plus grand problème chronologique de ce texte. Ibn Battûta date son départ du mois de septembre 1332 et son arrivée aux frontières de l'Inde, sur l'Indus, du 12 septembre 1333. Or les éléments chronologiques intermédiaires dont on dispose (fêtes, saisons, etc.) et la réalité du chemin parcouru à travers l'Asie Mineure, la Russie méridionale et l'Asie centrale indiquent clairement un itinéraire de trois années et non d'une seule. La question qui se pose par conséquent est la suivante : est-ce qu'il faut reculer de deux ans la date du départ de La Mecque ou avancer de deux ans celle de l'arrivée sur l'Indus ? La plupart des chercheurs ont adopté jusqu'ici la deuxième solution qui a principalement l'avantage de ne pas bouleverser la chronologie antérieure en réduisant, en fin de compte, le séjour à La Mecque, de 13271330, de trois ans à un an. Or, pour le séjour en Inde, on ne dispose de toute façon pas de chronologie précise et risquant d'être remise en cause. Cette solution a pour autre avantage de ne pas mettre en cause la parole de l'auteur en ramenant ainsi le problème à une simple erreur de recopiage : 1333 (733) à la place de 1335 (735); et enfin de "coller » avec presque tous les événements survenus en route, tous sauf un : la rencontre avec Tarmashirin, le souverain mongol de la Transoxiane, déposé et tué en 1334. Cette unique non concordance entre La Mecque et l'Indus peut s'arranger en reculant la date du départ de deux ans. Alors tous les événements collent, mais 
dans ce cas il faut soumettre à une révision drastique la chronologie antérieure à partir de 1328 et remettre en question la véracité de certains dires d'Ibn Battûta. Ce nouveau scénario, déjà abordé par Gibb, donnerait ceci :

Ibn Battûta rentre de son voyage en Irak et en Perse pour le pèlerinage de 1327 et passe l'année suivante à La Mecque jusqu'au pèlerinage de 1328. Ensuite, il part pour sa tournée dans l'océan Indien, laquelle a été avancée de deux ans, moins vingt et un jours, pour la ${ }_{\text {p018 }}$ concordance entre le calendrier solaire et le calendrier lunaire. Dans ce cas, il aurait menti en affirmant être resté à La Mecque pendant les années 1328 et 1329, et cela pourrait être appuyé par le fait qu'il ne cite pas de personnalités ayant accompli le pèlerinage en 1329. Pour le reste, il n'existe aucune visite ou rencontre dans l'océan Indien ou au sud de l'Arabie qui ne pourrait se placer en 1328-1329, avec tout de même une réserve sur les nouvelles de la mort en 1332 d'Abu'l Muwahib, le roi de Kilwa, qui dans ce cas n'auraient pas pu l'atteindre pendant le pèlerinage de 1332. Il faut maintenant penser qu'il a dû les apprendre en Inde ou au retour. Par contre, au-delà d'Oman, on devrait se rabattre sur un itinéraire direct Oman-Bahrein, en laissant de côté Hormuz et Lar pour la visite de 1347, afin de ramener notre voyageur le plus vite possible, fin décembre-début janvier 1330, à La Mecque, d'où il repartira aussitôt à travers Aidhab et la vallée du Nil, pour arriver au Caire à temps pour la fête de Malik Nasir, guéri de sa fracture du bras, le 25 mars 1330, puisque, dans cette hypothèse, le voyage d'Égypte de 1330 qui, dans l'introduction du premier volume, avait été placé entre les pèlerinages de 1329 et de 1330, ne peut ici se réaliser que dans ce contexte. Mais, une fois les dates requérant sa présence en Égypte " épuisées », c'est-à-dire après le 17 juin, on ne sait plus très bien quoi faire de lui. On devrait supposer qu'il traîne un peu. Il visite la partie est du delta qu'il n'avait probablement pas pu voir pendant son court passage de 1326, notamment Damiette, dont le gouverneur, Balban al-Muhsini, mentionné pour l'année 1326, mais en réalité nommé en 1329, était déjà mort en 1336, avant donc le passage d'Ibn Battûta en 1348. Il remonte ensuite vers la Syrie. Il va à Damas pour se marier, puisqu'au retour, en 1348, il se souviendra d'une épouse et de son enfant dont il aurait appris la naissance en Inde, et on peut alors supposer que, si ce mariage était antérieur aux séjours de La Mecque, il aurait appris la nouvelle dans cette ville. 
C'est un des arguments en faveur d'un passage en 1330, puisqu'en ${ }_{\mathrm{p} 019}$ 1332, il n'aurait pas eu le temps d'aller se marier à Damas. De plus, il ne mentionne pas cette ville dans son itinéraire de 1332. Il voit également à Tripoli le cadi Shams al-din al-Naqib transféré à Alep en cette même année 1330 (il meurt en 1345). Il n'aurait pas pu le rencontrer en 1326, année pour laquelle il le mentionne, puisqu'il n'est pas allé à cette date à Tripoli ni en 1332. De même à Alep, deux personnages cités pour l'année 1326, date où la ville n'a pas pu être visitée, Argun al-Dawadar, le gouverneur, et Badr al-din al-Zahra, sont morts respectivement en 1330 et 1331 . On peut ainsi ajouter cette ville à son itinéraire de 1330 et, à travers les étapes intermédiaires, placer une bonne partie de son voyage syrien sous cette année 1330. Ensuite on le retrouverait à Ladhikiya pour la fin de cette année, s'embarquant pour Alanya afin de reprendre l'itinéraire décrit avec une avance de deux ans moins vingt-deux jours, et rejoindre ainsi l'Indus en septembre 1333.

Tout cela est bien séduisant mais suppose qu'Ibn Battûta a menti aussi bien en ce qui concerne son séjour à La Mecque, séjour qu’il faudrait alors ramener de trois ans à un an, qu'au sujet des pèlerinages effectués, qui ne sont plus au nombre de 6 (7 avec celui de 1348) mais de 3 (4). Par conséquent, il faudrait aussi supposer que les événements relatés, concernant les pèlerinages de 1330 et 1332, qui par ailleurs correspondent aux faits, ne l'ont été que par ouï-dire. Cette hypothèse conduit en même temps à bâtir tout un itinéraire à travers l'Égypte et la Syrie, lequel peut, par ailleurs, exister indépendamment et se concilier avec un retour à La Mecque pour le pèlerinage de 1330, et conduit aussi à écourter celui du golfe Persique, en déplaçant l'excursion de l'océan Indien de deux ans, tout cela contre l'avis de l'auteur. C'est peut-être trop pour faire coïncider une rencontre. C'est pour cela que, tout en essayant d'indiquer cette possibilité, on a préféré s'en tenir, dans l'annotation et dans cette préface, à la chronologie traditionnelle (départ de La Mecque en septembre 1332), en attendant p020 que des éléments nouveaux puissent un jour éclaircir le mystère.

Notre auteur part donc de La Mecque en 1332, retraverse l'Égypte et la Syrie en visitant dans l'ordre Ghazza, Askalon, Ramla, Akka, Sur, Saïda, Beyrouth, Tripoli, Djabala et Ladhikiya, d'où il s'embarque pour l'Asie Mineure en 1332. Cette chronologie correspond au changement du gouverneur de Ladhikiya raconté pour 
l'année 1326, mais qui en réalité eut lieu en novembre 1332. L'auteur aurait été alors le témoin oculaire des événements, tandis que, dans l’hypothèse précédente, il ne les aurait appris qu'en 1348.

Avec l'Asie Mineure, Ibn Battûta aborde un des espaces nouveaux de l'islam, dont la conquête s'est faite en deux temps. Il arrive, lui, à l'époque où la seconde phase est en train de s'achever. La victoire des Seldjukides sur les Byzantins à Mantzikert, en 1071, leur avait ouvert le chemin de l'ensemble des territoires asiatiques de Byzance, et quelques années plus tard les Turcs se trouvaient aux portes de Constantinople, à Nicée. Mais, pendant la fin du XI ${ }^{\mathrm{e}}$ siècle, ce territoire avait été abandonné à lui-même, servant de débouché au trop-plein des tribus turkmènes qui arrivaient sans cesse d'Asie centrale vers le domaine iranien des Seldjukides, pour être transférées par eux, vers l'extrêmeouest de leurs possessions. Ce n'est qu'au début du XII ${ }^{\mathrm{e}}$ siècle, lorsque l'empire seldjukide commence à s'effondrer, qu'une branche de la famille régnante se met à organiser ces territoires de conquête pour former un État, celui des Seldjukides d'Anatolie. Or, entre-temps, les Byzantins avaient réussi à récupérer l'ouest et les zones côtières, du nord au sud de l'Asie Mineure. Ainsi l'État seldjukide commence sa carrière sur un territoire complètement enclavé. Ce n'est qu'au début du siècle suivant qu'Alauddin Kayqubad I ${ }^{\mathrm{er}}$ réussira à créer deux débouchés, vers la Méditerranée et vers la mer Noire, avec la conquête et la fortification de Sinop au nord et ${ }_{\mathrm{p} 021}$ d'Alanya au sud. A partir de ces points, un commerce important va se développer, et l'Asie Mineure se trouvera au centre des passages nord-sud et est-ouest des grandes routes. L'arrivée des Mongols va bouleverser encore une fois la situation. Elle est précédée d'une vague de tribus turkmènes, lesquelles fuient l'envahisseur en se réfugiant en Asie Mineure. Cette invasion déstabilise les structures déjà fragiles de l'État seldjukide ; les nouveaux arrivés sont finalement installés sur les marches, dans un demi-cercle allant de Sinop à Alanya par l'ouest, en face de Byzance. C'est ensuite l'arrivée des Mongols, la défaite des Seldjukides et leur vassalité face aux Ilkhans de la Perse jusqu'à la disparition progressive de leur État en 1308. Pendant cette période, les formations tribales se cristallisent sur les frontières sous forme de petits émirats et, tout en demeurant formellement soumises aux Seldjukides d'abord et aux Ilkhans ensuite, et ce jusqu'aux environs de 1335, elles entreprennent de nouvelles conquêtes. Ainsi débute une nouvelle avance du 
front islamique contre Byzance, en rayonnant à partir des possessions seldjukides et en ayant comme objectif la mer. Cet objectif est déjà atteint au cours des toutes premières années du XIV siècle. Arriver à la mer mettra un terme à l'expansion territoriale des émirats et leur expansion maritime, rapidement et courageusement entreprise, sera aussitôt bloquée par les puissances européennes, vénitienne et génoise en tête. Il ne reste alors qu'un seul émirat ayant devant lui un champ d'expansion possible, en faisant face à Byzance, de plus en plus affaiblie. Cet émirat, qui a la possibilité de sauter par-dessus les détroits vers le continent européen, c'est celui des Ottomans. C'est ainsi que ces derniers arriveront à dépasser, seuls, cette crise de croissance et absorberont progressivement tous les autres émirats avant de réunir une grande partie du monde musulman sous leur domination.

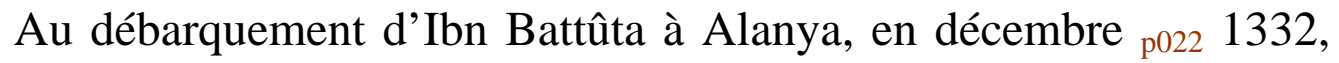
la situation se présente donc de la façon suivante : le centre et l'est de l'Asie Mineure se trouvent sous contrôle direct des Ilkhans avec un gouverneur siégeant à Kayseri ou Sivas. A l'époque, celui-ci avait pour nom Alauddin Artena ; il succède à Timurtash, fils de Tchoban, après la fuite de celui-ci en Égypte, en 1327. Après la dislocation de l'empire ilkhanide en 1336-1338 il constitue, à partir de ses possessions, un État qui durera jusqu'à l'arrivée de Timur, à la fin du siècle. Autour du domaine mongol s'égrène un arc de cercle de petits États musulmans, tandis que les deux extrêmes sont occupés par des formations chrétiennes : le royaume arménien de Cilicie, débouchant sur le golfe d'Alexandrette, au sud, et l'empire grec de Trébizonde sur le littoral anatolien de la mer Noire, au nord. L'empire grec avoisine à l'est un autre État chrétien, celui de la Géorgie. Entre les deux, et en faisant le tour du littoral, s'alignent pas moins d'une douzaine d'émirats, sans compter les partages entre les membres des familles souveraines. Ibn Battûta les visitera tous, sauf un.

Pour notre voyageur, l'Asie Mineure de l'époque est une sorte de paradis terrestre, un pays de cocagne rempli d'hôtes accueillants, de sultans généreux et de jeunes esclaves. Pays, aussi, résolument orthodoxe, où aucun virus de division et d'hérésie n'a encore pénétré. Cette image découle principalement de l'hospitalité manifestée par les akhis et c'est sur ce point qu'il nous faut nous arrêter pour un moment. 
Sur cette question, le problème se complique par le fait qu'Ibn Battûta constitue de loin la source principale sur les akhis de l'Asie Mineure. Ainsi toute recherche à ce sujet ne fait que nous renvoyer à son récit. Il nous reste donc peu de choses en dehors de celui-ci pour essayer de cerner le problème. Malgré les tendances à relier ce phénomène à des origines turques pré-islamiques, il faudrait, dans l'état actuel des recherches, s'orienter vers des antécédents arabo-islamiques connus ${ }_{\mathrm{p} 023}$ sous le nom générique de futuwwa. Mais, là aussi, le point est loin d'être fait. On peut situer la futuwwa, en tant qu'organisation urbaine, dans l'espace vacant laissé par la disparition progressive des structures tribales en milieu urbain, ainsi que par la hiérarchie politico-religieuse du califat et de ses états successifs. Or cet espace est très important puisqu'il englobe le petit peuple des villes, mais aussi les jeunes qui tardent à s'intégrer à une société patriarcale où l'autorité ne vient qu'avec l'âge. Par contre, la liaison de la futuwwa avec les milieux professionnels n'est pas évidente. On ne peut, au moins à l'origine, l'assimiler aux corporations. Ce n'est que plus tard, à l'époque ottomane, que les akhis seront confondus avec les corporations. Ainsi cette institution apparaît à ses débuts comme un organisme socio-politique visant peut-être à institutionnaliser un mode de vie marginal, mais visant aussi à conquérir une part des richesses produites et distribuées dans l'espace urbain. Ses membres, désignés sous le nom d'ayyarun (hors-la-loi) par les bien-pensants, " protégeront », en les rançonnant, les commerçants des marchés, fourniront des milices au profit de tel ou tel parti, se révolteront pendant les périodes troubles pour réclamer leur insertion dans... la police et finiront souvent par contrôler cette dernière à Bagdad. Ainsi récupérés occasionnellement par tel ou tel pouvoir, ils finiront par l'être institutionnellement. Sous l'effet de leur affinité avec les petits métiers, ils tendent d'une part à se muer en corporation, tandis que de l'autre, le soufisme, qui s'organise en confréries et qui s'implante dans le petit peuple à partir du XII ${ }^{\mathrm{e}}$-XIII ${ }^{\mathrm{e}}$ siècle, les réunit dans son giron. Ainsi futuwwa, confréries et corporations vont s’interpénétrer sans qu'une superposition soit, même partiellement, atteinte. Enfin, à cette même époque le calife al-Nasir (1181-1223) cherche dans la pratique quotidienne un nouveau souffle pour l'islam et le califat et codifie la futuwwa pour essayer de la transformer en une sorte d'ordre de chevalerie, initiant pour cela les souverains et les puissants de l'islam à une ${ }_{\mathrm{p} 024}$ pratique et une conception communes. Un des initiateurs de ce mouvement est 
Shihab al-din Abu Hafs Omar al-Suhrawardi, fondateur d'un ordre soufi des plus « intellectuels » auquel Ibn Battûta adhérera à Shiraz. Al-Suhrawardi, qui a aussi écrit un traité de futuwwa, un futuwwatnama, fut envoyé par al-Nasir comme ambassadeur missionnaire chez Alauddin Kayqubad I ${ }^{\text {er }}$, le plus grand des Seldjukides d'Anatolie (1219-1237). Ainsi la futuwwa semble avoir été implantée en Asie Mineure sous ses deux formes, populaire et aristocratique.

Dans le domaine seldjukide d'Asie Mineure, même pendant son époque de prospérité, les villes sont comme des navires dans une mer démontée. L'espace rural bouleversé par l'irruption à deux reprises d'un peuple nomade (à la fin du XI ${ }^{\mathrm{e}}$ siècle et au milieu du XIII ${ }^{\mathrm{e}}$ siècle) mettra des siècles à s'apaiser. Pendant la période seldjukide, les villes subsisteront plus par les sommes prélevées sur le commerce international que par l'espace agricole environnant. L'éclatement de l'État seldjukide, en tarissant le flux commercial, par l'insécurité qu'il entraine, constitue pour les villes un péril immédiat. Il est alors normal que les forces vives urbaines, faites d'artisans et du petit peuple, s'organisent en prenant les choses en main. Le phénomène n'est pas nouveau : les Saffarides, souverains du Sistan, dans l'Est iranien, au IX ${ }^{\mathrm{e}}$ siècle, furent hissés au pouvoir par les milices issues de la futuwwa et eurent comme fondateur un chaudronnier (saffar) ; Tabriz, évacuée en 1357 par les armées de la Horde d’Or qui l'avait occupée deux ans auparavant, sera administrée par un certain Akhidjuk (Petit Akhi) jusqu'à sa conquête par les Djelairides de Bagdad en 1359. Le mot akhi est turc et signifie généreux. Mais, par un glissement étymologique bien opportun, Ibn Battûta et les autres auteurs arabes l'assimilent au mot arabe «mon frère ». Selon les circonstances, les akhis jouent un rôle important dans la période située entre l'effondrement du pouvoir ${ }^{0225}$ seldjukide et la montée du pouvoir ottoman en Asie Mineure. A la fin du XIII ${ }^{\mathrm{e}}$ siècle, alors que les derniers rois fainéants seldjukides vivaient à Kayseri sous la tutelle des Mongols, on voit déjà un Akhi Ahmad Shaft gouverner Konya, la capitale historique des Seldjukides. En 1314, alors que le royaume seldjukide appartient déjà à l'histoire, et que l'émirat turkmène des karamanoghlu lutte contre les Mongols pour se tailler un domaine dans le centresud de l'Asie Mineure, cet émirat occupe Konya, gouverné par un Akhi Mustapha. Ibn Battûta cite également des akhis gouverneurs de villes importantes comme Nigde et Aksaray en Asie Mineure centrale. 
Ici se pose le problème du double aspect des organisations akhis rencontrées par Ibn Battûta : l'aspect officiel de celles se trouvant en territoire mongol, et l'aspect populaire de celles situées dans les émirats. Le chef des akhis, à Konya, qui était aux mains des Mongols jusqu'en 1327, est le cadi lui-même ; l'akhi gouverneur d'Aksaray est chérif ; c'est-à-dire descendant de Muhammad, titre traditionnellement aristocratique ; le chef akhi de Kayseri est un « émir considérable »; celui de Sivas porte le surnom de tchelebi, titre plutôt noble à l'époque. Donc on se trouve sans doute devant, d'une part, une futuwwa aristocratique, héritée de celle d'al-Nasir, d'Alauddin Kayqubad et d'al-Suhrawardi et inféodée, par la suite, aux Mongols pour gouverner sous leur égide, sinon en leur nom, et, de l'autre, face à des organisations plus " populaires », créées en pays fraîchement conquis, pour être des éléments d'équilibre entre la hiérarchie tribale, les pionniers accourus dans ce «far west » islamique et le peuple chrétien en voie d'assimilation. Entre les deux existent aussi des cas limites, comme cette " république des akhis » d'Ankara où, loin des Mongols, mais aussi en dehors des terres conquises par les Turkmènes, un chef de corporation arrive à implanter, pour une durée d'un demi-siècle, sa propre ${ }_{\text {p026 }}$ dynastie, appuyée par les corporations de la ville. Mais malheureusement Ibn Battûta n’a pas visité Ankara.

D’après la chronologie traditionnelle, Ibn Battûta débarque donc à Alanya vers le mois de décembre 1332. L'ancien port seldjukide sur la Méditerranée est convoité par les Lusignan, rois de Chypre qui organisent une expédition vers 1291 pour sa capture. L'attaque sera repoussée par les Karamanoghlu qui conserveront probablement la ville à partir de cette date. On ne connaît pas, par contre, ce Yusuf Beg mentionné par Ibn Battûta.

Notre auteur longe, par la suite, le littoral méditerranéen, en direction de l'ouest, pour arriver à Antalya, centre d'une branche de l'émirat des Hamitoghlu, connue sous le nom de Teke, l'autre branche possédant son centre à Egridir, plus au nord, auprès du lac du même nom, ville qui constituera l'étape suivante d'Ibn Battûta. Un troisième membre de la famille règne à Gölhisar, situé vers le sud-ouest. Les Hamitoghlu subiront en 1324 les attaques de Timurtash, fils de Tchoban, qui tente de réunifier le domaine anatolien des Mongols pour son propre compte. Des membres de la famille fuiront alors chez les mameluks pour revenir après la disgrâce de Timurtasch, en 1327. Par la 
suite, les Hamitoghlu s'effaceront progressivement de l'Histoire, jusqu'à disparaître à la fin du siècle.

A partir de ce point se pose le problème d'une longue déviation sur laquelle notre voyageur va bifurquer pour aller vers le nord-est de l'Asie Mineure. Il est vrai que le texte place cette déviation, sans donner par ailleurs d'explications ou de précisions, entre Milas et Birgi, villes situées plus à l'ouest, près du littoral égéen. Pour le trajet à partir de Mitas, le texte dit simplement : " de là, nous partîmes vers Konya », et, une fois que cet itinéraire prend fin à l'extrême est, à Erzeroum, il rajoute : " de là, nous nous rendîmes à Birgi », renouant ainsi p027 avec l'itinéraire principal interrompu. Une telle trajectoire est non seulement invraisemblable mais chronologiquement impossible : Ibn Battûta nous annonce qu'il se trouve à Egridir pendant le Ramadhan, c'est-à-dire à partir du 16 mai 1333. Or il sera à Manisa, après avoir repris son itinéraire principal, le 21 août. Il est impossible de réaliser cette déviation entre ces deux dates. Par ailleurs on peut se demander ce qu'il faisait depuis le mois de décembre jusqu'au mois de mai, entre Alanya et Egridir où il n'y avait que cinq étapes importantes à parcourir. Il est donc raisonnable de placer la déviation à partir d'Egridir qui est le point le plus proche de Konya, première étape de la déviation, ce qui permet de réaliser chronologiquement le trajet jusqu'à Erzeroum et de revenir à Egridir pour le mois de Ramadhan afin de reprendre de là l'itinéraire principal. Cette solution, qui réconcilie la géographie et la chronologie avec le texte, ne résout pourtant pas tous les problèmes concernant l'authenticité de cette déviation. On pourrait dire que, plus le récit s'enfonce vers l'est, moins il devient convaincant. La description de la dernière ville, Erzeroum, avec ses vignes et ses rivières inexistantes, est franchement suspecte. En plus, la traversée en plein hiver de ces régions réputées difficiles à cause des passages montagneux mériterait au moins d'être signalée. L'hiver suivant, notre voyageur racontera bien ses problèmes concernant des endroits beaucoup plus accessibles, et aussi, par la suite, ne manquera pas de mentionner son hiver en Russie. Or c'est la première fois que ce Maghrébin aura à franchir des défilés enneigés à plus de deux mille mètres d'altitude au mois de mars et il n'en souffle pas mot. Enfin, si dans l'itinéraire principal on aura droit à presque toutes les mosquées modestes bâties par les émirs turkmènes, on ne saura rien sur les très importants monuments seldjukides qui jalonnent sa route vers l'est, no- 
tamment à Konya. Mais signalons le problème et continuons à lui faire confiance. 0028

Dans cet itinéraire de déviation, plusieurs personnages sont rencontrés, mais les noms des akhis cités ne sont pas vérifiables et les informations fournies sur le gouverneur Artena et les Karamanoghlu ne sont pas très précises. Les Karamanoghlu, placés par les Seldjukides aux frontières du royaume arménien de Cilicie, à cause de leur proximité avec la capitale, Konya, se trouveront très vite impliqués dans les luttes intestines seldjukides et s'opposeront le plus souvent au parti du souverain appuyé par les Mongols. Ainsi ils deviendront rapidement la bête noire de ces derniers et chercheront par conséquent un appui chez les mameluks. Konya sera conquise une première fois en 1277, au nom d'un prétendant seldjukide et plusieurs fois ensuite en 1291, 1314 et 1327. Cela motivera des invasions successives des Mongols dont la dernière, celle de Timurtash, en 1324. Après la disparition de ce dernier, les Karamanoghlu semblent se maintenir en bons termes avec Artena - c'est du moins le cas à l'époque du passage d'Ibn Battûta. Mais la période est également obscure pour l'histoire des Karamanoghlu. Badr al-din Mahmud, fils de Karaman, le fondateur de l'émirat, est mort en 1308 et son fils Yakhshi lui succède. Ce dernier, qui occupe Konya en 1314, disparaît de la scène vers 13171318, et se trouve remplacé par son frère Badr al-din Ibrahim qu'Ibn Battûta dit avoir rencontré à Larende. Or on ne sait pas si Yakhshi est mort ou si l'émirat se trouve partagé entre les membres de la famille, Yakhshi Beg étant à Ermenek, la première capitale de l'émirat. On sait par ailleurs qu'un autre frère, Musa, qui gravitait autour des mameluks, s'installe à Larende depuis 1311-1312 et jusqu'à l'apparition de Badr al-din Ibrahim. Par la suite, il se mettra au service des mameluks et Ibn Battûta le rencontrera à La Mecque pendant le pèlerinage de 1328. Il va réapparaître sur la scène de l'émirat vers 1350. Enfin un autre frère de Yakhshi, Halil, qui possède Beysehir, ville citée sans autre précision par Ibn Battûta, aurait remplacé Badr al-din Ibrahim à la tête de l'émirat de 1333 (ou 1334) à ${ }_{\text {p029 }}$ 1348, mais on ne sait pas si ce dernier a conservé son fief de Larende. Mais alors qui possède Konya ? Les Karamanoghlu l'avaient occupée en 1327, mais Artena la récupère, après qu'il eut accédé à l'indépendance, pour la garder jusqu'à sa mort en 1352. Pendant la période de son occupation par les Karamanoghlu, elle serait aux mains de Fakhr al-din Ahmad, fils de 
Badr al-din Ibrahim, qui va succéder à son père en 1348-1349. Ibn Battûta aurait dû, selon sa méthode appliquée à son itinéraire principal, signaler les souverains de Beyehir et Konya. Or il ne dit rien, et les confusions de l'histoire des Karamanoghlu ne font que s'ajouter aux problèmes d’itinéraire de notre voyageur.

Revenant sur son itinéraire principal, et, à partir de Gölhisar, en route vers Lâdik, l'actuelle Denizli, Ibn Battûta, par peur « des brigands djermiyan ", se fait accompagner. Or les Germiyanoghlu n'étaient pas plus brigands que les autres, puisqu'ils formaient, eux aussi, un émirat, le seul qu'Ibn Battûta ne dit pas avoir visité. Celui-ci, implanté au centre-ouest de l'Asie Mineure et considéré au début du $\mathrm{XIV}^{\mathrm{e}}$ siècle comme un des plus importants émirats avec celui des Karamanoghlu, avait tenu sous sa suzeraineté pendant cette époque les petits émirats qui se lançaient vers la conquête du littoral égéen. Sa puissance et son agressivité, également attestées par d'autres sources, sont probablement à l'origine de sa réputation rapportée par notre voyageur. Son encerclement et l'absence de débouchés maritimes, qui le condamnent à l'inactivité, le pousseront vers un déclin rapide. A son arrivée à Lâdik, Ibn Battûta rencontre toutefois un souverain de la famille des Germiyanoghlu auquel il ne trouve rien à reprocher. Par la suite, en poursuivant son avance vers l'ouest, il pénètre dans des régions de plus en plus fraîchement conquises et passera, de ce fait, de l'aire d'influence mongole à celle des Byzantins.

A partir de 1261, le transfert de la capitale de l'empire byzantin de Nicée - l'actuelle Iznik au p030 nord-ouest de l'Asie Mineure - à Constantinople (reprise aux Latins qui la tenaient depuis 1204) déplace le centre d'intérêt de Byzance vers l'ouest. Michel VIII Paléologue, par sa politique "tous azimuts » de reconstitution de l'empire byzantin, néglige les territoires asiatiques en se contentant de miser sur l'écroulement de l'État seldjukide. Cela donne l'occasion aux Turkmènes de pousser leurs conquêtes et de fonder ou d'élargir leurs émirats. L’émir Menteché occupe le premier, entre 1260 et 1280, le Sud Sud-Ouest et est le fondateur éponyme d'un émirat. Des expéditions sporadiques et mal préparées des Byzantins n’ont que des résultats maigres et éphémères. Celle, en 1278, du futur Andronic II, fils de Michel VIII, qui fortifie Tralles sur le Méandre (l'actuelle Aydin) ne peut repousser la prise de la ville que jusqu'en 1282. En 1296, l'expédition du général Alexios Philanthropinos avec des mercenaires 
Alains restés sans solde aboutit à la révolte du général qui s’associe aux Turcs pour mieux piller le pays. Les résultats désastreux d'une dernière campagne menée par le fils et co-régent d'Andronic II, Michel IX, ne font qu'inciter les Turcs à occuper la basse vallée du Méandre (Menderes) et de l'Hermus (Gediz), aboutissant ainsi à Éphèse et à Smyrne. Cette conquête se fait à partir de 1304 par des chefs de guerre affiliés à la famille de Menteché et par la suite par Mehmed, fils d'Aydin, et par ses frères qui vont fonder l'émirat d'Aydinoghlu. Éphèse est conquise en 1303, Mehmed s'installe à Birgi à partir de 1308, tandis qu'un autre émir, Saruhan, occupe Magnésie (Manisa) en 1313 pour fonder un nouvel émirat portant son nom. Enfin la région de Pergame (Bergama) et celle de Balikesir, plus au nord, constituent le noyau d'un émirat éphémère, celui des Karasi. Smyrne se conquiert en deux étapes, le château supérieur vers 1317 et le château maritime vers 1329. Ainsi la conquête est accomplie peu avant le voyage d'Ibn Battûta, et, à l'arrivée de celui-ci, il ne reste plus que trois enclaves dans la région : celle de Philadelphie (Alasehir), à l'intérieur des terres, et les p031 deux Phocées, ancienne et nouvelle, sur le littoral, au nord de Smyrne.

Atteindre la mer ne semblait pas pouvoir freiner la progression des Turkmènes. A cela contribuait la décision de désarmer la flotte prise par Andronic II en 1284, devant l'état catastrophique des finances byzantines. Au début du XIV ${ }^{\mathrm{e}}$ siècle, une flotte constituée par Mas'ud, fils de Menteché, attaquait Rhodes, et Andronic II ne trouvait d'autre solution que de la livrer à l'ordre militaire des Hospitaliers de Saint Jean, en 1308. Cet acte sera en même temps un début de politique. Byzance, n'ayant pas les moyens de protéger ses mers, abandonne ses dernières possessions maritimes à des États occidentaux, à des institutions ou à des personnes privées occidentales capables d'arrêter, même temporairement, la progression turque. Parmi les plus célèbres, on trouve la famille génoise des Zaccaria.

Manuele Zaccaria reçoit de la part de Michel VIII la concession des mines d'alun de Phocée. En 1288 lui succède son frère Benedetto $\mathrm{I}^{\mathrm{er}}$ lequel bâtit au nord-nord-est de l'ancienne ville, et toujours sur le littoral, la nouvelle Phocée. Plus que concessionnaire, ce dernier est maître de ces deux villes qui vont bientôt être les seules enclaves chrétiennes sur le littoral. En 1304, incapable de défendre l'île de Chio, très proche de la côte, Andronic II la cède pour dix années renouvela- 
bles à Benedetto Zaccaria. Ses descendants y ajouteront le port maritime de Smyrne, constituant ainsi un système de défense contre l'expansion en mer des Turcs et qui leur permet de toucher tranquillement les gros revenus de l'alun de Phocée et du mastic de Chio. Mais ainsi, progressivement, le remède devient, pour Byzance, pire que le mal ; les Génois et les Vénitiens mettent la main sur tous les revenus de l'empire devenu incapable d'arrêter le vrai danger qui se précise : l'avance de l'émirat ottoman vers Constantinople. Alors Byzance cherche à moduler son jeu et essaye de nouvelles alliances. Par p032 ailleurs, en 1328, Andronic II, dont le règne fut aussi long qu'indécis, vient d'être renversé par son petit-fils Andronic III et enfermé dans un monastère ; on reviendra sur ce personnage. Le nouvel empereur, bien que jeune et plus dynamique, se fait battre le 10 mai 1329 à Pelekanon par Orhan, le deuxième souverain ottoman. Cette bataille ouvre la porte à la conquête des dernières possessions byzantines en Asie Mineure jusqu'aux banlieues de Constantinople. L'empereur va entreprendre, juste après, un certain nombre d'actions qui vont modifier le paysage politique dans la région de Smyrne pendant les années qui précèdent le passage d'Ibn Battûta. Une révolte se prépare avec l'aide du clergé orthodoxe et du peuple grec de Chio et, en automne 1329, la flotte byzantine s'empare de l'île. Entre-temps, Martino Zaccaria est obligé, pour concentrer ses forces, d'évacuer le fort maritime de Smyrne qui est alors occupé par Umur Beg. Celui-ci avait reçu cette ville comme fief de la part de son père Mehmed, souverain des Aydinoghlu. Après la récupération de Chio, Andronic III visite les deux Phocées. Dans l'ancienne, désormais considérée territoire byzantin, il reçoit l'émir Saruhan ainsi que des envoyés de Mehmed Aydinoghlu, lesquels se déclarent, d'après les historiens byzantins, vassaux de l'empereur. Une alliance s'esquisse donc, principalement contre les Latins, mais aussi contre les Ottomans. Celle-ci va durer, avec des fortunes diverses, jusqu’à la mort de Mehmed en janvier 1334. Elle est donc encore valable lors du passage d'Ibn Battûta. C'est ainsi que la soumission de Phocée à l'émir Saruhan, mentionnée par notre auteur, doit concerner la nouvelle Phocée où l'exploitation de l'alun échoit au Génois Andreolo Cattaneo. Cette alliance n’empêche toutefois pas les fils des deux émirs, Umur et Suleyman, de tenter un coup de main infructueux sur Gallipoli, probablement en 1332. Mais l'année suivante, plus conformément aux vœux d'Andronic III, Umur part en expédition contre les possessions latines 
de la Grèce. Il est de retour au début de l'été, ce qui explique l'arrivage frais d'esclaves, et Ibn ${ }_{\text {p0з3 }}$ Battûta ne manque pas de se servir dans le lot. Umur, succédant à son père, devient progressivement le personnage central de l'histoire de cette région. Il sera utilisé par Andronic III, puis après la mort de ce dernier en 1341, par Jean VI Cantacuzène dans sa lutte contre Jean V Paléologue, jusqu'à ce que le pape, les Vénitiens et les Génois, alarmés, organisent une expédition qui occupe le fort maritime de Smyrne en 1344. Umur est tué en tentant de le reprendre en mai 1348. L'événement a dû suffisamment retentir pour qu'Ibn Battûta en soit informé en Égypte, où il se trouvait à cette date, et l'ajoute à son récit.

Notre voyageur se meut ainsi dans un espace politique extrêmement complexe où s'opère une lutte tripartite entre Byzantins, Turcs et Occidentaux. Chacune de ces parties est composée à son tour d'éléments antagonistes : Génois, Catalans, Vénitiens et autres se disputent l'espace oriental; les émirats, concurrents au début, s'inquiètent par la suite de la progression ottomane. Les Byzantins sont occupés par les guerres civiles entre les deux Andronic et, par la suite, entre les deux Jean. Là aussi la vision simplificatrice qu'Ibn Battûta donne d'une société de purs combattants de la foi luttant contre les infidèles demande à être nuancée. Cela ne modifie pas pour autant l'image de la vie quotidienne que le voyageur aperçoit uniquement au travers de rapides passages.

La description terne qu'on aura de l'émirat de Karasi est à l'image de la rareté d'information que l'on possède à ce sujet et correspond à la durée éphémère de celui-ci. Il sera le premier à être absorbé par les Ottomans vers la fin du règne d'Orhan, c'est-à-dire vers le milieu du $\mathrm{XIV}^{\mathrm{e}}$ siècle. Par la suite, notre auteur pénètre en territoire ottoman et l'importance accordée à cet émirat est peut-être due au développement de celui-ci à l'époque de la rédaction du texte, en 1355, avec la conquête de Gallipoli en 1354, et le passage en Europe - à supposer que ${ }_{\text {p034 }}$ cet événement fût connu au Maroc à cette date. C'est sur le territoire ottoman qu'Ibn Battûta relate avec le plus de précision ses étapes au jour le jour. Toutefois, son témoignage n'apporte pas d'éléments nouveaux à l'histoire, relativement bien connue, de l'État ottoman. Il est à Nicée (Iznik) peu après sa conquête en mars 1331, et, Orhan étant absent, il est reçu par sa femme. Cela donne une indica- 
tion intéressante sur l'évolution des mœurs ottomanes depuis l'émirat jusqu'à l'empire.

Après avoir traversé le territoire ottoman et rencontré, à Gerede, un émir dont on ne connaît que le nom, Ibn Battûta termine sa tournée des émirats d'Asie Mineure par celui des Djandaroghlu. Ici, en revenant vers l'est, on se retrouve sur des anciennes terres de conquête, occupées pendant la première vague de la pénétration turque. Un émirat soumis aux Seldjukides, ayant comme centre Kastamonu, existe depuis 1204. C'est au nord-ouest de cette ville, dans la bourgade d'Eflani, qu'un certain Demir ou Timur fonde un petit noyau qui s'agrandit considérablement à l'époque de son fils Suleyman, pour absorber l'ancien émirat de Kastamonu et annexer Sinop, fief, jusqu'en 1322, du dernier prince héritier des Seldjukides. C'est ainsi qu'Ibn Battûta trouve à son passage un émirat allant de la frontière ottomane jusqu'à l'empire grec de Trébizonde. Il le traverse pour aboutir à Sinop, en terminant son trajet comme il avait commencé par un port seldjukide ouvert sur le grand commerce maritime. De là, il s’embarque pour la Crimée.

Dans ce voyage qui dure près de quatorze mois, Ibn Battûta commence à recueillir les fruits de ses investissements pieux. Le saint personnage qu'il s'est constitué suscite l'intérêt des émirs turkmènes et la contrepartie se mesure en esclaves, chevaux et autres biens. Ainsi, au fur et à mesure qu'il traverse ces terres pionnières, l'importance et la fortune de notre personnage augmentent, ce qui ne va pas parfois sans désagréments, le ${ }_{\text {p035 }}$ souci de ses biens entravant souvent sa marche. Dans ces conditions, et ayant assuré gîte et nourriture chez les akhis, ses préoccupations religieuses passent au second plan. On aura tout de même quelques témoignages sur l'activité religieuse de ces nouveaux pays.

En Anatolie, Ibn Battûta fait connaissance avec l'ordre soufi des mawiawis, en son lieu de naissance, Konya. Son fondateur, Djamal aldin Rumi (1207-1273), est fils d'un autre mystique, Baha al-din Walad (1148-1231), originaire de Balkh en Afghanistan. Le père et le fils, fuyant l'avance mongole, sont venus s'installer en Anatolie à partir de 1225 et furent invités à Konya par Alauddin Kayqubad I ${ }^{\mathrm{er}}$. La tradition soufi qu'ils introduisent en Anatolie est donc d'origine iranienne, mais sa filiation remonte jusqu'au grand mystique Ahmad al-Ghazali (mort 
en 1126), d'où descend également Abu Hafs al-Suhrawardi, bien que celui-ci représente la tradition irakienne. Ainsi les deux courants de cette mystique intellectuelle se retrouvent à Konya que Suhrawardi visite également à cette époque comme missionnaire de la futuwwa. Par ailleurs, les populations nomades subissent l'influence d'un mysticisme populaire syncrétique, mêlant des éléments chamaniques aux anciennes hérésies chrétiennes de l'Asie Mineure, rendant ainsi possible le grand brassage d'ethnies et de religions qui s'opère au long des $\mathrm{XIII}^{\mathrm{e}}$ et $\mathrm{XIV}^{\mathrm{e}}$ siècles. En définitive, l'ordre des mawlawis reste bien localisé et lié à l'aristocratie, seldjukide d'abord, ottomane ensuite.

Pour le reste, Ibn Battûta rencontre encore des rifais, ordre avec lequel il conserve le plus d'affinités. La mention, une fois dans une petite ville du centre-nord de l'Asie Mineure et une autre dans Smyrne à peine conquise et encore en ruine, du chef suprême de l'ordre, descendant d'al-Rifai n'est pas sans poser des problèmes. Elle montrerait, surtout dans le deuxième cas, le zèle déployé par les ordres soufis dans la conquête spirituelle, mais aussi militaire, de terres et de fidèles

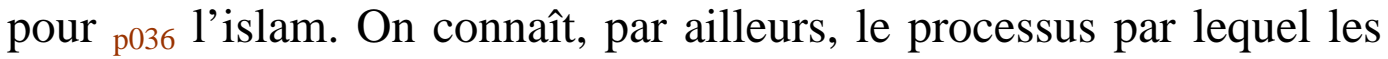
cheïkhs et les derviches, avec leurs institutions, les zawiyas, ont constitué un élément de base dans la conquête et la colonisation ethnique et religieuse de l'ouest de l'Asie Mineure dans un premier temps et des Balkans par la suite. L'abandon par Byzance des terres asiatiques à leur sort ; les exactions sur la population paysanne chrétienne d'une féodalité byzantine, latine, serbe ou bulgare, liée par-dessus le marché aux intérêts mercantiles des Génois et des Vénitiens ; les tentatives de rapprochement entre l'Église catholique et l'opposition farouche du clergé orthodoxe : tous ces éléments contribuèrent peut-être bien plus que la force, à pousser de larges masses au sein de la religion islamique où le mysticisme populaire et syncrétique préparait le terrain pour les recevoir à travers les ordres soufis et leurs zawiyas.

\section{RUSSIE MÉRIDIONALE ET CONSTANTINOPLE} Retour à la Table des Matières

La traversée vers la Crimée et la visite de l'empire de la Horde d'Or, après le parcours d'Asie Mineure aboutissant à Sinop, devenaient un itinéraire obligé pour Ibn Éthiopie en route vers l'Inde à travers l'Asie centrale. Par cette trajectoire, le voyageur marque en quel- 
que sorte les limites du monde musulman en le contournant, d'abord par l'ouest, puis par le nord. Pour nous, ce voyage constitue, comme celui de l'Asie centrale, une source précieuse concernant un peuple et un État qui ne se sont pas donné la peine d'écrire leur propre histoire et ne nous ont laissé que des traces infimes de leur passage, pourtant fracassant, dans l'histoire. C'est donc grâce à notre voyageur et à quelques autres - l'italien Jean du Plan Carpin (Piano Carpini), le Flamand Guillaume de Rubrouck, et à travers des informations de géographes arabes (al-Umari) ou de chroniqueurs russes — que l'on peut reconstituer la vie et l'histoire de ce royaume. p037

Pour la Crimée, où Ibn Éthiopie débarque en mars-avril 1334, l'éclairage est meilleur, car c'est là qu'aboutissent les routes de la fourrure et de la soie venant respectivement du Nord et de l'Est. Les Génois et les Vénitiens s'accrochent alors aux rivages, établissent des comptoirs et nous laissent leurs comptes et leurs registres, où on retrouve la séculaire concurrence entre les deux cités marchandes opposées à la méfiance mongole. La conquête de Constantinople par les croisés en 1204, sous le haut patronage de Venise, avait permis à cette puissance de pénétrer dans cette mer intérieure, jalousement gardée, la mer Noire. C'est ainsi que messires Niccolo et Mafeo Polo, le père et l'oncle de Marco, partirent à Soudak, en Crimée, ouvrir une succursale de leur maison mère installée à Constantinople. Mais Michel VIII Paléologue s’alliera aux Génois pour reconquérir Constantinople et ces derniers remplaceront les Vénitiens en mer Noire. Ils s'installent, à partir de 1266, à Kaffa qui devient le centre principal du transbordement des marchandises. En 1316, on les trouve à Azak et en 1318 à Kertch. Mais les Vénitiens reviennent aussi. Ils ont, depuis 1289, déjà un consul à Kertch et établissent une colonie à Azak en 1332, ainsi qu'à Tana, à l'embouchure du Don, dans le courant de la même année.

La position des Mongols face aux Européens apparaît hésitante. En tant qu'État essentiellement nomade — du moins à ses débuts l'empire de la Horde d'Or a besoin d'asseoir son économie urbaine sur le commerce à grande distance et, par conséquent, d'entretenir et de développer les grands itinéraires commerciaux dont il vient d'hériter. Les commerçants navigateurs européens sont des éléments essentiels dans cet ensemble. Mais les profits sont toujours difficiles à partager et les conflits sont courants. Il est aussi facile pour les Mongols de s'emparer des comptoirs que pour les Latins de s'enfuir sur 
leurs bateaux et de bloquer, par la suite, le commerce maritime. Après

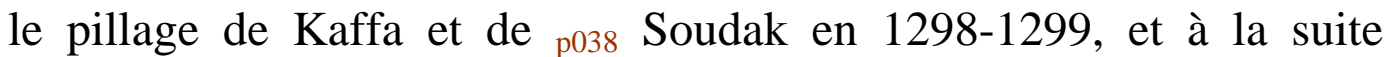
d'autres conflits au début du règne d'Uzbek Khan, un modus vivendi semble avoir été trouvé et l'époque du passage d'Ibn Éthiopie est plutôt paisible. Ce n'est que plus tard, en 1343-1345, que Djani Bek, le fils d'Uzbek, chassera les Italiens de Tana et viendra mettre le siège devant Kaffa. La menace du blocus arrange encore les choses en 1347 et finalement les Génois tiendront à Kaffa jusqu'à l'apparition des Ottomans en Crimée, à la fin du $\mathrm{XV}^{\mathrm{e}}$ siècle.

Au-delà, l'empire de la Horde d'Or apparaît comme une vaste formation tribale féodale où la famille de Gengis détient de grands apanages et couronne une hiérarchie de grands et petits féodaux appartenant aussi bien à l'ethnie mongole qu'à celles qui se trouvaient sur place lors de la conquête. Dans cet espace, d'anciens noyaux sédentaires persistent en Crimée, sur la basse Volga ou plus à l'est dans le Khwarezm, au sud du lac d'Aral, mais la plus grande partie des steppes constitue apparemment le domaine des grands troupeaux nomades et des caravanes marchandes. Au milieu de cet espace, des villes aussi rares que démesurées concentrent l'activité artisanale et commerciale du pays, le travail des peaux et des fourrures, mais aussi la fabrication d'objets quotidiens en fer ou en céramique. C'est le cas des deux Saray : Saray Batu et Saray Berke, bâties sur le cours inférieur de la Volga. C'est cette dernière qui deviendra la capitale sous Uzbek Khan, et l'on possède une description contemporaine de celle d'Ibn Éthiopie, rapportée par al-Umari : "Le très vertueux Shudja al-din Abd al-Rahman al-Kharezmi drogman m'a raconté que la ville de Saray a été bâtie par le khan Berke sur les bords de la Turan [Volga]. Elle se trouve au milieu d'une saline et n'a point de murailles. La résidence du khan est un grand palais surmonté d'un croissant d'or du poids de deux kantars égyptiens [1 kantar = env. $56 \mathrm{~kg}$ ]. Le palais est ceint de murs, de tours et de maisons où demeurent les émirs ; en hiver, ceux-ci p039 habitent avec le khan. Le fleuve, me dit Shudja alDin, a plus de trois fois la largeur du Nil. Il est sillonné de grands navires qui vont dans les pays russes et slaves ; c'est dans la terre de ces derniers qu'il prend sa source. Saray est une grande ville où il y a des marchés, des bains et des établissements religieux. C'est une cité où affluent les marchandises. Au milieu se trouve un étang dont l'eau provient de l'Itil [toujours la Volga]. On n'utilise celle-ci que pour les 
travaux ; quant à l'eau potable, on la tire du fleuve. On la puise dans des buires d'argile qui sont rangées sur des chars et vendues ensuite à travers la ville. » La ville, détruite par Timur, sera abandonnée par la suite. Des fouilles faites au $\mathrm{XIX}^{\mathrm{e}}$ siècle, permettent de déterminer un espace urbain qui s'étend sur plus de cinquante kilomètres et couvre une superficie de quarante mille carrés.

L'empire de la Horde d'Or est partagé en de grands apanages distribués aux fils de Djoetchi, fils aîné de Gengis Khan, à qui tout le Decht-i Kiptchak, la steppe russe, avait été attribué. Leurs descendants contrôlent toujours ces territoires lors du passage d'Ibn Battûta, lequel rencontre peut-être l'un d'entre eux en la personne de Tulek Timur, " gouverneur » de Crimée. Toutefois la descendance de Batu, qui est un des fils de Djoetchi, détient le pouvoir suprême et arrive avec Uzbek Khan au sommet de sa puissance. Berke (12571266), frère et successeur de Batu, fut le premier souverain mongol à devenir musulman. Mais l'islam ne se fixera, chez les Mongols de Russie, qu'à partir d’Uzbek Khan (1312-1341). Cette islamisation précoce, liée au conflit qui oppose les khans de la Horde d'Or aux Ilkhans de la Perse au sujet du Caucase, créera des rapprochements avec l’Égypte mameluke, ellemême ennemie héréditaire des Ilkhans, et aboutira à une alliance de longue durée. Au-delà de très nombreuses ambassades, lesquelles, scrupuleusement décrites par les chroniques égyptiennes, constituent des sources précieuses pour l'histoire de la Horde d'Or, Baybars construit une p 040 mosquée à Stary Krim, la capitale de la Crimée, en 1288, et Uzbek marie une de ses filles à Malik Nasir. Ce mariage, qui n’aboutit qu'après six ans de marchandages, est un échec. Il suffit, pour en comprendre les raisons, de comparer la liberté des femmes chez les Mongols, telle qu'elle est décrite par Ibn Battûta, avec les harems du Caire. Cela finit par un divorce, huit ans plus tard. Notre auteur rencontrera cette dame à La Mecque, pendant le pèlerinage de 1326. La politique matrimoniale fonctionne également, et à plusieurs reprises, avec Byzance. A part la mystérieuse Baïalun, plus ou moins identifiée à une fille naturelle d'Andronic III, Andronic II marie une de ses filles à Tokhta, oncle et prédécesseur d’Uzbek (1290-1312). Une fille de Michel VIII sera mariée à Nogai, personnage influent et faiseur de rois, à la fin du XIII ${ }^{\mathrm{e}}$ siècle. On avait même pu parler à cette époque d'une alliance groupant le khan de la Horde d'Or, l'empereur de Byzance, le sultan d'Égypte et le roi d'Aragon face aux tentatives 
de croisade contre Constantinople et la Terre sainte, menée par Charles d'Anjou, roi de Sicile, et le pape. Par ailleurs, l'intérêt porté par l'Europe aux routes commerciales traversant la steppe russe fait de l'empire de la Horde d'Or une grande puissance jusqu'à la mort d'Uzbek. C'est ainsi que ce dernier reçoit une ambassade du pape Benoît XII en 1339. Ensuite, après la disparition rapide de son héritier désigné, Tini Bek, son deuxième fils Djani Bek (1342-1357) conservera la stabilité du royaume et réalisera également le rêve de la dynastie en occupant Tabriz en 1355, sur Malik Ashraf le Tchobanide (voir préface du t. I). Mais il périt peu après dans un complot préparé par son fils Berdi Bek (1357-1359), et par la suite une vingtaine de khans se succéderont dans un laps de temps de dix-huit ans ; la lignée de Batu s'éteindra et les descendants des autres fils de Djoetchi entreront dans la course pour le pouvoir suprême, jusqu'à ce que ces luttes préparent l'avènement de Timur. L'empire survivra toutefois à Timur, avant d'éclater en 1502 en plusieurs États successivement absorbés par l'empire russe. Ibn p041 Battûta traverse donc la Horde d'Or au moment de sa maturité qui est aussi l'époque de son intégration dans le monde islamique. D’où la valeur de son témoignage.

Arrivé au Decht-i Kiptchak, la steppe russe tant décrite par les géographes arabes, Ibn Battûta se sent obligé d'adhérer aux légendes du Grand Nord et sera ainsi, pour la première fois, pris en flagrant délit de mensonge puisqu'il n'a matériellement pas eu le temps de voyager en dix jours, comme il le dit, jusqu'à Bulghar, capitale des Bulgares de la Volga, située près du confluent de ce fleuve avec la Kama, à plus de mille kilomètres du point de départ d’Ibn Battûta, au nord du Caucase. Bulghar, centre commercial important et lieu d'échange des fourrures avant l'arrivée des Mongols, restera principalement dans l'imaginaire islamique, comme une des limites du monde connu, celle du Grand Nord, où le temps se détraque, les journées s’allongent et suppriment les nuits. Le premier à décrire ce phénomène fut Ibn Fadlan qui alla en ambassade auprès du roi des Bulgares en 923 : « Ensuite, on est entré dans la yourte pour discuter avec le tailleur du souverain qui était originaire de Bagdad et se trouvait dans ces contrées par hasard. On est resté ensemble le temps de lire la moitié d'un sub [1/14] du Coran. On parlait en attendant l'appel à la prière de nuit. Lorsqu'on a entendu l'appel, on est sorti de la tente. Qu'est-ce que je vois alors ? Il faisait déjà jour. Je demande alors au muezzin : “Quel 
appel as-tu fait ? — Celui du matin, me répond-il. — Et la prière de la nuit ? - On l'a faite juste après celle du soir. — Et la nuit, qu'est-ce qu'elle est devenue ? - C'est comme cela, me répond-il. Avant que tu arrives, elle était encore plus courte ; elle a commencé à s'allonger ces jours-ci.” Et il a ajouté que, par peur de rater la prière du matin, il n’osait plus s'endormir la nuit depuis un mois. Quelqu'un qui met la marmite au feu le soir fait la prière du matin avant qu'elle bouille. » p042

Ce dernier exemple est célèbre parmi les curiosités du « monde extérieur " à l'islam. Le pays où le temps des prières se détraque ne pouvait que se trouver, par définition, au bout du monde. Et notre voyageur ne pouvait décemment pas avouer ne pas avoir vu cela de ses yeux. Au-delà de cette contrée commence d'ailleurs le pays de l'obscurité où le temps finit par se détraquer complètement, et où les habitants, êtres déjà semi-légendaires, pratiquent l'échange muet, autre thème courant qu'Ibn Battûta ne pouvait encore une fois ne pas reprendre à son compte, même s’il avoue ne pas y avoir été.

Là, donc, où l'islam s'arrête, la nature, le monde s'altèrent et les légendes commencent. Cela pourrait être également vrai pour Constantinople. Ibn Battûta aurait pu nous y transporter, à partir de Bursa ou d'Iznik, qui sont à une ou deux étapes de Constantinople. Or il lui faudra partir des bords de la Volga, traverser des déserts, de grandes chaleurs et de grands froids en marquant, ainsi, les limites du monde connu, de son monde, pour arriver à Constantinople la Grande, le centre, avec Rome, du monde différent, du monde opposé, celui de la chrétienté. Il est vrai qu'Ibn Battûta n’aurait pas osé aller tout seul à partir des territoires ottomans à Constantinople, ville ennemie, tandis qu'à partir d'Astrakhan l'occasion se présentait de faire part d'une ambassade officielle et de devenir ainsi intouchable. Mais ces raisons bien réelles n'invalident pas la valeur symbolique du voyage. La suspicion au sujet de la réalité de celui-ci est pourtant justifiée. Pour la première fois sur ce trajet, Ibn Battûta perd ses moyens, il paraît confondre l'itinéraire de l'aller et celui du retour, et le chemin suivi devient à la limite impossible à tracer. De même à Constantinople tout se brouille. Andronic III devient le takfur, titre cliché donné par les Arabes à tous les empereurs de Byzance et Andronic II ; en religion Antoine est appelé Girgis (Georges). Enfin la description donnée de la ville aurait pu être «pompée » dans n’importe lequel des innombra- 
bles récits que les ${ }_{\text {p043 }}$ géographes arabes nous donnent. Mais les choses ne sont pas aussi simples, et il faut tenir compte d'un élément essentiel : à Constantinople, Ibn Battûta perd réellement ses moyens. Comme il n'a jamais dû pouvoir apprendre convenablement une autre langue que l'arabe, il se trouve, déjà depuis le début de ce voyage, doublement handicapé en cheminant avec des Mongols qui parlent probablement le turc et sûrement pas le grec, et qui doivent lui expliquer ce que les Grecs disent et font. On peut supposer que son guide, à Constantinople, avait quelques notions d'arabe. Mais, à travers les quelques descriptions fantaisistes ou prétentieuses, on doit se rendre à l'évidence, ce guide n'a pas dû beaucoup servir notre voyageur, ni l'histoire. De toute façon, au-delà de tout cela, Ibn Battûta se trouve littéralement perdu, il n'a plus de repères, ses critères ne fonctionnent plus et il doit être suffisamment troublé de se trouver pour la première fois dans un espace " infidèle », donc fondamentalement " inacceptable » et « intraduisible ». Un autre esprit plus universel, par exemple Ibn Fadlan, qu'on vient de citer, se serait peut-être retrouvé. Ce n'est pas le cas d'Ibn Battûta, qui, même s'il ne raconte pas d'énormités comme le font très souvent d'autres descriptions arabes de Constantinople, regarde le monde à travers ses acquis religieux qu'il a si soigneusement collectés tout au long de sa route. Par conséquent, qu'il l'ait réellement fait ou pas, il reste toujours un peu «absent » de ce voyage.

Le point central de cette visite reste toutefois sa rencontre avec Andronic II. Que la visite soit effectuée en août-septembre 1334 ou deux ans auparavant, cette rencontre n'a pas pu exister puisque l'empereur mourut en février 1332. Alors pourquoi la raconter ? Le prestige d'avoir rencontré l'empereur régnant suffisait. Par ailleurs, le récit de sa rencontre avec l'ex-empereur-moine a un aspect trop favorable au christianisme pour qu'il ait eu besoin de l'inventer. Alors estce qu'il a menti ou a-t-il vraiment cru avoir rencontré l'empereurmoine ? ${ }_{\text {p044 }}$ On pourrait tenter de bâtir l'hypothèse suivante : Andronic II avait régné pendant quarante-six ans, fait très exceptionnel pour un empereur byzantin, et même si ce long règne n'a pas brillé d'un grand éclat, il a duré suffisamment pour se faire connaître dans les émirats turkmènes qu'Ibn Battûta parcourut pendant plus d'un an. Ses informateurs étaient sans doute au courant de son abdication et de son entrée dans les ordres, fait assez ordinaire à Byzance mais inhabituel 
en Orient et qui ne pouvait manquer de piquer la curiosité religieuse de notre homme. Par contre, en quittant les parages de Byzance, il n'a pas dû être informé de sa mort qui ne constituait sans doute pas un événement de première importance. Cette absence d'informations devient encore plus vraisemblable évidemment si on recule le tout de deux ans en faisant embarquer Ibn Battûta à Sinop au moment de la mort de l'empereur. Aussi, lorsqu'il arrive à Constantinople et se fait montrer les curiosités de la ville par un dragoman futé qui ne se prive pas de gonfler les splendeurs d'une capitale déjà à l'agonie aux yeux de l' "Arabe », il exprime le souhait de voir l'empereur-moine. Le dragoman ne se "dégonfle » pas, et tient à montrer cet exemple de piété à l'infidèle en lui faisant visiter n'importe quel dignitaire religieux, le barrage de la langue faisant le reste. Ainsi le faible Andronic réussit, à travers ce malentendu, à prolonger sa mémoire au sein du monde musulman.

Toujours selon la chronologie traditionnelle, Ibn Battûta fera l'aller-retour Astrakhan-Constantinople entre la mi-juin et la minovembre 1334 et il restera cinq semaines dans la capitale byzantine, de la mi-août à la fin septembre. Ensuite, c'est à travers la Volga gelée qu'il ira visiter Saray, et quittera enfin, à la fin de cette même année, la région pour la Transoxiane. p045

\section{L'ASIE CENTRALE}

\section{Retour à la Table des Matières}

La Transoxiane, avant-poste prospère de l'islam face à l'Asie centrale, reçut la première le choc terrible des invasions mongoles, pour ne jamais plus se relever complètement de ses ruines. C'est ici que s'est forgée principalement la légende noire des Mongols, et Ibn Battûta, qui passe un siècle plus tard, ne manque pas de nous la transmettre.

Cette région était gouvernée, au début du XIII ${ }^{\mathrm{e}}$ siècle, par les Khwarezmshahs, les shahs du Khwarezm, du nom de la région du bas Oxus, ou Amu Darya, qui avaient étendu leur domination, après la disparition de l'empire seldjukide, sur l'Afghanistan, le Khorasan et toute la moitié est de l'Iran actuel. Muhammad Khwarezmshah (1200-1220) songeait déjà à se proclamer protecteur du califat, et, par là, maître du 
monde islamique, lorsque les nuages de la tempête mongole sont apparus à l'horizon. Les descriptions que les chroniqueurs contemporains en donnent tiennent à nous installer dans l'horreur dès les premières pages. L'ambassade envoyée par le Khwarezmshah en 1215 pour établir les premiers contacts commence par rencontrer une montagne qui semblait être couverte de neige et n'était qu'un amas d'ossements humains. Ensuite elle patauge dans un marécage formé des corps en putréfaction pour arriver enfin devant Pékin où s'amoncellent les os de soixante mille jeunes femmes qui s'étaient jetées du haut des murailles pour éviter de tomber dans les mains des Mongols.

Tout cela, et bien d'autres choses, n'empêchent pas Muhammad Khwarezmshah de se montrer intraitable et de commettre la gaffe suprême en ordonnant le meurtre de plus de quatre cents marchands voyageant sous les auspices des Mongols, à Utrar, sur les bords du Sin Darya, en 1218. Même s'il fallait un prétexte pour l'invasion mongole, celui-ci venait d'être fourni. p046 Seulement, avant d'arriver en Transoxiane, il restait encore un ou deux peuples à liquider en route, ce qui donnera aux Khwarezmshahs un répit d'environ un an. C'est en poursuivant un de ces peuples, les Merkit, que les Mongols apparaîtront au nord-ouest de la mer d'Aral. Toujours inconscient du danger, Muhammad Khwarezmshah ira les forcer au combat malgré le refus initial des Mongols, déclarant ne vouloir s'occuper que d'un ennemi à la fois. Une bataille, pourtant indécise, laissera un tel souvenir au souverain qu'il passera l'année qui lui reste à vivre à fuir éperdument devant les Mongols, jusqu'à sa mort sur une petite île de la mer Caspienne en décembre 1220.

La conquête mongole commencera par Utrar qui fut prise fin 1219. Bukhara résista trois jours, plus douze pour la citadelle dont les défenseurs furent massacrés jusqu'au dernier, tandis que la ville fut seulement ( !) brûlée et ses murailles rasées. Ensuite, ce fut le tour de Samarkande qui, elle, résista cinq jours. Alors, une partie de l'armée se lança à la poursuite de Muhammad Khwarezmshah. En soumettant ou en détruisant les villes et les régions sur leur passage, selon la promptitude à la reddition de leurs habitants, les Mongols traversent le Khorasan, arrivent à Rey, au sud de l'actuelle Téhéran, et poussent ensuite jusqu'à Hamadan. Devant la disparition du souverain Khwarezmshah, ils allèrent passer l'hiver dans l'Azerbaïdjan où ils profitèrent de leur 
séjour pour battre les Géorgiens en février 1221. Au printemps de cette année, ils retournèrent à Hamadan pour mater une révolte avant d'envahir de nouveau la Géorgie et le Caucase et de remonter vers les plaines de la Russie du Sud où ils dispersèrent une coalition des forces locales en avançant jusqu'à la Crimée pour mettre à sac le comptoir génois de Sudak. Enfin, en traversant la Volga ils vinrent rejoindre Gengis en Transoxiane après un des plus longs raids de l'histoire. p047

Quant à Gengis, il descendit vers l'Afghanistan après avoir passé l'été de 1220 dans la région de Samarkande. Les habitants de Tirmidh voulurent résister, ce qui entraîna un siège de onze jours et le massacre de toute la population. On dit même qu'une femme, ayant avalé ses perles pour les soustraire au pillage, causa aux soldats le travail supplémentaire d'avoir à éventrer tous les cadavres. Au début de 1221, Balkh se soumit. Ce ne fut pas le cas de Merv qui a dû être conquise après huit jours de siège. Là, la tâche d'extermination était ardue puisqu'après une répartition méthodique chaque soldat se trouvait chargé du massacre de quatre cents victimes. Des troupes retournèrent même, quelques jours après, pour exterminer les quelques rescapés qui avaient pu se réfugier dans les caves ou les grottes des environs. Les plus mesurés parmi les chroniqueurs contemporains donnent sept cent mille victimes, tandis qu'un recensement des corps sur place aurait permis d'atteindre le chiffre d'un million trois cent mille. Il est vrai que Merv était une des villes des plus peuplées de l’islam.

La liste des massacres peut s'allonger indéfiniment avec quelques raffinements supplémentaires de ci de là. A Nishapur, où un général mongol fut tué dans une révolte d'habitants, il a été ordonné que les chiens et les chats feraient également partie du massacre et que la ville serait rasée et son site labouré. La liste sera close avec Hérat, laquelle, révoltée, ne sera soumise qu'en juin 1222. Ici, les estimations atteignent le chiffre de un million six cent mille morts, comprenant probablement les habitants des environs qui se réfugièrent dans la ville pendant le siège.

Après la conquête, les régions correspondant à l'Afghanistan et l'ouest du Pakistan actuel, ainsi que le Tadjikistan, le Kirghizistan et l'Uzbekistan soviétique (moins le Khwarezm) composèrent l'apanage de Tchaghatai, deuxième fils de Gengis, et de ses descendants. L'Iran sera gouverné par des vice-rois jusqu'à ce que ${ }_{\text {p048 }}$ Hulagu, fils de Tu- 
lui, lui-même fils cadet de Gengis, envoyé pour achever la conquête, crée l'empire ilkhanide en 1256. Enfin, le Khwarezm fera partie de l'apanage de Djoetchi, fils aîné de Gengis, et de ses descendants qui fonderont l'empire de la Horde d'Or.

Les Mongols ilkhanides de l'Iran qui seront les premiers à se sédentariser - au même moment que les Mongols de la Chine — et à adopter la religion locale, l'islam, s'opposeront assez vite aux descendants de Tchaghatai, restés nomades et shamanistes. Le Khorasan, qui comprenait alors en plus le nord-ouest de l'Afghanistan actuel, constituera la pomme de discorde. Cela rendra nécessaire l'existence d'un État tampon. Il sera formé autour de Hérat par une dynastie locale, les Kurt (ou Kart) à partir de 1245.

Les descendants de Tchaghatai se mêlèrent, dans un premier temps, aux luttes pour le pouvoir suprême dans l'empire mongol entre les fils d'Oegedei, troisième fils et successeur de Gengis, et ceux de Tului, le fils cadet. Le conflit sera résolu au profit de ces derniers, mais l'empire de Tchaghatai plus vulnérable, continuera à subir le contrecoup des dissensions internes jusqu'à la fin du XIII ${ }^{\mathrm{e}}$ siècle. C'est alors que Duwa (1282-1306), arrière-arrière-petit-fils de Tchaghatai, réussira à établir son pouvoir sur ses possessions. Mais, si les Mongols Ilkhans en Iran et les Mongols Yuan en Chine, finissent par prendre la relève des dynasties qui dans ces pays se succèdent cycliquement et s'insèrent ainsi dans la continuité socio-politique des régions qu'ils avaient conquises et si les Mongols de la Horde d'Or arrivent à surnager dans l'espace lâche et peu complexe des steppes russes, les Tchaghatai se trouvent eux à cheval sur des espaces fortement dissemblables. L'opposition se manifeste entre la Transoxiane, de tradition musulmane, urbaine et commerçante par-dessus tout, et l'Est, shaman et nomade, qui sera connu, plus tard, sous le nom de Turkistan. La structure tribale féodale mongole trouve sa raison d'être dans le contexte géopolitique de l'Est, ${ }^{049}$ tandis qu'une renaissance, même très relative, du réseau urbain à l'ouest montre l'intérêt primordial pour les finances et les structures mêmes d'un État, de la résurgence d'un flux commercial à travers la Transoxiane. Et cette résurgence passe plus ou moins à travers la reconversion à l'islam, condition principale du rétablissement des liens rompus avec le reste du monde islamique. Ghazan Khan l'Ilkhan s'était déjà rendu à cette évidence depuis 1295 et Uzbek Khan de la Horde d’Or l'avait aussi fait depuis 
1313. Le grand commerce ainsi rétabli à travers Saray, capitale d'Uzbek, vers le Khwarezm et sa capitale Urgentch, qui faisait aussi partie des dominions de la Horde d'Or, rendait nécessaire l’intégration de la Transoxiane des Tchaghatai. Or la fin du long règne de Duwa ravive les prétentions des descendants d'Oegedei, et les longues luttes qui suivent montrent, même si elles sont assez mal connues, le conflit des intérêts en présence.

Koentchek, premier fils de Duwa à lui succéder, est couronné à Almalik, la capitale traditionnelle des Tchaghatai située dans la région de l'est, et meurt en 1308 dans cette même région. Le souverain suivant est Taliqu, cousin éloigné de Duwa, qui était musulman, représentant, en quelque sorte le parti de l'Ouest. Il sera tué l'année suivante par Kebek, autre fils de Duwa, qui règnera (1309-1310) le temps de convoquer une assemblée de chefs mongols qui élisent à la royauté son frère Esen Buqa (1310-1318). Ce dernier essaie de créer un équilibre entre les deux parties de l'empire, mais c'est avec le retour de Kebek (1318-1326) que le centre de l'État se portera plus durablement vers la Transoxiane où le souverain s'établit près de Nakhshab, l'actuelle Karshi. Le fait que les chroniqueurs musulmans, y compris Ibn Battûta, louent son sens de justice montre qu'il était favorable aux musulmans et par conséquent aux activités urbaines et commerciales de la Transoxiane. Les règnes éphémères de ses deux frères et successeurs Iltchighidai (1326) et Duwa Timur (1326) semblent ${ }_{\mathrm{p} 050}$ constituer un retour du balancier, car c'est pendant le règne de ce dernier que le moine dominicain Thomas Mancasola lance une campagne d'évangélisation dans l'Asie centrale. Les Mongols reviennent ainsi périodiquement à la politique de protection du christianisme comme contrepoids à l'islam. Cette réaction est courte, comme les durées de règne l'indiquent, et avec Tarmashirin (1326-1334), sixième fils de Duwa, on revient officiellement à l'islam. C'est la période de la renaissance, passagère et relative, de la Transoxiane, à laquelle correspond la visite d'Ibn Battûta.

Ce dernier voit bien l'opposition entre les deux parties de l'empire, et c'est par elle qu'il explique la chute de Tarmashirin. Les chefs mongols de l'Est se révoltent contre le délaissement de cette partie de l'empire et élisent Buzan, un fils de Duwa Timur, souverain injuste, selon Ibn Battûta, et par conséquent protecteur des chrétiens et des juifs. Buzan disparaît cette même année 1334 et il lui succède 
Tchengshi, fils d'Ebügen, un autre fils de Duwa. Le centre de l'empire se déplace encore vers l'est ; Tchengshi réside à Almalik où le pape nomme un archevêque qui y bâtit une cathédrale. Mais la Transoxiane semble avoir acquis une puissance suffisante pour ne plus se soumettre à cet état de choses. C'est de cette époque, ou plutôt de celle du frère et successeur de Tchengshi, Yisun Timur (1338-1339), que date la révolte d'un cheikh nommé Khalil et présenté par Ibn Battûta comme descendant de Tchaghatai. Celui-ci, aidé par les Kurt de Hérat et par une famille des chefs héréditaires de Tirmidh, réussit à établir un pouvoir islamique en Transoxiane; on possède des monnaies, frappées à son nom, datées de 1342 et de 1344 . Or, pendant cette période, un autre descendant de Tchaghatai, Kazgan, se trouvant à la tête de l'empire (1343-1346), bâtit un palais à Nakhshab. De toute façon, ces événements, très mal connus, amènent un éclatement de fait de l'empire tchaghatai et l'autonomie relative des villes de la Transoxiane. Même dans le p051 Khwarezm, où l'éclatement de la Horde d'Or suit de près celui des Tchaghatai, une dynastie turque musulmane, les Soufides, apparaît à partir de 1364. Ce milieu facilitera finalement l'éclosion de Timur à la fin du siècle.

Ainsi, Ibn Battûta pénètre dans ce troisième empire mongol pendant les années qui suivent son islamisation — ou plutôt l'islamisation de sa classe dirigeante - et quelques années avant sa chute. En fait, tout se passe comme si, avec la pénétration de l'islam, ces empires nomades perdaient leur raison d'être. Mais cet intermède entre l'islamisation et la chute — qui va de 1295 à 1335 pour les Ilkhans, et de 1313 à 1359 pour la Horde d'Or — est encore plus courte pour les Tchaghatai et se résume pratiquement au règne de Tarmashirin.

La rencontre d'Ibn Battûta avec Tarmashirin pose, comme on l'a signalé plus haut, un problème chronologique lié à la date d'arrivée de notre auteur en Inde. Les chroniques concernant cette période de l'empire des Tchaghatai sont rares, voire inexistantes, et souvent la seule source est encore Ibn Battûta lui-même. On possède tout de même des monnaies de Buzan datant de 1334, et seulement de 1334 . Tchengshi, qui lui a succédé, est tué en 1338. D’autres sources donnent comme successeur éphémère à Tarmashirin son fils Sandjar, ce qui peut conduire à l'hypothèse de l'existence simultanée de deux souverains, à l'est et à l'ouest. Il est impossible d'aller plus loin dans l'état actuel de nos connaissances; disons seulement que, au cas où il 
faudrait dater la déposition de Tarmashirin de 1334, sa rencontre avec Ibn Battûta devrait avoir eu lieu en mars 1333 et non 1335. Il serait alors nécessaire de repousser de deux ans l'ensemble de la chronologie, en reprenant le scénario exposé plus haut. p052

En commençant à lire cette partie du récit, on se rend compte qu'au fur et à mesure que notre homme pénètre en Asie centrale, il acquiert, ou il se donne, de l'importance. Arrivé à Urgentch, le cadi de la ville vient personnellement à sa rencontre. Le vice-roi d'Uzbek Khan, qui appartient aussi très probablement à la famille impériale, et sa femme rivalisent pour lui offrir festins et récompenses ; ainsi il finit par recevoir mille pièces d'argent. Plus loin, dans la ville de Khat, l'émir et le cadi sortent également à sa rencontre. Enfin, il reste cinquante-quatre jours dans le camp de Tarmashirin, en relation étroite avec le souverain. Dans la Transoxiane, centre ancien de la culture islamique, dévasté par les Mongols et qui vient de revenir officiellement à l'islam, l'arrivée d'un pèlerin maghrébin transportant dans sa besace une bonne collection de lieux saints, assaisonnés de quelques pointes d'exotisme comme «Constantinople la Grande », serait donc capable de faire sensation!

A partir de Saray et jusqu'à son arrivée dans le camp de Tarmashirin, Ibn Battûta donne un itinéraire précis qui permet de dater ses déplacements. En suivant la chronologie traditionnelle qui le fait partir vers le 10 décembre 1334 de Saray, on le retrouve vers le 20 février 1335 dans le camp du souverain où il reste jusqu'à la mi-avril. Mais, Tarmashirin ayant probablement disparu de la scène de l'histoire à cette date, c'est précisément cette rencontre qui nous fait reculer la date de deux ans et ramener alors son arrivée à la mi-mars 1333 et son départ au début mai de la même année. Toutefois, il signale un froid excessif au moment de son départ, froid qui devient plus plausible dans l'hypothèse de la mi-avril que pour celle du début mai.

Au-delà du camp royal, on peut encore dater facilement son itinéraire à travers Samarkande et Tirmidh jusqu'à Balkh où il a dû arriver vers le 10 mai 1335, ou la fin mai 1333. Mais à partir de cette ville les cartes se brouillent, et un examen tant soit peu attentif du texte ${ }_{p 053}$ montre l'impossibilité d'un voyage au Khorasan. Cette impossibilité est avant tout chronologique. A la fin de ce parcours en Asie centrale, Ibn Battûta nous donne sa première date explicite depuis son départ de 
La Mecque. Cette date correspond au 12 septembre 1333, ou bien, selon l'autre interprétation, au 23 août 1335. Pour arriver au bord de l'Indus à ces dates, notre auteur part de Qunduz, au nord de l'Afghanistan, afin de traverser les montagnes d'Hindu Kush, à la mijuillet (ou au début août). Il a dû attendre dans cette localité une quarantaine de jours afin que les chaleurs atteignent leur maximum. Étant, en tout état de cause, arrivé à Qunduz en venant de Balkh, il a dû quitter cette ville vers le début (ou la fin) juin. Alors il lui reste, en tout et pour tout, pour son voyage du Khorasan, commençant et se terminant à Balkh, et dans les deux hypothèses, moins d'un mois, et cela pour parcourir deux mille cinq cents kilomètres et visiter huit villes.

A côté de l'aspect chronologique, pourtant déterminant, d'autres éléments viennent s’ajouter. A partir de Balkh et jusqu’à Qunduz, Ibn Battûta ne cite aucune rencontre avec des personnages vivants, aucun événement direct, si ce n'est l'achat d'un esclave à Nishapur, et ne donne aucune distance, sauf celle de Balkh à Hérat, laquelle risque fort d'être fausse, puisqu'il nous dit avoir parcouru plus de cinq cents kilomètres de terrain montagneux en sept jours. Toutefois, un allerretour Balkh-Hérat est toujours possible dans le temps qui reste. Le trajet de Balkh à cette ville est brièvement mentionné ; par contre, si l'histoire du souverain de cette ville, Mu'izz al-din Kurt, est relatée, Ibn Battûta ne dit pas l'avoir rencontré, ce qui n'est pas conforme à ses habitudes. On pourrait dire en conclusion que le voyage de Hérat, où notre auteur aurait, dans ce cas, passé la fête du Ramadhan, tombant le 26 mai 1335 (ou le 15 juin 1333), est possible mais non certain. L'autre hypothèse est celle d'un séjour prolongé pendant une bonne partie du mois de Ramadhan dans Balkh ou sa 054 région, en attendant l'été pour traverser l'Hindu Kush. Cela expliquerait l'absence de toute mention de la fête du Ramadhan de cette année, puisqu'elle intervient au cours d'un voyage fictif.

La raison de ce voyage imaginaire au Khorasan est sans doute liée au caractère sacré des lieux décrits, puisqu'il s'agit encore d'un pèlerinage. Déjà, en pénétrant dans la Transoxiane, Ibn Battûta retrouve un héritage sacré et surtout mystique dans cette terre lointaine, mais fertile de l'islam dont les racines subsistent à travers les ruines.

L’Asie centrale et le Khorasan furent des pépinières mystiques aussi importantes que l'Irak ou l’Égypte. Ces régions, lieux de ren- 
contre de l'islam, du shamanisme, du bouddhisme, de l'hindouisme, avec les anciennes traditions zoroastriennes, ont donné naissance aux courants malamatis du mysticisme musulman (voir préface du t. I), dont l'origine remonte à Abu Yazid al-Bistami, mort en 874, et c'est le tombeau de ce saint à Bistam qui constitue le point extrême de l'excursion imaginaire d'Ibn Battûta dans le Khorasan. Ces courants qui se développent au seuil des immenses territoires asiatiques par où vont déferler les peuples nomades des steppes influenceront de façon décisive les nouveaux venus, et ceux-ci, à leur tour, les transporteront vers d'autres lieux d'établissement définitif. Ainsi les Turcs, de passage en Transoxiane et dans le Khorasan, vont s'initier aux courants mystiques parallèlement à leur conversion à l'islam, pour les véhiculer, par la suite, vers l'Asie Mineure et l'Inde. Là, ces courants utiliseront leurs capacités syncrétiques pour convertir des chrétiens orthodoxes ou des hindous à un islam quasi animiste. Enfin, l'invasion mongole, avec l'anti-islamisme militant de ses débuts, déracinera les formations mystiques de la Transoxiane et du Khorasan. Les cheïkhs et les derviches se déplaceront alors vers l'extrême est ou l'extrême ouest afin de participer physiquement et p055 spirituellement à la conquête des nouvelles terres et des nouvelles âmes pour l'islam.

Ainsi, Ibn Battûta visite à Urgentch, capitale du Khwarezm, la tombe de Nadjm al-din Kubra, disciple d'Abu'l Nadjib Suhrawardi, aîné des fondateurs de l'ordre de ce nom, et fondateur lui-même de l'ordre soufi de Kubrawiyya qui se dispersera à travers plusieurs branches dans l'Inde et dans le Khorasan. Il mentionne également le tombeau du cheïkh Haidar dans la ville khorasanienne de Zaveh, l'actuelle Torbat-i Haydarieh (le Tombeau de Haidar). Ce dernier est connu comme disciple de Djamal al-din al-Sawadji, fondateur de l'ordre malamati de Qalandariya mentionné par Ibn Battûta au cours de son passage à Damiette (voir t. I, p. 116 et introduction). Haidar fonde également son propre ordre, la haidariyya, connu pour ses pratiques antinomiques dont l'utilisation des stupéfiants et les mutilations sexuelles. Celles-ci sont attestées par des voyageurs européens plus tardifs qui nous ont laissé des illustrations dont les plus anciennes datent du XVI $\mathrm{XI}^{\mathrm{e}}$ siècle.

Enfin, par ce voyage imaginaire à travers le Khorasan, Ibn Battûta brosse, par petites touches dispersées selon son habitude, le tableau politique de la région au cours de la période qui suivit l'éclatement de 
l'empire ilkhanide. Il faut alors essayer encore une fois de relier ces informations dans un cadre plus général.

La formation politique la plus solide dans la région est sans doute le royaume des Kurt, ayant pour centre Hérat et contrôlant, après l'éclatement de l'empire Tchaghatai, la quasi-totalité de l'Afghanistan actuel. Vassaux des Ilkhanides, les Kurt se sont mêlés à l'affaire de l'émir Tchoban (voir t. I, p. 449 et introduction) et ont accédé à l'indépendance après 1335, pour disparaître sous les coups de Timur, en 1389. p056

A cette stabilité relative de l'Afghanistan, le Khorasan oppose une situation plus complexe. Entre sa conquête en 1219-1221 et la fondation de l'empire ilkhanide en 1256, cette région était gouvernée par des vice-rois mongols, dont le dernier, appelé Arghun, chef de la tribu des Oirat, fut maintenu gouverneur du Khorasan sous Hulagu et ses successeurs. Il fit reconstruire la ville de Tus, et ses descendants s'y taillèrent un fief comprenant Djam et Nishapur. Ainsi, on trouvera en 1338 un petit-fils et homonyme d'Arghun comme seigneur de ces contrées. De même, un descendant d'un frère de Gengis Khan, appelé Togha Timur, qui fut mêlé pendant un moment aux luttes de succession de l'empire ilkhanide, et proclamé khan en 1338-1339 (voir introduction du t. I), se retira dans la région de Gurgan, entre le Mazanderan et le Khorassan, à l'est de la mer Caspienne, pour former une petite principauté. Au-delà de ces limites, des dynasties locales indéracinables gouvernent des régions isolées, comme les forêts du Mazanderan, entre les monts Alborz et la mer Caspienne, ou les oasis du Sistan, au-delà du grand désert iranien. Celles-ci, protégées par leurs montagnes et leurs déserts, se retirent à l'intérieur de leurs terres lorsqu'un pouvoir fort s'exerce sur l'ensemble de l'Iran, pour ressortir et se répandre dans les environs pendant les périodes de faiblesse du pouvoir central. Ainsi les souverains du Mazanderan descendent les pentes sud de l'Alborz pour occuper Simnan, tandis que les princes de Sistan entrent en relation avec les Kurt de Hérat.

Mais c'est au centre du Khorasan qu'un bouillonnement va se produire. Là, l'activisme shi'ite qui ronge son frein depuis l'élimination du mouvement ismaïlite (voir introduction du t. I) par Hulagu, les mouvements mystiques qui ne demandent que l'occasion d'exploser en révoltes sociales, et les mécontents ou persécutés de toutes sortes, 
se réunissent pour former ce que les historiens bien-pensants appellent une république de brigands : les serbedars (le mot signifie pendard, p057 desperado ou tout autre qualificatif du même ordre). Le fondateur en est un certain Abd al-Razzak, collecteur d'impôts au nom des Ilkhans qui préféra dépenser pour la cause les sommes reçues. Lancé sur la scène politique en 1336, il fut assassiné deux ans plus tard par son frère Mas'ud, lequel associe à son pouvoir un derviche shi'ite en devenant en même temps son disciple. La composante shi'ite et mystique du mouvement sera ainsi prépondérante tout au long de son histoire.

Les serbedars s'attaquent en 1338 à Arghun, le seigneur de Nishapur, et occupent cette ville ainsi que celle de Djam. Ensuite, c'est le tour de Togha Timur d'être battu et de perdre la ville de Gurgan. Devant ces succès, la puissance principale de la région, les Kurt, intervient. Une bataille est livrée en 1343 ; les serbedars sont vaincus mais point éliminés. Ils se limiteront dorénavant au Khorassan iranien actuel, ayant comme centre Sabzevar, au nord-ouest de Nishapur. Mas'ud mourut en 1346-1347, et ses successeurs, soumis à l'influence des différents groupes de derviches et guerroyant avec les autres princes locaux, survivront jusqu'à l'arrivée de Timur dans les années 1380. Ibn Battûta apprend les faits concernant la première partie de leur histoire à son retour vers le Proche-Orient en 1347, mais préfère les insérer, selon son habitude, dans cette partie du récit.

Quand notre homme a-t-il eu l'idée pour la première fois de partir pour l'Inde non pour un bref passage, mais pour une installation longue, sinon définitive ? Depuis son départ de La Mecque, deux ans plus tôt, comme il le précise lui-même, ou depuis son arrivée en Asie centrale ? Les deux hypothèses sont probablement vraies. Il avait déjà dû entendre des récits sur les fabuleuses richesses de l'Inde pendant son séjour à La Mecque, mais, ayant décidé, pour une raison ou une autre, de visiter l'Asie Mineure et la Russie, c'est en Asie centrale qu'il a dû se rendre compte de ce remue-ménage de personnages importants, quittant une région ${ }_{p 058}$ dévastée et politiquement peu sûre pour aller offrir leurs services au magnifique Muhammad bin Tughluk, empereur de - presque - tout le sous-continent indien. C'est ainsi qu'Ibn Battûta s'incorpore à la caravane des illustres voyageurs dont il cite abondamment les noms et les péripéties vers le nouvel eldorado de l'islam, l'Inde. 


\section{L'INDE (PREMIÈRE PARTIE)}

Retour à la Table des Matières

La description de l'Inde constitue la partie centrale des Voyages d'Ibn Battûta, aussi bien par son volume - elle couvre presque le tiers de l'ensemble de l'ouvrage - que par les informations. Elle se divise en cinq chapitres dont le premier et le dernier restent dans le style de l'ouvrage, tandis que les trois chapitres centraux se présentent sous un aspect assez différent. Le premier relate le voyage de notre auteur depuis l'Indus jusqu'à Dihli et se termine avec la description de cette ville. Le dernier est consacré à son départ définitif de Dihli, en vue d'une ambassade à la cour chinoise, à son voyage le long des côtes indiennes ainsi qu'à ses aventures aux Maldives, dans le sud de la péninsule, à Ceylan et au Bengale. Là aussi les informations sur les endroits visités se mêlent aux péripéties personnelles dans un ordre plus ou moins chronologique. Or, dans la partie centrale de son récit indien, notre voyageur se transforme en historien et chroniqueur de sultanat de Dilhi. Ainsi le deuxième chapitre relate l'histoire du sultanat depuis sa fondation jusqu'à l'avènement de Muhammad bin Tughluk, souverain contemporain d'Ibn Battûta ; le troisième est une présentation du bon et du mauvais gouvernement de ce souverain, et le quatrième, la chronique des événements de son règne jusqu'en 1347, date du retour d'Ibn Battûta au Proche-Orient, puisqu'en dictant son ouvrage, en 1355, notre auteur ne semble pas être au courant de la mort du souverain indien survenue en 1351. p059

On ne peut pas dire qu'au cours de ces trois chapitres son style se modifie sensiblement. A l'époque, les différences de style entre le récit d'histoire, le récit géographique et ce texte hybride qu'est le récit de voyage ne sont d'ailleurs pas bien marquées. Toutefois, l'auteur prend bien soin, pour une fois, de citer ses sources dans sa partie historique où, même si aucune date ne figure, un ordre chronologique est respecté et son récit s'écarte peu des autres sources. Il reste, enfin, qu'Ibn Battûta est une des trois ou quatre sources principales contemporaines qui nous font connaître l'histoire de l'Inde musulmane, et son texte, rédigé en dehors des influences de la cour de Dihli, est probablement le plus objectif. Ainsi, son récit constitue l'élément de base de tous les ouvrages traitant de l'Inde à l'époque, et ses témoignages 
et jugements sont encore âprement discutés parmi les historiens indiens.

Le découpage fait dans cette édition ne permet pas de concentrer l'ensemble du récit indien en un seul volume. Ainsi ce deuxième volume contient les trois premiers chapitres. Le reste se trouve au début du troisième volume. Cette partie de la préface sur l'Inde se rapporte donc au texte contenu dans ce volume.

Notre auteur, ayant cette fois consacré un chapitre entier à l'histoire du sultanat de Dihli, et les quelques problèmes posés par ce récit ayant été abordés dans les notes, il n’est plus besoin de les reprendre ici. Il suffit d'esquisser le cadre dans lequel les événements mentionnés se déroulent.

Les écrivains arabes - et Ibn Battûta ne fait pas exception - divisent l'Inde en deux parties fort inégales : le Sind, constitué par la vallée de l'Indus, et le Hind, qui contient tout le reste. La raison en est que le Sind fut conquis au début de l'expansion arabe, en 712, tandis que la conquête systématique du reste de l'Inde ne débute qu'à la fin du XII ${ }^{\mathrm{e}}$ siècle. Entre ces deux ${ }_{\mathrm{p} 060}$ dates, le Sind resta jusqu'à la fin du $\mathrm{IX}^{\mathrm{e}}$ siècle sous la tutelle du califat et fut, par la suite, gouverné par des dynasties musulmanes locales jusqu'à l'apparition des Ghaznavides dans l'Afghanistan actuel à partir de la fin du $\mathrm{x}^{\mathrm{e}}$ siècle. Ce nouvel État présentait déjà la première concentration de tribus turques islamisées en quête de nouvelles terres de colonisation, et c'est ainsi que Mahmut de Ghazna mènera ses dix-sept célèbres campagnes contre l'Inde en se rendant maître du Pendjab, la région des cinq affluents de l'Indus.

La gloire des Ghaznavides sera de courte durée. La grande vague turque qui fonde l'empire seldjukide les relègue à la taille d'un État local du sud de l'Afghanistan et, lorsque la puissance seldjukide déclinera à son tour, vers le milieu $\mathrm{du}_{\mathrm{XII}}{ }^{\mathrm{e}}$ siècle, ce ne sont plus les Ghaznavides mais une autre puissance locale, les Ghurides, qui prennent le contrôle de l'Afghanistan. Les derniers Ghaznavides sont chassés de leur capitale, Ghazna, vers 1160, et se réfugient à Lahore, dans le Pendjab ; les Ghurides contrôlent toute la région et, à partir de 1173, deux frères, Ghiyath al-din Muhammad dans le Ghur et Mu'izz al-din Muhammad à Ghazna, se partagent le pouvoir. C'est ce dernier qui entreprend la conquête du nord de l'Inde après avoir supprimé, en 
1181, les derniers Ghaznavides de Lahore ; la conquête est menée par des chefs de guerre turcs, et l'un d'entre eux, Qutb al-din Aibak, restera seul maître des possessions indiennes après la mort de Ghiyath aldin Muhammad en 1206 et la conquête des territoires afghans des Ghurides par les Khwarezmshahs.

La rapidité de la conquête des plaines indo-gangétiques, c'est-àdire de l'Inde du Nord, du Sind au Bengale, surprend, et plusieurs explications ont été évidemment proposées. Parmi elles se dégage un fait : l'extrême morcellement politique de ces régions à l'époque de la conquête musulmane. Des coalitions éphémères et mal préparées n’ont presque jamais pu résister ${ }_{\text {p061 }}$ aux attaques de la cavalerie turque. Par contre, dans le Deccan et dans l'extrême sud de la péninsule, à côté d'une multitude de petites formations, quatre dynasties se partagent la plus grande partie de la région. Ce sont les Yadavas de Deogir, la future Daulatabad, dans la région actuelle de Maharashtra ; les Kakatiyas de Warangal dans l'actuelle Andhra Pradesh ; les Hoysalas de Dvarasamudra, ville aujourd'hui disparue dans la Mysore et les Pandyas de Madura à l'extrême sud. Ces États ont réussi à opposer une résistance hindoue tout au long du XIII ${ }^{\mathrm{e}}$ siècle, en maintenant le sultanat dans les limites des plaines de l'Indus et du Gange, tandis qu'au nord les possessions musulmanes s'arrêtent aux premières collines annonçant l'Himalaya, occupées, d'est en ouest, par les royaumes hindous d'Assam, de Mithila, du Népal et du Cachemire. Dans ce dernier, la dynastie locale sera supplantée, en 1346, par une dynastie musulmane, mais le pays vivra séparé du reste de l'Inde jusqu'à la fin du XVI ${ }^{\mathrm{e}}$ siècle. Enfin, à l'est et à l'ouest, à la racine de la péninsule, l'Orissa et le Gudjarat maintiendront leurs royaumes hindous jusqu'au XIV ${ }^{\mathrm{e}}$ siècle, et même au-delà.

La conquête du Sud donnera un second souffle au sultanat de Dihli. Elle débute en 1295 par un raid du futur souverain Ala al-din Khaldji, et les richesses fabuleuses qu'il recueille lui ouvrent le chemin du pouvoir. Cette première opération montre aussi bien la quantité des trésors qui y sont accumulés que la faiblesse de leurs défenseurs. Les expéditions au sud deviennent alors monnaie courante aussi bien pour renflouer des trésors vides que pour préparer des nouvelles vocations à la conquête du pouvoir suprême. Ces expéditions, qui finiront par importer la crise économique à travers l'inflation de l'or, et la crise politique à travers l'inflation des prétendants, ne visent pas, dans un 
premier temps, la suppression des royaumes hindous, mais leur utilisation comme vaches à lait. Ce n'est que quand les royaumes les plus proches deviendront des enjeux de luttes p062 internes que leur suppression s’imposera ; Deogir sera définitivement annexé en 1317, Warangal en 1323. Plus au sud, Madura est également conquise, les derniers Pandya se retirent à l'extrémité de la péninsule, tandis que le dernier Hoysala arrive à ménager les conquérants.

Ainsi, à l'arrivée d'Ibn Battûta, Muhammad bin Tughluk contrôle la plus grande partie de la péninsule, mais pas pour longtemps. Il part, en 1335, pour mater la révolte d'un de ses lieutenants à Madura, mais, l'armée ayant été décimée par une épidémie, un premier État musulman se fonde dans cette région. Par la suite, les interminables révoltes du règne de Muhammad Tughluk aboutiront à l'indépendance du Deccan avec la création du royaume bahmanide, en 1347. Au sud de cette barrière, les Hindous se regroupent pour fonder l'empire des Vijayanagara, et les territoires du nord éclatent progressivement en plusieurs États.

L'arrivée d'Ibn Battûta en Inde correspond donc à l'apogée, mais aussi au commencement de la fin du sultanat de Dihli. Même si notre voyageur ne semble pas être conscient de son déclin, son récit, très explicite, permet de le tracer. On y reviendra dans l'introduction du troisième volume.

A l'époque du séjour d'Ibn Battûta, la diffusion du mysticisme islamique en Inde était en très bonne voie. Absorbant les pratiques mystiques et ascétiques hindoues ; profitant de la crise religieuse qui résulte de l'apparition de l'islam comme religion dominante, laquelle renie l'hindouisme dans son principe même ; utilisant la crise politique issue de la domination d'une nouvelle caste de guerriers turcs ou afghans, le mysticisme islamique s'enracine au point de devenir la religion de fait des grandes masses populaires. Sa toute-puissance ne peut pas ne pas avoir de débordements politiques, et les grands saints ont tendance à se ${ }_{\mathrm{p} 063}$ transformer en faiseurs de rois. Ces derniers sont obligés de mener une politique à deux faces : ménager ces saints personnages pour s'attirer les faveurs populaires et les mater quand ils deviennent trop dangereux. Muhammad bin Tughluk ira précisément assez loin dans cette dernière politique, et c'est peut-être une des rai- 
sons de sa mauvaise réputation, encore qu'il semble l'avoir largement méritée.

Parmi les grands ordres soufis, deux se partagent plus particulièrement les faveurs de la population. Le premier est une excroissance indienne du très officiel ordre irakien des suhrawardis. Plusieurs disciples du fondateur Shihab al-din Abu Hafs Umar s'installent en Inde, et le plus célèbre d'entre eux, Baha al-din Zakariya (1183-1267), fonde une lignée héréditaire, de cheikhs à Multan où Ibn Battûta rencontre son petit-fils, Rukn al-din, et raconte longuement les démêlés du petit-fils et successeur de Rukn al-din avec Muhammad bin Tughluk. Un autre disciple de ce même Baha al-din, Djalal al-din Bukhari, s'installera à Uch sur l'Indus, et c'est probablement d'un de ses successeurs qu'Ibn Battûta, déjà vieil adepte de la Suhrawardiyya, reçoit de nouveau le froc à son passage dans cette ville. Cet ordre, relativement fidèle à ses origines, dans les limites du contexte indien, mènera une politique aussi bien orthodoxe qu'aristocratique et "séculaire ", en gardant de bonnes relations avec le pouvoir et les docteurs de la loi islamique.

Le deuxième grand ordre de l'époque est plus spécifiquement indien, même si son fondateur est né au Sistan, dans l'Est iranien. Mawdud al-Tchishti (1142-1236), déjà mentionné par Ibn Battûta à propos d'événements à Hérat, s'installe pourtant en Inde, et meurt à Ajmer. Son principal disciple, personnage le plus célèbre de la Tchishtiyya, était Qutb al-din Bakhtiyar Kaki, qui s'installa à Dihli, et au nom duquel le célèbre Qutb Minar, le grand minaret de Dihli, semble avoir été érigé. p064 Son tombeau devint un des principaux centres de pèlerinage. Un de ses disciples, Farid al-din Mas'ud, mort en 1271, créa le centre héréditaire d'Adjodhan, l'actuel Pakpattan — visité par Ibn Battûta - et diffusa l'ordre dans l'ensemble de l'Inde musulmane. Le principal cheikh de l'ordre de la génération suivante fut $\mathrm{Ni}$ zam al-din Awliya, qui joua une rôle politique en se mêlant sans doute à la disparition controversée de Ghiyath al-din Tughluk, père de $\mathrm{Mu}-$ hammad. Enfin, le chef de file de l'ordre, à l'époque d'Ibn Battûta, était Nasir al-din, dit "la lumière de Dihli », qui eut plusieurs fois maille à partir avec le souverain. La grande popularité de l'ordre et son implantation à Dihli le rendaient probablement plus influent et par là plus redouté par le pouvoir. Ibn Battûta rend compte de ces personnages, mais il ne semble pas être particulièrement impliqué. 
La rencontre d'Ibn Battûta avec ces saints personnages, morts ou vivants, est relatée au cours du premier chapitre indien, c'est-à-dire dans le récit du voyage à Dihli et de la description de cette ville. Notre auteur va ensuite s'engager dans la grande digression qui vise à dessiner une vaste fresque de la société indienne de l'époque. On l'abordera au cours de l'introduction du troisième volume afin de permettre au lecteur de prendre connaissance de l'ensemble du récit. 


\section{L'océan Indien et le golfe Persique}

Retour à la Table des Matières

Je quittai La Mecque à cette époque-là, me dirigeant vers le Yaman, et j'arrivai à Haddah ${ }^{1}$, qui est à moitié chemin entre La Mecque et Djouddah. Puis j'atteignis cette dernière ville ${ }^{2}$ qui est ancienne, et située sur le bord de la mer ; on dit que Djouddah a été fondée par les Persans ${ }^{3}$. A l'extérieur de cette cité, il y a des citernes antiques, et dans la ville même des puits pour l'eau, creusés dans la pierre dure. Ils sont très rapprochés l'un de l'autre, et l'on ne peut pas les compter, tant leur nombre est considérable ${ }^{4}$. L'année dont il s'agit manqua de pluie, et l'on transportait l'eau à Djouddah, de la distance d'une journée. Les pèlerins en demandaient aux habitants des maisons. p067

\section{ANECDOTE}

Parmi les choses étranges qui me sont arrivées à Djouddah se trouve ceci : un mendiant aveugle, conduit par un jeune garçon, s’arrêta à ma porte, demandant de l'eau. Il me salua, m’appela par mon

1 L'actuelle Hadda, à vingt-cinq kilomètres de La Mecque, à l'endroit où la route de Djedda traverse le Wadi Fatima.

2 « La cité de Djedda est sise sur le bord de la mer ; ses habitations sont, pour la plupart, des cabanes en roseaux. Elle a des fondouks construits en pierre et en argile, en haut desquels il y a des chambres en roseau, pareilles à nos ghorfas ; ces fondouks ont des terrasses, où l'on cherche le repos, la nuit, contre l'accablement de la chaleur. On voit en cette ville des vestiges antiques qui démontrent que ce fut jadis une cité considérable » (IBN DJUBAIR).

Ibn al-Mudjawir, dans sa Description de l'Arabie méridionale, mentionne une occupation de Djedda par les Persans après la destruction de Siraf en 977 par un tremblement de terre (voir plus loin n. 146) ainsi que leur éviction par des Arabes locaux. des citernes. 
nom, et prit ma main, quoique je ne l'eusse jamais connu et qu'il ne me connût pas non plus ; je fus étonné de cela. Ensuite, il saisit mon doigt avec sa main, et il dit : " Où est alfatkhah ? ", c’est-à-dire la bague. Or, au moment de ma sortie de La Mecque, un pauvre était venu à moi, et m'avait demandé l'aumône. Je n'avais alors rien sur moi, et je lui livrai mon anneau. Lorsque cet aveugle m'en demanda des nouvelles, je lui répondis : " Je l’ai donné à un fakir. » Il répliqua : "Va à sa recherche, car il y a sur cet objet une inscription qui contient un des grands secrets. » Je fus très stupéfait de l'action de cet homme, et de ce qu'il savait à ce sujet. Mais Dieu sait le mieux ce qui le concerne !

A Djouddah, il y a une mosquée principale, célèbre par son caractère de sainteté ; on la nomme la mosquée djâmi' de l'Ebène, et la prière y est exaucée ${ }^{5}$. Le commandant de la ville était Abou Ya'koûb, fils d'Abd arrazzâk ; son kâdhi et aussi son khathib était le docteur 'Abd Allah, de La Mecque, et sectateur de Châfi'y. Quand arrivait le vendredi, et que les gens se rendaient au temple pour la prière, le moueddhin venait, et comptait les personnes de Djouddah qui étaient présentes. Si elles complétaient le chiffre quarante, alors le prédicateur prononçait le sermon, et faisait avec elles la prière du vendredi. Dans le cas contraire, il récitait quatre fois la prière de midi, ne tenant aucun compte de ceux qui ${ }_{\text {p06s }}$ n’étaient point de Djouddah, quelque grand que fût leur nombre ${ }^{6}$.

«On y trouve une mosquée bénie qui porte le nom de Omar bin al-Khattab (le second calife), et une autre mosquée qui a deux piliers en bois d’ébène, avec la même affectation à Omar. Suivant une autre opinion, celle-ci se rapporterait à Harun al-Rashid » (IBN DJUBAIR).

6 Selon l'école shafi'ite, la prière du vendredi n'est valide que si l'assistance compte au moins quarante personnes. Dans ce cas, ce nombre est restreint aux seuls habitants de Djedda. 


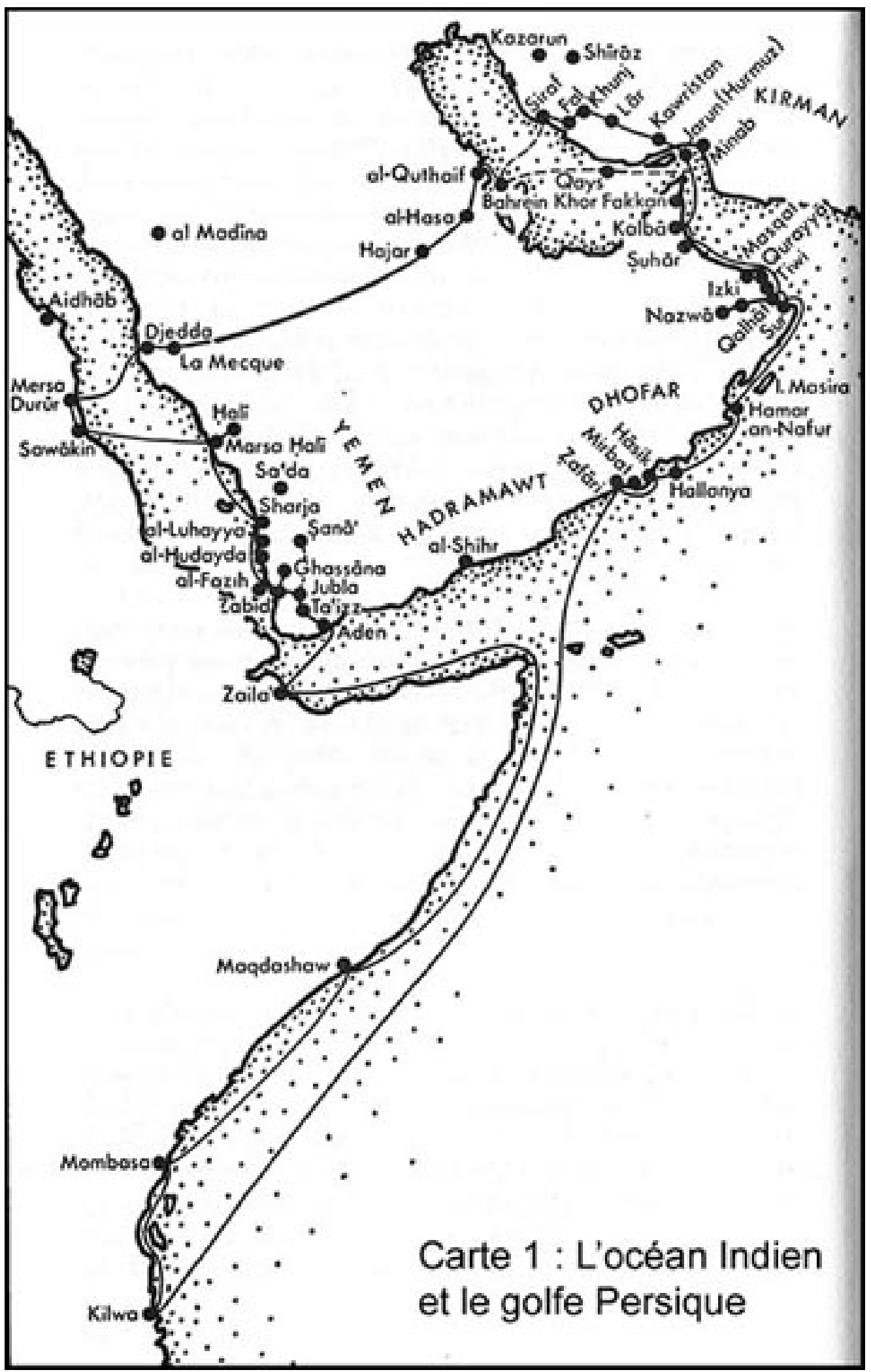


Nous nous embarquâmes dans cette ville sur un bâtiment appelé djalbah ${ }^{7}$ et qui appartenait à Râchid eddîn Alalfy alyamany, originaire de l'Abyssinie. Le cherîf Mansoûr, fils d'Abou Nemy ${ }^{8}$, monta sur un autre bâtiment de ce genre, et me pria d'aller avec lui. Je ne le fis pas, car il avait embarqué des chameaux sur son navire, et je fus effrayé de cela, vu que je n'avais point, jusqu'à ce moment, traversé la mer. Il y avait alors à Djouddah une troupe d'habitants du Yaman qui avaient déjà déposé leur provisions de route et leurs effets dans les navires, et qui étaient prêts pour le voyage.

\section{ANECDOTE}

Lorsque nous prîmes la mer, le cherîf Mansoûr ordonna à un de ses esclaves de lui apporter une 'adîlah ${ }^{9}$ de farine, c'est-à-dire la moitié d'une charge, ainsi qu'un pot de beurre, à enlever l'un et l'autre des navires des gens du Yaman. Il le fit, et apporta ces objets au cherîf. Les marchands vinrent à moi tout en pleurs ; ils me dirent que dans le milieu de l'adîlah il y avait dix milles dirhems en argent, et me priè-

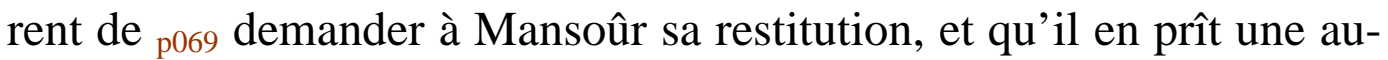
tre en échange. J'allai le trouver et lui parlai à ce sujet, en lui disant que, dans le centre de cette 'adîlah, il y avait quelque chose appartenant aux marchands. Il répondit : « Si c'est du vin, je ne le leur rendrai pas ; mais si c'est autre chose, ce sera pour eux. » On l'ouvrit, et l'on trouva des pièces d'argent, que Mansoûr leur rendit. Il me dit alors : «Si c'eût été 'Adjlân ${ }^{10}$ il ne les aurait point rendues. » Celui-ci est le fils de son frère Romaïthah ; il était entré peu de jours auparavant dans la maison d'un marchand de Damas, qui se rendait dans le Yaman, et il avait enlevé la majeure partie de ce qui s'y trouvait. 'Adjlân

Grandes barques faites de planches jointes avec des cordes de fibres de cocotier dont les patrons « entassent [les pèlerins] [...] à les y faire asseoir les uns sur les autres et ils manœuvrent celles-ci comme si c'était des cages à poulets pleines. Ce qui pousse ces gens-là à agir ainsi, c'est leur cupidité et leur avidité à louer leurs barques. Cela va à tel point que le maître d'une djalba en récupère le prix en un seul voyage et n'a plus ensuite à s'inquiéter de ce que la mer en fera: “A nous les planches. Aux pèlerins leurs âmes !” répètent-ils en un dicton qui a cours parmi eux » (IBN DJUBAIR).

8 Pour Abu Numay et sa famille, voir t. I, p. 313 et ci-dessous chap. 3., n. 59.

9 Mesure ou sac.

10

Voir également t. I, p. 314, et ci-dessous chap. 3, n. 60. 
est maintenant émir de La Mecque ; il a redressé sa conduite, et a fait paraître de l'équité et de la vertu.

Nous voyageâmes sur cette mer pendant deux jours avec un vent favorable ; puis il changea, et nous détourna de la route que nous suivions. Les vagues de la mer entrèrent au milieu de nous dans le navire ; l'agitation fut grande parmi les passagers, et nos frayeurs ne cessèrent que quand nous abordâmes à un port appelé Ras Dawâir ${ }^{11}$, entre 'Aïdhâb et Sawâkin. Nous descendîmes à terre, et trouvâmes sur le rivage une cabane de roseaux ayant la forme d'une mosquée. Il y avait à l'intérieur une quantité considérable de coquilles d'œufs d'autruche, remplies d'eau. Nous en bûmes, et nous nous en servîmes pour cuisiner.

Je vis dans ce port une chose étonnante : c'est un golfe, à l'instar d'un torrent, formé par la mer. Les gens prenaient leur vêtement, qu'ils tenaient par les extrémités, et ils le retiraient de cet endroit rempli de poissons. Chacun de ceux-ci était de la longueur d'une coudée ; et ils les nomment alboûry ${ }^{12}$. Ils en font bouillir une ${ }_{\mathrm{p} 070}$ grande quantité, et rôtissent le reste. Une troupe de Bodjâh ${ }^{13}$ vint à nous ; ce sont les habitants de cette contrée ; ils ont le teint noir, sont vêtus de couvertures jaunes, et ceignent leur tête de bandeaux rouges de la largeur d'un doigt. Ils sont forts et braves ; leurs armes sont la lance et le sabre ; ils ont des chameaux qu'ils nomment sohb ${ }^{14}$, et qu'ils montent avec des selles. Nous leur louâmes des chameaux, et partîmes avec eux par une plaine abondante en gazelles. Les Bodjâh ne les mangent point, de sorte qu'elles s'apprivoisent avec l'homme et ne s'enfuient point à son approche.

Après deux jours de marche, nous arrivâmes à un campement d’Arabes appelés les Fils de Câhil ${ }^{15}$; ils sont mélangés avec les Bod-

Il s’agirait d'après Gibb de l'actuel Mersa Darur, à cinquante-trois milles au nord de Sawakin ou de Mersa cheïkh Barud à quatorze milles au sud du précédent.

Voir t. I, chap. 1, n. 71, encore qu'il soit peu probable qu'il s'agisse du même poisson.

Voir t. I, chap. 1, n. 209.

14

Voir t. I, chap. 1, n. 211.

15

Généralement connus sous le nom de Kawahla. Bien que d'origines diverses, ils prétendent descendre de Kahil, fils d’un petit-fils de Fatima. 
jâh, et connaissent leur langue. Ce jour même nous atteignîmes l'île de Sawâkin ${ }^{16}$.

Elle est à environ six milles du continent, et n'a point d'eau potable, ni de grains, ni d'arbres. On y apporte l'eau dans des bateaux, et il y a des citernes pour recueillir l'eau de pluie. C'est une île vaste, où l'on trouve de la viande d'autruche, de gazelle et d'onagre; elle a beaucoup de chèvres, ainsi que du laitage et du beurre, dont on exporte une partie à La Mecque. La seule céréale qu'on y récolte, c'est le djordjoûr, c'est-à-dire une sorte de millet, dont le grain est très gros ; on en exporte aussi à La Mecque. p071

\section{DU SULTAN DE SAWÂKIN}

C'était au temps de mon arrivée dans cette île, le cherîf Zeïd, fils d'Abou Nemy ${ }^{17}$. Son père a été émir de La Mecque, ainsi que ses deux frères, après ce dernier. Ce sont 'Athîfah et Romaïthah, que nous avons mentionnés plus haut. La domination de cette île lui appartient, comme préposé des Bodjâh, qui sont ses alliés par sa mère. Il a avec lui une troupe formée de Bodjâh, de fils de Câhil, et d'Arabes Djohaïnah ${ }^{18}$.

Nous nous embarquâmes à l'île de Sawâkin pour le pays du Yaman. On ne voyage pas la nuit sur cette mer, à cause de la quantité de ses écueils, mais seulement depuis le lever du soleil jusqu'au soir ; alors on jette l'ancre, on descend à terre, et le lendemain matin on remonte sur le bâtiment. Ces gens appellent robbân le chef du navire ${ }^{19}$, qui se tient toujours à la proue de celui-ci pour avertir l'homme du gouvernail de l'approche des écueils ; ils nomment ces derniers annabât ${ }^{20}$.

Ce port situé dans le Soudan actuel acquerra de l'importance après la destruction d'Aidhab au XV $\mathrm{X}^{\mathrm{e}}$ siècle. Il se compose de deux petites îles très proches de la terre et situées à l'intérieur d'un golfe très enclavé.

Ce personnage ne se retrouve pas dans les généalogies de la famille d’Abu Numay.

18 Tribu de l'Arabie du Sud dont la plupart des tribus arabes du Soudan prétendent descendre.

19 Rubban est le pilote et non le chef du navire (nakhuda).

20

Al-nabat : littéralement les plantes. 
Six jours après notre départ de l'île de Sawâkin, nous arrivâmes à la ville de Hali $^{21}$. Elle est connue sous le nom de Hali d'Ibn Ya'koûb ; c'était un des sultans du Yaman, et il demeura anciennement dans cette ville. Elle est vaste, d'une belle construction, et habitée par deux peuplades d'Arabes, qui sont les Benou Harâm et les Benou Kinânah ${ }^{22}$. La mosquée principale de cette ${ }_{p 072}$ ville est une des plus jolies mosquées djâmi's, et l'on y trouve une multitude de fakirs entièrement livrés au culte de Dieu.

Parmi eux, on remarque le pieux cheïkh, le serviteur de Dieu, l'ascète Kaboûlah alhindy, un des plus grands dévots. Son vêtement consiste en une robe rapiécée, et un bonnet de feutre. Il a une cellule attenante à la mosquée, et dont le sol est recouvert de sable, sans natte ni tapis d'aucune sorte. Je n'y ai vu, lorsque je le visitai, rien autre chose qu'une aiguière pour les ablutions, et un tapis de table, en feuilles de palmier, sur lequel étaient des morceaux secs de pain d'orge, et une petite soucoupe contenant du sel et des origans (plantes aromatiques). Quand quelqu'un venait le voir, il commençait par lui offrir cela, et il informait de cet événement ses camarades, et chacun apportait ce qu'il avait, sans aucune difficulté. Lorsqu'ils ont fait la prière de l'après-midi, ils se réunissent pour célébrer les louanges de Dieu devant le cheïkh, jusqu'au moment de la prière du coucher du soleil. Après celle-ci, chacun d'eux garde sa place pour se livrer aux prières surérogatoires, jusqu'à l'instant de la dernière prière du soir. Ensuite, ils célèbrent de nouveau les louanges de Dieu, jusqu'à la fin du premier tiers de la nuit. Ils se séparent après cela, et ils reviennent à la mosquée au commencement de la troisième partie de la nuit, et veillent jusqu'au point du jour. Alors ils célèbrent les louanges de Dieu, jusqu'au moment de la prière du lever du soleil, après quoi ils se retirent. Il y en a quelques-uns qui restent dans la mosquée jusqu'après l'accomplissement de la prière de l'avant-midi. Telle est toujours leur manière d'agir. J'avais désiré passer avec eux le restant de ma vie,

La ville de Haly se trouve en Arabie à une cinquantaine de kilomètres à l'intérieur des terres sur la route reliant Djedda au Yémen ; son port porte le même nom. Quant à Ibn Ya'qub, il est inconnu par ailleurs.

Les Banu Haram sont une fraction importante de la tribu des Nahd. Les Banu Kinana sont originaires de l'Arabie du Nord. Al-Khazradji, l'historien du Yémen, mentionne un Musa bin Ali al-Kinani souverain de Haly au milieu du XIII ${ }^{\mathrm{e}}$ siècle. 
mais je n'ai pas reçu cette faveur. Dieu très haut m'accordera en échange sa grâce et son aide ! p073

\section{DU SULTAN DE HALI}

Son sultan est 'Amir, fils de Dhouwaïb, un des Benou Kinânah ${ }^{23}$. Il est au nombre des hommes de mérite, lettrés et poètes. Je voyageai en sa compagnie depuis La Mecque jusqu'à Djouddah, et il avait fait le pèlerinage l'an trente. Quand je fus arrivé dans sa capitale, il me donna l'hospitalité, me traita honorablement, et je fus son hôte pendant plusieurs jours ; puis je pris la mer sur un navire qui lui appartenait, et arrivai à la ville de Sardjah ${ }^{24}$.

C'est une petite ville, habitée par une troupe des fils d'Allahba ${ }^{25}$, qui sont une peuplade de négociants du Yaman, dont la plupart habitent Sa'dâ. Ils sont remplis de mérite et de générosité ; ils donnent à manger aux voyageurs, assistent les pèlerins, les embarquent sur leurs bâtiments, et les approvisionnent pour la route avec leur argent. Ils sont connus sous ce rapport, et sont célèbres pour cela. Que Dieu augmente leurs richesses, qu'il multiplie ses faveurs envers eux, et les aide à faire le bien! Il n’y a point dans aucun pays de personnage qui les égale en cela, excepté le cheïkh Bedr eddîn Annakkâs, demeurant dans la ville de Kahmah ${ }^{26}$. Il accomplit de pareilles actions mémorables et de semblables bienfaits. Nous restâmes une seule nuit à Sardjah, jouissant de l'hospitalité des gens susmentionnés. Puis nous nous rendîmes au Port-Neuf ${ }^{27}$, sans y mettre pied ${ }_{\mathrm{p} 074}$ à terre, ensuite au Havre des Portes ${ }^{28}$, et enfin à la ville de Zebîd ${ }^{29}$.

23

24

25

26

27

28

Inconnu par ailleurs.

Lieu situé à une journée de marche au nord d'al-Luhayya, port actuel du nord du Yémen.

Probablement les descendants du chérîf Izz al-din Hiba bin Fadl qui habitait la ville de San'a (sur les hauts plateaux du nord du Yémen) à l'époque de sa conquête par le deuxième souverain Rasulide Shams al-din Yusuf en 1254.

Petite ville au nord de Zabid.

Marsa al-Hadith, non identifiée.

Décrit par Ibn al-Mudjawir comme un port d'embarquement pour Aden. Il serait construit par un marchand iranien en 1138, mais sa localisation exacte est inconnue. Situé à trois fersakhs de Zabid, il devait se trouver près du port actuel d'al-Fazih. 
C'est une grande cité du Yaman, à quarante parasanges de San'â, et la plus considérable du pays, après celle-ci, tant pour son étendue que pour la richesse de ses habitants. Elle possède de vastes jardins, beaucoup d'eau et de fruits, tels que bananes et autres. Zebîd n'est point situé sur le littoral, mais dans l'intérieur des terres. C'est une des capitales du pays de Yaman ; elle est grande, très peuplée, et pourvue de palmiers, de vergers et d'eau. Zebîd est la plus belle ville du Yaman et la plus jolie ; ses habitants se distinguent par leur naturel affable, la bonté de leur caractère, l'élégance de leurs formes, et les femmes y sont douées d'une beauté très éclatante. Cette ville est située dans la vallée d'Alhossaïb, au sujet de laquelle on raconte, dans quelques traditions, que le Prophète avait dit à Mo'âdh, dans ses recommandations : « Ô Mo’âdh, quand tu seras arrivé dans la vallée du Hossaïb, hâte ta marche ${ }^{30}$ ».

Les habitants de cette ville célèbrent les samedis des palmiers, lesquels sont bien connus ${ }^{31}$. Ils sortent, en effet, chaque samedi, à l'époque du commencement de la maturité, et lors de la complète maturité des dattes, et se rendent dans les enclos de palmiers. Il ne reste dans la ville aucun de ses habitants ni des étrangers. Les musiciens sortent aussi, il en est de même des marchands, p075 qui vont débiter les fruits et les sucreries. Les femmes quittent la ville, portées par des chameaux dans des litières. Outre la beauté parfaite que nous avons mentionnée, elles possèdent de belles qualités et des vertus. Elles honorent l'étranger, et ne refusent point de se marier avec lui, comme le font les femmes de notre pays. Quand ce dernier veut partir, sa femme sort avec lui, et lui dit adieu. S'ils ont un enfant, elle en prend soin, et fournit à ses besoins, jusqu'au retour de son père. Elle ne lui réclame rien, ni pour sa dépense journalière, ni pour ses vêtements, ni pour autre chose, pendant le temps de son absence. Lorsqu'il réside dans le

Capitale médiévale des plaines, sunnites et shafi'ites, du Yémen face aux hauts plateaux shi'ites zaydites, dont la capitale était San’a.

Pour Mu'adh bin Djabal, voir t. I, chap. 3, n. 52. Le hadith continue : « [...] parce qu'il se trouve là des femmes ressemblant aux houris aux yeux noirs du Paradis. " Ce qui n’est pas l'avis de tout le monde : «Je n'ai pas rencontré dans tout le Yémen, en plaine ou en montagne, un seul joli visage qui attirerait l'œil, ou une seule élégance ou délicatesse dont on puisse témoigner » (IBN AL-MUDJAWIR). païenne. 
pays, elle se contente de bien peu de chose pour les frais de nourriture et d'habillement. Mais les femmes de cette contrée ne quittent jamais leur patrie. Si l'on donnait à l'une d'elles ce qu'il y a de plus précieux pour la déterminer à quitter son pays, elle ne le ferait sans doute pas.

Les savants de cette contrée et ses légistes sont des gens probes, religieux, sûrs, vertueux, et d'un excellent naturel. J'ai vu dans la ville de Zebîd le savant et pieux cheïkh Abou Mohammed assa'âny ; le fakîh, le soûfy contemplatif, Abou'l'abbâs alabïâny, et le jurisconsulte traditionnaire Abou 'Aly azzebîdy. Je me mis sous leur protection : ils m'honorèrent, me donnèrent l'hospitalité, et j'entrai dans leurs vergers. Je fis connaissance chez l'un d'eux avec le légiste, le juge et savant Abou Zeïd 'abd arrahmân assoûfy, un des hommes distingués du Yaman. On mentionna devant lui le serviteur de Dieu, l'ascète et l'humble Ahmed, fils d'Al'odjaïl alyamany ${ }^{32}$, qui était du nombre des grands personnages, et de ceux qui font des prodiges. p076

\section{ANECDOTE MIRACULEUSE}

On raconte que les docteurs de la secte des zeïdites et leurs grands personnages allèrent une fois rendre visite au cheïkh Ahmed, fils d'Al'odjaïl, qui s'assit pour les recevoir en dehors de la zâouïah. Ses disciples allèrent à leur rencontre, mais le cheïkh ne quitta pas sa place. Les zeïdites le saluèrent, il leur toucha la main, et leur dit : "Soyez les bienvenus!" On se mit à discourir sur la matière de la prédestination, et les sectaires avancèrent qu'il n'y avait pas de fatalité, et que celui qui agissait était le créateur de ses actions ${ }^{33}$. Le cheïkh répondit : "Si la chose est telle que vous le dites, levez-vous donc de la place où vous êtes ! » Ils le voulurent faire, sans pouvoir y réussir. Alors le cheïkh les laissa dans cet état, et entra dans la zâouïah. Ils restèrent ainsi, mais la chaleur les incommoda ; ils furent tourmentés par l'ardeur du soleil, et gémirent de ce qui leur était arrivé. Alors les compagnons du cheïkh allèrent le trouver, et lui dirent : "Ces gens

1212-1291 connu en son époque comme juriste, sa légende de sainteté a dû être forgée par la suite. Les autres savants cités par Ibn Battûta n’ont pas été identifiés. 
sont venus à résipiscence envers Dieu, et ont abandonné leur secte impie. » Le cheïkh sortit, et, prenant leurs mains, il leur fit promettre de revenir à la vérité, et de quitter leur doctrine perverse. Il les fit, après cela, entrer dans sa zâouïah, où ils restèrent ses hôtes pendant trois jours, à l'expiration desquels ils retournèrent dans leur pays.

J'allai visiter la tombe de ce saint personnage, qui se trouve dans un village nommé Ghaçânah ${ }^{34}$, au-dehors de Zebîd. Or je rencontrai son fils, le pieux Abou'lwalîd Ismaîl ${ }^{35}$, qui me donna l'hospitalité, et chez lequel je passai la nuit. Je fis mon pèlerinage au tombeau du cheïkh, et restai avec son fils pendant trois jours ; puis p077 je partis en sa compagnie pour visiter le jurisconsulte Abou'lhaçân azzeïla’y ${ }^{36}$. Celui-ci est au nombre des hommes les plus pieux, et commande les pèlerins du Yaman, lorsqu'ils vont à La Mecque en pèlerinage. Les habitants de ces contrées, ainsi que les Bédouins, l'estiment et l'honorent beaucoup.

Nous arrivâmes à Djoblah ${ }^{37}$, qui est une jolie petite ville, pourvue de palmiers, de fruits et de canaux. Quand le fakîh Abou'lhaçân azzeïla'y fut informé de l'arrivée du cheïkh Abou'lwalîd, il vint à sa rencontre, et le fit descendre dans sa zâouïah. Je le saluai, en compagnie d'Abou'lwalîd, et nous restâmes chez lui pendant trois jours, avec le traitement le plus agréable.

Puis nous partîmes, mais Abou'lhaçân envoya avec nous un fakîr, et nous nous dirigeâmes vers la ville de Ta'izz, résidence du roi du Yaman. C'est une des plus belles et des plus grandes villes du pays ; et ses habitants sont orgueilleux, insolents et durs, comme cela a lieu, le plus souvent, dans les villes où demeurent les rois. Ta'izz a trois quartiers ; l'un est occupé par le sultan, ses mamloûcs, ses domestiques, et par les grands de l'État. Je ne me souviens pas maintenant de son nom. Le second est habité par les commandants et les troupes, et

Ce village était déjà connu à l'époque sous le nom de Bait al-Faqih (la Maison du Juriste), sous lequel il figure encore aujourd'hui sur les cartes, à mi-chemin entre Zabid et al-Hudayda. elle fut au $\mathrm{XI}^{\mathrm{e}}$ siècle la capitale de la dynastie ismaïlite des Sulaihis. 
il s’appelle 'Odaïnah. Dans le troisième réside la généralité du peuple ; on y voit le grand marché, et il se nomme Almohâleb ${ }^{38}$. p078

\section{DU SULTAN DU YAMAN}

C'est le sultan belliqueux Noûr eddîn 'Aly, fils du sultan secouru de Dieu, Hizbar eddîn Dâoûd, fils du sultan victorieux Yoûcef, fils d'Aly, fils de Raçoûl ${ }^{39}$. Son aïeul a été célèbre sous ce dernier nom, car un des khalifes 'abbâcides l'envoya dans le Yaman en qualité d'émir, et plus tard ses enfants jouirent de la royauté d'une manière indépendante. Le sultan actuel suit un ordre admirable, tant dans ses audiences que lorsqu'il monte à cheval. Quand j'arrivai dans cette ville de Ta'izz, en compagnie du fakir que le cheïkh, le jurisconsulte Abou'lhaçan azzeïlay', avait envoyé avec moi, nous allâmes ensemble chez le grand juge, l'imâm traditionnaire Safy eddîn Atthabary almekky ${ }^{40}$. Nous le saluâmes ; il nous accueillit fort bien, et nous reçûmes l'hospitalité chez lui pendant trois jours. Le quatrième, qui était un jeudi, jour dans lequel le sultan donne audience générale, le grand juge m’y conduisit, et je saluai le prince.

La manière de lui adresser le salut consiste à toucher la terre avec le doigt indicateur, puis à le porter sur la tête, et à dire : "Que Dieu fasse durer ta puissance ! » Je fis comme le kâdhi, et celui-ci s’assit à la droite du roi, qui m’ordonna de m'asseoir devant lui. Alors il m'interrogea touchant mon pays, sur notre maître le commandant des musulmans, le très généreux Abou Sa'îd ; que Dieu soit satisfait de lui ! sur le roi d’Égypte, celui de l’Irak, et le roi du Loûr. Je répondis à

La ville est citée par Yaqut (c. 1225) et Ibn al-Mudjawir (c. 1230) comme une forteresse célèbre, mais elle a dû prendre son essor sous les Rasulides. Le premier quartier cité par Ibn Battûta s’appelait Mu’izziya. Udaina se trouvait au pied de la citadelle. Quant à al-Mahalib, il n’est pas attesté par ailleurs.

Al-Malik al-Mudjahid Nur al-din, cinquième souverain Rasulide (1321-1361), fils de Mu'ayyad Daud (1296-1321), fils de Muzaffar Yusuf, deuxième souverain (1250-1295). L’ancêtre Rasul, un Turkmène, arriva au Yémen avec les conquérants Ayyubides.

Les Tabari étaient cadis de La Mecque de père en fils pendant cette période (voir t. I, chap. 4, n. 214). Toutefois, ce membre de la famille est inconnu. Le grand cadi de Ta'izz était à l'époque Djamal al-din Muhammad bin Yusuf alSabri, mort en 1342. 
toutes les questions qu'il me fit à leur égard. Son vizir ${ }_{\text {p079 }}$ était en sa présence, et il lui ordonna de m’honorer et de me donner l'hospitalité.

Voici l'ordre suivi dans les audiences de ce roi ; il s'assied sur une estrade, recouverte et ornée d'étoffes de soie, et il a à sa droite et à sa gauche les militaires. Ceux qui sont à côté de lui, ce sont les porteurs de sabres et de boucliers, puis viennent les archers, et devant ceux-ci, à droite et à gauche le chambellan, les grands de l'État et le secrétaire intime. L'émir Djandâr ${ }^{41}$ est aussi devant le monarque, et enfin les châouchs ${ }^{42}$, qui sont au nombre de ses gardes, se tiennent debout à distance. Lorsque le sultan prend sa place, ils crient tous : «Au nom de Dieu ! » et quand il se lève, ils répètent la même exclamation, de sorte que tous ceux qui se trouvent dans la salle d'audience connaissent l'instant où il quitte sa place, de même que celui où il s'assied. Une fois le sultan assis, tous ceux qui ont l'habitude de le venir saluer entrent, et saluent le monarque ; puis chacun d'eux se tient à l'endroit qui lui est destiné, à droite ou à gauche ; personne ne quitte sa place, et aucun ne s'assied, à moins que le sultan ne le lui ordonne. Dans ce cas, celui-ci dit à l'émir Djandâr : " Commande à un tel de s'asseoir. » Alors ce dernier s'avance à une petite distance du lieu où il se tenait debout, et s'assied sur un tapis, placé devant ceux qui sont debout, à droite et à gauche.

On apporte ensuite les mets, qui sont de deux sortes : ceux destinés à la généralité des assistants et ceux réservés à quelques individus particuliers. Les derniers sont pour le sultan, le grand juge, les principaux chérîfs et jurisconsultes et pour les hôtes. Les autres servent pour le restant des chérîfs, des jurisconsultes et des juges, pour les cheïkhs, les émirs, et les notables de l'armée. La place de chacun à table est déterminée ; personne ne la quitte ni ne foule les autres. Tel est exactement aussi l'ordre qu'observe le roi de l'Inde dans ses repas; et je p080 ne sais point si les sultans de l'Inde l'ont pris de ceux du Yaman, ou bien si ces derniers l'ont emprunté des sultans de l'Inde.

Voir t. I, chap. 5, n. 262. 
Je restai plusieurs jours l'hôte du sultan du Yaman, qui me combla de bienfaits et me pourvut d'une monture ; puis je partis, me dirigeant vers la ville de San'â ${ }^{43}$.

C'est l'ancienne capitale du pays de Yaman, grande cité, d'une belle construction, bâtie de briques et de plâtre ; elle est abondamment pourvue d'arbres, de fruits et de grains ; son climat est tempéré et son eau excellente. Une chose étonnante, c'est que la pluie, dans les pays de l'Inde, du Yaman et de l'Abyssinie, ne tombe que dans le temps des grandes chaleurs, et que, le plus souvent, elle tombe dans cette saison tous les jours après midi ${ }^{44}$. C'est pour cela que les voyageurs se hâtent, vers ce moment, d'arriver à la station, afin de ne pas être atteints par la pluie. Les habitants des villes se retirent dans leurs demeures, car les pluies, dans ces contrées, sont des ondées très copieuses. San'â est entièrement pavée, et lorsqu'il pleut, l'eau lave et nettoie toutes ses rues. La mosquée djâmi' de cette ville est au nombre des plus belles mosquées et elle contient la tombe d'un des prophètes, sur qui soit le salut !

Je partis pour la ville d'Aden ${ }^{45}$, le port du pays de Yaman, situé au bord du grand océan; les montagnes p081 l'environnent, et l'on n'y peut entrer que par un seul côté. C'est une grande ville, mais elle ne possède ni grains, ni arbres, ni eau douce. Elle a seulement des citernes pour recevoir l'eau de pluie ${ }^{46}$, car l'eau potable se trouve loin de la ville. Souvent les Arabes défendent d'en puiser, et se mettent entre

San'a, capitale des hauts plateaux, se trouve à deux cents kilomètres au nord de Ta'izz, et cette excursion constitue un détour considérable sur le chemin d'Ibn Battûta.

44

«Tous les après-midi souffle un vent froid et vivifiant, après lequel le ciel devient nuageux et la pluie tombe pour une ou deux heures; ensuite le ciel s'éclaircit. » Toutefois, cette description d'Ibn al-Mudjawir concerne la région de Ta'izz.

«Aden est située au pied d'une montagne [...] c'est une petite ville mais très forte en murailles, tours et remparts. [...] Cette ville a un grand commerce avec Le Caire ainsi qu'avec les Indes, et les Indes commercent avec elle. Il y a beaucoup de marchands très riches. [...] La ville est un lieu de rencontre pour les marchands » (Tomé PIRÈs, c. 1500).

La coutume de construire des digues et des citernes caractéristiques de la vieille culture sabéenne a laissé des traces dans le territoire d'Aden. On trouve les vestiges de quelque cinquante réservoirs dans toute la péninsule. ils auraient été construits par des Persans venus de Siraf. 
les eaux et les habitants de la ville, jusqu'à ce que ceux-ci se soient accommodés avec eux, au moyen d'argent et d'étoffes. La chaleur est grande à Aden. Cette ville est le port où abordent les Indiens ; de gros vaisseaux y arrivent de Cambaie Tânah, Cawlem, Kâlikoûth, Fandarâïnah, Châliyât, Mandjaroûr, Fâkanwar, Hinaour, Sindâbour, etc. ${ }^{47}$. Des négociants de l'Inde demeurent dans cette ville, ainsi que des négociants égyptiens. Les habitants d'Aden se partagent en marchands portefaix et pêcheurs. Parmi les premiers, il y en a qui possèdent de grandes richesses, et quelquefois un seul négociant est propriétaire d'un grand navire avec tout ce qu'il contient, sans qu'aucune autre personne soit associée avec lui, tant il est riche par lui-même. On remarque à ce sujet, chez ces négociants, de l'ostentation et de l'orgueil.

\section{ANECDOTE}

On m’a raconté qu'un des négociants envoya un de ses esclaves pour lui acheter un bélier, et qu'un autre négociant expédia aussi un esclave à lui pour le même objet ; or il arriva, par hasard qu'il n'y

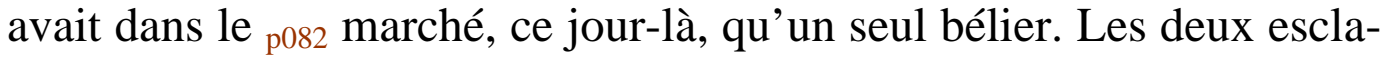
ves enchérirent pour l'avoir, en sorte que son prix se monta à quatre cents dinars ; et l'un d'eux l'acheta en disant : " Certes, le capital que je possède est de quatre cents dînârs ; si mon maître me rembourse la dépense faite pour le bélier, tant mieux ; sinon je le payerai de mon argent, je me serai défendu et je l'aurai emporté sur mon compétiteur. » Il s'en alla chez son maître avec le bélier, et, quand le négociant fut informé de l'événement, il donna la liberté à l'esclave et lui fit cadeau de mille dînârs. L'autre esclave retourna frustré chez son maître ; celui-ci le battit, lui prit tout son pécule et le chassa de sa présence ${ }^{48}$.

Je logeai à Aden chez un négociant appelé Nâcir eddîn Alfary. Environ vingt négociants assistaient tous les soirs à son repas, et le nom-

Cambay dans le Gudjarat, Tana à proximité de Bombay, Quilon à l'extrémité sud de l'Inde, Calicut, Pandalayini au nord de Calicut, Beypore au sud de Calicut, Mangalore, Baccanore, Honavar et Goa. L'ensemble de ces villes sont des ports de la côte occidentale de l'Inde et seront décrites dans le t. III.

La même anecdote, avec un poisson à la place du bélier, est racontée par Ibn al-Mudjawir au sujet de deux marchands de Siraf. 
bre de ses esclaves et de ses domestiques était encore plus considérable que celui des convives. Malgré tout ce que nous venons de dire, les habitants d'Aden sont des gens religieux, humbles, probes et doués de qualités généreuses. Ils sont favorables aux étrangers, font du bien aux pauvres et payent ce qu'on doit à Dieu, c'est-à-dire la dîme aumônière, ainsi qu'il est ordonné.

Je vis dans cette ville son kâdhi, le pieux Sâlim, fils d'Abd Allah Alhindy, dont le père avait été un esclave portefaix. Quant à Sâlim, il s'adonna à la science, il y acquit le rang de chef et de maître, et c'est un des meilleurs kâdhis et des plus distingués. Je fus son hôte pendant plusieurs jours.

Après être parti d'Aden, je voyageai par mer durant quatre jours ${ }^{49}$ et j'arrivai à la ville de Zeïla' ${ }^{50}$. C'est la p083 $_{\text {capitale des Berberah }}{ }^{51}$, peuplade de Noirs qui suit la doctrine de Châfi'y ${ }^{52}$, Leur pays forme un désert, qui s'étend l'espace de deux mois de marche, à commencer de Zeïla' et en finissant par Makdachaou. Leurs bêtes de somme sont des chameaux, et ils possèdent aussi des moutons, célèbres par leur graisse. Les habitants de Zeïla’ ont le teint noir, et la plupart sont hérétiques.

Zeïla’ est une grande cité, qui possède un marché considérable ; mais c'est la ville la plus sale qui existe, la plus triste et la plus puante. Le motif de cette infection, c'est la grande quantité de poisson que l'on y apporte, ainsi que le sang des chameaux que l'on égorge dans les rues. A notre arrivée à Zeïla', nous préférâmes passer la nuit en

Le départ d'Ibn Battûta d'Aden doit se placer dans la deuxième moitié du mois de janvier 1331, ce qui correspond à l'époque des moussons qui rendaient possible le voyage.

Port situé dans la Somalie actuelle immédiatement au sud de Djibouti ; il était à l'époque un des principaux débouchés de l'arrière-pays éthiopien dont les plaines se trouvaient sous la domination du royaume musulman d'Ifat et les plateaux sous la dynastie salomonienne (chrétienne). « En ce qui concerne le peuple de Zeila et leurs tribus, ils n'ont pas de rois. Mais ils sont divisés en sept tribus. Ils sont musulmans et leurs prêcheurs récitent les prières publiques au nom de leurs sept chefs » (MUFAZZAL, XIV ${ }^{\mathrm{e}}$ siècle).

En principe, les Barbara des géographes arabes contiennent les tribus hamitiques qui ne sont ni abbyssines (Habash), ni nègres (Zendj), et principalement les Somalis, mais ici Ibn Battûta parle de Noirs.

52 Gibb traduit rafidhis, c'est-à-dire shi'ites, et dans ce cas apparemment zaydites. 
mer, quoiqu'elle fût très agitée, plutôt que dans la ville, à cause de la malpropreté de celle-ci.

Après être partis de Zeïla', nous voyageâmes sur mer pendant quinze jours, et arrivâmes à Makdachaou ${ }^{53}$, ville extrêmement vaste. Les habitants ont un grand nombre de chameaux, et ils en égorgent plusieurs centaines chaque jour. Ils ont aussi beaucoup de moutons, et sont de riches marchands. C'est à Makdachaou que l'on ${ }_{\mathrm{p} 084}$ fabrique les étoffes qui tirent leur nom de celui de cette ville, et qui n'ont pas leurs pareilles. De Makdachaou, on les exporte en Égypte et ailleurs ${ }^{54}$. Parmi les coutumes des habitants de cette ville est la suivante : lorsqu'un vaisseau arrive dans le port, il est abordé par des sonboûks, c'est-à-dire de petits bateaux ${ }^{55}$. Chaque sonboûk renferme plusieurs jeunes habitants de Makdachaou, dont chacun apporte un plat couvert, contenant de la nourriture. Il le présente à un des marchands du vaisseau, en s'écriant : "Cet homme est mon hôte "; et tous agissent de la même manière. Aucun trafiquant ne descend du vaisseau, que pour se rendre à la maison de son hôte d'entre ces jeune gens, sauf toutefois le marchand qui est déjà venu fréquemment dans la ville, et en connaît bien les habitants. Dans ce cas, il descend où il lui plaît. Lorsqu'un commerçant est arrivé chez son hôte, celui-ci vend pour lui ce qu'il a apporté et lui fait ses achats. Si l'on achète de ce marchand quelque objet pour un prix au-dessous de sa valeur, ou qu'on lui vende autre chose hors de la présence de son hôte, un pareil marché est frappé de réprobation aux yeux des habitants de Makdachaou. Ceux-ci trouvent de l'avantage à se conduire ainsi.

Lorsque les jeunes gens furent montés à bord du vaisseau où je me trouvais, un d'entre eux s'approcha de moi. Mes compagnons lui dirent : " Cet individu n'est pas un marchand, mais un jurisconsulte. » Alors le jeune homme appela ses compagnons et leur dit : «Ce per-

53. Comptoir fondé au $\mathrm{X}^{\mathrm{e}}$ siècle par des migrants arabes et peut-être persans, Mogadiscio, était gouverné jusqu'au XIII ${ }^{\mathrm{e}}$ siècle par une fédération de tribus. « Ils n'ont roi, mais quatre cheïkhs, ce qui veut dire quatre hommes qui ont le gouvernement de toute cette île [sic] » (Marco POLO). Un sultanat héréditaire y fut établi à partir de la fin du XIII siècle.

Le commerce de coton tissé était florissant. «[...] il était exporté vers l'Égypte, l'Arabie et le golfe Persique, mais commença à décliner après la destruction des colonies arabes de la côte par les Portugais » (GUILLAIN).

Voir t. I, chap. 5, n. 62. 
sonnage est l'hôte du kâdhi. » Parmi eux se trouvait un des employés du kâdhi, qui lui fit connaître cela. Le magistrat se rendit sur le rivage de la mer, accompagné d'un certain nombre de thâlibs ${ }^{56}$; il me dépêcha un de ${ }_{\text {p085 }}$ ceux-ci. Je descendis à terre avec mes camarades, et saluai le kâdhi et son cortège. Il me dit : " Au nom de Dieu, allons saluer le cheïkh. - Quel est donc ce cheïkh ? répondis-je - C’est le sultan, répliqua-t-il. » Car ce peuple a l'habitude d'appeler le sultan cheïkh. Je répondis au kâdhi : « Lorsque j'aurai pris mon logement, j'irai trouver le cheïkh. » Mais il repartit : « C'est la coutume, quand il arrive un légiste, ou un chérîf, ou un homme pieux, qu’il ne se repose qu'après avoir vu le sultan. » Je me conformai donc à leur demande, en allant avec eux trouver le souverain.

\section{DU SULTAN DE MAKDACHAOU}

Ainsi que nous l'avons dit, le sultan de Makdachaou n'est appelé par ses sujets que du titre de cheïkh. Il a nom Abou Becr, fils du cheïkh Omar ${ }^{57}$, et est d'origine berbère; il parle l'idiome makdachain, mais il connaît la langue arabe. C'est la coutume, quand arrive un vaisseau, que le sonboûk du sultan se rende à son bord, pour demander d'où vient ce navire, quels sont son propriétaire et son roubbân, c'est-à-dire son pilote ou capitaine, quelle est sa cargaison et quels marchands ou autres individus se trouvent à bord. Lorsque l'équipage du sonboûk a pris connaissance de tout cela, on en donne avis au sultan, qui loge près de lui les personnes dignes d'un pareil honneur.

Quand je fus arrivé au palais du sultan, avec le kâdhi susmentionné, qui s'appelait Ibn Borhân eddîn et était originaire d'Égypte ${ }^{58}$, un eunuque en sortit et salua le p086 juge, qui lui dit : " Remets le dépôt

Étudiants.

57. Sur les sultans de Mogadiscio jusqu'au XVI ${ }^{\mathrm{e}}$, on ne connaît que le fondateur de la dynastie à la fin du XII ${ }^{\mathrm{e}}$ siècle, Abu Bakr bin Fakhr al-din, et cet Abu Bakr qui n’est cité que par Ibn Battûta.

58

Il faudrait probablement lire al-Muqri à la place d'al-Misri (originaire d’Égypte), puisque la fonction du cadi était héréditaire dans la tribu des Muqri à la suite d'un compromis établi à l'avènement du sultan Abu Bakr bin Fakhr al-din. Un certain Burhan al-din faqih (jurisconsulte) vivant au début du XIV ${ }^{\mathrm{e}}$ siècle apparaît dans une généalogie du XVIII ${ }^{\mathrm{e}}$ siècle. 
qui t'est confié, et apprends à notre maître le cheïkh que cet homme-ci est arrivé du Hidjâz. » L'eunuque s'acquitta de son message et revint, portant un plat dans lequel se trouvaient des feuilles de bétel et des noix d'arec. Il me donna dix feuilles du premier, avec un peu de faoufel et en donna la même quantité au kâdhi ; ensuite il partagea entre mes camarades et les disciples du kâdhi ce qui restait dans le plat. Puis il apporta une cruche d'eau de roses de Damas, et en versa sur moi et sur le kâdhi, en disant : « Notre maître ordonne que cet étranger soit logé dans la maison des thâlibs. »C'était une maison destinée à traiter ceux-ci. Le kâdhi m’ayant pris par la main, nous allâmes à cette maison, qui est située dans le voisinage de celle du cheïkh, décorée de tapis et pourvue de tous les objets nécessaires. Plus tard ledit eunuque apporta de la maison du cheïkh un repas ; il était accompagné d'un des vizirs, chargé de prendre soin des hôtes, et qui nous dit : "Notre maître vous salue et vous fait dire que vous êtes les bienvenus »; après quoi il servit le repas et nous mangeâmes. La nourriture de ce peuple consiste en riz cuit avec du beurre, qu'ils servent dans un grand plat de bois, et par-dessus lequel ils placent des écuelles de coûchân ${ }^{59}$, qui est un ragoût composé de poulets, de viande, de poisson et de légumes. Ils font cuire les bananes, avant leur maturité, dans du lait frais, et ils les servent dans une écuelle. Ils versent le lait caillé dans une autre écuelle, et mettent par-dessus des limons confits et des grappes de poivre confit dans le vinaigre et la saumure, du gingembre vert et des mangues qui ressemblent à des pommes, sauf qu'elles ont un noyau. Lorsque la mangue est parvenue à sa maturité, elle est extrêmement douce et se mange comme un fruit ; mais, avant cela, elle est acide comme le limon, et on la confit dans du vinaigre. Quand les habitants de Makdachaou ont mangé une bouchée de riz, ils avalent p087 de ces salaisons et de ces conserves au vinaigre. Un seul de ces individus mange autant que plusieurs de nous : c'est là leur habitude ; ils sont d'une extrême corpulence et d'un excessif embonpoint.

Lorsque nous eûmes mangé, le kâdhi s’en retourna. Nous demeurâmes en cet endroit pendant trois jours, et on nous apportait à manger trois fois dans la journée, car telle est leur coutume. Le quatrième jour, qui était un vendredi, le kâdhi, les étudiants et un des vizirs du curry. 
cheïkh vinrent me trouver, et me présentèrent un vêtement. Leur habillement consiste en un pagne de filoselle, que les hommes s'attachent au milieu du corps, en place de caleçon, qu'ils ne connaissent pas ; en une tunique de toile de lin d'Égypte, avec une bordure ; en une fardjîyeh de kodsy $^{60}$ doublée, et en un turban d'étoffe d'Égypte, avec une bordure. On apporta pour mes compagnons des habits convenables.

Nous nous rendîmes à la mosquée principale, et nous y priâmes derrière la tribune grillée. Lorsque le cheïkh sortit de cet endroit, je le saluai avec le kâdhi. Il répondit par des vœux en notre faveur, et conversa avec le kâdhi dans l'idiome de la contrée ; puis il me dit en arabe : "Tu es le bienvenu, tu as honoré notre pays et tu nous as réjouis. » Il sortit dans la cour de la mosquée, et s'arrêta près du tombeau de son père, qui se trouve en cet endroit ; il y fit une lecture dans le Coran et une prière, après quoi les vizirs, les émirs et les chefs des troupes arrivèrent et saluèrent le sultan. On suit, dans cette cérémonie, la même coutume qu'observent les habitants du Yaman. Celui qui salue place son index sur la terre, puis il le pose sur sa tête, en disant : «Que Dieu perpétue ta gloire!»

Après cela, le cheïkh franchit la porte de la mosquée, p088 revêtit ses sandales, et ordonna au kâdhi et à moi d'en faire autant. Il se dirigea à pied vers sa demeure, qui était située dans le voisinage du temple, et tous les assistants marchaient nu-pieds. On portait au-dessus de la tête du cheïkh quatre dais de soie de couleur, dont chacun était surmonté d'une figure d'oiseau en or. Son vêtement consistait ce jour-là en une robe flottante de kodsy vert, qui recouvrait de beaux et amples habits de fabrique égyptienne. Il était ceint d'un pagne de soie et coiffé d'un turban volumineux. On frappa devant lui les timbales et l'on sonna des trompettes et des clairons. Les chefs des troupes le précédaient et le suivaient ; le kâdhi, les jurisconsultes et les chérîfs l'accompagnaient. Ce fut dans cet appareil qu'il entra dans sa salle d'audience.

Robe flottante d'étoffe de Jérusalem. Un voyageur chinois qui a visité Mogadiscio vers 1417-1419 note que les hommes avaient des cheveux en boucles qui pendaient de tous les côtés et portaient des étoffes de coton ceintes autour de la taille et que les femmes appliquaient un vernis jaune sur leurs têtes rasées et portaient des disques à leurs oreilles ainsi que des anneaux d'argent autour du cou. 
Les vizirs, les émirs et les chefs des troupes s'assirent sur une estrade, située en cet endroit. On étendit pour le kâdhi un tapis, sur lequel nul autre que lui ne prit place. Les fakîhs et les cherîfs accompagnaient ce magistrat. Ils restèrent ainsi jusqu'à la prière de trois à quatre heures de l'après-midi. Lorsqu'ils eurent célébré cette prière en société du cheïkh, tous les soldats se présentèrent et se placèrent sur plusieurs files, conformément à leurs grades respectifs ; après quoi on fit résonner les timbales, les clairons, les trompettes et les flûtes. Pendant qu'on joue de ces instruments, personne ne bouge et ne remue de sa place, et quiconque se trouve alors en mouvement s'arrête, sans avancer ni reculer. Lorsqu'on eut fini de jouer de la musique militaire, les assistants saluèrent avec leurs doigts, ainsi que nous l'avons dit, et s'en retournèrent. Telle est leur coutume chaque vendredi.

Lorsqu'arrive le samedi, les habitants se présentent à la porte du cheïkh, et s'asseyent sur des estrades, en dehors de la maison. Le kâdhi, les fakîhs, les chérîfs, les gens pieux, les personnes respectables et les pèlerins entrent dans la seconde salle et s'asseyent sur des estrades en bois destinées à cet usage. Le kâdhi se tient sur une estrade séparée, et chaque classe a son estrade particulière, que personne ne par-

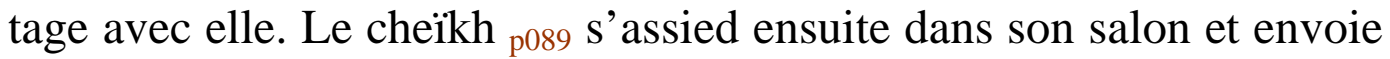
chercher le kâdhi, qui prend place à sa gauche, après quoi les légistes entrent, et leurs chefs s'asseyent devant le sultan ; les autres saluent et s'en retournent. Les chérîfs entrent alors, et les principaux d'entre eux s'asseyent devant lui ; les autres saluent et s'en retournent. Mais, s'ils sont les hôtes du cheïkh, ils s'asseyent à sa droite. Le même cérémonial est observé par les personnes respectables et les pèlerins, puis par les vizirs, puis par les émirs, et enfin par les chefs des troupes, chacune de ces classes succédant à une autre. On apporte des aliments; le kâdhi, les chérîfs et ceux qui sont assis dans le salon mangent en présence du cheïkh, qui partage ce festin avec eux. Lorsqu'il veut honorer un de ses principaux émirs, il l'envoie chercher et le fait manger en leur compagnie ; les autres individus prennent leur repas dans le réfectoire. Ils observent en cela le même ordre qu'ils ont suivi lors de leur admission près du cheïkh.

Celui-ci rentre ensuite dans sa demeure ; le kâdhi, les vizirs, le secrétaire intime, et quatre d'entre les principaux émirs, s’asseyent, afin de juger les procès et les plaintes. Ce qui a rapport aux prescriptions de la loi est décidé par le kâdhi ; les autres causes sont jugées par les 
membres du conseil, c’est-à-dire les vizirs et les émirs. Lorsqu'une affaire exige que l'on consulte le sultan, on lui écrit à ce sujet, et il envoie sur-le-champ sa réponse, tracée sur le dos du billet, conformément à ce que décide sa prudence. Telle est la coutume que ces peuples observent continuellement.

Je m'embarquai sur la mer dans la ville de Makdachaou, me dirigeant vers le pays des Saouâhil ${ }^{61}$ et la ville de Couloua, dans le pays des Zendjs ${ }^{62}$. Nous p090 arrivâmes à Manbaça ${ }^{63}$, grande île, à une distance de deux journées de navigation de la terre des Saouâhil. Cette île ne possède aucune dépendance sur le continent, et ses arbres sont des bananiers, des limoniers et des citronniers. Ses habitants recueillent aussi un fruit qu'ils appellent djammoûn ${ }^{64}$, et qui ressemble à l'olive ; il a un noyau pareil à celui de l'olive, mais le goût de ce fruit est d'une extrême douceur. Ils ne se livrent pas à la culture, et on leur apporte des grains des Saouâhil. La majeure partie de leur nourriture consiste en bananes et en poisson. Ils professent la doctrine de Châfi'y, sont pieux, chastes et vertueux ; leurs mosquées sont construites très solidement en bois. Près de chaque porte de ces mosquées se trouvent un ou deux puits, de la profondeur d'une ou deux coudées ; on y puise l'eau avec une écuelle de bois, à laquelle est fixé un bâton mince, de la longueur d'une coudée. La terre, à l'entour de la mosquée et du puits, est tout unie. Quiconque veut entrer dans la mosquée commence par se laver les pieds ; il y a près de la porte un morceau de natte très grossier, avec lequel il les essuie. Celui qui désire faire les lotions tient la coupe entre ses cuisses, verse l'eau sur ses mains et fait son ablution. Tout le monde ici marche nu-pieds.

Nous passâmes une nuit dans cette île ; après quoi nous reprîmes la mer pour nous rendre à Couloua ${ }^{65}$ grande ville située sur le littoral, et

Les côtes. Le singulier sahil signifiait également entrepôt ou comptoir.

Le « Noir » ou « nègre » dans le vocabulaire arabe. Le mot, d'origine sanskrite ou persane, désignait à l'origine les Noirs de la côte orientale de l'Afrique.

Mombasa, qui n’est séparée de la terre ferme que par un chenal, n’avait pas encore une grande importance à l'époque.

65 Kilwa, la Quiloa des chroniques portugaises, est l'actuelle Kilwa Kisiwani en Tanzanie. Kilwa aurait été fondée à la fin du $\mathrm{X}^{\mathrm{e}}$ siècle par des Arabes (ou Persans) zaydites et constituait un centre important pour l'exportation de l'or. Ibn Battûta a dû y arriver vers le début mars 1331. 
dont les habitants sont pour la plupart des Zendjs, d'un teint extrêmement noir. Ils ont à la figure des incisions semblables à celles p091 qu'ont les Lîmiîn de Djenâdah ${ }^{66}$. Un marchand m'a dit que la ville de Sofâlah ${ }^{67}$ est située à la distance d'un demi-mois de marche de Couloua, et qu'entre Sofâlah et Yoûfi ${ }^{68}$, dans le pays des Lîmiîn, il y a un mois de marche. De Yoûfi, on apporte à Sofâlah de la poudre d'or. Couloua est au nombre des villes les plus belles et les mieux construites ; elle est entièrement bâtie en bois ; la toiture de ses maisons et en dîs ${ }^{69}$, et les pluies y sont abondantes. Ses habitants sont adonnés au djihâd ${ }^{70}$, car ils occupent un pays contigu à celui des Zendjs infidèles. Leurs qualités dominantes sont la piété et la dévotion, et ils professent la doctrine de Châfi'y.

\section{Du SULTAN DE COULOUA}

Lorsque j'entrai dans cette ville, elle avait pour sultan Abou'lmozhaffer Haçan, surnommé également Abou'lmewâhib ${ }^{71}$, cause de la multitude de ses dons et de ses actes de générosité. Il faisait de fréquentes ${ }_{\mathrm{p} 092}$ incursions dans le pays des Zendjs, les attaquait et leur enlevait du butin, dont il prélevait la cinquième partie, qu'il dépensait de la manière fixée dans le Coran. Il déposait la part des

Limi, ou Lamlam, est le nom donné par les géographes arabes aux tribus de l'intérieur, celles de l'Afrique inconnue, supposées anthropophages. Djanawa était également le nom donné au pays situé au sud de l'Afrique de l'Ouest islamisé ; il prendra à travers le portugais la forme de Guinée en français.

Sofala était le comptoir le plus méridional des Arabes en Afrique orientale ; situé au sud du Zambèze, elle drainait la production d'or de l'intérieur.

Youfi est le royaume de Nupe en Afrique de l'Ouest, dont Ibn Battûta reparlera au t. III. Pour les Arabes, mais aussi pour les Européens, qui ne connaissaient ni l'intérieur ni la configuration de l'Afrique, les régions connues leur paraissaient communiquer entre elles. En 1658, Thévenot, qui écrit du Caire au sujet d'un royaume du sud-est du Soudan, le Nana, estime que " c'est dans ce pays-là que sont les mines d'où l'on tire l'or qui passe dans les côtes de Sofala et de Guinée ».

Le dis serait l'Ampelodesmos tenax.

70

La guerre sainte.

71 Une nouvelle dynastie arriva au pouvoir vers la fin du XIII ${ }^{\mathrm{e}}$ siècle dans la personne de Hasan bin Talut (1277-1294). Hasan bin Sulaiman, connu sous le nom d'Abu'l-Mawahib (le Père des dons), était le petit-fils de ce dernier (c. 1310-1332). 
proches du Prophète dans une caisse séparée, et lorsque des chérîfs venaient le trouver il la leur remettait ${ }^{72}$, Ceux-ci se rendaient près de lui de l'Irâk, du Hidjâz et d'autres contrées. J'en ai trouvé à sa cour plusieurs du Hidjâz, parmi lesquels Mohammed, fils de Djammâz; Mansoûr, fils de Lebîdah, fils d'Abou Nemy, et Mohammed, fils de Chomaïlah, fils d'Abou Nemy. J'ai vu, à Makdachaou, Tabl, fils de Cobaïch, fils de Djammâz ${ }^{73}$, qui voulait aussi se rendre près de lui. Ce sultan est extrêmement humble, il s'assied et mange avec les fakirs, et vénère les hommes pieux et nobles.

\section{RÉCIT D’UNE DE SES ACTIONS GÉNÉREUSES}

Je me trouvais près de lui un vendredi, au moment où il venait de sortir de la prière, pour retourner à sa maison. Un fakir du Yaman se présenta devant lui, et lui dit : «O Abou'lmewâhib ! - Me voici, répondit-il ; ô fakir ! quel est ton besoin ? Donne-moi ces vêtements qui te couvrent. - Très bien, je te les donnerai.— Sur l'heure.— Oui, certes, à l'instant. » Il retourna à la mosquée, entra dans la maison du prédicateur, ôta ses vêtements, en prit d'autres, et dit au fakir : « Entre, et prend-les. » Le fakir entra, les prit, les lia dans une serviette, les plaça sur sa tête, et s'en retourna. Les ${ }_{\mathrm{p} 093}$ assistants comblèrent le sultan d'actions de grâces, à cause de l'humilité et de la générosité qu'il avait montrées. Son fils et successeur désigné reprit cet habit au fakir, et lui donna en échange dix esclaves. Le sultan, ayant appris combien ses sujets louaient son action, ordonna de remettre au fakir dix autres esclaves et deux charges d'ivoire ; car la majeure partie des présents, dans ce pays, consiste en ivoire ${ }^{74}$, et l'on donne rarement de l'or.

« Sachez que, quel que soit le butin que vous preniez, le cinquième appartient à Dieu, au Prophète et à ses proches, aux orphelins, aux pauvres et au voyageur... » (Coran, VIII, 41). Les proches du Prophète sont, selon la tradition, ses descendants par sa fille Fatima, les chérîfs. Quant à la guerre sainte faite par Abu'l-Mawahib, il s’agirait plutôt de la traite des esclaves.

Pour Djammaz et ses fils, émirs de Medina, voir t. I, p. 273, et chap. 4, n. 72 ; pour Abu Numay et sa descendance, émirs de La Mecque, t. I, p. 313, et chap. 4, n. 211.

Au Moyen Age, l'ivoire du Zendj est très recherché. Des navires arabes l'emportent au pays d'Oman; de là, les commerçants le chargent pour l'Inde et la Chine. 
Lorsque ce sultan vertueux et libéral fut mort, son frère Dâoûd devint le roi ${ }^{75}$, et tint une conduite tout opposée. Quand un pauvre venait le trouver, il lui disait : "Celui qui donnait est mort, et n'a rien laissé à donner. » Les visiteurs séjournaient à sa cour un grand nombre de mois, et seulement alors il leur donnait très peu de chose ; si bien qu'aucun individu ne vint plus le trouver.

Nous nous embarquâmes à Couloua pour la ville de Zhafâr alhoumoûdh ${ }^{76}$. Le mot Zhafâr est indéclinable, et sa dernière lettre est toujours accompagnée de la voyelle kesrah (i, Zhafâri). Elle est située à l'extrémité du Yaman, sur le littoral de la mer des Indes, et l'on en exporte dans l'Inde des chevaux de prix ${ }^{77}$. La traversée dure un mois plein, si le vent est favorable, et pour ma part j'ai fait une fois en vingt-huit jours le voyage entre ${ }_{\mathrm{p} 094}$ Kâlikouth, ville de l'Inde, et Zhafâr ${ }^{78}$, Le vent était propice, et nous ne cessâmes pas d'avancer nuit et jour. La distance qu'il y a par terre entre Zhafâr et 'Aden est d'un mois, à travers le désert. Entre Zhafâr et Hadhramaout il y a seize jours, et entre la même ville et 'Omân vingt jours de marche. La ville de Zhafâr se trouve dans une campagne déserte, sans village ni dépendances ${ }^{79}$. Le marché est situé hors de la ville, dans un faubourg appelé Hardjá ${ }^{80}$, et c'est un des plus sales marchés, des plus puants et des plus abondants en mouches, à cause de la grande quantité de fruits et de poissons que l'on y vend. Ces derniers consistent, pour la plupart,

75

76
Ancienne ville située dans la province de Dhofar de l'actuel sultanat d'Oman, à cinq kilomètres à l'est de l'actuelle Salala. L'appellation Zhafar al-Humudh (aux Plantes Salines et Amères) n'est pas autrement expliquée, à moins que ce ne soit une déformation de Zhafar al-Habudi, surnom des souverains (originai- res de Habuda dans le Hadramawt) qui possédaient la ville avant sa conquête par les Rasulides du Yémen en 1278-1279.
« Et encore vous dis très véritablement qu'on y exporte maints bons destriers arabes vers d'autres contrées de quoi les marchands font grand gain et grand profit » (Marco POLO).
Voir t. III, p. 349.
La bourgade voisine de Mirbat aurait été détruite par Ahmad al-Habudi, fon- dateur de la dynastie. Elle figure toutefois aujourd'hui sur les cartes, tandis que Zhafar a disparu. Ce même souverain aurait transféré Zhafar en 1223 de l'intérieur au bord de la mer.
Al-Hadja est situé à l'ouest de la ville : « un bourg plaisant au bord de la mer » (IBN AL-MUDJAWIR).

77

80 
en sardines, qui sont dans ce pays extrêmement grasses. Une chose étonnante, c'est que les bêtes de somme s'y nourrissent de ces sardines, et il en est ainsi des brebis ${ }^{81}$. Je n'ai point vu pareille chose dans aucune autre contrée. Presque tous les débitants du marché sont des femmes esclaves, qui sont habillées de noir.

La principale culture des habitants de Zhafâr consiste en millet qu'ils arrosent au moyen de puits très profonds. Pour cela, ils préparent un énorme seau, auquel ils adaptent plusieurs cordes, à chacune desquelles s'attache, par la ceinture, un esclave mâle ou femelle. Ils tirent le seau le long d'une grosse pièce de bois, placée en haut du puits, et le renversent dans une citerne, qui sert pour arroser. Ils ont aussi une sorte de blé, qu'ils nomment 'alas, mais qui, en vérité, est une espèce d'orge. Le riz est importé de l'Inde dans ce pays, et il p095 constitue la principale nourriture de ses habitants. Les dirhems de cette ville sont un alliage de cuivre et d'étain, et n'ont pas cours ailleurs ${ }^{82}$. Les habitants sont des marchands, et vivent exclusivement du trafic.

Ils ont cette habitude, quand un navire arrive, soit de l'Inde, soit d'un autre pays, que les esclaves du sultan se dirigent vers le rivage, qu'ils montent sur un bateau et se rendent à bord de ce bâtiment. Ils portent avec eux des habillements complets, pour le maître du navire ou son préposé, pour le robbân, qui est le capitaine, et pour le kirâny, c'est-à-dire le scribe du bâtiment. On amène aussi pour ces individus trois chevaux, sur lesquels ils montent. On bat devant eux les tambours, et l'on sonne les clairons, depuis le bord de la mer jusqu'au palais du sultan, et ils vont saluer le vizir et le commandant des gardes. On envoie le repas d'hospitalité pendant trois jours à tous ceux qui se trouvent sur le navire ; après cela, ils mangent dans le palais du sultan. Ces gens agissent ainsi pour se concilier l'esprit des maîtres des bâtiments.

« La nourriture de leurs animaux est composée d'un poisson séché appelé aid, qu'ils utilisent également comme engrais » (IBN AL-MUDJAWIR). " Sachez très véritablement que leurs bêtes [...] sont accoutumées à manger du poisson, qui forme la plus grande part de leur nourriture quotidienne » (Marco POLO). papier) visant à empêcher l'exportation du métal argent. 
Les habitants de Zhafâr sont modestes, doués d'un bon naturel, vertueux, et ils aiment les étrangers. Leurs vêtements sont en coton, qui est importé de l'Inde, et ils attachent des pagnes à leur ceinture, en place de caleçon. La plupart se ceignent seulement d'une serviette au milieu du corps, et en mettent une autre sur le dos, à cause de la grande chaleur. Ils se lavent plusieurs fois dans la journée. La ville possède beaucoup de mosquées, dans chacune desquelles il y a de nombreux cabinets pour les purifications. On fabrique à Zhafâr de très belles étoffes de soie, de coton et de lin. La maladie qui attaque le plus souvent les gens de cette ville, hommes et femmes, c'est l'éléphantiasis ; elle consiste en un gonflement des deux pieds. Le plus grand nombre des hommes sont tourmentés par des hernies; que Dieu nous en ${ }_{\text {p096 }}$ préserve ! Une des belles habitudes de cette population consiste à se tenir mutuellement par la main dans la mosquée, immédiatement après la prière du matin, et celle de trois heures. Ceux qui sont au premier rang s'appuient sur le côté qui regarde La Mecque, et ceux qui les suivent leur prennent la main. Ils agissent encore ainsi après la prière du vendredi, se tenant tous ensemble par les mains.

Un des avantages particuliers, et une des merveilles de cette ville, c'est que, toutes les fois qu'un personnage se dirige vers elle, avec de mauvais desseins, la fraude se retourne contre lui-même, et un obstacle s'élève entre lui et la place. On m'a raconté que le sultan Kothb eddîn Temehten, fils de Thoûrân châh, seigneur de Hormouz, l'attaqua une fois par terre et par mer ; mais que Dieu très haut déchaîna contre lui un vent violent. Ses vaisseaux furent brisés ; il renonça alors au siège de la ville, et fit la paix avec son roi ${ }^{83}$. On m'a pareillement rapporté qu'Almalic almodjâhid, sultan du Yaman, avait désigné un de ses cousins, avec une armée nombreuse, dans le but d'arracher Zhafâr des mains de son roi, qui était aussi un de ses cousins. Lorsque le susdit commandant sortit de sa maison, un mur tomba sur lui et sur plusieurs de ses compagnons, et ils périrent tous. Le roi Hormuz contre Zhafar datant de l'époque habudite, en 1262. 
abandonna alors son projet, il ne donna aucune suite au siège de Zhafâr, et cessa de prétendre à cette cité ${ }^{84}$.

Une autre chose merveilleuse, c'est que les habitants de cette ville sont ceux des hommes qui ressemblent le plus, dans leurs usages, aux gens du Maghreb. Je logeai, par exemple, dans la maison du prédicateur de la mosquée principale, lequel était 'Iça, fils d'Aly, homme jouissant d'une grande considération, et doué d'une p097 âme généreuse. Il avait des femmes esclaves, nommées à l'instar de celles de la Mauritanie. L'une s'appelait Bokhaït, l'autre Zâd almâl ${ }^{85}$, noms que je n'avais entendu prononcer dans aucun autre pays. Presque tous les habitants de Zhafâr portent la tête découverte et sans turban. Dans chacune de leurs maisons il y a une natte de feuilles de palmier, suspendue dans l'intérieur du logement, et sur laquelle le chef de famille se place pour prier, et cela précisément à la manière des Occidentaux. Enfin, ils se nourrissent de millet. Cette similitude entre les deux peuples confirme l'opinion d'après laquelle les Sanhâdjah et autres tribus de la Mauritanie tirent leur origine de Himyar, famille du Yaman ${ }^{86}$.

Dans le voisinage de Zhafâr, et entre ses vergers, se voit la zâouïah du pieux cheïkh, le serviteur de Dieu, Abou Mohammed, fils d'Abou Becr, fils d'Iça ${ }^{87}$, originaire de cette ville. Elle jouit d'une grande vénération chez ces peuples, qui s'y rendent matin et soir, et se mettent sous sa protection. Quand l'individu qui cherche un refuge y est entré, le sultan n'a plus de pouvoir sur lui. J'y ai vu une personne, qu'on m’affirma être là retirée depuis plusieurs années, sans que le souverain lui eût fait subir aucun mauvais traitement. Dans le temps de mon séjour à Zhafâr, le secrétaire du sultan se mit sous la protection de cette zâouïah, et y resta jusqu'à ce que la bonne harmonie eût été rétablie entre eux deux. J'ai été dans cette zâouïah, et j'y ai passé une nuit sous l'hospitalité des deux cheïkhs, Abou'l'abbâs Ahmed et Abou

84

85

86

87

Pour al-Malik al-Mudjahid, voir plus haut p. 73. Cette expédition n’est pas connue par ailleurs.

Bukhait, diminutif de Bakht (Bonheur) et Zâd al-mâl (Que ta richesse augmente).

Cette croyance est basée sur la légende d'une conquête pré-islamique de l’Afrique du Nord-Ouest par les rois Himyarites du Yémen.

Une pierre tombale trouvée sur place signale un certain Abu Muhammad bin Abi Bakr bin Sa’d mort en 1315. 
'Abd Allah Mohammed, fils, l'un et l'autre, du cheïkh Abou Becr susmentionné, et j'ai reconnu chez tous deux un grand mérite. Quand nous eûmes lavé nos mains, après le repas, Abou'l'abbâs prit l'eau qui nous ${ }_{\text {p098 }}$ avait servi pour cet usage, et en but. Il envoya une servante avec le restant à sa femme et à ses enfants, qui le burent. C'est ainsi que ces individus agissent à l'égard des visiteurs dont ils conçoivent une opinion favorable. De cette façon même, je reçus l'hospitalité du kâdhi de Zhafâr, le pieux Abou Hâchim 'Abd Almalic azzebîdy. Il me servait en personne, il lavait mes mains, et ne chargeait nul autre de ces soins.

A peu de distance de ladite zâouïah est la chapelle sépulcrale des prédécesseurs du sultan Almalic almoghîth ${ }^{88}$. Elle est en grande vénération dans ce pays ; et c'est là que se réfugient, jusqu'à ce qu'ils soient satisfaits, ceux qui cherchent à obtenir quelque chose. Les troupes ont l'habitude de se mettre sous la protection de ce monument, lorsque le mois s'est écoulé sans qu'elles aient reçu leur solde ; et elles y restent jusqu'à ce qu'elles l'obtiennent.

A une demi-journée de distance de Zhafâr se trouvent les Ahkâf ${ }^{89}$, qui ont été jadis les demeures du peuple d'Âd. On y voit une zâouïah, et une mosquée au bord de la mer, entourée par un village qu'habitent les pêcheurs de poissons ${ }^{90}$. Dans la zâouïah est un tombeau, avec l'épitaphe suivante : «Ceci est le sépulcre de Hoûd, fils d'Abir ${ }^{91}$, sur qui soient la meilleure bénédiction et le salut ! » J'ai déjà dit qu'il y a dans la mosquée ${ }_{\text {pog9 }}$ de Damas un endroit avec cette inscription " Ceci est le sépulcre de Hoûd, fils d'Abir ${ }^{92}$. " Mais le plus probable c'est

Voir plus loin, n. 97. Une pierre tombale au nom d'al Wathiq (1292-1311), fils du roi du Yémen Muzaffar Yusuf (1250-1295), a été trouvée sur place.

" Rappelle-toi le frère des Ad, quand il avertit son peuple dans le pays d'alAhqaf » (Coran, XLVI, 21). Les Ad sont un peuple du sud de l'Arabie et leur " frère » est Hud, leur prophète, selon le Coran. Les Ahkâf (littér. Collines de Sable) ont été localisées en plusieurs endroits et ici probablement sur un ancien site sabéen.

Ibn Battûta confond apparemment deux sites sabéens. Un, situé à une quinzaine de kilomètres à l’intérieur, des terres, près d'une grotte sur le Djebel Qara et un autre au bord de la mer à une quinzaine de kilomètres à l'ouest de Zhafar.

91 Il s'agit probablement d'une tradition locale, le tombeau le plus connu de Hud étant localisé au lieu-dit Qabr Hud, à l’est de Tarim dans le Hadramawt. 
que sa tombe est dans ces monticules de sable, car c'était là son pays ; et Dieu sait le mieux la vérité ! Zhafâr possède des vergers où sont beaucoup de bananes d'une forte dimension. On a pesé devant moi un de ces fruits, qui se trouvait avoir le poids de douze onces ; il est d'un goût agréable, et très sucré. Où y voit aussi le bétel, de même que le coco, qui est connu sous le nom de noix de l'Inde. On ne trouve ces deux dernières productions que dans l'Inde et dans cette ville de Zhafâr, à cause de sa ressemblance avec l'Inde, et de son voisinage de ce pays. Il est toutefois juste de dire que, dans la ville de Zebîd, on remarque dans le jardin du sultan de petits cocotiers. Et, puisque nous venons de parler du bétel et du coco, nous allons décrire ces deux plantes et mentionner leurs propriétés.

\section{DU BÉTEL}

Le bétel ${ }^{93}$ est un arbre qu'on plante a l'instar des ceps de vigne, et on lui prépare des berceaux avec des cannes, ainsi qu'on le pratique pour la vigne ; ou bien on le plante dans le voisinage des cocotiers, et le bétel grimpe sur ceux-ci, comme le font encore les ceps de vigne et l'arbre à poivre. Le bétel ne donne pas de fruit, et ce sont ses feuilles que l'on recherche. Elles ressemblent à celles de la ronce ; leur meilleure partie est la partie jaune, et on les cueille tous les jours. Les Indiens font un très grand cas du bétel. Quand un individu se rend dans la maison d'un de ses amis, et que celui-ci lui présente cinq feuilles de cet arbre, c'est comme s'il lui donnait le monde et tout ce qu'il renferme ; surtout si p100 celui qui les donne est un prince ou un grand personnage. Ce cadeau, chez les Indiens, est plus prisé en lui-même, et montre mieux l'honneur que l'on veut faire à quelqu'un, qu'un don d'argent et d'or.

La manière de s'en servir consiste à prendre avant le bétel de la noix faoufel, qui ressemble à la noix de muscade ${ }^{94}$, et à la briser, jusqu'à ce qu'elle soit réduite en petits fragments. Alors on les met dans la bouche et on les mâche. On prend après cela les feuilles du bétel,

« Le bétel est une variété de poivrier de Malaisie, dont les feuilles, mêlées de chaux vive et de noix d'arec, donnent un masticatoire tonique et astringent » ( V. MONTEIL). 
sur lesquelles on met une très petite quantité de chaux, et on les mâche avec le faoufel. Il a la propriété de parfumer l'haleine, de chasser ainsi les mauvaises odeurs de la bouche, d'aider à la digestion des aliments, et d'empêcher que l'eau bue à jeun ne soit nuisible. Son emploi porte à la gaieté, de même qu'aux plaisirs de l'amour. On le place la nuit au chevet du lit, et lorsqu'un individu se réveille, ou est réveillé par sa femme ou sa concubine, il en prend, et chasse par ce moyen la mauvaise odeur de sa bouche. On m'a raconté que les jeunes filles, esclaves du sultan et des princes dans l'Inde, ne mangent que du bétel. Nous parlerons de cela quand il sera question de l’Inde.

\section{Du COCO}

C'est la noix de l'Inde, fruit d'un arbre des plus singuliers, quant à son état, et des plus admirables pour ses particularités. Il ressemble au palmier, et il n'y a pas d'autre différence entre les deux, si ce n'est que l'un produit des noix, et l'autre des dattes. La noix du cocotier ressemble à la tête de l'homme, car on y aperçoit des ouvertures semblables aux deux yeux, et à la bouche. Quand elle est verte, son intérieur est pareil au cerveau de l'homme; et tout autour de la noix on voit des filaments qui offrent l'image des cheveux. Les habitants de Zhafâr, et autres contrées, font avec ces fibres des ${ }_{\mathrm{p} 101}$ cordes, qui leur servent à joindre les planches des navires, en place de clous de fer, et ils en font aussi des câbles pour les bâtiments. Il y a de ces noix, et surtout celles qui croissent dans les îles Maldives, qui ont la dimension de la tête d'un homme.

On prétend dans ces pays qu'un des médecins de l'Inde était, à une époque reculée, attaché à un roi de cette contrée, et en très grande considération près de lui ; mais que ce dernier avait un vizir, entre lequel et le médecin régnait une inimitié réciproque. Celui-ci dit un jour au roi : «Si l'on coupait la tête de ce vizir, et qu'ensuite on l'enterrât, il en sortirait un palmier, qui produirait de magnifiques dattes, lesquelles seraient d'une grande utilité aux Indiens et autres peuples du monde. » Le roi lui répondit : " Et s’il ne sort pas de la tête du vizir ce que tu prétends ?... » Le médecin répliqua : «Dans ce cas, fais de ma tête ce que tu auras fait de celle du vizir. » Le roi ordonna de couper la tête de ce dernier, ce qui fut exécuté ; le médecin la prit et planta un 
noyau de datte dans le cerveau, et le soigna jusqu'à ce qu'il devînt un arbre et qu'il produisît cette noix !... Mais cette anecdote est un conte mensonger, et nous ne l'avons mentionnée qu'à cause de sa grande célébrité chez les peuples de l’Inde.

Parmi les propriétés de cette noix, il faut observer qu'elle donne de la force au corps, qu'elle produit l'embonpoint, et augmente l'incarnat du visage. Quant au secours qu'elle procure pour les plaisirs de l'amour, son action en cela est admirable. Une des merveilles de ce fruit, c'est que, dans son commencement, lorsqu'il est encore vert, celui qui coupe avec un couteau une partie de son écorce, et qui creuse ainsi la tête de la noix, y boit une eau très douce et extrêmement fraîche, mais dont la nature, au contraire, est chaude, et excite aux plaisirs de Vénus. Il arrive que, après avoir avalé cette eau, il prend un morceau de l'écorce, et le façonne à l'instar d'une cuiller, avec laquelle il enlève l'aliment qui se trouve dans l'intérieur de la noix, et dont le goût ressemble à celui de l'œuf, lorsqu'il est rôti, mais qu'il p102 n'est point encore tout à fait cuit ; et il s'en nourrit. C'était là ma nourriture tout le temps de mon séjour aux îles Maldives, qui fut d'une année et demie. Une autre merveille de cette noix, c'est que l'on fabrique avec elle de l'huile, du lait et du miel.

Quand on veut en extraire du miel, les domestiques qui ont soin de cette sorte de palmiers, et qui s'appellent alfâzâniyah, montent sur le cocotier, matin et soir, à l'époque où ils veulent recueillir l'eau de cet arbre, dont ils font le miel et à laquelle ils donnent le nom d'athwâk ${ }^{95}$. Pour cela, ils coupent le rameau d'où sort le fruit, et ils en laissent subsister la longueur de deux doigts, où ils attachent un petit chaudron. L'eau qui coule du rameau tombe goutte à goutte dans cet ustensile, et s'il a été attaché le matin, le domestique revient le soir, portant avec lui deux coupes, faites avec l'écorce de la noix mentionnée plus haut ; l'une de celles-ci est remplie d'eau. Il verse le liquide qui se trouve dans le chaudron dans la coupe vide, et lave le rameau avec l'eau contenue dans l'autre; il enlève ensuite un peu de son bois, et y fixe de nouveau le chaudron ; puis il agit le matin suivant comme il avait pratiqué le soir, et quand il a ainsi réuni une quantité suffisante de ce liquide il le cuit à l'instar de la liqueur des raisins, 
lorsque l'on fait le $r o b b^{96}$. On a de la sorte un miel excellent, d'une grande utilité, qu'achètent les marchands de l'Inde, du Yaman et de la Chine, lesquels l'importent dans leurs pays, et dont ils fabriquent des sucreries.

Le lait de coco se prépare de la manière qui suit : dans chaque maison il y a un meuble, ressemblant à un fauteuil, sur lequel une femme s'assied, tenant à la main un bâton qui est garni, à une des extrémités, d'un morceau de fer proéminent. On fait dans la noix une ouverture par laquelle passe ce fer en guise d'éperon avec ce fer on casse ce qui se trouve dans l'intérieur de la noix. On recueille tout ce qui en sort dans un grand plat, p103 jusqu'à ce que le coco soit entièrement vide ; puis on fait macérer dans l'eau toutes ces parties concassées, qui prennent la couleur blanche et le goût du lait frais, et qu'on mange généralement avec le pain.

Pour obtenir l'huile, on prend la noix de coco, après sa maturité et sa chute de l'arbre ; on ôte son écorce, puis on coupe le contenu par morceaux, qu'on place au soleil. Quand ils sont desséchés, on les cuit dans des chaudières, et on en extrait l'huile. On emploie celle-ci pour l'éclairage, aussi bien que pour la préparation des aliments ; les femmes s'en servent pour mettre sur leurs cheveux, et elle est ainsi d'une grande utilité.

\section{DU SULTAN DE ZHAFÂR}

C'est le sultan Almalic almoghîth, fils d'Almalic alfâiz, cousin du roi du Yaman ${ }^{97}$. Son père était commandant de Zhafâr, sous la suzeraineté du seigneur du Yaman, auquel il devait un présent, qu’il lui envoyait chaque année ; mais plus tard Almalic almoghîth se fit prince indépendant de Zhafâr, et se refusa à l'envoi du tribut. Il arriva alors ce que nous avons raconté plus haut, savoir : l'intention qu'eut le roi du Yaman de le combattre, la nomination de son cousin pour cet objet,

Suc épaissi.

97 Le dernier des souverains Habudites, Salim bin Idris, fut évincé en 1278 par le Rasulide Muzaffar Yusuf qui a nommé en 1292 son fils al-Wathiq ; si al-Faiz indiqué ici comme père d'al-Mugith est bien fils d'al-Wathiq, al-Mugith doit être cousin au second degré du sultan du Yémen al-Mudjahid Nur al-din (voir ci-dessus n. 39). 
et la chute de la muraille sur lui. Le sultan de Zhafâr a dans l'intérieur de la ville un palais appelé Alhisn ${ }^{98}$, qui est magnifique et vaste ; la mosquée principale est vis-à-vis de cet édifice.

Il est d'usage de jouer des tambours, des clairons, des trompettes et des fifres à la porte du sultan, tous les jours, après la prière de trois

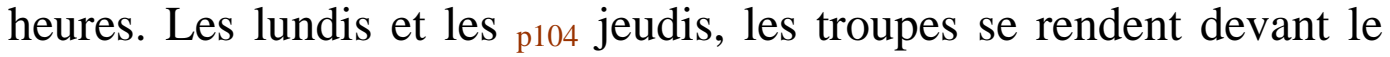
palais, et elles restent une heure au-dehors de la salle d'audience ; puis elles s'en retournent. Le sultan ne sort pas, et personne ne le voit, excepté le vendredi, où il se rend à la prière, et retourne tout de suite après à son palais. Il ne défend à qui que ce soit l'entrée de la salle d'audience à la porte de laquelle se tient assis le commandant des gardes, et c'est à lui que s'adressent ceux qui ont quelque chose à solliciter, ou quelque plainte à porter. Celui-ci expose l'affaire au sultan, et apporte immédiatement la réponse. Quand ce prince désire monter à cheval, on fait sortir du château ses montures, ainsi que ses armes et ses mamloûcs, jusqu'à ce que l'on arrive à l'extérieur de la ville. On amène un chameau, portant une litière recouverte d'un rideau blanc brodé d'or, dans laquelle se placent le sultan et son commensal, de façon que nul ne les voie. Lorsque ce roi est arrivé dans son jardin, s'il veut monter un cheval, il le fait, et descend alors de son chameau. Une autre de ses habitudes, c'est que personne ne doit se trouver à côté de lui sur son chemin ni s'arrêter pour le regarder, soit pour se plaindre, soit pour tout autre motif. Celui qui oserait commettre pareille chose serait sévèrement battu ; c'est à cause de cela que l'on voit les gens s'enfuir, et éviter de suivre la même route que le sultan, lorsqu'ils apprennent sa sortie.

Le vizir de ce prince est le jurisconsulte Mohammed al'adeny. Il était d'abord instituteur de jeunes enfants ; il enseigna ainsi au sultan la lecture et l'écriture, et lui fit promettre de le nommer son vizir s'il devenait roi. Quand cela arriva, le prince accomplit sa promesse ; mais le ministre ne remplissait pas bien ses fonctions; il possédait seulement le nom de vizir, et un autre avait l'autorité attachée à l'emploi. du XIX ${ }^{\mathrm{e}}$ siècle. 
Nous nous embarquâmes sur mer à Zhafâr, nous dirigeant vers l'Omân, dans un petit navire appartenant à un individu nommé Aly, fils d'Idrîs almassîry, originaire de l'île de Massîrah. Le deuxième jour, nous ${ }_{\text {p105 }}$ abordâmes au port de Hâcic ${ }^{99}$, habité par des gens de race arabe, pêcheurs de profession. Ici se trouve l'arbre qui fournit l'encens ${ }^{100}$; ses feuilles sont minces, et lorsqu'on pratique des incisions dans celles-ci il en dégoutte une liqueur semblable au lait, et qui devient ensuite une gomme ; et c'est là l'encens, qui est très abondant dans ce pays. Les habitants de ce port ne vivent que de la pêche d'un genre de poisson appelé alloukham et qui ressemble à celui qui est nommé chien de mer. On le coupe par tranches, et aussi par lanières ; on le fait sécher au soleil, on le sale, et on s'en nourrit. Les maisons de ces gens sont faites avec les arêtes des poissons, et leurs toits avec des peaux de chameaux.

Nous voyageâmes encore quatre jours depuis le port de Hâcic ; ensuite nous arrivâmes à la montagne Loum'àn ${ }^{101}$, Elle est située au milieu de la mer, et à son sommet se voit un couvent construit en pierre, mais dont la couverture est formée d'arêtes de poissons. A l'extérieur de l'édifice se voit un étang, qui est le produit de l'eau pluviale.

MENTION D'UN SAINT PERSONNAGE QUE NOUS VÎMES SUR CETTE MONTAGNE

Après avoir jeté l'ancre au pied de cette montagne, nous la gravîmes pour nous rendre audit couvent, et nous y trouvâmes un vieillard qui dormait. Nous prononçâmes la formule du salut, il se réveilla, et nous rendit les salutations par signes. Nous lui adressâmes la parole, mais il ne nous répondit pas, et secoua ${ }_{\text {p106 }}$ seulement la tête. Les marins lui apportèrent des mets, et il refusa de les recevoir. Nous lui de-

Bandar Hasik, toujours dans le Dhofar, à cent vingt kilomètres à l'est de Zhafar.

100 Marco Polo mentionne l'encens à Zhafar : « Et encore vous dis que l'encens blanc y naît fort bon, en abondance. »

${ }^{101}$ La description correspond à l'île de Hallaniya, du groupe des Kuria Muria, où Marco Polo placerait ses îles mâle et femelle, mais cette île n'est qu'à une cinquantaine de kilomètres à l'est de Hasik. 
mandâmes de prier pour nous ; il remua les lèvres, mais nous ne sûmes pas ce qu'il disait. Il portait une robe rapiécée, un bonnet de feutre, et il n'avait avec lui ni petite outre, ni aiguière, ni bâton ferré, ni chaussure. Les gens de l'équipage dirent qu'ils ne l'avaient jamais vu dans cette montagne. Nous passâmes la journée en ce lieu et nous priâmes avec ce cheïkh dans l'après-midi et au moment du coucher du soleil. Nous lui présentâmes des aliments, qu'il ne voulut pas accepter, et il continua à prier jusqu'à la nuit close. Alors il fit l'appel à la prière correspondante à cette heure, et nous la célébrâmes en sa compagnie. Il avait une belle voix et lisait fort bien. Quand ladite prière eut été terminée, il nous fit signe de nous retirer, ce que nous accomplîmes, après lui avoir dit adieu ; et nous étions très étonnés de sa conduite. Après l'avoir quitté, je voulus retourner vers lui ; mais, quand je me fus approché, je fus retenu par un sentiment de vénération à son égard, et la crainte l'emporta. Mes camarades étaient revenus aussi sur leurs pas, et je m'en retournai avec eux.

Nous nous embarquâmes de nouveau, et après deux jours nous arrivâmes à l'île des Oiseaux ${ }^{102}$, qui est dépourvue de population. Nous jetâmes l'ancre, nous montâmes dans l'île, et nous la trouvâmes remplie d'oiseaux ressemblant aux moineaux, mais plus gros que ceux-ci. Les gens du navire apportèrent des œufs, les firent cuire et les mangèrent. Ils se mirent à chasser ces mêmes oiseaux, et en prirent un bon nombre, qu'ils firent cuire aussi, sans les avoir préalablement égorgés. Il y avait, assis à mon côté, un marchand de l'île de Massîrah qui habitait Zhafâr et dont le nom était Moslim. Je le vis manger ces oiseaux avec les matelots, et je ${ }_{\mathrm{p} 107}$ lui reprochai une telle action. Il en fut tout honteux, et il me répondit: " Je croyais qu’ils leur avaient coupé la gorge $^{103}$. " Après cela, il se tint éloigné de moi, par l'effet de la honte, et il ne m’approchait que lorsque je l'appelais.

Ma nourriture, pendant le voyage sur ce navire, était composée de dattes et de poissons. Les marins pêchaient, matin et soir, une sorte de

${ }^{102}$ Une toute petite île située dans le golfe de Masira, près des côtes, et appelée Hamar Nafur. Elle est décrite comme fréquentée par des milliers d'oiseaux.

103

Selon la loi et la pratique musulmanes, pour qu'un animal soit comestible, il faut que sa gorge soit tranchée. 
poisson nommé en persan chîr mâhy ${ }^{104}$ mots dont la signification est « le lion du poisson ». En effet, chîr veut dire « lion » et mâhy " poisson ». Il ressemble à celui qui est appelé chez nous tâzart. Ces gens ont l'habitude de le couper par petites tranches, de les faire rôtir, et d'en donner une seulement par personne à tous ceux qui montent le navire, sans accorder de préférence à qui que ce soit, y compris même le maître du bâtiment. Ils mangent ce poisson avec les dattes. J'avais avec moi du pain et du biscuit, que j’avais emportés de Zhafâr ; et, lorsqu'ils furent épuisés, je me nourris, comme eux, de ce poisson. Nous célébrâmes en mer la fête des Sacrifices ${ }^{105}$; un vent violent souffla contre nous toute la journée ; il commença après l'aurore, et dura jusqu'au lever du soleil (le jour suivant). Il fut bien près de nous submerger.

\section{PRODIGE}

Il y avait avec nous sur le navire un pèlerin de l'Inde nommé Khidhr, mais qu'on appelait Maoulânâ, car il savait par cœur le Coran et il écrivait bien. Quand il vit l'extrême agitation de la mer, il enveloppa sa tête dans son manteau, et fit semblant de dormir. Lorsque Dieu $_{\text {p108 }}$ eut dissipé le danger qui nous menaçait, je lui dis : " ô notre maître Khidhr, qu'as-tu vu ? » il me répondit : "Pendant la bourrasque, j'ouvrais les yeux pour voir si les anges qui saisissent les âmes venaient. Je ne les voyais point, et je m'écriais “Louange à Dieu !" car, si la submersion devait avoir lieu, ils viendraient prendre possession des âmes ; puis je fermais les yeux, et ensuite je les ouvrais de nouveau, pour regarder ce que je viens de dire, jusqu'à ce que Dieu eût détourné de nous le péril. » Un navire appartenant à un négociant nous avait devancés ; il fut submergé, et il n’en échappa qu'une seule personne, qui se sauva à la nage, après de grands efforts.

Je goûtai, sur le bâtiment, un genre de mets que je n'avais jamais mangé auparavant, et que je ne goûtai plus après cette fois. Il avait été préparé par un des marchands de l'Omân, et consistait en millet dhou-

104 Poisson aux écailles blanches et à la chaire délicieuse d’après les dictionnai105 res.

On est donc le 14 septembre 1331. 
rah, non moulu, que cet individu fit cuire, et sur lequel il versa du saïlân, qui est un miel tiré des dattes ${ }^{106}$; puis nous le mangeâmes.

Nous continuâmes notre voyage et nous arrivâmes à l'île de Massîrah, patrie du maître du navire sur lequel nous étions embarqués. Son nom se prononce à la manière du mot massîr (ce que l'on devient, issue, etc.), avec addition du tâ (hâ), qui marque le féminin. C'est une île vaste, et ses habitants n'ont point d'autre nourriture que des poissons ${ }^{107}$. Nous n'y débarquâmes pas, à cause de l'éloignement où sa rade est du rivage. Au reste, j'avais pris en horreur ces gens-là, lorsque je les eus vus manger les oiseaux sans leur couper la gorge. Nous y restâmes un jour, pendant lequel le patron du navire descendit à terre chez lui, puis il revint.

Après cela nous marchâmes un jour et une nuit, et ${ }_{\mathrm{p} 109}$ nous arrivâmes à la rade d'un gros bourg au bord de la mer nommé Soûr ${ }^{108}$. De cet endroit, nous vîmes la ville de Kalhât, située au pied d'une montagne, et qui nous sembla très proche. Nous jetâmes l'ancre un peu avant midi, et, quand nous aperçûmes ladite ville, je désirai m’y rendre à pied et y passer la nuit, car je détestais la société de nos marins. Je pris des informations touchant la distance, et l'on me dit que j'arriverais à Khalât à trois ou quatre heures de l'après-midi du même jour. Alors je louai un des matelots pour m'indiquer la route, et Khidhr, l'Indien dont nous avons déjà parlé, vint avec moi. Je laissai dans le bâtiment mes compagnons avec mes effets, et ils devaient venir me rejoindre le lendemain. Je pris un paquet de mes propres habillements, que je remis au guide, afin qu'il m'évitât la fatigue de les porter, et je saisis dans ma main une lance.

Mais ce guide voulait s'emparer de mes habillements. Il nous conduisit à un canal formé par la mer et où ont lieu le flux et le reflux, et il se disposa à le traverser avec les hardes. Je lui dis alors : « Passele toi seul et laisse ici les effets ; nous traverserons si nous le pouvons,

${ }^{106}$ Voir t. I, chap. 5, n. 40.

${ }^{107}$ L'île de Massira, proche des côtes d'Oman. Ses habitants sont décrits comme des ichtyophagi, des mangeurs de poissons par l'auteur du Périple, fait vers l'année soixante de l'ère chrétienne.

Port situé immédiatement à l'ouest de la pointe la plus orientale de l'Arabie, le Ras al-Hadd. Qalhat est situé à une vingtaine de kilomètres à vol d'oiseau vers le nord-ouest. 
sinon nous remonterons pour chercher le gué. » Il revint sur ses pas, et nous vîmes peu après des hommes qui passèrent le canal à la nage, ce qui nous prouva que l'intention du guide était de nous noyer, et de se sauver avec les vêtements. Alors je simulai l'allégresse ; mais je me tins sur mes gardes, je serrai ma ceinture et je brandis ma lance; le conducteur eut peur de moi. Nous montâmes jusqu'à ce que nous eussions rencontré un passage ; ensuite nous nous trouvâmes dans une plaine déserte et sans eau. Nous eûmes soif et souffrîmes beaucoup ; mais Dieu nous envoya un cavalier, suivi de plusieurs camarades, dont l'un tenait en main une petite outre pleine d'eau. Il me donna à boire, ainsi qu'à mon compagnon, et nous continuâmes à marcher, pensant p110 que la ville était tout près de nous tandis que nous en étions séparés par de larges fossés, dans lesquels nous cheminâmes plusieurs milles.

Quand ce fut le soir, le guide voulut nous entraîner du côté de la mer, qui n'offre pas ici de chemin, car le rivage est une suite de rochers. Son intention était que nous fussions embarrassés parmi les pierres, et qu'il pût ainsi s'en aller avec le paquet; mais je lui dis : " Nous ne marcherons que sur la route où nous sommes. " Or il y avait environ un mille de distance de ce point à la mer. Lorsque la soirée fut devenue obscure, il nous dit : "Certes, la ville est proche de nous ; allons, marchons, afin que nous puissions passer la nuit audehors de la ville, en attendant l'aurore! » Je craignis d'être attaqué par quelqu'un pendant la route, et je ne savais pas au juste quel intervalle il restait encore à parcourir. Je répondis donc au conducteur : « Il vaut mieux que nous sortions du chemin et que nous dormions, et quand nous serons au matin, nous nous rendrons, s'il plaît à Dieu, à la ville. » J'avais vu, en effet, une troupe d'hommes au pied d'une montagne qui se trouvait en cet endroit ; j'eus peur qu'ils ne fussent des voleurs, et me dis, à part moi : «Il est préférable de se dérober aux regards. » Quant à mon camarade, il était vaincu par la soif, et n’approuvait pas ma détermination.

Cependant, je quittai la route, et me dirigeai vers un de ces arbres appelés oumm Ghaïlân ${ }^{109}$, car j'étais fatigué et je souffrais ; mais je simulais la force et la constance, par crainte du guide. Mon compa-

${ }^{109}$ Épine d'Égypte, espèce d'acacia. 
gnon était malade et n'avait plus d'énergie. Je plaçai le conducteur entre lui et moi, je mis le paquet de hardes entre mes vêtements et mon corps, et je tins ma lance à la main. Mon camarade dormit, ainsi que le guide ; pour moi, je restai éveillé, et toutes les fois que ce dernier bougeait, je lui parlais, pour lui montrer que je ne dormais pas. Nous demeurâmes ainsi jusqu'à l'aurore ; nous nous dirigeâmes alors

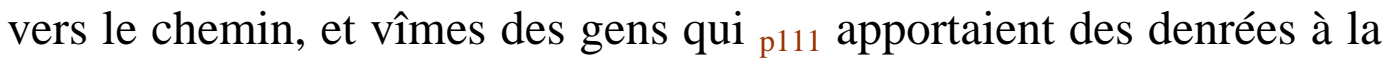
ville. J'envoyai le guide pour chercher de l'eau, mon compagnon ayant pris les habillements ; et il y avait entre nous et la ville des vallons et des fossés. Le guide nous apporta de l'eau, que nous bûmes, et cela se passait à l'époque des chaleurs.

Enfin, nous arrivâmes à Khalât, où nous entrâmes dans un état d'extrême souffrance. Ma chaussure était devenue trop étroite pour mon pied, de sorte qu'il s'en fallut de peu que le sang ne coulât de dessous les ongles. Lorsque nous atteignîmes la porte de la ville, il arriva, pour comble de malheur, que le gardien nous dit : " Il faut absolument que tu ailles avec moi chez le commandant de la ville, afin qu'il soit informé de ton aventure, et qu'il sache d'où tu viens. » J'allai avec lui, et je trouvai que l'émir était un homme de bien et d'un bon naturel. Il me fit des questions sur mon état, il me donna l'hospitalité, et je restai près de lui six jours. Pendant ce temps, je ne pus point me tenir debout sur mes pieds, tant ils étaient endoloris.

La ville de Kalhât est située sur le littoral ${ }^{110}$; elle possède de beaux marchés, une des plus jolies mosquées qu'on puisse voir, et dont les murailles sont recouvertes de faïence colorée de Kâchân, qui ressemble au zélîdj. Cette mosquée est très élevée, elle domine la mer et le port, et sa construction est due à la pieuse Bîbi Merïam ${ }^{111}$. Le

110 «Calatu (Qalhat) est une grande cité qui est dans le golfe de Calatu. [...] Cette cité a un très bon port, et vous dis très véritablement qu'il y arrive de l'Inde maintes nefs avec maintes marchandises et les y vendent fort bien, parce que, de cette ville, se portent les marchandises et les épices vers l'intérieur, à mainte cité et village » (Marco POLO).

111 Qalhat, tout au long de la période de sa prospérité, resta soumise aux princes d'Hormuz, œ qui n'empêcha pas des gouverneurs de Qalhat de s'instaurer comme souverains d'Hormuz. Un d'entre eux, Mahmud Qalhati, régna sur Hormuz de 1243 à 1277. Après sa mort, un de ses esclaves turcs, Ayaz, usurpa le pouvoir (c. 1291-1311), et à la mort de ce dernier sa femme, Bibi Maryain, régna sur Qaihat jusqu’aux environs de 1320. 
sens du mot bîbi, chez ces gens, c'est «femme libre, noble ». J'ai mangé à Kalhât du poisson ${ }_{\text {p112 }}$ tel que je n'en ai jamais goûté dans aucun autre pays ; je le préférais à toute sorte de viandes, et c'était là ma seule nourriture. Les habitants le font rôtir sur des feuilles d'arbre, le mettent sur du riz, et le mangent ; quant à ce dernier, il leur est apporté de l'Inde. Kalhât est habité par des marchands qui tirent leur subsistance de ce qui leur arrive par la mer de l'Inde. Lorsqu'un navire aborde chez eux, ils s'en réjouissent beaucoup. Bien qu'ils soient arabes, ils ne parlent point un langage correct. Après chaque phrase qu'ils prononcent, ils ont l'habitude d'ajouter la particule non. Ils disent par exemple: "Tu manges, non; tu marches, non; tu fais telle chose, non ${ }^{112}$. » La plupart sont schismatiques ${ }^{113}$, mais ils ne peuvent point pratiquer ostensiblement leur croyance, car ils sont sous l'autorité du sultan Kothb eddîn Temehten, roi de Hormouz ${ }^{114}$, qui fait partie de la communion orthodoxe.

Près de Kalhât se voit le bourg de Thîby ${ }^{115}$. Ce nom se prononce comme le mot thîb, lorsque celui qui parle le met en rapport d'annexion avec lui-même (ce qui fait thîby, "mon parfum », etc.). C'est un des plus jolis bourgs et des plus admirables par sa beauté ; il possède des canaux dont le cours est rapide, des arbres verdoyants, des vergers nombreux, et l'on en exporte des fruits à Kalhât. Il fournit une sorte de banane appelée almorouârîd, c'est-à-dire, en persan, perles, et qui est y très abondante. On en exporte aussi à Hormouz et ailleurs. On y voit encore du bétel, mais ses feuilles sont petites. Quant aux dattes, on les apporte de l’Omân dans ces contrées. p113

Nous nous dirigeâmes ensuite vers ce dernier pays, et marchâmes six jours dans une plaine déserte; puis nous arrivâmes dans le pays d'Omân le septième jour ${ }^{116}$. C'est une province fertile, riche en canaux, en arbres, en vergers, en enclos plantés de palmiers, et en beau-

112 Cette habitude est également signalée par ailleurs.

113 Kharidjites ibadites (voir introduction au tome I).

114 Qutb al-din Tehemten (1319-1347), arrière-petit-fils de Mahmud Qalhati, a dû reconquérir Hormuz sur un usurpateur, Shihab al-din Yusuf, à partir de Qalhat.

115 L'actuel Tiwi, à une quinzaine de kilomètres au nord de Qalhat sur la côte.

116 L’Oman proprement dit, les régions avoisinant le Djabal Akhdar, au nord du sultanat actuel d'Oman. 
coup de fruits de différentes espèces. Nous entrâmes dans la capitale de ce pays, qui est la ville de Nazoua ${ }^{117}$.

Elle est située au pied d'une montagne ; des canaux l'entourent, ainsi que des vergers, et elle possède de beaux marchés et des mosquées magnifiques et propres. Ses habitants ont coutume de prendre leurs repas dans les cours des mosquées, chacun d'eux apportant ce qu'il possède ; ils mangent ainsi tous ensemble, et les voyageurs sont admis à leur festin. Ils sont forts et braves, toujours en guerre entre eux. Ils sont de la secte ibâdhite, et font quatre fois la prière du vendredi, à midi. Après cela, l'imâm lit des versets du Coran et débite un discours, à l'instar du prône, dans lequel il fait des vœux pour Abou Becr et 'Omar, et passe sous silence 'Othmân et 'Aly ${ }^{118}$. Quand ces gens veulent parler de ce dernier, ils emploient comme métonymie le mot homme, et ils disent: "On raconte au sujet de l'homme ", ou bien : "l'homme dit». Ils font des vœux pour le scélérat, le maudit Ibn Moldjam ${ }^{119}$ et l'appellent «le pieux serviteur de Dieu, le vainqueur de la sédition ». Leurs femmes sont très corrompues, et ils n'en éprouvent aucune jalousie et ne blâment point leur conduite. Nous raconterons bientôt, après cet article, p114 une anecdote qui témoignera de ce que nous venons d'avancer.

\section{DU SULTAN D’OMÂN}

Le sultan d'Omân est un Arabe de la tribu d'Azd, fils d'Alghaouth, et il est connu sous le nom d'Abou Mohammed, fils de Nebhân ${ }^{120}$. Chez ces peuples, Abou Mohammed est une dénomination usitée pour tous les sultans qui gouvernent l'Omân, comme celle d'atâbec est employée pour les rois des Loûr. Il a l'habitude de s'asseoir, pour donner

\footnotetext{
117 Nizwa, sur les flancs sud du Djebel Akhdar, capitale des imams d’Oman.

118 La raison de l'absence du khutba, le sermon solennel du vendredi, est liée à la nécessité de la présence, selon les kharidjites, de l'imam à la cérémonie ; or les souverains de l'époque étaient considérés comme des usurpateurs (voir cidessous n. 120). Les kharidjites n'acceptaient que les deux premiers califes.

119 Voir t. I, chap. 5, n. 180.

120 Les Nabhanides ont usurpé le pouvoir des imams électifs en 1162 et ont régné jusqu'en 1481. Au retour de l'imamat, tout souvenir des Nabhanides étant volontairement effacé, on ne possède quasiment aucune information sur cette époque.
} 
ses audiences, dans un endroit situé hors de son palais; il n'a ni chambellan ni vizir, et tout individu, étranger ou non, est libre de l'approcher. Ce sultan honore son hôte suivant la coutume des Arabes ; il lui assigne le repas de l'hospitalité et lui fait des présents proportionnés à son rang; il est doué de qualités excellentes. On mange à sa table la viande de l'âne apprivoisé ${ }^{121}$, et l'on en vend dans le marché, car ces gens croient qu'elle est permise ; mais ils la cachent à l'étranger, et ne la font jamais paraître en sa présence.

Parmi les villes de l'Omân est celle de Zaky ${ }^{122}$, je ne l'ai point visitée, mais on m'a assuré que c'est une grande cité. Il renferme aussi Alkouriyyât, Chaba, Calba, Khaour-Fouccân et Souhâr ${ }^{123}$, Ce sont des villes toutes bien pourvues de canaux, de jardins et de p115 palmiers. La plus grande partie du pays d'Omân est placée sous le gouvernement de Hormouz.

\section{ANECDOTE}

Je me trouvais un jour chez ce sultan Abou Mohammed, fils de Nebhân, quand une femme très jeune, belle et d'une figure admirable vint à lui. Elle se tint debout devant le prince, et lui dit : "O Abou Mohammed ! le démon s’agite dans ma tête. » Il lui répondit : " Va-ten et chasse ce démon. » Elle répliqua : " Je ne le peux pas et je suis sous ta protection, ô Abou Mohammed ! » Le sultan reprit : "Sors, et fais ce que tu voudras. " J'ai su, après avoir quitté ce roi, que cette femme, et toutes celles qui agissent comme elle, se mettent ainsi sous la tutelle du sultan et se livrent ensuite au libertinage. Ni son père ni son plus proche parent n'ont le pouvoir de s'en montrer jaloux, et s'ils la tuent ils sont condamnés à mort, car elle est protégée par le sultan.

Je partis de l'Omân pour le pays de Hormouz. On nomme ainsi une ville située sur le rivage de la mer, et que l'on appelle aussi Moûghos-

121

La viande de l'âne apprivoisé est interdite par un hadith du Prophète ; par contre, les tribus de l'intérieur d'Oman mangeaient la viande de l'âne sauvage.

122 Izki, à une cinquantaine de kilomètres à l'est de Nizwa.

123 Qurayat, entre Tiwi et Masqat sur la côte ; Sohar, au nord de l'actuel sultanat d'Oman; Kalba et Khor Fakkan, sur le golfe d'Oman, faisant partie de l'émirat actuel de Fujaira (Émirats arabes unis). Shaba seule n'a pas été identifiée. 
tân ${ }^{124}$. La nouvelle ville de Hormouz s'élève en face de la première, au milieu de la mer ${ }^{125}$, et elle n’en est séparée que par un canal de trois parasanges de largeur. Nous arrivâmes à la nouvelle Hormouz, qui forme une île, dont la capitale se nomme Djeraoun. C'est une cité grande et belle qui possède des marchés bien approvisionnés. Elle sert d'entrepôt à l'Inde et au Sind ; les marchandises de l'Inde sont p116 transportées de cette ville dans les deux Irâks, le Fars et le Khorâçân. C'est dans cette place que réside le sultan. L'île où se trouve la ville a de longueur un jour de marche; la plus grande partie se compose de terres d'une nature saline et de montagnes de sel, de l'espèce appelée dârâni ${ }^{126}$. On fabrique avec ce sel des vases destinés à. servir d'ornements et les colonnes sur lesquelles on place les lampes. La nourriture des habitants consiste en poissons et en dattes qui leur sont apportées de Basrah et d'Omân. Ils disent dans leur langue : Khormâ we mâhy louti pâdichâhy, c'est-à-dire, en arabe : " La datte et le poisson sont le manger des rois. » L'eau potable a une grande valeur dans cette île, et il y a des fontaines et des réservoirs artificiels, où l'eau de pluie est recueillie. Ils sont à une certaine distance de la ville, et les habitants s'y rendent avec de grandes outres, qu'ils remplissent et qu'il portent sur leur dos jusqu'à la mer. Alors ils les chargent sur des barques et les apportent à la ville. J'ai vu, en fait de choses merveilleuses, près de la porte de la mosquée djâmi', entre celle-ci et le marché, une tête de poisson aussi élevée qu'une colline, et dont les yeux étaient aussi larges que des portes ${ }^{127}$. Des hommes entraient dans cette tête par un des yeux et sortaient par l'autre.

Je rencontrai à Djeraoun le cheïkh pieux et dévot Abou'l'haçan alaksarâny, originaire du pays de Roûm ${ }^{128}$. Il me traita, me visita et

${ }^{124}$ L'ancienne ville de Hormuz se situait sur le continent, à une quinzaine de kilomètres de la côte, à l'intérieur d'un estuaire et à l'emplacement de la ville actuelle de Minab. Mughistan était le nom du district de la région de Kirman avoisinant la côte.

Hormuz fut transférée par Ayaz (voir n. 111 ci-dessus) sur l'île de Djarun, située en face de l'estuaire de Minab et au nord du détroit du même nom.

126 Il faudrait lire darabi, de Darabdjird, situé au sud-est de Shiraz où des collines de sel multicolore servent à la fabrication de vases. Le sol de l'île de Djarun est également constitué de sel et l'eau était amenée du continent.

127 Apparemment une baleine, appelée bal ou wal dans les textes arabes.

128 Le pays de Roum est l’Asie Mineure. 
me fit présent d'un vêtement. Il me donna la ceinture de l'amitié, dont il se servait pour maintenir sa robe retroussée ; elle aide celui qui est assis et lui sert, pour ainsi dire de support. La plupart des fakirs persans portent cette espèce de ceinture. p117

A six mille de cette ville est un sanctuaire que l'on appelle le sanctuaire de Khidhr et d'Elie ${ }^{129}$; on dit qu'ils y font leurs prières. Des bénédictions et des preuves évidentes attestent la sainteté de cet endroit. Il y a là un ermitage habité par un cheïkh, qui y reçoit les voyageurs. Nous passâmes un jour près de lui, et nous partîmes de là afin de visiter un homme pieux retiré à l'extrémité de cette île. Il a creusé une grotte pour lui servir d'habitation, et celle-ci contient un ermitage, une salle de réception et un petit appartement qu'occupe une jeune esclave, laquelle appartient au saint personnage. L'ermite a des esclaves, qui demeurent hors de la caverne, et font paître ses bœufs et ses moutons. Il était jadis au nombre des principaux marchands; il fit le pèlerinage du temple de La Mecque, renonça à tous les attachements du monde, et se retira ici pour se livrer à la dévotion. Auparavant, il remit son argent à un de ses confrères, afin qu'il le lui fit valoir dans le commerce. Nous passâmes une nuit près de cet homme, et il nous fit un accueil très hospitalier. Les signes distinctifs de la bonté et de la piété étaient reconnaissables sur sa personne.

\section{HisTOIRE DU SULTAN DE HORMOUZ}

C’est le sultan Kothb eddîn Temehten, fils de Thourân châh ${ }^{130}$, il est au nombre des sultans généreux ; son caractère est très humble, ses qualités sont louables. Il a coutume de visiter les jurisconsultes, les hommes pieux et les chérîfs qui arrivent dans sa capitale et de leur rendre les honneurs qui leur sont dus. Lorsque nous entrâmes dans son île, nous le trouvâmes préparé pour la guerre dans laquelle il était engagé contre les deux fils ${ }_{\mathrm{p} 118}$ de son frère Nizhâm eddîn ${ }^{131}$. Toutes les

129 Voir t. I, chap. 3, n. 298.

${ }^{130}$ Voir ci-dessus n. 114. Il faut lire fils de Kurdan Chah, lequel succéda à Ayaz et régna jusqu'en 1317.

131 Ici, selon son habitude, Ibn Battûta mélange les deux visites qu'il a effectuées à Hormuz, celle d'octobre-novembre 1331 et celle de mai-juin 1347. Qutb aldin Tehemten avait conquis le pouvoir en 1319 avec l'aide de son frère Nizam 
nuits il se disposait à combattre, quoique la disette régnât dans l'île. Son vizir Chems eddîn Mohammed, fils d'Aly, son kâdhi 'Imâd eddîn achchéouancâry et plusieurs hommes distingués vinrent nous trouver, et s'excusèrent sur les occupations que leur donnait la guerre. Nous passâmes seize jours auprès d'eux. Lorsque nous voulûmes nous en retourner, je dis à un de mes compagnons : "Comment partirons-nous sans voir ce sultan ? » Nous allâmes à la maison du vizir, qui se trouvait dans le voisinage de la zâouïah où j'étais descendu, et je lui dis : « Je désire saluer le roi. » Il répondit : Bismillâhi ${ }^{132}$, me prit par la main et me conduisit au palais du roi. Cet édifice est situé sur le rivage de la mer, et les vaisseaux sont à sec dans son voisinage.

J'aperçus tout à coup un vieillard couvert de vêtements étriqués et malpropres. Sur sa tête il portait un turban, et il était ceint d'un mouchoir. Le vizir le salua, et je fis de même ; mais j'ignorais que c'était le roi. Il avait à ses côtés le fils de sa sœur, Aly châh, fils de Djélâl eddîn Alkîdjy ${ }^{133}$, avec lequel j'étais en relations. Je commençai à converser avec lui, car je ne connaissais pas le roi ; mais le vizir me le fit connaître. Je fus honteux vis-à-vis du monarque, parce que j'avais osé causer avec son neveu au lieu de m'entretenir avec lui, et je m'excusai auprès de ce prince. Ensuite il se leva et entra dans son palais, suivi par les émirs, les vizirs et les grands du royaume ; j'entrai aussi en compagnie du ${ }_{\text {p119 }}$ vizir. Nous trouvâmes le roi assis sur son trône, et portant absolument les mêmes habits que j'ai mentionnés tout à l'heure. Dans sa main était un chapelet de perles, dont personne n'a vu les pareilles, car les pêcheries de ces coquillages se trouvent soumises à l'autorité de ce prince ${ }^{134}$. Un des émirs s'assit à son côté, et je m’assis à côté de cet émir.

Le sultan m'interrogea touchant mon état de santé, le temps de mon arrivée et les rois que j'avais vus dans le cours de mes voyages : je l'informai de ces diverses circonstances. On apporta des mets ; les

al-din Kayqubad, mais ce dernier ne se révolta qu’en 1344-1345. Sa mort étant survenue en 1346, ses fils continuèrent la lutte à partir de l'île de Qays jusqu'à la mort de Tehemten, au printemps de 1347, peu après le passage d'Ibn Battûta, lequel a eu donc connaissance de ces événements à sa deuxième visite.

132 Au nom de Dieu; soit.

133 Personnage appartenant probablement à la maison royale de Kidj, dont les liens avec celle de Hormuz sont connus, Pour Kidj, voir t. I, chap. 5, n. 255.

134 Situées dans l’île de Qays ; voir plus loin n. 145. 
assistants en mangèrent, mais le prince n'en goûta pas avec eux. Après le repas, il se leva ; je lui fis mes adieux et m’en retournai.

Voici le motif de la guerre qui existait entre le sultan et ses deux neveux. Le premier s'embarqua un jour sur une mer, à la ville neuve, afin de se rendre en partie de plaisir au vieux Hormouz et à ses jardins. La distance qui sépare ces deux villes, par mer, est de trois parasanges, ainsi que nous l'avons dit plus haut. Le frère du sultan, Nizhâm eddîn, se révolta contre lui, et s'arrogea le pouvoir. Les habitants de l'île lui prêtèrent serment, ainsi que les troupes. Kothb eddîn conçut des craintes pour sa sûreté, et s'embarqua pour la ville de Kalhât, dont il a été parlé ci-dessus, et qui fait partie de ses États. Il y séjourna plusieurs mois, équipa des vaisseaux et fit voile vers l'île. Les habitants de celle-ci le combattirent, de concert avec son frère, et l'obligèrent de s'enfuir à Kalhât. Il renouvela la même tentative à plusieurs reprises; il n'eut aucun succès, jusqu'à ce qu'il recourût au stratagème d'envoyer à une des femmes de son frère un émissaire qui la détermina à l'empoisonner. L'usurpateur étant mort, le sultan marcha de nouveau vers l'île et y fit son entrée. Ses deux neveux s'enfuirent, avec les trésors, les biens et les troupes, dans l'île de Kaïs, où se trouvent les pêcheries de perles. De cet endroit ils se mirent à intercepter le chemin à ceux des habitants de l'Inde et du Sind qui se

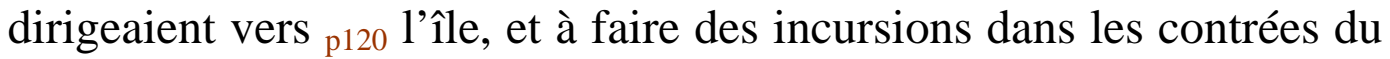
littoral ; de sorte que la plupart furent dévastées.

Nous partîmes de la ville de Djeraoun pour visiter un pieux personnage dans la ville de Khondjopâl. Lorsque nous eûmes franchi le détroit, nous louâmes des montures aux Turcomans ${ }^{135}$, qui sont les habitants de ce pays. On n'y voyage pas, si ce n'est avec eux, à cause de leur bravoure et de la connaissance qu'ils possèdent des chemins. On trouve en ces lieux un désert, d'une étendue de quatre jours de marche, où les voleurs arabes exercent leurs brigandages ${ }^{136}$, et où le

135 Il s’agit probablement des nomades appelés aujourd’hui Qashqa’i.

136 «Dans cette plaine, plusieurs villes, bourgs et villages ont des murs de terre épais et hauts et de hautes tours pour se défendre de leurs ennemis, le peuple Caraunas, qui est très nombreuse, cruelle et méchante race de voleurs qui vont courant le pays et faisant grand mal » (Marco PoLO). On ne connaît pas plus ces Caraunas que les Qufs qui seraient originaires de l'Arabie du Sud, à moins que ce ne soient des Kurdes, mais il reste que la région était à l'époque un repaire de « brigands et voleurs de grands chemins » (MUSTAWFI). 
vent appelé semoûm ${ }^{137}$ souffle durant les mois de tamoûz ${ }^{138}$. Ce vent fait mourir tous ceux qu'il rencontre dans le désert, et l'on m'a raconté que quand il a tué quelqu'un, et que les compagnons du mort veulent laver son corps, chacun des membres se détache des autres parties.

Dans ce désert se trouvent de nombreux tombeaux, p121 renfermant ceux qui ont été tués par ce vent. Nous voyagions durant la nuit, et lorsque le soleil était levé, nous nous mettions à l'ombre sous les arbres, du genre de ceux nommés oumm Ghaïlân ${ }^{139}$. Nous marchions depuis l'asr jusqu'au lever du soleil. Dans ce désert et dans la contrée qui l'avoisine habitait le voleur Djemâl allouc, qui jouit en ces lieux d'une grande réputation.

\section{ANECDOTE}

Djemâl allouc était un habitant du Sidjistân, d'origine persane ${ }^{140}$. Allouc signifie «Celui qui a la main coupée », et, en effet, la main de cet homme avait été coupée dans un combat. Il commandait un corps considérable de cavaliers arabes et persans, à l'aide desquels il exerçait le brigandage sur les chemins. Il fondait des ermitages et fournissait à manger aux voyageurs, avec l'argent qu'il volait. On rapporte qu'il prétendait ne pas employer la violence, excepté contre ceux qui ne donnaient pas la dîme aumônière de leurs biens. Il persévéra long-

137

« On appelle ce vent pestiféré bad-samoun, c'est-à-dire vent de poison ; mais sur les lieux on l'appelle samyel. Il se lève seulement entre le 15 juin et le 15 août, qui est le temps de l'excessive chaleur le long de ce golfe ; ce vent [...] tue les gens, qui frappe par une manière d'étouffement, surtout quand c'est de jour. Son effet le plus surprenant n'est pas même la mort qu'il cause, c'est que les corps qui en meurent sont comme dissous, sans perdre pour autant leur figure ni même leur couleur ; en sorte qu'on dirait qu'ils ne sont qu'endormis, quoiqu'ils soient morts, et que, si on les prend quelque part, la pièce en demeure à la main » (CHARDIN, 1668).

138 Tammouz et haziran sont respectivement les mois de juillet et juin du calendrier syrien ; ce qui indique que ces impressions doivent également dater du second voyage d'Ibn Battûta, effectué en juin-juillet, tandis que le premier a dû se faire en novembre.

139 Voir n. 109 ci-dessus.

140 Ce personnage sera capturé et exécuté par Muhammad bin Muzaffar (voir t. I, chap. 5, n. 146) avant 1318. 
temps dans cette conduite ; lui et ses cavaliers faisaient des incursions et traversaient des déserts que nul autre qu'eux ne connaissait, et ils y enterraient de grandes et de petites outres pleines d'eau. Lorsque l'armée du sultan les poursuivait, ils entraient dans le désert et déterraient ces outres. L'armée renonçait à les poursuivre, de peur de périr. Dejmâl persista donc dans cette conduite pendant un certain nombre d'années, ni le roi de l'Irâk ni aucun prince ne pouvant le vaincre ; puis il fit pénitence et se livra à des exercices de dévotion jusqu'à sa mort. Son tombeau, qui se trouve dans son pays, le Sidjistân, est visité comme un lieu de pèlerinage. p122

Nous traversâmes ce désert jusqu’à ce que nous fussions arrivés à Cawrestân ${ }^{141}$, petite ville où l'on voit des rivières et des jardins, et dont l'air est très chaud. Nous marchâmes durant trois jours dans un désert semblable au premier, et nous arrivâmes à Lâr ${ }^{142}$, grande ville pourvue de sources, de rivières considérables et de jardins, et qui possède de beaux marchés. Nous y logeâmes dans la zâouïah du pieux cheïkh Abou Dolaf Mohammed, celui-là même que nous avions le projet de visiter à Khondjopâl. Dans celle-ci se trouvait son fils Abou Zeïd Abd errahmân, ainsi qu'une troupe de fakirs. Une de leurs coutumes consiste à se réunir chaque jour dans l'ermitage, après la prière de l'asr; puis ils font le tour des maisons de la ville; on leur donne dans chaque maison un pain ou deux, et c'est avec cela qu'ils nourrissent les voyageurs. Les habitants des maisons sont accoutumés à cette offrande ; ils la regardent comme faisant partie de leurs aliments et la préparent pour ces religieux, afin de les aider dans leurs distributions de vivres. Dans chaque nuit du jeudi au vendredi, les fakirs et les dévots de la ville se rassemblent dans cet ermitage, et chacun d'eux apporte autant de dirhems qu'il a pu s'en procurer. Ils le mettent en commun et les dépensent dans cette nuit même ; ils la passent en acte de dévotion, comme la prière, la mention répétée du nom de Dieu, et la lecture du Coran; enfin, ils s'en retournent après la prière de l'aurore.

141 «Un assez bon village nommé Cauvrestan », à quatre étapes de Lar et à une de Bender Abbas (TAVERNIER, 1665).

142 Le nom de Lar apparaît pour la première fois en tant que région chez Mustawfi, contemporain d’Ibn Battûta, et en tant que ville ici. 


\section{DU SULTAN DE LÂR}

Il y a dans cette ville un sultan d'origine turcomane nommé Djélâl eddîn ${ }^{143}$. Il nous envoya les mets de ${ }_{\mathrm{p} 123}$ l'hospitalité ; mais nous ne le visitâmes point et ne le vîmes pas.

Nous partîmes de Lâr pour la ville de Khondjopâl ${ }^{144}$; le khâ de ce mot est remplacé quelquefois par un hâ. C'est là qu'habite le cheïkh Abou Dolaf, que nous voulions visiter. Nous logeâmes dans son ermitage, et lorsque j’y fus entré, je vis le cheïkh assis par terre, dans un coin. Il était couvert d'une tunique de laine verte, tout usée, et portait sur la tête un turban de laine noir. Je le saluai ; il me rendit poliment mon salut, m’interrogea touchant le temps de mon arrivée et sur mon pays, et me donna l'hospitalité. Il m'envoyait des aliments et des fruits par un de ses fils, qui était au nombre des gens pieux, très humble, jeûnant presque continuellement et fort assidu à dire ses prières. La condition de ce cheïkh Abou Dolaf est extraordinaire et étrange, car la dépense qu'il fait dans cet ermitage est considérable : il distribue des dons superbes, fait présent aux autres de vêtements et de chevaux de selle ; en un mot, il fait du bien à tous les voyageurs, de sorte que je n'ai pas vu son pareil dans cette contrée ; et pourtant on ne lui connaît pas d'autre ressource que les offrandes qu'il reçoit de ses frères et de ses compagnons. Aussi beaucoup de personnes prétendent qu'il tire du trésor invisible de Dieu les sommes nécessaires à sa dépense.

Dans son ermitage se trouve le tombeau du pieux cheïkh, de l'ami de Dieu, du pôle, Dâniiâl ${ }^{145}$, dont le nom est célèbre dans ce pays, et qui jouit d'un rang éminent parmi les contemplatifs. Ce sépulcre est

143 Lar avait une dynastie locale installée depuis la période pré-islamique, mais d'après les chroniques le souverain régnant à l'époque s’appelait Bakalindjar II (1331-1352).

Khundj-u Bal est un district situé à l'ouest de Lar ; son nom est composé de celui de deux villes : Khundj à une soixantaine de kilomètres à l'ouest de Lar, sur un des chemins menant à Shiraz, et Bal ou Fal, entre Khundj et la mer, près de l'actuel Galeh Dar. Il n'existe donc pas de ville de Khundj-u Bal, mais Ibn Battûta doit parler de la première (voir note suivante).

145 Cheikh Daniyal avait joué un rôle dans la conquête du pouvoir par Ayaz à Hormuz en 1291. Barros mentionne déjà au XVI ${ }^{\mathrm{e}}$ siècle une mosquée au nom de ce cheikh située à Khundj, et cette ville possède encore aujourd'hui une mosquée à ce nom. 
surmonté ${ }_{\text {p124 }}$ d'une haute coupole, élevée par le sultan Kothb eddîn Temehten, fils de Thoûrân châh. Je passai un seul jour près du cheïkh Abou Dolaf, à cause de l'empressement à partir de la caravane que j'accompagnais.

J'appris qu'il y avait dans cette ville de Khondjopâl un ermitage habité par plusieurs hommes pieux qui se livraient à des pratiques de dévotion. Je m’y rendis dans la soirée, et je les saluai, eux et leur cheïkh. Je vis des gens comblés de bénédictions, et sur la personne desquels les exercices de piété avaient laissé des traces profondes. Ils avaient le teint jaune, le corps maigre ; ils gémissaient beaucoup et pleuraient abondamment. Lorsque j'arrivai auprès d'eux, ils m'apportèrent des aliments, et leur chef dit : "Faites-moi venir mon fils Mohammed. » Celui-ci était retiré dans un coin de la zâouïah ; il vint nous trouver, et il ressemblait à un mort échappé de son tombeau, tant les actes de dévotion l'avaient exténué. Il salua et s'assit. Son père lui dit : " Ô mon cher fils, partage le repas de ces voyageurs, afin que tu participes à leurs bénédictions ! » Il jeûnait alors ; mais il rompit le jeûne avec nous. Ces gens-là sont de la secte de Châfi'y ; lorsque nous eûmes cessé de manger, ils firent des vœux en notre faveur, et nous nous en retournâmes.

De là nous nous rendîmes à la ville de Kaïs, nommée aussi Sîrâf ${ }^{146}$. Elle est située sur le rivage de la mer de l'Inde, qui est contiguë à celles du Yaman et de la Perse ; on la compte au nombre des districts du Fars. C'est une ville d'une étendue considérable et sur un sol p125 excellent. Elles est entourée de jardins magnifiques, où croissent des plantes odoriférantes et des arbres verdoyants. L'eau que boivent ses habitants provient de sources qui coulent des montagnes voisines. Les Sîrâfiens sont Persans et distingués par une noble origine. Parmi

146 Siraf, situé sur la côte au sud de Kangan et près de la localité actuelle de Taheri, fut le port le plus important du golfe au $\mathrm{X}^{\mathrm{e}}$ siècle. Détruit par un séisme en 977, il fut progressivement abandonné au profit de Qays et Yaqut qui le visitera au début du XIII ${ }^{\mathrm{e}}$ siècle, le trouvera en ruines. Ibn Battûta a donc dû confondre avec l'île de Qays qui fut le siège, à partir de la fin du XIII siècle, d'une dynastie marchande fondée par Djamal al-din Ibrahim al-Sawamili, richissime commerçant du golfe ; la ville fut conquise sur ses descendants en 1331 par Tehemten. 
eux se trouve une tribu d'Arabes des Benou-Sefâf ${ }^{147}$, et ce sont ces derniers qui plongent à la recherche de perles.

\section{DE LA PÊCHERIE DES PERLES}

La pêcherie des perles est située entre Sîrâf et Bahraïn ${ }^{148}$, dans un golfe dont l'eau est calme, et qui ressemble à un grand fleuve. Lorsque les mois d'avril et de mai sont arrivés, des barques nombreuses se rendent en cet endroit, montées par les pêcheurs et des marchands du Fars, de Bahraïn et d'Alkathîf. Le pêcheur place sur son visage, toutes les fois qu'il veut plonger, une plaque en écaille de tortue, qui le couvre complètement. Il fabrique aussi avec cette écaille un objet semblable à des ciseaux, qui lui sert à comprimer ses narines ; puis il attache une corde à sa ceinture et plonge. Ces gens-là diffèrent les uns des autres dans la durée du temps qu'ils peuvent rester sous l'eau. Parmi eux il y en a qui y demeurent une heure ou deux, ou plus que cela. Quand le plongeur arrive au fond de la mer, il y trouve les coquillages fixés dans le sable, au milieu de petites pierres ; il les détache avec la main, ou les enlève à l'aide d'un couteau dont il s'est muni dans cette intention, et les place dans un sac de cuir suspendu à son cou. Lorsque la respiration commence à lui manquer, il agite la corde ; l'homme qui tient cette corde sur le rivage sent son appel, et le remonte à bord de la barque. On lui enlève son sac, et l'on ouvre les coquillages ; on p126 $\mathrm{y}$ trouve à l'intérieur des morceaux de chair que l'on détache avec un couteau. Dès que ceux-ci sont mis en contact avec l'air, ils se durcissent et se changent en perles, et toutes sont rassemblées, les petites comme les grosses. Le sultan en prélève le quint ${ }^{149}$, et le reste est acheté par les marchands qui se trouvent dans les barques. La plupart sont créanciers des plongeurs, et reçoivent toutes les perles en échange de leur créance, ou bien une quantité proportionnée à la dette.

\footnotetext{
147 Tribu arabe, originaire d’Oman, établie sur le littoral du Fars.

148 L'ensemble de ce récit semble être de seconde main et le site des pêcheries ne peut pas être déterminé.

149 Si le récit qui précède contient des passages fantaisistes, cette dernière partie correspond aux pratiques de l’époque.
} 
De Sîrâf, nous allâmes à la ville de Bahraïn ${ }^{150}$, qui est une cité considérable, belle, possédant des jardins, des arbres et des rivières. On s'y procure de l'eau à peu de frais : il suffit pour cela de creuser la terre avec les mains, et on trouve l'eau. Il y a en cet endroit des enclos de palmiers, de grenadiers, de citronniers, et l'on y cultive le coton. La température y est très chaude, les sables y abondent, et souvent ils s'emparent de quelques habitations. Il y avait entre Bahraïn et Omân un chemin que les sables ont envahi, et sur lequel, pour cette raison, la communication a été interrompue. On ne se rend plus d'Omân en cette ville, si ce n'est par mer. Dans le voisinage de Bahraïn se trouvent deux hautes montagnes, dont l'une à l'occident, qui s'appelle Coceïr, l'autre à l'orient, qui s'appelle Oweïr. Elles ont passé en proverbe, car on dit « Coceïr et Oweïr : or tout cela n'est pas bon ${ }^{151}$ » (à cause du danger qu'elles offrent aux navigateurs). p127

Nous nous rendîmes de Bahraïn à la ville d'Alkothaï ${ }^{152}$, dont le nom se prononce à l'instar du diminutif du mot kathf ${ }^{153}$. C'est une place grande, belle et possédant beaucoup de palmiers. Elle est habitée par des tribus d'Arabes, qui sont des râfidhites outrés, et manifestent ouvertement leur hérésie, sans craindre personne. Leur moueddhin prononce les paroles suivantes dans l'appel à la prière, après les deux professions de foi : « J'atteste qu'Aly est l'ami de Dieu ${ }^{154}$. » Il ajoute, après les deux formules : "Accourez à la prière, accourez au salut ", la formule suivante: «Accourez à la meilleure des œuvres ». Il dit

${ }^{150}$ Le nom de Bahrein désignait à l'époque la côte située en face de l'île actuelle de Bahrein ; l'île elle-même s'appelait Uwal. Par contre, il n'existait pas de ville portant le nom de Bahrein, et les deux principales villes de la côte seront mentionnées par la suite.

${ }^{151}$ Le proverbe dit : « Kusair et Uwair et un troisième, et dans tout cela rien de bon. » Il ne s'agit pas de montagnes mais d’un groupe de récifs situés dans le détroit de Hormuz.

152 Al-Qatif, sur la côte, en face de l'île de Bahrein, était un des derniers bastions des Karmates (voir introduction du t. I). La région fut conquise en 1305 par un Arabe quraishite appelé Djarwan al-Maliki qui fonda une dynastie shi'ite locale. Toutefois, Qatif semble avoir été conquis, en même temps que l'île de 153 Vendanges.

${ }^{154}$ Voir t. I, chap. 5, n. 6. 
après le dernier tecbîr ${ }^{155}$ : « Mohammed et Aly sont les meilleurs des hommes, et quiconque s'est déclaré leur ennemi a été infidèle. »

De Kathîf, nous allâmes à Hedjer, maintenant appelé Alhaça ${ }^{156}$, ville au sujet de laquelle on dit en proverbe : "C'est comme celui qui apporte des dattes à Hedjer. » Car il s'y trouve plus de palmiers que dans aucune autre ville; aussi les habitants en font-ils manger les fruits à leurs bêtes de somme. Ces habitants sont des Arabes appartenant pour la plupart à la tribu d'Abd Alkaïs, fils d'Aksa ${ }^{157}$. p128

D’Alhaça, nous nous rendîmes à la ville d'Alyemâmah, aussi appelée Hadjr ${ }^{158}$. C'est une ville belle, fertile, possédant des rivières et des arbres. Elle est habitée par des tribus d'Arabes qui appartiennent pour la plupart aux Benou Hanîfah ${ }^{159}$, dont elle est de toute antiquité la capitale, et qui ont pour émir Thofaïl, fils de Ghânim.

Je quittai Yemâmah, en compagnie de cet émir, afin de faire le pèlerinage. On était alors dans l'année 732, (et j'arrivai ainsi à La Mecque). Dans cette même année, Almelic annâcir, sultan d’Égypte, fit le pèlerinage ${ }^{160}$, ainsi qu'un certain nombre de ses émirs. Ce fut la dernière fois qu'il l'accomplit, et il accorda des présents magnifiques aux habitants des deux villes saintes et nobles, et aux personnages qui s'y étaient fixés par esprit de dévotion. Pendant le même voyage, Almelic annâcir tua l'émir Ahmed, de qui l'on dit qu'il était le père. Il fit aussi périr le principal de ses émirs, Bectomoûr assâky ${ }^{161}$.

155 Louange du nom de Dieu.

156 L'actuel al-Hufuf, à l'intérieur des terres, al-Hasa étant le nom de la province.

${ }^{157}$ Une des principales tribus du nord-est de l'Arabie établies depuis le $\mathrm{VI}^{\mathrm{e}}$ siècle 158 dans la région.

58 Auparavant capitale du Nadjd, actuellement al-Yamama, à quatre-vingt-dix kilomètres au sud-est de Riyadh, près d'al-Salamiya.

159 Les Banu Hanifa d'al-Yamama sont célèbres dans l'histoire de l'islam pour leur résistance désespérée aux forces islamiques en 633 ; par contre, leur histoire ultérieure dans cette région n’est pas connue.

160 Le pèlerinage de Malik Nasir en cette année 1332 est attesté par les sources.

161 Ibn Battûta relate une version populaire de la mort de Baktamur (voir t. I, chap. 1, n. 140) dont les détails sont donnés dans les chroniques. 


\section{ANECDOTE}

On raconte qu'Almelic annâcir donna à Bectomoûr assâky une jeune esclave. Lorsque l'émir voulut s'en approcher, elle lui dit : « Je suis enceinte des œuvres du roi Annâcir. » Alors Bectomoûr la respecta, et dans la suite elle mit au monde un fils qu'il appela l'émir p129 Ahmed, et qui grandit sous sa tutelle. La noblesse de cet enfant se révéla, et il fut connu sous le nom de fils d'Almelic annâcir. Or, pendant ce pèlerinage, lui et Bectomoûr complotèrent de tuer le monarque ; après quoi l'émir Ahmed serait devenu maître du royaume. En conséquence. Bectomôur emporta avec lui des étendards, des tambours, des vêtements [royaux] et de l'argent. La nouvelle du complot fut révélée à Almelic annâcir. Alors celui-ci envoya chercher l'émir Ahmed, un jour qu'il faisait extrêmement chaud ; et l'émir vint le trouver. Le sultan avait devant lui des coupes pleines de boisson ; il en but une et en présenta à l'émir Ahmed une autre, dans laquelle il y avait du poison. Ahmed l'ayant vidée, Melic Nâcir donna l'ordre de décamper sur-lechamp, afin d'occuper le temps. Le cortège royal se mit en marche ; mais il n'était pas encore arrivé à la prochaine station que l'émir Ahmed rendit le dernier soupir. Bectomoûr fut affligé de sa mort, déchira ses vêtements et refusa de boire et de manger. Cette nouvelle étant parvenue à Melic Nâcir, il vint le trouver, lui donna des marques d'intérêt, lui adressa des consolations et, prenant une coupe dans laquelle il y avait du poison, il la lui présenta et lui dit : « Je t'en adjure par ma vie, ne boiras-tu pas pour amortir le feu qui brûle ton cœur? » Bectomoûr vida le vase et mourut sur l'heure. On trouva chez lui les vêtements, insigne de la souveraineté et des sommes considérables, et c'est ainsi que fut vérifiée l'accusation qui avait été portée contre lui d'attenter aux jours d'Almelic annâcir. 


\section{L'Asie Mineure}

Retour à la Table des Matières

Lorsque le pèlerinage fut terminé, je me dirigeai vers Djouddah, afin de m'embarquer pour le Yaman et l'Inde ; mais cela ne me réussit pas ; je ne pus me procurer de compagnons, et je passai à Djouddah environ quarante jours. Il y avait en cette ville un navire appartenant à un individu nommé Abd Allah Attoûnecy, qui voulait se rendre à Koceïr ${ }^{162}$, dans le gouvernement de Koûs. Je montai à bord, afin d'examiner dans quel état se trouvait ce navire, mais il ne me satisfit pas, et je ne me plus pas à l'idée de voyager sur ce bâtiment. Cela fut un effet de la bonté de Dieu, car ce vaisseau partit, et lorsqu'il fut arrivé au milieu de la mer, il coula à fond, dans un endroit appelé Râs Aby Mohammed ${ }^{163}$. Le propriétaire du navire et quelques marchands se sauvèrent dans une barque, non sans de grands efforts ; ils se virent sur le point de périr, et il en périt même quelques-uns. Le reste des passagers fut englouti, et il y avait à bord environ soixante et dix pèlerins.

Cependant, je montai ensuite dans une barque, pour me rendre à 'Aïdhâb ; mais, le vent nous ayant repoussés vers un port appelé Ras Dawâir ${ }^{164}$, nous partîmes de ${ }_{p 131}$ cet endroit, par la voie de terre, avec les Bodjâh, et nous traversâmes un désert où se trouvaient beaucoup d'autruches et de gazelles. On y rencontrait des Arabes des tribus de Djohaïnah et de Benou Câhil, qui sont soumises aux Bodjâh ${ }^{165}$. Nous arrivâmes près des sources nommées Mefroûr et Aldjedîd. Les vivres

\footnotetext{
162 Le port de la mer Rouge le plus proche de la vallée du Nil, à cinq étapes de

163 Le cap Abu Muhammad n'est pas identifiable. Qus.

164 Voir chap. 1, n. 11.

165 4. Pour les Bedja, voir t. I, chap. 2, n. 209 pour les Banu Kahil, ci-dessus chap. 1, n. 15 et pour les Djuhaina n. 18.
} 
nous manquèrent ; nous achetâmes des brebis à une troupe de Bodjâh dont nous fîmes rencontre dans le désert, et nous nous approvisionnâmes de la chair de ce bétail. Je vis dans ce désert un jeune garçon arabe, qui m'adressa la parole en sa langue et m'informa que les Bodjâh l'avaient fait prisonnier. Il prétendait n’avoir pris depuis une année aucun autre aliment que du lait de chameau.

La viande que nous avions achetée ayant été consommée, il ne nous resta aucune provision de route; j'avais avec moi environ une charge de dattes, des espèces appelées assaïhâny et alberny ${ }^{166}$, que je réservais pour faire des présents à mes amis. Je les distribuai à la caravane, et nous en vécûmes pendant trois jours.

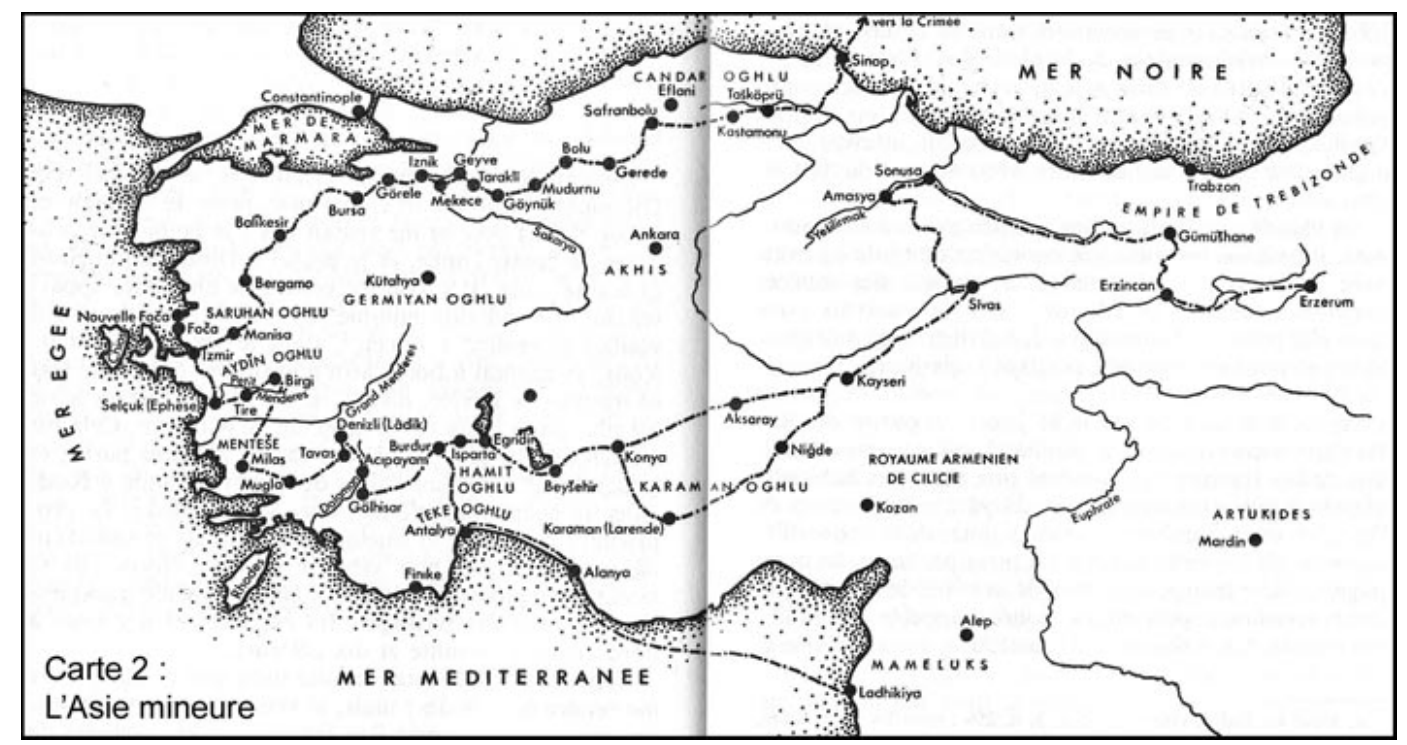

Après une marche de neuf jours, à partir du Ras Dawâïr, nous arrivâmes à 'Aïdhâb ${ }^{167}$, où quelques individus de la caravane nous avaient précédés. Les habitants vinrent à notre rencontre, avec du pain, des dattes et de l'eau, et nous passâmes plusieurs jours dans cette

166 La datte al-birni, « pour laquelle il a été dit : “elle rend malade au début mais il n’y a pas de maladie en elle” [...] la sayhani, appelée ainsi parce que, quand un jour le Prophète passa en tenant Ali par la main elle cria : "Celui-ci est Muhammad le prince des Prophètes, et celui-ci Ali le prince des Croyants et le 167 père des imams immaculés !" " (BURTON).

Pour Aidhab, voit t. I, chap. 2, n. 208. 
ville. Après avoir loué des chameaux, nous partîmes, en compagnie d'une troupe d'Arabes de la tribu de Daghîm, et nous arrivâmes près d'une source appelée Aldjanîb. Nous campâmes ensuite à Homaïthira,

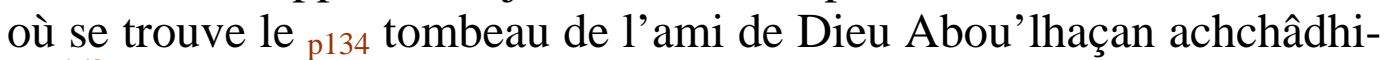
ly ${ }^{168}$. Nous le visitâmes pour la seconde fois, et nous passâmes une nuit dans son voisinage, après quoi nous arrivâmes à la bourgade d'Al'athouâny ${ }^{169}$, située sur le bord du Nil, vis-à-vis de la ville d'Adfou, dans le Sa'îd supérieur.

Nous passâmes le Nil pour nous rendre à la ville d'Esna, puis à Arment, puis à Alaksor, où nous vîmes une seconde fois le cheïkh Abou'lhaddjâdj alaksory. Nous nous rendîmes ensuite à la ville de Koûs, puis à Kina, où nous visitâmes derechef le cheïkh Abd Arrahîm alkinâwy. De là nous vînmes à Hou, à Ikhmîm, à Acioûth, à Manfaloûth, à Manlaouy, à Alochmoûnaïn, à Moniat ibn Alkhacîb, à Behneçah, à Boûch et à Moniat-Alkâïd. Toutes ces localités ont déjà été mentionnées par nous.

Enfin nous arrivâmes à Misr, où je m'arrêtai plusieurs jours, après quoi je partis pour la Syrie, par le chemin de Bilbeïs, en compagnie du pèlerin Abd Allha, fils d'Abou Becr, fils d'Alferhân attoûzery. Il ne cessa de m'accompagner durant plusieurs années, jusqu'à ce que nous fussions sur le point de quitter l'Inde, et il mourut à Sendaboûr, ainsi que nous le dirons ci-dessous. Cependant, nous arrivâmes à la ville de Ghazzah, puis à la ville d'Abraham (Hébron), où nous renouvelâmes la visite de sa sépulture, puis à Jérusalem, à Ramlah, à Acre, à Tripoli, à Djabalah, où nous visitâmes pour la seconde fois le mausolée d'Ibrâhîm, fils d'Adhem, et enfin à Lâdhikiyah. Toutes ces villes ont été décrites par nous ci-dessus.

Nous nous embarquâmes sur mer à Ladhikiyah, dans un grand vaisseau appartenant à des Génois, et dont le p135 patron était nommé Martelemîm ${ }^{170}$. Nous nous dirigeâmes vers la terre de Turquie, connue sous le nom de pays des Grecs. On l'a nommée ainsi parce

168 Pour Shadili et Mumaithira, voir t. I, chap. 2, n. 23 et 27.

169 Voir t. I, chap. 2, n. 205. Également tous les noms de lieux cités ci-dessous 170 jusqu'à Ladhikiya se trouvent dans le t. I.

170 Le mot arabe utilisé ici pour le vaisseau : qurqura, indique un grand navire marchand à deux ou trois ponts. Martelemin pourrait signifier Bartolomeo. 
qu'elle a été jadis le pays de cette nation. C'est de là que vinrent les anciens Grecs et les Ioûnânis ${ }^{171}$. Par la suite, les musulmans la conquirent, et il s'y trouve maintenant beaucoup de chrétiens, sous la protection des Turcomans ${ }^{172}$ mahométans. Nous naviguâmes pendant dix jours avec un bon vent ; le chrétien [c'est-à-dire le maître du bâtiment] nous traita avec considération, et n'exigea pas de nous le prix de notre passage ${ }^{173}$.

Le dixième jour, nous arrivâmes à la ville d'Alâia ${ }^{174}$, où commence le pays de Roûm. C'est une des plus belles contrées du monde, et Dieu y a réuni les beautés dispersées dans le reste de l'univers. Ses habitants sont les plus beaux des hommes et les plus propres sur leurs vêtements ; ils se nourrissent des aliments les plus exquis, et ce sont les plus bienveillantes créatures de Dieu. C’est pourquoi on dit : « La Bénédiction se trouve en Syrie et la bonté dans le Roûm. » On n’a eu en vue dans cette phrase que les habitants de cette contrée. p136

Lorsque nous nous arrêtions dans un ermitage ou dans une maison de ce pays, nos voisins des deux sexes prenaient soin de nous; les femmes n'étaient pas voilées. Quand nous quittions ces bonnes gens, ils nous faisaient des adieux comme s'ils avaient été de nos parents et des membres de nos familles; tu aurais vu les femmes pleurer, et s'attrister de notre séparation. Une des coutumes de ce pays consiste en ce que l'on cuit le pain une seule fois tous les huit jours, et l'on prépare alors ce qui doit suffire à la nourriture de toute la semaine. Les hommes venaient nous trouver, le jour où l'on cuisait, apportant du pain chaud, et des aliments exquis dont ils nous faisaient présent.

${ }^{171}$ Rum (de Rome) est le nom donné par les Arabes, et ensuite par les Turcs, aux Byzantins, tandis que les Yunan (Ioniens) sont les anciens Grecs.

172 La protection, dhimma, d'où le nom de dhimmis donné aux chrétiens et les juifs, "gens du livre ", placés sous la "protection » des musulmans. L'Asie Mineure byzantine avait été conquise et colonisée par les Turkmènes dans un premier temps, après la victoire des Seldjukides à Mantzikert en 1071, et dans un deuxième temps avec la fondation et le développement des principautés turkmènes sur les marches de l'État seldjukide d'Anatolie à partir de la fin du XIII $^{\mathrm{e}}$ siècle.

173 Naul en arabe, nolo en italien, nolis.

174 Ala'iyya, l'actuelle Alanya à l'est du golfe d'Adalia. Le « Kalon Oros » byzantin, Candelore dans les chroniques latines, tire son nom d'Alauddin Kayqubad I ${ }^{\mathrm{er}}$, sultan seldjukide d'Anatolie (1219-1237) qui l'a conquis en 1220 et la fortifia comme débouché de son État sur la Méditerranée. 
Ils nous disaient : « Les femmes vous envoient cela et implorent vos prières. »

Tous les habitants de ce pays professent la doctrine de l'imâm Abou-Hanîfah, et ils sont fermes dans la sonnah. Il n'y a parmi eux ni kadary, ni râfidhy, ni mo'tazily, ni khâridjy, ni mobtadi ${ }^{175}$. C'est un mérite par lequel Dieu les a favorisés ; mais ils mangent du hachîch, et ne réprouvent pas l'usage de cette plante.

La ville d'Alâïa, mentionnée ci-dessus, est une grande place située sur le rivage de la mer et habitée par des Turcomans. Des marchands de Misr (Le Caire), d'Alexandrie, de la Syrie y descendent ; elle est très abondante en bois, que l'on transporte de cette ville à Alexandrie et à Damiette et de là dans tout le reste de l'Égypte. 'Alâïa possède un château situé à l'extrémité supérieure de la ville ${ }^{176}$. C'est un édifice admirable et très fort, construit par le sultan illustre 'Alâ eddîn Arroûmy. Je visitai le kâdhi de cette ville, Djélâl eddîn Alarzendjâny. Il monta avec moi dans la citadelle un vendredi, et nous y fîmes la prière. Il me traita avec ${ }_{\text {p137 }}$ honneur et me donna l'hospitalité, ainsi que Chems eddîn, fils d'Arredjîhâny, dont le père, 'Alâ eddîn, mourut à Mâly ${ }^{177}$, dans le Soudân.

\section{Du SULTAN D’ALÂÏA}

Le samedi, le kâdhi Djélâl eddîn monta à cheval avec moi, et nous nous mîmes en route, afin de visiter le roi d'Alâia, Youcef bec ${ }^{178}$, fils de Karamâr. Son habitation était située à dix milles de la ville, et nous le rencontrâmes assis, tout seul, près du rivage, au haut d'une colline

${ }^{175}$ Les qadaris sont partisans de la doctrine du libre arbitre; le terme mubtadi (novateur) désigne les hérétiques ; pour les autres termes, voir l'introduction du t. I.

${ }^{176}$ Le château construit par Alauddin Kayqubad I ${ }^{\text {er }}$, sur des fondations byzantines et qui existe encore aujourd'hui.

177 Capitale du royaume noir du Mali (voir t. III, p. 411).

178 Ala'iyya fut conquise en 1293 par les Karamanoghlu, successeurs des Seldjukides dans le centre-sud de l'Anatolie. Umari, géographe contemporain d'Ibn Battûta, cite également Yusuf comme gouverneur d'Ala'iyya au nom des Karamanoghlu, mais ce personnage ne figure pas dans les généalogies de cette dynastie. 
qui se trouve dans cet endroit. Les émirs et les vizirs se tenaient plus bas, et les soldats étaient rangés à sa droite et à sa gauche. Il avait les cheveux teints en noir. Je lui donnai le salut, et il m'interrogea touchant le temps de mon arrivée. Je l'informai de ce qu'il désirait savoir et je pris congé de lui ; il m’envoya un présent.

Je me rendis d'Alâïa à Anthâlïah ${ }^{179}$. Le nom de cette dernière ville ne diffère pas de celui d'Anthâkïah, en Syrie, si ce n'est que le câf y est remplacé par un lâm. C'est une des plus belles villes du monde : elle est extrêmement vaste, c'est la plus jolie cité que l'on puisse voir, et la mieux construite. Chaque classe de ses habitants est entièrement séparée des autres. Les marchands chrétiens y demeurent dans un endroit appelé almînâ ${ }^{180}$. Leur quartier est entouré d'un mur, dont les portes sont fermées extérieurement pendant la nuit et durant la p138 prière du vendredi. Les Grecs, anciens habitants d'Anthâlïah, demeurent dans un autre endroit; ils y sont également séparés des autres corps de nation et entourés d'un mur. Les Juifs habitent aussi un quartier séparé et ceint d'une muraille. Le roi, les gens de sa cour et ses esclaves habitent une ville entourée d'un mur qui la sépare des quartiers susmentionnés.

Toute la population musulmane demeure dans la ville proprement dite, où se trouve une mosquée principale, un collège, des bains nombreux et des marchés considérables, disposés dans l’ordre le plus merveilleux. Cette ville est entourée d'un grand mur, qui renferme aussi toutes les constructions que nous avons énumérées. Elle contient de nombreux jardins, et produit des fruits excellents, parmi lesquels est l'abricot admirable nommé dans le pays kamar eddîn ${ }^{181}$. Son noyau renferme une amande douce ; on fait sécher ce fruit et on le transporte en Égypte, où il est considéré comme quelque chose de rare. Il y a dans cette ville des sources d'une eau excellente, agréable au goût et très fraîche pendant l'été.

Nous logeâmes à Anthâlïah dans la medréceh dont le supérieur était Chihâb eddîn Alhamawy. Une des coutumes des habitants de

179 Antalya, l’antique Attaleia et médiévale Satalia, occupée en 1207 par le Seldjukide Ghiyasuddin Kayhusrav I ${ }^{\mathrm{er}}$.

180 Le port ; par « chrétiens », on entend ici les marchands occidentaux.

${ }^{181}$ Voir t. I, chap. 5, n. 104. 
cette ville consiste en ce que plusieurs enfants lisent tous les jours, avec de belles voix, après la prière de l'asr, dans la mosquée djâmi' et dans la medréceh, la soûrate de la Victoire, celle de l'empire et la soûrate 'Amma ${ }^{182}$,

\section{DES FRÈRES-JEUNES-GENS ${ }^{183}$ (« ALAKHIYYET ALFITIÂN »)}

Le singulier d'akhiyyet est akhy, qui se prononce comme le mot $a k h$, frère, lorsque celui qui parle ${ }_{\mathrm{p} 139}$ [c'est-à-dire la première personne] le met en rapport d'annexion avec lui-même [ce qui fait akhy, mon frère]. Les Akhiyyet existent dans toute l'étendue du pays habité par des Turcomans en Asie Mineure, dans chaque province, dans chaque ville et dans chaque bourgade. On ne trouve pas, dans tout l'univers, d'hommes tels que ceux-ci, remplis de la plus vive sollicitude pour les étrangers, très prompts à leur servir des aliments, à satisfaire les besoins d'autrui, à réprimer les tyrans, à tuer les satellites de la tyrannie et les méchants qui se joignent à eux. Alakhy signifie, chez eux, un homme que des individus de la même profession, et d'autres jeunes gens célibataires et vivant seuls, s'accordent à mettre à leur tête. Cette communauté s'appelle aussi foutouwweh ${ }^{184}$. Son chef bâtit un ermitage et y place des tapis, des lampes et les meubles nécessaires. Ses compagnons travaillent pendant le jour à se procurer leur subsistance ; ils lui apportent après l'asr ce qu'ils ont gagné. Avec cela ils achètent des fruits, des mets et autres objets qui sont consommés dans l'ermitage. Si un voyageur arrive ce jour-là dans la place, ils le logent chez eux ; ces objets leur servent à lui donner le repas de l'hospitalité, et il ne cesse d'être leur hôte jusqu'à son départ. S'il n'arrive pas d'étrangers, ils se réunissent pour manger leurs provisions ; puis ils

182 Les sourates 48, 67 et 78 du Coran.

183 Situées entre les confréries religieuses et les guildes professionnelles, les akhis constituent une des organisations typiques d'Asie Mineure dans cette période de conquête et de bouillonnement politique et religieux. Toutefois, le plus grand nombre de renseignements qu'on possède sur eux proviennent d'Ibn Battûta (voir aussi l'introduction).

${ }^{184}$ Pour les futuwwas, associations professionnelles ou populaires urbaines du monde musulman, voir l'introduction. Les akhis constituent la forme anatolienne de la futuwwa arabe. A cette époque, aussi bien la futuwwa que les akhis sont liés avec les confréries soufis. 
chantent et dansent. Le lendemain, ils retournent à leur métier, et après l'asr ils viennent trouver leur chef, avec ce qu'ils ont gagné. Ils sont appelés les jeunes-gens et l'on nomme leur chef, ainsi que nous l'avons dit, Alakhy. Je n'ai pas vu dans tout l'univers d'hommes plus bienfaisants qu'eux ; les habitants de Chîrâz et ceux d'Ispahân leur p140 ressemblent sous ce rapport, si ce n'est que ces jeunes-gens aiment davantage les voyageurs, et leur témoignent plus de considération et d’intérêt.

Le second jour après notre arrivée à Anthâlïah, un de ces fitiâns vint trouver le cheïkh Chihâb eddîn Alhamawy et lui parla en turc, langue que je ne comprenais pas alors ${ }^{185}$. Il portait des vêtements usés et avait sur sa tête un bonnet de feutre. Le cheïkh me dit : " Sais-tu ce que veut dire cet homme ? » Je répondis : " Je l'ignore. — Il vous invite, reprit-il, à un festin, toi et tes compagnons. " Je fus étonné de cela et je lui dis : "C’est bien. » Mais, lorsqu'il s’en fut retourné, je dis au cheïkh : "C'est un homme pauvre ; il n'a pas le moyen de nous traiter et nous ne voulons pas l'incommoder. » Le cheïkh se mit à rire et répliqua : "Cet individu est un des chefs des jeunes-gens-frères, c'est un cordonnier et il est doué d'une âme généreuse ; ses compagnons, qui sont au nombre de deux cents artisans, l'ont mis à leur tête ; ils ont bâti un ermitage pour y recevoir des hôtes, et ce qu'ils gagnent pendant le jour ils le dépensent durant la nuit. » Lorsque j'eus fait la prière du coucher du soleil, cet homme revint nous trouver et nous nous rendîmes avec lui dans sa zâouïah.

Nous trouvâmes un bel ermitage, tendu de superbes tapis grecs, et où il y avait beaucoup de lustres en verres de l'Irâk. Dans la salle de réception se voyaient cinq baïçoûs : on appelle ainsi une espèce de colonne ou candélabre de cuivre porté sur trois pieds ; à son extrémité supérieure il a une sorte de lampe, aussi de cuivre, au milieu de laquelle il $\mathrm{y}$ a un tuyau pour la mèche. Cette lampe est remplie de graisse fondue, et on place à son côté des vases de cuivre, pleins de graisse, et dans lesquels se trouvent des ciseaux pour arranger les mèches. Un des frères est préposé à ce soin et on lui donne le nom de tcherâghtchy ${ }^{186}$, Une troupe de jeunes-gens étaient rangés dans le sa-

185 Et qu'il n’a pas dû apprendre depuis.
${ }^{186}$ Tchiraghdji : lampiste ; du persan tchiragh, lampe. 
lon ; leur costume était un ${ }_{\mathrm{p} 141} k_{a b a{ }^{187}}$, et ils portaient aux pieds des bottines. Chacun d'eux avait une ceinture, à laquelle pendait un couteau de la longueur de deux coudées. Leur tête était couverte d'une kalançoueh ${ }^{188}$ blanche, en laine, au sommet de laquelle était cousue une pièce d'étoffe, longue d'une coudée et large de deux doigts. Lorsqu'ils tiennent leurs séances, chacun d'eux ôte sa kalançoueh et la place devant lui ; une autre kalançoueh, d'un bel aspect, en zerdkhâny ${ }^{189}$ ou toute autre étoffe, reste sur sa tête. Au milieu de leur salle de réunion se trouve une espèce d'estrade, placée pour les étrangers. Lorsque nous eûmes pris place près d'eux, on apporta des mets nombreux, des fruits et des pâtisseries ; ensuite ils commencèrent à chanter et à danser. Leurs actes nous frappèrent d'admiration ; notre étonnement de leur générosité et de la noblesse de leur âme fut très grand. Nous les quittâmes à la fin de la nuit, et les laissâmes dans leur zâouïah.

\section{DU SULTAN D’ANTHÂLÏAH}

C'est Khidrh bec, fils de Yoûnis bec ${ }^{190}$. Nous le trouvâmes malade, lors de notre arrivée dans cette ville : nous le visitâmes dans son palais, et il était alité. Il nous p142 parla dans les termes les plus affables et les plus bienveillants ; nous lui fîmes nos adieux et il nous envoya des présents.

187

188

189

Du persan zard, jaune ; probablement étoffe de soie fine ressemblant au taffetas.

190 Cette dynastie turkmène qui a contrôlé tout au long du XIV ${ }^{\mathrm{e}}$ siècle le littoral du golfe d'Antalya et l'arrière-pays, dit "région des lacs », formait deux branches engendrées par deux frères: Dundar Beg, dont les descendant seront connus sous le nom des Hamit-Oghlu, à Egridir, et Yunus Beg, qui donnera souche aux Teke-Oghlu à Antalya. Timurtash, le fils de Tchoban (voir t. I), soumettra les deux branches de la principauté en 1324 et donnera Antalya à un fils de Yunus, Mahmud. Après la fuite de Timurtash en Égypte en 1327, un autre fils Hizir (Khidr) contrôlera Antalya. C’est lui que rencontrera Ibn Battûta. Peu après son frère Sinan al-din lui succédera. 
Nous nous mîmes en route pour la ville de Bordoûr ${ }^{191}$, petite cité, riche en jardins et en rivières, et possédant un château situé sur la cime d'une haute montagne. Nous logeâmes dans la maison de son prédicateur. Les frères se réunirent et voulurent nous héberger ; mais celui-ci n’y consentit pas. Ils préparèrent pour nous un repas dans un jardin appartenant à l'un d'eux, et où ils nous conduisirent. C'était une chose merveilleuse que la joie et l'allégresse qu'ils montraient, à cause de notre présence. Cependant, ils ignoraient notre langue comme nous ignorions la leur, et il n'y avait pas de truchement qui pût nous servir d'intermédiaire. Nous passâmes un jour chez eux, et nous nous en retournâmes.

Nous partîmes ensuite de Bordoûr pour Sabarta ${ }^{192}$, ville bien construite, pourvue de beaux marchés, de nombreux jardins et de plusieurs rivières ; elle a un château bâti sur une haute montagne. Nous y arrivâmes le soir, et nous nous logeâmes chez son kâdhi.

Nous quittâmes cet endroit pour nous rendre à Akrîdoûr ${ }^{193}$, qui est une grande ville, bien peuplée et possédant de beaux marchés, des rivières, des arbres, et des jardins. Elle a aussi un lac d'eau douce, par lequel les vaisseaux se rendent en deux jours à Akchehr, à Bakchehr et autres villes et bourgades ${ }^{194}$. Nous y logeâmes ${ }_{\mathrm{p} 143}$ dans une école située en face de la grande mosquée, et où enseignait le savant professeur, le dévot pèlerin, le vertueux Moslih eddîn. Ce personnage a professé en Égypte et en Syrie, et il a habité l'Irâk pendant quelque temps. C’était un homme disert et éloquent, une des merveilles de son siècle. Il nous traita avec la plus grande considération et nous reçut de la manière la plus honorable.

191 L'actuel Burdur, près du lac du même nom, à cent soixante kilomètres au nord d'Antalya. Il ne reste plus aucune trace du château.

192 Isparta, l'antique Baris, conquise en 1203 par les Seldjukides, faisait à l'époque partie de la principauté des Hamid-Oghlu.

193 Egridir, à trente kilomètres à l'est d'Isparta et au bord du lac du même nom, était à l’époque la capitale des Hamid-Oghlu.

194 Aksehir se trouve à cent vingt-cinq kilomètres au nord-est d'Egridir, derrière les montagnes de Sultan Dagh et Beysehir au sudest, au bord du lac du même nom. Alors, soit Ibn Battûta se trompe en supposant toutes ces villes au bord du même lac, soit il faut interpréter cette phrase comme si le chemin pour ces deux villes passait à travers le lac. 


\section{DU SULTAN D’AKRÎDOÛR}

Le sultan de cette ville est Abou Ishâk bec, fils d'Addendâr bec ${ }^{195}$, un des principaux souverains de ce pays. Il habita l'Égypte du vivant de son père, et fit le pèlerinage de La Mecque. Il est doué de belles qualités, et c'est sa coutume d'assister chaque jour à la prière de l'asr, dans la mosquée djâmi'. Lorsque cette prière est terminée, il s’adosse au mur de la kiblah; les lecteurs du Coran s'asseyent devant lui, sur une estrade de bois élevée, et lisent la soûrate de la Victoire, celle de l'empire et la sourate 'Amma, avec de belles voix qui agissent sur les âmes et font que les cœurs s'humilient, les corps frissonnent et les yeux versent des larmes. Après cette cérémonie, le sultan retourne à son palais.

Nous passâmes près de ce prince les premiers jours du moi de ramadhân ${ }^{196}$. Il s'asseyait, chacune des nuits de ${ }_{\text {p144 }}$ ce mois, sur un tapis qui touchait immédiatement la terre, sans estrade, et il s'appuyait sur un grand coussin. Le docteur Moslih eddîn s'asseyait à son côté, je m'asseyais à côté du fakîh, et les grands de son empire, ainsi que les émirs de sa cour, venaient après nous. On apportait ensuite des aliments. Le premier mets avec lequel on rompait le jeûne était du therîd ${ }^{197}$, servi dans une petite écuelle et recouvert de lentilles trempées dans le beurre et sucrées. Les Turcs servent d'abord le therîd parce qu'ils le regardent comme un mets de bon augure. "Le Prophète, disent-ils, le préférait à tous les autres mets, et nous commençons par le manger à cause de cela. » On apporte ensuite les autres plats ; c'est

Après l'occupation de la principauté par Timurtash (voir n. 29 ci-dessus) et le meurtre de Dundar Beg, ses fils se réfugièrent en Égypte. Un premier, nommé Hizir (à ne pas confondre avec son cousin d'Antalya), apparaît en 1327 pour récupérer les possessions paternelles. Son frère Ishak lui succède l'année suivante, et il régnera jusqu'en 1344.

196 Le premier du mois de ramadhan de l’année 733 correspond au 16 mai 1333. Ibn Battûta a dû débarquer à Alanya fin décembre ou début janvier 1333. Si on place le point de départ de la longue digression qui le mènera vers le centre et le nord-est d'Anatolie à Egridir, le point le plus proche de Konya, l'étape suivante de cette déviation, et non à Milas (voir plus loin et carte) où le texte le place, notre voyageur aurait le temps de parcourir ce trajet de déviation jusqu’à Erzeroum et revenir à Egridir pour le Ramadhan.

Potage composé de bouillon et de pain émietté. D’après la tradition attribuée au Prophète au sujet de sa femme Aïsha, celui-ci aurait dit : "La supériorité d'Aïsha sur les autres femmes est comme celle du tharid sur les autres mets. » 
ainsi qu'agissent les Turcs pendant toutes les nuits du mois de ramadhân.

Le fils du sultan mourut un jour de ce même mois ${ }^{198}$. Ces gens n’ajoutèrent rien aux lamentations habituelles pour implorer la miséricorde divine en faveur du mort, ainsi que font en pareil cas les habitants de l'Égypte et de la Syrie, et, contrairement à ce que nous avons raconté ci-dessus touchant les pratiques des Loûrs, quand le fils de leur sultan vint à mourir ${ }^{199}$. Lorsque le prince eût été enseveli, le sultan et les thâlibs ${ }^{200}$ continuèrent pendant trois jours à visiter son tombeau, après la prière de l'aurore. Le jour qui suivit ses obsèques, je sortis avec les autres personnes dans le même but. Le sultan m'aperçut marchant à pied ; il m'envoya un cheval et me fit faire ses excuses. Lorsque je fus de retour à la medréceh, je renvoyai le cheval ; mais le sultan refusa de le reprendre et dit : « Je l'ai donné comme cadeau, et p145 non comme prêt. » Il m'envoya aussi un vêtement et une somme d'argent.

Nous nous rendîmes d'Akrîdoûr à Koul Hissâr ${ }^{201}$, petite ville entourée d'eau de tous côtés; des roseaux ont poussé au milieu des eaux. On n'y arrive que par un seul chemin, semblable à une chaussée, pratiqué entre les roseaux et l'eau, et où il ne passe qu'un cavalier à la fois. La ville, qui est située sur une colline au milieu du lac, est très forte et on ne peut la prendre. Nous y logeâmes dans la zâouïah d’un des jeunes-gens-frères.

\section{Du SULTAN DE KoUl HissÂR}

C'est Mohammed Tchelebi, et ce dernier mot, dans la langue du pays de Roûm, signifie monsieur, seigneur ${ }^{202}$. Il est frère du sultan

198 C’est le fils de son frère Mehmed, souverain de Gölhisar (qui sera mentionné plus loin) qui succédera à Ishâk.

199 Voir t. I, p. 393 et suiv.

${ }^{200}$ Voir t. I, chap. 1, n. 58.

201 40. Gölhisar, à quatre-vingt-dix kilomètres au sud-ouest de Burdur, au bord d'un petit lac.

${ }^{202}$ Ce titre est donné aux chefs soufis, aux princes et plus tard, dans l'empire ottoman, aux lettrés. 
Abou Ishâk, roi d'Akrîdoûr. Lorsque nous arrivâmes dans sa capitale, il en était absent. Nous y passâmes quelques jours, au bout desquels le sultan revint. Il nous traita avec considération, et nous fournit des montures et des provisions de route. Nous partîmes par le chemin de Karâ Aghâdj ${ }^{203}$; karâ signifie noir, et aghâdj bois. C'est une plaine verdoyante, habitée par des Turcomans. Le sultan envoya avec nous plusieurs cavaliers, chargés de nous conduire jusqu'à la ville de Lâdhik, parce qu'une troupe de brigands, appelés les Djermîân ${ }^{204}$, interceptent les chemins dans ${ }_{\mathrm{p} 146}$ cette plaine. On dit qu'ils descendent de Yezîd, fils de Mo’âwiyah, et ils possèdent une ville appelée Coûtâhiyah. Dieu nous préserva de leurs attaques, et nous arrivâmes à la ville de Lâdhik, appelée aussi Doûn Ghozloh, ce qui signifie la Ville des Porcs ${ }^{205}$.

Elle est au nombre des villes les plus grandes et les plus admirables. Il s'y trouve sept mosquées où l'on fait la prière du vendredi ; elle possède de beaux jardins, des rivières qui coulent abondamment, des sources jaillissantes et des marchés superbes. On y fabrique des étoffes de coton brodées d'or, qui n'ont pas leurs pareilles, et dont la durée est fort longue, à cause de l'excellente qualité du coton et de la force des fils employés. Elles sont connues par un nom emprunté de celui de la ville où elles se fabriquent. La plupart des personnes qui exercent des métiers à Lâdhik sont des femmes grecques ; car il y a ici beaucoup de Grecs tributaires. Ils payent au sultan des redevances, telles que la capitation et autres. Leur signe distinctif consiste en des bonnets longs, parmi lesquels il y en a de rouges et de blancs. Les femmes des Grecs portent de grands turbans.

203 Plaine arrosée par la rivière Dalaman, dont le centre est le bourg actuel d'Acipayam.

${ }^{204}$ Les Germiyan-Oghlu sont la seule principauté turkmène anatolienne qu’Ibn Battûta ne visitera pas. Ses renseignements tirent apparemment leur origine de l'appréhension des autres souverains face à la puissance et à l'agressivité des Germiyan-Oghlu, lesquels, enclavés dans le centre-ouest d'Anatolie, n’avaient d'autre issue pour s'étendre que de soumettre les principautés voisines. Leur capitale à l'époque était Kutahya et leur souverain Mehmed Beg (1325 ?1360 ?).

${ }^{205}$ L'antique Laodhikeia du Méandre, dont le nom fut déformé en Lâdik à l'époque de la conquête. Le nom de Dongouzlou, dû probablement à la présence des chrétiens, éleveurs de porcs, est à l'origine du nom actuel de la ville : Denizli. 
Les gens de cette ville ne réprouvent pas les mauvaises mœurs; bien plus, les habitants de tout ce pays en usent de même. Ils achètent de belles esclaves grecques et les laissent se prostituer; chacune d'elles doit payer une redevance à son maître. J'ai entendu dire, en cette ville, que les jeunes filles esclaves y entrent dans le bain avec les hommes, et que quiconque veut se livrer à la débauche se satisfait dans le bain, sans que personne lui en fasse reproche. On m'a raconté que le kâdhi de cette ville possède des jeunes filles esclaves livrées à ce sale trafic.

Lors de notre arrivée à Lâdhik, nous passâmes par un marché. Des individus sortirent de leurs boutiques ${ }_{\mathrm{p} 147}$ au-devant de nous, et prirent la bride de nos chevaux. D'autres personnes voulurent les en empêcher, et la dispute se prolongea entre les deux partis, si bien que plusieurs individus tirèrent leurs couteaux. Nous ignorions ce qu'ils disaient. En conséquence, nous eûmes peur d'eux et nous pensâmes que c'étaient ces Djermiân qui pratiquent le brigandage sur les chemins, que c'était là leur ville et qu'ils voulaient nous piller ; mais Dieu nous envoya un homme qui avait fait le pèlerinage et qui connaissait la langue arabe. Je lui demandai ce que ces gens nous voulaient. Il répondit : "Ce sont des fitiâns. Ceux qui sont arrivés les premiers près de vous sont les compagnons d'alfata Akhy Sinân, et les autres, les compagnons d'alfata Akhy Thoûmân ${ }^{206}$. Chaque troupe désire que vous logiez chez elle. » Nous fûmes étonnés de la générosité de leur âme.

Ils firent ensuite la paix, à condition qu'ils tireraient au sort, et que nous logerions d'abord chez ceux en faveur desquels le sort se déclarerait. Il échut à Akhy Sinân. Il apprit cette nouvelle, et vint nous trouver avec plusieurs de ses compagnons, qui nous donnèrent le salut. Nous logeâmes dans un ermitage qui lui appartenait, et l'on nous offrit différentes espèces de mets. Akhy Sinân nous conduisit ensuite au bain, y entra avec nous et se chargea de me servir lui-même ; ses compagnons furent préposés au service des miens, trois ou quatre d'entre eux prenant soin d'un de ceux-ci. Quand nous fûmes sortis du bain, on apporta un festin somptueux, des sucreries et beaucoup de fruits, et lorsque nous eûmes fini de manger, les lecteurs du Coran lu-

${ }^{206}$ Evliya Tchelebi, le voyageur turc du XVII ${ }^{\mathrm{e}}$ siècle, en passant par Denizli y trouva les tombeaux d’Akhi Sinan et d'Akhi Tuman, vénérés comme des saints. 
rent des versets de ce livre divin. Puis tous ces hommes commencèrent à chanter et à danser. Ils informèrent le sultan de notre arrivée, et le lendemain au soir il nous envoya chercher. Nous l'allâmes trouver, ainsi que son fils, comme nous le raconterons ci-dessous. p148

Nous retournâmes ensuite à l'ermitage ; nous rencontrâmes le frère Thoûman et ses compagnons, qui nous attendaient. Ils nous menèrent à leur zâouïah, et imitèrent la conduite de leurs confrères en ce qui regardait le bain et le repas. Ils y ajoutèrent même quelque chose, en répandant sur nous de l'eau de rose, après que nous fûmes sortis du bain. Ensuite ils retournèrent avec nous à la zâouïah, et se conduisirent absolument comme leurs compagnons, ou mieux encore, sous le rapport de l'excellence des mets, des sucreries et des fruits; il en fut ainsi de la lecture du Coran après la fin du repas, du chant et de la danse. Nous passâmes plusieurs jours près d'eux à la zâouïah

\section{DU SULTAN DE LÂDHIK}

C'est Yenendj bec ${ }^{207}$, et il est au nombre des principaux sultans du pays de Roûm. Lorsque nous fûmes descendus dans l'ermitage d'Akhy Sinân, ainsi que nous l'avons raconté, il nous envoya le prédicateur, le donneur d'avertissements, le savant 'Alâ eddîn Alkasthamoûny, et le fit accompagner par des chevaux en nombre égal au nôtre. Cela se passait dans le mois de ramadhân. Nous allâmes le trouver et nous lui donnâmes le salut. C'est la coutume des rois de ce pays de témoigner de l'humilité envers les voyageurs, de leur parler avec douceur, mais de leur faire peu de présents. Nous fîmes avec ce prince la prière du coucher du soleil ; on lui servit à manger ; nous rompîmes le jeûne près de lui et nous nous en retournâmes. Il nous envoya des dirhems. Son fils Mourâd bec nous manda ensuite ; il habitait un p149 jardin situé hors de la ville, car c'était alors la saison des fruits. Il envoya un nombre de chevaux égal au nôtre, ainsi qu'avait fait son père. Nous

${ }^{207}$ Ladik avait été donnée comme fief par les Seldjukides aux descendants d’un de leurs vizirs, Sahib Ata, à la fin du XIII ${ }^{\mathrm{e}}$ siècle. Au cours de leur expansion, les Germiyan sont entrés en conflit avec les Sahib Ata et la ville a changé trois fois de mains, pour échoir définitivement en 1289 à Ali Beg, de la famille des Germiyan. Yinantch était le fils de ce dernier. Mort après 1335, c'est son fils Murad Arslan, mentionné plus loin, qui lui succéda. 
allâmes à son jardin et nous passâmes près de lui la nuit entière. Il avait un légiste qui servit d'interprète entre nous et le prince.

Nous nous en retournâmes au matin, et, la fête de la rupture du jeûne nous ayant trouvés à Lâdhik ${ }^{208}$, nous nous rendîmes au lieu de la prière. Le sultan sortit avec son armée et les jeunes-gens-frères sortirent aussi, tous munis de leurs armes. Les individus de tous les corps de métiers portaient des étendards, des clairons, des trompettes et des tambours. Ils s'efforcent de remporter les uns sur les autres le prix de la louange, et de se surpasser par l'éclat de leur costume et l'excellence de leurs armes. Ils ont avec eux des bœufs, des moutons et des charges de pain ; ils égorgent les animaux près des sépultures, et font des aumônes avec leur chair et avec le pain. Ils se rendent d'abord aux tombeaux, puis au lieu de la prière. Lorsque nous eûmes fait la prière de la fête, nous entrâmes avec le sultan dans son palais, et l’on servit des aliments. Une table séparée fut dressée pour les docteurs de la loi, les cheïkhs et les fitiâns. Une autre table est destinée aux fakîrs et aux malheureux ; car dans ce jour ni pauvre ni riche n'est repoussé du palais du sultan.

Nous séjournâmes quelque temps dans cette ville, à cause du danger qu'offraient les chemins ; mais, une caravane s'étant préparée à partir, nous marchâmes avec elle pendant un jour et une portion de la nuit suivante, et nous arrivâmes à la forteresse de Thaouâs ${ }^{209}$, qui est grande. On raconte que Sohaïb, compagnon de Mahomet, était originaire de cette place ${ }^{210}$. p150

Nous passâmes la nuit hors de ses murailles, et arrivâmes au matin près de sa porte. Les habitants du fort nous interrogèrent, du haut du mur, sur notre arrivée, et nous satisfîmes à leurs questions. Alors le commandant du château, Eliâs bec ${ }^{211}$, sortit à la tête de ses troupes, afin d'explorer les environs de la forteresse et le chemin, de peur que les voleurs ne fondissent sur les troupeaux. Lorsque ces hommes eu-

\footnotetext{
208 Le 15 juin 1333.

209 L'actuel Tavas, à quarante kilomètres par la route au sud de Denizli.

210 Suhail serait, d'après la tradition, d'origine grecque.

211 Ilyas Beg est mentionné par Umari comme souverain d'une principauté ayant comme centre Tavas qui sera absorbée par la suite par les Menteché (voir plus loin).
} 
rent fait le tour de la place, les troupeaux sortirent ; et c'est ainsi qu'ils agissent continuellement. Nous logeâmes dans le faubourg de cette forteresse, dans la zâouïah d'un homme pauvre. L'émir de la place nous envoya les mets de l'hospitalité, ainsi que des provisions de route.

De Thaouâs nous nous rendîmes à Moghlah ${ }^{212}$, et nous logeâmes dans l'ermitage d'un des cheïkhs de cet endroit, qui était au nombre des hommes généreux et vertueux. Il venait souvent nous trouver dans sa zâouïah, et n'arrivait jamais sans apporter des mets ou des fruits, ou des sucreries. Nous rencontrâmes dans cette ville Ibrahîm bec, fils du sultan de la ville de Mîlâs, dont nous parlerons ci-après. Il nous traita avec considération, et nous fit présent de vêtements.

Nous nous rendîmes ensuite à Mîlâs ${ }^{213}$, qui est une des plus belles et des plus grandes villes du pays de Roûm ; elle abonde en fruits, en jardins et en eaux, et nous y logeâmes dans la zâouïah d'un des jeunes-gens-frères. Celui-ci surpassa de beaucoup, sous le rapport de la générosité, du repas d'hospitalité, de l'entrée dans le ${ }_{\mathrm{p} 151}$ bain, et autres actions louables et actes bienséants, ceux qui l'avaient précédé près de nous. Nous rencontrâmes à Mîlâs un homme vertueux et âgé, nommé Bâbâ echchouchtery ${ }^{214}$; on racontait que son âge dépassait cent cinquante ans ; mais il avait encore de la force et de l'activité ; son intelligence était ferme et sa mémoire excellente. Il fit des vœux en notre faveur et nous obtînmes sa bénédiction.

\section{DU SULTAN DE MîLÂS}

C'est le sultan honoré Chodjâ' eddîn Orkhân bec, fils d'Almentecha ${ }^{215}$. Il est au nombre des meilleurs souverains, il est

212 A cent treize kilomètres par la route au sud-ouest de Tavas, l'actuelle Mugla. Ibn Battûta entre ici dans l'émirat de Menteché.

${ }^{213}$ A quatre-vingt-un kilomètres au nord-ouest de Mugla, aujourd’hui sous préfecture de cette dernière ville ; c'est l'antique Mylasa, capitale de la Carie. La région fut conquise en 1261 par les Turkmènes au nom des Seldjukides.

${ }^{214}$ Son tombeau, mentionné par Evliya Tchelebi, est encore de nos jours objet de vénération.

${ }^{215}$ Les anciennes régions de la Lycie et de la Carie, aux mains des Byzantins, sont conquises par des Turkmènes, venus de la mer à partir des rivages du 
doué d'une jolie figure et tient une belle conduite. Sa compagnie habituelle se compose de légistes, qui jouissent près de lui d'une grande considération. Plusieurs de ces hommes vivent à sa cour, parmi lesquels le fakîh Alkhârezmy, homme excellent et versé dans les diverses branches des sciences. Le sultan était mécontent de lui, lorsque je le vis, parce qu'il avait fait un voyage à la ville d'Ayâ Soloûk, qu'il en avait visité le prince et avait accepté ses dons. Ce docteur me pria de dire devant le roi, touchant son affaire, des choses capables d'effacer les mauvaises impressions qu'il avait dans l'esprit. Je fis son éloge en présence du sultan, et je rapportai ce que je connaissais de la science de ce jurisconsulte et de son mérite. Je ne cessai de parler ainsi, jusqu'à ce que la colère du prince contre lui eût disparu. Ce sultan nous fit du bien, et nous donna des montures et des provisions de route. Sa résidence était dans la ${ }_{\mathrm{p} 152}$ ville de Bardjîn, voisine de Mîlâs ; ces deux villes ne sont séparées que par une distance de deux milles ${ }^{216}$. Celle de Bardjîn est nouvelle, située sur une colline, et pourvue de beaux édifices et de mosquées. Le sultan avait commencé d'y bâtir une mosquée djâmi', dont la construction n'était pas encore achevée ${ }^{217}$. Nous le vîmes dans cette ville, et nous y logeâmes dans la zâouïah du jeunehomme-frère Aly.

Nous partîmes lorsque le sultan nous eut fait du bien, comme nous l'avons dit ci-dessus, et arrivâmes à Koûniyah ${ }^{218}$ ville grande, bien bâtie, abondante en eaux, en rivières, en jardins et en fruits. Elle produit l'abricot appelé kamar eddîn, dont il a été question plus haut, et

golfe d’Antalya. Menteché Beg, le fondateur éponyme de la dynastie, mourut après 1282, laissant un fils, Mas'ud, à Muas (1282 ?-1318 ?) et un autre, Kirman, à Finike. Le successeur de Mas'ud fut son fils Orhan (1318 ?-1344 ?), rencontré par Ibn Battûta. Son fils Ibrahim, que notre auteur mentionne à Mugla, lui succédera.

216 Par la suite, Pecin ou Becin, à cinq kilomètres au sud de Mitas.

217 Une inscription sur cette mosquée porterait, d'après Evliya Tchelebi, la date de 7(3)2 (1331-1332), mais le chiffre du milieu n’est pas sûr.

${ }^{218}$ Ici commence dans le texte le digression qui va mener Ibn Battûta jusqu'à Erzeroum au nord-est d'Anatolie. Konya étant à six cents kilomètres à l'est de Mitas, il serait plus logique de placer cette digression à partir d'Egridir et Beysehir, cette dernière ville étant distante de quatre-vingt-dix kilomètres de Konya (voir aussi n. 33, ci-dessus). Konya fut la capitale des Seldjukides d'Anatolie jusqu'à la fin de leur règne en 1308. Disputée ensuite aux Mongols par les Karamanoghlu, elle fut occupée par ces derniers après la fuite de Timurtash en 1327. 
on l'exporte aussi de cette ville en Égypte et en Syrie. Les rues de Koûniyah sont fort vastes, ses marchés admirablement disposés et les gens de chaque profession y occupent une place séparée. On dit que cette ville a été bâtie par Alexandre, et elle fait partie des États du sultan Bedr eddîn, fils de Karamân, dont nous reparlerons ci-dessous ; mais le souverain de l'Irak s'en est quelquefois emparé, à cause de sa proximité des villes qu'il possède dans ce pays.

Nous logeâmes à Koûniyah dans la zâouïah du kâdhi de cette ville, nommé Ibn Kalam châh ${ }^{219}$. Il est au nombre des fitiâns et son ermitage est un des plus grands qui ${ }_{\mathrm{p} 153}$ existent. Il a beaucoup de disciples, dont l'affiliation à la chevalerie remonte au prince des croyants 'Aly, fils d'Abou Thâlib ${ }^{220}$. Le vêtement qui, chez eux, sert d'insigne à cette distinction est le caleçon. C'est ainsi que les soûfis revêtent le froc comme marque de leur corporation. Le kâdhi agit encore d'une façon plus généreuse et plus belle que les personnes qui l'avaient précédé, en nous traitant avec considération et en nous donnant l'hospitalité. Il envoya son fils à sa place, pour nous introduire dans le bain.

On voit dans cette ville le mausolée du cheïkh, de l'imâm pieux, du pôle, Djélâl eddîn, connu sous le nom de Maoulânâ ${ }^{221}$, Cet homme jouissait d'une grande considération, et il y a dans le pays de Roûm une confrérie qui lui doit sa naissance et qui porte son nom. On appelle donc ceux qui en font partie djelâliens, à l'instar des ahmediens

219 Tadj al-din bin Kalam Shah, mentionné par d'autres sources.

220 La futuwwa, organisation populaire d'un pouvoir politique grandissant dans la société urbaine musulmane, fut récupérée par le calife abbasside al-Nasir (1181-1223) et transformée en une sorte d'ordre de chevalerie qui devait relier les souverains de l'islam sous le saint patronage d'Ali. Al-Nasir enverra, comme ambassadeur-missionnaire au profit de cette cause, auprès du souverain seldjukide de Konya Alauddin Kayqubad I ${ }^{\mathrm{er}}$ (1219-1237), Abu Hafs Omar al-Suhrawardi, le fondateur de l'ordre soufi « aristocratique » du même nom (voir introduction du t. I). Ainsi l'implantation de la futuwwa dans la capitale seldjukide a dû conserver un caractère différent de celui, plus populaire, des akhis des autres villes.

221 Djalal al-din al-Rumi, dit Mawlana (Notre Maître) [1207-1284], est le fondateur de l'ordre soufi des mawiawis, connus en Occident sous le nom de « derviches tourneurs ». L’ordre est inspiré de la tradition khorasanienne du soufisme. Djalal al-din est originaire de Balkh, et son silsila (affiliation) retrouve celui des suhrawardis. Protégé par les seldjukides et ensuite par les Ottomans, l’ordre s’est surtout implanté parmi les classes dirigeantes. 
dans l'Irâk, et des haïderiens dans le Khorâçân ${ }^{222}$. Par-dessus le mausolée de Djélâl eddîn, on a élevé une grande zâouïah, où l'on sert de la nourriture aux voyageurs ${ }^{223} \cdot$ p154

\section{ANECDOTE}

On raconte que Djélâl eddîn était, au début de sa carrière, un légiste et un professeur. Les étudiants se réunissaient auprès de lui, dans son école, à Koûniyah. Un homme qui vendait des sucreries entra un jour dans la medréceh, portant sur sa tête un plateau de pâtes douces, coupées en morceaux, dont chacun se vendait une obole. Lorsqu'il fut arrivé dans la salle des leçons, le cheïkh lui dit : "Apporte ton plateau. » Le marchand y prit un morceau de sucrerie et le donna au cheïkh ; celui-ci le reçut dans sa main et le mangea. Le pâtissier s'en alla sans faire goûter de sa marchandise à aucune autre personne. Le cheïkh laissa la leçon, sortit pour le suivre et négligea ses disciples ${ }^{224}$, Ceux-ci l'attendirent longtemps ; enfin, ils allèrent à sa recherche, mais ne purent découvrir où il se tenait. Il revint les trouver au bout de quelques années; mais son esprit était dérangé ; il ne parlait plus qu'en poésie persane liée (dont les hémistiches rimaient l'un avec l'autre, et qu'on ne comprenait pas). Ses disciples le suivaient en écrivant les vers qu'il récitait, et ils en composèrent un livre, qu'ils appelèrent Mathnawy ${ }^{225}$. Les habitants de ce pays révèrent cet ouvrage, en méditent le contenu, l'enseignent et le lisent dans leurs zâouïahs, toutes les nuits du jeudi au vendredi. On voit aussi à Koûniyah le tombeau du jurisconsulte Ahmed, qui, à ce qu'on raconte, fut le professeur du susdit Djélâl eddîn. p155

${ }^{222}$ Les rifais (voir introduction du t. I). Pour les haidaris voir plus loin p. 313 et introduction.

${ }^{223}$ Le complexe contenant le tombeau de Mawlana et la zawiya existe toujours à Konya.

224 Il s’agit de Shams al-din Tabrizi, dont les rapports avec Mawiana datent de 1244. Ils durèrent quinze mois, jusqu'à ce que les disciples et la famille de Mawlana, inquiets de l'influence de Tabrizi, décident de le tuer.

225 Double, répété ; forme poétique contenant des vers de la même mesure, et dont les deux hémistiches riment ensemble. Écrit en persan considéré par les adeptes de l’ordre comme contenant le sens caché du Coran et appelé «le Coran en persan $"$. 
Nous partîmes de Koûniyah pour Lârendah ${ }^{226}$, ville belle et abondante en eaux et en jardins.

\section{DU SULTAN DE LÂRENDAH}

Le sultan de cette ville est le roi Bedr eddîn, fils de Karamân ${ }^{227}$, elle appartenait à son frère utérin Moûça. Celui-ci la céda à Melic Nâcir, qui lui donna en place un équivalent, et y envoya un émir et une armée ${ }^{228}$, mais ensuite le sultan Bedr eddîn s'en empara et y bâtit un palais royal ; son autorité s'y consolida. Je rencontrai ce sultan hors de la ville, qui revenait d'une partie de chasse. Je descendis devant lui de ma monture, et il descendit de la sienne ; je le saluai et il s'avança vers moi. C'est la coutume des rois de ce pays de mettre pied à terre, lorsqu'un voyageur descend de sa monture devant eux. Son action leur plaît, et ils lui témoignent alors beaucoup de considération ; mais, s’il les salue sans descendre de cheval, cela leur déplaît, les mécontente, et devient une cause de désappointement pour le voyageur. C'est ce qui m'est arrivé avec un de ces rois, ainsi que je le raconterai. Lorsque j'eus donné le salut à celui-ci et que je fus remonté à cheval après lui, il m'interrogea touchant mon état de santé et le temps de mon arrivée ; j'entrai avec lui dans la ville. Il ordonna de me donner l'hospitalité la plus parfaite ; il m'envoya des mets copieux, des fruits et des sucreries dans des ${ }_{\mathrm{p} 156}$ bassins d'argent, ainsi que des bougies. Il me donna des vêtements, une monture et d'autres présents.

L'actuelle Karaman, à cent sept kilomètres au sud-est de Konya, détruite par l’Ilhan Gaikhatu après 1291, fut rebâtie vers 1311 par le Karamanoghlu Musa qui en fit sa résidence.

Badr al-din Ibrahim, fils de Badr al-din Mahmud (1300-1308) et petit-fils de Karaman, fondateur éponyme de la dynastie, succéda à son frère Yakhchi et prit possession de Larende vers 1317-1318. Il abdiqua en 1333, l'année de passage d'Ibn Battûta, au profit de son frère Khalil, mais conserva probablement une partie de l'émirat comme fief.

Musa posséda Larende de 1311 à 1318. Il fut comme la plupart des Karamanoghlu allié aux mameluks; Ibn Battûta le rencontra au pèlerinage de La Mecque en 1328 (voir t. I, p. 472). Toutefois, il ne semble pas que des détachements mameluks soient venus à Larende. 
Nous ne séjournâmes pas longtemps près de ce prince, et nous nous rendîmes à Aksera ${ }^{229}$, une des villes les plus belles et les plus solidement bâties du pays de Roûm. Des sources d'eau courante et des jardins l'entourent de tous côtés ; trois rivières la traversent, et l'eau coule près de ses maisons. Elle a des arbres et des ceps de vignes, et elle renferme dans son enceinte un grand nombre de vergers. On y fabrique des tapis de laine de brebis, appelés de son nom, et qui n'ont leurs pareils dans aucune autre ville ${ }^{230}$. On les exporte en Égypte, en Syrie, dans l'Irâk, dans l'Inde, à la Chine et dans le pays des Turcs. Cette ville obéit au roi de l'Irâk. Nous y logeâmes dans la zâouïah du chérîf Hoceïn, lieutenant de l'émir Artena ${ }^{231}$. Celui-ci est le représentant du roi de l'Irâk, dans la portion du pays de Roûm dont il s'est emparé. Le chérîf Hoceïn fait partie de la corporation des fitiâns, et commande à une nombreuse confrérie. Il nous traita avec une extrême considération, et se conduisit comme ceux qui l'avaient précédé.

Nous partîmes ensuite pour la ville de Nacdeh ${ }^{232}$, qui appartient au roi de l'Irâk. C'est une place considérable et très peuplée, mais dont une partie est en ruines. La rivière appelée fleuve Noir la traverse. Celui-ci est au nombre des plus grands fleuves et porte trois ponts, p157 dont un dans l'intérieur de la ville et deux à l'extérieur. On y a placé, tant au-dedans qu'au-dehors de la ville, des roues hydrauliques qui arrosent les jardins. Les fruits sont fort abondants à Nacdeh. Nous y logeâmes dans la zâouïah du jeune-homme Akhy Djâroûk, qui remplit à Nacdeh les fonctions de commandant. Il nous traita généreusement, selon la coutume de ces jeunes-gens.

Nous passâmes trois jours à Nacdeh ; puis nous partîmes pour la ville de Kaïçârïah ${ }^{233}$, qui appartient aussi au prince de l'Irak. C'est

229 68. Aksaray se trouve sur le chemin de Konya à Kayseri et non sur celui de Konya à Nigde par Larende apparemment suivi par Ibn Battûta. Mais il peut très bien s’agir d'un itinéraire de retour. La ville construite par le Seldjukide Izzeddin Kilidj Arslan II en 1171 était, d'après Mustawui, un endroit fertile produisant d'excellentes céréales et d'abondants raisins.

«Dans la province de Turcomanie [...] sont faits les plus beaux tapis du monde et des plus magnifiques couleurs » (Marco POLO).

231 Voir t. I, chap. 5, n. 250.

232 Nigde sur la petite rivière de Kara Su (rivière Noire), qui n'a rien d'un grand fleuve.

233 Kayseri, à cent vingt kilomètres au nord-est de Nigde. 
une des grandes villes du pays de Roûm ; une armée des habitants de l'Irak y réside, ainsi qu'une des khâtoûns de l'émir 'Ala eddîn Artena, nommé plus haut, laquelle est au nombre des princesses les plus nobles et les plus vertueuses. Elle est parente du roi de l'Irâk, et on l'appelle Agha ${ }^{234}$ ce qui signifie Grand. Toutes les personnes qui ont quelque parenté avec le sultan sont appelées de ce titre. Le nom de cette princesse est Taghy Khâtoûn, et nous la visitâmes. Elle se leva devant nous, nous donna un salut grâcieux, nous parla avec bonté, et ordonna de nous servir des aliments. Nous mangeâmes, et lorsque nous nous en fûmes retournés elle nous envoya, par un de ses esclaves, un cheval sellé et bridé, une robe d'honneur et des dirhems, et elle nous fit présenter ses excuses.

Nous logeâmes à Caïçârïah dans la zâouïah du jeune-homme-frère, l'émir Aly. C'est un émir considérable et un des principaux frères de ce pays. Il est le supérieur d'une corporation composée de plusieurs des chefs et des grands de la ville ${ }^{235}$. Son ermitage est au nombre des plus beaux par ses tapis, ses lampes, l'abondance de ses mets, et la solidité de sa construction. Les notables de la p158 ville d'entre ses compagnons, ainsi que les autres, se rassemblent chaque nuit auprès de lui, et font, pour traiter généreusement les nouveaux venus, beaucoup plus que n'en font les autres. Une des coutumes de ce pays consiste en ce que, dans toute localité où il n'y a pas de sultan, c'est l'akhy qui remplit les fonctions de gouverneur ${ }^{236}$. Il donne des chevaux et des vêtements aux voyageurs, et leur fait du bien selon la mesure de leur mérite. L'ordre que suit ce gouverneur, dans l'exercice de son autorité et ses promenades à cheval, est le même que celui des rois.

Nous nous rendîmes ensuite à la ville de Sîwâ ${ }^{237}$. C'est une des possessions du roi de l'Irâk, et la plus grande ville qui lui appartienne

${ }^{234}$ Le terme agha, dérivé du mongol (frère aîné), est devenu un terme honorifique.

235 C'est encore la futuwwa sous sa forme aristocratique (voir ci-dessus n. 59).

${ }^{236}$ A la fin de la domination seldjukide en Anatolie, Konya avait des gouverneurs akhis, et en 1314 le Karamanoghlu Yakhchi conquit Konya sur Akhi Mustafa ; 237 de même à Ankara existait un gouvernement akhi.

Une des villes les plus importantes d'Anatolie à l'époque l'ancienne Sebaste, siège des gouverneurs mongols depuis 1304 . 
dans ce pays. Ses émirs et ses percepteurs y font résidence. Elle est bien construite; ses rues sont larges et ses marchés regorgent de monde. On y voit une maison qui ressemble à un collège et qui est appelée la maison du seïdat ${ }^{238}$. Il n’y loge que des chérîfs et leur chef y habite ; on leur y assigne, pour tout le temps de leur séjour, des lits, de la nourriture, des bougies et autres objets, et lorsqu'ils partent on leur fournit des provisions de route.

Quand nous fûmes arrivés près de cette ville, les compagnons du jeune-homme Akhy Ahmed Bitchakty sortirent à notre rencontre. Bitchak signifie en turc couteau, et le nom de Bitchaktchy est dérivé de ce mot. Ils formaient une troupe nombreuse ; les uns étaient à cheval, les autres à pied. Nous rencontrâmes ensuite les compagnons du jeune-homme Akhy Tcheleby. Celui-ci est un des principaux frères, et son rang surpasse celui ${ }_{\mathrm{p} 159}$ d'Akhy Bitchaktchy. Ses compagnons nous invitèrent à loger chez eux ; mais cela ne me fut pas possible, car ils avaient été prévenus par les autres. Nous entrâmes dans la ville avec eux tous; ils se vantaient à l'envi les uns des autres; ceux qui étaient arrivés les premiers près de nous témoignèrent la plus vive allégresse de ce que nous descendions chez eux. Ils agirent en toutes choses, repas, bain, séjour pendant la nuit, comme ceux qui les avaient précédés.

Nous passâmes trois jours chez eux, au milieu de la plus parfaite hospitalité. Le kâdhi vint ensuite nous trouver, accompagné d'une troupe d'étudiants, amenant avec eux des chevaux de l'émir 'Alâ eddîn Arténa, lieutenant du roi de l'Irâk dans le pays de Roûm. Ainsi nous montâmes à cheval pour l'aller trouver. Il vint au-devant de nous jusqu'au vestibule de son palais, nous donna le salut et nous souhaita la bienvenue ; il s'exprimait en arabe avec éloquence. Il me questionna touchant les deux Irâks, Isfahân, Chîrâz, le Kermân ${ }^{239}$, le sultan Atâbec, la Syrie, l'Égypte et les sultans des Turcomans. Il voulait que je louasse ceux d'entre les derniers qui s’étaient montrés généreux, et que je blâmasse les avares. Je n'agis pas ainsi, mais je fis l'éloge de

${ }^{238}$ La maison des sayyids, descendants de Muhammad. Celle de Sivas avait été fondée par l'Ilkhan Ohazan et restaurée par le vizir Rashid al-din (voir t. I, chap. 5, n. 231).

239

Probablement Hormuz, qui est considérée comme incluse dans la province de Kirman. 
tous indistinctement. Il fut content de moi, à cause de cette conduite, et m'en fit compliment; puis il ordonna d'apporter des mets et nous mangeâmes. Il nous dit : "Vous serez mes hôtes. » Akhy Tcheleby lui répondit : "Ils n'ont pas encore logé dans mon ermitage ; qu’ils demeurent donc chez moi ; les mets de ton hospitalité leur y seront remis. » L’émir répliqua : " Qu'il en soit ainsi ! » En conséquence, nous nous transportâmes dans l'ermitage d'Akhy Tcheleby, et nous y passâmes six jours, traités par lui et par l'émir, après quoi celui-ci envoya un cheval, un vêtement et des pièces d'argent. Il écrivit à ses lieutenants, dans les pays voisins, de nous donner l'hospitalité, de nous p160 traiter avec honneur et de nous fournir des provisions de route.

Nous partîmes pour la ville d'Amâciyah ${ }^{240}$, place grande et belle, possédant des rivières, des vergers, des arbres, et produisant beaucoup de fruits. Sur ses rivières on a placé des roues hydrauliques pour arroser les jardins et fournir de l'eau aux maisons. Elle a des rues spacieuses et des marchés fort larges ; son souverain est le roi de l'Irâk. Dans son voisinage se trouve la ville de Soûnoça ${ }^{241}$, qui appartient aussi au roi de l'Irâk, et où habitent les descendants de l'ami de Dieu Aboul'l'abbâs Ahmed arrifâ'y ; parmi eux, le cheïkh Izz eddîn, qui est à présent chef d'Arriwâk et propriétaire du tapis à prier d'Arrifâ'y, et les frères d'Izz eddîn, le cheïkh Aly, le cheïkh Ibrahîm et le cheïkh Yahia, tous fils du cheïkh Ahmed Cutchuc. Ce dernier est le fils de Tâdj eddîn Arrifâ'y ${ }^{242}$, Nous logeâmes dans leur zâouïah, et nous les trouvâmes supérieurs à tous les autres hommes.

240 Amasya sur le Yesilirmak, ayant appartenu au début du XIV siècle à Gazi Tchelebi, souverain de Sinop (voir plus loin n. 162), elle sera incorporée à partir de 1341 au royaume d'Artena.

${ }^{241}$ L'actuel village de Sonusa, à soixante-dix kilomètres par la route, à l'est d'Amasya, en aval du Yesilirmak.

Pour les descendants d'al-Rifai et Ahmad Kutchuk (le Petit), voir t. I, chap. 5, n, 28. La région était gouvernée pendant le $\mathrm{XIV}^{\mathrm{e}}$ siècle par une famille appelée " fils de Tadjuddin », dont le souverain à l'époque était Tadjuddin Dogan Shah (1308-1348), mais il est difficile d'établir une relation quelconque avec les Rifais cités par Ibn Battûta, dont la liaison avec cette région n'est pas connue par ailleurs. 
Puis nous nous rendîmes à la ville de Cumich ${ }^{243}$, qui ${ }_{\text {p161 }}$ appartient au roi de l'Irâk. C'est une ville grande et peuplée, où il vient des marchands de l'Irâk et de la Syrie, et où il se trouve des mines d'argent. A deux jours de distance, on rencontre des montagnes élevées et âpres ${ }^{244}$, où je n'allai pas. Nous logeâmes à Cumich, dans l'ermitage du frère Medjd eddîn, et nous y passâmes trois jours, défrayés par lui. Il se conduisit comme ceux qui l'avaient précédé. Le lieutenant de l'émir Artena vint nous trouver, et nous envoya les mets de l'hospitalité et des provisions de route.

Nous partîmes de cette place et nous arrivâmes à Arzendjân ${ }^{245}$, qui est du nombre des villes du prince de l'Irâk. C'est une cité grande et peuplée ; la plupart de ses habitants sont des Arméniens, et les musulmans y parlent la langue turque. Arzendjân possède des marchés bien disposés ; on y fabrique de belles étoffes, qui sont appelées de son nom ${ }^{246}$. Il y a des mines de cuivre, avec lequel on fabrique des vases, ainsi que les baïçoûs que nous avons décrits. Ils ressemblent aux candélabres en usage chez nous. Nous logeâmes à Arzendjân, dans la zâouïah du fata Akhy Nizhâm eddîn, laquelle est une des plus. belles qui existent. Ce personnage est aussi un des meilleurs et des principaux jeunes-gens ; et il nous traita parfaitement. p162

243 A partir de ce point, la réalité de l’itinéraire d’Ibn Battûta devient problématique. Gümüshane, l’Argyroupolis des Byzantins, les deux mots signifiant Ville d'Argent, devait appartenir à l'époque au royaume byzantin de Trébizonde. En plus, la ville, située à plus de trois cents kilomètres à l'est de Sonusa, devait être très difficilement accessible par cette voie à l'époque où on peut placer le voyage d'Ibn Battûta, c'est-à-dire au mois de mars.

244 83. Peut-être les montagnes de Kop sur la route allant de Gümüshane à Erzeroum, livrant passage à près de deux mille quatre cents mètres, ce qui expliquerait le détour d’Ibn Battûta par Erzincan, si on maintient la réalité de l’itinéraire.

245 « Les gens sont pour la plus grande part arméniens et sujets des Tartares. Il y a maints villages et bonnes cités. Mais la plus noble destout le royaume est Arçingan, qui a un archevêque gouvernant les chrétiens » (Marco PoLO, parlant de l’Arménie).

« (... Arçingan, où l'on fait les meilleurs boquerants qui soient au monde » (Marco POLO). Le nom boquerant ou bougran vient probablement de celui de Bukhara. 
D’Arzendjân, nous allâmes à Arz-erroûm ${ }^{247}$, une des villes qui appartiennent au roi de l'Irâk. Elle est fort vaste, mais en grande partie ruinée, à cause d'une guerre civile qui survint entre deux tribus de Turcomans qui l'habitaient. Trois rivières la traversent, et la plupart de ses maisons ont des jardins où croissent des arbres et des ceps de vignes. Nous y logeâmes dans l'ermitage du fata Akhy Thoûmân. Cet homme est fort âgé : on dit qu'il a plus de cent trente années. Je l'ai vu, qui allait et venait à pied, appuyé sur un bâton. Sa mémoire était encore ferme ; il était assidu à faire la prière aux heures déterminées, et il ne se reprochait rien, si ce n'est de ne pouvoir jeûner. Il nous servit lui-même pendant le repas, et ses fils nous servirent dans le bain. Nous voulûmes le quitter le second jour, mais cela lui déplut ; il refusa d'y consentir et dit: "Si vous agissez ainsi, vous diminuerez ma considération ; car le terme le plus court de l'hospitalité est de trois jours. » Nous passâmes donc trois jours près de lui.

Puis nous partîmes pour la ville de Birgui ${ }^{248}$. Nous arrivâmes après quatre heures du soir, et nous rencontrâmes un de ses habitants, à qui nous demandâmes où se trouvait la zâouïah du frère dans cette ville. Il répondit : " Je vous y conduirai. » Nous le suivîmes ; mais il nous mena à sa propre demeure, située au milieu d'un jardin qui lui appartenait, et il nous logea tout en haut de la terrasse de sa maison. Des arbres ombrageaient cet endroit, et c'était alors le temps des grandes chaleurs. Cet homme nous apporta toutes sortes de fruits,

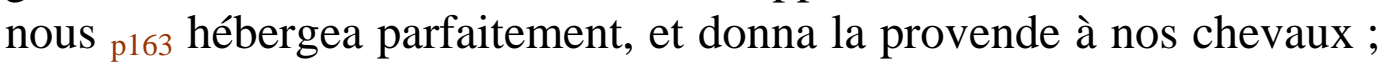
nous passâmes la nuit chez lui.

Nous avions appris qu'il se trouvait dans cette ville un maître distingué, nommé Mohiy eddîn, et notre hôte, qui était un étudiant, nous conduisit dans le collège. Ce professeur venait d'y arriver, monté sur une mule fringante; ses esclaves et ses serviteurs l'entouraient à droite et à gauche, et les étudiants marchaient devant lui. Il portait des

247 Auparavant appelée Qaliqala par les Arabes et Karin par les Arméniens, elle fut nommée Arzan al-Rum (Arzan des Byzantins) après que des Arméniens émigrés d'Arzan, détruite par les Seldjukides en 1049, y émigrèrent. A part cela, la ville, située à près de deux mille mètres d'altitude, ne possède pas de vignes ni de rivières qui la traversent.

Ici on trouve l'itinéraire interrompu à Milas. Birgi, située à proximité du byzantin Pyrgion, fut conquise en 1307-1308 par Mehmed, fils d’Aydin, fondateur de la principauté des Aydinoghlu. 
vêtements amples et superbes, brodés d'or. Nous le saluâmes ; il nous souhaita la bienvenue, nous fit un gracieux salut et nous parla avec bonté ; puis il me prit par la main et me fit asseoir à son côté. Bientôt après arriva le kâdhi Izz eddîn Firichta ; ce mot persan signifie ange, et le juge a été surnommé ainsi à cause de sa piété, de sa chasteté et de sa vertu. Il s'assit à la droite du professeur. Celui-ci commença à faire une leçon sur les sciences fondamentales et celles dérivées ou accessoires. Lorsqu'il eut achevé, il se rendit dans une cellule située dans l'école, il ordonna de la garnir de tapis et m’y logea. Puis il m’envoya un festin copieux.

Ce personnage me manda après la prière du coucher du soleil. Je me rendis près de lui, et le trouvai dans une salle de réception située dans un jardin qui lui appartenait. Il y avait en cet endroit un réservoir, dans lequel l'eau descendait d'un bassin de marbre blanc, entouré de faïence de diverses couleurs. Le professeur avait devant lui une troupe d'étudiants ; ses esclaves et ses serviteurs étaient debout à ses côtés. Il était assis sur une estrade recouverte de beaux tapis peints, et lorsque je le vis, je le pris pour un roi. Il se leva devant moi, vint à ma rencontre, me prit par la main et me fit asseoir à son côté, sur son estrade. On apporta des mets ; nous en mangeâmes et nous retournâmes dans la medréceh. Un des disciples me dit que c'était la coutume de tous les étudiants qui s'étaient trouvés cette fois près du maître d'assister chaque nuit à son repas. Ce professeur écrivit au sultan pour l'informer de notre arrivée, et dans sa lettre il fit notre éloge. Le prince se trouvait alors sur une montagne voisine, où il passait l'été, à cause de p164 l'extrême chaleur. Cette montagne était froide, et il avait coutume d'y passer le temps des chaleurs ${ }^{249}$.

249 Bozdag, au nord de Birgi, culminant à deux mille cent trente mètres. 


\section{DU SULTAN DE BIRGUI}

C'est Mohammed, fils d'Aïdîn ${ }^{250}$, un des meilleurs souverains, des plus généreux et des plus distingués. Lorsque le professeur lui eut expédié un message pour l'informer de ce qui me concernait, il m'envoya son lieutenant, afin de m'inviter à l'aller trouver. Le professeur me conseilla d'attendre jusqu'à ce qu'il me mandât une seconde fois. Une plaie qui venait de se déclarer sur son pied l'empêchait de monter à cheval, et lui avait fait même discontinuer ses leçons. Cependant, le sultan m'ayant envoyé chercher une seconde fois, cela lui fit de la peine et il me dit : « Je ne puis monter à cheval, et c’était mon intention de t'accompagner, afin de convenir avec le sultan du traitement auquel tu as droit. » Mais il brava la douleur, enveloppa autour de son pied des lambeaux d'étoffe, et monta à cheval sans placer le pied dans l'étrier. Moi et mes compagnons nous montâmes aussi à cheval, et nous gravîmes la hauteur sur un chemin qui avait été taillé dans le roc et bien aplani.

Nous arrivâmes vers une heure au campement du sultan, et nous descendîmes sur les bords d'une rivière, à l'ombre des noyers. Nous trouvâmes le prince dans une grande agitation et ayant l'esprit préoccupé, à cause de la fuite de son fils cadet, Soleïmân, qui s'était retiré près ${ }_{\mathrm{p} 165}$ de son beau-père, le sultan Orkhân bec ${ }^{251}$. Lorsqu'il reçut la nouvelle de notre arrivée, il nous envoya ses deux fils, Khidhr bec et 'Omar bec ${ }^{252}$. Ces deux princes donnèrent le salut au docteur. Celuici leur ayant ordonné de me saluer, ils obéirent et m'interrogèrent touchant mon état et le temps de mon arrivée, puis ils s'en retournèrent.

250

La vallée du Méandre (Menderes), conquise dans les premières années du siècle par les Menteché et reprise quelques années plus tard par les Catalans au service d’Andronic II Paléologue, empereur byzantin, fut finalement soumise par Mehmed fils d'Aydin et ses frères, au début vassaux des Germiyan et indépendants à partir de 1317. Mehmed Beg mourut quelques mois après le passage d'Ibn Battûta, au début de l’année 1334.

Pour Orhan Beg, voir n. 54 ci-dessus. Suleyman, quatrième fils de Mehmed, avait reçu comme fief Tire (voir plus loin). Après la mort de son père, il rentrera en possession de son fief jusqu'à sa mort en 1349.

Umur, héros d'une des plus anciennes épopées turques d'Anatolie, reçut de la part de son père Izmir comme fief et succéda à celui-ci (1334-1348). Khizir, fils aîné de Mehmed Beg, reçut Éphèse et succéda à Umur (1348-1360). 
Le sultan m'envoya une tente, appelée chez les Turcs khargâh ${ }^{253}$. Elle se compose de morceaux de bois, réunis en forme de coupole, et sur lesquels on étend des pièces de feutre. On ouvre la partie supérieure pour laisser entrer la lumière et l'air, à l'instar du bâdhendj ou ventilateur, et l'on bouche cette ouverture lorsqu'il est nécessaire. On apporta un tapis qu'on étendit par terre ; le docteur s'assit et j'en fis autant; ses compagnons et les miens étaient en dehors de la tente, à l'ombre des noyers. Ce lieu (comme nous l'avons dit) est très froid il me mourut un cheval cette nuit, à cause de la violence du froid.

Le lendemain, le professeur monta à cheval pour aller trouver le sultan, et s'exprima à mon égard selon ce que lui dicta sa bonté ; puis il revint me trouver et m'informa de cela. Au bout d'un certain temps, le prince nous envoya chercher tous les deux. Nous nous rendîmes à sa demeure ; nous le trouvâmes debout et le ${ }_{p 166}$ saluâmes. Le docteur s'assit à sa droite ; pour moi, je pris place immédiatement après celuici. Il m’interrogea sur mon état et mon arrivée, et m’adressa des questions relativement au Hidjâz, à l'Égypte, à la Syrie, au Yaman, aux deux Irâks et à la Perse, après quoi on servit des aliments ; nous mangeâmes et nous nous en retournâmes. Le sultan nous envoya du riz, de la farine et du beurre, dans des ventricules de brebis : telle est la coutume des Turcs.

Nous restâmes plusieurs jours dans cet état; le sultan nous envoyait chercher chaque jour, pour assister à son repas. Il vint une fois nous visiter après l'heure de midi. Le docteur occupa la place d'honneur du salon; je me plaçai à sa gauche et le sultan s'assit à sa droite. Il en agit ainsi à cause de la considération dont les hommes de loi jouissent chez les Turcs. Il me pria de lui écrire des paroles mémorables, ou traditions du Prophète ${ }^{254}$. J'en traçai plusieurs pour lui, et le docteur les lui présenta sur l'heure. Le sultan prescrivit à ce savant de lui en écrire un commentaire en langue turque ; puis il se leva et

253 « Les maisons sur lesquelles ils dorment, ils les construisent sur des roues avec des baguettes entrelacées qui convergent toutes en haut de manière à former une espèce de cheminée qu'ils recouvrent d'un feutre blanc. Ils enduisent très souvent ce feutre de chaux et de poudre d'os afin que le tout resplendisse davantage. Cependant, ils emploient aussi quelquefois le noir. Ils suspendent devant la porte une peau chatoyante. Ce feutre est couvert de peintu254 res » (Guillaume DE RUBROUCK).

La capacité de réciter des hadiths par cœur faisait la renommée des lettrés. 
sortit. En se retirant, il vit nos serviteurs qui nous faisaient cuire des aliments, à l'ombre des noyers, sans aromates ni herbes potagères. Il ordonna pour cela de châtier son trésorier, et nous envoya des épices et du beurre.

Cependant, notre séjour sur cette montagne se prolongea ; l'ennui me prit, et je désirai m’en retourner. Le docteur aussi était las de demeurer en cet endroit, et il expédia un message au sultan, pour l'informer que je voulais me remettre en route. Le lendemain, le souverain envoya son lieutenant, et celui-ci parla au professeur en turc, langue que je ne connaissais pas alors. Ce dernier lui répondit dans le même langage ; l'officier s'en retourna. Le professeur me dit : "Saistu ce que veut cet homme ? » Je répliquai : « Je l'ignore. " « Le sultan, reprit-il, m’a envoyé demander ce qu'il te ${ }_{\mathrm{p} 167}$ donnerait ; j'ai dit à son messager : "Le prince possède de l'or, de l'argent, des chevaux et des esclaves. Qu'il lui donne là-dessus ce qu'il préférera.” L'officier alla donc retrouver le sultan, puis il revint près de nous et nous dit: "Le souverain ordonne que vous séjourniez tous deux ici aujourd'hui, et que vous descendiez avec lui demain, dans son palais en ville”. »

Le jour suivant, il envoya un excellent cheval de ses écuries, et descendit avec nous dans la ville. Les habitants sortirent à sa rencontre, et parmi eux le kâdhi dont il a été question tout à l'heure. Le sultan fit ainsi son entrée, accompagné par nous. Lorsqu'il eut mis pied à terre à la porte de son palais, je m'en allais avec le professeur, me dirigeant vers la medréceh ; mais il nous rappela, et nous ordonna d'entrer avec lui dans son palais. Lorsque nous fûmes arrivés dans le vestibule, nous y trouvâmes environ vingt serviteurs du sultan, tous doués d'une très belle figure et couverts de vêtements de soie. Leurs cheveux étaient divisés et pendants ; leur teint était d'une blancheur éclatante et mêlé de rouge. Je dis au docteur : " Quelles sont ces belles figures ? - Ce sont, me répondit-il, des pages grecs. »

Nous montâmes avec le sultan un grand nombre de degrés, jusqu’à ce que nous fussions arrivés dans un beau salon, au milieu duquel se trouvait un bassin plein d'eau ; il y avait, en outre, à chacun des angles une figure de lion en bronze, qui lançait de l'eau par la gueule. Des estrades, contiguës les unes aux autres et couvertes de tapis, faisaient le tour de ce salon ; sur une de celles-ci se trouvait le coussin du sultan. Lorsque nous fûmes arrivés près de cette dernière, le souverain 
enleva de sa propre main son coussin et s'assit avec nous sur le tapis. Le docteur prit place à sa droite, le kâdhi, à la suite du fâkîh, quant à moi, je venais immédiatement après le juge. Les lecteurs du Coran s'assirent au bas de l'estrade; car ils ne quittent jamais le sultan, quelque part qu'il donne audience. On apporta des plats d'or et d'argent, remplis de sirop délayé où l'on avait exprimé du jus de citron et mis de petits biscuits, cassés p168 en morceaux; il y avait dans ces plats des cuillers d'or et d'argent. On apporta en même temps des écuelles de porcelaine, remplies du même breuvage, et où il y avait des cuillers de bois. Les gens scrupuleux se servirent de ces écuelles de porcelaine et de ces cuillers de bois ${ }^{255}$. Je pris la parole pour rendre des actions de grâces au sultan et faire l'éloge du docteur ; j’y mis le plus grand soin, cela plut au sultan et le réjouit.

\section{ANECDOTE}

Tandis que nous étions assis avec le sultan, il arriva un vieillard dont la tête était couverte d'un turban garni d'un appendice qui tombait par-derrière. Il salua le prince, et le juge et le docteur se levèrent en son honneur. Il s'assit vis-à-vis du sultan, sur l'estrade, et les lecteurs du Coran étaient au-dessous de lui. Je dis au docteur : " Quel est ce cheïkh ? » Il sourit et garda le silence ; mais je renouvelai ma question, et il me répondit : " C’est un médecin juif ; nous avons tous besoin de lui, et à cause de cela nous nous sommes levés lorsqu'il est entré, ainsi que tu as vu. » Je fus saisi de colère et je dis au juif : " Ô maudit, fils de maudit, comment oses-tu t'asseoir au-dessus des lecteurs du Coran, toi qui n'es qu'un juif ? » Je lui fis des reproches et j'élevai la voix. Le sultan fut étonné et demanda le sens de mes paroles. Le professeur l'en informa, et le juif se fâcha et sortit du salon, dans le plus piteux état. Lorsque nous nous en fûmes retournés, le fakîh me dit : "Tu as bien fait; que Dieu te bénisse! Nul autre que toi n’aurait osé parler ainsi à ce juif. Tu lui as appris à se connaître. ” p169

255 Interdiction de l'utilisation d'ustensiles en or en Islam. 


\section{AUTRE ANECDOTE}

Pendant cette audience, le sultan m'interrogea et me dit : " As-tu vu une pierre tombée du ciel ! » Je répondis : « Je n’en ai jamais vu et n’en ai pas entendu parler. - Une pierre, reprit-il, est tombée du ciel près de la ville où nous sommes. " Puis il appela plusieurs individus et leur ordonna d'apporter l'aérolithe. Ils apportèrent une pierre noire, compacte, très brillante et excessivement dure. Je conjecturai que son poids s'élevait à un quintal. Le sultan ordonna de faire venir des tailleurs de pierres, et il en vint quatre, auxquels il commanda de frapper l'aérolithe. Ils le frappèrent quatre fois, tous ensemble, comme un seul homme, avec des marteaux de fer ; mais, à mon grand étonnement, ils ne laissèrent aucune trace sur la pierre. Le sultan ordonna de la reporter où elle se trouvait auparavant.

Le troisième jour après notre entrée dans la ville avec le sultan, ce prince donna un grand festin, auquel il invita les légistes, les cheïkhs, les chefs de l'armée et les principaux habitants de la ville. Lorsqu'on eut mangé, les lecteurs du Coran lurent avec leurs belles voix; puis nous retournâmes à notre demeure, dans la medréceh. Le sultan nous envoyait chaque nuit des mets, des fruits, des sucreries et des bougies ; puis il me donna cent mithkâls ${ }^{256}$ ou pièces d'or, mille dirhems, un vêtement complet, un cheval et un esclave grec, appelé Mîkhâîyl. Il fit remettre à chacun de mes compagnons un vêtement et des pièces d'argent. Nous dûmes tous ces bienfaits à la compagnie du professeur Mohiy eddîn. (Que Dieu l'en récompense !) Il nous fit ses adieux et nous partîmes. La durée de notre séjour près de celui-ci, tant sur la montagne que dans la ville, avait été de quatorze jours. p170

Nous nous dirigeâmes ensuite vers la ville de Tîreh ${ }^{257}$, qui fait partie des États de ce sultan, et qui est une belle cité, possédant des rivières, des jardins et des arbres fruitiers. Nous y logeâmes dans la zâouïah du fata Akhy Mohammed. Cet homme est au nombre des plus saints personnages ; il pratique une grande abstinence, et a des com-

2561 mithqal $=4,25 \mathrm{~g}$.

257 Tire, à cinquante kilomètres sud-ouest de Birgi. Après avoir visité la capitale de la principauté, Ibn Battûta revient maintenant vers le sud-ouest pour visiter les fiefs des fils de Mehmed Beg. 
pagnons qui suivent sa manière de vivre. Il nous donna l'hospitalité et fit des vœux en notre faveur.

Nous partîmes pour la ville d'Ayâ Soloûk ${ }^{258}$ cité grande, ancienne et vénérée par les Grecs. Il y a ici une vaste église construite en pierres énormes ; la longueur de chacune est de dix coudées et au-dessus, et elles sont taillées de la manière la plus admirable. La mosquée djâmi' de cette vile est une des plus merveilleuses mosquées du monde, et n'a pas sa pareille en beauté. C'était jadis une église appartenant aux Grecs ; elle était fort vénérée chez eux, et ils s’y rendaient de divers pays. Lorsque cette ville eut été conquise, les musulmans firent de cette église une mosquée cathédrale ${ }^{259}$. Ses murs sont en marbre de différentes couleurs, et son pavé est de marbre blanc. Elle est couverte en plomb et a onze coupoles de diverses formes, au milieu de chacune desquelles se trouve un bassin d'eau. Un fleuve la traverse ${ }^{260}$, sur les deux rives duquel sont plantés des arbres de diverses espèces, des ceps de vignes et des berceaux de jasmin. Elle a quinze portes. p171

L'émir de cette ville est Khidrh bec, fils du sultan Mohammed, fils d'Aïdîn. Je l'avais vu chez son père à Birgui ; je le rencontrai ensuite en dehors de cette ville, et je le saluai sans descendre de cheval. Cela lui déplut, et ce fut le motif du désappointement que j'éprouvai de sa part. La coutume de ces princes est de mettre pied à terre devant un voyageur, lorsqu'il leur en donne l'exemple, et cela leur fait plaisir. Khidrh bec ne m'envoya qu'une pièce d'étoffe de soie dorée, que l'on appelle annakh ${ }^{261}$. J'achetai dans cette ville une jeune vierge chrétienne, moyennant quarante dînârs d'or ${ }^{262}$.

258 Altération du nom Aghios Théologos (saint Jean l’Évangéliste) donné par les Byzantins à l'antique Éphèse à cause de la basilique de Saint-Jean bâtie par Justinien. La ville s'appelle aujourd'hui Seluk.

Une nouvelle mosquée, existant de nos jours, fut construite à proximité par Isa, cinquième fils et troisième successeur de Mehmed Beg (1360-1390), et la basilique de Saint-Jean fut détruite, probablement par Timur en 1402.

260 L'antique Caïstre, l'actuel petit Menderes.

${ }^{261}$ Al-makh, terme persan désignant les brocards de soie.

${ }^{262}$ Mathieu, nommé métropolite d’Éphèse par le patriarche orthodoxe de Constantinople et installé dans son diocèse à partir de 1339, n'aura comme ouailles que les esclaves des Turcs et des Juifs. 
Nous nous dirigeâmes ensuite vers Yazmîr ${ }^{263}$, grande ville située sur le rivage de la mer, mais dont la portion la plus considérable est en ruine. Elle possède un château contigu à sa partie supérieure. Nous logeâmes en cette ville dans la zâouïah du cheïkh Ya'koûb, un des Ahmédiens, homme pieux et vertueux. Nous rencontrâmes près de Yazmîr le cheïkh Izz eddîn ibn Ahmed arrifâ'y ${ }^{264}$, qui avait avec lui Zâdeh alakhlâthy, un des principaux cheïkhs, et cent fakirs, de ceux qui sont privés de leur raison. L'émir avait fait dresser pour eux des tentes ; et le cheïkh Ya'koûb leur donna un festin, auquel j'assistai ; j'eus ainsi une entrevue avec ces malheureux.

L'émir de cette ville est Omar bec, fils du sultan Mohammed, fils d'Aïdîn, dont il a été question tout à l'heure, et il habite une citadelle. Lors de notre arrivée, $p 172$ il se trouvait près de son père ; mais il revint cinq jours après. Une de ses actions généreuses, ce fut de venir me visiter à la zâouïah ; il me donna le salut et me fit des excuses. Puis il m'envoya un repas copieux, il me donna un petit esclave chrétien haut de cinq empans nommé Nikoûlah et deux vêtements de kemkha ${ }^{265}$. C'est une étoffe de soie fabriquée à Baghdad, à Tibrîz, à Neïçaboûr et dans la Chine. Le docteur qui remplissait près de cet émir les fonctions d'imâm m'apprit qu'il ne lui était pas resté, à cause de sa générosité, d'autre esclave que celui qu'il me donna. Que Dieu ait pitié de lui ! Il fit aussi présent au cheïkh Izz eddîn de trois chevaux tout harnachés, de grands vases d'argent remplis de dirhems (cette sorte d'ustensile est nommée chez les Turcs almichrebeh ${ }^{266}$ ), de vêtements de drap, de mer'izz, de kodsy ${ }^{267}$ et de kemkha ; enfin, de jeunes esclaves des deux sexes.

Ledit émir était généreux et pieux, il combattait souvent contre les infidèles ${ }^{268}$. Il avait des vaisseaux de guerre avec lesquels il faisait

263 Smyrne (Izmir) possédait à l'époque deux châteaux : un sur le mont Pagus, dont les ruines subsistent encore, conquis en 1317 par Mehmet Beg, et un près du port tenu par Martino Zaccaria, Génois, seigneur de l'île de Chio, occupé en 1329 par Umur Beg.

264 Voir p. 161.

265 Brocard tissé avec des fils d'or ou d'argent.

266 Machraba : gobelet.

${ }^{267}$ Étoffe de laine et étoffe de Jérusalem de qualité inconnue.

${ }^{268}$ Umur a fait sa première expédition contre les Dardanelles en 1332. 
des incursions dans les environs de Constantinople la Grande ; il prenait des esclaves, du butin et dissipait tout cela par sa générosité et sa libéralité ; puis il retournait à la guerre sainte, si bien que ses attaques devinrent très pénibles pour les Grecs, qui eurent recours au pape. Celui-ci ordonna aux chrétiens de Gênes et de France de faire la guerre au prince Yazmîr, ce qui eut lieu. De plus, il fit partir de Rome une armée, et ces troupes attaquèrent la ville de Yazmîr pendant la nuit, avec un grand nombre de vaisseaux ; elles s'emparèrent du port et de la ville. L'émir Omar descendit du château à leur rencontre, les combattit, et succomba martyr de la foi, avec un grand ${ }_{\mathrm{p} 173}$ nombre de ses guerriers ${ }^{269}$. Les chrétiens s'établirent solidement dans la ville ; mais ils ne purent s'emparer du château, à cause de sa force.

Nous partîmes de cette ville pour celle de Maghnîciyah ${ }^{270}$, et nous y logeâmes, le soir du jour d'arafah ${ }^{271}$, dans l'ermitage d'un des jeunes-gens. C'est une ville grande et belle, située sur la pente d'une montagne, et dont le territoire possède beaucoup de rivières, de sources, de jardins et d'arbres fruitiers.

\section{DU SULTAN DE MAGHNîCIYAH}

Il se nomme Sâroû khân ${ }^{272}$, et lorsque nous arrivâmes dans cette ville nous le trouvâmes dans la chapelle sépulcrale de son fils, qui était mort depuis plusieurs mois. Il y passa avec la mère du défunt, la nuit de la fête ${ }^{273}$, et la matinée suivante. Le corps du jeune prince

${ }^{269}$ Umur attaquera plus ou moins en accord avec Andronic III Paléologue les possessions latines dans les îles et en Grèce. Par la suite, Jean VI Cantacuzène voudra se servir de lui dans sa lutte contre les Paléologues. Après son entrée à Constantinople en 1347, l'empereur cherchera à se débarrasser d'Umur en s'alliant avec les Latins. Umur sera tué sous les murs d'Izmir en mai 1348. Ibn Battûta a dû apprendre ces événements en Égypte où il se trouvait en ce moment.

L’antique Magnésie, l'actuelle Manisa, à quarante-trois kilomètres au nord-est d'Izmir. Elle fut conquise sur les Byzantins par Saruhan, fondateur de la dynastie turkmène du même nom en 1313.

271 C'est-à-dire le jour de la station à Arafat pendant le pèlerinage qui tombait en cette année 1333 le 21 août.

272 Saruhan et ses frères s’établirent dans la vallée de Gediz à partir des premières années du XIV ${ }^{\mathrm{e}}$ siècle. Saruhan mourut en 1345.

273 La fête du Sacrifice, le 22 août. 
avait été embaumé, et placé dans un cercueil de bois recouvert de fer étamé ; on le voyait ainsi suspendu au milieu d'une chapelle sans toit ${ }^{274}$, afin que l'odeur du cadavre pût s'exhaler au-dehors, après quoi on la recouvrira d'un toit, la bière sera placée en évidence sur le p174 Sol, et les vêtements du mort seront déposés sur celle-ci. J'ai vu agir de cette façon d'autres souverains que celui de Maghnîciyah. Nous saluâmes ce dernier en cet endroit, nous fîmes avec lui la prière de la fête, et nous retournâmes à la zâouïah.

Le jeune esclave qui m'appartenait prit nos chevaux, et partit pour les mener à l'abreuvoir, avec un autre esclave, appartenant à un de mes compagnons ; mais ils tardèrent à revenir, et quand le soir fut arrivé on ne reconnut d'eux aucune trace. Le jurisconsulte et professeur, l'excellent Molih eddîn, habitait dans cette ville; il alla avec moi trouver le sultan, et nous lui apprîmes cet événement. Le souverain envoya à la recherche de ces fugitifs, et on ne les trouva pas alors, car les habitants étaient occupés à célébrer la fête. Ils s'étaient dirigés tous deux vers une ville appartenant aux infidèles, située sur le rivage de la mer, à une journée de marche de Maghnîciyah, et nommée Foûdjah $^{275}$. Ceux-ci occupent une place très forte, et envoient chaque année un présent au sultan de Maghnîciyah, qui s'en contente, à cause de la force de leur ville. Lorsque l'heure de midi [du jour suivant] fut écoulée, quelques Turcs ramenèrent les deux fugitifs, ainsi que les chevaux. Ils racontèrent que, les esclaves ayant passé près d'eux le soir précédent, ils avaient conçu des soupçons à leur égard, et avaient insisté jusqu'à ce qu'ils avouassent le projet qu'ils avaient formé de s’enfuir.

Nous partîmes ensuite de Maghnîciyah, et nous passâmes la nuit près d'une horde de Turcomans, campés dans un pâturage qui leur appartenait. Nous ne ${ }_{\text {p175 }}$ trouvâmes pas chez eux de quoi nourrir nos

274 Probablement réminiscence d’une coutume sibérienne où le corps du défunt était placé sur un arbre jusqu’à ce qu'il se dessèche.

275 Les frères Manuele et Benedetto I Zaccaria reçurent de Michel VIII Paléologue la concession d'alun de Phocée, ville située au bord de la mer au nord d'Izmir. Benedetto y construisit entre 1286 et 1296 un nouveau port appelé Nouvelle Phocée, au nord-est de l'ancienne. En 1329, Andronic III délogea les Zaccaria de l'île de Chio et d'ancienne Phocée, la nouvelle restant aux mains des Génois dans la personne d'Andreolo Cattaneo. Saruhan est l'allié d’Andronic dans sa lutte contre les Génois. 
bêtes de somme pendant cette nuit. Nos compagnons montèrent la garde à tour de rôle, de peur d'être volés. Quand ce fut le tour du docteur 'Afif eddîn Atoûzery, je l'entendis qui lisait le chapitre de la Vache ${ }^{276}$, et je lui dis : « Lorsque tu voudras dormir, préviens-moi, afin que je voie qui devra monter la garde. » Puis je m’endormis ; mais il ne me réveilla que quand le matin fut arrivé, et déjà les voleurs m'avaient pris un cheval, qui était monté d'ordinaire par ledit 'Afif eddîn, avec sa selle et sa bride. C'était un animal excellent, que j'avais acheté à Ayâ Soloûk.

Nous partîmes le lendemain et nous arrivâmes à Berghamah ${ }^{277}$, ville en ruine, qui possède une citadelle grande et très forte, située sur la cime d'une montagne. On dit que le philosophe Platon était un des habitants de cette ville, et la maison qu'il occupait est encore connue sous son nom ${ }^{278}$. Nous logeâmes à Berghamah dans l'ermitage d'un fakir ahmédien ; mais un des grands de la ville survint, nous emmena à sa maison, et nous traita avec beaucoup de considération.

\section{Du SULTAN DE BERGHAMAH}

Il est appelé Yakhchy khân ${ }^{279}$. Khân, chez ces peuples, signifie la même chose que Sultan, et yakhchy veut dire excellent. Nous le trouvâmes dans son habitation d'été ; on lui annonça notre arrivée, et il nous envoya un festin et une pièce de cette étoffe appelée kodsy. p176

Nous louâmes quelqu'un pour nous montrer le chemin, et nous voyageâmes dans des montagnes élevées et âpres, jusqu'à ce que nous fussions arrivés à Balîkesrî́ ${ }^{280}$. C'est une ville belle, bien peuplée et pourvue de beaux marchés, mais il n’y avait pas de mosquée djâmi’

${ }^{276}$ La deuxième sourate du Coran et la plus longue.

${ }^{277}$ L'antique Pergame, conquise vers 1306 par Karasi Beg, fondateur de la dynastie du même nom. A une centaine de kilomètres au nord de Manisa.

278 Il s'agirait plutôt du médecin Gallien.

279 Yakhshi, qui devint souverain de Bergama après la mort de son père Karasi vers 1320, fut connu comme corsaire et fit des expéditions infructueuses vers la Thrace en 1341 et 1342. Il fut expulsé de Bergama probablement vers 13441345 par le sultan ottoman Orhan.

${ }^{280}$ Balikkesir succéda probablement à une place forte byzantine appelée Palaiocastron, à cent vingt kilomètres au nord de Bergama. 
où l'on pût faire la prière du vendredi. Les habitants voulurent en bâtir une à l'extérieur, tout près de la ville. Ils en construisirent les murailles, mais ils n’y mirent pas de toit. Ils y priaient néanmoins, et y célébraient l'office du vendredi, à l'ombre des arbres. Nous logeâmes à Balîkesri, dans l'ermitage du jeune-homme Akhy Sinân, qui est au nombre des hommes les plus distingués de sa corporation. Le juge et prédicateur de cette cité, le légiste Moûça, vint nous visiter.

\section{DU SULTAN DE BALÎKESRI}

Il se nomme Domoûr khân ${ }^{281}$, et il ne possède aucune bonne qualité. C'est son père qui a bâti cette ville, dont la population s'est accrue d'un grand nombre de vauriens, sous le règne du prince actuel ; «car les hommes suivent la religion de leur roi » (tel roi, tel peuple). Je visitai ce prince, et il m'envoya une pièce d'étoffe de soie. J'achetai dans cette ville une jeune esclave chrétienne, nommée Marghalîthah.

De là, nous nous rendîmes à Boursa ${ }^{282}$, ville grande et possédant de beaux marchés et des larges rues. Des jardins et des sources d'eau vive l'entourent de toutes parts. Proche de ses murailles coule un canal, dont l'eau est très chaude et tombe dans un grand étang. On a bâti p177 près de celui-ci deux édifices, dont l'un est consacré aux hommes et l'autre aux femmes. Les malades viennent chercher leur guérison dans cette source d'eau thermale, et s'y rendent des contrées les plus éloignées. Il y a là une zâouïah pour les voyageurs ; ils y logent et y sont nourris tout le temps de leur séjour, c'est-à-dire trois journées. Elle a été construite par un roi turcoman.

Nous logeâmes à Boursa dans la zâouïah du jeune-homme Akhy Chems eddîn ${ }^{283}$, un des principaux jeunes-gens, et nous passâmes près de lui le jour de l'âchourâ ${ }^{284}$. Il prépara un grand festin, et invita les chefs de l'armée et des habitants de la ville, pendant la nuit. Ils

${ }^{281}$ Fils ou neveu de Yakhshi, petit-fils de Karasi, il régna jusqu’à la conquête de l'émirat par les Ottomans en 1345.

282 Bursa, conquise par Orhan quelques jours avant la mort de son père Osman en 1326. Célèbre jusqu'à nos jours pour ses sources d'eau chaude.

283 Identifié comme le père d'Akhi Hasan, conseiller spirituel du sultan Orhan.

${ }^{284}$ Le 10 de muharram, tombant le 21 septembre 1333. 
rompirent le jeûne chez lui, et les lecteurs du Coran firent une lecture avec leurs belles voix. Le légiste et prédicateur Medjd eddîn Alkoûnewy était présent ; il prononça un sermon et une exhortation, et fut très éloquent. Ensuite on se mit à chanter et à danser, et ce fut une nuit très imposante. Ce prédicateur était un homme fort pieux ; il jeûnait habituellement, et ne rompait le jeûne que tous les trois jours; il ne mangeait que ce qu'il avait gagné par le travail de ses mains, et l'on disait qu'il n'acceptait de repas chez qui que ce fût. Il n'avait ni habitation ni d'autre meubles que les vêtements dont il se couvrait; il ne dormait que dans le cimetière, et il prêchait et exhortait dans les réunions. Un certain nombre d'hommes faisaient pénitence entre ses mains, dans chaque assemblée. Je le cherchai, après cette nuit-là, mais je ne le trouvai pas. Je me rendis au cimetière sans le rencontrer ; et l'on me dit qu'il y allait lorsque tout le monde dormait.

\section{ANECDOTE}

Pendant que nous nous trouvions, cette nuit de l'âchourâ, dans l'ermitage de Chems eddîn, le susdit ${ }_{\text {p178 }}$ Medjed eddîn y prononça un sermon à la fin de la nuit. Un des fakirs poussa un grand cri, à la suite duquel il perdit connaissance. On répandit sur lui de l'eau de rose, mais il ne recouvra pas ses sens ; on réitéra cette effusion sans plus de succès. Les assistants n'étaient pas d'accord touchant son état : les uns disaient qu'il était mort, les autres qu’il n'était qu'évanoui. Le prédicateur termina son discours, les lecteurs du Coran firent leur lecture, et nous récitâmes la prière de l'aurore. Enfin le soleil se leva ; alors on s'assura de la position de cet homme, et l'on reconnut qu'il était mort. Que Dieu ait compassion de lui ! On s'occupa de laver son corps et de l'envelopper dans un linceul. Je fus du nombre de ceux qui assistèrent à la prière que l’on récita sur lui et à son enterrement.

Ce fakir était appelé le Criard ; et l'on raconte qu'il se livrait aux exercices de la dévotion dans une caverne située dans une montagne voisine. Lorsqu'il savait que le prédicateur Medjd eddîn devait prêcher, il l'allait trouver, et assistait à son sermon. Il n'acceptait à manger de personne. Quand Medjd eddîn prêchait, il criait fort et perdait connaissance. Ensuite il revenait à lui, faisait ses ablutions et une prière de deux rec'ahs ; mais, lorsqu'il entendait Medjd eddîn, il se 
remettait à crier, il agissait ainsi à plusieurs reprises dans une même nuit. C'est à cause de cela qu'il fut surnommé le Criard. Il était estropié de la main et du pied, et il ne pouvait pas travailler ; mais il avait une mère qui le nourrissait du produit de son fuseau. Lorsqu'elle fut morte, il se sustentait au moyen des plantes de la terre.

Je rencontrai dans cette ville le pieux cheïkh 'Abd Allah almisry, le voyageur ; c'était un homme de bien. Il fit le tour du globe, sauf qu'il n’entra pas dans la Chine, ni dans l'île de Serendîb, ni dans le Maghreb, ni dans l'Espagne, ni dans le Soûdân. Je l'ai surpassé en visitant ces régions. $\mathrm{p} 179$

\section{DU SULTAN DE BOURSA}

C’est Ikhtiyâr eddîn Orkhân bec, fils du sultan 'Othmân tchoûk ${ }^{285}$. En turc, tchoûk signifie petit. Ce sultan est le plus puissant des rois turcomans, le plus riche en trésors, en villes et en soldats. Il possède près de cent châteaux forts, dont il ne cesse presque jamais de faire le tour. Il passe plusieurs jours dans chacun d'eux, afin de les réparer et d'inspecter leur situation. On dit qu'il ne séjourna jamais un mois entier dans une ville. Il combat les infidèles et les assiège. C'est son père qui a conquis sur les Grecs la ville de Boursa, et le tombeau de celuici se voit dans la mosquée de cette ville, qui était auparavant une église des chrétiens ${ }^{286}$. On raconte que ce prince assiégea la ville de Yeznîc pendant environ vingt ans, et qu'il mourut avant de la prendre. Son fils, que nous venons de mentionner, en fit un siège durant douze ans, et s'en rendit maître ${ }^{287}$. Ce fut là que je le vis, et il m'envoya beaucoup de pièces d'argent.

285

Deuxième souverain ottoman (1326-1356), fils et successeur du fondateur de la dynastie Osman I ${ }^{\mathrm{er}}$ (1299-1326). Au passage d'Ibn Battûta, l'émirat ottoman ne semble pas avoir été plus important en étendue et en puissance que les autres, mais, situé face à un État byzantin de plus en plus affaibli et déchiré, il se trouvait promu à un grand avenir.

${ }^{286}$ L'ancien monastère de Saint-Elie sur la citadelle. Le tombeau actuel d’Osman, 287 situé au même emplacement, a été reconstruit à la fin du XIX ${ }^{\mathrm{e}}$ siècle.

Iznik fut prise par Orhan en mars 1331. 
Nous partîmes de Boursa pour la ville de Yeznîc. Avant d'arriver, nous passâmes une nuit dans une bourgade appelée Corleh ${ }^{288}$, dans la zâouïah d'un des jeunes-gens-frères.

En quittant cette bourgade, nous marchâmes un jour entier parmi des rivières dont les bords étaient plantés de grenadiers, qui portaient les uns des fruits doux, les autres des fruits acides. Nous arrivâmes ensuite près ${ }_{p 180}$ d'un lac, à huit milles de Yeznîc, qui produit des roseaux. On ne peut entrer dans cette ville que par un seul chemin, semblable à un pont, et sur lequel il ne peut passer qu'un cavalier à la fois. La ville de Nicée est ainsi défendue, et le lac l'entoure de tous côtés ${ }^{289}$. Mais elle est en ruine et n'est habitée que par un petit nombre d'hommes au service du sultan ${ }^{290}$. L'épouse de ce prince, Beïaloûn khâtoûn ${ }^{291}$, y réside et commande à ces hommes : c'est une femme pieuse et excellente.

La ville est entourée de quatre murs, dont chacun est séparé de l'autre par un fossé rempli d'eau ${ }^{292}$. On y entre par des ponts de bois, que l'on enlève à volonté. A l'intérieur de la ville se trouvent des jardins, des maisons, des terres et des champs ensemencés. Chaque habitant a sa demeure, son champ et son verger, contigus les uns aux autres. L'eau potable est fournie par des puits, situés dans le voisinage. Cette ville produit toutes sortes de fruits ; les noix et les châtaignes y abondent, et sont à bas prix. Les Turcs appellent celles-ci kasthanah, et les noix koûz. On y trouve aussi le raisin nommé 'adhâri ${ }^{293}$, dont je n'ai vu le pareil en aucun endroit ; il est extrêmement doux, très gros, d'une couleur claire et a la peau mince. Chaque grain n'a qu'un seul pépin.

\footnotetext{
288 L'actuel Gürle, à mi-chemin entre Bursa et Iznik.

289 Iznik, l'ancienne Nicée, se trouve à l'extrémité est du lac du même nom, mais elle n'est pas entourée d'eau.

290 A la conquête de ta ville, les anciens habitants l'avaient abandonné et elle fut repeuplée progressivement par la suite.

291 L'épouse d'Orhan, d’origine grecque, s’appelait Nilüfer. Il est possible qu’Ibn Battûta, qui mentionnera ce même nom pour une des épouses d’Uzbek Khan, utilise le nom Bayalun comme titre.

292 La ville avait uniquement deux murailles séparées par un fossé.

293 Ainsi appelés parce qu'ils ressemblent aux bouts des doigts des jeunes filles.
} 
Le jurisconsulte, l'imâm, le dévot pèlerin, 'Alâ eddîn assulthanyoûky nous donna l'hospitalité dans cette ville. C'est une homme vertueux et généreux ; je n’allais jamais lui rendre visite sans qu’il me servît à manger. Sa figure était belle, et sa conduite plus belle encore. Il alla trouver avec moi la khâtoûn susmentionnée ; elle me ${ }_{\text {p181 }}$ traita avec honneur, me donna un festin et me fit du bien. Quelques jours après notre arrivée à Yeznîc, le sultan Orkhân bec, dont nous avons parlé ci-dessus, arriva dans cette ville. Je séjournai à Yeznîc environ quarante jours, à cause de la maladie d'un cheval qui m'appartenait. Lorsque je fus las du retard, j'abandonnai cette bête, et je partis avec trois de mes compagnons, une jeune fille et deux esclaves. Il n'y avait avec nous personne qui parlât bien la langue turque et qui pût nous servir d'interprète. Nous en avions un qui nous quitta à Yeznîc.

Après être sortis de cette ville, nous passâmes la nuit dans une bourgade appelée Mekedja ${ }^{294}$, chez un légiste qui nous traita avec considération et nous donna le festin de l'hospitalité.

Nous le quittâmes et nous nous remîmes en route. Une femme turque nous précédait à cheval, accompagnée d'un serviteur ; elle se dirigeait vers la ville de Yenidja, et nous suivions ses traces. Cette femme étant arrivée près d'une grande rivière appelée Sakary (ce mot signifie infernale) ${ }^{295}$, comme si elle tirait son nom de l'Enfer ; que Dieu nous en préserve ! cette femme, dis-je, entreprit de passer le fleuve. Lorsqu'elle parvint au milieu du courant, sa monture fut sur le point de se noyer avec elle, et la jeta en bas de son dos. Le serviteur qui l'accompagnait voulut la sauver; mais le fleuve les entraina tous les deux. Il y avait sur la rive des gens qui se jetèrent à la nage après eux, et retirèrent la femme ayant encore un souffle de vie. L'homme fut aussi retrouvé, mais il était mort. Que Dieu ait compassion de lui ! p182

Ces gens nous informèrent que le bac se trouvait plus bas, et nous nous dirigeâmes vers celui-ci. Il consiste en quatre poutres, liées avec des cordes, et sur lesquelles on place les selles des montures et les effets ; il est tiré par des personnes postées sur l'autre rive. Les hommes y montent, et on fait passer à la nage les bêtes de somme. C'est ainsi

\footnotetext{
294 Mekece, à mi-chemin entre Iznik et Geyve sur le fleuve Sakarya.

295 Fausse étymologie à partir de saqar (grande chaleur), un des noms de l'enfer ; le nom Sakarya est une déformation du grec Sangarios.
} 
que nous pratiquâmes, et nous arrivâmes la même nuit à Câouiyah ${ }^{296}$. Ce mot est formé à l'instar du nom d'agent féminin, dérivé de cay, cautérisation (ou mieux du verbe caoua, cautériser et signifie " celle qui cautérise »). Nous y logeâmes dans l'ermitage d'un des frères ; nous lui parlâmes en arabe ; il ne nous comprit pas, et nous adressa la parole en turc, mais nous ne le comprîmes pas à notre tour. Il dit alors : " Appelez le fakîh, car il connaît l'arabe. » Celui-ci arriva et nous parla en persan ; nous lui répondîmes en arabe ; il ne comprit pas nos paroles, et dit au jeune-homme dans l'idiome persan : Ichân 'araby kuhna mîkouân wemen 'araby nau mîdânem. Ichân veut dire " ces gens-ci »; kuhna signifie " ancien »; mîkouân (mîgoûiend), "ils disent »; men, « moi »; nau, " nouveau »; mîdânem, " nous connaissons (je connais) ». Le fakîh voulait seulement, par ce discours, se mettre à couvert du déshonneur, parce que ces gens-là croyaient qu'il connaissait la langue arabe, tandis qu'il ne la savait pas. Il leur dit donc: "Ces étrangers parlent l'arabe ancien et je ne connais que l'arabe moderne.» Le jeune-homme pensa que la chose était conforme à ce que disait le fakîh, et cette opinion nous servit près de lui, car il mit tous ses soins à nous traiter honorablement, et se dit: " Il est nécessaire de témoigner de la considération à ces gens-ci, puisqu'ils parlent la vieille langue arabe, qui était celle du Prophète et de ses compagnons. " Nous ne comprîmes pas alors les paroles du fakîh ; mais je les gravai dans ma mémoire, et lorsque j'eus appris la langue persane, j'en saisis le sens. p183

Nous passâmes la nuit dans la zâouïah, dont le propriétaire fit partir avec nous un guide qui nous conduisit à Ienidja ${ }^{297}$, ville grande et belle ; et nous y cherchâmes après la zâouïah du frère. Sur ces entrefaites, nous rencontrâmes un de ces fakirs privés de la raison, et je lui dis : " Cette maison est-elle la zâouïah du frère ? — Oui », me répondit-il. Je fus joyeux de cela, puisque j'avais ainsi trouvé quelqu'un qui comprenait la langue arabe. Mais, lorsque je l'eus mis à l'épreuve, le secret fut divulgué, vu qu'il ne savait de cet idiome que le seul mot na'am', « oui, c'est bien ». Nous logeâmes dans la zâouïah, et un des étudiants nous apporta des aliments. Le frère n'était pas présent, mais

296 Geyve, en aval sur le Sakarya et sur la ligne de chemin de fer Istanbul-Ankara. ${ }^{297}$ Yenice, appelée plutôt aujourd'hui Taraklï, petite bourgade à trente-six kilomètres par la route, au sud-est de Geyve. 
la familiarité s'établit entre nous et ce thâlib. Il ne connaissait pas la langue arabe, mais il nous montra de la bonté et parla au gouverneur de la ville, qui me donna un de ses cavaliers.

Celui-ci se dirigea avec nous vers Keïnoûc ${ }^{298}$, petite ville habitée par des Grecs infidèles, qui vivent sous la protection des musulmans. Il n'y a qu'une seule maison occupée par des mahométans, qui commandent au Grecs. La ville fait partie des États du sultan Orkhân bec. Nous y logeâmes dans la maison d'une vieille infidèle, et c'était alors la saison de l'hiver et de la neige. Nous fîmes du bien à cette femme, et nous passâmes la nuit chez elle. Il n'y a dans cette ville ni ceps de vignes ni arbres, et l'on n'y cultive que du safran. Notre vieille hôtesse nous en apporta beaucoup, car elle nous prenait pour des marchands et pensait que nous lui achèterions son safran.

Lorsque le matin fut arrivé, nous montâmes à cheval ; le cavalier (ou guide) que le jeune-homme avait envoyé avec nous de Kâouïyah prit congé de nous et fit partir à sa place un autre cavalier, qui devait nous conduire à la ville de Mothorni. Or il était tombé ${ }_{\mathrm{p} 184}$ pendant la nuit beaucoup de neige, qui avait effacé les chemins. Ce guide prit les devants et nous suivîmes ses traces, jusqu'à ce que nous fussions arrivés, vers le milieu du jour, à une bourgade de Turcomans, qui nous apportèrent des vivres, dont nous mangeâmes. Notre guide parla aux Turcomans, et l'un d'eux partit à cheval avec nous. Il nous fit traverser des lieux âpres, des montagnes et un cours d'eau, que nous dûmes passer plus de trente fois. Lorsque nous fûmes sortis de ces difficultés, il nous dit: "Donnez-moi un peu d'argent. " Nous lui répondîmes : "Lorsque nous serons arrivés à la ville, nous t'en donnerons et nous te rendrons satisfait. » Il ne fut pas content de cela, ou bien il ne comprit pas le sens de nos paroles. Il prit un arc appartenant à un de mes compagnons, et s'éloigna à courte distance ; puis il revint et nous rendit l'arc. Je lui donnai quelques pièces d'argent, il les prit, s'enfuit et nous laissa, ignorants de quel côté nous devions nous diriger; car nous n'apercevions aucun chemin.

Nous cherchions à reconnaître les traces du chemin sous la neige, et nous les suivîmes jusqu'à ce que nous fussions arrivés, vers le coucher du soleil, à une montagne sur laquelle on distinguait clairement la 
route, à cause de la grande quantité de pierres qui s'y trouvaient. Je craignis la mort tant pour moi que pour mes compagnons, car je m'attendais à ce que la neige tombât pendant la nuit, et il n'y avait aucune habitation en cet endroit. Si nous descendions de nos montures, nous péririons ; si nous marchions pendant la nuit, nous ne saurions de quel côté nous diriger. J'avais un cheval excellent, et je songeai à me tirer du danger; car je disais en moi-même : "Lorsque je serai sain et sauf, peut-être pourrai-je trouver un expédient pour sauver mes compagnons. » Il en fut ainsi. Je les recommandai à Dieu, et je me mis en marche.

Les habitants de ce pays construisent sur les sépulcres des maisons de bois que celui qui les aperçoit prend d'abord pour des habitations, jusqu'à ce qu'il reconnaisse que ce sont des tombeaux. J'en vis un grand ${ }_{\mathrm{p} 185}$ nombre. Lorsque l'heure de la prière de la nuit fut écoulée, j'arrivai à des maisons et je dis : « O mon Dieu ! fais qu'elles soient habitées. » En effet, je les trouvai habitées, et Dieu me fit arriver à la porte d'une demeure où je vis un vieillard. Je lui adressai la parole en arabe ; il me parla en turc et me fit signe d'entrer. Je l'informai de la situation de mes compagnons ; mais il ne me comprit pas. Il se trouva, grâce à la bonté de Dieu, que cette maison était une zâouïah appartenant à des fakîrs, et que l’homme placé à la porte en était le supérieur. Quand les fakîrs qui se trouvaient à l'intérieur de l'ermitage m'entendirent parler au cheïkh, l'un d'eux, qui était connu de moi, sortit et me donna le salut. Je l'instruisis de ce qui était arrivé à mes compagnons, et je lui conseillai de partir avec les autres fakîrs, afin de les délivrer. Ils y consentirent, et se dirigèrent avec moi vers eux. Nous revînmes tous ensemble à l'ermitage, et rendîmes grâces à Dieu de notre délivrance. C'était la nuit du jeudi au vendredi. Les habitants de la bourgade se réunirent, et passèrent la nuit à prier Dieu. Chacun d'eux apporta les aliments qu'il put se procurer et notre peine cessa.

Nous partîmes à l'aurore et nous arrivâmes à la ville de Mothorni ${ }^{299}$, au moment de la prière du vendredi. Nous logeâmes dans la zâouïah de l'un des jeunes-gens-frères, où était déjà une troupe de voyageurs. Nous n’y trouvâmes pas d'écurie pour nos montures. Nous

299 Mudurnu est à cinquante kilomètres à l'est de Göynük et le chemin est effectivement montagneux. 
fîmes la prière du vendredi. Nous étions inquiets, à cause de la quantité de la neige, du froid et du manque d'écurie. Sur ces entrefaites, nous vîmes un pèlerin, habitant de Mothorni, qui nous donna le salut ; il connaissait la langue arabe. Je fus joyeux de le voir, et le priai de nous indiquer une écurie à louer pour nos montures. Il me répondit : «Quant à ce qui est de les attacher dans une habitation, cela n'est pas possible ; car les portes des ${ }_{186}$ maisons de cette ville sont petites et des bêtes de somme ne sauraient y passer ; mais je vous indiquerai un banc dans la place où les voyageurs et ceux qui viennent pour assister au marché attachent leurs montures. » Il nous le montra effectivement, nous y liâmes nos montures, et l'un de mes compagnons s'établit dans une boutique vide, située en face de ce banc, afin de les garder.

\section{ANECDOTE}

Voici une aventure surprenante qui nous arriva. J'envoyai un des serviteurs acheter de la paille pour les bêtes de somme, et j'en expédiai un autre pour se procurer du beurre. Un d'eux revint avec de la paille; mais l'autre revint en riant, et ne rapportant rien. Nous l'interrogeâmes touchant le motif de ses rires. Il répondit : « Nous nous arrêtâmes près d'une boutique dans le marché, et nous demandâmes du beurre à son propriétaire. Il nous fit signe d'attendre et parla à son garçon. Nous remîmes à celui-ci des pièces d'argent ; il tarda quelque temps, et nous rapporta de la paille. Nous la lui prîmes et lui dîmes : " Nous voulons du beurre (samn). - Ceci, répondit-il, est du samn. » Il nous fut démontré par là que l'on dit, dans la langue des Turcs, samn pour exprimer de la paille. Quant au beurre, on le nomme chez eux roûghân.

Lorsque nous eûmes rencontré ce pèlerin, qui connaissait la langue arabe, nous le priâmes de nous accompagner à Khasthan oûniyah, qui est éloignée de Mothorni de dix jours de marche. Je lui fis présent d'un de mes vêtements, dont l'étoffe était de fabrique égyptienne ; je lui donnai une somme d'argent, qu'il laissa à sa famille, je lui assignai une monture et lui promis de le bien traiter. Il partit avec nous. Nous découvrîmes qu'il était très riche, et qu'il possédait des créances sur diverses personnes ; mais qu'il avait des sentiments bas, un caractère vil, et qu'il agissait mal. Nous lui remettions des drachmes pour notre 
dépense ; mais il prenait le ${ }_{\mathrm{p} 187}$ pain qui restait, achetait avec cela des épices, des herbes potagères et du sel, et gardait pour lui le prix de ces denrées. On me raconta qu'il volait, en outre, sur l'argent destiné à la dépense. Nous le supportions à cause des désagréments que nous souffrions par notre ignorance de la langue turque. La conduite de cet homme alla si loin que nous lui en fîmes des reproches outrageants, et nous lui disions, à la fin de la journée : «O pèlerin, combien nous astu volé aujourd'hui sur la dépense ? » Il répondait : «Tant. » Nous riions de lui et nous nous contentions de cela. Voici quelques-unes de ses méprisables actions.

Un de nos chevaux étant mort dans une station, il l'écorcha de ses propres mains et en vendit la peau. Nous logeâmes une certaine nuit chez une sœur de ce pèlerin, qui habitait une bourgade. Elle nous apporta de la nourriture et des fruits secs, savoir : des poires, des pommes, des abricots et des pêches, que l'on met détremper dans l'eau, jusqu'à ce qu'ils ramollissent ; après quoi, on les mange et l'on boit l'eau. Nous voulûmes récompenser cette femme ; son frère le sut et nous dit: "Ne lui donnez rien, mais remettez-moi ce que vous lui destiniez. " Nous lui donnâmes quelque chose pour le satisfaire ; mais nous remîmes en cachette un présent à sa sœur, et il n’en sut rien.

Nous arrivâmes ensuite à la ville de Boûli ${ }^{300}$. Lorsque nous en fûmes tout près, nous rencontrâmes une rivière qui semblait, à première vue, peu considérable ; mais, quand quelques-uns de nos compagnons y furent entrés, ils lui trouvèrent un courant très fort et très agité. Cependant, ils la franchirent tous, et il ne resta qu'une petite esclave, qu'ils craignirent de faire passer. Mon cheval étant meilleur que les leurs, je fis monter cette ${ }_{\mathrm{p} 188}$ jeune fille en croupe, et j'entrepris de traverser la rivière. Lorsque je fus arrivé au milieu, il s'abattit sous moi et la fille tomba. Mes compagnons la retirèrent de l'eau, ayant à peine un dernier souffle de vie. Quant à moi, je fus préservé du danger.

Nous entrâmes dans la ville, et nous nous dirigeâmes vers la zâouïah d'un des jeunes-gens-frères. C'est une de leurs coutumes de tenir toujours un feu allumé dans leurs ermitages, pendant toute la du-

300 Bolu, à cinquante-deux kilomètres au nord-est de Mudurnu sur la roue actuelle d’Istanbul à Ankara ; elle faisait partie à l'époque des possessions ottomanes, ayant été conquise vers la fin du règne d’Osman. 
rée de l'hiver. Ils placent à chaque angle de la zâouïah un foyer, et y adaptent des conduits ou évents, par lesquels la fumée monte, sans incommoder les habitants. On donne à ces évents le nom de bakhâry, dont le singulier est bakhîry.

Ibn Djozay dit ce qui suit : « Safy eddîn Abd al'azîz, fils de Sarâya alhilly ${ }^{301}$, a mentionné heureusement le bakhîry dans les vers suivants, où il a employé des expressions détournées. C'est la mention ici faite du bakhîry, qui me les remet en mémoire. »

Certes, depuis que vous avez laissé le bakhîry, les cendres sont répandues sur son foyer indigent.

Si vous aviez voulu qu'il fût au soir le père de la flamme, vos mules seraient venues apportant du bois ${ }^{302}$.

Nous revenons au récit du voyageur. Lorsque nous entrâmes dans l'ermitage, nous trouvâmes le feu allumé ; j'ôtai mes vêtements, j'en mis d'autres et je me réchauffai devant le feu. Le frère apporta des aliments et des fruits en abondance. Que Dieu bénisse cette admirable classe d'hommes! Combien leurs âmes sont généreuses, combien sont grandes leur libéralité et leur tendresse pour les étrangers ! Comme ils sont propices au voyageur, comme ils l'aiment et sont remplis d'une tendre sollicitude pour lui ! L'arrivée d'un étranger auprès p189 d'eux est comme son arrivée chez celui de ses proches qui l'aime le mieux. Nous passâmes cette nuit de la manière la plus agréable.

Nous partîmes au matin et arrivâmes à Gheredaï Boûli ${ }^{303}$, grande et belle ville, située dans une plaine. Elle a des rues et des marchés fort étendus ; elle est au nombre des villes les plus froides, et se compose de quartiers séparés les uns des autres, dont chacun est habité par une classe d'hommes distincte, qui ne se mêle avec aucune autre.

301 Célèbre poète irakien contemporain, mort en 1349.

302 Allusion à deux personnages cités par le Coran, sourate CXI (voir t. I, chap. 4, 303 n. 199).

${ }^{3}$ Gerede de Bolu, l'actuelle Gerede, à cinquante kilomètres à l'est de Bolu sur la route d'Istanbul à Ankara. De Bursa jusqu'à Gerede, Ibn Battûta cite toutes ses étapes. 


\section{DU SULTAN DE KEREDEH}

C'est Châh bec ${ }^{304}$, un des sultans de ce pays qui jouissent d'un médiocre pouvoir. Il est beau de visage, il tient une belle conduite et a un bon caractère ; mais il est peu libéral. Nous fîmes dans cette ville la prière du vendredi, et nous y logeâmes dans une zâouïah. Je rencontrai le jurisconsulte et prédicateur Chems eddîn addimichky, le hanbalite. Il était fixé dans cette ville depuis un bon nombre d'années, et y avait eu plusieurs enfants. C'est le légiste et prédicateur de ce sultan, et il jouit auprès de lui d'un grand crédit. Il nous visita dans la zâouïah, et nous informa que le sultan venait nous voir. Je lui rendis grâces de son action; j'allai au-devant du sultan et je le saluai. Il s'assit, et m’interrogea touchant mon état de santé et mon arrivée et touchant les sultans que j'avais vus. Je l'informai de tout cela. Il resta une heure, après quoi il s'en retourna, et m'envoya une monture toute sellée et un vêtement. p190

Nous nous rendîmes à Borloû ${ }^{305}$, petite ville située sur une colline, et au bas de laquelle il y a un fossé ; elle a un château placé sur la cime d'une haute montagne. Nous y logeâmes dans un beau collège ; le pèlerin qui voyageait avec nous en connaissait le professeur et les étudiants, et assistait avec eux aux leçons. Dans quelque situation qu'il se trouvât, il ne cessait de faire partie du corps des étudiants, et il professait la doctrine hanéfite. L'émir de cette ville, Aly bec, fils du sultan illustre Soleïman pâdichâh, roi de Kasthamoûniyah, dont il sera parlé plus loin, nous invita. Nous l'allâmes trouver dans le château, et nous le saluâmes. Il nous souhaita la bienvenue, nous traita avec honneur et m'interrogea touchant mes voyages et ma situation. Je satisfis à ses questions, et il me fit asseoir à son côté. Son kâdhi et secrétaire, le pèlerin Alâ eddîn Mohammed, un des principaux Khathîb ${ }^{306}$, était présent. On apporta des aliments et nous mangeâmes ; après quoi les lecteurs du Coran firent une lecture avec des voix touchantes et des modulations admirables.

${ }^{304}$ Pratiquement rien n’est connu de cet émirat et de son souverain appelé Shahin ${ }_{305}$ par al-Umari. Gerede fut conquise par les Ottomans en 1354.

305 L'actuelle Safranbolu, à soixante-quinze kilomètres au nord-est de Gerede. 306 Secrétaire. 
Nous nous en retournâmes, et nous partîmes le lendemain matin pour Kasthamoûniyah ${ }^{307}$, qui est au nombre des plus grandes et des plus belles villes. Elle abonde en biens, et les denrées y sont très bon marché. Nous y logeâmes dans l'ermitage d'un cheïkh appelé le Sourdaud à cause de la dureté de son oreille, et je fus témoin d'une chose merveilleuse de sa part. En effet, un des étudiants traçait avec son doigt les lettres dans l'air ou parfois sur le sol, en présence de ce cheïkh, qui le comprenait et lui répondait. On lui racontait par ce moyen des histoires tout entières, qu'il saisissait parfaitement.

Nous restâmes à Kasthamoûniyah environ quarante ${ }_{\text {p191 }}$ jours. Nous achetions, moyennant deux dirhems, la moitié d'un mouton bien gras, et pour deux dirhems une quantité de pain qui nous suffisait pour la journée ; or nous étions au nombre de dix. Nous prenions des sucreries au miel pour la même somme, et cela nous suffisait à tous. Nous nous procurions des noix pour un dirhem, et des châtaignes pour la même somme ; nous en mangions tous, et il en restait encore. Nous payions la charge de bois un seul dirhem, et cela pendant un froid violent. Je n'ai vu aucune ville où le prix des denrées soit moins considérable.

Je rencontrai à Kasthamoûniyah le cheïkh, l'imâm savant, le moufti, le professeur Tâdj eddîn Assulthânyoûky, un des principaux savants de son temps. Il avait enseigné dans les deux Irâks et à Tibrîz, et avait habité cette dernière ville pendant quelque temps ; il avait aussi professé à Damas, et avait jadis séjourné dans les deux villes saintes, La Mecque et Médine. Je rencontrai aussi à Kasthamoûniyah le savant professeur Sadr eddîn Soleïmân alfenîky, originaire de Fenîkah ${ }^{308}$, dans le pays de Roûm. Il me traita dans son école, située près du marché aux chevaux ${ }^{309}$. Je vis aussi dans cette ville le cheïkh vénérable et pieux Dâdâ émîr Aly. Je le visitai dans sa zâouïah, située dans le voisinage du même marché, et je le trouvai étendu sur le dos. Un de ses serviteurs le mit sur son séant ; un autre lui ayant soulevé les paupiè-

${ }^{307}$ Kastamonu, à cent sept kilomètres à l'est de Safranbolu ; fief de la famille turkmène des Tchoban depuis 1204, elle fut conquise au plus tard vers 1320 par les Djandaroghlu.

308 Finike, sur la côte sud de l'Anatolie, au sud-ouest d'Antalya, était à l'époque aux mains d'une branche de la famille des Menteché (voir ci-dessus n. 54). 309 Kastamonu était célèbre pour ses chevaux d'après al-Umari. 
res il ouvrit les yeux, me parla dans un arabe fort élégant et me dit : "Sois le bienvenu!" Je l'interrogeai sur son âge et il me répondit "J'étais au nombre des compagnons du khalife Almostancir Billah ; lorsqu'il mourut, j'étais âgé de trente ans, et j'ai maintenant soixantetrois ans ${ }^{310}$. » Je ${ }_{\mathrm{p} 192}$ lui demandai de prier pour moi, ce qu'il fit, et je m’en retournai.

\section{DU SULTAN DE KASTHAMOÛNIYAH}

C'est le sultan illustre Soleïman pâdchâh ${ }^{311}$; il est vieux, car son âge dépasse soixante et dix ans; il a une belle figure, une longue barbe, et son extérieur est majestueux et imposant. Les fakîhs et les gens de bien ont accès près de lui. Je le visitai dans sa salle de réception ; il me fit asseoir à son côté et m'interrogea touchant mon état, le temps de mon arrivée, et touchant les deux villes saintes, l'Égypte et la Syrie. Je satisfis à ses questions. Il commanda de me loger dans son voisinage, et me donna ce jour-là un beau cheval blanc, un vêtement et m'assigna une somme pour mon entretien, ainsi que du fourrage. Il m'assigna ensuite, sur une bourgade dépendante de la ville et éloignée de celle-ci d'une demi-journée, une certaine quantité de froment et d'orge qui fut perdue pour moi. En effet, je ne trouvai personne qui voulût me l'acheter, à cause du bas prix des denrées, et j'en fis don au pèlerin qui nous accompagnait.

C'est la coutume de ce sultan de donner une audience tous les jours, après la prière de l'asr. On apporte alors des aliments, on ouvre les portes et l'on n'empêche aucun individu de manger, qu'il soit citadin ou habitant de la campagne, étranger ou voyageur. Au commencement de la journée, ce prince tient une audience particulière. Son fils vient alors le trouver, lui baise les mains et s'en retourne à sa propre salle de réception. Les grands de l'empire viennent ensuite, mangent chez le souverain et s'en retournent.

${ }^{310}$ Mustansir Billah, l’avant-dernier calife de Bagdad, étant mort en 640 (1242), Ibn Battûta se trompe dans ses calculs, mais cela fait quand même cent vingttrois années lunaires d’âge pour le cheikh.

311

Shudja al-din Sulaiman (1301-1340), fils de Demir Djandar qui possédait depuis 1291 le petit fief d’Eflani, au nord-est de Safranbolu. 
C'est aussi sa coutume de se rendre à cheval, le ${ }_{\mathrm{p} 193}$ vendredi, à la mosquée, qui est éloignée de son palais. Elle se compose de trois étages construits en bois. Le sultan, les grands de sa cour, le kâdhi, les jurisconsultes et les chefs des troupes prient dans l'étage inférieur. L'éfendi ${ }^{312}$ frère du sultan, ses compagnons, son successeur désigné, qui est le plus jeune de ses enfants et que l'on appelle Aldjewâd ${ }^{313}$, ses compagnons, ses esclaves, ses serviteurs et le reste de la population prient dans l'étage supérieur. Les lecteurs du Coran se rassemblent et s'asseyent en cercle devant le mihrâb ; l'orateur et le kâdhi s'asseyent près d'eux. Le sultan se trouve placé en face du mihrâb. Les lecteurs lisent le chapitre de la Caverne ${ }^{314}$ avec de belles voix, et répètent les versets d'après un ordre admirable. Lorsqu'ils ont fini leur lecture, le khathîb monte en chaire et prêche ; après quoi il récite la prière. Quand celle-ci est finie, on fait des prières surérogatoires; le lecteur lit une deuxième partie du Coran devant le sultan, puis ce dernier et ceux qui l'ont accompagné s'en retournent.

Alors le lecteur du Coran fait une lecture devant le frère du sultan. Lorsqu'il l'a terminée, celui-ci et ses compagnons se retirent, et le même individu fait une lecture devant le sultan. Quand il a fini, le mo'arrif, qui est la même chose que le modhakkir ${ }^{315}$ se lève, célèbre en vers turcs le sultan et son fils, et fait des vœux en leur faveur ; après quoi il se retire. Le fils du souverain se rend au palais de son père, après avoir, sur son chemin, baisé la main de son oncle, qui se tient debout en l'attendant. Ils entrent ensuite tous deux près du sultan, et le frère de ce dernier s'avance vers lui, baise sa main et s'assied devant ce prince. Le fils du sultan s'avance ${ }_{\mathrm{p} 194}$ ensuite, baise la main de son père et s'en retourne dans son propre salon, où il s'assied en compagnie de ses officiers. Lorsqu'arrive le temps de la prière de l'aprèsmidi, ils la célèbrent tous ensemble; le frère du sultan lui baise la main et se retire, et il ne revient le visiter que le vendredi suivant. Quant à son fils, il vient chaque matin, ainsi que nous l'avons dit.

\footnotetext{
312 Du grec afthentes (seigneur). Il s’agit ici d'une des premières utilisations de ce terme en turc. Ce frère est peut-être l'émir Yaqub, seul frère de Sulaiman connu par ailleurs qui succéda au fils de ce dernier Ibrahim (1342-1345).

${ }^{313}$ Il n'est pas connu par ailleurs. Sulaiman aura pour successeur à sa mort son fils Ibrahim, à l'époque émir de Sinop (voir plus loin).

314 XVIII $^{\mathrm{e}}$ du Coran.

315 Sorte de chambellan. Voir également p. 407 et suiv.
} 
Nous partîmes de Kasthamoûniyah et descendîmes dans une grande zâouïah, située dans une bourgade, et qui est au nombre des plus beaux ermitages que j'aie vus dans cette contrée. Elle a été construite par un puissant émir appelé Fakhr eddîn, qui fit pénitence de ses péchés ${ }^{316}$. Il donna à son fils l'inspection sur cet édifice et la surveillance des moines qui y demeurent. Les revenus de la bourgade ont été légués à cet établissement. L'émir susnommé a construit en face de la zâouïah un bain gratuit ; chaque passant peut y entrer sans être obligé de rien payer. Il a bâti aussi dans la bourgade un marché qu'il a légué à la mosquée djâmi'. Sur les biens légués à cette zâouïah, il assigna à chaque fakir qui arriverait des deux villes saintes et nobles, ou de la Syrie, de l'Égypte, des deux Irâks, du Khorâçan, etc., un vêtement complet, et, de plus, cent dirhems pour le jour de son arrivée, et trois cents le jour de son départ. Tout cela sans préjudice de sa nourriture durant son séjour, c'est-à-dire du pain, de la viande, du riz cuit au beurre et des sucreries. Il assigna à chaque fakir du pays de Roûm dix dirhems, outre le droit de se faire héberger pendant trois jours.

Nous partîmes de cette zâouïah et passâmes la nuit suivante dans une autre zâouïah, située sur une haute ${ }_{195}$ montagne où il n'y avait pas d'habitants. Elle avait été bâtie par un des jeunes-gens-frères, originaire de Kasthamoûniyah et appelé Nizhâm eddîn, qui lui légua une bourgade dont le revenu devait être dépensé à traiter, dans cet édifice, les allants et venants.

Nous partîmes de là pour Sanoûh ${ }^{317}$, ville très populeuse et qui réunit la force à la beauté. La mer l'entoure de tous côtés, sauf un seul, qui est celui de l'orient. Elle a en cet endroit une porte, et l'on n'y entre qu'avec la permission de son émir. C'est Ibrâhîm bec ${ }^{318}$, fils du sultan Soleïmân pâdichâh, dont il a été question ci-dessus. Lorsqu'on lui eut demandé la permission en notre faveur, nous pénétrâmes dans la ville et nous logeâmes dans la zâouïah d'Izz eddîn Akhy Tchélébi,

${ }^{316}$ D’après la description, il doit s’agir de la madrasa fondée à Täsköprü, quarante-quatre kilomètres au nord-est de Kastamonu, par Muzaffar al-din Yülük Arslan Beg, émir Tcobanoghlu de Kastamonu (1284-1292). De nouvelles donations de biens ont été faites par Sulaiman en 1329.

317 Sinop, un des principaux ports anatoliens de la mer Noire à l'époque, située 318 sur une péninsule reliée à la terre ferme du côté ouest (et non est).

Ibrahim, émir de Sinop probablement à partir de 1322 et souverain des Djandaroghlu (1340-1342). 
située hors de la porte de la mer. De cet endroit, on grimpe sur une montagne qui s'avance dans la mer, comme celle du port Mîna à Ceuta ${ }^{319}$, et où il se trouve des vergers, des champs cultivés et des ruisseaux. La plupart des fruits qu'elle produit sont des figues et des raisins. C'est une montagne inaccessible et qu'on ne saurait escalader. Il s’y trouve onze bourgades habitées par des Grecs infidèles, sous la protection des musulmans. Sur sa cime, il y a un ermitage appelé l'ermitage de Khirdhr et d'Elie ${ }^{320}$, et qui n'est jamais dépourvu de dévots. Près de celui-ci se trouve une source, et les prières qu'on y prononce sont exaucées. Au bas de cette montagne est le tombeau du pieux et saint compagnon de Mahomet, Bélâl l'Abyssin ${ }^{321}$; il est ${ }_{\text {p196 }}$ surmonté d'une zâouiiah où l'on sert de la nourriture à tout venant.

La mosquée djâmi' de la ville de Sinope est au nombre des plus belles cathédrales ${ }^{322}$. Elle a au milieu un bassin d'eau, surmonté d'une coupole soutenue par quatre piliers. Chaque pilier est accompagné de deux colonnes de marbre, au-dessus desquelles se trouve une tribune, où l'on monte par un escalier de bois. C'est une construction du sultan Perouâneh, fils du sultan Ala eddîn Erroûmy. Il priait le vendredi en haut de cette coupole. Il fut remplacé par son fils Ghâzy Tchélébi, et lorsque celui-ci fut mort, le sultan Soleïmân, dont il a été parlé ci-dessus, s'empara de Sinope ${ }^{323}$. Ghâzi Tchélébi était un homme brave et audacieux; Dieu l'avait doué d'une aptitude toute particulière à rester longtemps sous l'eau et à nager avec vigueur. Il

${ }^{319}$ Ce promontoire de six kilomètres de long s’appelle Bozdagh ; le Djabal Mina commande le côté est de la péninsule de Ceuta.

320 Voir t. I, chap. 3, n. 298.

321 Tombeau également mentionné à Damas (voir t. I, chap. 3, n. 256).

322 Construite en 1267 par Sulaiman Pervane, vizir seldjukide, elle a persisté à travers plusieurs restaurations jusqu'à nos jours. Elle est connue sous le nom de mosquée d'Alauddin.

${ }^{323}$ Ici Ibn Battûta prend des libertés avec l’histoire. Sulaiman Pervane était vizir du Seldjukide Kilidj Arslan II et maître réel du royaume pendant la minorité du fils de ce dernier, Ghiyasuddin Kayhusrev III. Après avoir reconquis Sinop entre-temps occupée par le royaume de Trébizonde, Pervane installa un de ses fils, fondant ainsi un émirat qui dura de 1277 à 1300. A cette date, les Pervane furent remplacés par Ghazi Tchelebi, Seldjukide et fils du dernier souverain Mas'ud II. La date du passage de Sinop aux Djandar n'est pas connue. L'existence supposée d'un autre Ibrahim Beg, fils et successeur de Ghazi Tchelebi et l'incertitude sur la date de la mort de ce dernier compliquent les choses. 
s'embarquait souvent sur des navires de guerre, afin de combattre les Grecs. Lorsque les deux flottes étaient en présence et que l'on était occupé à combattre, il plongeait sous les vaisseaux grecs, la main armée d'un fer aigu, avec lequel il les perçait. Les ennemis n'apprenaient le sort qui les menaçait qu'en se voyant couler à fond. Des vaisseaux ennemis envahirent une fois le port de ${ }_{\text {p197 }}$ Sinope ; Ghâzi Tchélébi les coula à fond et fit prisonniers ceux qui les montaient ${ }^{324}$.

Il avait un mérite sans égal ; seulement on raconte qu'il faisait une grande consommation de hachîch et qu'il mourut à cause de cela, car il partit un jour pour la chasse, exercice qu'il aimait passionnément, et il poursuivit une gazelle, qui se réfugia au milieu des arbres. A cette vue, il accéléra beaucoup la course de son cheval ; mais un arbre, s'étant rencontré sur son chemin, le frappa à la tête et la brisa ; il mourut de cette blessure. Le sultan Soleïmân s'empara de la ville de Sinope, où il mit, en qualité de gouverneur, son fils Ibrahîm. On dit que ce prince mange du hachîch, tout comme son prédécesseur. Au reste, les habitants de toute l'Asie Mineure ne blâment pas l'usage de cette drogue. Je passai un jour près de la porte de la mosquée djâmi' de Sinope ; il y a en cet endroit des estrades où les habitants s'asseyent. J'y vis plusieurs des chefs de l'armée, devant lesquels se tenait un serviteur, qui portait dans ses mains un sac, rempli d'une substance semblable au hinna ${ }^{325}$. L'un d'eux y puisait avec une cuiller et mangeait de cette substance. Je le regardais faire, ignorant ce que contenait le sac. J'interrogeai là-dessus quelqu'un qui m'accompagnait, et il m’apprit que c’était du hachîch.

Le kâdhi de cette ville nous y traita ; il était en même temps substitut de l'émîr et son précepteur, et il était appelé Ibn ’Abd Arrazzâk.

${ }^{324}$ L’événement daterait, d’après les sources génoises, de 1324, mais selon ces dernières Ghazi Tchelebi aurait attaqué dix navires génois lui rendant visite à 325 Sinop. La date pose encore des problèmes sur l'arrivée des Djandaroghlu.

Henné : poudre colorante. 


\section{ANECDOTE}

Lorsque nous fûmes entrés à Sinope, les habitants nous virent prier, les mains pendantes sur les côtés du ${ }_{\mathrm{p} 198}$ corps ${ }^{326}$. Ils sont hanéfites et ne connaissent pas la secte de Mâlic, ni sa manière de prier. Or celle qui est préférée, d'après sa doctrine, consiste à laisser pendre les mains sur les côtés. Quelques-uns d'entre eux avaient vu, dans le Hidjâz et dans l'Irak, des râfidhites prier en laissant ainsi pendre leurs mains. Ils nous soupçonnèrent de partager les doctrines de ces derniers, et nous interrogèrent là-dessus. Nous leur apprîmes que nous suivions la doctrine de Mâlik. Mais ils ne se contentèrent pas de cette assertion, et le soupçon s'affermit dans leur esprit à un tel point que le lieutenant du sultan nous envoya un lièvre, et ordonna à un de ses serviteurs de rester près de nous, afin de voir ce que nous en ferions. Nous l'égorgeâmes, le fîmes cuire et le mangeâmes. Le serviteur s'en retourna et instruisit son maître de notre conduite. Alors tout soupçon cessa sur notre compte et l'on nous envoya les mets de l'hospitalité. En effet, les râfidhites ne mangent pas de lièvre.

Quatre jours après notre arrivée à Sinope, la mère de l'émîr Ibrahîm y mourut et je suivis son cortège funèbre. Son fils le suivit à pied et ayant la tête découverte. Les émirs et les esclaves firent de même, et ils portaient leurs vêtements retournés à l'envers ${ }^{327}$. Quant au kâdhi, au prédicateur et aux jurisconsultes, ils retournèrent aussi leurs habits, mais ils ne découvrirent pas leur tête ; seulement ils y mirent des mouchoirs de laine noire, en place de turbans. On servit des aliments aux pauvres pendant quarante jours, car telle est la durée du deuil chez ces peuples.

$\underline{\text { Retour à la Table des Matières }}$

${ }^{326}$ La manière malikite de prier, au lieu de tendre les avant-bras comme c'est le cas dans la coutume hanafite.

327 Même coutume chez les Atabeks du Lur (voir t. I. 393). 


\section{La Russie méridionale}

$\underline{\text { Retour à la Table des Matières }}$

Nous séjournâmes à Sinope environ quarante jours, attendant une occasion favorable de nous rendre par mer à la ville de Kiram ${ }^{328}$. Nous louâmes un vaisseau appartenant à des Grecs, et nous attendîmes encore onze jours, dans l'espoir d'un vent favorable ; après quoi nous nous embarquâmes. Au bout de trois jours, lorsque nous nous trouvions déjà parvenus au milieu de la mer, celle-ci devint très agitée ; notre situation fut pénible et nous vîmes la mort de très près. Je me trouvai dans la cabine du vaisseau en compagnie d'un habitant du Maghreb, qui s'appelait Abou Becr. Je lui ordonnai de monter sur le tillac du navire, afin d'examiner l'état de la mer. Il obéit, vint me rejoindre dans la cabine et me dit : « Je vous recommande à Dieu. » Une tempête sans pareille survint; puis le vent changea et nous repoussa jusqu'aux environs de la ville de Sinope, que nous venions de quitter. Un des marchands voulut descendre dans le port de cette ville ; mais j'empêchai le propriétaire du vaisseau de le faire débarquer. Bientôt le vent redevint favorable, et nous nous remîmes en route. Lorsque nous eûmes parcouru la moitié de la mer, elle fut de nouveau très agitée, et nous nous vîmes dans une situation pareille à la précédente. Enfin le vent se remit, et nous aperçûmes les montagnes du continent voisin. p201

${ }^{328}$ Sinop, seul port des Seldjukides sur la mer Noire au XIII ${ }^{\mathrm{e}}$ siècle, constituait le lien principal entre l'Anatolie et la Crimée. Ibn Battûta a dû s'embarquer vers le mois de mars 1334. 


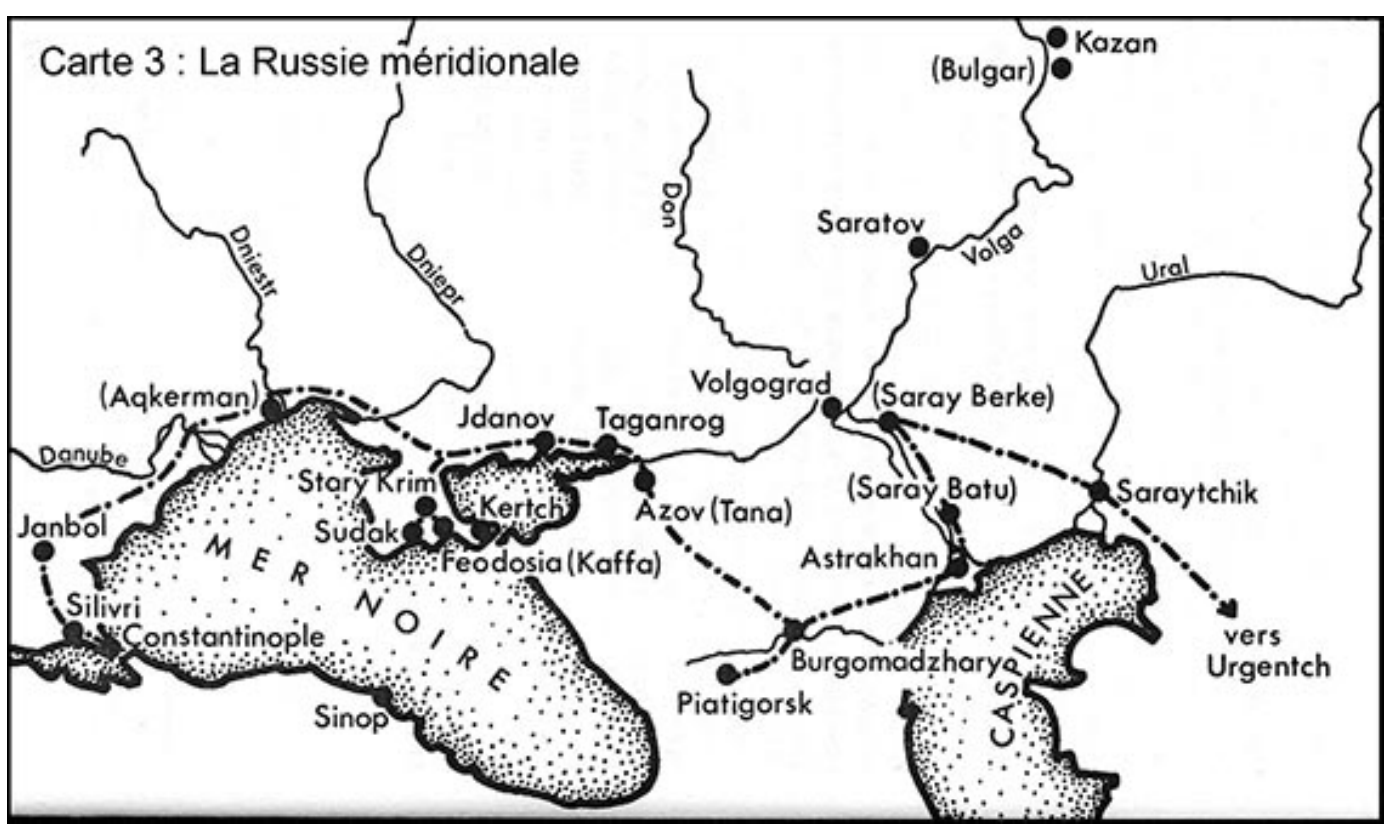

Nous nous dirigeâmes vers un port appelé $\operatorname{Kerch}^{329}$ et voulûmes y entrer. Des hommes, qui se trouvaient sur la montagne, nous firent signe de ne pas y aborder. En conséquence, nous craignîmes pour notre vie, dans la croyance qu'il se trouvait là des vaisseaux ennemis, et nous retournâmes vers le continent. Lorsque nous nous approchâmes, je dis au maître de vaisseau : " Je veux descendre ici. » Il me fit descendre sur le rivage. J'y vis une église ${ }^{330}$, je m'y rendis et y trouvai un moine. J'aperçus, sur une des murailles de l'église, la représentation d'un Arabe, coiffé d'un turban et ceint d'un sabre. Dans sa main était une lance et devant lui brûlait une lampe. Je dis au moine : «Quelle est cette figure ? » Il me répondit : « C'est la figure du prophète Aly ${ }^{331}$ ", et je fus étonné de sa réponse. Nous passâmes cette nuit dans l'église et nous fîmes cuire des poulets ; mais nous ne pûmes les manger, car ils étaient au nombre des provisions que nous avions

${ }^{329}$ Kertch, sur la rive ouest du détroit du même nom reliant la mer Noire à celle d'Azov. La Crimée faisait à l'époque partie de l'empire mongol de la Horde d’Or, mais les Génois s'étaient établis sur son littoral méridional, ayant comme centre Kaffa, l'actuelle Feodosia, et possédaient un consul à Kertch.

330 Kertch était un siège épiscopal depuis 1332.

331 A moins qu'il ne s'agisse d'Elie. 
embarquées dans le vaisseau, et tous les objets qui se trouvaient à bord étaient imprégnés de l’odeur de la mer.

L'endroit où nous débarquâmes faisait partie de la plaine connue sous le nom de Decht Kifdjak ${ }^{332}$. Decht, dans la langue des Turcs, signifie la même chose que Sahrâ, en arabe. Cette plaine est verdoyante et fleurie ; mais il ne s'y trouve ni montagne, ni arbre, ni colline, ni pente. Il n'y a pas de bois à brûler, et l'on y connaît point d'autre combustible que, la fiente d'animaux, p202 laquelle est appelée tezec. Tu verrais les principaux d'entre les indigènes ramasser ce fumier, et le porter dans les pans de leurs vêtements. On ne voyage pas dans cette plaine, sinon sur des chariots. Elle s'étend l'espace de six mois de marche, dont trois dans les états du sultan Mohammed Uzbec, et trois dans ceux d'autres princes. Le lendemain de notre arrivée dans ce port, un des marchands, nos compagnons, alla trouver ceux des habitants de cette plaine qui appartiennent à la nation connue sous le nom de Kifdjak, et qui professent la religion chrétienne ${ }^{333}$. Il loua d'eux un chariot traîné par des chevaux. Nous y montâmes, et nous arrivâmes à la ville de Cafa, grande cité qui s'étend sur le bord de la mer, et qui est habitée par des chrétiens, la plupart génois ${ }^{334}$. Ils ont un chef appelé Addemedîr. Nous y logeâmes dans la mosquée des musulmans.

\section{ANECDOTE}

Lorsque nous fûmes descendus dans cette mosquée et que nous y eûmes resté environ une heure, nous entendîmes retentir de tous côtés

332 Steppe des Kiptchaks, peuple appelé Huns (Khoun) par les Hongrois, Polovtsi par les Russes, Comani par les Byzantins et qui se nommait lui-même Kiptchak. Il a remplacé les Khazars en Russie méridionale avant d'être évincé par les Mongols. Le nom de Dasht'i-Qiptchaq était donné par les géographes arabes aux steppes russes.

Une partie des Kiptchaks était convertie au christianisme à la suite de leurs contacts avec les Byzantins et les Russes.

${ }^{334}$ Kaffa était l'aboutissement des routes maritimes partant de Constantinople et de Sinope. En 1420, sa population était estimée à quarante mille personnes. On pourrait traduire le nom du « chef » de la ville par Demetrio, mais on ne possède pas plus de renseignements sur sa personne. 
le son des cloches ${ }^{335}$. Je n'avais alors jamais entendu ce bruit; j'en fus effrayé et j'ordonnai à mes compagnons de monter sur le minaret, de lire le Coran, de louer Dieu et de réciter l'appel à la prière ; ils obéirent. Or nous aperçûmes qu'un homme s'était introduit près de nous, couvert d'une cuirasse et armé. Il nous salua et nous le priâmes de nous ${ }_{\text {p203 }}$ apprendre qui il était. Il nous fit savoir qu'il était le kâdhi des musulmans de l'endroit, et ajouta : «Lorsque j'ai entendu la lecture du Coran et l'appel à la prière, j'ai tremblé pour vous, et je suis venu vous trouver comme vous voyez. » Puis il s'en retourna; mais nous n'éprouvâmes que de bons traitements.

Le lendemain, l'émir vint nous visiter et nous fit servir un festin. Nous mangeâmes chez lui et nous nous promenâmes dans la ville, que nous trouvâmes pourvue de beaux marchés. Tous ses habitants sont des mécréants. Ensuite nous descendîmes dans le port, et nous vîmes qu'il était admirable. Il s'y trouvait environ deux cents vaisseaux, tant bâtiments de guerre que de transport, petits et grands. Ce port est au nombre des plus célèbres de l'univers.

Nous louâmes un chariot et nous nous rendîmes à Kiram ${ }^{336}$, ville grande et belle, qui fait partie des États du sultan illustre Mohammed Uzbec khân ; elle a un gouverneur nommé par lui et appelé Toloctomoûr ${ }^{337}$. Nous avions été accompagnés pendant le voyage par un des serviteurs de cet émir. Cet homme ayant annoncé à son maître notre arrivée, celui-ci m’envoya un cheval par son imâm Sa'd eddîn. Nous logeâmes dans un ermitage, dont le supérieur était Zâdeh alkhorâçâny. Ce cheïkh nous témoigna de la considération, nous complimenta sur notre arrivée, et nous traita généreusement. Il est fort vénéré de ces peuples ; je vis les habitants de la ville, kâdhis, prédicateurs, jurisconsultes et autres, venir le saluer. Ce cheïkh Zâdeh m’apprit qu'un

335 Son déplaisant aux oreilles musulmanes d'après le hadith du Prophète : « Les anges n'entreront pas dans la maison où sonnent des cloches. »

La médiévale Solghat, l'actuelle Stary Krim d'où la péninsule tire son nom, ville à quarante-deux kilomètres de Feodosia à l'intérieur des terres.

${ }^{337}$ Il est également mentionné dans les sources européennes sous le nom de Tolaktemur. La région de Crimée constituait l'apanage de Toka Timur, fils de Djoetchi et petit-fils de Gengis Khan, ancêtre des khans de Crimée, tandis que Uzbek Khan, le souverain régnant de ta Horde d'Or, descendait de Batu, autre fils de Djoetchi. Ce personnage semble donc être Tulek Timur, descendant à la cinquième génération de Toka Timur. 
moine ${ }_{\text {p204 }}$ chrétien habitait un monastère situé hors de la ville, qu'il s’y livrait aux pratiques de la dévotion et jeûnait très fréquemment ; qu'il allait même jusqu'à jeûner quarante jours de suite ; après quoi il rompait le jeûne avec une seule fève ; enfin, qu'il découvrait clairement les choses cachées. Le cheïkh me pria de l'accompagner dans une visite à ce personnage. Je refusai ; mais, dans la suite, je me repentis de ne l'avoir pas vu, et de ne pas avoir ainsi reconnu la vérité de ce qu'on disait de lui.

Je vis à Kiram le grand kâdhi de cette ville, Chems eddîn Assâily, juge des hanéfites ; le kâdhi des châfeïtes, qui s’appelait Khidrh ; le jurisconsulte et professeur 'Ala eddîn alassy ; le prédicateur des châfeïtes, Abou Becr, qui remplissait les fonctions d'orateur dans la mosquée djâmi', fondée dans cette ville par le défunt Almélic annâcir ${ }^{338}$. Je vis aussi le cheïkh, le sage et pieux Mozhaffer eddîn (il était grec de naissance, mais il embrassa sincèrement l'islamisme); enfin le cheïkh pieux et dévot Mozhhir eddîn qui était au nombre des légistes les plus considérés. L'émir Toloctomoûr était alors malade, et nous allâmes le visiter ; il nous témoigna de la considération et nous traita bien. Il était sur le point de se mettre en route pour la ville de Serâ, résidence du sultan Mohammed Uzbec. Je me disposai à partir en sa compagnie, et j'achetai pour cela des chariots.

\section{DESCRIPTION DES CHARIOTS SUR LESQUELS ON VOYAGE DANS CE PAYS}

Les habitants de cette contrée les appellent 'arabahs, et ce sont des chariots dont chacun est pourvu de quatre grandes roues ${ }^{339}$. Il y en a

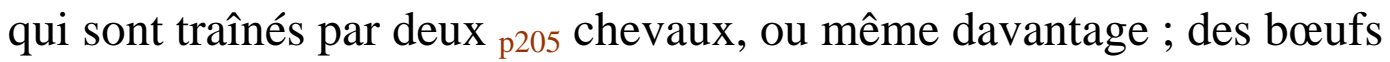
et des chameaux les traînent également, selon la pesanteur ou la légèreté du char. L'individu qui conduit l'arabah monte sur un des chevaux qui tirent ce véhicule, et sa monture est sellée. Il tient dans sa

${ }^{338}$ Un architecte et 1000 dinars furent envoyés par Baïbars, le sultan d’Égypte, en 1288 pour la construction de la mosquée de Krim. Mais la mosquée principale fut bâtie par Uzbek Khan en 1314.

339 «Les maisons sur lesquelles ils dorment, ils les construisent sur des roues [...]. Et ils font ces maisons si grandes qu'elles ont parfois trente pieds de largeur. J’ai compté attelés à un seul chariot vingt-deux bœufs, onze qui marchaient en ligne parallèlement à la largeur du chariot et onze qui les précédaient » (Guillaume DE RUBROUCK). 
main un fouet, afin d'exciter les chevaux à la marche, et un grand morceau de bois, avec lequel il les touche, lorsqu'ils se détournent du chemin. On place sur le chariot une espèce de pavillon, fait de baguettes de bois liées ensemble avec de minces lanières de cuir. Cette sorte de tente est très légère, elle est recouverte de feutre ou de drap, et il y a des fenêtres grillées, par lesquelles celui qui est assis en dedans voit les gens, sans en être vu. Il y change de position à volonté ; il dort, il mange, il lit et il écrit pendant la marche. Ceux de ces chariots qui portent les bagages, les provisions de route et les magasins de vivres sont recouverts d'un pavillon pareil, fermant par une serrure.

Lorsque je voulus me mettre en route, je préparai, pour mon usage, un chariot recouvert de feutre, et où je pris place avec une jeune esclave qui m'appartenait ; un autre plus petit, pour mon compagnon 'Afîf eddîn Ettoûzery ; et pour mes autres compagnons, un grand chariot, traîné par trois chameaux, sur l'un desquels était monté le conducteur de l'arabah.

Nous partîmes en compagnie de l'émir Toloctomoûr, de son frère 'Iça et de ses deux fils, Cothloûdomoûr et Sâroûbec. Ledit émir fut aussi accompagné dans ce voyage par son imam Sad' eddîn, par le prédicateur Abou Becr, le kâdhi Chems eddîn, le jurisconsulte Cherf eddîn Moûça, et le nomenclateur Alâ eddîn. Les fonctions de ce dernier officier consistent à se tenir devant l'émir dans sa salle de réception, et, lorsqu'arrive le kâdhi, à se lever devant lui et à dire à haute voix : "Bismillâhi (au nom de Dieu), voici notre seigneur, notre maître, le chef des kâdhis et des magistrats, p206 celui qui rend des réponses juridiques et des sentences claires et évidentes; au nom de Dieu ! " Lorsqu'arrive un jurisconsulte respecté ou un homme considérable, le nomenclateur dit ces mots : " Au nom de Dieu ! voici notre seigneur, N... de la religion ; bismillâhi ! » Les assistants se préparent à recevoir le nouveau venu, ils se lèvent devant lui, et lui font place dans la salle.

C'est la coutume des Turcs de voyager dans cette plaine de la même manière que les pèlerins voyagent sur la route du Hidjâz. Ils se mettent en marche après la prière de l'aurore, campent vers neuf ou dix heures du matin, repartent après l'heure de midi, et s'arrêtent de nouveau le soir. Lorsqu'ils se sont arrêtés quelque part, ils délient leurs chevaux, leurs chameaux et leurs bœufs des arabahs où ils sont 
attachés et les mettent en liberté, afin qu'ils se repaissent, soit de nuit, soit de jour. Personne ne fait donner de fourrage à un herbivore, pas même le sultan. C'est le propre de cette plaine, que ses plantes remplacent l'orge pour les bêtes de somme, et aucun autre pays ne possède cette propriété. Pour ce motif, les bêtes de somme sont en grand nombre dans le Kifdjak ; elles n'ont ni pasteurs ni gardiens, à cause de la sévérité des lois des Turcs contre le vol. Voici quelle est leur jurisprudence à cet égard : celui en la possession duquel on trouve un cheval dérobé est obligé de le rendre à son maître, et de lui en donner neuf semblables; s'il ne peut le faire ${ }^{340}$, ses enfants sont saisis en remplacement de cette amende; si enfin il n'a pas d'enfant, il est égorgé comme une brebis.

Ces Turcs ne mangent pas de pain ni aucun autre aliment solide. Ils préparent un mets avec un ingrédient que l'on trouve dans leur pays, qui ressemble à l'anly et que l'on appelle addoûghy ${ }^{341}$. Pour cela, ils placent de ${ }_{\mathrm{p} 207}$ l'eau sur le feu, et, lorsqu'elle bout, ils y versent un peu de ce doûghy. S'ils ont de la viande, ils la coupent en petits morceaux et la font cuire avec ces grains. Ensuite, on sert à chaque personne sa portion dans une écuelle, on verse par-dessus du lait caillé, et on avale le tout. Ils boivent encore, après cela, du lait de jument aigri, qu'ils appellent kimizz.

Ce sont des gens forts, vigoureux et d'un bon tempérament. Ils font quelquefois usage d'un mets qu'ils appellent alboûrkhâny. C'est une pâte qu'ils coupent en petits morceaux ; ils y font un trou au milieu et les placent dans un chaudron ; lorsqu'ils sont cuits, ils répandent dessus du lait aigri et les avalent. Ils ont aussi une liqueur fermentée, fabriquée avec les grains du doûghy dont il a été question précédemment. Ces gens regardent comme une honte l'usage des sucreries. Je me trouvais un jour près du sultan Uzbec pendant le mois de ramadhân. On apporta de la viande de cheval, qui est celle dont ces peuples mangent le plus, de la viande de mouton et du richta, lequel est une espèce de vermicelle, que l'on fait cuire, et que l'on boit avec du lait caillé. J’apportai cette même nuit au sultan un plateau de sucreries,

340

«Si un homme a volé un cheval ou tout autre chose pour quoi il doive perdre la vie, il est tranché en deux avec une épée ; mais, s’il peut payer et veut donner neuf fois tant ce qu'il a volé, il se sauve » (Marco POLO).

Anli est le mot berbère pour le millet ; al-dugi est ici le millet concassé. 
qu'avait préparées un de mes compagnons, et je les lui présentai. Il y porta son doigt et le fourra ensuite dans la bouche, mais il s'en tint là. L'émir Toloctomoûr me raconta qu'un des principaux esclaves de ce sultan avait environ quarante enfants ou petits-enfants, et que le sultan lui dit un jour : " Mange des sucreries et je vous affranchirai tous »; mais que cet homme refusa et répondit : "Quand bien même tu devrais me tuer, je n'en mangerais pas. »

Lorsque nous fûmes sortis de la ville de Kiram, nous campâmes près de l'ermitage de l'émir Toloctomoûr, dans un endroit appelé Sedjidjân, et il m'envoya inviter à l'aller trouver. J'enfourchai mon cheval, car j'en savais un toujours prêt à être monté par moi et que conduisait le cocher de l'arabah ; je m'en servais quand je voulais. Je me rendis donc à l'ermitage, et je trouvai ${ }_{\text {p208 }}$ que l'émir y avait préparé des mets abondants, parmi lesquels il y avait du pain ${ }^{342}$. On apporta ensuite, dans de petites écuelles, une liqueur de couleur blanchâtre, et les assistants en burent. Le cheïkh Mozhaffer eddîn était assis tout près de l'émir, et je venais après le cheïkh. Je dis à celui-ci : « Qu'estce que cela ? - C'est, me répondit-il, de l'eau de dohn. » Je ne compris pas ce qu'il voulait dire ; je goûtai de ce breuvage, mais je lui trouvai une saveur acide, et je le laissai. Lorsque je fus sorti, je m'informai de cette boisson ; on me dit : "C'est du nebîdh, fait avec des grains de doûghy. » Ces peuples, en effet, sont du rite hanéfite, et le nebîdh est considéré par eux comme permis. Ils appellent cette boisson fabriquée avec du doûghy du nom d'alboûzah ${ }^{343}$. Le cheïkh Mozhaffer eddîn m'avait sans doute dit : "C'est de l'eau de dokhn. » Mais il avait une prononciation barbare, et je crus qu'il disait : "C'est de l'eau de $d o h n{ }^{344}$."

Après avoir dépassé dix-huit stations, à partir de Kiram, nous arrivâmes près d'un grand amas d'eau, que nous mîmes un jour entier à traverser à gué ${ }^{345}$. Lorsque les bêtes de somme et les voitures y furent

\footnotetext{
342 Rare chez les Mongols.

343 Boza, boisson épaisse, légèrement fermentée, fabriquée à partir des graines de millet. Le nebidh, à l'origine boisson de dattes légèrement fermentée, désigne ${ }^{34}$ les boissons peu alcoolisées autorisées par l'école hanafite.

Dokhn : millet ; dohn : graisse.

345 Probablement la rivière de Mius à l'ouest de Taganrog. Ibn Battûta a dû remonter la Crimée et longer le littoral nord de la mer d’Azov.
} 
entrées en grand nombre, la boue augmenta et le passage devint plus difficile. L'émir pensa à ma commodité, et me fit partir devant lui, avec un de ses serviteurs. Il écrivit en ma faveur une lettre à l'émir d'Azâk pour l'informer que je désirais me rendre près du roi, et pour l'engager à me traiter avec considération. Nous marchâmes jusqu'à ce que nous atteignissions un autre amas d'eau, que nous mîmes une demi-journée à traverser ; puis ayant ${ }_{\text {p209 }}$ encore voyagé pendant trois jours, nous arrivâmes à la ville d'Azâk ${ }^{346}$, qui est située sur le rivage de la mer.

C'est une place bien bâtie ; les Génois et d'autres peuples s’y rendent avec des marchandises. Un des jeunes-gens-frères, Akhy Bitchaktchy, y habite ; il est au nombre des grands personnages, et donne à manger aux voyageurs. Lorsque la lettre de l'émir Toloctomoûr parvint au gouverneur d'Azâk, Mohammed Khodjah alkhârizmy ${ }^{347}$, il sortit à ma rencontre accompagné du kâdhi et des étudiants et me fit apporter des aliments. Quand nous lui eûmes donné le salut, nous nous arrêtâmes dans un endroit où nous mangeâmes. Nous arrivâmes ensuite à la ville, et nous logeâmes en dehors, non loin d'un couvent appelé le couvent de Khidhr et d'Elie. Un cheïkh habitant à Azâk, et appelé Radjab Ennahr Meliky, par allusion à une bourgade de l'Irâk ${ }^{348}$, sortit de la ville, et nous donna un beau festin dans un ermitage qui lui appartenait. L'émir Toloctomoûr arriva deux jours après nous, et l'émir Mohammed sortit à sa rencontre, avec le kâdhi et les étudiants ; on prépara pour lui des festins, et l'on dressa trois tentes contiguës l'une à l'autre ; l'une d'elles était de soie de diverses couleurs et magnifique, et les deux autres de toile de lin. On les entoura d'une serâtcheh, ou enceinte de toile, que l'on appelle chez nous afrâdj ${ }^{349}$. En dehors se trouvait le vestibule, qui a la même forme que le bordj, ou tour, dans notre pays. Lorsque l'émir fut descendu de cheval, on étendit devant lui des pièces de soie, sur lesquelles il marcha. Ce fut par une suite de sa générosité et de sa bonté qu’il me fit

\footnotetext{
${ }^{346}$ La médiévale Tana, l’actuelle Azov. Le nom turc d’Azak apparaît sur des monnaies à partir de 1317. D’abord les Génois vers 1316, puis les Vénitiens en 1332 y installèrent des colonies commerciales.

347 Mentionné comme gouverneur dans un texte vénitien de 1334.

348 A trente kilomètres au sud de Bagdad sur le canal Royal (nahr al-Malik).

349 Terme berbère utilisé au Maroc pour désigner le camp royal.
} 
partir avant lui, afin que cet autre émir vît dans quelle estime il me tenait.

Nous arrivâmes ensuite à la première tente, qui était p210 préparée pour que Toloctomoûr s'y reposât. A la place d'honneur était un grand siège de bois, incrusté d'or et revêtu d'un beau coussin, pour que l'émir pût s'y asseoir. Celui-ci me fit marcher devant lui, et il agit ainsi à l'égard du cheïkh Mozhaffer eddîn; puis il monta et s'assit entre nous deux. Nous nous trouvions ainsi tous trois sur le coussin. Le kâdhi et le prédicateur de Toloctomoûr s'assirent, de même que le kâdhi et les étudiants de cette ville, à la gauche de l'estrade et sur de riches tapis. Les deux fils de l'émir Toloctomoûr, son frère, l'émir Mohammed et ses enfants se tinrent debout, en signe de respect. Après cela on apporta des aliments, consistant en chair de cheval et autres viandes, ainsi que du laitage de jument. Puis on servit la boisson dite boûzah. Lorsqu'on eût fini de manger, les lecteurs du Coran firent une lecture avec leurs belles voix. Ensuite on dressa une chaire et le prédicateur y monta. Les lecteurs du Coran s'assirent devant lui, et il fit un discours éloquent, pria pour le sultan pour l'émir et pour les assistants. Il parlait d'abord en arabe, puis il traduisait ses paroles en turc. Dans l'intervalle, les lecteurs du Coran répétaient des versets de ce livre avec des modulations merveilleuses ; puis ils commencèrent à chanter. Ils chantaient d'abord en arabe et ils nomment cela alkaoul $^{350}$, puis en persan et en turc ce qu'ils appellent almolamma ${ }^{351}$. On apporta plus tard d'autres mets, et l'on ne cessa d'agir ainsi jusqu'au soir. Toutes les fois que je voulus sortir, l'émir m’en empêcha. Enfin, on apporta un vêtement pour l'émir, et d'autres pour ses deux fils, pour son frère, pour le cheïkh Mozhaffer eddîn, et pour moi. On amena dix chevaux pour l'émir et pour son frère, six pour ses deux fils, pour chaque grand de sa suite un cheval, et un aussi pour moi.

Les chevaux sont très nombreux dans cette contrée et ${ }_{\text {p211 }}$ ils coûtent fort peu. Le prix d'un excellent cheval est de cinquante ou soixante dirhems du pays, qui correspondent à un dînâr du Maghreb, ou environ. Ces chevaux sont les mêmes que l'on connaît en Égypte

${ }^{350}$ Littéralement, « la parole », mais figurant dans des dictionnaires persans comme une forme de chanson.

351 Bigarré ; terme appliqué à des poèmes composés des vers alternants persans et turcs. 
sous le nom d'acâdîch ${ }^{352}$. C'est d'eux que les habitants tirent leur subsistance, et ils sont aussi nombreux dans ce pays que les moutons dans le nôtre, ou même bien davantage : un seul Turc en possède quelquefois des milliers. C'est la coutume des Turcs établis dans ce pays, et possesseurs de chevaux, de placer, sur les 'arabahs dans lesquels montent leurs femmes, un morceau de feutre de la longueur d'un empan, lié à un bâton mince, long d'une coudée, et fixé à l'un des angles du chariot. On y place un morceau par chaque millier de chevaux, et j'en ai vu qui avaient dix morceaux et au-dessus. Ces chevaux sont transportés dans l'Inde, et il y en a dans une caravane jusqu'à six mille, tantôt moins et tantôt plus. Chaque marchand en a cent ou deux cents, plus ou moins. Les marchands prennent à gage, pour chaque troupe de cinquante chevaux, un gardien qui en a soin et les fait paître comme des moutons; cet homme se nomme chez eux alkachy ${ }^{353}$ monte un des chevaux et tient dans sa main un long bâton auquel est attachée une corde. Quand il veut saisir un de ces animaux, il se place vis-à-vis de celui-ci avec le cheval qu'il a pour monture ; il lui lance la corde au cou, le tire à soi, monte sur son dos, et laisse paître l'autre.

Lorsque les marchands sont arrivés avec leurs chevaux dans le Sind, ils leur font manger des grains, parce que les plantes du Sind ne sauraient remplacer l'orge. Il meurt beaucoup de ces animaux, et il en est aussi dérobé. On fait payer aux propriétaires un droit de sept dînârs d'argent par cheval dans une localité du Sind appelée Chechnakâr ${ }^{354}$; ils sont aussi taxés à Moltân, p212 capitale du Sind. Autrefois, ils étaient imposés au quart de la valeur de ce qu'ils importaient. Mais le roi de l'Inde, le sultan Mohammed, a aboli ce droit ; il a ordonné que l'on perçût sur les marchands musulmans la zekâh ${ }^{355}$, et sur les infidèles, le dixième. Malgré cela, il reste aux marchands de chevaux un grand bénéfice, car ils vendent dans l'Inde un cheval de peu de valeur cent dînârs d'argent ; ceux-ci équivalant, en or du Maghreb, à vingtcinq dinars. Souvent, ils en retirent le double ou le triple de cette somme. Un excellent cheval vaut cinq cents dînârs ou davantage. Les

\footnotetext{
352 Pluriel d’iqdish, cheval de race mélangée et aussi cheval hongre.

353 Terme uighur, ulaktchi.

354 Probablement Hashtnagar, à vingt kilomètres au nord-ouest de Pashawar.

355 Dîme aumônière, consistant en deux et demi pour cent du capital en général, mais de cinq pour cent pour les chevaux.
} 
habitants de l'Inde ne les achètent pas pour la marche précipitée et la course, car ils revêtent dans les combats des cottes de mailles, et ils en couvrent aussi leurs chevaux. Ils prisent seulement, dans un cheval, sa force et la longueur de ses pas. Quant aux chevaux qu'ils recherchent pour la course, on les leur amène du Yaman, de l'Omân et du Fars. Un de ces derniers se vend depuis mille jusqu’à quatre mille dînârs.

Lorsque l'émir Toloctomoûr fut parti d'Azâk, je restai dans cette ville trois jours après lui, jusqu'à ce que l'émir Mohammed Khodjah m'eût préparé les objets nécessaires pour le voyage. Je me mis alors en route pour Mâtchar ${ }^{356}$, qui est une cité considérable, et l'une des plus belles villes qui appartiennent aux Turcs ; elle est située sur un grand fleuve. Il s'y trouve des jardins, et les fruits y abondent. Nous y logeâmes dans l'ermitage du cheïkh pieux et dévot, du vénérable Mohammed albathâïhy, originaire des Bathâïh, ou marais de l'Irâk. Il était le successeur et vicaire du cheïkh Ahmed arrifâ'y, dont Dieu soit satisfait. Il y avait dans sa zâouïah environ soixante et dix fakîrs arabes, persans, p213 turcs et grecs, tant mariés que célibataires. Leurs moyens d'existence consistaient en aumônes. Les habitants de ce pays ont une très bonne opinion des fakîrs, et toutes les nuits ils amènent à l'ermitage des chevaux, des bœufs et des moutons. Le sultan et les princesses viennent visiter le cheïkh et recevoir ses bénédictions ; ils le traitent avec la plus grande libéralité, et lui font des présents considérables, particulièrement les femmes. Celles-ci répandent de nombreuses aumônes et recherchent les bonnes œuvres. Nous fîmes dans la ville de Mâdjar la prière du vendredi. Lorsque l'on se fut acquitté de cette prière, le prédicateur Izz eddîn monta en chaire. C'était un des docteurs ès lois et des hommes distingués de Bokhâra ; il avait un bon nombre de disciples, et de lecteurs du Coran, qui lisaient ce livre devant lui. Il prêcha et exhorta les assistants en présence de l'émir et des grands de la ville; puis le cheïkh Mohammed albathâihy se leva et dit : « Le jurisconsulte et prédicateur désire voyager, et nous voulons pour lui des provisions de route. " Ensuite il ôta une tunique d'étoffe de laine qui le couvrait et ajouta: "Voilà le don que je lui fais. " Parmi les assistants, les uns se dépouillèrent, les autres donnèrent un

${ }^{356}$ Identifiée comme l'actuel Burgomadzhary sur la rivière Kuma dans le district actuel de Stavropol, à quatre cent cinquante kilomètres environ au sud-est d'Azov. 
cheval, d'autres de l'argent. Beaucoup de ces divers objets furent recueillis pour le docteur.

Je vis dans le bazar de cette ville un juif qui me salua et me parla en arabe. Je l'interrogeai touchant son pays, et il me dit qu'il était originaire d'Espagne, qu'il était arrivé par la voie de terre, qu'il n'avait pas voyagé sur mer, et était venu, par le chemin de Constantinople la Grande, de l'Asie Mineure et du pays des Circassiens ${ }^{357}$. Il ajouta que l'époque de son départ de l'Espagne remontait à quatre mois. Les marchands voyageurs, qui connaissent ces matières, m'informèrent de la vérité de son discours.

Je fus témoin, dans cette contrée, d'une chose p214 remarquable, c'est-à-dire de la considération dont les femmes jouissent chez les Turcs ; elles y tiennent, en effet, un rang plus élevé que celui des hommes. Quant aux femmes des émirs, la première fois que j'en vis une, ce fut lorsque je sortis de Kiram. J'aperçus alors la princesse, femme de l'émir Salthiyah, dans son chariot. Toute la voiture était recouverte de drap bleu d'un grand prix ; les fenêtres et les portes du pavillon étaient ouvertes. Devant la princesse se tenaient quatre jeunes filles, d'une exquise beauté et merveilleusement vêtues. Par-derrière venaient plusieurs autres chariots, où se trouvaient les jeunes filles qui la servaient. Lorsqu'elle approcha de la station de l'émir, elle descendit de l'arabah ; environ trente jeunes filles descendirent aussi, pour soulever les pans de sa robe. Ses vêtements étaient pourvus de boutonnières ; chaque jeune fille en prenait une ; elles soulevaient ainsi les pans de tous côtés, et de cette manière la khâtoûn marchait avec majesté. Lorsqu'elle fut arrivée près de l'émir, il se leva devant elle, lui donna le salut et la fit asseoir à son côté, les jeunes esclaves entourant leur maîtresse. On apporta des outres de kimizz, ou lait de cavale. Elle en versa dans une coupe, s'assit sur ses genoux devant l'émir, et la lui présenta. Lorsqu'il eut bu, elle fit boire son beau-frère, et l'émir la fit boire à son tour. On servit des aliments, la princesse en mangea avec l'émir, il lui donna un vêtement et elle s'en retourna. C'est de cette manière que sont traitées les femmes des émirs, et nous parlerons ci-après des femmes du roi. Quant à celles des trafiquants et des petits marchands, je les ai vues aussi. L'une de celles-ci sera, par exemple,

${ }^{357}$ La partie nord-ouest du Caucase, proche du littoral de la mer Noire. 
dans un chariot traîné par des chevaux. Près d'elle se trouveront trois ou quatre jeunes filles, portant les pans de sa robe, et sur sa tête sera

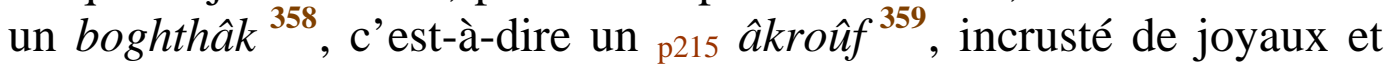
garni, à son extrémité supérieure, de plumes de paons. Les fenêtres de la tente du chariot seront ouvertes, et l'on verra la figure de cette femme ; car les femmes des Turcs ne sont pas voilées. Une autre, en observant ce même ordre et accompagnée de ses serviteurs, apportera au marché des brebis et du lait, qu'elle vendra aux gens pour des parfums. Souvent la femme est accompagnée de son mari, que quiconque le voit prend pour un de ses serviteurs. Il n'a d'autre vêtement qu'une pelisse de peau de mouton, et il porte sur sa tête un haut bonnet qui est en rapport avec cet habit, et qu'on appelle alcula ${ }^{360}$.

Nous nous préparâmes à partir de la ville de Madjar, pour nous diriger vers le camp du sultan, qui était placé à quatre journées de distance, dans un endroit nommé Bichdagh ${ }^{361}$. Le sens de bich, dans la langue des Turcs, est cinq, et dagh a la signification de montagne. Dans ces cinq montagnes se trouve une source d'eau thermale, dans laquelle les Turcs se lavent ; car ils prétendent que quiconque s'y est baigné est à l'abri des attaques de la maladie. Nous nous mîmes donc en marche vers l'emplacement du camp, et nous y arrivâmes le premier jour de ramadhân ${ }^{362}$. Nous trouvâmes que le cortège du sultan avait changé de place, et nous revînmes au lieu d'où nous étions partis, parce que le camp devait être planté dans le voisinage. Je dressai ma tente sur une colline située en cet endroit ; je fixai devant la tente un p216 étendard et je plaçai les chevaux et les chariots par-derrière.

358 «Les femmes ont un ornement de tête qu'elles appellent boca ou botta. Elles le font d'écorce d'arbre ou de tout autre matière la plus légère qu'elles puissent trouver. Cette coiffure est longue d'une coudée et davantage et carrée par en haut comme un chapiteau. Elles recouvrent cet ornement d'une étoffe de soie précieuse et sur cette espèce de chapiteau elles fixent des tuyaux de plumes également de la longueur d'une coudée et plus. Et dans ces tuyaux elles placent des plumes de paon et tout à l'entour des plumes de queues de malart (mâle de cane sauvage) avec des pierres précieuses " (Guillaume DE RUBROUCK).

Bonnet haut, de forme conique.

${ }^{360}$ Kulâh en persan : bonnet.

${ }^{361}$ L'actuel P'atigorsk sur un affluent amont de Kuma, au nord du Caucase. Les 362 sources thermales existent toujours.

Le 6 mai 1334. 
Sur ces entrefaites arriva le cortège impérial que les Turcs appellent ordou ${ }^{363}$. Nous vîmes ainsi une grande ville qui se meut avec ses habitants, qui renferme des mosquées et des marchés, et où la fumée des cuisines s'élève dans les airs ; car les Turcs font cuire leurs mets pendant le voyage même. Des chariots traînés par des chevaux, transportent ces peuples, et lorsqu'ils sont arrivés au lieu du campement ils déchargent les tentes qui se trouvent sur les 'arabahs et les dressent sur le sol car elles sont très légères. Ils en usent de même avec les mosquées et les boutiques. Les épouses du sultan passèrent près de nous, chacune avec son cortège séparé. Lorsque la quatrième en rang vint à passer (c'est la fille de l'émir 'Iça bec, et nous en parlerons ciaprès), elle vit la tente dressée au sommet de la colline, et l'étendard qui était planté devant, lequel indiquait un nouvel arrivé. Elle envoya des pages et des jeunes filles, qui me saluèrent et me donnèrent le salut de sa part. Pendant ce temps, elle était arrêtée à les attendre. Je lui envoyai un présent, par un de mes compagnons et par le mo'arrif ou chambellan de l'émir Toloctomoûr. Elle accueillit ce don comme un présage favorable, et ordonna que je logeasse dans son voisinage ; puis elle se remit en marche. Le sultan arriva ensuite et campa dans son quartier séparé.

\section{DU SULTAN ILLUSTRE MOHAMMED UZBEC KHÂN}

Son nom est Mohammed Uzbec ${ }^{364}$, et le sens de khân, chez les Turcs, est celui de sultan. Il possède un grand royaume, il est très puissant, illustre, élevé en dignité, vainqueur des ennemis de Dieu, les habitants de ${ }_{\text {p217 }}$ Constantinople la Grande, et plein d'ardeur pour les combattre. Ses États sont vastes, et ses villes considérables. Parmi celles-ci, on compte Cafa, Kiram, Mâdjar, Azâk, Sordak ${ }^{365}$, Khârezm et sa capitale, Asserâ ${ }^{366}$.

\footnotetext{
${ }_{364}^{363}$ Horde, le camp du souverain.

${ }^{364}$ Uzbek Khan (1312-1341), souverain mongol de la Horde d’Or. A partir d'Uzbek, les souverains de la Horde d'Or deviennent musulmans.

365 Soldaïa, l'actuel Sudak en Crimée, au sud-est de Feodosia, comptoir vénitien 366 et le principal port de la Crimée avant la montée de Kaffa.

Saray. Une première ville de ce nom fut fondée par Batu, le premier souverain de la Horde d'Or (1227-1256), comme résidence d'hiver près de l'actuel village de Selitrennoje à cent kilomètres en amont d'Astrakhan sur la Volga. La
} 
C'est un des sept plus grands et plus puissants rois du monde, savoir : notre maître le prince des croyants, l'ombre de Dieu sur la terre, chef de la troupe victorieuse, laquelle ne cessera de défendre la vérité jusqu'au jour de la résurrection ; que Dieu affermisse son autorité et ennoblisse sa victoire ! le sultan d'Égypte et de Syrie ; le sultan des deux Irâks ; le sultan Uzbec, dont il est ici question ; le sultan du Turkistân et de Mâwarâ'nnahi ${ }^{367}$; le sultan de l'Inde ; le sultan de la Chine. Lorsque le sultan Uzbec est en voyage, il n'a avec lui, dans son camp, que ses mamloûcs et les grands de son empire. Chacune de ses femmes occupe un quartier séparé ; quand il veut se rendre près de l'une d'elles, il l'envoie prévenir, et elle se prépare à le recevoir. Il observe, dans ses audiences, dans ses voyages et dans ses affaires un ordre surprenant et merveilleux.

Il a coutume de s'asseoir le vendredi, après la prière, dans un pavillon appelé le pavillon d'or, et qui est richement orné et magnifique. Il est formé de baguettes de bois, revêtues de feuilles du même métal. Au milieu est un trône de bois recouvert de lames d'argent doré ; ses pieds sont d'argent massif, et leur partie supérieure est incrustée de pierreries. Le sultan s'assied sur le trône, ayant à sa droite la princesse Thaïthoghly, après laquelle vient la khâtoûn Kebec, et à sa gauche la p218 khâtoûn Beïaloûn, que suit la khâtoûn Ordodjy. Le fils du sultan, Tîna bec, est debout au bas du trône, à droite, et son second fils, Djâni bec, se tient debout au côté opposé. La fille d’Uzbec, It Cudjudjuc, est assise devant lui, Lorsqu'une de ces princesses arrive, il se lève devant elle et la tient par la main, jusqu'à ce qu'elle soit montée sur le trône. Quant à Thaïthoghly, qui est la reine, et la plus considérée des khâtoûns aux yeux d’Uzbec, il va au-devant d'elle jusqu'à la porte de la tente, lui donne le salut, la prend par la main, et quant elle est montée sur le trône, et qu'elle est assise, alors seulement il s'assied. Tout cela se passe aux yeux des Turcs, et sans aucun voile. Les principaux émirs arrivent après ces cérémonies, et leurs sièges sont dressés à droite et à gauche ; car, lorsque chacun d'eux vient à la réception du sultan, un page l'accompagne, portant son siège. Les fils de roi, cou-

nouvelle Saray fut probablement fondée par Berke (1257-1266), plus au nord, 367 sur le site de l'actuel Car'ov, à soixante-dix kilomètres à l'est de Stalingrad.

La Transoxiane, c’est-à-dire les souverains mongols de la lignée de Djaghatay (voir plus loin). 
sins germains, neveux et proches parents du sultan se tiennent debout devant lui. Les enfants des principaux émirs restent debout vis-à-vis d'eux, près de la porte de la tente. Les chefs des troupes se tiennent également debout derrière les fils des émirs, à droite et à gauche. Ensuite les sujets entrent pour saluer le sultan, selon leurs rangs respectifs, trois par trois ; ils saluent, s'en retournent et s'asseyent à quelque distance.

Lorsque la prière de l'après-midi a été prononcée, la reine s'en retourne. Les autres khâtoûns s'en vont aussi et la suivent jusqu'à son campement. Quand elle y est rentrée, elles retournent à leur propre quartier, montées sur des chariots. Chacune est accompagnée d'environ cinquante jeunes filles, montées sur des chevaux. Devant l'arabah, il y a environ vingt femmes âgées ${ }^{368}$, à cheval, entre les pages et le chariot, et derrière le tout, environ cent jeunes esclaves. Devant les pages sont environ cent esclaves âgés, à cheval, et autant à pied. Ceux-ci tiennent dans leurs mains des baguettes, et ont des p219 épées attachées à leurs ceintures ; ils marchent entre les cavaliers et les pages. Tel est l'ordre que suit chaque princesse en arrivant et en s'en retournant.

Je me logeai dans le camp, non loin du fils du sultan, Djâni bec, dont il sera encore fait mention ci-après. Le lendemain de mon arrivée, je visitai le sultan, après la prière de trois à quatre heures. Il avait déjà rassemblé les cheïkhs, les kâdhis, les docteurs de la loi, les chérîfs, les fakîrs, et il avait fait préparer un festin considérable. Nous rompîmes le jeûne en sa présence. Le noble seigneur, chef des descendants de Mahomet, Ibn 'Abd Elhamîd, ainsi que le kâdhi Hamzah parlèrent tous deux de moi, en termes favorables, et conseillèrent au sultan de me traiter honorablement. Ces Turcs ne suivent pas l'usage de loger les voyageurs et de leur assigner une somme pour leur entretien. Ils se contentent de leur envoyer des brebis et des chevaux destinés à être égorgés, et des outres de kimizz ou lait de jument. C'est là leur manière de montrer de la générosité. Quelques jours plus tard, je fis la prière de l'après-midi avec le sultan, et lorsque je voulus m'en retourner il m'ordonna de m'asseoir. On apporta des aliments liquides, comme on en apprête avec la graine appelée doûghy ; puis on 
servit de la viande bouillie, tant de mouton que de cheval. Dans la même nuit, je présentai au sultan un plateau de sucreries. Il y porta le doigt, qu'il mit ensuite dans sa bouche ; mais il s’en tint là.

\section{DÉTAILS SUR LES KHÂTOÛNS ET SUR L'ORDRE QU’ELLES OBSERVENT}

Chacune d'elles monte dans un chariot, et la tente dans laquelle la princesse se tient sur ce véhicule a un dôme d'argent doré, ou de bois incrusté d'or. Les chevaux qui traînent l'arabah sont couverts de housses de soie dorée, Le conducteur qui monte un des chevaux est ${ }_{\text {p220 }}$ un jeune homme qui est appelé alkachy ${ }^{369}$, La khâtoûn est assise dans son chariot, ayant à sa droite une espèce de duègne, que l'on nomme oûloû khâtoûn, c'est-à-dire la conseillère, et à sa gauche une autre duègne, nommée cutchuc khâtoûn ${ }^{370}$, c'est-à-dire la camériste. Elle a devant elle six petites esclaves, appelées filles, d'une beauté exquise et parfaite, et enfin derrière elle deux autres toutes pareilles, sur qui elle s'appuie. Sur la tête de la khâtoûn se trouve un boghthâk ${ }^{371}$ qui est une espèce de petite tiare, ornée de joyaux, et terminée à sa partie supérieure par des plumes de paon. La princesse est couverte d'étoffes de soie incrustées de pierreries, et semblables au menoût ${ }^{372}$ que revêtent les Grecs. Sur la tête de la conseillère et de la camériste est un voile de soie, dont les bords sont brodés d'or et de perles. Chacune des filles porte sur la tête un bonnet qui ressemble à l'âkroûf ${ }^{373}$, et à la partie supérieure duquel est un cercle d'or incrusté de joyaux, et surmonté de plumes de paon. Chacune est vêtue d'une étoffe de soie dorée, qui s'appelle annekh ${ }^{374}$. Il y a devant la khâtoûn dix ou quinze eunuques grecs et indiens, revêtus d'étoffes de soie dorée, incrustées de pierreries, et portant chacun à la main une massue d'or ou d'argent, ou bien de bois recouvert d'un de ces métaux. Derrière le char de la khâtoûn en viennent environ cent autres, dans chacun desquels sont

\footnotetext{
${ }^{369}$ Du kiptchak kosci : esclave, page.

370 Ulu : la grande ; kücük : la petite.

371 Voir n. 31 ci-dessus.

372 D’après Defremery, de melluta, lui-même du grec malloté, mais qui signifie tissus de laine.

373 Voir n. 35 ci-dessus.

${ }^{374}$ Voir chap. 2, n. 100.
} 
trois ou quatre esclaves, grandes et petites, vêtues de soie et coiffées de bonnets. Derrière ces chariots marchent environ trois cents autres, que traînent des chameaux et des bœufs, et qui portent les trésors de la khâtoûn, ses richesses, ses vêtements, son mobilier et ses provisions de bouche. Chaque 'arabah a son esclave, chargé d'en prendre soin, et marié à une ${ }_{\text {p221 }}$ des jeunes femmes mentionnées ci-dessus. La coutume des Turcs est que celui-là seul des jeunes esclaves mâles qui a une épouse parmi les jeunes esclaves de l'autre sexe puisse s'introduire au milieu d'elles. Chaque princesse suit l'ordre que nous venons d'exposer, et nous allons maintenant les mentionner toutes séparément.

\section{DE LA GRANDE KHÂTOÛN}

Celle-ci est la reine, mère des deux fils du sultan, Djâni bec et Tîna bec, dont nous parlerons ci-après. Mais elle n'est pas la mère de la fille du sultan, It Cudjudjuc ; la mère de cette princesse est la reine qui a précédé celle d’à présent. Le nom de cette khâtoûn est Thaïthoghly ${ }^{375}$; elle est la plus favorisée des femmes de ce sultan, et c'est près d'elle qu'il passe la plupart des nuits. Le peuple la respecte, à cause de la considération que lui témoigne le souverain, et bien qu'elle soit la plus avare des khâtoûns. Quelqu'un en qui j'ai confiance, et qui connaît bien les aventures de cette reine, m'a conté que le sultan la chérit à cause d'une qualité particulière qu'elle possède. Celle-ci consiste en ce que le sultan la trouve chaque nuit semblable à une vierge. Un autre individu m'a raconté que cette princesse descendait de la femme qui, à ce qu'on prétend, fut cause que Salomon perdit le pouvoir pour un temps. Lorsqu'il l'eut recouvré, il ordonna de la conduire dans une plaine sans habitations ; en conséquence, elle fut menée dans le désert de Kifdjak ${ }^{376}$. Ce même individu assure ${ }_{\text {p222 }}$ que

375 Connue par une lettre du pape Benoît XII datée du 17 août 1340 et adressée à " l'impératrice des Tartares septentrionaux Taydola » et exprimant l'espoir que « Taydola, favorable aux chrétiens, se convertisse », ainsi que par une lettre du doge Andrea Dandolo à Djani Bek mentionnant « Thaytholu Katou ».

${ }^{376}$ La tradition juive raconte que Salomon, à la suite de ses fautes ou de la perte de son anneau magique, fut temporairement dépossédé de la royauté ; il erra à travers le monde, appuyé sur un bâton, la seule chose qui lui restait ; un démon, prenant l'apparence de Salomon, se serait alors assis sur le trône royal. 
la matrice de la khâtoûn ressemble, par sa forme, à un anneau, et qu'il en est ainsi chez toutes les femmes qui descendent de celle en question. Je n'ai rencontré, dans le Kifdjak ni ailleurs, personne qui m’ait certifié avoir vu une femme ainsi conformée, ou qui en ait même entendu parler, si l'on excepte le cas de cette khâtoûn. Seulement un habitant de la Chine m'a informé que, dans ce pays, il y a une espèce de femmes qui ont cette même conformation. Une pareille femme n'est pas tombée entre mes mains ; je ne connais donc pas la vérité du fait.

Le lendemain de mon entrevue avec le sultan, Je visitai cette khâtoûn. Je la trouvai assise au milieu de dix femmes âgées, qui paraissaient comme ses servantes. Devant elle, il y avait environ cinquante de ces petites esclaves nommées par les Turcs les filles; devant celles-ci se trouvaient des plats creux d'or et d'argent, remplis de cerises, qu'elles étaient occupées à nettoyer. Devant la khâtoûn, il y avait un plat d'or plein des mêmes fruits, qu'elle mondait aussi. Nous la saluâmes. Il y avait parmi mes compagnons un lecteur du Coran, qui lisait ce livre à la manière des Égyptiens, avec une méthode excellente et une voix agréable. Il fit une lecture, après laquelle la reine ordonna qu'on apportât du lait de jument. On en apporta dans des coupes de bois élégantes et légères. Elle en prit une de sa propre main et me l'avança. C'est la plus grande marque de considération chez les Turcs. Je n'avais pas bu de kimizz auparavant ; mais je ne pus me dispenser d'en accepter. Je le goûtai, je n’y trouvai aucun agrément, et le passai à un de mes compagnons. La khâtoûn m'interrogea touchant beaucoup de circonstances de notre voyage, et nous répondîmes à ses questions ;

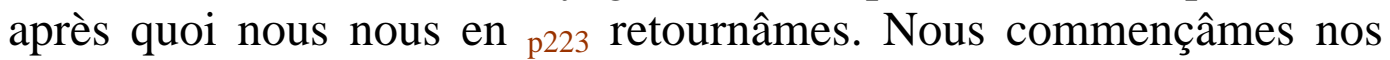
visites par cette princesse, à cause de la considération dont elle jouit auprès du roi.

DE LA SECONDE KHÂTOÛN, QUI VIENT IMMÉDIATEMENT APRÈS LA REINE

Son nom est Kebec khâtoûn ; et le mot kebec, en turc, veut dire le son de la farine. Elle est fille de l'émir Naghathaï, qui est encore en

Salomon recouvra ensuite, avec son anneau, toutes ses prérogatives. Le Coran résume: "Oui, nous avons éprouvé Salomon en plaçant un corps sur son trône ; mais il se repentit ensuite » (XXXVIII, 34). A partir de là, un grand nombre de légendes se sont développées. 
vie ; mais il souffre de la goutte, et je l'ai vu. Le lendemain de notre visite à la reine, nous visitâmes cette seconde khâtoûn, et nous la trouvâmes assise sur un coussin, occupée à lire le noble Coran. Devant elle se tenaient environ dix femmes âgées, et environ vingt filles qui brodaient des étoffes. Nous la saluâmes ; elle répondit très bien à notre salut, et nous parla avec bonté. Notre lecteur fit une lecture dans le Coran ; elle lui accorda des éloges, et ordonna d'apporter du kimizz. On en servit, et elle m'avança elle-même la coupe, comme l'avait fait la reine ; après quoi nous nous en retournâmes.

\section{DE LA TROISIÈME KHÂTOÛN}

Elle se nomme Beïaloûn, et elle est fille du roi de Constantinople la Grande, le sultan de Tacfoûr ${ }^{377}$. Nous p224 la visitâmes, et la trouvâmes assise sur un trône incrusté d'or et de pierreries, et dont les pieds étaient d'argent. Devant elle environ cent jeunes filles grecques, turques, nubiennes, se tenaient debout ou assises, Des eunuques étaient placés auprès de cette princesse, et il y avait devant elle des chambellans grecs. Elle s'informa de notre état, de notre arrivée, de l'éloignement de notre demeure ; elle pleura de tendresse et de compassion, et s'essuya le visage avec un mouchoir qu'elle tenait entre ses mains. Elle ordonna d'apporter des aliments, ce qui fut fait ; et nous mangeâmes en sa présence, pendant qu'elle nous regardait. Lorsque nous voulûmes nous en retourner, elle nous dit : "Ne vous séparez pas de nous pour toujours, revenez nous voir, et informez-nous de vos besoins. " Elle montra des qualités généreuses, et nous envoya, aussitôt après notre sortie, des aliments, beaucoup de pain, du beurre, des moutons, de l'argent, un vêtement magnifique, et treize chevaux, dont trois excellents. Ce fut en compagnie de cette khâtoûn que je fis mon

${ }^{377}$ Les empereurs byzantins sont connus dans la littérature arabe sous le nom de takfur, dérivé de l'arménien tagavor. On possède une seule mention indirecte de cette princesse, qui ne figure pas dans les généalogies byzantines, dans la lettre écrite en 1341 par l'homme de lettres et moine byzantin Grégoire Akindynos à son ami David Dishypatos, alors moine dans les Balkans. Elle rapportait la réception à Constantinople d'une lettre de la fille de l'empereur, épouse du souverain des Scythes (c'est-à-dire les Mongols) annonçant une expédition de soixante mille hommes contre la région danubienne et la Thrace. Bayalun devait être alors une fille naturelle d’Andronic III Paléologue. 
voyage à Constantinople la Grande, ainsi que nous le raconterons cidessous.

\section{DE LA QUATRIÈME KHÂTOÛN}

Son nom est Ourdoudjâ ; ourdou, dans la langue des Turcs, signifie le camp, et cette princesse fut ainsi nommée parce qu'elle naquit dans un camp. Elle est fille du grand émir 'Iça bec, émir aloloûs ${ }^{378}$, et le sens de ce dernier mot est émir des émirs. J’ai vu ce personnage, qui était encore en vie, et marié à la fille du sultan, It Cudjudjuc. Cette quatrième khâtoûn est au nombre des princesses les meilleures, les plus généreuses de caractère, et les plus compatissantes. C'est elle qui m'envoya un message lorsqu'elle vit ma tente sur la colline, lors du passage du camp, comme nous l'avons raconté p225 ci-dessus. Nous la visitâmes, et nous reçûmes de la bonté de son caractère et de la générosité de son âme un traitement qui ne pourrait être surpassé. Elle commanda d'apporter des mets, et nous mangeâmes devant elle ; puis elle demanda du kimizz, et mes compagnons en burent. La khâtoûn nous interrogea touchant notre état, et nous satisfîmes à ses questions. Nous rendîmes aussi visite à sa sœur, femme de l'émir 'Aly, fils d'Arzak.

\section{DE LA FILLE DU SULTAN ILLUSTRE UZBEC}

Elle se nomme It Cudjudjuc, c'est-à-dire la Caniche ; car ît signifie chien, et cudjudjuc petit ${ }^{379}$. Nous avons déjà dit que les Turcs, ou Mongols, reçoivent les noms que le sort a désignés, ainsi que font les Arabes. Nous nous rendîmes près de cette khâtoûn, fille du roi, laquelle se trouvait dans un camp séparé, à environ six milles de celui de son père. Elle ordonna de mander les docteurs de la loi, les kâdhis, le seigneur chétif Ibn 'Abd elhamîd, le corps des étudiants, les cheïkhs et les fakirs. Son mari, l'émir 'Iça, dont la fille est l'épouse du sultan, assistait à cette réunion. Il s'assit avec la princesse sur un même tapis ;

Ulus, en mongol, désigne une fédération de tribus gouvernée par un chef supérieur. 
il souffrait de la goutte, et ne pouvait marcher ni monter à cheval, et il montait seulement dans un chariot. Lorsqu'il voulait visiter le sultan, ses serviteurs le descendaient de voiture, et l'introduisaient dans la salle d'audience en le portant. C'est dans le même état que je vis l'émir Naghathaï, père de la seconde khâtoûn : car la maladie de la goutte est fort répandue parmi ces Turcs. Nous vîmes chez cette khâtoûn, fille du sultan, en fait d'actions généreuses et de bonnes qualités, ce que nous n'avions vu chez aucune autre. Elle nous fit des présents magnifiques, et nous combla de bienfaits. Que Dieu l'en récompense ! p226

\section{DES DEUX FILS DU SULTAN}

Ils sont nés de la même mère, qui est la reine Thaïthoghly, dont nous avons parlé ci-dessus. L'aîné s'appelle Tîna bec ${ }^{380}$, bec a le sens d'émir, et tîn celui de corps ; c'est donc comme s'il se nommait Emir du Corps. Le nom de son frère est Djâni bec ${ }^{381}$. Djân signifie l'âme ; c'est comme s'il s'appelait Emir de l'Ame. Chacun de ces deux princes a son camp séparé. Tîna bec était au nombre des hommes les plus beaux, et son père l'avait déclaré son successeur. Il jouissait près d'Uzbec d'une grande considération et d'un rang distingué. Mais Dieu ne voulut pas qu'il possédât le royaume paternel. Lorsque son père fut mort, il régna fort peu de temps, puis il fut tué, à cause d'affaires honteuses qui lui survinrent. Son frère Djâni bec lui succéda ; il était meilleur et plus vertueux que son aîné. Le seigneur chérîf Ibn 'Abd alhamîd avait pris soin de l'éducation de Djâni bec.

Ledit chérif, le kâdhi Hamzah, l’imâm Bedr eddîn Alkiwâmy, l'imâm et professeur de lecture coranique Hoçâm eddîn Albokhâry et d'autres personnes me conseillèrent, lorsque j'arrivai, de me loger dans le camp de Djâni bec, à cause de son mérite ; et j’agis de la sorte.

380 Tini Bek, successeur de son père pour quelques mois en 1342-1343. Il faut chercher l'étymologie du nom plutôt dans le turc tin, esprit, que dans le persan tan, corps.

381 Il succéda à son frère en l'éliminant (1342-1357). 


\section{RÉCIT DE MON VOYAGE À LA VILLE DE BOLGHÂR}

J'avais entendu parler de la ville de Bolghâr ${ }^{382}$. Je voulus m'y ren-

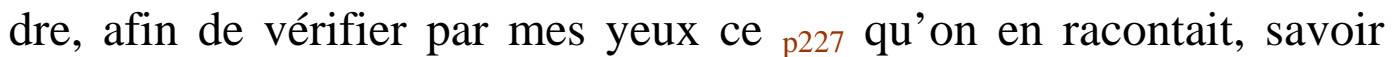
l'extrême brièveté de la nuit dans cette ville, et la brièveté du jour dans la saison opposée. Il y avait entre Bolghâr et le camp du sultan une distance de dix jours de marche. Je demandai à ce prince quelqu'un pour m'y conduire, et il envoya avec moi un homme qui me mena à Bolghâr, et me ramena près du sultan. J'arrivai dans cette ville pendant le mois de ramadhân. Lorsque nous eûmes fait la prière du coucher de soleil, nous rompîmes le jeûne ; on appela les fidèles à la prière du soir, tandis que nous faisions notre repas. Nous célébrâmes cette prière, ainsi que les prières terâwih, chef', witr, et le crépuscule du matin parut aussitôt après ${ }^{383}$. Le jour est aussi court à Bolghâr dans la saison des jours courts, c'est-à-dire l'hiver. Je passai trois journées dans cette ville.

\section{DU PAYS DES TÉNÈBRES}

J'avais désiré entrer dans la terre des Ténèbres ${ }^{384}$; on y pénètre en passant par Bolghâr, et il y a entre ces deux points une distance de quarante jours ; mais ensuite je renonçai à mon projet, à cause de la grande difficulté que présentait le voyage, et du peu de profit qu'il promettait. On ne voyage pas vers cette contrée, sinon avec de petits chariots tirés par de gros chiens ; car, ce désert étant couvert de glace,

${ }^{382}$ Les ruines de la ville de Bulghar se trouvent à cent quinze kilomètres au sud de Kazan, à sept kilomètres de la rive gauche de la Volga. Capitale des Bulgares de la Volga convertis à l'islam au $\mathrm{X}^{\mathrm{e}}$ siècle, elle fut prise par les Mongols en 1237 et conserva son caractère de centre commercial pendant cette période. Étant située à plus de mille kilomètres au nord de Bes Dag, il est impossible qu’Ibn Battûta ait pu réaliser ce voyage au courant du mois de Ramadhan.

383 Prières spéciales observées pendant le Ramadhan.

384 «[...] encore vers tramontane est une province qui est appelée la vallée de l'Obscurité, et l'on peut dire qu'elle est bien nommée, parce qu'en tout temps il y fait sombre, sans soleil, ni lune, ni étoiles; la plus grande partie de l'année, il y fait aussi obscur que chez nous au crépuscule du soir, lorsqu'on y voit et n'y voit point. C'est à cause de l'épais brouillard qui s'y étend toujours, et n'est jamais ni détruit ni chassé » (Marco PoLO). Le thème est très populaire à l'époque et aussi bien Marco Polo qu'Ibn Battûta qui ne se sont jamais aventurés vers le Grand Nord puisent dans les mêmes sources. 
les pieds des hommes et les sabots des bêtes de charge y glissent. Mais les chiens ont ${ }_{\text {p228 }}$ des ongles, et leurs pattes ne glissent pas sur la glace. Il n'entre dans ce désert que de riches marchands, dont chacun a cent chariots ou environ, chargés de provisions de bouche, de boissons et de bois à brûler. Il ne s'y trouve, en effet, ni arbres, ni pierres, ni habitations. Le guide des voyageurs dans cette contrée, c'est le chien qui l'a déjà traversée nombre de fois. Le prix d'un tel animal monte jusqu'à mille dinars ou environ. Le chariot est attaché à son cou, trois autres chiens sont attelés avec celui-là ; il est le chef, et tous les autres chiens le suivent avec les 'arabahs. Lorsqu'il s'arrête, ils s'arrêtent aussi. Le maître de cet animal ne le maltraite pas et ne le gronde point. Quand on sert des aliments, il fait d'abord manger les chiens, avant les hommes. Si le contraire a lieu, le chef des animaux est mécontent ; il s'enfuit et abandonne son maître à sa perte. Lorsque les voyageurs ont marché quarante jours dans ce désert, ils campent près du pays des Ténèbres. Chacun d'eux laisse en cet endroit les marchandises qu'il a apportées, puis ils vont tous à leur station accoutumée. Le lendemain, ils reviennent examiner leurs marchandises. Ils trouvent vis-à-vis de celles-ci des peaux de martre-zibeline, de petitsgris et d'hermine. Si le propriétaire des marchandises est satisfait de ce qu'il voit vis-à-vis de sa pacotille, il le prend ; sinon, il le laisse. Les habitants du pays des Ténèbres augmentent les objets qu'ils ont laissés ; mais souvent aussi ils enlèvent leurs marchandises et laissent celles des trafiquants étrangers. C'est ainsi que se fait leur commerce. Les gens qui se dirigent vers cet endroit ne connaissent pas si ceux qui leur vendent et leur achètent sont des génies ou des hommes, et ils ne voient jamais personne ${ }^{385}$.

L'hermine est la plus belle espèce de fourrure. Une pelisse de cette dernière vaut, dans l'Inde, mille dînârs, dont le change en or du Maghreb équivaut à deux cent cinquante dînârs. Elle est d'une extrême

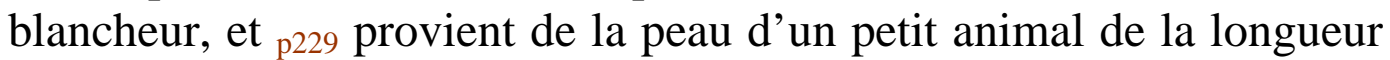
d'un empan. La queue de celui-ci est longue, et on la laisse dans la fourrure, dans son état naturel.

${ }^{385}$ Abu'l-Feda, le géographe contemporain d’Ibn Battûta, raconte la même histoire. 
La zibeline est inférieure en prix à l'hermine ; une pelisse de cette fourrure vaut quatre cents dînârs et au-dessous. Une des propriétés de ces peaux, c'est que la vermine ne s'y met pas, aussi les princes et les grands de la Chine en placent une attachée à leur pelisse, autour du cou. Les marchands de la Perse et des deux Irâks en usent de même.

Je revins de la ville de Bolghâr avec l'émir que le sultan avait envoyé en ma compagnie. Je retrouvai le camp de ce souverain dans l'endroit appelé Bichdagh, le 28 de ramadhân; j'assistai avec le prince à la prière de la Rupture du jeûne. Le jour de cette solennité se trouva être un vendredi ${ }^{386}$.

\section{DESCRIPTION DE L'ORDRE QUE CES PEUPLES OBSERVENT DANS LA FÊTE DE LA RUPTURE DU JEÛNE}

Le matin de cette fête, le sultan monta à cheval, accompagné de ses nombreux soldats. Chaque khâtoûn prit place dans son chariot, suivie de ses troupes particulières. La fille du sultan monta aussi dans un chariot, la couronne en tête, parce qu'elle était la vraie reine, ayant hérité de sa mère de la dignité royale ${ }^{387}$. Les fils du sultan montèrent à cheval, chacun avec son armée. Le kâdhi des kâdhis Chihâb eddîn Assâilly était arrivé, pour assister à la fête, accompagné d'une troupe de jurisconsultes et de cheïkhs. Ils montèrent à cheval, p230 ainsi que le kâdhi Hamzah, l'imâm Bedr eddîn alkiwâmy et le chérîf Ibn 'Abd alhamîd, en compagnie de Tîna bec, héritier présomptif du sultan. Ils avaient avec eux des timbales et des étendards. Le kâdhi Chihâb eddîn pria avec eux, et prononça un magnifique sermon.

Cependant, le sultan monta à cheval et arriva à une tour de bois nommée chez ce peuple alcochc ${ }^{388}$; il y prit place accompagné de ses khâtoûns. Une seconde tour avait été élevée à côté, et l'héritier présomptif du sultan, ainsi que sa fille, la maîtresse du tâdj, ou couronne, s’y assirent. Deux autres tours furent construites auprès de celles-là, à

\footnotetext{
386 La fête de la Rupture du jeûne datait pour l'année 1334, du dimanche 5 juin.

387 Sa mère était probablement la première femme de Uzbek, appelée Baalin dans les chroniques russes (encore une Bayalun ?), morte en 1323; mais on ne voit pas comment elle aurait pu hériter de sa mère la dignité royale.

388 Kuskh, d’où kiosque.
} 
droite et à gauche de la première, où se placèrent les fils du sultan et ses proches. Des sièges, appelés sandaly ${ }^{389}$, furent dressés, pour les émirs et les fils de rois, à droite et à gauche de la tour du souverain, et chacun s'assit sur son siège. Ensuite on dressa des disques ou cibles, pour lancer des flèches, et chaque émir de thoûmân ${ }^{390}$ avait sa cible particulière. L'émir de thoûmân, chez ces peuples, est celui qui a sous ses ordres dix mille cavaliers. Les émirs de cette espèce, présents en cet endroit, étaient au nombre de dix-sept, conduisant ensemble cent soixante et dix mille hommes, et l'armée d’Uzbec dépasse ce chiffre. On éleva pour chaque émir une sorte de tribune, sur laquelle il s'assit pendant que ses soldats tiraient de l'arc devant lui. Ils s'occupèrent ainsi durant une heure. On apporta ensuite des robes d'honneur, et un de ces vêtements fut donné à chaque émir. Après l'avoir revêtu, il s'avançait sous la tour du sultan, et lui rendait hommage. Cette cérémonie consiste à toucher la terre avec le genou droit, et à étendre le pied sous ce genou, pendant que l'autre jambe reste perpendiculaire. Après cela on amène un cheval sellé et bridé ; on lui soulève le sabot et l'émir le baise ; puis il le conduit lui-même à son siège, et là il le monte $_{\text {p231 }}$ et se tient en place avec son corps d'armée. Chaque émir de thoûmân accomplit le même acte.

Alors le sultan descend de la tour et monte à cheval, ayant à sa droite son fils et successeur désigné, et à côté de celui-ci sa fille, la reine It Cudjudjuc ; à sa gauche il a son second fils, et devant lui les quatre khâtoûns dans des chariots recouverts d'étoffes de soie dorée. Les chevaux qui traînent ces voitures portent des housses, également de soie dorée. Tous les émirs, grands et petits, les fils de rois, les vizirs, les chambellans, les grands de l'empire mettent pied à terre et marchent ainsi devant le sultan jusqu'à ce qu'il arrive au withâk, qui est une grande tente, afrâdj ${ }^{391}$. On a dressé en cet endroit une vaste bârghâh ${ }^{392}$ ou salle d'audience. La bârghâh, chez les Turcs, est une grande tente, soutenue par quatre piliers de bois, recouverts de feuilles d'argent doré. Au sommet de chaque pilier, il y a un chapiteau d'argent doré, qui brille et resplendit, et cette bârghâh apparaît de loin

Sandali en persan : fauteuil, trône.

Du turc tümen : dix mille.

${ }^{391}$ Withaq, du turc otagh : tente ; pour afradj, voir ci-dessus n. 22.

392 Du persan bargâh : salle d'audience, tribunal.
} 
comme une colline. On place à sa droite et à sa gauche des tendelets de toile de coton et de lin, et partout le sol est recouvert de tapis de soie ; le grand trône est dressé au milieu, et les Turcs l'appellent attakht ${ }^{393}$. Il est en bois incrusté de pierreries, et ses planches sont revêtues de feuilles d'argent doré ; ses pieds sont en argent massif doré, et il est recouvert d'un vaste tapis. Au milieu de ce grand trône est un coussin, sur lequel s'assirent le sultan et la grande khâtoûn ; à la droite, un autre, sur lequel s'assirent sa fille It Cudjudjuc et la khâtoûn Ordodja ; à sa gauche, un troisième, où prirent place la khâtoûn Beïaloûn et la khâtoûn Kebec. On avait dressé, à la droite du trône, un siège sur lequel s'assit Tîna bec, fils du sultan, et à la gauche un autre, destiné au second fils de ce souverain, Djâni bec. Plusieurs sièges

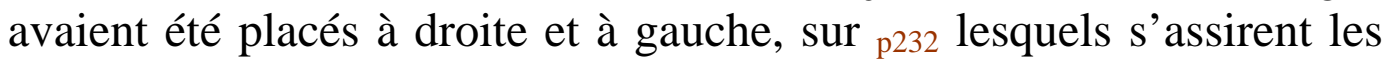
fils de rois et les grands émirs, puis les petits émirs, comme ceux de hézâreh ${ }^{394}$, lesquels commandent à mille hommes. On servit ensuite des mets sur ces tables d'or et d'argent, dont chacune était portée par quatre hommes ou davantage.

Les mets des Turcs consistent en chair de cheval ou de mouton bouillie. Une table est placée devant chaque émir. Le bâwerdjy ${ }^{395}$, c'est-à-dire l'écuyer tranchant, arrive, vêtu d'habits de soie, pardessus lesquels est attachée une serviette de la même étoffe. Il porte à sa ceinture plusieurs couteaux dans leurs gaines. Chaque émir a un bâwerdjy, et lorsque la table a été dressée cet officier s’assied devant son maître. On apporte une petite écuelle d'or ou d'argent, renfermant du sel dissous dans de l'eau. Le bâwerdjy coupe la viande en petits morceaux. Ces gens-là possèdent une grande habileté pour dépecer la viande, de façon qu'elle se trouve mélangée d'os; car les Turcs ne mangent que de celle-là.

On apporte ensuite des vases à boire, d'or et d'argent. La principale boisson des Turcs, c'est un vin préparé avec le miel ; car ils sont de la secte hanéfite et regardent comme permis l'usage d'un tel vin ${ }^{396}$. Lorsque le sultan veut boire, sa fille prend la coupe dans sa

\footnotetext{
393

394 Du persan hezar : mille.

Al-takht : trône en persan.

395 Du mongol bao'urchin : office important de la cour mongole.

396 Voir ci-dessus n. 16.
} 
main ; elle fait une salutation en fléchissant le genou devant son père, puis elle lui présente la coupe. Lorsque le sultan a bu, elle prend une autre coupe, la donne à la grande khâtoûn, qui y boit ; puis elle la présente aux autres khâtoûns, selon leur rang. Après cela l'héritier présomptif saisit la coupe, fait une salutation respectueuse devant son père, lui donne à boire, ainsi qu'aux khâtoûns et à sa sœur, en les saluant toutes. Cela fait, le second fils du sultan se lève, prend la coupe, donne à boire à son frère et le salue. Ensuite les principaux émirs se lèvent, chacun d'eux offre à boire à l'héritier présomptif, et le salue. Les fils de rois se lèvent à leur tour, p233 servent à boire au second fils du sultan et le saluent. Enfin, les émirs d'un rang inférieur se lèvent, et servent à boire aux fils de rois. Pendant ce temps-là, ils chantent des mawâliyahs ${ }^{397}$.

On avait dressé une grande tente vis-à-vis de la mosquée, pour le kâdhi, le prédicateur, le chérif, tous les jurisconsultes et les cheïkhs. Je me trouvais avec eux. On nous apporta des tables d'or et d'argent, portées chacune par quatre des principaux Turcs ; car les grands seuls vont et viennent, en ce jour, devant le sultan ; et il leur ordonne de porter à qui il veut les tables qu'il désigne. Parmi les docteurs de la loi, il y en eut qui mangèrent, et d'autres qui s'abstinrent de prendre leur repas sur ces tables d'argent et d'or. Aussi loin que ma vue pouvait s'étendre, à droite et à gauche, je vis des chariots chargés d'outres, pleines de lait de jument aigri. Le sultan ordonna de les distribuer aux assistants, et l'on m'amena une voiture chargée de ce breuvage. Je le donnai aux Turcs mes voisins.

Nous nous rendîmes ensuite à la mosquée, afin d'y attendre le moment de la prière du vendredi. Le sultan ayant tardé d'arriver, il y eut des personnes qui dirent qu'il ne viendrait pas, parce que l'ivresse s’était emparée de lui ; d'autres disaient qu’il ne négligerait pas la prière du vendredi. Après une longue attente, le sultan arriva en se balançant à droite et à gauche. Il salua le seigneur cherîf et lui sourit ; il l'appelait du nom d'âthâ, qui signifie père en langue turque. Nous fîmes la prière du vendredi, et les assistants regagnèrent leurs demeures. Le sultan retourna dans la salle d'audience, et y resta ainsi jusqu'à la 
prière de l'après-midi. Alors tous les Turcs s'en allèrent ; les épouses et la fille du roi passèrent cette nuit-là auprès de lui.

Lorsque la fête fut terminée, nous partîmes avec le sultan et le camp, et nous arrivâmes à la ville de Hâddj p234 Terkhân ${ }^{398}$. Le mot terkhân, chez les Turcs, désigne un lieu exempté de toute imposition. Le personnage qui a donné son nom à cette ville était un dévot pèlerin (hâddj) turc, qui s'établit sur l'emplacement qu'elle occupe. Le sultan exempta cet endroit de toute charge, à la considération de cet homme. Le lieu devint une bourgade ; celle-ci s'accrut et devint une ville. Elle est au nombre des plus belles cités ; elle a des marchés considérables, et est bâtie sur le fleuve Itil ${ }^{399}$, un des plus grands fleuves de l'univers. Le sultan séjourne en cet endroit jusqu'à ce que le froid devienne violent et que le fleuve gèle, ainsi que les rivières qui s'y réunissent. Alors le sultan donne ses ordres aux habitants de ce pays, lesquels apportent des milliers de charges de paille, et la répandent sur la glace qui recouvre le fleuve. Les bêtes de somme de cette contrée ne mangent pas de paille, parce qu'elle leur fait du mal ; et il en est de même dans l'Inde. La nourriture de ces animaux consiste seulement en herbe verte, à cause de la fertilité du pays. On voyage dans des traîneaux sur ce fleuve et les canaux, ses affluents, l'espace de trois journées de marche. Souvent les caravanes le traversent, quoique l'hiver approche de son terme ; mais elles sont parfois submergées et périssent.

Lorsque nous fûmes arrivés à la ville de Hâddj Terkhân, la khâtoûn Beïaloûn, fille du roi des Grecs, demanda au sultan la permission de visiter son père, afin de faire ses couches près de lui, et de revenir ensuite. Il lui accorda cette autorisation. Je le priai qu'il me permît de partir en compagnie de la princesse, afin de voir Constantinople la

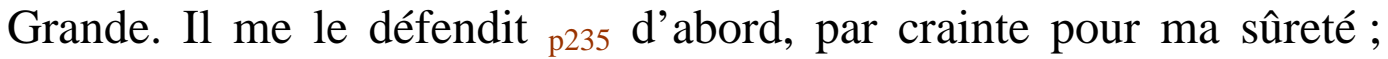
mais je le sollicitai et lui dis : "Je n'entrerai à Constantinople que sous ta protection et ton patronage, et je ne craindrai personne. » Il me donna la permission de partir, et nous lui fîmes nos adieux. Il me fit

398 Il s'agit d'Astrakhan, à l'embouchure de la Volga. L'origine du mot doit résider soit dans le nom d'un souverain Hazare, soit dans celui des As (Ossètes), peuple du nord du Caucase. Par contre, de fausses étymologies le font dériver 399 du turc tarkan, titre royal, ou du mongol darkan, personnage exempt d'impôts.

Nom donné par les Arabes à la Volga. 
présent de quinze cents ducats, d'une robe d'honneur et d'un grand nombre de chevaux. Chaque khâtoûn me donna des lingots d'argent, que ces peuples appellent saoum, pluriel de saoumah ${ }^{400}$. La fille du sultan me fit un cadeau plus considérable que les leurs, et elle me fournit des habits et une monture. Je me trouvai possesseur d'un grand nombre de chevaux, de vêtements et de pelisses de petit-gris et de zibeline.

\section{RÉCIT DE MON VOYAGE À CONSTANTINOPLE}

Nous nous mîmes en route le 10 de chawwâl ${ }^{401}$, en compagnie de la khâtoûn Beïaloûn et sous sa protection. Le sultan l'accompagna l'espace d'une journée de marche ; puis il retourna sur ses pas, avec la reine et le successeur désigné. Les autres khâtoûns marchèrent encore une journée en société de la princesse ; après quoi elles s'en retournèrent. L'émir Beïdarah escortait Beïaloûn, avec cinq mille de ses soldats. La troupe de la khâtoûn s'élevait à environ cinq cents cavaliers, parmi lesquels ses serviteurs étaient au nombre d'à peu près deux cents, tant mamloûcs ${ }^{402}$ que Grecs ; le reste se composait de Turcs. Elle était accompagnée d'environ deux cents jeunes filles esclaves, la plupart grecques. Elle avait près de quatre cents chariots et deux mille chevaux, tant pour le trait que pour la selle ; environ ${ }_{\mathrm{p} 236}$ trois cents bœufs et deux cents chameaux, aussi pour traîner les 'arabahs. La princesse avait encore avec elle dix pages grecs, et autant d'Indiens ; leur chef à tous s'appelait Sunbul l'Indien ; quant au chef des Grecs, il se nommait Mikhâil, et les Turcs l'appelaient Loûloû ${ }^{403}$. Il était au nombre des plus braves guerriers. La princesse avait laissé la plupart de ses femmes esclaves et de ses bagages dans le camp du sultan, parce qu'elle n'était partie que pour visiter son père et faire ses couches.

\footnotetext{
400 Petites barres d'argent qui valaient à l'époque 5 florins d'or. Le terme, dérivé du bulgare ancien som, désigne encore dans le turc oriental les roubles et dans le turc occidental l'argent - ou l'or - pur.

401 Le 14 juin 1334.

402 Ici, esclaves.

403 Perle ; nom donné souvent aux eunuques.
} 
Cependant, nous marchions vers la ville d'Ocac ${ }^{404}$, qui est une place d'une importance moyenne, bien construite, riche en biens, mais d'une température très froide. Entre elle et Sérâ, capitale du sultan, il $\mathrm{y}$ a dix jours de marche. A un jour de distance d'Ocac se trouvent les montagnes des Russes, qui sont chrétiens ${ }^{405}$; ils ont des cheveux roux, des yeux bleus, ils sont laids de visage et rusés de caractère. Ils possèdent des mines d'argent, et on apporte de leur pays des saoums, c'est-à-dire des lingots d'argent, avec lesquels on vend et on achète dans cette contrée. Le poids de chaque lingot est de cinq onces.

Dix jours après être partis de cette cité, nous arrivâmes à Sordâk ${ }^{406}$. C'est une des villes de la vaste plaine du Kifdjak ; elle est située sur le rivage de la mer, et son port est au nombre des plus grands ports et des plus beaux. Il y a en dehors de la ville des jardins et des rivières. Des Turcs l'habitent, avec une troupe de Grecs qui ${ }_{\text {p237 }}$ vivent sous leur protection, et sont des artisans ; la plupart des maisons sont construites en bois. Cette cité était autrefois fort grande ; mais la majeure partie en fut ruinée, à cause d'une guerre civile qui s'éleva entre les Grecs et les Turcs. La victoire resta d'abord aux premiers, mais les Turcs reçurent du secours de leurs compatriotes, qui massacrèrent sans pitié les Grecs et expulsèrent la plupart des survivants. Quelques autres sont restés dans la ville jusqu'à présent, sous le patronage des Turcs ${ }^{407}$.

Dans chaque station de ce pays on apportait à la khâtoûn des provisions, consistant en chevaux, brebis, bœufs, doûghy ${ }^{408}$ lait de jument, de vache et de brebis. On voyage dans cette contrée matin et soir. Chacun des émirs de ces lieux accompagnait la khâtoûn, avec son corps d'armée, jusqu'à l'extrême limite de son gouvernement, par

\footnotetext{
${ }^{404}$ Ici, il ne s’agit pas de l’Ukak mentionnée par Marco Polo et située sur la Volga au sud de Saratov, mais de la ville appelée Locaq dans les portulans médiévaux et située sur le littoral nord de la mer d’Azov à proximité de Mariupol (Jdanov).

405 L'information est vague ; il existait toutefois des gisements de plomb argentifère près de la rivière Mius, entre Azov et Ukak.

406 Sudak (voir ci-dessus n. 38), située au sud de la péninsule de Crimée, ne pouvait pas se trouver sur la route. Elle a dû être visitée par Ibn Battûta pendant son passage à Kaffa et Staryi Krim (voir p. 204).

${ }^{407}$ Le récit se réfère probablement à la prise de Sudak par Uzbek Khan en 1322. 408 Voir ci-dessus n. 14.
} 
considération pour elle, et non point par crainte pour sa sûreté, car le pays est tranquille.

Nous arrivâmes à la ville nommée Bâbâ Salthoûk ${ }^{409}$. Bâbâ a, chez les Turcs, la même signification que chez les Berbers (c'est-à-dire celle de père) ; seulement, ils font sentir plus fortement le bâ (b). On dit que ce Salthoûk était un contemplatif ou un devin, mais on rapporte de lui des choses que réprouve la loi religieuse. La ville de Bâbâ Salthoûk est la dernière appartenant aux Turcs ; entre celle-ci et le

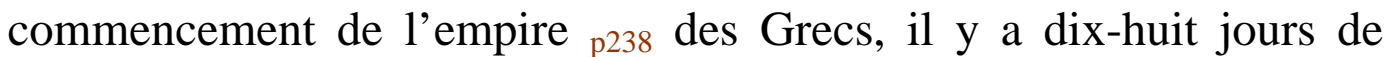
marche dans un désert entièrement dépourvu d'habitants. Sur ces dixhuit jours, on en passe huit sans trouver d'eau. En conséquence, on en fait provision pour ce temps, et on la porte sur des chariots, dans des outres tant petites que grandes. Nous entrâmes dans ce désert pendant les froids ; nous n'eûmes donc pas besoin de beaucoup d'eau ${ }^{410}$. Les Turcs transportaient du lait dans de grandes outres, le mêlaient avec le doûghy cuit, et le buvaient ; cela les désaltérait pleinement.

Nous fîmes nos préparatifs à Bâbâ Salthoûk, pour traverser le désert. Ayant eu besoin d'un surcroît de chevaux, je me rendis près de la khâtoûn et l'informai de cette circonstance. Or j'avais pris l'habitude d'aller la saluer matin et soir ; et toutes les fois qu'on lui apportait des provisions elle m'envoyait deux ou trois chevaux et des moutons; je m'abstenais d'égorger les chevaux. Les esclaves et les serviteurs qui étaient avec moi mangeaient en compagnie des Turcs, nos camarades. De cette manière, je réunis environ cinquante chevaux. La khâtoûn m'en assigna quinze autres, et ordonna à son chargé d'affaires, Sâ-

D'après la tradition turque, Sari Saltuk est un saint qui colonisa avec un groupe de Turkmènes la Dobrudja, le littoral actuel de la Roumanie, après 1260 ; il y mourut après 1300. Son tombeau se trouve à Babadagh, au nord de la Dobrudja, mais il ne peut s’agir de la ville indiquée par Ibn Battûta, la frontière mongole se trouvant beaucoup plus au nord où ces derniers avaient occupé Akkerman (l'actuel Belgorod) au sud de l'estuaire du Dniestr. Or Evliya Tchelebi mentionne, vers 1660, un village appelé Sari-Ata Sultan à seize heures d'Akkerman ( $a t a=b a b a=$ père), où il rencontre le tombeau d'un saint dont la légende se rapproche de celle de Baba — ou Sari — Saltuk.

${ }^{410}$ Ici, Ibn Battûta semble avoir mélangé l'itinéraire de l'aller avec celui du retour, puisque le désert en question est la steppe de Nogai se trouvant au nord de la Crimée, donc bien avant Akkerman, et le froid mentionné doit correspondre au passage du retour, fin octobre. 
roûdjah le Grec ${ }^{411}$ d'en choisir de gras, parmi les chevaux destinés à être mangés. Elle me dit : «Ne crains rien; si tu as besoin d'un plus grand nombre, nous t'augmenterons. » Nous entrâmes dans le désert, au milieu du mois de dhou'lka'dah ${ }^{412}$. Nous avions marché dix-neuf jours, depuis celui où nous avions quitté le sultan, jusqu'à l'entrée du désert, et nous nous étions reposés pendant cinq jours. Nous marchâmes dans ce désert durant dix-huit jours, matin et soir. Nous n'éprouvâmes rien que ${ }_{\text {p239 }}$ d'avantageux ; grâces en soient rendues à Dieu ! Au bout de ce temps, nous arrivâmes à la forteresse de Mahtoûly ${ }^{413}$, où commence l'empire grec.

Or les Grecs avaient appris la venue de la princesse dans son pays. Cafâly ${ }^{414}$ Nicolas, le Grec, arriva près d'elle dans cette forteresse, avec une armée considérable et d'amples provisions. Des princesses et des nourrices arrivèrent aussi du palais de son père, le roi de Constantinople. Entre cette capitale et Mahtoûly, il y a une distance de vingtdeux jours de marche, dont seize jusqu'au canal et six depuis cet endroit jusqu'à Constantinople. A partir de Mahtoûly, on ne voyage plus qu'avec des chevaux et des mulets, et l'on y laisse les chariots, à cause des lieux âpres et des montagnes qui restent à franchir. Le susdit Cafâly amena un grand nombre de mulets, et la princesse m'en envoya six. Elle recommanda au gouverneur de la forteresse ceux de mes compagnons et de mes esclaves que j'y laissai avec les chariots et les bagages ; et cet officier leur assigna une maison.

L'émir Beïdarah s'en retourna avec ses troupes, et la princesse n'eut plus pour compagnons de voyage que ses propres gens. Elle abandonna sa chapelle dans cette forteresse, et la coutume d'appeler les hommes à la prière fut abolie. On apportait à la princesse, parmi les provisions, des liqueurs enivrantes dont elle buvait ; on lui offrait aussi des porcs, et un de ses familiers m’a raconté qu'elle en man-

\footnotetext{
411 Le nom est turc mais signifie blondin.

412 Ici on retrouve l'itinéraire d'aller, vers le 14 juillet. Et il faut lire par la suite 29 jours au lieu de 19 (15 juin-13 juillet).

${ }^{413}$ La frontière de l'empire byzantin se trouvait à Diainpolis, l'actuelle Janbol sur le Tundza en Bulgarie. La distance mentionnée pourrait correspondre à la réalité, avec la différence qu’à la place d'un désert on traverse le delta du Danube.

${ }^{414}$ Kephalé : chef en grec.
} 
geait. Il ne resta près d'elle personne qui fît la prière, excepté un Turc, qui priait avec nous. Les sentiments cachés se modifièrent, à cause de notre entrée dans le pays des infidèles ; mais la princesse prescrivit à l'émir Cafâly de me traiter avec honneur p240 aussi, dans une circonstance, cet officier frappa un de ses esclaves parce qu'il s'était moqué de notre prière.

Cependant, nous arrivâmes à la forteresse de Maslamah, fils d'Abd Almelic ${ }^{415}$. Elle est située au bas d'une montagne sur un fleuve très considérable, que l'on appelle Isthafîly ; il n'en reste que des vestiges ; mais, hors de son enceinte, il y a un grand village. Nous marchâmes ensuite pendant deux jours, et nous arrivâmes au canal ${ }^{416}$, sur le rivage duquel s'élève une bourgade considérable. Nous vîmes que c'était le moment du flux, et nous attendîmes jusqu'à ce que vînt l'instant du reflux ; alors nous passâmes à gué le canal, dont la largeur est d'environ deux milles ; puis nous marchâmes l'espace de quatre milles dans des sables, et parvînmes au second canal, que nous traversâmes aussi à gué ; sa largeur est d'environ trois milles. Nous fîmes ensuite deux milles dans un terrain pierreux et sablonneux, et nous atteignîmes le troisième canal, lorsque déjà le flux avait recommencé. Nous éprouvâmes en le passant beaucoup de fatigue ; sa largeur est d'un mille ; celle du canal tout entier est donc de douze milles, en comptant les parties où il y a de l'eau et celles qui sont à sec. Mais dans les temps de pluie il est entièrement rempli d'eau, et on ne le traverse qu'avec des barques.

Sur le rivage de ce troisième canal s'élève la ville de Fenîcah ${ }^{417}$, qui est petite, mais belle et très forte ; ses ${ }_{\text {p241 }}$ églises et ses maisons

415 Maslama, fils du calife Abd al-Malik, commandait l’expédition qui assiégea Constantinople en 716-717. Les légendes ont brodé autour de cette expédition, mais cette forteresse n'est pas connue, et le fleuve cité par la suite n'est pas identifiable.

416 Ibn Battûta marche à reculons, puisqu'ici on retrouve apparemment l'embouchure du Danube.

417 Les incertitudes de l'itinéraire rendent cette identification extrêmement malaisée. Si elle se trouve au sud de l'embouchure du Danube, ce doit être Vicina, enclave byzantine à la fin du XIII ${ }^{\mathrm{e}}$ siècle, occupée par les Mongols avant 1338 ; le fait qu'elle soit une enclave explique peut-être sa situation au nord de la première ville byzantine identifiée comme Janbol. Par contre, l'endroit où le cortège fut accueilli pourrait correspondre à Agathonike, la moderne Kizil Agatch en aval sur la Tundza au sud de Janbol. 
sont jolies ; des rivières la traversent et des vergers l'entourent. On y conserve, d'une année à l'autre, des raisins, des poires, des pommes et des coings. Nous y passâmes trois jours, la princesse occupant le palais que son père possède en cet endroit. Au bout de ce temps, son frère utérin, appelé Cafâly Karâs ${ }^{418}$, arriva avec cinq mille cavaliers, armés de toutes pièces. Lorsqu'ils se disposèrent à paraître devant la princesse, le frère de celle-ci monta sur un cheval gris, se vêtit d'habits blancs, et fit porter au-dessus de sa tête un parasol brodé de perles. Il mit à sa droite cinq fils de rois et à sa gauche un pareil nombre, revêtus également d'habits blancs et ombragés sous des parasols brodés d'or. Il plaça devant lui cent fantassins et autant de cavaliers, qui avaient couvert leurs corps et celui de leurs chevaux d'amples cottes de mailles ; chacun d'eux conduisait un cheval sellé et carapaçonné, qui portait les armes d'un cavalier, savoir : un casque enrichi de pierreries, une cotte de mailles, un carquois, un arc et un sabre ; dans la main, il tenait une lance, au sommet de laquelle il y avait un étendard. La plupart de ces lances étaient couvertes de feuilles d'or et d'argent. Les chevaux de main étaient les montures du fils du sultan. Ce prince partagea ses cavaliers en plusieurs escadrons, dont chacun comprenait deux cents hommes. Ils avaient un commandant, qui envoya en avant dix cavaliers armés de toutes pièces, et conduisant chacun un cheval. Derrière le chef de corps se trouvaient dix étendards de diverses couleurs, portés par dix cavaliers, et dix timbales que portaient au cou autant de cavaliers, accompagnés de six autres, qui sonnaient du clairon, de la trompette et jouaient de la flûte ou du fifre, instrument que l'on appelle aussi ghaïthah ${ }^{419}$.

La princesse monta à cheval, en compagnie de ses ${ }_{\mathrm{p} 242}$ esclaves, de ses suivantes, de ses pages et de ses eunuques ; tous ceux-ci étaient au nombre d'environ cinq cents, et vêtus d'étoffes de soie brodées d'or et de pierreries. La princesse était couverte d'un manteau de l'étoffe appelée annakh et aussi annécîdj ${ }^{420}$, lequel était brodé de pierres précieuses. Elle avait sur la tête une couronne incrustée de pierreries, et

418 On voit mal le frère utérin d'une fille naturelle d'un empereur byzantin faire partie de la cérémonie d'accueil. Quant au fils aîné d’Andronic III, le futur Jean $\mathrm{V}$, il avait deux ans à l'époque.

Cornemuse.

420 Al-nakh : voir chap. 2, n. 100 ; al-nasidj : étoffe tissée. 
son cheval était couvert d'une housse de soie brodée d'or ; il avait aux quatre pieds des anneaux d'or, et à son cou des colliers enrichis de pierres précieuses ; le bois de sa selle était revêtu d'or et orné de pierreries. La rencontre de la princesse et de son frère eut lieu dans une plaine, à environ un mille de la ville ; le second mit pied à terre devant sa sœur, car il était plus jeune qu'elle; il baisa son étrier et elle l'embrassa sur la tête. Les émirs et les fils de rois descendirent de cheval et baisèrent tous aussi l'étrier de la princesse, laquelle partit ensuite avec son frère.

Nous arrivâmes le lendemain à une grande ville, située sur le rivage de la mer, et dont je ne me rappelle plus le nom avec certitude ${ }^{421}$. Elle possède des rivières et des arbres, et nous campâmes hors de son enceinte. Le frère de la princesse, héritier désigné du trône, vint avec un cortège magnifique et une armée considérable, savoir dix mille hommes couverts de cottes de mailles. Il portait sur sa tête une couronne, il avait à sa droite environ vingt fils de rois et à sa gauche un pareil nombre. Il avait disposé sa cavalerie absolument dans le même ordre que son frère, sauf que la pompe était plus grande et le rassemblement plus nombreux. Sa sœur le rencontra, vêtue du même costume qu'elle avait la première fois. Ils mirent pied à terre en même temps, et l'on apporta une tente de soie, dans laquelle ils entrèrent, et j'ignore comment se passa leur entrevue.

Nous campâmes à dix milles de Constantinople, et le p243 lendemain la population de cette ville, hommes, femmes et enfants, en sortit, tant à pied qu'à cheval, dans le costume le plus beau et avec les vêtements les plus magnifiques. Dès l'aurore, on fit retentir les timbales, les clairons et les trompettes ; les troupes montèrent à cheval, et le sultan, ainsi que sa femme, mère de la khâtoûn, les grands de l'empire et les courtisans sortirent. Sur la tête de l'empereur se voyait un pavillon, que portaient un certain nombre de cavaliers et de fantassins, tenant dans leurs mains de longs bâtons, terminés à la partie supérieure par une espèce de boule de cuir, et avec lesquels ils soutenaient le pavillon. Au centre de celui-ci se trouvait une sorte de dais, supporté à l'aide de bâtons par des cavaliers. Lorsque le sultan se fut avancé, les

421 S'il s'agit d'un endroit proche de Constantinople, il doit correspondre à Selymbria, l'actuelle Silivri sur le bord de la mer de Marmara à soixante-dix kilomètres de Constantinople. 
troupes se mêlèrent et le bruit devint considérable. Je ne pus pénétrer au milieu de cette foule, et je me tins près des bagages de la princesse et de ses compagnons, par crainte pour ma sûreté. On m'a raconté que, quand la princesse approcha de ses parents, elle mit pied à terre et baisa le sol devant eux ; puis elle baisa les sabots de leurs montures, et ses principaux officiers en firent autant. Notre entrée dans Constantinople la Grande eut lieu vers midi, ou un peu après. Cependant, les habitants faisaient retentir les cloches, de sorte que les cieux furent ébranlés par le bruit mélangé de leurs sons.

Lorsque nous parvînmes à la première porte du palais du roi, nous y trouvâmes environ cent hommes, accompagnés de leur chef, qui se tenait sur une estrade. Je les entendis qui disaient : " les Sarazzins, les Sarazzins ", mot qui désigne chez eux les musulmans ; et ils nous empêchèrent d'entrer. Les compagnons de la princesse leur dirent : « Ces gens-là sont de notre suite. » Mais ils répondirent : "Ils n’entreront qu'avec une permission. " Nous restâmes donc à la porte, et l'un des officiers de la khâtoûn s'en alla, et lui envoya quelqu'un pour l'instruire de cet incident. Elle se trouvait alors près de son père, à qui elle raconta ce qui nous concernait. L'empereur ordonna de nous laisser entrer, et nous ${ }_{\mathrm{p} 244}$ assigna une maison dans le voisinage de celle de la princesse. De plus, il écrivit en notre faveur un ordre prescrivant de ne nous causer aucun empêchement dans quelque partie de la ville que nous allassions, et cela fut proclamé dans les marchés. Nous restâmes durant trois jours dans notre demeure, où l'on nous envoyait des provisions, savoir : de la farine, du pain, des moutons, des poulets, du beurre, des fruits et du poisson; ainsi que de l'argent et des tapis. Le quatrième jour nous visitâmes le sultan.

\section{DE L’EMPEREUR DE CONSTANTINOPLE}

Il se nomme Tacfoûr, fils de l'empereur Djirdjîs ${ }^{422}$. Ce dernier est encore en vie, mais il a embrassé la vie religieuse, s'est fait moine, et

${ }^{422}$ Pour takfur, voir ci-dessus, n. 50 En réalité, il s’appelait Andronic III (13281341). Son père, Michel IX, co-empereur, était mort en 1320 ; il a donc succédé à son grand-père Andronic II (1283-1328) après une longue guerre civile à l'issue de laquelle Andronic II, vaincu, se fit moine ; il mourut le 12 février 1332, donc avant l'arrivée d’Ibn Battûta. 
se livre uniquement à des actes de dévotion dans les églises; c'est pourquoi il a abandonné le royaume à son fils. Nous parlerons de lui ci-après. Le quatrième jour depuis notre arrivée à Constantinople, la khâtoûn m'envoya l'eunuque Sunbul, l'Indien, qui me prit par la main et me fit entrer dans le palais ${ }^{423}$. Nous franchîmes quatre portes, près de chacune desquelles se trouvaient des bancs, où se tenaient des hommes armés, dont le chef était placé sur une estrade garnie de tapis. Lorsque nous fûmes arrivés à la cinquième porte, l'eunuque Sunbul me laissa et entra; puis il revint, accompagné de quatre eunuques grecs. Ceux-ci me fouillèrent, de peur que je n'eusse sur moi un couteau. Le chef me dit : "Telle est leur coutume ; 245 on ne peut se dispenser d'examiner minutieusement quiconque pénètre près du roi, que ce soit un grand personnage ou un homme du peuple, un étranger ou un regnicole. » C'est aussi l'usage dans l'Inde.

Lorsqu'on m'eut fait subir cet examen, le gardien de la porte se leva, prit ma main et ouvrit la porte. Quatre individus m'entourèrent, dont deux saisirent mes manches, et les deux autres me tenaient parderrière. Ils me firent entrer dans une grande salle d'audience, dont les murs étaient en mosaïque ; on y avait représenté des figures de productions naturelles, soit animales, soit minérales. Il y avait au milieu du salon un ruisseau dont les deux rives étaient bordées d'arbres ; des hommes se tenaient debout à droite et à gauche ; on gardait le silence, et personne ne parlait. Au milieu de la salle de réception, il y avait trois hommes debout, auxquels mes quatre conducteurs me confièrent, et qui me prirent par mes habits, comme avaient fait les premiers. Un autre individu leur ayant fait un signe, ils s’avancèrent avec moi. Un d'eux, qui était juif, me dit en arabe : «Ne crains rien ; ils ont coutume d'agir ainsi envers les étrangers ; je suis l'interprète, et je tire mon origine de la Syrie. » Je lui demandai comment je devais saluer, et il reprit : «Dis : Que le salut soit sur vous !»

J'arrivai ensuite à un grand dais, où je vis l'empereur assis sur son trône, ayant devant lui sa femme, mère de la khâtoûn ${ }^{424}$. Celle-ci, ainsi que ses frères, se tenaient au bas du trône. A la droite du souverain

${ }^{423}$ Le palais des Paléologues était situé dans l'angle nord-ouest de la ville. Une partie des ruines est connue aujourd'hui sous le nom de Tekfur Saray.

424 Jeanne, fille d'Amédée $\mathrm{V}$ de Savoie, sa deuxième femme ; ils étaient mariés en 1326. 
il y avait six hommes, quatre à sa gauche et autant derrière lui ; tous étaient armés. Avant que je le saluasse et que je parvinsse près de lui, il me fit signe de m'asseoir un instant, afin que ma crainte s'apaisât. J'agis ainsi, puis j'arrivai près du monarque et je le saluai. Il m'invita, par un geste, à m'asseoir, mais je n'en fis rien. Il me questionna au sujet de Jérusalem, de la roche bénie ${ }_{\mathrm{p} 246}$ d'Alkomâmah ${ }^{425}$ du berceau de Jésus, de Bethléem et d'Alkhalîl ; puis il m’interrogea touchant Damas, Le Caire, l'Irâk et l'Asie Mineure. Je répondis à toutes ses demandes, le juif faisant entre nous l'office d'interprète. Mes paroles lui plurent, et il dit à ses enfants : "Traitez cet homme avec considération et protégez-le. » Puis il me fit revêtir d'un habit d'honneur et m'assigna un cheval sellé et bridé, ainsi qu'un parasol d'entre ceux qu'il fait porter au-dessus de sa tête ; car c'est là une marque de protection. Je le priai de désigner quelqu'un pour se promener chaque jour à cheval avec moi dans la ville, afin que j'en visse les raretés et les merveilles, et que je pusse les raconter dans ma patrie. Il obtempéra à mon désir. Une des coutumes de ce peuple, c'est que l'individu qui reçoit du roi un habit d'honneur et qui monte un cheval de ses écuries doit être promené dans les places de la ville aux sons des trompettes, des clairons et des timbales, afin que la population le voie. Le plus souvent on agit de la sorte avec les Turcs qui viennent des États du sultan Uzbec, et cela pour qu'ils ne souffrent pas de vexations. On me conduisit ainsi dans les marchés.

\section{DESCRIPTION DE LA VILLE}

Elle est extrêmement grande et divisée en deux portions que sépare un grand fleuve, où se font sentir le flux et le reflux, à la manière de ce qui a lieu dans le fleuve de Salé, ville du Maghreb ${ }^{426}$. Il y avait anciennement sur ce fleuve un pont de pierres ; mais il a été détruit, et maintenant on passe l'eau dans des barques. Le nom du fleuve est Absomy ${ }^{427}$. Une des deux ${ }_{\text {p247 }}$ portions de la ville s'appelle Estham-

\footnotetext{
425 L'église du Saint-Sépulcre (voir t. I, p. 163).

426 Le Bou Regreg, qui sépare Rabat de Salé.

${ }^{427}$ Al-psomi : le pain en grec. On imaginerait plutôt une facétie de dragoman. Il s'agit évidemment de la Corne d'Or. Il est également peu probable qu'il y ait eu un pont à l’époque.
} 
boûl ${ }^{428}$; c'est celle qui s'élève sur le bord oriental de la rivière, et c'est là qu'habitent le sultan, les grands de son empire et le reste de la population grecque. Ses marchés et ses rues sont larges, et pavés de dalles de pierres. Les gens de chaque profession y occupent une place distincte, et qu'ils ne partagent avec ceux d'aucun autre métier. Chaque marché est pourvu de portes que l'on ferme pendant la nuit; la plupart des artisans et des marchands y sont des femmes. Cette partie de la ville est située au pied d'une montagne qui s'avance dans la mer, l'espace d'environ neuf milles, sur une largeur égale, ou même plus considérable. Sur la cime du mont s’élève une petite citadelle, ainsi que le palais du sultan. La muraille fait le tour de cette montagne, qui est très forte, et que personne ne saurait gravir du côté de la mer. Elle contient environ treize villages bien peuplés, et la principale église se trouve au milieu de cette portion de la ville.

Quant à la seconde partie de celle-ci, on la nomme Galata ${ }^{429}$; elle est située sur le bord occidental de la rivière, et ressemble à Ribâth alfath par sa proximité de la mer. Elle est destinée particulièrement aux chrétiens francs, et ils l'habitent. Ces gens-là sont de plusieurs nations ; il y a parmi eux des Génois, des Vénitiens, des individus de Rome et d'autres de France. L'autorité sur eux appartient à l'empereur de Constantinople, qui met à leur tête un des leurs, dont ils agréent le choix, et qu'ils appellent alkomes ${ }^{430}$. Ils doivent un tribut annuel à l'empereur ; mais ils se révoltent souvent contre lui, et il leur fait la guerre jusqu'à ce que le pape rétablisse la paix entre eux. Tous sont voués au commerce, et leur port est un des plus grands qui existent. J'y ai vu ${ }_{\mathrm{p} 248}$ environ cent navires, tels que des galères et autres gros bâtiments. Quant aux petits, ils ne peuvent être comptés, à cause de leur multitude. Les marchés de cette portion de la ville sont beaux, mais les ordures y dominent ; une petite rivière fort sale les traverse. Les églises de ces peuples sont dégoûtantes aussi, et elles n’offrent rien de bon.

Istanbul, le nom actuel de la ville est une déformation du grec eis ten polin : à la ville. On le trouve pour la première fois chez Yaqut (v. 1220).

429 La ville génoise, située de l'autre côté de la Corne d’Or, comparée à Rabat. 430 Comes, c'est-à-dire comte ; toutefois, le magistrat génois s’appelait podestat. 


\section{DESCRIPTION DE LA GRANDE ÉGLISE OU CATHÉDRALE}

Je n'en décrirai que l'extérieur ; car, quant à l'intérieur, je ne l'ai pas vu. Elle est appelée, chez les Grecs, Ayâ Soûfiâ, et l'on raconte qu'elle a été fondée par Assaf, fils de Barakhïâ ${ }^{431}$, qui était fils de la tante maternelle de Salomon. C'est une des plus grandes églises des Grecs ; elle a une muraille qui en fait le tour, comme si c'était une ville, et ses portes sont au nombre de treize. Elle a pour dépendance un terrain consacré, d'environ un mille, qui est pourvu d'une grande porte. Personne n'est empêché de pénétrer dans cette enceinte, et j'y suis entré avec le père du roi, dont il sera fait mention ci-après. Cet enclos consacré ressemble à une salle d'audience ; il est recouvert de marbre et traversé par un ruisseau qui sort de l'église, et qui coule entre deux quais, élevés d'environ une coudée et bâtis en marbre veiné, sculpté avec l'art le plus admirable. Des arbres sont plantés avec symétrie de chaque côté du cours d'eau ; et, depuis la porte de l'église jusqu'à celle de cette enceinte, il y a un berceau de bois très haut sur lequel s'étendent des ceps de vigne, et dans le bas des jasmins et des plantes odoriférantes. En dehors de la porte de l'enclos s'élève un grand dôme de bois, où se trouvent des bancs de la même matière, sur lesquels s'asseyent les gardiens de cette porte ; et à la droite du p249 dôme, il y a des estrades et des boutiques, la plupart en bois, où siègent les juges et les écrivains des bureaux de la trésorerie ${ }^{432}$. Au milieu de ces boutiques existe une coupole en bois, à laquelle on monte par un escalier de charpente, et où se trouve un grand siège recouvert en drap, sur lequel s'assied leur juge, dont nous reparlerons plus loin. A la gauche du dôme, situé à la porte de ce lieu, s’étend le marché des droguistes. Le canal que nous avons décrit se divise en deux bras, dont un passe par ce marché et l'autre par celui où sont les juges et les écrivains.

A la porte de l'église, il y a des bancs où se tiennent les gardiens, qui ont le soin d'en balayer les avenues, d'en allumer les lampes et d'en fermer les portes. Ils ne permettent à personne d'y entrer, jusqu'à

${ }^{431}$ Vizir de Salomon selon les légendes juives et musulmanes. Evliya Tchelebi présente également Salomon comme le premier fondateur de l'église de Sainte-Sophie.

${ }^{432}$ Une basilique civile et une agora existaient, d'après les témoignages des écrivains byzantins, à proximité de Sainte-Sophie. 
ce qu'il se soit agenouillé devant la croix, qui jouit de la plus grande vénération parmi ces gens. Ils prétendent que c'est un reste de celle sur laquelle fut crucifié le personnage ressemblant à Jésus ${ }^{433}$. Elle se trouve au-dessus de la porte de l'église, et elle est placée dans un coffret d'or, de la longueur d'environ dix coudées. On a mis en travers de cette enveloppe un autre coffret d'or, pareil au premier, de manière à figurer une croix. Cette porte est revêtue de lames d'argent et d'or, et ses deux anneaux sont d'or pur. On m'a rapporté que le nombre des moines et des prêtres qui demeurent dans l'église s'élève à plusieurs milliers, et que quelques-uns d'entre eux descendent des apôtres de Jésus ; que dans son enceinte se trouve une autre église destinée particulièrement aux femmes, et où il y a plus de mille vierges vouées uniquement aux pratiques de la dévotion. Quant aux femmes âgées et vivant dans le veuvage, qui s'y trouvent aussi, leur nombre est encore plus considérable.

Le roi, les grands de son empire et le reste de la population ont coutume de venir, chaque matin, visiter cette ${ }_{\text {p250 }}$ église. Le pape ${ }^{434}$ s'y rend une fois l'an et, lorsqu'il est à quatre journées de distance de la ville, le roi sort à sa rencontre, met pied à terre devant lui, et, au moment de son entrée dans la ville, il marche devant le pontife. Il vient le saluer matin et soir pendant tout le temps de son séjour à Constantinople, et jusqu’à son départ.

\section{DES MONASTÈRES DE CONSTANTINOPLE}

Le mot mânistâr s'écrit comme le mot mâristân, si ce n'est que, dans le premier, le noûn (n) vient avant le râ $(r)^{435}$. Le monastère, chez les Grecs, correspond à la zâouïah des musulmans, et les édifices de cette espèce sont nombreux à Constantinople. Parmi ceux-ci, on distingue le couvent qu'a fondé le roi Djirdjîs, père du roi de Constantinople, dont nous ferons mention ci-après. Il est situé hors d’Esthanboûl, vis-à-vis de Galata.

\footnotetext{
433 Voir t. I, chap. 3, n. 32.

434 Pour notre malheur, Ibn Battûta avait un dragoman très inventif.

435 Manistar : monastère ; maristan : hôpital.
} 
On cite encore deux monastères à l'extérieur de la grande église, à droite de l'entrée ; ils sont placés dans un jardin, et une rivière les traverse ; l'un d'eux est consacré aux hommes et l'autre aux femmes, et chacun comprend une église. Ils sont entourés de cellules destinées aux hommes et aux femmes qui se sont voués aux pratiques de la dévotion. Chacun de ces deux monastères a été l'objet de legs destinés à pourvoir au vêtement et à l'entretien des religieux, et ils ont été fondés par un roi.

On mentionne aussi deux monastères, à la gauche de l'entrée de la grande église, et semblables aux deux précédents ${ }^{436}$. Ils sont aussi entourés de cellules ; l'un d'eux est habité par des aveugles, et le second par des vieillards qui ne peuvent plus travailler, parmi ceux qui p251 ont atteint soixante ans ou environ. Chacun d'eux reçoit l'habillement et la nourriture sur des legs consacrés à cette destination. A l'intérieur de chaque couvent de Constantinople est un petit appartement destiné à servir de retraite au roi, fondateur de l'édifice ; car la plupart de ces rois, lorsqu'ils ont atteint soixante ou soixante et dix ans, construisent un monastère et revêtent des moçoûhs, c'est-àdire des vêtements de crin ; ils transmettent la royauté à leur fils, et s’occupent, jusqu’à leur mort, d'exercices de dévotion. Ils déploient la plus grande magnificence dans la construction de ces monastères, les bâtissant de marbre et les ornant de mosaïques, et ces édifices sont en grand nombre dans la ville.

J'entrai, avec le Grec que le roi avait désigné pour m’accompagner à cheval, dans un monastère que traversait un canal ; on y voyait une église où se trouvaient environ cinq cents vierges, revêtues d'habits de poil (ou de bure) ; sur leurs têtes, qui étaient rasées, elles portaient des bonnets de feutre. Ces filles étaient douées d'une exquise beauté ; mais les austérités avaient laissé sur elles des traces profondes. Un jeune garçon, assis dans une chaire, leur lisait l'Évangile, avec une voix telle que je n'en ai jamais entendue de plus belle. Il était entouré de huit autres enfants, également assis dans des chaires et accompagnés de leur prêtre. Quand ce garçon eût fini de lire, un autre fit la lecture. Le Grec, mon conducteur, me dit : "Celles-ci sont des filles de rois, qui se sont vouées au service de cette église ; il en est de même 
de ces jeunes lecteurs, qui ont une autre église à l'extérieur de celleci. » J'entrai également, avec le Grec, dans une église située dans un jardin ; nous y trouvâmes environ cinq cents vierges, ou même davantage. Un enfant leur faisait la lecture, du haut d'une estrade, et il tait accompagné d'une troupe de jeunes garçons assis, comme les précédents, dans des chaires. Le Grec me dit : « Ces femmes sont des filles de vizirs et d'émirs, qui se livrent, en cette église, à des exercices de dévotion. " J'entrai, avec le même individu, dans des églises où se trouvaient des vierges, filles des principaux ${ }_{\mathrm{p} 252}$ habitants de la ville, et dans d'autres églises, occupées par de vieilles femmes et des veuves ; enfin, dans des églises habitées par des moines. Il y a, dans chacune de ces dernières, cent hommes, plus ou moins. La majeure partie de la population de cette ville consiste en moines, en religieux et en prêtres. Les églises y sont innombrables. Les habitants, soit militaires ou autres, grands et petits, placent sur leur tête de vastes parasols, hiver comme été. Les femmes portent des turbans volumineux.

\section{DU ROI DJIRDJÎS, LE MÊME QUI S’EST FAIT MOINE}

Ce roi donna l'investiture de la royauté à son fils et se consacra, dans la retraite, à des actes de dévotion. Il bâtit un monastère hors de la ville, sur le rivage, ainsi que nous l'avons dit. Je me trouvais un jour en compagnie du Grec, désigné pour monter à cheval avec moi, lorsque nous rencontrâmes tout à coup ce roi, marchant à pied, vêtu d'habits de crin, et coiffé d'un bonnet de feutre. Il avait une longue barbe blanche et une belle figure, qui présentait des traces des pratiques pieuses auxquelles il se livrait. Devant et derrière lui marchaient une troupe de moines. Il tenait à la main un bâton et avait au cou un chapelet. Lorsque le Grec le vit, il mit pied à terre et me dit : «Descends, car c'est le père du roi ${ }^{437}$ " Quand le Grec l'eut salué, il lui demanda qui j'étais, puis il s'arrêta et m'envoya chercher. Je me rendis près de lui ; il me prit par la main et dit à ce Grec, qui connaissait la langue arabe : «Dis à ce Sarrazin, c’est-à-dire musulman, que je

437 Même dans l'hypothèse où on avancerait la visite d’Ibn Battûta de deux ans, il n’aurait pas pu rencontrer Andronic mort le 12 février 1332. De plus, en religion il s’appelait Antonios, et non Georges (Djirdjis), comme le nomme Ibn Battûta. 
presse la main qui est entrée à Jérusalem et le pied qui a marché dans la Sakhrah ${ }^{438}$, dans la grande église appelée Komâmah et ${ }_{\text {p253 dans }}$ Bethléem. » Cela dit, il mit la main sur mes pieds et la passa ensuite sur son visage. Je fus étonné de la bonne opinion que ces gens-là professent à l'égard des individus d'une autre religion que la leur, qui sont entrés dans ces lieux. L'ancien roi me prit ensuite par la main et je marchai avec lui. Il me questionna au sujet de Jérusalem et des chrétiens qui s'y trouvaient, et il m'adressa de longues interrogations. J'entrai en sa compagnie dans le terrain consacré, dépendant de l'église, et que nous avons décrit tout à l'heure. Lorsqu'il approcha de la principale porte, une troupe de prêtres et de moines sortit pour le saluer ; car il était un de leurs chefs dans le monachisme. Dès qu'il les vit, il lâcha ma main, et je lui dis : " Je désire entrer avec toi dans l'église. » Il dit à l'interprète : «Apprends-lui que quiconque y entre doit absolument se prosterner devant la principale croix ; c'est là une chose prescrite par les anciens, et qu'on ne peut transgresser. Je le quittai donc ; il entra seul, et je ne le revis plus.

\section{Du JUGE DE CONSTANTINOPLE}

Lorsque j'eus pris congé de ce roi, devenu moine, j'entrai dans le marché des écrivains. Le kâdhi m’aperçut et m'envoya un de ses aides, lequel questionna le Grec qui m'accompagnait. Celui-ci lui dit que j'étais un savant musulman. Quand cet émissaire fut retourné près du magistrat et qu'il l'eut instruit de cela, celui-ci me dépêcha un de ses officiers. Or les Grecs appellent le juge Annedjchi Cafâly ${ }^{439}$, L'envoyé me dit : "Annedjchy Cafâly te demande. » Je montai pour le voir dans le dôme qui a été décrit ci-dessus, et j'aperçus un vieillard d'une belle figure et ayant une chevelure superbe. Il portait l'habit des moines, lequel est en gros drap noir, et il avait devant lui environ dix écrivains occupés à p254 écrire. Il se leva devant moi, ainsi que ses employés, et me dit : «Tu es l'hôte du roi, et il convient que nous te traitions avec honneur. » Il m’interrogea touchant Jérusalem, la Syrie et l'Égypte, et prolongea la conversation. Une foule considérable s’amassa autour de lui. Il me dit enfin : "Il faut absolument que tu

438 La Roche, c'est-à-dire la mosquée d’Omar.
439 L'origine du terme n’est pas identifiable. 
viennes à ma maison et je t’y traiterai. » Je le quittai et ne le revis plus.

\section{RÉCIT DE MON DÉPART DE CONSTANTINOPLE}

Lorsqu'il sembla aux Turcs qui étaient dans la société de la khâtoûn qu'elle professait la religion de son père, et qu'elle désirait rester près de lui, ils demandèrent à cette princesse la permission de retourner dans leur pays. Elle la leur accorda, leur fit de riches présents, et envoya avec eux une personne chargée de les reconduire dans leur patrie. C'était un émir, appelé Sâroûdjah Assaghîr, qui commandait à cinq cents cavaliers. La princesse m'envoya chercher, et me donna trois cents dînârs en or du pays, qu'on appelle alberbérah ${ }^{440}$, mais cet or n'est pas bon. Elle y joignit deux mille drachmes de Venise, une pièce de drap, de la façon des filles esclaves, et qui était de la meilleure espèce, dix vêtements de soie, de toile de lin et de laine, et enfin deux chevaux que me donnait son père. La princesse m'ayant recommandé à Sâroûdjah, je lui fis mes adieux et m'en retournai. J'avais séjourné chez les Grecs un mois et six jours ${ }^{441}$.

Nous voyageâmes en compagnie de Sâroûdjah, qui me témoignait de la considération, jusqu'à ce que nous fussions arrivés à l'extrémité du pays des Grecs, où nous avions laissé nos compagnons et nos chariots. Nous remontâmes dans ceux-ci, et nous entrâmes dans le désert. Sâroûdjah alla avec nous jusqu'à la ville de Bâbâ ${ }_{\text {p255 }}$ Salthoûk, et s'y arrêta trois jours, en qualité d'hôte, après quoi il retourna dans son pays.

On était alors au plus fort de l'hiver. Je revêtais trois pelisses et deux caleçons, dont un doublé ; je portais aux pieds des bottines de laine, et par-dessus une autre paire de toile de lin doublée, et enfin, par-dessus le tout, une troisième paire en borghâly ${ }^{442}$, c'est-à-dire en cuir de cheval, fourré de peau de loup. Je faisais mes ablutions avec de l'eau chaude, tout près du feu, mais il ne coulait pas une goutte

\footnotetext{
${ }^{440}$ Hyperpyra : les pièces d’or byzantines, qui commençaient à être dévaluées à l'époque.

${ }^{441}$ Il a dû quitter Constantinople le 22-23 septembre 1334.

${ }^{442}$ Bulghari : cuir de Bulgarie.
} 
d'eau qui ne gelât pas à l'instant. Lorsque je me lavais la figure, l'eau, en touchant ma barbe, se changeait en glace, et si je secouais ma barbe, il en tombait une espèce de neige. L'eau qui dégouttait de mon nez se gelait sur mes moustaches. Je ne pouvais monter moi-même à cheval, à cause du grand nombre de vêtements dont j'étais couvert ; en sorte que mes compagnons étaient obligés de me mettre à cheval.

J'arrivai enfin à la ville de Hâddj Terkhân, où nous avions pris congé du sultan Uzbec. Nous apprîmes qu'il en était parti, et qu'il habitait en ce moment la capitale de son royaume. Nous marchâmes pendant trois jours sur le fleuve Itil et sur les rivières voisines, qui étaient alors gelés. Lorsque nous avions besoin d'eau, nous cassions des morceaux de glace, et nous les mettions à fondre dans un chaudron ; puis nous buvions de cette eau, et nous nous en servions pour faire notre cuisine.

Nous arrivâmes ensuite à la ville de Serâ, qui est aussi connue sous le nom de Serâ Berekeh ${ }^{443}$, et c'est la capitale du sultan Uzbec. Nous visitâmes ce souverain ; il nous interrogea touchant les événements de notre voyage, touchant le roi des Grecs et sa capitale. Nous l'instruisîmes de ce qu'il désirait savoir. Il ordonna de nous loger et de nous fournir les objets nécessaires à notre entretien.

Serâ est au nombre des villes les plus belles, et sa ${ }_{\mathrm{p} 256}$ grandeur est très considérable; elle est située dans une plaine et regorge d'habitants ; elle possède de beaux marchés et de vastes rues. Nous montâmes un jour à cheval, en compagnie d'un des principaux habitants, afin de faire le tour de la ville et d'en connaître l'étendue. Notre demeure était à l'une de ses extrémités. Nous partîmes de grand matin, et nous n'arrivâmes à l'autre extrémité qu'après l'heure de midi. Alors nous fîmes la prière et prîmes notre repas. Enfin nous n'atteignîmes notre demeure qu'au coucher du soleil. Nous traversâmes aussi une fois la ville en largeur, aller et retour, dans l'espace d'une demi-journée. Il faut observer que les maisons y sont contiguës les unes aux autres, et qu'il n'y a ni ruines ni jardins. Il s'y trouve treize mosquées principales pour faire la prière du vendredi ; l'une de celles-ci appartient aux châfeïtes. Quant aux autres mosquées, elles sont en très grand nombre. Serâ est habité par des individus de plu- 
sieurs nations, parmi lesquels on distingue les Mongols, qui sont les indigènes et les maîtres du pays ; une partie professe la religion musulmane; les Ass ${ }^{444}$, qui sont musulmans; les Kifdjaks ${ }^{445}$; les Tcherkesses ; les Russes ; les Grecs, et tous ceux-là sont chrétiens. Chaque nation habite un quartier séparé, où elle a ses marchés. Les négociants et les étrangers, originaires des deux Irâks, de l'Égypte, de la Syrie, etc. habitent un quartier qui est entouré d'un mur, afin de préserver les richesses des marchands. Le palais du sultan, à Serâ, est appelé Althoûn-Thâch. Althoûn signifie or, et thâch tête ${ }^{446}$.

Le kâdhi de Serâ, Bedr eddîn ala'radj, est au nombre des meilleurs kâdhis. On y trouve aussi, parmi les professeurs des châfeïtes, le docteur, l'imâm distingué Sadr eddîn Soleïmân Alleczy ${ }^{447}$, qui est un homme de ${ }_{\text {p257 }}$ mérite ; et parmi les mâlekites, Chems eddîn Almisry, qui est en butte aux reproches touchant le manque de pureté de sa foi. On voit à Serâ l'ermitage du pieux pèlerin Nizhâm eddîn ; il nous y traita et nous montra de la considération. On y voit encore celui du docteur et du savant imâm No'mân eddîn Alkhârezmy, que je visitai. Il est au nombre des cheïkhs distingués ; c'est un homme doué de belles qualités, d'une âme généreuse, plein d'humilité, mais fort rude envers les riches. Le sultan Uzbec le visite chaque vendredi ; mais ce cheïkh ne va pas à sa rencontre et ne se lève pas devant le roi. Celui-ci s'assied vis-à-vis du cheïkh, lui parle du ton le plus doux et s'humilie devant lui, et le cheïkh tient une conduite tout opposée. Sa manière d'agir avec les fakîrs, les malheureux et les étrangers est le contraire de sa conduite envers le sultan ; car il leur témoigne de l'humilité, leur parle du ton le plus doux et les honore. Il me traita avec considération (que Dieu l'en récompense !) et me fit présent d'un jeune esclave turc. Je fus témoin d'un miracle de sa part.

\footnotetext{
${ }^{444}$ Les Ossètes, peuple qui habite aujourd'hui le Caucase du Nord, dont les ancêtres, les Alains, sont d'origine indo-européenne.

445 Voir ci-dessus n. 5.

446 Confusion entre tas, pierre, et bas, tête.

${ }^{447}$ Le Lezgui. Les Lezguiens sont un peuple du Caucase.
} 


\section{ACTION MIRACULEUSE DE CE CHEÏKH}

J'avais désiré me rendre de Serâ à Khârezm ; mais le cheïkh me le défendit, en me disant : "Attends quelques jours encore, puis mets-toi en route. » Ma volonté s'y opposa. Je trouvai une grande caravane qui se préparait à partir, et parmi laquelle il y avait des marchands de ma connaissance. Je convins que je partirais avec eux, et j'annonçai au cheïkh cet accord; mais il me dit: « Tu ne peux te dispenser d'attendre ici. » Néanmoins, je me disposai au départ ; mais un de mes esclaves s'enfuit, et je restai à cause de son évasion. Ce retard est au nombre des miracles évidents. Au bout de trois jours, un de mes compagnons trouva mon esclave fugitif à Hâddj Terkhân et me le ramena. Je partis alors pour Khârezm.

Entre cette ville et la résidence royale de Serâ, il y a un désert de quarante jours de marche, dans lequel on ne voyage pas avec ses chevaux, à cause de la disette du fourrage. Les chameaux seuls y traînent les chariots. 


\section{L'Asie centrale}

$\underline{\text { Retour à la Table des Matières }}$

Après être partis de Serâ, nous marchâmes pendant dix jours et arrivâmes à la ville de Serâtchoûk ${ }^{448}$. Le mot tchoûk signifiant petit, c'est comme si l'on disait le Petit-Serâ. Cette ville est située sur le bord d'un fleuve immense, que l'on appelle Oloû Soû, ce qui signifie la Grande Eau. Il est traversé par un pont de bateaux semblable à celui de Baghdâd ${ }^{449}$. C'est ici que nous cessâmes de voyager avec des chevaux traînant des chariots ; nous les vendîmes moyennant quatre dînârs d'argent par tête, et moins encore, à cause de leur état d'épuisement et de leur peu de valeur dans cette ville. Nous louâmes des chameaux pour tirer les chariots. On voit à Serâtchoûk une zâouïah appartenant à un pieux personnage turc avancé en âge, que l'on appelle Athâ, c'est-à-dire Père. Il nous y donna l'hospitalité et fit des vœux en notre faveur. Le kâdhi nous traita aussi ; mais j'ignore son nom.

Après notre départ de Serâtchoûk, nous marchâmes, durant trente jours, d'une marche rapide, ne nous arrêtant que deux heures chaque jour, l'une vers dix heures de la matinée, et la seconde au coucher du soleil. Chacune de ces stations durait seulement le temps nécessaire p261 pour faire cuire le doûghy ${ }^{450}$ et pour le boire. Or il est cuit après un seul bouillon. Ces peuples ont de la viande salée et séchée au soleil, qu'ils étendent par-dessus cette boisson ; enfin, ils versent sur le tout du lait aigri. Chaque homme mange et dort seulement dans son chariot durant le temps de la marche. J'avais dans mon 'arabah trois

\footnotetext{
${ }^{448}$ L'actuelle Saraïtchik, à soixante kilomètres au nord de l'embouchure de l'Oural, appelé Ulu Su par les Turcs et Yayik par les géographes arabes.

${ }^{449}$ Décrit t. I, p. 438.

450 Voir p. 207.
} 
jeunes filles. C'est la coutume des voyageurs d'user de vitesse en franchissant ce désert, à cause du peu d'herbage qu'il produit : les chameaux qui le traversent périssent pour la plupart, et ceux qui survivent ne servent de nouveau que l'année suivante, lorsqu'ils ont repris de l'embonpoint. L'eau, dans ce désert, se trouve dans des endroits placés des intervalles déterminés, à deux ou trois jours de distance l'un de l'autre ; elle est fournie par la pluie ou par des puits creusés dans le gravier ${ }^{451}$.

Lorsque nous eûmes traversé ce désert, ainsi que nous l'avons dit, nous arrivâmes à Khârezm ${ }^{452}$. C'est la plus grande et la plus belle ville des Turcs; elle possède de jolis marchés, de vastes rues, de nombreux édifices, et se recommande par des beautés remarquables. Ses habitants sont si nombreux qu'elle tremble, pour ainsi dire, sous leur poids, et qu'ils la font ressembler, par leurs ondulations, à une mer agitée. Je m'y promenai à cheval pendant un jour, et j'entrai dans

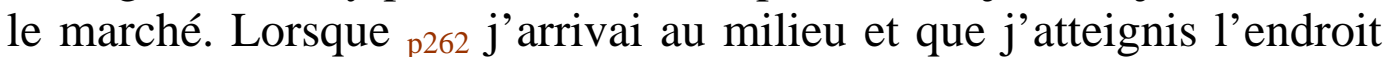
où l'on se serrait le plus, et que l'on appelle chaour ${ }^{453}$, je ne pus dépasser ce lieu, à cause de la foule qui s'y pressait. Je voulus revenir sur mes pas ; cela me fut également impossible, et par le même motif. Je demeurai confondu, et je ne parvins à m'en retourner qu'après de grands efforts. Quelqu'un me dit que ce marché était peu fréquenté le vendredi, parce qu'on ferme ce jour-là le marché de la Kaïçârieh ${ }^{454}$, et d'autres marchés. Je montai à cheval le vendredi, et je me dirigeai vers la mosquée cathédrale et le collège.

${ }^{451}$ Ibn Battûta traverse ce désert en décembre 1334-janvier 1335. En mars 922, quand Ibn Fadhlan le traversa, dans l'autre sens, la neige arrivait aux genoux des chameaux et la caravane faillit périr.

Le Khwarezm en tant que région correspond à la partie inférieure du fleuve Amu Darya, au sud du lac d'Aral et, ici, en tant que ville, à l'ancienne Gurgandj, l'actuelle Kunya Urgentch, située sur le delta d'Amu Darya. Conquise par les Mongols en 1221 et détruite, elle fut rebâtie sur un site voisin en 1231 et appartenait à l'époque à l'empire de la Horde d’Or. Elle était située sur les grands axes commerciaux; al-Umari (v. 1340) constate que les prix étaient presque identiques à ceux de Saray et que les deux places utilisaient les mêmes poids et mesures. La ville fut encore une fois détruite par Timur en 1388.

454 Voir t. I, chap. 3, n. 105. 


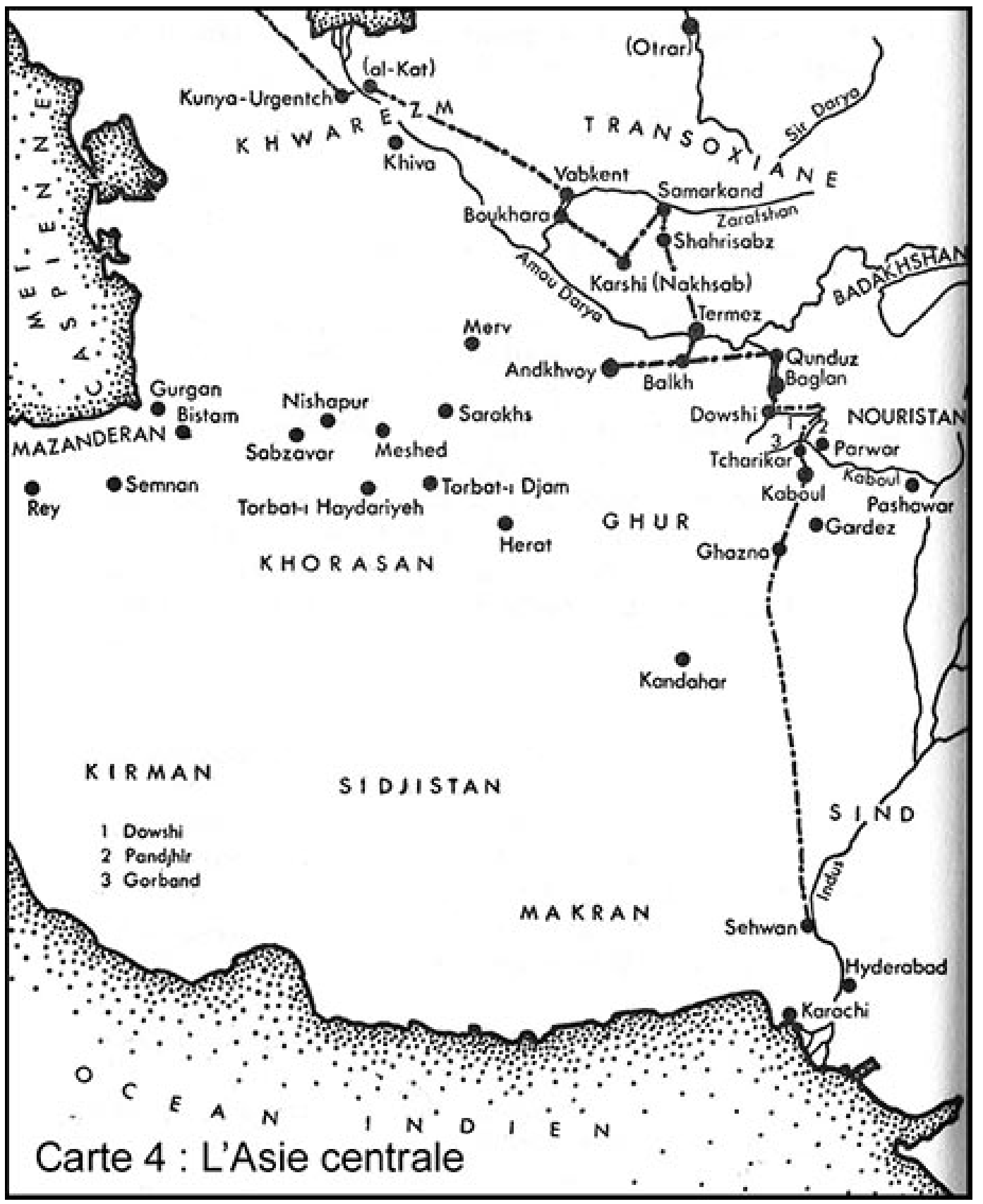

Cette ville fait partie des États du sultan Uzbec ${ }^{455}$, qui y a placé un puissant émir nommé Kothloûdomoûr ${ }^{456}$. C’est cet émir qui a cons-

455 Voir p. 217 et suiv.

456 Kutlugh-Timur doit être un descendant à la cinquième génération de Djoetchi, fils de Gengis, par le fils de Djoetchi Toka-Timur qui avait reçu comme apa- 
truit le collège et ses dépendances ; la mosquée a été bâtie par sa femme, la pieuse princesse Torâbec ${ }^{457}$. On voit à Khârezm un hôpital, auquel est attaché un médecin syrien connu sous le nom d'Assahioûny, qui est un adjectif relatif dérivé de Sahioûn ${ }^{458}$ nom d'une ville de Syrie.

Je n'ai pas vu, dans tout l'univers, d'hommes meilleurs que les habitants de Khârezm ni qui aient des âmes plus généreuses ou qui chérissent davantage les étrangers ${ }^{459}$. Ils observent, dans leurs prières, une coutume louable que je n'ai point remarquée chez d'autres peuples : cette coutume consiste en ce que chaque moueddhin des mosquées de Khârezm fait le tour des maisons occupées par des voisins de

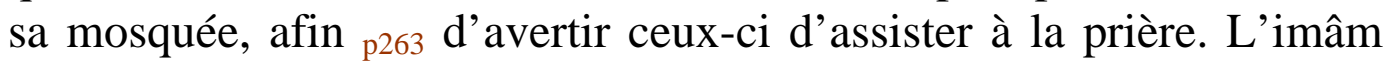
frappe, en présence de toute la communauté, quiconque a manqué à la prière faite en commun ; il y a un nerf de bœuf, suspendu dans chaque mosquée, pour servir à cet usage ${ }^{460}$. Outre ce châtiment, le délinquant doit payer une amende de cinq dînârs, qui est appliquée aux dépenses de la mosquée, ou employée à nourrir les fakîrs et les malheureux. On prétend que cette coutume est en vigueur chez eux depuis les temps anciens.

Auprès de Khârezm coule le fleuve Djeïhoûn, un des quatre fleuves qui sortent du Paradis ${ }^{461}$. Il gèle dans la saison froide, comme le fleuve Itil. On marche alors sur la glace qui le recouvre, et il demeure gelé durant cinq mois ${ }^{462}$. Souvent des imprudents ont osé le passer au moment où il commençait à dégeler, et ils ont péri. Durant l'été on

nage la Crimée. Il avait aidé Uzbek khan à conquérir le pouvoir en 1313 et fut nommé gouverneur du Khwarezm.

${ }^{457}$ Le mausolée de Turabak Khatoun existe toujours dans les ruines de l'ancienne Urgentch.

458 Voir t. I, chap. 3, n. 138.

${ }^{459}$ Un auteur contemporain, Abd al-Razzak Samarkandi, qualifie Urgentch de " rendez-vous des personnages les plus distingués du monde ».

460 13. Cet usage était encore en cours à Bukhara au début du XIX ${ }^{\mathrm{e}}$ siècle.

${ }^{461}$ L'Amu Darya voit t. I, p. 128 et chap. 2, n. 126. L’Itil, c'est la Volga.

${ }^{462}$ Ibn Fadhlan reste à Urgentch pendant deux mois en décembre 923-février 922 : « Le Djeihun avait gelé d'un bout à l'autre. L’épaisseur de la glace était de dix-sept empans. Les chevaux, les mulets et les ânes passaient sur la glace, comme sur un chemin. La couche de glace restait telle quelle sans bouger. La glace est ainsi restée pendant trois mois. » 
navigue sur l'Oxus, dans des bateaux, jusqu'à Termedh ${ }^{463}$, et l'on rapporte de cette ville du froment et de l'orge. Cette navigation prend dix jours à quiconque descend le fleuve.

Dans le voisinage de Khârezm se trouve un ermitage, bâti auprès du mausolée du cheïkh Nedjm eddîn Alcobra ${ }^{464}$, qui était au nombre des plus saints personnages. On y sert de la nourriture aux voyageurs. Le supérieur de cet ermitage est le professeur Seïf eddîn, fils d'Açabah, un des principaux habitants de Khârezm. p264 Dans cette ville se trouve encore un ermitage dont le supérieur est le pieux, le dévot Djélâl eddîn Assamarkandy, un des hommes les plus pieux qui existent ; il nous y traita.

Près de Khârezm, on voit le tombeau de l'imâm très savant Abou'lkâcim Mahmoûd, fils d'Omar azzamakhchary ${ }^{465}$, au-dessus duquel s'élève un dôme. Zamakhchar est une bourgade à quatre milles de distance de Khârezm.

Lorsque j'arrivai à Khârezm, je logeai en dehors de cette ville. Un de mes compagnons alla trouver le kâdhi Sadr eddîn Abou Hafs'Omar albecry ${ }^{466}$, Celui-ci m’envoya son substitut Noûr alislâm, la Lumière de l'islamisme, qui me donna le salut, et retourna ensuite près de son chef. Le kâdhi vint en personne, accompagné de plusieurs de ses adhérents, et me salua. C'était un tout jeune homme, mais déjà vieux par ses œuvres ; il avait deux substituts dont l'un était le susdit Noûr alislâm et l'autre Noûr eddîn Alkermâny, un des principaux jurisconsultes. Ce personnage se montre hardi dans ses décisions et ferme dans la dévotion.

Lorsque j’eus mon entrevue avec le kâdhi, il me dit : "Cette ville est remplie d'une population extrêmement dense, et vous ne réussirez pas facilement à y entrer de jour. Noûr alislâm viendra vous trouver, pour que vous fassiez votre entrée avec lui à la fin de la nuit. » Nous

\footnotetext{
463 Voir plus loin, n. 95.

${ }^{464}$ Nadjm al-din Kubra (1145-1221), saint personnage de l'ordre soufi des suhrawardi et fondateur de son propre ordre, la Kubrawiyya, fut tué par les Mongols lors de la prise d’Urgentch ; son tombeau est toujours préservé.

465 Auteur d'un commentaire grammatical du Coran, mort en 1143.

466 Gibb traduit sadr et non Sadr al-din, sadr étant le titre donné aux cadis en chef à l'est de l'Iran et en Transoxiane.
} 
agîmes ainsi, et nous logeâmes dans un collège tout neuf, où il ne se trouvait encore personne.

Après la prière du matin, le kâdhi vint nous visiter, accompagné de plusieurs des principaux de la ville, parmi lesquels Mewlânâ Homân eddîn, Mewlânâ Zeïn eddîn Almokaddécy, Mewlânâ Ridha eddîn Iahia, Mewlânâ Fadhl allah Arridhawy, Mewlânâ Djélâl eddîn Al'imâdy et Mewlânâ Chems eddîn Assindjary, chapelain de ${ }_{\text {p265 }}$ l'émir de Khârezm. Ces hommes étaient vertueux et doués de qualités fort louables. Le principal dogme de leur croyance est l' 'tizâl ${ }^{467}$, mais ils ne le laissent pas voir, parce que le sultan Uzbec et son vice-roi en cette ville, Kothloûdomoûr, sont orthodoxes.

Durant le temps de mon séjour à Khârezm, je priais le vendredi avec le kâdhi Abou Hafs 'Omar, et dans sa mosquée. Lorsque j'avais fini de prier, je me rendais avec lui dans sa maison, qui est voisine de la mosquée. J'entrais en sa compagnie dans son salon, qui est un des plus magnifiques que l'on puisse voir. Il était décoré de superbes tapis ; ses murs étaient tendus de drap ; on y avait pratiqué de nombreuses niches, dans chacune desquelles se trouvaient des vases d'argent doré et des vases de verre de l'Irâk. C'est la coutume des habitants de ce pays d'en user ainsi dans leurs demeures. On apportait ensuite des mets en grande quantité, car le kâdhi est au nombres des hommes aisés et opulents et qui vivent très bien. Il est l'allié de l'émir Kothloûdomoûr, ayant épousé la sœur de sa femme, nommée Djîdjâ Aghâ ${ }^{468}$.

On trouve à Kharezm plusieurs prédicateurs ${ }^{469}$, dont le principal est Mewlânâ Zeïn eddîn Almokaddecy. On y voit aussi le khathîb Mewlânâ Hoçâm eddîn Almecchâthy, l'éloquent prédicateur, et un des quatre meilleurs orateurs que j'aie entendu dans tout l'univers.

L'émir de Khârezm est le grand émir Kothloûdomoûr, dont le nom signifie le Fer béni ; car kothloû veut dire béni, et domoûr est l'équivalent du mot fer. Cet émir est fils de la tante maternelle du sultan illustre Mohammed Uzbec ; il est le principal de ses émirs et son

\footnotetext{
${ }^{467}$ Pour les mu'tazilites, voir l'introduction du t. I.

468 Pour le titre d'agha, voir ci-dessus chap. 2, n. 73.

${ }^{469}$ Gibb traduit "prédicateurs et revivalistes ", les seconds incitant l'auditoire à se souvenir des promesses de récompense et de punition du Coran.
} 
vice-roi dans le Khorâçân. Son fils, Hâroûn Bec, a épousé la fille du sultan et de la reine Thaïthogly, dont il a été question ci-dessus. Sa femme, la khâtoûn Torâbec, ${ }^{266}$ s'est signalée par d'illustres actes de générosité. Lorsque le kâdhi vint me voir pour me saluer, ainsi que je l'ai raconté, il me dit : "L'émir a appris ton arrivée, mais il a un reste de maladie qui l'empêche de te visiter, " Je montais à cheval avec le kâdhi, pour rendre visite à l'émir. Nous arrivâmes à son palais, et nous entrâmes dans un grand michwer ${ }^{470}$, dont la plupart des appartements étaient en bois. De là nous passâmes dans une petite salle d'audience où se trouvait un dôme de bois doré dont les parois étaient tendues de drap de diverses couleurs et le plafond recouvert d'une étoffe de soie brochée d'or. L'émir était assis sur un tapis de soie étendu pour son usage particulier ; il tenait ses pieds couverts, à cause de la goutte dont il souffrait, et qui est une maladie fort répandue parmi les Turcs. Je lui donnai le salut, et il me fit asseoir à son côté.

Le kâdhi et les docteurs s'assirent aussi. L'émir m'interrogea touchant son souverain, le roi Mohammed Uzbec, la khâtoûn Beïaloûn, le père de cette princesse et la ville de Constantinople. Je satisfis à toutes ses questions. On apporta ensuite des tables, sur lesquelles se trouvaient des mets, c'est-à-dire des poulets rôtis, des grues, des pigeonneaux, du pain pétri avec du beurre, et que l'on appelle alculidja ${ }^{471}$, du biscuit et des sucreries. Ensuite on apporta d'autres tables couvertes de fruits, savoir des grenades épluchées, dans des vases d'or ou d'argent, avec des cuillers d'or. Quelques-uns de ces fruits étaient dans des vases de verre de l'Irâk, avec des cuillers de bois ${ }^{472}$. Il y avait aussi des raisins et de melons superbes.

Parmi les coutumes de cet émir est la suivante : le kâdhi vient chaque jour à sa salle d'audience et s'assied, dans un endroit destiné à cet usage, avec les docteurs de la loi et ses secrétaires. Un des principaux

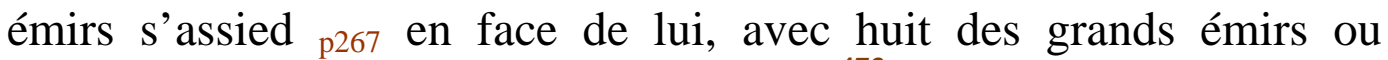
cheïkhs turcs, qui sont appelés alarghodji ${ }^{473}$. Les habitants de la ville viennent soumettre leurs procès à la décision de ce tribunal. Les cau-

\footnotetext{
470 Partie d'un palais séparée du reste de l'édifice.

471 Al-kulitché : pain de forme ronde, en persan.

472 Probablement destinés aux hommes pieux qui s'interdisaient l'usage de la vaisselle d'or, selon les préceptes de l'islam.

473 Yargudji, d'où yargic (juge) en turc moderne.
} 
ses qui sont du ressort de la loi religieuse sont jugées par le kâdhi ${ }^{474}$; les autres le sont par ces émirs. Leurs jugements sont justes et fermes ; car ils ne sont pas soupçonnés d'avoir de l'inclination pour l'une des parties, et ne se laissent pas gagner par des présents.

Lorsque nous fûmes de retour au collège, après l'entrevue avec l'émir, il nous envoya du riz, de la farine, des moutons, du beurre, des épices et plusieurs charges de bois à brûler. On ignore l'usage du charbon dans toute cette contrée, ainsi que dans l'Inde, le Khorâçân et la Perse. Quant à la Chine, on y brûle des pierres, qui s'enflamment comme le charbon ${ }^{475}$. Lorsqu'elles sont converties en cendres, on les pétrit avec de l'eau, puis on les fait sécher au soleil, et on s'en sert une seconde fois pour faire la cuisine, jusqu'à ce qu'elles soient tout à fait consumées.

\section{ANECDOTE, ET ACTION GÉNÉREUSE DE CE KHÂDI ET DE L’ÉMIR}

Je faisais ma prière un certain vendredi, selon ma coutume, dans la mosquée du kâdhi Abou Hafs. Il me dit : "L'émir a ordonné de te payer une somme de cinq cents dirhems, et de préparer à ton intention un festin qui coûtât cinq cents autres pièces d'argent, et auquel assisteraient les cheïkhs, les docteurs et les principaux de la ville. Lorsqu'il eut donné cet ordre, je lui dis : “Ô ${ }_{\text {p268 }}$ émir, tu feras préparer un repas dans lequel les assistants mangeront seulement une ou deux bouchées! Si tu assignes à cet étranger toute la somme, ce sera plus utile pour lui.” Il répondit “J'agirai ainsi”, et il a commandé de te payer les mille dirhems entiers. » L'émir les envoya, avec son chapelain Chems eddîn Assindjary, dans une bourse portée par son page. Le change de cette somme en or du Maghreb équivaut à trois cents dînârs ${ }^{476}$.

J'avais acheté ce jour-là un cheval noir, pour trente-cinq dînârs d'argent, et je le montai pour aller à la mosquée. J'en payai le prix sur

\footnotetext{
474 Mariages, héritages et autres causes s’apparentant au droit civil.

475 « Il est vrai que par toute la province du Catai il y a une manière de pierres noires qui s'extrait des montagnes et qui brûlent en faisant des flammes comme bûches elles se consument tout entières comme le charbon de bois. Elles tiennent le feu et produisent la cuisson mieux que ne fait le bois » (Marco POLO).

${ }^{476}$ Un dinar marocain pesait 4,722 g contre 4,233 g pour un dinar de l’Est.
} 
cette somme de mille dirhems. A la suite de cet événement, je me vis possesseur d'un si grand nombre de chevaux que je n'ose le répéter ici, de peur d'être accusé de mensonge. Ma position ne cessa de s'améliorer, jusqu'à mon entrée dans l'Inde. Je possédais beaucoup de chevaux ; mais je préférais ce cheval noir et je l'attachais devant tous les autres. Il vécut trois années entières à mon service, et après sa mort, ma situation changea.

La khâthoûn Djîdjâ Aghâ, femme du kâdhl, m’envoya cent dinars d'argent. Sa sœur Torâbec, femme de l'émir, donna en mon honneur un festin, dans l'ermitage fondé par elle, et y réunit les docteurs et les chefs de la ville. Dans cet édifice, on prépare de la nourriture pour les voyageurs. La princesse m'envoya une pelisse de martre-zibeline et un cheval de prix. Elle est au nombre des femmes les plus distinguées, les plus vertueuses et les plus généreuses. (Puisse Dieu la récompenser par ses bienfaits !)

\section{ANECDOTE}

Lorsque je quittai le festin que cette princesse avait donné en mon honneur et que je sortis de l'ermitage, p269 une femme s'offrit à ma vue, sur la porte de cet édifice. Elle était couverte de vêtements malpropres et avait la tête voilée. Des femmes, dont j’ai oublié le nombre, l'accompagnaient. Elle me salua; je lui rendis son salut, sans m'arrêter et sans faire autrement attention à elle. Lorsque je fus sorti, un certain individu me rejoignit et me dit : «La femme qui t'a salué est la khâtoûn. » Je fus honteux de ma conduite, et je voulus retourner sur mes pas, afin de rejoindre la princesse, mais je vis qu'elle s'était éloignée. Je lui fis parvenir mes salutations par un de ses serviteurs, et je m'excusai de ma manière d'agir envers elle, sur ce que je ne la connaissais pas.

\section{DESCRIPTION DU MELON DE KHÂREZM}

Le melon de Khârezm n'a pas son pareil dans tout l'univers, tant à l'est qu'à l'ouest, si l'on en excepte celui de Bokhâra. Le melon d'Isfahân vient immédiatement après celui-ci. L'écorce du premier est verte et le dedans est rouge ; son goût est extrêmement doux, mais sa 
chair est ferme. Ce qu'il y a d'étonnant, c'est qu'on le coupe par tranches, qu'on le fait sécher au soleil, qu'on le place dans des paniers, ainsi qu'on en use chez nous avec les figues sèches et les figues de Malaga ; et, dans cet état, on le transporte de Khârezm à l'extrémité de l'Inde et de la Chine. Il n'y a pas, parmi tous les fruits secs, un fruit plus agréable au goût. Pendant le temps de mon séjour à Dihly, dans l'Inde, toutes les fois que des voyageurs arrivaient, j'envoyais quelqu'un pour m'acheter, de ces gens-là, des tranches de melon. Le roi de l'Inde, lorsqu'on lui apportait de ces melons, m'en envoyait, parce qu'il connaissait mon goût pour cet aliment. C'est la coutume de ce prince de donner en présent aux étrangers des fruits de leur pays, et de les favoriser de cette manière. p270

\section{ANECDOTE}

Un chérîf, du nombre des habitants de Kerbelâ, m’avait accompagné de Serâ à Khârezm. Il s’appelait 'Aly, fils de Mançoûr, et exerçait la profession de marchand. Je le chargeais d'acheter pour moi des vêtements et d'autres objets. Il m'achetait un habit pour dix dinars, et me disait : " Je l'ai payé huit pièces d'or. " Il portait à mon compte huit dînârs, et payait de sa bourse les deux autres. J'ignorai sa conduite jusqu'à ce qu'elle me fût révélée par d'autres personnes. Outre cela, le chérîf m’avait prêté plusieurs dînârs. Lorsque je reçus le présent de l'émir de Khârezm, je lui rendis ce qu'il m'avait prêté, et je voulus ensuite lui faire un cadeau, en retour de ses belles actions. Il le refusa et jura qu'il ne l'accepterait pas. Je voulus donner le présent à un jeune esclave qui lui appartenait et que l'on appelait Câfoûr ; mais il m’adjura de n’en rien faire. Ce chérîf était le plus généreux habitant des deux Irâks que j'eusse encore vu. Il résolut de se rendre avec moi dans l'Inde ; mais, dans la suite, plusieurs de ses concitoyens arrivèrent à Khârezm, afin de faire un voyage en Chine ; et il forma le projet de les accompagner. Je lui fis des représentations à ce sujet; mais il me répondit : " Ces habitants de ma ville natale retourneront auprès de ma famille et de mes proches, et rapporteront que j'ai fait un voyage dans l'Inde pour mendier. Ce serait un sujet de blâme pour moi d'agir ainsi, et je ne le ferai pas. » En conséquence, il partit avec eux pour la 
Chine. J'appris par la suite, durant mon séjour dans l'Inde, que cet homme, lorsqu'il fut arrivé dans la ville d'Almâlik ${ }^{477}$, située à l'extrémité de la principauté de Mavéra'nnhar et à l'endroit où commence la Chine, s'y arrêta, et envoya à la Chine un jeune esclave, à lui appartenant, avec ce qu'il possédait de marchandises. p271 L'esclave tarda à revenir. Sur ces entrefaites, un marchand arriva de la patrie du chérîf à Almâlik et se logea dans le même caravansérail que lui. Le chérîf le pria de lui prêter quelque argent, en attendant le retour de son esclave. Le marchand refusa; ensuite il ajouta à la honte de la conduite qu'il avait tenue en manquant de secourir le chérîf, celle de vouloir encore lui faire supporter la location de l'endroit du khân où il logeait lui-même. Le chérîf apprit cela ; il en fut mécontent, entra dans son appartement et se coupa la gorge. On survint dans un instant où il lui restait encore un souffle de vie, et l'on soupçonna de l'avoir tué un esclave qui lui appartenait. Mais il dit aux assistants : « Ne lui faites pas de mal ; c'est moi qui me suis traité ainsi »; et il mourut le même jour. Puisse Dieu lui faire miséricorde !

Ce chérîf m’a raconté le fait suivant, comme lui étant arrivé. Il reçut un jour un prêt, d'un certain marchand de Damas, six mille dirhems. Ce marchand le rencontra dans la ville de Hamâh, en Syrie, et lui réclama son argent. Or il avait vendu à terme les marchandises qu'il avait achetées avec cette somme. Il fut honteux de ne pouvoir payer son créancier, entra dans sa maison, attacha son turban au toit, et voulut s'étrangler. Mais, la mort ayant tardé à l'atteindre, il se rappela un changeur de ses amis, l'alla trouver et lui exposa son embarras. Le changeur lui prêta une somme avec laquelle il paya le marchand.

Lorsque je voulus partir de Khârezm, je louai des chameaux et j'achetai une double litière. J'avais pour contrepoids, dans un des côtés de cette litière, 'Afîf eddîn Attaouzéry. Mes serviteurs montèrent quelques-uns de mes chevaux, et nous couvrîmes les autres avec des housses, à cause du froid. Nous entrâmes dans le désert qui s'étend entre Khârezm et Bokhâra, et qui a dix-huit journées d'étendue. Pendant ce temps, on marche dans des sables entièrement inhabités, si

477 Almalik, située dans la vallée d’Ili, près de l’actuelle frontière sino-soviétique, était la capitale de l'empire mongol de Tchaghatai, qui comprenait la Transoxiane (Mavera'unnahr). Voir ci-dessous n. 38. 
l'on en excepte une seule ville. Je fis mes adieux à l'émir Kothloûdomûr, qui me fit don d'un habit d'honneur, ainsi p272 que le kâdhi. Ce dernier sortit de la ville avec les docteurs pour me dire adieu. Nous marchâmes pendant quatre jours, et nous arrivâmes à la ville d'Alcât ${ }^{478}$. Il n'y a pas sur le chemin de Khârezm à Bokhâra d'autre lieu habité que cette ville ; elle est petite, mais belle. Nous logeâmes en dehors, près d'un étang qui avait été gelé par la rigueur du froid, et sur lequel les enfants jouaient et glissaient. Le kâdhi d'Alcât, appelé Sadr acchéri'ah, le Chef de la loi, apprit mon arrivée. Je l'avais précédemment rencontré dans la maison du kâdhi de Khârezm. Il vint me saluer avec les étudiants et le cheïkh de la ville, le vertueux et dévot Mahmoûd alkhaïwaky ${ }^{479}$. Le kâdhi me proposa de visiter l'émir d'Alcât ; mais le cheïkh Mahmoûd lui dit : « Il convient que l'étranger reçoive la visite, au lieu de la faire; si nous avons quelque grandeur d'âme, nous irons trouver l'émir et nous l'amènerons. » Ils agirent de la sorte. L'émir, ses officiers et ses serviteurs arrivèrent au bout d'une heure, et nous saluâmes ce chef. Notre intention était de nous hâter dans notre voyage. Mais il nous pria de nous arrêter, et donna un festin dans lequel il réunit les docteurs de la loi, les chefs de l'armée, etc. Des poètes y récitèrent les louanges de l'émir. Ce prince me fit présent d'un vêtement et d'un cheval de prix. Nous suivîmes la route connue sous le nom de Sibâieh ${ }^{480}$.

Dans ce désert, on marche l'espace de six journées sans rencontrer d'eau. Au bout de ce temps, nous arrivâmes à la ville de Wabkéneh ${ }^{481}$, éloignée d'un jour de ${ }_{\text {p273 }}$ marche de Bokhâra. C'est une belle ville qui possède des rivières et des jardins. On y conserve des raisins d'une année à l'autre, et ses habitants cultivent un fruit qu'ils appellent al'alloû ${ }^{482}$. Ils le font sécher, et on le transporte dans l'Inde et à

${ }^{478}$ Kath, située sur la rive est d’Amu Darya, était l'ancienne capitale du Khwarezm. Partiellement détruite au début du $\mathrm{X}^{\mathrm{e}}$ siècle par une inondation, elle fut reconstruite au sud-ouest de son ancien site. Elle a dû apparemment peu souffrir de l'invasion mongole.

479 De Khiva, située à l'ouest de l'Amu Darya, future capitale du Khwarezm.

480 Ce nom n’a pas été retrouvé ailleurs. Ibn Fadhlan voyage de Bukhara à Kath en bateau en descendant l'Amu Darya. Ibn Battûta a dû longer le désert situé à l'est de la rivière.

481 L'actuelle Vabkent, à une quarantaine de kilomètres au nord-est de Bukhara.

${ }^{482}$ Al-alu : la prune en persan. Les prunes jaunes de Bukhara étaient célèbres. 
la Chine ; on verse de l'eau par-dessus et l'on boit ce breuvage. Le goût de ce fruit est doux lorsqu'il est encore vert ; mais, quand il est séché, il contracte une saveur légèrement acide ; sa partie pulpeuse est abondante. Je n'ai pas vu son pareil dans l'Andalousie, ni dans le Maghreb, ni en Syrie.

Nous marchâmes ensuite, pendant toute une journée, au milieu de jardins contigus les uns aux autres, de rivières, d'arbres et de champs cultivés, et nous arrivâmes à la ville de Bokhâra ${ }^{483}$, qui a donné naissance au chef des mohaddiths Abou Abd Allah Mohammed, fils d'Isma'ïl albokhâry ${ }^{484}$. Cette ville a été la capitale des pays situés audelà du fleuve Djeïhoûn ${ }^{485}$. Le maudit Tenkîz. Le Tatar, l'aïeul des rois de l'Irâk ${ }^{486}$, l'a dévastée. Actuellement ses mosquées, ses collèges et ses marchés sont ruinés, à l'exception d'un petit nombre. Ses p274 habitants sont méprisés ; leur témoignage n’est pas reçu à Khârezm, ni ailleurs, à cause de leur réputation de partialité, de fausseté et d'impudence. Il n'y a plus aujourd'hui à Bokhâra d'homme qui possède quelques connaissances, ou qui se soucie d'en acquérir.

483 Bukhara, conquise par les armées de Gengis Khan en 1220, fut repeuplée peu après. Détruite deux fois de suite par les Ilkhans de Perse en 1279 et 1316, elle n’a pas pu se relever de ses ruines et ne joua pas de rôle prépondérant dans l'empire des Tchaghataï ou dans celui des Timurides.

${ }^{484}$ Le plus célèbre compilateur de hadiths, traditions du Prophète, (810-870) ; son ouvrage, le Sahih, en contient 7397.

${ }^{485}$ Le terme grec Transoxiane et arabe Mavera’unnahr ont le même sens ; il s’agit de territoires situés entre l’Amu Darya (Oxus, Djeihun) et le Siri Darya (Iaxartes, Seihun).

486 Temudjin, devenu souverain des Mongols en 1206, avait pris le nom de Gengis, forme mongole du turc Tenkiz ou Teniz, Océan ; d’où la transcription arabe. Les Tatars étaient à l'origine une tribu turque mongolisée qui dominait les autres tribus mongoles à l'époque de la naissance de Gengis. Elle sera la première soumise par lui, mais son nom restera, à travers les chroniques chinoises, arabes ou russes, attaché à celui des Mongols. Enfin les rois de l’Irak sont évidemment les Ilkhans de la Perse, descendants de Hulagu, petit-fils de Gengis. 


\section{RÉCIT DES COMMENCEMENTS DES TATARS ET DE LA DESTRUCTION DE BOKHÂRA ET D’AUTRES VILLES PAR CE PEUPLE}

Tenkîz khân était forgeron ${ }^{487}$, dans le pays de Khithâ ${ }^{488}$. Il avait une âme généreuse, un corps vigoureux, une stature élevée. Il réunissait ses compagnons et leur donnait à manger. Une bande d'individus se rassemblèrent auprès de lui, et le mirent à leur tête. Il s'empara de son pays natal, il devint puissant, ses forces augmentèrent, et son pouvoir fut immense. Il fit la conquête du royaume de Khithâ, puis de la Chine, et ses troupes prirent un accroissement considérable. Il conquit les pays de Khoten, de Câchkhar et d'Almâlik ${ }^{489}$. Djélâl eddîn Sindjar, fils de Khârezm châh, était roi du Khârezm, du p275 Khorâçân et du Mavérâ'nnahi ${ }^{490}$ et possédait une puissance considérable. En conséquence, Tenkîz le craignit, s’abstint de l'attaquer et n'exerça aucun acte d'hostilité contre lui.

Or il arriva que Tenkîz envoya des marchands avec des productions de la Chine et du Khithâ, telles qu'étoffes de soie et autres, dans la ville d'Othrâr, la dernière place des États de Djélâl eddîn. Le lieutenant de ce prince à Othrâr lui annonça l'arrivée de ces marchands et lui fit demander quelle conduite il devait tenir envers eux. Le roi lui

${ }^{487}$ Gengis était fils d'un chef de clan et son arrière-grand-père était chef d'une première confédération mongole. La légende du forgeron est aussi mentionnée par Guillaume de Rubrouck qui visita Qaraqorum, la capital mongole, en 1254. Elle tire peut-être son origine du nom de naissance de Gengis, Temudjin (Forgeron ; de tämür, timur, demir : fer), ou de la vieille légende turque, reprise par les Mongols, d'Ergenekon, où le futur clan souverain enfermé dans un territoire enclavé put sortir grâce à un forgeron qui fit fondre une montagne de fer. Cette légende, appliquée à Gengis-Temudjin, symbolise bien l'expansion mongole, n'attachant aucun caractère péjoratif aux origines de Gengis, comme semble vouloir faire Ibn Battûta. Ceci expliquerait comment Rubrouck a pu la recueillir à Qaraqorum et à une époque si précoce.

Nom donné à la Chine du Nord, tirant son origine des Khitans qui y avaient fondé un empire de 907 à 1122.

La conquête de la Chine commencée en 1209 se termina en 1279, sous Qubilai ; Khotan et Kashgar dans le Sinkiang, ainsi qu’Almalik furent conquises en 1218.

490 Les Khwarezmshahs ont régné sur cette région depuis la fin du XII ${ }^{\mathrm{e}}$ siècle jusqu’à l’arrivée des Mongols. Ibn Battûta mélange ici Muhammad Khwarezmshah, surnommé Sindjar (1200-1220), de l'époque duquel date l'épisode d’Otrar raconté plus loin, et son fils Djalal al-din, personnage devenu légendaire, qui combattit les Mongols, de l'Inde jusqu'en Anatolie, pendant dix ans (1221-1231). 
écrivit de s'emparer de leurs richesses, de leur infliger un châtiment exemplaire, de les mutiler et de les renvoyer ensuite dans leur pays ; car Dieu avait décidé d'affliger et d'éprouver les habitants des contrées de l'Orient, en leur inspirant une résolution imprudente, un dessein méchant et de mauvais augure.

Lorsque le gouverneur d'Othrâr se fut conduit de la sorte, Tenkîz se mit en marche, à la tête d'une armée innombrable, pour envahir les pays musulmans. Quand ledit gouverneur reçut l'avis de son approche, il envoya des espions, afin qu'ils lui apportassent des nouvelles de l'ennemi. On raconte que l'un d'eux entra dans le camp d'un des émirs de Tenkîz, sous le déguisement d'un mendiant, et ne trouva personne qui lui donnât à manger. Il s'arrêta près d'un Tatar ; mais il ne vit chez cet homme aucune provision, et n'en reçut pas le moindre aliment. Lorsque le soir fut arrivé, le Tatar prit des tripes, ou intestins desséchés qu'il conservait, les humecta avec de l'eau, fit une saignée à son cheval, remplit ces boyaux du sang qui coulait de cette saignée, les lia et les fit rôtir ; ce mets fut toute sa nourriture. L'espion, étant retourné à Othrâr, informa le gouverneur de cette ${ }_{\text {p276 }}$ ville de ce qui regardait les ennemis, et lui déclara que personne n'était assez puissant pour les combattre ${ }^{491}$. Le gouverneur demanda du secours à son souverain Djélâl eddîn. Ce prince le secourut par une armée de soixante et dix mille hommes, sans compter les troupes qu'il avait précédemment. Lorsque l'on en vint aux mains, Tenkîz les mit en déroute ; il entra de vive force dans la ville d'Othrâr, tua les hommes et fit prisonniers les enfants. Djélâl eddîn marcha en personne contre lui ; et ils se livrèrent des combats si sanglants qu'on n'en avait pas encore vus de pareils sous l'islamisme ${ }^{492}$. Enfin Tenkîz s'empara du

491 «Quand l’armée part pour la guerre ou pour toute autre nécessité, plus volontiers et bravement que le reste du monde, ils se soumettent aux labeurs, et maintes fois, s'il le faut, l'homme ira ou demeurera tout un mois sans autre nourriture que le lait d'une jument et la chair des bêtes qu'il tuera avec son arc. Et son cheval paîtra n'importe quelle herbe il trouvera au bord des pistes en marchant, tant qu'il n'a nul besoin de porter avoine, foin ou paille [...] Ce sont les gens au monde qui plus durement travaillent et supportent fatigue, font la plus faible dépense et se contentent d'un petit manger ; et voilà pourquoi mieux sont que d'autres pour conquérir cités, terres et royaumes » (Mar492 co POLO).

Otrar, située sur le Siri Darya, fut conquise en 1219, Bukhara et Samarkande en 1220, enfin Urgentch en 1221. C'est pan la suite que Djalal al-din infligea 
Mavérânnahr, détruisit Bokhâra, Samarkand et Termedh, et passa le fleuve, c'est-à-dire le Djeïhoûn, se dirigeant vers Balkh, dont il fit la conquête. Puis il marcha sur Bârniân, qu'il prit également ; enfin, il s'avança au loin dans le Khorâçân et dans l'Irâk 'Adjem ${ }^{493}$. Les musulmans se soulevèrent contre lui à Balkh et dans le Mavérâ'nnahr. Il revint sur eux,entra de vive force dans Balkh, et ne la quitta qu'après en avoir fait un monceau de ruines ${ }^{494}$; il fit p277 ensuite de même à Termedh. Cette ville fut dévastée, et elle n’est jamais redevenue florissante depuis lors mais on a bâti, à deux milles de là, un ville que l'on appelle aujourd'hui Termedh. Tenkîz massacra les habitants de Bâmiân, et la ruina de fond en comble, excepté le minaret de sa mosquée djârni'. Il pardonna aux habitants de Bokhâra et de Samarkand ; puis il retourna dans l'Irâk ${ }^{495}$. La puissance des Tatars ne cessa de faire des progrès au point qu'ils entrèrent de vive force dans la capitale de l'islamisme et dans le séjour du khalifat, c'est-à-dire à Baghdâd, et qu'ils égorgèrent le khalife Mosta'cim Billah, l'Abbâcide.

Voici ce que dit Ibn Djozaï : « Notre cheïkh, le kâdhi des kâdhis, Abou'l Bérécât, fils du pèlerin (Ibn alhâddj), m’a fait le récit suivant “J'ai entendu dire ce qui suit au prédicateur Abou 'Abd Allah, fils de Réchîd : Je rencontrai à La Mecque Noûr eddîn, fils d’Azzeddjâdj, un des savants de l'Irâck, accompagné du fils de son frère. Nous conversâmes ensemble et il me dit : Il a péri dans la catastrophe causée par les Tatars, dans l'Irâk, vingt-quatre mille savants. Il ne reste plus de toute cette classe que moi et cet homme, désignant du geste le fils de son frère.” "

Mais revenons au récit de notre voyageur.

aux Mongols leur seule défaite du vivant de Gengis, à Parwar, au nord de Kaboul, mais finit par être battu sur les bords de l’Indus le 25 novembre 1221.

Tirmidh, Balkh (voir plus loin) et Bamiyan, capitale à l'époque du nord de l'Afghanistan, furent conquises également en 1221. Par la suite un raid mené par Tului, fils cadet de Gengis et père de Hulagu, pénétra en Iran et détruisit Merv, Nishapur, Rey, Qazvin et Tabriz.

${ }^{494}$ L'historien Ibn al-Athir parle aussi de cette révolte, mais Balkh paraît avoir déjà été détruite au passage de 1221.

495 Il ne retourna pas en Irak mais en Mongolie ; la conquête de Bagdad a été faite en 1258 par Hulagu. 
Nous logeâmes, dit-il, dans le faubourg de Bokhâra, nommé Feth Abâd ${ }^{496}$, le Séjour de la victoire, où se trouve le tombeau du cheïkh, du savant, du pieux et dévot Seîf eddîn albâkharzy ${ }^{497}$; cet homme était au nombre des principaux saints. L'ermitage qui porte son nom, et où nous descendîmes, est considérable. Il jouit de legs importants, à

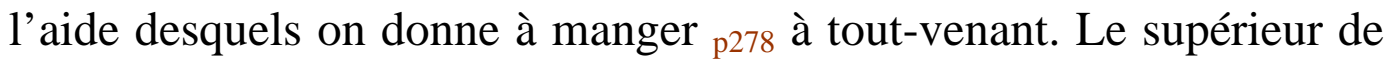
cet ermitage est un descendant de Bâkharzy ; c'est le pèlerin, le voyageur Yahia albâkharzy. Ce cheïkh me traita dans sa maison, et y réunit les principaux habitants de la ville. Les lecteurs du Coran firent une lecture avec de belles voix ; le prédicateur fit un sermon, et on chanta des chansons turques et persanes, d'après une méthode excellente Nous passâmes en cet endroit une nuit admirable, et qui peut compter parmi les plus merveilleuses. J'y rencontrai le jurisconsulte, le savant et vertueux Sadr accherî’ah, le Chef de la loi, qui était arrivé de Hérât ${ }^{498}$; c'était un homme pieux et excellent. Je visitai à Bokhâra le tombeau du savant imâm Abou 'Abd Allah albokhâry ${ }^{499}$, professeur des musulmans et auteur du recueil [de traditions] intitulé : Aldjâmi'ssahîh, la Collection véridique. Sur ce tombeau se trouve cette inscription : "Ceci est la tombe de Mohammed, fils d'Ismâ'ïl albokhâry, qui a composé tels et tels ouvrages. » C'est ainsi qu'on lit, sur les tombes des savants de Bokhâra, leurs noms et les titres de leurs écrits. J'avais copié un grand nombre de ces épitaphes ; mais je les ai perdues avec d'autres objets, lorsque les infidèles de l'Inde me dépouillèrent sur mer.

Nous partîmes de Bokhâra, afin de nous rendre au camp du sultan pieux et honoré Alâ eddîn Thermachîrîn, dont il sera question ciaprès. Nous passâmes par Nakhcheb ${ }^{500}$, ville dont le cheïkh Abou

496 Le faubourg situé au-delà de la porte est de la ville.

${ }^{497}$ Ce disciple de Nadjm al-din Kubra (voir ci-dessus n. 17), mort en 1261, aurait converti Berke, le souverain de la Horde d’Or. Son tombeau, toujours existant, et les bâtiments qui l'accompagnent furent édifiés par Sorgaqtani, épouse de Tului, laquelle était néanmoins chrétienne.

498 Il s’agit peut-être de Fakhr al-din Khisar, qui portait le titre de sadr et fut nommé cadi de Hérat en 1314-1315.

${ }^{499}$ Voir ci-dessus n. 37. Son tombeau serait dans le village de Khartank à deux farsakhs de Samarkande, d'après ses premiers biographes.

500 Nakhshab, située sur la route reliant Bukhara à Balkh, à quatre jours de la première et à huit de la seconde était choisie depuis Gengis, en 1220, pour les campements d’été. Les souverains Tchaghataïdes Kebek (1318-1326) et Kaz- 
Torâb ${ }_{\text {p279 }}$ annakhchéby ${ }^{501}$ a emprunté son surnom. C'est une petite cité, entourée de jardins et de canaux. Nous logeâmes hors de ses murs, dans une maison appartenant à son gouverneur. J'avais avec moi une jeune esclave qui était enceinte et près de son terme ; j'avais résolu de la conduire à Samarkand, pour qu'elle y fit ses couches. Or il se trouva qu'elle était dans une litière qui fut chargée sur un chameau. Nos camarades partirent de nuit et cette esclave les accompagna, avec les provisions et d'autres objets à moi appartenant. Pour moi, je restai près de Nakhcheb, afin de me mettre en route de jour, avec quelques autres de mes compagnons. Les premiers suivirent un chemin différent de celui que nous prîmes. Nous arrivâmes le soir du même jour au camp du sultan. Nous étions affamés, et nous descendîmes dans un endroit éloigné du marché ; un de nos camarades acheta de quoi apaiser notre faim. Un marchand nous prêta une tente où nous passâmes la nuit. Nos compagnons partirent le lendemain à la recherche des chameaux et du reste de la troupe ; ils les trouvèrent dans la soirée, et les amenèrent avec eux. Le sultan était alors absent du camp pour une partie de chasse. Je visitai son lieutenant, l'émir Takbogha ; il me logea dans le voisinage de sa mosquée et me donna une kharghâ ; c'est une espèce de tente, que nous avons décrite cidessus ${ }^{502}$. J'établis la jeune esclave dans cette kharghâ ; et elle y accoucha dans la même nuit. On m'informa que l'enfant était du sexe masculin, mais il n'en était pas ainsi : ce ne fut qu'après l'akîkah ${ }^{503}$ qu'un de mes compagnons m'apprit que l'enfant était une fille. Je fis venir les esclaves femelles, et je les interrogeai ; elles me ${ }_{\text {p280 }}$ confirmèrent la vérité du fait. Cette fille était née sous une heureuse étoile ; depuis sa naissance, j'éprouvai toutes sortes de joies et de satisfactions. Elle mourut deux mois après mon arrivée dans l'Inde, ainsi que je le raconterai ci-dessous.

gan (1343-1346) y ont construit des palais et c'est ainsi que la ville acquit son nom actuel Karshi (Palais en mongol).

${ }^{501}$ Un des ancêtres de la tradition khorasanienne du soufisme. Il aurait fait une quarantaine de fois le pèlerinage et mourut en 859 en route pour La Mecque.

502 Voir ci-dessus chap. 2, n. 92.

503 Cérémonie su septième jour de la naissance au cours de laquelle on sacrifie une brebis ou une chèvre selon le rite malikite. On rase également les cheveux du nouveau-né, on les pèse et on distribue une quantité égale d’or ou d'argent. 
Je visitai dans ce camp le cheïkh, le jurisconsulte, le dévot Mewlânâ Hoçâm eddîn alyâghi (le sens de ce dernier mot, en turc, est le rebelle), qui est un habitant d'Othrâr, et le cheïkh Haçan, beau-frère du sultan.

\section{HISTOIRE DU SULTAN DU MAVÉRÂ'NNAHR (LA TRANSOXIANE)}

C'est le sultan honoré 'Alâ eddîn Thermachîrmn ${ }^{504}$ qui est un prince très puissant. Il possède des armées nombreuses, un royaume considérable et un pouvoir étendu ; il exerce l'autorité avec justice. Ses provinces sont situées entre celles de quatre des plus puissants souverains de l'univers : le roi de la Chine, le roi de l'Inde, le roi de l'Irâk et le roi Uzbec. Ces quatre princes lui font des présents, et lui témoignent de la considération et du respect. Il est parvenu à la royauté après son frère Iltchacathaï ${ }^{505}$. Ce dernier était infidèle, et il était monté sur le trône après son frère aîné Kebec ${ }^{506}$. Kebec était aussi infidèle ; mais il était juste dans l'exercice de son p281 autorité, rendait justice aux opprimés, et traitait les musulmans avec égard et considération.

\section{ANECDOTE}

On raconte que ce roi Kebec, s'entretenant un jour avec le jurisconsulte et prédicateur Bedr eddîn al meldâny, lui dit : « Tu prétends que Dieu a mentionné toutes choses dans son livre respectable [c’est-

504 Tarmashirin (1326-1334) était le sixième fils et septième successeur de Duwa (1282-1306) qui avait plus ou moins réussi à stabiliser l'empire mongol des Tchaghatai, coincé entre les grandes formations mongoles sédentarisées des Ilkhans en Perse et des Yuan en Chine. Tarmashirin fut un des premiers souverains de sa lignée à accepter l'islamisme : toutefois, l'origine de son nom, Darma Shri est bouddhiste.

Iltchigidaï (1326), quatrième fils de Duwa. Entre lui et Tannashirin, il y a encore le règne éphémère de Duwa Timur (1326). Ces souverains étaient bouddhistes et pendant le règne d'Iltchigidaï les dominicains répandirent une propa506 gande catholique en Asie centrale.

Kebek régna de 1309 à 1310 et de 1318 à 1326, l’intervalle étant rempli par un autre frère, Esen Buqa. Il fut le premier de sa lignée à centrer son empire sur la Transoxiane en choisissant comme résidence Nakhshab. D’autres auteurs attestent sa justice. 
à-dire le Coran] ? » Le docteur répondit : « Oui, certes. — Où donc se trouve mon nom dans ce livre ? » Le fakîh repartit : « Dans ce verset : "[ton maître généreux], qui t'a façonné (rakkebec) d'après la forme qu'il a voulue ${ }^{507, " ~}$ " Cela plut à Kebec ; il s'écria : Iakhchy, ce qui, en turc, veut dire excellent ; il témoigna à cet homme une grande considération, et accrut celle qu'il montrait aux musulmans.

\section{AUTRE ANECDOTE}

Parmi les jugements rendus par Kebec, on raconte le suivant. Une femme vint se plaindre à lui d'un des émirs ; elle exposa qu'elle était pauvre et chargée d'enfants, qu'elle possédait du lait, avec le prix duquel elle comptait les nourrir ; mais que cet émir le lui avait enlevé de force et l'avait bu. Kebec lui dit : " Je le ferai fendre en deux; si le lait sort de son ventre, il sera mort justement ; sinon je te ferai fendre en deux après lui. » La femme dit : " Je lui abandonne mes droits sur ce lait, et je ne lui réclame plus rien. » Kebec fit couper en deux cet émir, et le lait coula de son ventre ${ }^{508}$.

Mais revenons au sultan Thermachîrîn.

Lorsque j'eus passé quelques jours dans le camp, que ${ }_{\text {p282 }}$ les Turcs appellent ordou ${ }^{509}$, je m'en allai un jour, pour faire la prière de l'aurore dans la mosquée, selon ma coutume. Quand j'eus fini ma prière, un des assistants me dit que le sultan se trouvait dans la mosquée. Après que ce prince se fut levé de son tapis à prier, je m’avançai pour le saluer. Le cheïkh Haçan et le légiste Hoçâm eddîn Alyâghi se levèrent, et instruisirent le sultan de ma situation et de mon arrivée depuis quelques jours. Il me dit en turc : Khoch mîsen, yakhchi mîsen, kothloû eïoûsen. Le sens de khoch mîsen est : "Es-tu bien portant ? " Yakhchi mîsen signifie : "Tu es un homme excellent »; enfin, kothloû ëoûsen signifie : «Ton arrivée est bénie ${ }^{510}$ ».

\footnotetext{
507 LXXXII, 8.

${ }^{508}$ Voir t. I, chap. 3, n. 79.

${ }^{\mathbf{5 0 9}}$ Voir ci-dessus chap. 3, n. 36.

${ }^{510}$ La traduction approximative serait : «Que tu sois heureux. »
} 
Le sultan était couvert en ce moment d'une tunique de kodsy, ou étoffe de Jérusalem, de couleur verte ; il portait sur sa tête une calotte de pareille étoffe. Il retourna à pied à sa salle d'audience ; ses sujets se présentaient devant lui sur la route, pour lui exposer leurs griefs. Il s'arrêtait pour chaque plaignant, grand ou petit, homme ou femme ; ensuite il m'envoya chercher. J'arrivai près de lui et je le trouvai dans une tente, en dehors de laquelle les hommes se tenaient, à droite et à gauche. Tous les émirs étaient assis sur des sièges ; leurs serviteurs se tenaient debout derrière et devant eux. Tous les soldats étaient assis sur plusieurs rangs ; devant chacun d'eux se trouvaient ses armes ; ils étaient alors de garde, et devaient rester en cet endroit jusqu'à quatre heures de l'après-midi ; d'autres devaient venir les relever et rester jusqu'à la fin de la nuit. On avait placé en ce lieu des tentures d'étoffe de coton, sous lesquelles ces hommes étaient abrités.

Lorsque je fus introduit près du roi, dans la tente, je le trouvai assis sur un siège semblable à une chaire à prêcher, et recouvert de soie brochée d'or. Le dedans de la tente était doublé d'étoffe de soie dorée ; une couronne incrustée de perles et de pierres précieuses était p283 suspendue, à la hauteur d'une coudée, au-dessus de la tête du sultan. Les principaux émirs étaient assis sur des sièges, à la droite et à la gauche du prince. Des fils de rois ${ }^{511}$, portant dans leurs mains des émouchoirs, se tenaient devant lui. Près de la porte de la tente étaient postés le lieutenant du souverain, le vizir, le chambellan et le secrétaire de l'alâmah, que les Turcs appellent al thamgha (al signifie rouge, et thamgha parafe) ${ }^{512}$. Tous les quatre se levèrent devant moi, lorsque j'entrai, et m'accompagnèrent à l'intérieur. Je saluai le sultan, et il m’interrogea touchant La Mecque, Médine, Jérusalem, Hébron, Damas, l'Égypte, Almélic annâcir, les deux Irâks, leur souverain et la Perse. Le secrétaire de l'alâmah nous servait de truchement. Ensuite le moueddhin appela les fidèles à la prière de midi, et nous nous en retournâmes.

Nous assistions aux prières, en compagnie du sultan, et cela pendant des journées d'un froid excessif et mortel. Le sultan ne négligeait

511 Apparemment les princes de sa lignée.

${ }^{512}$ Le sceau impérial, le porteur, appelé tamgaci, étant ainsi un garde des sceaux dans le sens originel du terme. 
pas de faire la prière de l'aurore ni celle du soir avec les fidèles. Il s'asseyait pour réciter les louanges de Dieu, en langue turque, après la prière de l'aurore jusqu'au lever du soleil. Tous ceux qui se trouvaient dans la mosquée s'approchaient de lui ; il leur prenait la main et la leur pressait. Ils agissent de même à la prière de l'après-midi. Lorsqu'on apportait au sultan un présent de raisins secs ou de dattes (or les dattes sont rares chez eux et ils les recherchent fort), il en donnait de sa propre main à tous ceux qui se trouvaient dans la mosquée.

\section{ANECDOTE}

Parmi les actions généreuses de ce roi, je citerai la suivante: j'assistai un jour à la prière de l'après-midi, et le p284 sultan ne s'y trouva pas. Un de ses pages vint avec un tapis, qu'il étendit en face du mihrâb, où le prince avait coutume de prier. Il dit à l'imâm Hoçâm eddîn Alyâghi : " Notre maître veut que tu l'attendes un instant pour faire la prière, jusqu'à ce qu'il ait achevé ses ablutions. » L'imâm se leva et dit en persan : " Le namâz [c'est-à-dire la prière] est-il pour Dieu ou pour Thermachîrîn ? » Puis il ordonna au moueddhin de réciter le second appel à la prière ${ }^{513}$. Le sultan arriva lorsqu'on avait déjà terminé deux rec'ahs ou génuflexions de la prière. Il fit les deux dernières rec'ahs derrière tout le monde, et cela dans l'endroit où les fidèles déposent leurs sandales, près de la porte de la mosquée ; après quoi, la prière publique fut achevée, et il accomplit seul les deux rec'ahs qu'il avait passées. Puis il se leva, s'avança en riant vers l'imâm, afin de lui prendre la main, et s'assit en face du mihrâb. Le cheïkh et imâm était à son côté, et moi j'étais à côté de l'imâm. Le prince me dit: "Quand tu seras retourné dans ton pays, racontes-y qu'un fakîr persan agit de la sorte avec le sultan des Turcs. »

Ce cheïkh prêchait les fidèles tous les vendredis ; il ordonnait au sultan d'agir conformément à la loi, et lui défendait de commettre des actes illégaux ou tyranniques. Il lui parlait avec dureté ; le sultan se taisait et pleurait. Le cheïkh n’acceptait aucun présent du prince, ne

${ }^{513}$ Le premier appel à la prière, l'ézan (adhan), est répété avec quelques variations à l'intérieur de la mosquée une fois que l'assistance est alignée pour la prière. Ce deuxième appel est nommé iqama. 
mangeait même pas à sa table, et ne revêtait pas d'habits donnés par lui ; en un mot, c'était un des plus vertueux serviteurs de Dieu. Je voyais souvent sur lui une tunique d'étoffe de coton, doublée et piquée de coton, toute usée et toute déchirée. Sur sa tête il portait un haut bonnet de feutre, dont le pareil pouvait valoir un kîrâth ${ }^{514}$, p285 et il n'avait pas d'imâmah ${ }^{515}$. Je lui dis un jour: "Ô mon seigneur, qu'est-ce que cette tunique dont tu es vêtu ? Certes elle n'est pas belle. » Il me répondit : « $\mathrm{O}$ mon fils, cette tunique ne m'appartient pas, mais elle appartient à ma fille. » Je le priai d'accepter quelquesuns de mes vêtements. Il me dit: " J'ai fait vœu à Dieu, il y a cinquante ans, de ne rien recevoir de personne; si j'acceptais un don de quelqu'un, ce serait de toi. »

Lorsque j’eus résolu de partir, après avoir séjourné près de ce sultan durant cinquante-quatre jours, il me donna sept cents dînârs, et une pelisse de zibeline qui valait cent dînârs, et que je lui demandai, à cause du froid. Lorsque je la lui eus demandée, il prit mes manches et se mit à me la passer de sa propre main, marquant ainsi son humilité, sa vertu et la bonté de son caractère. Il me donna deux chevaux et deux chameaux. Quand je voulus lui faire mes adieux, je le rencontrai au milieu du chemin, se dirigeant vers une réserve de chasse. La journée était excessivement froide ; en vérité, je ne pus proférer une seule parole, à cause de la violence du froid. Il comprit cela, sourit et me tendit la main ; après quoi, je m’en retournai.

Deux ans après mon arrivée dans l'Inde, nous apprîmes que les principaux de ses sujets et de ses émirs s'étaient réunis dans la plus éloignée de ses provinces qui avoisinent la Chine. C'est là que se trouvait la plus grande partie de ses troupes. Ils prêtèrent serment à un de ses cousins nommé Bouzoun Oghly ${ }^{516}$; or tous les ${ }_{\mathrm{p} 286}$ fils de rois

${ }^{514}$ Le qirat ou carat était le 1/24 du mithqal d'or ou le 1/16 du dirham d'argent.

515 Pièce de mousseline que l'on roule autour de la calotte ; turban.

516 L'islamisation et le recentrage de l'empire sur la Transoxiane, qui procèdent du même objectif : profiter de la production agricole et artisanale, ainsi que du flux commercial d'un pays de vieille civilisation, indisposent les chefs tribaux, shamanistes du vieux noyau oriental de l'empire. D'où la réaction qui se manifeste en 1334 avec Buzan, fils de Duwa Timur (voir ci-dessus, n. 58) et donc neveu de Tarmashirin. On possède des monnaies de Buzan datant de 1334, mais avec la déposition de Tarmashirin on entre dans une période d'anarchie et il n'est pas impossible que des règnes se superposent et que ces événements 
sont appelés par les Turcs oghly ${ }^{517}$. Bouzoun était musulman ; mais c'était un homme impie et méchant. Les Tartares le reconnurent pour roi et déposèrent Thermachîrîn, parce que ce dernier avait agi contrairement aux préceptes de leur aïeul commun, le maudit Tenkîz, celui-là même qui a dévasté les contrées musulmanes, et dont il a été question ci-dessus. Tenkîz avait composé un livre contenant ses lois, et qui est appelé, chez ces peuples, Aliaçâk ${ }^{518}$. Il est d'obligation pour les Tartares de déposer tout prince qui désobéit aux prescriptions de ce livre. Parmi ses préceptes, il y en a un qui leur commande de se réunir une fois tous les ans. On appelle ce jour Thoi ${ }^{519}$, c'est-à-dire jour de Festin. Les descendants de Tenkîz et les émirs viennent à cette réunion de tous les points de l'empire. Les khâtoûns et les principaux officiers de l'armée y assistent aussi. Si le sultan a changé quelque chose aux prescriptions de Tenkîz, les chefs des Tartares s'approchent de lui et lui disent : « Tu as fait tel et tel changement et tu t'es conduit ainsi. Il est donc devenu nécessaire de te déposer. » Ils le prennent par la main, le font descendre de dessus son trône et y placent un autre descendant de Tenkîz. Si un des principaux émirs a commis une faute dans son gouvernement, ils prononcent contre lui la peine qu'il a méritée.

Le sultan Thermachîrîn avait mis fin aux jugements prononcés ce jour-là, et abrogé la coutume de cette réunion. Les Tartares supportèrent avec beaucoup de peine cette conduite du sultan. Ils lui reprochaient aussi d'avoir séjourné quatre ans de suite dans la portion des États contigu au Khorâçân, et de n'être pas venu dans p287 la portion qui touche à la Chine. Il est d'usage que le roi se rende chaque année dans ces régions, qu'il y examine leur situation et l'état des troupes qui s'y trouvent; car c'est de là que leurs rois sont originaires ${ }^{520}$. Leur capitale est la ville d'Almâlik.

qui ne sont nulle part datés se soient déroulés en 1335 (voir la préface pour les problèmes de chronologie).

${ }^{517}$ Le titre serait plutôt oghlan.

518 Yasa ou Yasak, le code édicté par Gengis.

519 Le toy (festin) est ici employé dans le sens de kurultay (assemblée), mais les deux termes désignent une réunion officielle des dignitaires mongols. 
Lorsque les Tartares eurent prêté serment à Bouzoun, il se mit en marche avec une armée considérable. Thermachîrîn craignit quelque complot de la part de ses émirs, ne se fia point à eux, et monta à cheval, accompagné de quinze cavaliers seulement, afin de gagner la province de Ghaznah, qui faisait partie de son empire. Le vice-roi de cette province était le principal de ses émirs et son confident, Boronthaïh. Cet émir aime l'islamisme et les musulmans ; il a construit dans son gouvernement environ quarante ermitages, où l'on distribue des aliments aux voyageurs. Il commande à une armée nombreuse. Je n’ai pas rencontré parmi tous les mortels que j'ai vus dans toute l'étendue de l'univers, un homme d'une stature plus élevée que la sienne.

Lorsque Thermachîrîn eut traversé le fleuve Djeïhoûn, et qu'il eut pris le chemin de Balkh, il fut vu d'un Turc, au service de Ianki, fils de son frère Kebec. Or le sultan Thermachîrîn avait tué son frère Kebec ${ }^{521}$, dont il a été question plus haut. Le fils de ce prince, Ianki, restait à Balkh. Lorsque le Turc l'informa de la rencontre de son oncle, il dit : " Il ne s'est enfui qu'à cause de quelque affaire grave qui lui sera survenue. » il montai cheval avec ses officiers, se saisit de Thermachîrîn et l'emprisonna.

Cependant Bouzoun arriva à Samarkand et à Bokhâra dont les habitants le reconnurent pour souverain. Ianki lui amena Thermachîrîn. On raconte que quand ce ${ }_{\mathrm{p} 288}$ prince fut arrivé à Nécef, près de Samarkand, il y fut mis à mort et y fut enseveli ${ }^{522}$, et que le cheïkh Chems eddîn Guerden Burîdâ est le gardien de son mausolée. On dit aussi que Thermachîrîn ne fut pas tué, ainsi que nous le raconterons cidessous. Guerden (en persan) signifie cou et burîdâ (burîdeh) coupé. Ce cheïkh fut appelé de ce nom à cause d'une blessure qu'il avait reçue au cou ; je l'ai rencontré dans l'Inde et je parlerai de lui ci-après.

Lorsque Bouzoun fut devenu roi, le fils du sultan Thermachîrîn, Béchâï Oghoul (ou mieux Oghly, d'après un manuscrit), sa sœur et le

521 D’après l' « Anonyme d’Iskandar », pratiquement la seule source historique qui traite de ces événements Kebek serait mort de mort naturelle. De même on ne connaît pas ce Ianki, à moins qu'il ne s'agisse de Tchengshi, successeur de Buzan (1334-1338), généralement connu comme fils d’Ebügen, septième fils de Duwa, mais parfois donné comme fils de Kebek.

522

Cette Necef est la même que Nakhshab mentionnée plus haut. D’après d'autres sources aussi, Tarmashirin serait mort dans cette ville. 
mari de celle-ci, Fîroûz s'enfuirent à la cour du roi de l'Inde. Il les traita avec considération et leur assigna un logement splendide, à cause de l'amitié et de l'échange de lettres et de présents qui existaient entre lui et Thermachîrîn, à qui il donnait le titre de frère. Dans la suite, un individu arriva du Sind et prétendit être Thermachîrîn. Les hommes furent d'opinions différentes touchant ce qui le regardait. 'Imâd almulc Sertîz, affranchi du roi de l'Inde et vice-roi du Sind, apprit cela. Il était appelé Mélic'Arz, le Roi des revues, car c'était devant lui que les troupes de l'Inde passaient en revue, et il en avait le commandement. Il résidait à Moltân, capitale du Sind. Il envoya près de cet individu quelques Turcs qui avaient connu Thermachîrîn. Ils revinrent et dirent à Sertîz que cet homme était vraiment Thermachîrîn. Sur ce rapport, Sertîz ordonna d'élever pour lui une sérâdjeh ou afrâdj, c'est-à-dire une tente ${ }^{523}$, Elle fut dressée en dehors de la ville. Sertîz fit, pour recevoir cet individu, les préparatifs que l'on fait ordinairement pour les princes. Il sortit à sa rencontre, mit pied à terre devant lui, le salua et le conduisit respectueusement à la sérâdjeh, où cet homme entra à cheval, selon la coutume des rois. Personne ne ${ }_{\text {p289 }}$ douta que ce ne fût Thermachîrîn. Il envoya annoncer son arrivée au roi de l'Inde. Le roi lui dépêcha des émirs, afin qu'ils allassent audevant de lui avec les mets de l’hospitalité.

Il y avait au service du roi de l'Inde un médecin qui avait précédemment servi Thermachîrîn, et qui était devenu le premier des médecins de l'Inde. Il dit au roi : " J'irai trouver cet homme, et je saurai si ses prétentions sont fondées. J’ai soigné un abcès que Thermachîrîn avait au-dessous du genou, et dont la marque est restée visible ; je saurai la vérité par ce moyen. » Ce médecin alla donc trouver le nouveau venu, et se joignit aux émirs qui étaient chargés de le recevoir. Il fut admis en sa présence et resta assidûment près de lui à la faveur de leur ancienne connaissance ; enfin, un jour après, il palpa ses jambes et découvrit la cicatrice. Cet homme lui fit des reproches et lui dit : « Tu veux regarder l'abcès que tu as guéri ; en voici la place. » En même temps il lui fit voir la cicatrice. Le médecin connut par là, à n’en plus douter, que cet homme était Thermachîrîn. Il retourna près du roi de l'Inde et lui annonça la nouvelle. 
Quelque temps après, le vizir Khodjah Djihân Ahmed, fils d'Aïâs, et le chef des émirs, Kothloû Khân ${ }^{524}$, qui avait été précepteur du sultan de l'Inde dans son enfance, allèrent trouver ce roi et lui dirent : " Ô seigneur du monde, ce sultan Thermachîrîn es arrivé ; il est véritable que cet hommes est bien le sultan. Il y a ici environ quarante mille de ses sujets, son fils et son gendre ${ }^{525}$. As-tu bien examiné ce qui arrivera s'ils se joignent à lui ? » Ce discours fit une vive impression sur le sultan, et il ordonna d'amener Thermachîrîn en toute hâte. Lorsque ce prince parut devant le sultan, il reçut l'ordre de lui témoigner son respect, comme tout le monde, et fut traité sans considération. Le sultan lui ${ }_{\mathrm{p} 290}$ dit : Yâ mâder gâny, " Ô fils d'une prostituée ! » (ce qui est un reproche déshonorant), comme tu mens! Tu dis que tu es Thermachîrîn ; cependant ce prince a été tué et voici le gardien de son mausolée. Par Dieu, sans la crainte de commettre un crime, certes, je te tuerais! Qu'on lui donne, ajouta-t-il cinq mille dinars, qu'on le mène à la maison de Béchâï Oghoul et de sa sœur, les deux enfants de Thermachîrîn, et qu'on leur dise : " Cet imposteur prétend être votre père. " Cet homme alla donc trouver le prince et sa sœur ; ils le reconnurent et il passa la nuit près d'eux, surveillé par des gardiens. Le lendemain matin, il fut tiré de cette maison ; le prince et la princesse craignirent qu'on ne les fît périr, à cause de cet homme. En conséquence, ils le désavouèrent pour leur père. Il fut exilé de l'Inde et du Sind, et prit le chemin de Kîdj et du Mecrân. Les habitants des provinces situées sur sa route lui témoignaient du respect, lui donnaient l'hospitalité et lui faisaient des présents. Il arriva enfin à Chîrâz. Le prince de cette ville, Abou Ishâk, le traita avec considération et lui assigna une somme suffisante pour son entretien. Lorsque j'entrai dans Chîrâz, à mon retour de l'Inde, on me dit que cet homme y était encore. Je désirais le voir ; mais je ne le fis pas, parce qu'il demeurait dans une maison où personne ne le visitait sans la permission du sultan Abou Ishâk, et que je craignis les conséquences de cette visite. Dans la suite je me repentis de ne l'avoir pas vu.

Mais revenons à Bouzoun.

524 Pour ces personnages, voir plus loin p. 353 et 354.

525 Ces éléments sont peut-être en liaison avec une invasion controversée de Tarmashirin en Inde en 1326-1327. 
Lorsque ce prince se fut emparé de la royauté, il tourmenta les musulmans, traita injustement ses sujets, et permit aux chrétiens et aux juifs de réparer leurs temples. Les musulmans se plaignirent de cela, et attendirent impatiemment que quelque revers vînt atteindre Bouzoun. La conduite tyrannique de ce prince arriva à la connaissance de Khâlîl, fils du sultan Yaçaoûn ${ }^{526}$, p291 celui-là même qui avait été vaincu dans sa tentative pour s'emparer du Khorâçân. Il se rendit près du roi de Hérât, qui était le sultan Hoçaïn, fils du sultan Ghiyâth eddîn alghoûry ${ }^{527}$, lui révéla ses projets et le pria de l'aider d'hommes et d'argent, à condition qu'il partagerait avec lui son royaume, lorsqu'il en aurait fait la conquête. Le roi Hoçaïn fit partir avec lui une armée considérable. Entre Hérât et Termedh, il y a neuf jours de distance. Lorsque les émirs musulmans apprirent l'arrivée de Khalîl, ils lui firent leur soumission et lui témoignèrent leur désir de combattre les infidèles ${ }^{528}$. Le premier qui vint le trouver fut 'Alâ almulc Khodhâwend Zâdeh, prince de Termedh ${ }^{529}$. C'était un émir puissant, un descendant de Mahomet par Hoçaïn. Il joignit Khalîl avec quatre mille musulmans. Khalîl fut joyeux de son arrivée, l’investit du vizirat et lui confia l'exercice de l'autorité. 'Alâ almulc était au nombre des hommes les plus braves. D'autres émirs vinrent de toutes parts se réunir à Khalîl, qui engagea le combat contre Bouzoun. Les troupes de celui-ci

526 Yasa’ur, descendant de Tchaghataï, n’a jamais été souverain ; il se mêla dans les luttes entre Tchaghataïdes et Ilkhans, envahit le Khorasan à deux reprises en 1314 et 1319 et fut tué en 1320 . On ne lui reconnaît qu'un seul fils, Kazgan, qui régna de 1343 à 1346. Par contre, ce Khalil est connu comme un derviche turc, prétendant être un descendant de Gengis Khan et chef spirituel de Baha al-din Naqshabandi (1318.1389), fondateur éponyme d'un ordre mystique. On possède des monnaies frappées à son nom datant de 1342 et 1344 . Il a dû apparaître dans le vide politique installé en Transoxiane après la mort de Tchengshi et le retrait de son frère Yisen Timur (1338-1340) Almalik. Il n’est donc peut-être pas directement lié à la mort de Buzan.

527 Voir plus loin p. 302 et n. 109.

528 Il s'agit apparemment d'une alliance des chefs mongols musulmans, c'est-àdire principalement ceux de la Transoxiane contre les Mongols païens de l'Est.

${ }^{529}$ Les Sayyids, descendants de Muhammad, de Tirmidh (voir plus loin n. 95), avaient acquis suffisamment d'importance dès le début du XIII ${ }^{\mathrm{e}}$ siècle pour que Muhammad Khwarezmshah, en conflit avec le calife abbasside al-Nasir, nomme un "anticalife » dans la personne d'un membre de cette famille, connue plus tard sous le nom de Khudawandzade. Le personnage cité par Ibn Battûta comme «prince » de Tirmidh semble donc descendre de cette même famille. 
passèrent du côté de Khalîl, et lui p292 livrèrent Bouzoun chargé de chaînes. Khalîl le fit étrangler avec des cordes d'arc ; car c'est la coutume de ces peuples de ne faire périr les fils des rois que par strangulation.

Le royaume tout entier fut soumis à Khalîl. Il passa ses troupes en revue à Samarkand. Elles montaient à quatre-vingt mille hommes, couverts de cuirasses et dont les chevaux étaient bardés de fer ${ }^{530}$. Il congédia l'armée avec laquelle il était venu de Hérât et marcha vers le pays d'Almâlik. Les Tartares mirent à leur tête un des leurs, et rencontrèrent Khalîl à la distance de trois journées de marche d'Almâlik, dans le voisinage de Tharâz ${ }^{531}$. Le combat fut chaud, et les deux armées tinrent ferme. L'émir Khodhâwend Zâdeh, vizir de Khalîl, fit, à la tête de vingt mille musulmans, une charge à laquelle les Tartares ne purent résister. Ils furent mis en déroute et eurent un grand nombre de morts. Khalîl s'arrêta trois jours à Almâlik, et en sortit pour exterminer ceux des Tartares qui avaient survécu. Ils se soumirent à lui. Alors il s’avança jusqu'à la frontière du Khithâ et de la Chine et conquit les villes de Karâkoroum et de Bichbâligh ${ }^{532}$. Le sultan de la Chine envoya contre lui des troupes, mais dans la suite la paix fut conclue entre eux. La puissance de Khalîl devint considérable, et les autres rois le craignirent ; il montra de l'équité, plaça des troupes à Almâlik, y laissa son vizir Khodhâwend Zâdeh, et retourna à Samarkand et à Bokhâra.

Par la suite, les Turcs voulurent exciter du désordre : ils calomnièrent le vizir près de Khalîl, prétendant qu'il avait l'intention de se révolter et disait qu'il était plus digne du trône que Khalîl, à cause de sa parenté avec le ${ }_{\text {p293 }}$ Prophète, de sa libéralité et de sa bravoure. Khalîl envoya un vice-roi à Almâlik, en remplacement du vizir, et ordonna à celui-ci de venir le trouver avec un petit nombre de personnes. Dès qu’il fut arrivé, il le tua sans plus ample information. Ce meurtre fut la

530 Jean du Plan Carpin, qui fut envoyé à Qaraqorum en 1243, mentionne les cuirasses mongoles.

531 Sur la rivière Talas, à trois cents miles à l'ouest d'Almalik.

532 Qaraqorum, sur la rivière Orkhon, était située au nord de la Mongolie actuelle, Beshbaliq dans la région de Turfan, en Turkistan chinois. Ces berceaux de l'empire mongol étaient sous le contrôle de l'empire mongol des Yuan de Chine dont les souverains portaient également le titre de Khan suprême des Mongols. 
cause de la ruine de son royaume. Lorsque l'autorité de Khalîl fut devenue considérable, il se révolta contre le prince de Hérât, qui l'avait fait hériter du trône, et lui avait fourni des troupes et de l'argent. Il lui écrivit de faire la prière en son nom, dans le royaume de Hérât, et de frapper à son coin la monnaie d'or et d'argent. Cette conduite mécontenta fort Mélic Hoçaïn ; il fit à Khalîl une réponse très grossière. Khalîl se prépara à le combattre. Mais les troupes musulmanes ne le secoururent pas et le jugèrent rebelle à son bienfaiteur. Cette nouvelle parvint à Mélic Hoçaïn. Il fit marcher son armée sous le commandement de son cousin germain Mélic Wernâ. Les deux armées en vinrent aux mains. Khalîl fut mis en déroute, fait prisonnier et mené à Mélic Hoçaïn. Ce prince lui accorda la vie, le logea dans un palais, lui donna une jeune esclave et lui assigna une pension. C'est dans cet état que je le laissai, à la fin de l'année 747, lors de ma sortie de l'Inde ${ }^{533}$.

Mais revenons à notre propos.

Lorsque j'eus fait mes adieux au sultan Thermachîrîn, je me dirigeai vers la ville de Samarkand ${ }^{534}$, une des plus grandes, des plus belles et des plus magnifiques cités du monde. Elle est bâtie sur le bord d'une rivière nommée rivière des Foulons, et couverte de machines hydrauliques, qui arrosent des jardins. C'est près de ${ }_{p 294}$ cette rivière que se rassemblent les habitants de la ville, après la prière de quatre heures du soir, pour se divertir et se promener. Ils y ont des estrades et des sièges pour s'asseoir, et des boutiques où l'on vend des fruits et d'autres aliments. Il y avait aussi sur le bord du fleuve des palais considérables et des monuments qui annonçaient l'élévation de l'esprit des habitants de Samarkand. La plupart sont ruinés, et une grande partie de la ville a été aussi dévastée. Elle n’a ni muraille ni portes. Des jardins se trouvent compris dans l'intérieur de la ville. Les habitants de Samarkand possèdent des qualités généreuses, et ont de l'amitié pour les étrangers ; ils valent mieux que ceux de Bokhâra.

533 Il faudrait lire «j’ai laissé la situation », puisqu’Ibn Battûta ne passa pas par Hérat à son retour en 1347.

534 Samarkande est située sur la rive ouest de Zarafshan dans l'actuel Uzbekistan soviétique. Ibn Battûta doit confondre avec la rivière des Foulons qui coule à Nakhshab. La ville, détruite par les Mongols en 1219, n’a repris de l'importance qu'à la fin du $\mathrm{XIV}^{\mathrm{e}}$ siècle, quand elle est devenue la capitale de Timur. 
Près de Samarkand est le tombeau de Kotham, fils d'Abbâs, fils d'Abd almotthalib ${ }^{535}$, qui fut tué lors de la conquête de cette ville par les musulmans. Les habitants de Samarkand sortent chaque nuit du dimanche au lundi et du jeudi au vendredi, pour visiter ce tombeau. Les Tartares y viennent aussi en pèlerinage, lui vouent des offrandes considérables, et y apportent des bœufs, des moutons, des dirhems et des dînârs. Tout cela est dépensé pour traiter les voyageurs et pour l'entretien des serviteurs de l'ermitage et du tombeau béni. Au-dessus de ce monument est un dôme élevé sur quatre pilastres à chaque pilastre sont jointes deux colonnes de marbre il y en a de vertes, de noires, de blanches et de rouges. Les murailles du dôme sont de marbre nuancé de diverses couleurs, peint et doré ; et son toit est en plomb. Le tombeau est recouvert de planches d'ébène incrustées d'or et de pierreries, et revêtues d'argent aux angles. Au-dessus de lui sont suspendues trois lampes d'argent. Les tapis du dôme sont de laine et de coton ${ }^{536}$. En ${ }_{\text {p295 }}$ dehors coule un grand fleuve, qui traverse l'ermitage voisin, et sur les bords duquel il y a des arbres, des ceps de vigne et des jasmins. Dans l'ermitage se trouvent des habitations où logent les voyageurs. Les Tartares, durant le temps de leur idolâtrie, n’ont rien changé à l'état de cet endroit béni ; au contraire, ils regardaient sa possession comme d'un heureux augure, à cause des miracles dont ils y étaient témoins.

L’inspecteur général ${ }^{537}$, de ce sépulcre béni et de ce qui lui est contigu, lorsque nous y logeâmes, était l'émir Ghiyâth eddîn Mohammed, fils d'Abd alkâdir, fils d'Abd al'azîz, fils de Yoûcef, fils du khalife Almostancir Billah, l'Abbâcide. Le sultan Thermachîrîn l'éleva à cette dignité, lorsqu'il arriva de l'Irâk à sa cour ; mais il se trouve actuellement près du roi de l'Inde, et il sera fait mention de lui ci-après. Je vis à Samarkand le kâdhi de cette ville, appelé, chez les

535 Qutham aurait été tué en 676, pendant le siège de cette ville, mais il s’agit probablement d'un culte promu par les abbassides pour la gloire de leur famille. Le tombeau, connu sous le nom de Mazarshah ou Shah Zindeh, constitue aujourd'hui une des principales antiquités de la ville.

536 Il doit plutôt s’agir de tapis suspendus autour du mausolée.

537 Surintendant des revenus affectés à la fondation pieuse constituée pour entretenir le tombeau. L’histoire de Ghiyath al-din, déjà mentionné (t. I, p. 326), sera contée plus loin p. 429 et suiv. 
Tartares, Sadr aldjihân ${ }^{538}$, le Chef du monde. C'était un homme vertueux et doué de belles qualités. Il se rendit dans l'Inde après moi, mais il fut surpris par la mort dans la ville de Moltân, capitale du Sind.

\section{ANECDOTE}

Lorsque ce kâdhi fut mort à Moltân, le secrétaire chargé d'annoncer au roi les nouvelles lui écrivit cet événement, et lui apprit que ce personnage était venu dans l'intention de visiter sa cour, mais que la mort l'en avait empêché. A cette nouvelle, le roi ordonna d'envoyer à ses enfants je ne me rappelle plus combien de milliers de dînârs, et de compter à ses serviteurs ce qu'il leur aurait donné, s'ils étaient arrivés à la cour du vivant de leur maître et avec lui. Le roi de l'Inde a, dans chaque ville ${ }_{\mathrm{p} 296}$ de ses États, un correspondant qui lui écrit tout ce qui se passe dans cette ville et lui annonce tous les étrangers qui y arrivent. Dès l'arrivée d'un de ceux-ci, on écrit de quel pays il vient ; on prend note de son nom, de son signalement, des ses vêtements, de ses compagnons, du nombre de ses chevaux et de ses serviteurs, de quelle manière il s'assied et mange ; en un mot, de toute sa manière d'être, de ses occupations et des qualités ou des défauts qu'on remarque en lui. Le voyageur ne parvient à la cour que quand le roi connaît tout ce qui le regarde, et les largesses que le prince lui fait sont proportionnées à son mérite.

Nous partîmes de Samarkand et nous traversâmes la ville de Nécef ${ }^{539}$, a laquelle doit son surnom Abou Hafs 'Omar Annécéfy ${ }^{540}$, auteur du livre intitulé Almanzhoûmah, Le Poème, et traitant des questions controversées entre les quatre fakîhs ${ }^{541}$.

538 Pour le titre de sadr, voir ci-dessus, n. 19.

539 Ibn Battûta semble croire que Nakhshab, déjà visitée (voir ci-dessus n. 53). et « Necef » sont deux villes différentes. Or il s’agit de la même (voir aussi n. 75 ci-dessus). Par contre, cette ville située sur le chemin de Samarkande à Tirmidh pourrait être Kish, l'actuelle Shahrisabz.

540 Al-Nasafi est mort en 1142. La versification de son ouvrage était destinée à faciliter la mémorisation des sujets théologiques traités.

541 C'est-à-dire les fondateurs des quatre écoles du sunnisme (voir introduction du t. I). 
Ensuite nous arrivâmes à la ville de Termedh ${ }^{542}$, qui a donné naissance à l'imâm Abou 'Iça Mohammed, fils d'Iça, fils de Soûrah attermedhy ${ }^{543}$, auteur du Aldjâmi' alkebîr, la Grande Collection, qui traite des traditions. C'est une grande ville, bien construite, pourvue de beaux marchés, traversée par des rivières, et où l'on voit de nombreux jardins. Des raisins et surtout des coings, d'une qualité supérieure, y sont fort abondants, ainsi ${ }_{\mathrm{p} 297}$ que la viande et le lait. Les habitants lavent leur tête dans des bains chauds avec du lait, en place de terre glaise. Il y a chez le propriétaire de chaque bain de grands vases remplis de lait. Lorsque quelqu'un entre dans le bain, il en prend dans un petit vase et se lave la tête avec ce lait, qui rafraîchit les cheveux et les rend lisses. Les habitants de l'Inde emploient pour leurs cheveux l'huile de sésame, qu'ils appellent assîrâdj. Après quoi, ils lavent leur tête avec de la terre glaise. Cela fait du bien au corps, rend les cheveux lisses et les fait pousser. C'est par ce moyen que la barbe des habitants de l'Inde et des gens qui demeurent parmi eux devient longue.

L’ancienne ville de Termedh était bâtie sur le bord du Djeïhoûn. Lorsque Tenkîz l'eut ruinée, la ville actuelle fut construite à deux milles du fleuve. Nous y logeâmes, dans l'ermitage du vertueux cheïkh 'Azîzân, un des principaux cheïkhs et des plus généreux, qui possède beaucoup d'argent, ainsi que des maisons et des jardins, dont il dépense le produit à recevoir les voyageurs. Je joignis, avant mon arrivée dans cette ville, son prince 'Ala elmulc Khodhâwend Zâdeh ${ }^{544}$. Il y envoya l'ordre de me fournir les provisions dues à un hôte. On nous les apportait chaque jour, pendant le temps de notre résidence à Termedh. Je rencontrai aussi le kâdhi de cette ville, Kiwâm eddîn, qui était en route, afin de voir le sultan Thermachîrîn, et de lui demander la permission de faire un voyage dans l'Inde. Le récit de mon entrevue avec lui et avec ses deux frères, Dhiâ eddîn et Borhân eddîn, à Moltân, et du voyage que nous fîmes tous ensemble dans l'Inde, sera donné cidessous. Il sera fait aussi mention, s'il plaît à Dieu, de ses deux autres frères, 'Imâd eddîn et Seïf eddîn, de ma rencontre avec eux à la cour

${ }^{542}$ L'actuelle Termez sur la rive nord de l'Amu Darya à la frontière soviétoafghane. Elle fut rasée en 1220 par les Mongols.

543 Mort en 892, auteur d'une des grandes collections de hadiths.

${ }^{544}$ Voir ci-dessus, n. 82. 
du roi de l'Inde, de ses deux fils, de leur arrivée près du même souverain, après le meurtre de leur père, de leur mariage avec les deux filles du vizir Khodjah Djihân, et de tout ce qui arriva à cette occasion. p298

Nous passâmes ensuite le fleuve Djeïhoûn, pour entrer dans le Khorâçân, et, à compter de notre départ de Termedh et du passage du fleuve, nous marchâmes un jour et demi, dans un désert et des sables où il n'y a aucune habitation, jusqu'à la ville de Balkh ${ }^{545}$, qui est en ruine et inhabitée. Quiconque la voit la pense florissante, à cause de la solidité de sa construction. Elle a été jadis considérable et étendue. Les vestiges de ses mosquées et de ses collèges subsistent encore, ainsi que les peintures de ses édifices, tracées avec de la couleur d'azur. Le vulgaire attribue la production de la pierre d'azur à la province de Khorâçân ; mais on la tire des montagnes de Badakhchân, qui ont donné leur nom au rubis badakhchy, ou, comme l'appelle le vulgaire, al-balakhch, rubis balais ${ }^{546}$. Cette contrée sera mentionnée ci-après, s’il plaît à Dieu.

Le maudit Tenkîz a dévasté Balkh et a démoli environ le tiers de sa [principale] mosquée, à cause d'un trésor qui, à ce qu'on lui avait rapporté, était caché sous une colonne de ce temple. C'est une des plus belles et des plus vastes mosquées du monde. La mosquée de Ribâth alfeth ${ }^{547}$, dans le Maghreb, lui ressemble par la grandeur de ses colonnes ; mais celle de Balkh est plus belle sous les autres rapports. p299

545

Balkh, l'antique Bactres, ville très importante du Khorasan oriental, le nordouest de l'Afghanistan actuel, fut détruite à deux reprises pendant l'invasion mongole et n'a jamais pu complètement se relever.

546 «En cette province sont produites les pierres précieuses appelées balasci, qui sont très belles et de grande valeur. On les appelle balasci d'après Badascian, la province ou royaume où on les trouve. [...] Et sachez encore en vérité que dans une autre montagne de la même contrée on trouve les pierres dont est fait l'azur, et c'est le plus fin et le meilleur qui soit au monde. Les pierres dont je vous ai parlé et dont on fait l'azur forment des veines qui naissent en montagne comme les autres. Et cette veine est appelée lapis-lazzuli » (Marco PoLO). Le Badakhshan se trouve à l'extrême nord-est de l'Afghanistan.

${ }^{547}$ La mosquée de Rabat commencée par le calife almohade Abu Yusuf Ya’qub (1189-1199). 


\section{ANECDOTE}

Un homme versé dans la science de l'histoire m’a raconté que la mosquée de Balkh a été construite par une femme, dont le mari, appelé Dâoûd, fils d'Aly ${ }^{548}$, était émir ou gouverneur de Balkh pour les Abbâcides. Il advint que le khalife se mit un jour en colère contre les habitants de Balkh, à cause d'une action qu'ils avaient commise. Il envoya dans leur ville quelqu'un chargé de leur faire payer une amende considérable. Lorsque cet officier fut arrivé à Balkh, les femmes et les enfants de la ville se rendirent près de cette femme dont il a été question plus haut comme ayant construit la mosquée, et qui était l'épouse de leur émir. Ils se plaignirent à elle de leur situation et de l'amende qui leur était imposée. Elle envoya à l'émir, qui était venu pour lever sur eux cette taxe, un vêtement brodé de perles, à elle appartenant, et dont la valeur surpassait la somme que l'émir avait reçu l'ordre de leur faire payer. Elle lui dit, en même temps : " Porte ce vêtement au khalife, car je le donne comme une offrande en faveur des habitants de Balkh, à cause de leur triste situation. » Cet émir alla trouver le khalife, jeta le vêtement devant lui et lui raconta ce qui s'était passé. Le khalife fut honteux, et dit : " Est-ce que cette femme sera plus généreuse que nous ? » Il ordonna à l'émir de dispenser de l'amende les habitants de Balkh, et de retourner dans cette ville, afin de rendre à la femme du gouverneur son vêtement. En outre, il remit aux Balkhiens le tribut d'une année. L'émir revint à Balkh, se rendit à la demeure de la femme du gouverneur, lui répéta ce qu'avait dit le khalife, et lui rendit le vêtement. Elle lui dit : « Est-ce que l'œil du khalife a fixé cet habillement ? " Il répondit : « Oui. — En ce cas, reprit-elle, je ne revêtirai point un habit sur lequel est tombé le regard d'un homme qui n'est pas au nombre de ceux dont le ${ }_{p 300}$ mariage avec moi est défendu [père, frère, fils, etc.]. » Elle ordonna de le vendre, et c'est avec le prix qu'on en retira que furent bâtis la mosquée, l'ermitage et un caravansérail situé vis-à-vis de la mosquée, et construit avec les pierres appelées keddhâns, moellons. Ce dernier est encore en bon état. Il resta un tiers du prix du vêtement ; et on raconte que cette femme ordonna d'ensevelir cette somme sous une des colonnes de la mosquée, afin qu'on pût s'en servir en cas de besoin.

548 Le personnage pourrait être un souverain local mort vers 871, mais l'histoire n'est pas connue par ailleurs. 
Tenkîz fut instruit de cette histoire ; il ordonna de renverser les colonnes de la mosquée. Environ le tiers fut abattu; mais on ne trouva rien. Le reste fut laissé dans son premier état.

A l'extérieur de Balkh se trouve un tombeau, qu'on dit être celui d'Occâchah, fils de Mihçan alaçady, compagnon de Mahomet, celuilà même qui entrera dans le Paradis sans avoir de compte à rendre au jour du jugement ${ }^{549}$. Au-dessus de ce tombeau s'élève un ermitage vénéré, dans lequel nous logeâmes. Près de l'ermitage on voit un superbe étang, ombragé d'un grand noyer, à l'abri duquel les voyageurs s'arrêtent pendant l'été. Le cheïkh de cet ermitage est appelé Alhâddj Khord, c'est-à-dire le Petit Pèlerin. C'est un homme vertueux. Il monta à cheval avec nous, et nous fit voir les mausolées de la ville, parmi lesquels on remarque celui de Hizkîl ${ }^{550}$, le prophète, qui est surmonté d'un beau dôme. Nous visitâmes aussi à Balkh un grand nombre de tombeaux d'hommes de bien, que je ne me rappelle plus à présent. Nous nous arrêtâmes près de la maison d'Ibrâhîm, fils d'Adhem ${ }^{551}$. C'est une maison considérable, construite en pierres de couleur blanche et semblables au moellon. Les grains de l'ermitage y étaient dépo-

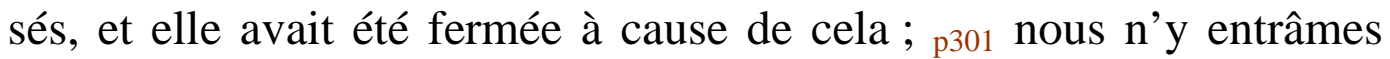
donc pas. Elle est située dans le voisinage de la mosquée principale.

Nous partîmes de Balkh, et nous marchâmes pendant sept jours dans les montagnes du Kouhistân ${ }^{552}$. On y trouve des villages nombreux, bien peuplés, arrosés d'eaux courantes et plantés d'arbres verdoyants, dont la plupart sont des figuiers. Il y a un grand nombre d'ermitages, habités par des hommes pieux qui se sont voués au service de la divinité. Au bout de cet espace de temps, nous arrivâmes à la ville de Hérât, la plus grande des cités encore florissantes dans le Khorâçân. Il y a quatre grandes villes dans cette province : deux florissantes, Hérât et Neïçâboûr ${ }^{553}$, et deux en ruines, Balkh et

549 Okkasha fut tué dans une guerre tribale en Arabie en 632.

550 Ézéchiel. Le site le plus connu de son tombeau se trouve près de Hilla (voir t. I, chap. 5, n. 189), mais Ibn Battûta ne le mentionne pas à cet endroit.

551 Voir t. I, p. 197 et chap. 3, n. 151.

552 Il s'agit de la région montagneuse située entre Balkh et Hérat en ligne directe ; 553 or la route principale contourne cette région par le nord.

${ }^{3}$ Hérat, visitée par le géographe Yaqut en 1217, est décrite comme la ville la plus grande et la plus riche que celui-ci aurait vue. Quatre ans plus tard, elle 
Merve ${ }^{554}$. Hérât est fort étendue et très peuplée ; ses habitants sont vertueux, chastes et dévots ; ils professent la doctrine de l'imâm Abou Hanîfah ${ }^{555}$. Leur ville est exempte de désordre.

\section{DU SULTAN DE HÉRÂT}

C’est le sultan illustre Hoçaïn, fils du sultan Ghiyâth eddîn Alghoûry ${ }^{556}$; il est doué d'une bravoure reconnue, et il a obtenu la faveur divine et la félicité. Sur deux champs de bataille, il a reçu du secours et de l'assistance de Dieu des preuves bien capables d'exciter

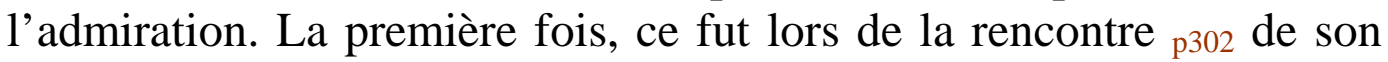
armée avec le sultan Khalîl, qui s'était révolté contre lui et qui finit par devenir son prisonnier. La seconde bataille, dans laquelle il fut également favorisé de Dieu, fut celle qu'il livra en personne à Ma'çoûd, sultan des râfidhites ou hérétiques, et qui se termina par la ruine de la puissance de Ma'çoûd, par sa fuite et par la perte de son royaume (ou de ses trésors, d'après une autre leçon). Le sultan Hoçaïn monta sur le trône après la mort de son frère, nommé Alhâfizh, qui lui-même avait succédé à leur père Ghiyâth eddîn ${ }^{557}$.

\section{HISTOIRE DES RÂFIDHITES}

Il y avait dans le Khorâçân deux hommes, appelés l'un Ma'çoûd et l'autre Mohammed, et qui avaient cinq compagnons audacieux. Ils étaient connus dans l'Irâk sous le nom de Chotthâr, Brigands, Vo-

sera détruite par les Mongols, mais elle récupérera peu après. Pour Nishabur, voir plus loin n. 143.

554 Merv, ville fortifiée et célèbre pour ses bibliothèques, fut également détruite en 1221.

555 Pour l’école hanafite du sunnisme, voir la préface du t. I.

556 Mu'iz al-din Husain (1331-1370), troisième fils et successeur de Ghiyath aldin (voir t. I, chap. 5, n. 237, 238). La famille était originaire de la région 557 montagneuse de Ghur, située à l'est d'Hérat.

${ }^{5}$ Ghiyath al-din, mort en 1328, auquel succédèrent ses fils Shams al-din II (1328-1329), Hafiz (1329-1331) et Husain. 
leurs ; dans le Khorâçân, sous celui de Serbedârs ; et enfin, dans le Maghreb, sous celui de Sokoûrah, Oiseaux de proie, Vautours ${ }^{558}$.

Tous sept convinrent de se livrer au désordre et au brigandage, et de piller l'argent des habitants. Le bruit de leurs excès se répandit ; ils établirent leur séjour sur une montagne inexpugnable, située au voisinage de la ville de Beïhak, appelée aussi Sebzévâr ${ }^{559}$. Ils se plaçaient en embuscade pendant le jour, en sortaient le soir et durant la nuit, fondaient sur les villages, coupaient les communications et s'emparaient des richesses des habitants. Les méchants et les malfaiteurs, leurs pareils, pз0з vinrent en foule se joindre à eux ; leur nombre devint considérable, leur puissance augmenta, et les hommes les craignaient. Ils fondirent sur la ville de Beïhak et la prirent; puis ils s'emparèrent d'autres villes, acquirent de l'opulence, rassemblèrent des troupes et se procurèrent des chevaux. Maç'oûd prit le titre de sultan. Les esclaves s'enfuyaient de la maison de leurs maîtres et se retiraient près de lui. Chacun de ces esclaves fugitifs recevait de lui un cheval et de l'argent; et, s'il montrait de la bravoure, Maç'oûd le nommait chef d'un détachement. Son armée devint nombreuse et sa puissance considérable. Tous ses partisans embrassèrent la doctrine des shiites, et entreprirent d'extirper les sonnites du Khorâçân et de soumettre cette province tout entière aux dogmes râfidhites. Il y avait à Mechhed Thoûs un cheïkh râfidhite nommé Haçan ${ }^{560}$, qui était considéré par eux comme un homme pieux. Il les assista dans leur entreprise et ils le proclamèrent khalife ; il leur ordonna d'agir avec équité. Ils firent paraître une si grande probité que des dînârs et des dirhems tombaient à terre, dans leur camp, et que personne ne les ramassait, jusqu'à ce que leur propriétaire survînt et les ramassât. Ils s'emparèrent de Neïçâboûr. Le sultan Thoghaïtomoûr ${ }^{561}$ envoya

${ }^{558}$ Les Serbedars (littér. : pendards, desperados) ont succédé aux Ilkhans dans l'ouest du Khorasan. Leur premier chef, Abd al-Razzak, fonctionnaire d'Abu Said, se révolta dès la mort de celui-ci en 1335 et fut tué par son frère Mas'ud en 1338. Celui-ci régna jusqu'en 1344. Quant à Muhammad, il est peut-être un de ses successeurs, Muhammad Aïtimur (1346-1348).

559 La ville de Sabzevar, dans le district de Baïhak, conquise par Abd al-Razzak en 1337-1338.

560 Il s’agit du darwish Hasan Djuri, délivré de la prison de Nishabur et devenu bras droit de Mas'ud.

561 Pour Togha Timur, voir t. I, chap. 5, n. 253. 
contre eux des troupes, mais ils les mirent en déroute. Le sultan fit alors marcher son lieutenant, Arghoûn Châh ${ }^{562}$, qui fut vaincu et fait prisonnier. Ils le traitèrent avec bonté. Thoghaïtomoûr les combattit en personne, à la tête de cinquante mille Tartares ; mais ils le défirent, s'emparèrent de plusieurs villes, p304 entre autres de Sarakhs, de Zâveh, de Thoûs, une des principales places du Khorâçân. Ils établirent leur khalife dans le mechhed, mausolée, d'Aly, fils de Moûça Arridha ${ }^{563}$. Ils prirent aussi la ville de Djâm et campèrent tout auprès, avec l'intention de marcher contre Hérât, dont ils n'étaient qu'à six journées de distance.

Lorsque cette nouvelle parvint à Mélic Hoçaïn, il rassembla les émirs, les troupes et les habitants de la ville, et leur demanda s'ils étaient d'avis d'attendre l'ennemi en dedans des murs, ou de marcher à sa rencontre et d'engager le combat. L'avis général fut de sortir contre l'ennemi. Les habitants de Hérât forment une seule et même tribu appelée Ghoûriens. On dit qu'ils sont originaires du canton de Ghaour, en Syrie, et que de là vient leur nom ${ }^{564}$. Tous firent leurs préparatifs, et se réunirent de toutes parts, car ils étaient domiciliés dans les villages et dans la plaine de Badghîs ${ }^{565}$. Cette plaine a une étendue de quatre journées ; son gazon reste toujours vert, et c'est là que paissent les bêtes de somme et les chevaux des Ghoûriens. La plupart des arbres qui l'ombragent sont des pistachiers, dont les fruits s’exportent dans l'Irâk.

562 Arghun bin Nawruz bin Arghun était mongol, de la tribu des Oirat. Son grandpère fut émir de Khorassan et lui-même se tailla après 1335 une principauté comprenant Tus, Nishabour, et Merv. Pour son père Nawruz, voir t. I, chap. 5, n. 239. Battu par les Serbedars qui conquirent cette ville en 1338, Arghun se réfugia chez Togha Timur. Ses descendants, connus sous le nom des Djani Kurbani, conservèrent, en luttant avec les Serbedars, la région jusqu'à l'arrivée de Timur.

563 Le tombeau d'Ali Riza, huitième imam shi'ite mort en 817 , qui se trouve à Mashad.

564 Il s'agit d'un simple rapprochement d'homonymie.

565 Région située au nord d'Hérat. 
Les habitants de la ville de Simnân ${ }^{566}$ secoururent ceux de Hérât. Ils marchèrent tous ensemble contre les râfidhites, au nombre de cent vingt mille, tant cavaliers que fantassins. Le roi Hoçaïn les commandait. Les râfidhites se réunirent au nombre de cent cinquante mille cavaliers, et la rencontre eut lieu dans la plaine de Boûchendj ${ }^{567}$. Les deux armées tinrent ferme d'abord ; ${ }_{305}$ mais ensuite les râfidhites eurent le dessous, et leur sultan, Maç’oûd, prit la fuite. Leur khalife, Haçan, tint bon avec vingt mille hommes, jusqu'à ce qu'il fût tué, ainsi que la plupart de ses soldats; environ quatre mille autres furent faits prisonniers. Quelqu'un qui assista à cette bataille m'a conté que l'action commença vers neuf heures de la matinée et que la fuite des Serbédâriens eut lieu peu de temps après midi. Après l'heure de midi, le roi Hoçaïn mit pied à terre et pria. On lui apporta ensuite de la nourriture. Lui et les principaux de ses compagnons mangèrent, tandis que les autres décapitaient les prisonniers.

Après cette grande victoire, Hoçaïn retourna dans sa capitale. Dieu se servit des mains de ce prince pour faire triompher les sonnites et éteindre le feu du désordre. Cette rencontre eut lieu après ma sortie de l'Inde, en l'année $7488^{568}$.

Un homme, du nombre des dévots, des gens de bien et de mérite, nommé Mewlânâ Nizhâm eddîn ${ }^{569}$, avait passé sa jeunesse à Hérât. Les habitants de cette ville l'aimaient et avaient recours à ses avis. Il les prêchait et leur adressait des exhortations. Ils convinrent avec lui de redresser les actes illicites. Le prédicateur de la ville, nommé Mélic Wernâ, cousin germain du roi Hoçaïn et marié à la veuve de son père, se ligua avec eux pour cet objet. Il était au nombre des hommes les plus beaux, tant au physique qu'au moral ; le roi le craignait, et nous rapporterons ci-dessous son histoire. Dès que ces individus appre-

566 Simnan, située à cent cinquante kilomètres à l’est de Téhéran, fut conquise après l'éclatement de l'empire ilkhanide par Iskandar bin Ziyar (1334-1360), souverain du Mazanderan, Le Serbedar Mas'ud sera tué dans une bataille contre ce prince en 1344.

${ }^{567}$ La bataille fut livrée près de l'actuelle Torbat-i Haydariya, au sud de Mashad en juillet 1342 .

568 C'est-à-dire 1347. Ibn Battûta confond encore les dates (voir note précédente).

569 L'histoire de ce personnage est également contée par l'historien Khwandamir d'une façon sensiblement similaire et datée de l'année 1337-1338. 
naient un acte défendu par la loi, lors même qu'il avait été commis par le roi, ils le réformaient. p306

\section{ANECDOTE}

On m’a raconté qu'ils reçurent un jour avis qu'un acte illicite s’était passé dans le palais de Mélic Hoçaïn ; ils se réunirent, afin de le redresser. Le roi se fortifia contre eux dans l'enceinte de son palais. Ils se rassemblèrent alors près de la porte de cet édifice, au nombre de six mille hommes. Le roi eut peur d'eux ; il fit venir le jurisconsulte et les grands de la ville. Or il venait de boire du vin; ils exécutèrent sur lui, dans son palais, la peine prescrite par la loi ${ }^{570}$ et s'en retournèrent.

\section{ÉVÉNEMENT QUI FUT LA CAUSE DU MEURTRE DU SUSDIT JURISCONSULTE NIZHÂL EDDÎN}

Le roi Hoçaïn craignait les Turcs, habitants du désert voisin de la ville de Hérât, qui avaient pour roi Thoghaïtomoûr, dont il a été fait mention ci-dessus, et qui étaient au nombre d'environ cinquante mille hommes. Il leur faisait des présents chaque année et les caressait. C'était ainsi qu'a agissait avant sa victoire sur les râfidhites ; mais, après qu'il eut vaincu ces hérétiques, il traita les Turcs comme ses sujets. Ils avaient coutume de venir à Hérât, et souvent ils y buvaient du vin ; ou bien un d'eux y venait étant ivre. Or Nizhâm eddîn punissait, d'après les termes de la loi, ceux des Turcs qu'il rencontrait ivres. Ces Turcs sont des gens braves et audacieux ; ils ne cessent d'attaquer à l'improviste les villes de l'Inde et de faire des captifs ou de massacrer leurs habitants. Souvent ils faisaient prisonnière quelque musulmane, qui habitait dans l'Inde parmi les infidèles. Lorsqu'ils amenaient leurs captives dans le Khorâçân, Nizhâm eddîn les délivrait de leurs mains. Le signe distinctif des femmes musulmanes, dans l'Inde, consiste à ne pas se percer les oreilles, tandis que les femmes infidèles ${ }_{p 307}$ percent les leurs. Il advint un jour qu'un émir turc, nommé Tomouralthi, fit

${ }^{570}$ C'est-à-dire quatre-vingts coups de fouet dans le cas d'un homme libre, selon le rite hanafite. 
prisonnière une femme et la pressa vivement de satisfaire ses désirs ; elle s'écria qu'elle était musulmane. Aussitôt le docteur la retira des mains de l'émir. Celui-ci en fut fortement blessé ; il monta à cheval, accompagné de plusieurs milliers de ses soldats, fondit sur les chevaux de Hérât, qui se trouvaient dans leurs pâturages ordinaires, dans la plaine de Badghîs, et les emmena, ne laissant aux habitants de Hérât aucune bête qu'ils pussent monter ou traire. Les Turcs se retirèrent, avec ces animaux, sur une montagne voisine où l'on ne pouvait les forcer. Le sultan et ses soldats ne trouvèrent pas de montures pour les poursuivre.

Hoçaïn envoya aux Turcs un député, pour les inviter à restituer le bétail et les chevaux qu'ils avaient pris et leur rappeler le traité qui existait entre eux. Ils répondirent qu'ils ne rendraient pas leur butin avant qu'on ne leur eût livré le jurisconsulte Nizhâm eddîn. Le sultan repartit : " Il n’y a pas moyen de consentir à cela. » Le cheïkh Abou Ahmed aldjesty, petit-fils du cheïkh Maoudoûd aldjesty ${ }^{571}$, occupait dans le Khorâçân un rang élevé, et ses discours étaient respectés des habitants. Il monta à cheval, entouré d'un cortège de disciples et d'esclaves, également à cheval, et dit [au sultan] : " Je conduirai le docteur Nizhâm eddîn près des Turcs, afin qu'ils soient apaisés par cette démarche ; puis, je le ramènerai. » Les habitants étaient disposés à se conformer à ses discours, et le docteur Nizhâm eddîn vit qu'ils étaient d'accord là-dessus. Il monta à cheval, avec le cheïkh Abou Ahmed, et se rendit près des Turcs. Tomouralthi se leva à son approche et lui dit : "Tu m'as pris ma femme "; en même temps, il le frap-

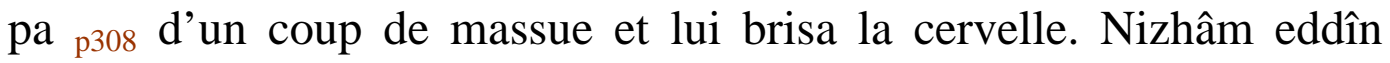
tomba mort. Le cheïkh Abou Ahmed fut tout interdit, et s'en retourna dans sa ville. Les Turcs rendirent le bétail et les chevaux qu'ils avaient pris.

Au bout d'un certain temps, ce Turc, qui avait tué le docteur, se rendit à Hérât. Plusieurs des disciples du fakîh le rencontrèrent, et s'avançèrent vers lui comme pour le saluer; mais ils avaient sous

${ }^{571}$ Mawdud al-Tchishti (1142-1236), originaire de Tchisht en Sidistan, l'est de l'Iran actuel, est le fondateur éponyme d'un ordre mystique, célèbre surtout en Inde. Ahmad Tchishti est mentionné par les sources comme intermédiaire entre Ghiyath al-din, souverain de Hérat et Yasa'ur, prince Tchaghataïde, au cours d’événements datant de 1319. 
leurs vêtements des épées, avec lesquelles ils le tuèrent ; ses camarades prirent la fuite. Quelque temps après, le roi Hoçaïn envoya en ambassade auprès du roi du Sidjistân ${ }^{572}$ son cousin germain Mélic Werna, qui avait été l'associé du docteur Nizhâm eddîn, dans le redressement des actes prohibés par la loi. Lorsque ce prince fut arrivé dans le Sidjistân, le roi lui envoya l'ordre d'y rester et de ne pas revenir à sa cour. Mais il se dirigea vers l'Inde, et je le rencontrai, lorsque je sortis de ce pays, dans la ville de Sîwécitân, dans le Sind ${ }^{573}$. C'était un homme distingué ; il avait un goût inné pour l'exercice de l'autorité, la chasse, la fauconnerie, les chevaux, les esclaves, les serviteurs, les vêtements précieux et dignes des rois. Or la situation de quiconque a de semblables goûts dans l'Inde n'est pas heureuse. Quant à lui, le roi de l'Inde le nomma gouverneur d'une petite ville. Un habitant de Hérât, établi dans l'Inde, le tua dans cette ville, à cause d'une jeune esclave. On dit que le roi de l'Inde aposta son meurtrier, par suite des machinations du roi Hoçaïn, et que ce fut à cause de cela que Hoçaïn rendit hommage au roi de l'Inde, après la mort de Mélic Wernâ. Le roi de l'Inde lui fit des présents et lui donna la ville de Bacâr ${ }^{574}$, dans le Sind, dont le revenu monte chaque année à cinquante mille dînârs d'or. p309

Mais revenons à notre sujet.

Nous partîmes de Hérât pour la ville de Djârn ${ }^{575}$. C'est une ville de moyenne importance, mais jolie et possédant des jardins, des arbres, de nombreuses sources et des rivières. La plupart de ses arbres sont des mûriers, et la soie y abonde. On attribue la construction de cette ville au pieux et dévot Chihâb eddîn Ahmed aldjâm ${ }^{576}$, dont nous raconterons l'histoire ci-après. Son petit-fils était le cheïkh Ahmed, connu sous le nom de Zâdeh (fils, en persan), qui fut tué par le

${ }^{572}$ Le Sidjistan possédait à l'époque une dynastie locale soumise aux Mongols. Le souverain mentionné est probablement Qutb al-din Muhammad (13311345).

Il s’agirait de la ville de Sehwan sur l'Indus, au nord de Hyderabad où Ibn Battûta ira voir le sultan avant son départ, en décembre 1341.

574 Bhakkar, sur l'Indus, au nord de Multan.

575 L'actuelle Torbat-e Djam sur la route menant de Hérat à Nishabur, à michemin entre les deux villes.

576 (1049-1142) ; saint si célèbre dans la région que même Timur visita sa tombe. L’histoire de son descendant sera racontée t. III, p. 147. 
roi de l'Inde, et aux enfants duquel Djâm appartient actuellement ; car cette cité est indépendante de l'autorité du sultan, et ces individus y jouissent d'une grande opulence. Quelqu'un en qui j'ai confiance m'a raconté que le sultan Abou Sa'îd, roi de l'Irâk, ayant fait un voyage dans le Khorâçân, campa près de cette ville, où se trouvait l'ermitage du cheïkh. Celui-ci lui donna un festin magnifique ; il distribua à chaque tente du camp royal un mouton, donna un mouton par quatre hommes, et fournit à chaque bête employée dans le camp, cheval, mulet ou âne, sa provende pour une nuit. Il ne resta pas dans tout le camp un seul animal qui n’eût reçut sa part de l'hospitalité du cheïkh.

HISTOIRE DU CHEÏKH CHIHÂB EDDÎN, DONT LE SURNOM A ÉTÉ DONNÉ À LA VILLE DE DJÂM

On raconte que c'était un homme de plaisir et fort adonné à la boisson. Il avait environ soixante camarades de débauche, qui avaient coutume de se réunir chaque jour dans la demeure de l'un d'eux. Le tour de chacun revenait donc au bout de deux mois. Ils persévérèrent p310 quelque temps dans cette conduite. Enfin, un jour, le tour du cheïkh Chihâb eddîn arriva. Mais la nuit même qui précéda ce jour, il résolut de faire pénitence et de se réconcilier avec Dieu ; mais il se dit en lui-même : "Si je dis à mes compagnons qu'avant qu'ils fussent réunis chez moi j'avais fait pénitence, ils penseront que c'est par impuissance de les traiter. » Il fit donc servir les choses que ses pareils faisaient servir auparavant, tant mets que boissons, et fit mettre le vin dans les outres. Ses camarades arrivèrent, et lorsqu'ils furent disposés à boire, ils ouvrirent une outre. Un d'eux y goûta, et il trouva que la liqueur qu'elle contenait avait un goût douceâtre ${ }^{577}$. Ensuite on ouvrit une seconde outre, puis une troisième, et on les trouva toutes dans le même état. Les convives interpellèrent le cheïkh à ce sujet. Il leur confessa franchement ses pensées secrètes ${ }^{578}$, leur fit connaître sa pénitence et leur dit: "Par Dieu, ceci n’est pas autre chose que le vin que vous buviez auparavant ! »Il firent tous pénitence, bâtirent cet ermitage et s'y retirèrent pour adorer Dieu. Beaucoup de miracles et de visions extatiques se montrèrent à ce cheïkh.

577 C'est-à-dire qu’elle n’était pas alcoolisée.

578 L’original dit : «il leur confessa l'âge de son chameau ». 
Nous partîmes de Djâm pour Thoûs ${ }^{579}$, une des plus illustres et des plus grandes villes du Khorâçân. Elle a été la patrie du célèbre imâm Abou Hâmid alghazzâly ${ }^{580}$, dont on y voit encore le tombeau.

Nous allâmes de Thoûs à la ville du Mausolée ${ }_{\mathrm{p} 311}$ d'Arridha ${ }^{581}$. Ce dernier est 'Aly, fils de Moûça alcâzhim, fils de Dja'far assâdik, fils de Mohammed albâkir, fils d'Aly Zain al'âbidîn, fils d'Alhoçaïn le martyr, fils du prince des croyants 'Aly, fils d'Abou Thâlib ${ }^{582}$ Mechhed est aussi une grande et vaste ville, abondante en fruits, en eaux et en moulins. Atthâhir Mohammed Châh y habitait. Thâhir a la même signification chez ce peuple que Nakîb ${ }^{583}$ chez les Égyptiens, les Syriens, les Irâkiens. Les Indiens, les Sindis, les Turkistanais disent, en place de ces mots : "Le seigneur illustre. » Mechhed était encore habité par le kâdhi, le chérif Djélâl eddîn, que je rencontrai ensuite dan l'Inde, ainsi que par le chérîf 'Aly et ses deux fils, Emîr Hindoû et Daoulet Châh ${ }^{584}$ qui m'accompagnèrent depuis Termedh jusque dans l'Indoustan. C'étaient des hommes vertueux.

Le mausolée vénéré est surmonté d'un dôme élevé, et se trouve compris dans un ermitage. Dans le voisinage de celui-ci, il y a un collège et une mosquée. Tous ces bâtiments sont d'une construction élégante, et leurs murailles sont revêtues de faïence colorée. Sur le tom-

579 Tus, ville importante du Khorasan, fut dévastée une fois par Gengis en 1220. Reconstruite par l'émir Oirat, Arghun resta comme apanage à ses descendants qui créèrent une principauté. Conquise par le chef serbedar Karrabi (13541358), elle resta sous l'autorité de ces derniers jusqu'à l'arrivée de Timur. Celui-ci dévasta définitivement Tus qui n’a jamais pu se relever et fut remplacée par Mashad.

Al-Ghazali, le plus célèbre des théologiens du Moyen Age islamique, né et mort à Tus (1058-1111), professeur à la madrasa Nizamiyya de Bagdad. Son tombeau a disparu.

581 L'actuelle Mashad (lieu de martyre), l'ancien quartier de Sanabad de Tus où l’imam Riza fut enterré.

582 Ali Riza, huitième imam des shi’ites (799-818), fut proclamé héritier du califat par le calife al-Mamun à l'époque de l'extrême libéralisation abbasside et empoisonné quelques années plus tard, au début de la réaction. Son tombeau, le seul tombeau d'imam situé en terre iranienne, est devenu rapidement un lieu de pèlerinage, mais celui-ci se développa principalement après l'avènement des Safavides au XVI ${ }^{\mathrm{e}}$ siècle.

583 Tahir (le Pur). Le Naqib ul-Ashraf est le chef des descendants de Muhammad, et par conséquent d'Ali, dans une ville.

${ }^{584}$ Un sharif amir Ali sera mentionné plus loin, mais pas Djalal al-din. 
beau est une estrade de planches, recouvertes de feuilles d'argent, et au-dessus de ce tombeau sont suspendues des lampes du même métal. Le seuil de la porte du dôme est en argent. La porte elle-même est cachée par un voile de soie brochée d'or, Le plancher est couvert de plusieurs sortes de tapis. Vis-à-vis de ce tombeau on voit ${ }_{\text {p312 }}$ celui du prince des croyants, Hâroûn Errachid ${ }^{585}$, surmonté d'une estrade sur laquelle on place des candélabres, que les habitants du Maghreb appelle alhicec et alménâïr. Lorsqu'un râfidhite entre dans le mausolée pour le visiter, il frappe de son pied le tombeau de Rachîd et bénit, au contraire, le nom de Ridha.

Nous partîmes pour la ville de Sarakhs ${ }^{586}$, qui a donné naissance au vertueux cheïkh Lokmân assarakhsy ${ }^{587}$. De Sarakhs, nous allâmes à Zâveh ${ }^{588}$, patrie du vertueux, cheïkh Kothb eddîn Haïder ${ }^{589}$, qui a donné son nom à la congrégation des fakirs Haïdéry, lesquels placent des anneaux de fer à leurs mains, à leur cou, à leurs oreilles et même à leur verge, de sorte qu'ils ne peuvent avoir commerce avec une femme. Étant partis de Zâveh, nous arrivâmes à la ville de Neïçaboûr ${ }^{590}$, une des quatre capitales du Khorâçân. Elle est appelée le Petit Damas, à cause de la quantité de ses fruits, de ses jardins et de ses eaux, ainsi qu'à cause de sa beauté. Quatre canaux la traversent, et ses marchés sont beaux et vastes. Sa mosquée est admirable ; elle est située au milieu du marché, et touche à quatre collèges, arrosés par une

585 Harun al-Rashid, le grand calife abbasside, mourut à Tus, en 809, lors d’une expédition au Khorassan.

586 Ville située à l'est de Mashad sur la frontière irano-soviétique, sur ha route allant de Mashad à Merv.

${ }^{587}$ Le cheïkh est mentionné dans d'autres sources mais on ne connaît pas les dates de sa naissance ou de sa mort.

${ }^{588}$ L'actuelle Torbat-e Haydariya, au sud-ouest de Mashad. L’itinéraire d’Ibn Battûta zigzague.

589 Qutb al-din Haidar, mort en 1221, était un disciple de Djamal al-din al-Sawi, fondateur de l'ordre mystique malamati des qalandaris (voir t. I, préface, et chap. 2 n. 81 et 82). Il fonda lui-même l’ordre des haidairis, répandu en Asie Mineure et en Inde, et aurait introduit l'utilisation du haschisch comme moyen pour arriver à l'extase.

590 Détruite par les Mongols en 1221 et par un séisme en 1280, elle était cependant la capitale de la principauté des Djani Kurbani (voir ci-dessus n. 115) en 1338, quand elle fut conquise par le Serbedar Mas’ud. Vers la fin du siècle, elle passa sous la domination des Kurt de Hérat avant d'être conquise par Timur. 
eau abondante et habités par beaucoup d'étudiants, p313 qui apprennent la jurisprudence et la manière de lire le Coran. Ces quatre collèges sont au nombre des plus beaux de la province. Mais les medrécehs du Khorâçân, des deux Irâks, de Damas, de Baghdâd et de Misr, quoiqu'elles atteignent le comble de la solidité et de l'élégance, sont toutes inférieures à la medréceh bâtie près de la citadelle de la résidence royale de Fez par notre maître, le prince des croyants Almotéwekkil 'Ala Allah, le champion dans la voie de Dieu, le plus savant des rois, la plus belle perle du collier des khalifes équitables, Abou 'Inân ; que Dieu le fasse prospérer et rende son armée victorieuse ! Ce dernier collège n'a point d'égal en étendue ni en élévation ; les habitants de l'Orient ne sauraient reproduire les ornements en plâtre qui s'y trouvent.

On fabrique à Neïçâboûr des étoffes de soie, telles que le nekh, le kemkhâ et autres ${ }^{591}$ que l'on exporte dans l'Inde. Dans cette ville se trouve l'ermitage du cheïkh, de l'imâm savant, du pôle, du dévot Kothb eddîn Anneïçâboûry, un des prédicateurs et des pieux imâms. Je logeai chez lui ; il me reçut très bien et me traita avec considération. Je fus témoin de prodiges et de miracles merveilleux opérés par lui.

\section{MIRACLE DE CE CHEÏKH}

J'avais acheté à Neïçâboûr un jeune esclave turc. Le cheïkh le vit avec moi et me dit : "Ce page ne te convient pas ; revends-le. » Je lui répondis : «C'est bien. » Et je revendis l'esclave, le lendemain même, à un marchand. Puis je fis mes adieux au cheïkh et je partis. Lorsque je fus arrivé dans la ville de Besthâm, un de mes amis m'écrivit de Neïçâboûr et me raconta que l'esclave en question avait tué un enfant turc, et avait ${ }_{\mathrm{p} 314}$ été tué en expiation de ce meurtre. Cela est un miracle évident de la part de ce cheïkh.

591 Les soieries et les cotonnades de Nishabur figuraient parmi les exportations les plus célèbres du Khorassan au $\mathrm{X}^{\mathrm{e}}$ siècle d'après Ibn Hauqal. Pour le nekh et le kemkha, voir chap. 2, n. 100 et 104. 
De Neïçâboûr je me rendis à Besthâm ${ }^{592}$, qui a donné naissance au cheïkh, au célèbre contemplatif Abou Yézîd albesthâmy ${ }^{593}$, dont on y voit le tombeau, renfermé sous le même dôme que le corps d'un des enfants de Dja'far Assâdik ${ }^{594}$. On trouve encore à Besthâm le tombeau du vertueux cheïkh, de l'ami de Dieu, Abou'l Haçan alkharrakâny ${ }^{595}$. Je logeai en cette ville dans l'ermitage du cheïkh Abou Yézîd albesthâmy. Je partis de Besthâm, par le chemin de Hendokhîr, pour Kondoûs et Baghlân ${ }^{596}$, villages habités par des cheïkhs et des hommes de bien, et où se trouvent des jardins et des rivières. Nous logeâmes à Kondoûs près d'une rivière, sur les bords de laquelle s'élève un ermitage appartenant à un supérieur de fakirs, originaire d'Égypte et nommé Chîr Siâh, c’est-à-dire le Lion noir. Le gouverneur de ce canton nous y traita. C'était un natif de Mouçoul, qui habitait un grand jardin dans le voisinage. Nous séjournâmes environ quarante jours près de ce village, afin de refaire nos chameaux et nos chevaux ; car il y a là d'excellents pâturages et un gazon abondant. On y jouit d'une

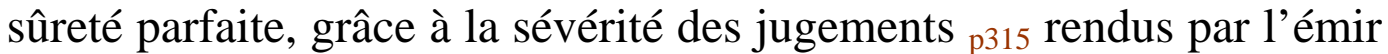
Boronthaïh ${ }^{597}$. Nous avons déjà dit que la peine prononcée par les lois des Turcs contre celui qui dérobe un cheval consiste à faire rendre au voleur l'animal volé et neuf autres en sus ${ }^{598}$. S'il ne les possède pas, on lui enlève, en leur place, ses enfants. Mais, s'il n'a pas d'enfants, on l'égorge comme une brebis. Les Turcs laissent leurs bêtes de somme absolument sans gardien, après que chacun a marqué sur la

592 Bistam, à l'est des montagnes d'Alborz, au nord de la route actuelle de Téhéran à Mashad. Ville prospère à l'époque de Yaqut (1220).

593 Communément appelé Bayezid, un des plus célèbres mystiques de l’islam, placé à la tête des silsilas des malamatis, mort en 874 . Son tombeau est toujours vénéré.

Non mentionné par ailleurs, mais plusieurs tombeaux de fils d'imams, appelés imamzadehs, se trouvent dispersés en Iran, dont celui de Muhammad, fils de

${ }_{596}^{595}$ Considéré comme héritier spirituel d'al-Bistami, mort en 1034. Dja'far al-Sadik, le sixième imam à Gorgan, au nord de Bistam.

${ }^{596}$ Là encore, Ibn Battûta opère un saut dans l'espace pour se retrouver dans la région de Balkh. Hendokhir correspondrait à l'actuel Andkhvoy sur le chemin de Hérat à Balkh, à l'est de Shebergan. Qonduz est à l'est de Balkh sur un affluent sud d'Amu Darya portant le même nom que la ville. Enfin Baghlan est au sud de Qonduz, sur la route de Kaboul. Andkhvoy est mentionné sous le nom d'Andakhud par Ibn Hawqal à la fin du $\mathrm{X}^{\mathrm{e}}$ siècle.

597 Également mentionné plus haut p. 288, mais inconnu par ailleurs.

598 Voir chap. 3, n. 13. 
cuisse les bêtes qui lui appartiennent. Nous en usâmes de même dans ce canton. Il advint que nous nous mîmes en quête de nos chevaux, dix jours après de notre arrivée ; il nous en manquait trois. Mais au bout de quinze jours les Tartares nous les ramenèrent à notre demeure, de peur de subir les peines portées par la loi. Nous attachions chaque soir deux chevaux vis-à-vis de nos tentes, afin de pouvoir nous en servir la nuit, si le besoin l'exigeait. Une certaine nuit nous perdîmes ces deux chevaux, et nous quittâmes bientôt après le pays. Au bout de vingt-deux jours, on nous les ramena sur le chemin.

Un autre motif de notre séjour , ce fut la crainte de la neige ; car il y a au milieu de la route une montagne nommée Hindoû Coûch ${ }^{599}$, c'est-à-dire "Qui tue les Indous », parce que beaucoup d'entre les esclaves mâles et femelles que l'on emmène de l'Inde meurent dans cette montagne, à cause de la violence du froid et de la quantité de neige. Elle s'étend l'espace d'un jour de marche tout entier. Nous attendîmes jusqu'à l'arrivée des chaleurs ${ }^{600}$. Nous commençâmes à traverser cette montagne, à la fin de la nuit, et nous ne cessâmes de marcher jusqu'au soir du jour suivant. Nous étendions des pièces de feutre devant les chameaux, afin qu'ils n'enfonçassent pas dans la neige, Après nous être mis ${ }_{\mathrm{p} 316}$ en route, nous arrivâmes à un endroit nommé Ander ${ }^{601}$, et où a jadis existé une ville dont les vestiges ont disparu. Nous logeâmes dans un grand bourg où se trouvait un ermitage appartenant à un homme de bien, nommé Mohammed almehrouy, chez lequel nous descendîmes. Il nous traita avec considération, et lorsque nous lavions nos mains, après le repas, il buvait l'eau qui nous avait servi à cet usage, à cause de la bonne opinion qu'il avait de nous, et de son extrême bienveillance à notre égard. Il nous accompagna jusqu'à ce que nous eussions gravi la montagne de Hindoû Coûch. Nous trouvâmes sur cette montagne une source d'eau chaude, avec laquelle nous nous lavâmes la figure. Notre peau fut excoriée et nous souffrîmes beaucoup. Nous nous arrêtâmes dans un endroit nommé Bendj

${ }^{599}$ L'extrême ouest de la chaîne de Hindu Kush se trouve entre Baghlan et Kaboul. Ibn Battûta est un des premiers à citer ce nom.

600 Cette indication qui nous ramène à la fin du printemps 1335 (ou 1333) rend difficile l'excursion en Khorasan.

601

La région d’Andarab sur la haute vallée de la rivière Dowshi aboutissant au défilé de Khawak, situé à plus de quatre mille mètres. 
Hîr ${ }^{602}$. Bendj (pendj) signifie cinq, et hîr montagne. Le nom de Bendj Hîr veut donc dire Cinq Montagnes. Il y avait jadis là une ville belle et peuplée, sur un fleuve considérable et dont les eaux sont de couleur bleue, comme celles de la mer ${ }^{603}$. Il descend des montagnes de Badakhchân, où l'on trouve le rubis que l'on appelle balakhch, rubis balais. Tenkîz, roi des Tartares, a ruiné cette contrée, et depuis lors elle n'est pas redevenue florissante. C'est là que se trouve le mausolée du cheïkh Sa'îd almekky, lequel est vénéré de ces peuples. Nous arrivâmes ensuite à la montagne de Péchâii ${ }^{604}$, où se trouve l'ermitage du p317 vertueux cheïkh Athâ Aouliâ. Atha veut dire, en turc, père ; quant au mot aouliâ, il appartient à la langue arabe ; le nom Athâ Aouliâ signifie donc le Père des amis de Dieu. On appelle aussi cet individu Sîçad Sâléh. Sîçad veut dire, en persan, trois cents, et sâléh signifie année. En effet, les habitants de cet endroit prétendent que le cheïkh est âgé de trois cent cinquante ans. Ils ont pour lui une grande vénération et viennent, pour le visiter, des villes et des villages voisins. Les sultans et les princesses se rendent près de lui. Il nous traita avec considération et nous donna un repas; nous campâmes sur le bord d'une rivière, près de son ermitage, et nous lui rendîmes visite. Je le saluai et il m'embrassa ; sa peau était lisse, et je n'en ai pas vu de plus douce. Quiconque le voit s'imagine qu'il n'est âgé que de cinquante ans. Il m'a dit que tous les cent ans il lui poussait de nouveaux cheveux et de nouvelles dents, et qu'il avait vu Abou Rohm, celui-là même dont le tombeau se trouve à Moultân, dans le Sind. Je lui demandai de me réciter une tradition, et il me raconta des anecdotes. Mais je conçus des doutes touchant ce qui le concernait, et Dieu sait le mieux s’il est sincère.

${ }^{602}$ Lieu important pour ses mines d'argent.

${ }^{603}$ Gibb précise « comparables au volume et non à la couleur de la mer ». Le Pandjhir, qui vient effectivement du nord-est qui est la direction du Badakhshan, est un affluent du Ghorband, lui-même affluent de la rivière de Kaboul qui se jette dans l'Indus. En remontant la vallée du Dowshi, où effectivement des sources d'eau chaude existent, et en descendant celle du Pandjhir, Ibn Battûta passe à l'est du chemin actuel.

604 «...] à dix bonnes journées du Badascian vers le midi est une province nommée Pasciai, où ils ont un langage à eux. Les gens sont idolâtres qui adorent les idoles, et ils sont gens bruns » (Marco POLO). C'est la région appelée plus tard Kafiristan, à cause de la persistance de l'idolâtrie, et aujourd'hui Nuristan, dans la vallée du Pandjhir. 
Nous partîmes ensuite pour Pervan ${ }^{605}$, où je rencontrai l'émir Boronthaïh. Il me fit du bien, me témoigna de la considération, et écrivit à ses préposés dans la ville de Ghaznah de me traiter avec honneur. Il a déjà été question de lui et de la haute stature qu'il avait reçue en partage. Il avait près de lui une troupe de cheïkhs et de fakîrs, qui habitaient des ermitages.

De Pervan nous allâmes à Tcharkh ${ }^{606}$; c'est un grand bourg, qui possède de nombreux jardins et dont ${ }_{p 318}$ les fruits sont excellents. Nous y arrivâmes pendant l'été et nous y trouvâmes une troupe de fakîrs et d'étudiants ; nous y fîmes la prière du vendredi. Le chef de la localité, Mohammed altcharkhy, nous donna un repas. Dans la suite, je le revis dans l'Inde.

De Tcharkh nous partîmes pour Ghaznah, capitale du sultan belliqueux Mahmoûd, fils de Sébuctéguin ${ }^{607}$, dont le nom est célèbre. Il était au nombre des plus grands souverains, et avait le surnom de Yemîn Eddaulah. Il fit de fréquentes incursions dans l'Inde, et y conquit des villes et des châteaux forts. Son tombeau se trouve dans cette ville ; il est surmonté d'un ermitage. La majeure partie de Ghaznah est dévastée, et il n'en subsiste plus qu'une petite portion ; mais cette ville a jadis été considérable. Son climat est très froid ; ses habitants en sortent pendant l'hiver et retirent à Kandahâr ${ }^{608}$, ville grande et riche, située à trois journées de distance de Ghaznah, mais que je ne visitai pas. Nous logeâmes hors de Ghaznah, dans une bourgade située sur une rivière qui coule sous la citadelle. L'émir de la ville, Merdec Agha, nous traita avec égard. Merdec signifie le petit, et agha veut dire celui dont l'origine est illustre.

\footnotetext{
605 Au confluent du Pandjhir et du Gorband.

606 Tcharikar ; ici Ibn Battûta rejoint la route actuelle de Kaboul.

${ }^{607}$ Ghazna, au sud-ouest de Kaboul, sur la route de Kaboul-Kandahar, fut la capitale des Ghaznavides (962-1186), la dynastie turque qui amorça la conquête musulmane de l'Inde. Le souverain le plus important de la dynastie fut Mahmud (999-1030), célèbre par ses campagnes indiennes. Après la mort de Mahmud, le royaume s’épuisa dans ses luttes contre les Ghurides, originaires 608 de Ghur à l'est de Hérat, ce qui amena la ruine de Ghazna.

${ }^{08}$ Ghazna se trouve à une altitude de deux mille deux cents mètres et le Kandahar à mille quarante mètres au-dessus de la mer.
} 
Nous partîmes ensuite pour Câboul ${ }^{609}$; c'était jadis une ville importante ; mais ce n'est plus qu'un village, habité par une tribu de Persans, appelés Afghâns. Ils occupent des montagnes et des défilés et jouissent d'une ${ }_{\mathrm{p} 319}$ puissance considérable ; la plupart sont des brigands. Leur principale montagne s'appelle Coûh Soleïmân ${ }^{610}$. On raconte que le prophète Soleïmân gravit cette montagne, et regarda de son sommet l'Inde, qui était alors remplie de ténèbres. Il revint sur ses pas, sans entrer dans ce pays, et la montagne fut appelée d'après lui. C'est là qu'habite le roi des Afghâns. A Câboul se trouve l'ermitage du cheïkh Ismâ'ïl l'Afghân ${ }^{611}$, disciple du cheïkh 'Abbâs, un des principaux saints.

De Câboul, nous allâmes à Kermâch ${ }^{612}$, forteresse située entre deux montagnes, et dont les Afghâns se servent pour exercer le brigandage. Nous les combattîmes en passant près du château. Ils étaient placés sur la pente de la montagne ; mais nous leur lançâmes des flèches et ils prirent la fuite. Notre caravane était peu chargée de bagages, mais elle était accompagnée d'environ quatre mille chevaux. J'avais des chameaux, par la faute desquels je fus séparé de la caravane. J'avais avec moi plusieurs individus, parmi lesquels se trouvaient des Afghâns. Nous jetâmes une portion de nos provisions, et nous abandonnâmes sur la route les charges des chameaux qui étaient fatigués. Nos chevaux retournèrent les prendre le lendemain, et les emportèrent. Nous rejoignîmes la caravane, après la dernière prière du soir, et nous passâmes la nuit à la station de Chech Naghâr ${ }^{613}$, le dernier endroit habité sur les confins du pays des Turcs. p320

609 Il s’agit évidemment d’une confusion. Kaboul a dû être visitée par Ibn Battûta avant Ghazna. Idrisi (1154) parle aussi de Kaboul comme d'une ancienne ville importante.

${ }^{610}$ La chaîne du Sulaiman, qui surplombe la vallée de l’Indus, se trouve beaucoup plus au sud, dans le Pakistan actuel.

611 Il s'agit peut-être de Djabir al-Ansari, fils du poète et philosophe de Hérat, Ismail Abdallah al-Ansari, mort en 1089, lui-même disciple d'Abul' Hasan alKharaqani (voir ci-dessus, n. 148).

612 Karmash, située au sud-est de Gardez, elle-même à l'est de Ghazna.

613 L'identification de ce nom avec le district de Hashtnagar, situé à une vingtaine de kilomètres au nord-est de Peshawar, ferait traverser à Ibn Battûta le défilé de Khyber, sur la route de Kaboul à Peshawar, ce qui ne correspond pas à l’itinéraire suivi, lequel descend vers le sud. 
Nous entrâmes ensuite dans le grand désert, qui s'étend l'espace de quinze journées de marche ${ }^{614}$. On n'y voyage que dans une seule saison, après que les pluies sont tombées dans le Sind et l'Inde, c'est-àdire au commencement du mois de juillet. Dans ce désert souffle le vent empoisonné ${ }^{615}$ et mortel qui fait tomber les corps en putréfaction, de sorte que les membres se séparent après la mort. Nous avons dit ci-dessus que ce vent souffle aussi dans le désert, entre Hormouz et Chirâz. Une grande caravane, dans laquelle se trouvait Khodhâwend Zâdeh, kâdhi de Termedh, nous avait précédés. Il lui mourut beaucoup de chameaux et de chevaux ; mais, par la grâce de Dieu, notre caravane arriva saine et sauve à Bendj $A b$, c'est-à-dire au fleuve du Sind ${ }^{616}$. Bendj signifie cinq, et $a ̂ b$ eau. Le sens de ces deux mots est donc les Cinq Rivières. Elles se jettent dans le grand fleuve, et arrosent cette contrée. Nous en reparlerons, s'il plaît à Dieu. Nous arrivâmes près de ce fleuve, à la fin de dhou'lhiddjeh, et nous vîmes briller cette même nuit la nouvelle lune de moharrem de l'année $734^{617}$. De cet endroit, les préposés aux nouvelles écrivirent dans l'Inde pour y transmettre l'avis de notre arrivée, et firent connaître au souverain de ce pays ce qui nous concernait.

C’est ici que finit le récit de ce premier voyage. Louange à Dieu, maître des mortels.

Retour à la Table des Matières

614 Ce passage indiquerait une descente vers le sud à partir des environs de Ghazna et à l'ouest de la chaîne du Sulaiman afin d'atteindre l'Indus aux environs de Sehwan, au nord de Hyderabad.

615 Le simoun (voir chap. I, n. 137).

616 L'Indus.

${ }^{617}$ Le 12 septembre 1333. Pour la discussion sur cette date, voir l'introduction. 


\section{Le voyage à Dihli}

Retour à la Table des Matières

Au NOM DU DIEU CLÉMENT ET MISÉRICORDIEUX

Q'IL SOIT PROPICE À NOTRE SEIGNEUR MOHAMMED, À SA FAMILLE, À SES COMPAGNONS, ET QU'IL LEUR ACCORDE LA PAIX !

Voici ce que dit le cheïkh Abou 'Abd Allah Mohammed, fils d'Abd Allah, fils de Mohammed, fils d'Ibrâhîm Allewâty atthandjy ${ }^{618}$, connu sous le nom d'Ibn Batoutah. (Que Dieu lui fasse miséricorde !)

Lorsque fut arrivé le premier jour du mois divin de moharrem, commencement de l'année 734, nous parvînmes près du fleuve Sind, le même que l'on désigne sous le nom de Pendj-âb, nom qui signifie les Cinq Rivières. Ce fleuve est un des plus grands qui existent ; il déborde dans la saison des chaleurs, et les habitants de la contrée ensemencent la terre après son inondation, ainsi que font les habitants de l'Égypte, lors du débordement du Nil. C'est à partir de ce fleuve que commencent les États du sultan vénéré, Mohammed Châh, roi de l'Inde et du Sind ${ }^{619}$. p323

Quand nous arrivâmes près du fleuve, les préposés aux nouvelles vinrent nous trouver et écrivirent l'avis de notre arrivée à Kothb almulc, gouverneur de la ville de Moultân. A cette époque, le chef des émirs du Sind était un esclave du sultan, appelé Sertîz, qui est

${ }^{618}$ Voir t. I, chap. 1, n. 1.

${ }^{619}$ Muhammad bin Tughluk, ainsi que tous les autres sultans de Dihli, seront passés en revue plus loin. Le Sind, du sanskrit Sindhu (l'Indus), est le nom donné à la vallée de ce fleuve, conquise par les Arabes dès le VIII ${ }^{\mathrm{e}}$ siècle et constituant une province séparée par rapport au reste de l'Inde dont les premières invasions datent de Mahmut de Ghazna au début du $\mathrm{XI}^{\mathrm{e}}$ siècle et la conquête systématique de la fin du XII ${ }^{\mathrm{e}}$ siècle. 
l'inspecteur des autres esclaves et devant lequel les troupes du sultan passent en revue ${ }^{620}$. Le nom de cet individu signifie Celui qui a la tête vive ; car ser (en persan) veut dire tête, et tîz vif, impétueux. Il se trouvait, au moment de notre arrivée, dans la ville de Siwécitân ${ }^{621}$, située dans le Sind, à dix jours de marche de Moultân. Entre la province du Sind et la résidence du sultan, qui est la ville de Dilhy, il y a cinquante journées de marche. Lorsque les préposés aux nouvelles écrivent du Sind au sultan, la lettre lui parvient en l'espace de cinq jours, grâce au bérîd ou à la poste.

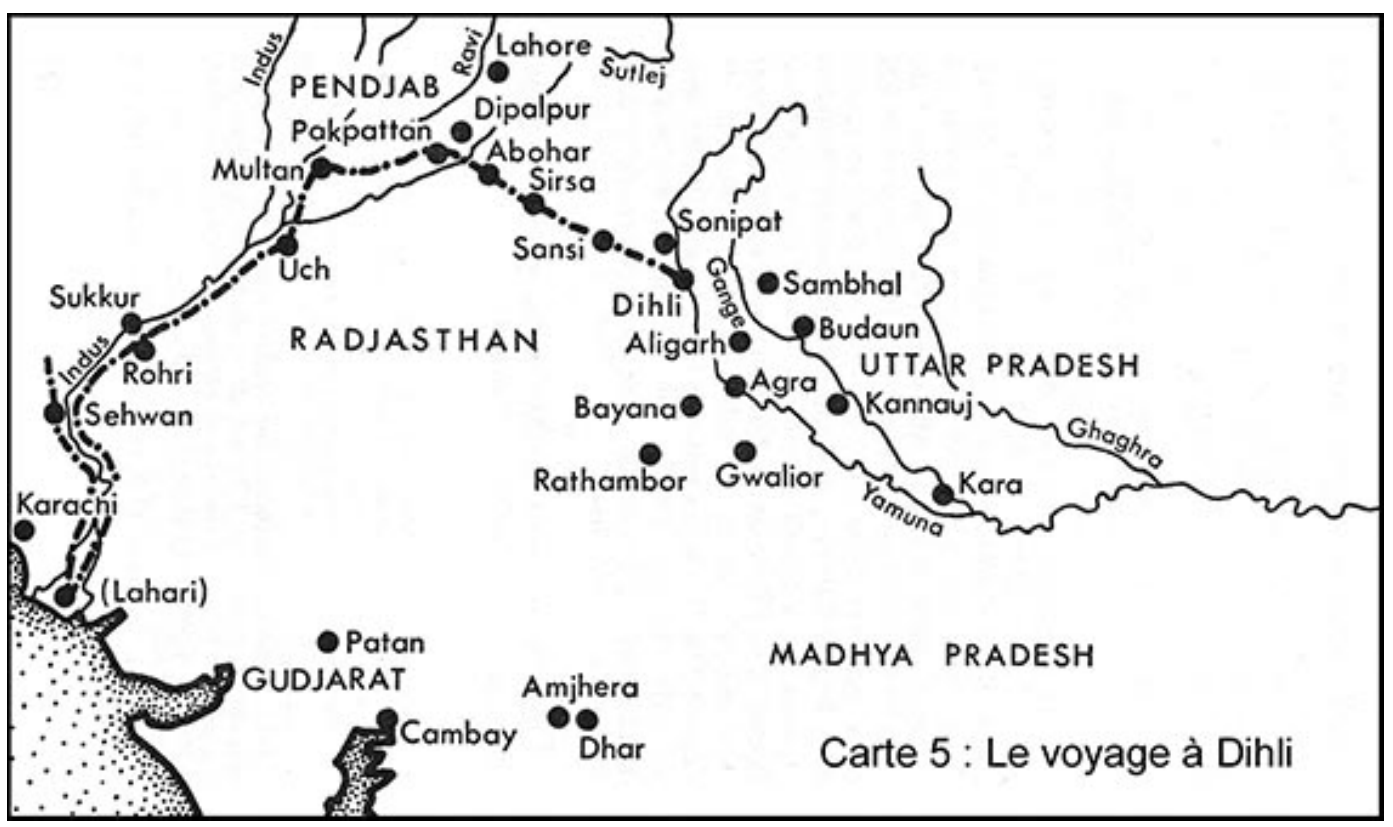

\section{DESCRIPTION DU BÉRÎD}

Le bérîd, dans l'Inde, est de deux espèces. Quant à la poste aux chevaux, on l'appelle oulâk ${ }^{622}$. Elle a lieu au moyen de chevaux appartenant au sultan et stationnés tous les quatre milles. Pour la poste aux piétons, voici en quoi elle consiste : chaque mille est partagé en

\footnotetext{
${ }^{620}$ Voir aussi plus haut p. 44.

621 Voir chap. 4, n. 126.

${ }^{622}$ Ulak est le mot turc encore utilisé ; le nom de berid était également donné à la poste mameluke d'Égypte.
} 
trois distances égales que l'on appelle addâouah ${ }^{623}$, ce qui veut dire le tiers d'un mille. Quant au mille, il se nomme, chez les Indiens, alcoroûh ${ }^{624}$. Or, à chaque tiers de mille, il y a une bourgade bien peuplée, à l'extérieur de laquelle se trouvent trois tentes où se tiennent assis des hommes tout prêts à partir. Ces gens ont serré leur ceinture, et près de chacun se trouve un fouet long de deux coudées, et terminé à sa partie supérieure par des sonnettes ${ }_{\text {p324 }}$ de cuivre. Lorsque le courrier sort de la ville, il tient sa lettre entre ses doigts et, dans l'autre main, le fouet garni de sonnettes. Il part donc, courant de toutes ses forces. Quand les gens placés dans les pavillons entendent le bruit des sonnettes, ils font leurs préparatifs pour recevoir le courrier, et, à son arrivée près d'eux, un d'entre eux prend la lettre de sa main et part avec la plus grande vitesse. Il agite son fouet jusqu'à ce qu'il soit arrivé à l'autre dâouah. Ces courriers ne cessent d'agir ainsi jusqu'à ce que la lettre soit parvenue à sa destination ${ }^{625}$.

Cette espèce de poste est plus prompte que la poste aux chevaux, et l'on transporte souvent par son moyen ceux des fruits du Khorâçân qui sont recherchés dans l'Inde. On les dépose dans des plats, et on les transporte en courant jusqu'à ce qu'ils soient parvenus au sultan. C'est encore ainsi que l'on transporte les principaux criminels; on place chacun de ceux-ci sur un siège que les courriers chargent sur leur tête et avec lequel ils marchent en courant. Enfin, c'est de la même manière que l'on transporte l'eau destinée à être bue par le sultan, lorsqu'il se trouve à Daoulet Abâd. On lui porte de l'eau puisée dans le fleuve Gange, où les Indiens se rendent en pèlerinage, ce fleuve est à quarante journées de cette ville.

623

De l'urdu kurok; il vaut le tiers d'un farsakh ou parasange.

625

« Il est vrai qu'entre un poste et l'autre, sur quelque route que ce soit, est placé tous les trois miles un hameau d'environ quarante maisons, où vivent des coureurs également affectés aux messageries du Grand Sire ; et vous dirai comment. Ils portent une grande ceinture, tout autour garnie de sonnettes, pour que, quand ils vont, ils soient ouïs de fort loin [...] Lorsque le roi veut envoyer une lettre par courrier, il la remet à un de ces coureurs, et il s'en va, toujours au grand galop, mais pas plus loin que trois milles, c'est-à-dire d'un poste à l'autre. Et l'autre, au bout de ces trois milles, qui, de bien loin, l'entend venir, se prépare incontinent et se tient prêt avant son arrivée, lui aussi muni de clochettes » (Marco PoLO). Seulement ici il s’agit de la Chine. Dans la Perse safavide le coureur, appelé shatir, porte un «caleçon avec une ceinture à trois sonnettes qui viennent lui battre sur les ventres. » (TAVERNIER). 
Lorsque les «nouvellistes » écrivent au sultan pour ${ }_{\mathrm{p} 325}$ l'informer de l'arrivée de quelqu'un dans ses États, il prend une pleine connaissance de la lettre. Ceux qui l'écrivent y mettent tout leur soin, faisant connaître au prince qu'il est arrivé un homme, conformé de telle manière et vêtu de telle sorte. Ils enregistrent le nombre de ses compagnons, de ses esclaves, de ses serviteurs et de ses bêtes de somme ; ils décrivent comment il en use dans la marche et dans le repos, et racontent toutes ses dépenses. Ils ne négligent aucun de ces détails. Lorsque le voyageur arrive au Moultân, qui est la capitale du Sind, il y séjourne jusqu'à ce qu'on reçoive un ordre du sultan touchant sa venue à la cour et le traitement qui lui sera fait. Un individu est honoré, en ce pays, selon ce qu'on observe de ses actions, de ses dépenses et de ses sentiments, puisque l'on ignore quel est son mérite et quels sont ces ancêtres.

C'est la coutume du roi de l'Inde, du sultan Abou'l-Modjâhid Mohammed châh, d'honorer les étrangers, de les aimer et de les distinguer d'une manière toute particulière, en leur accordant des gouvernements ou d'éminentes dignités. La plupart de ses courtisans, de ses chambellans, de ses vizirs, de ses kâdhis et de ses beaux-frères, sont des étrangers. Il a publié un ordre portant que ceux-ci, dans ses États, fussent appelés du titre d'illustres : ce mot est devenu pour eux un nom propre.

Aucun étranger admis à la cour de ce roi ne peut se passer de lui offrir un cadeau et de le lui présenter, en guise d'intercesseur auprès de lui. Le sultan l'en récompense par un présent plusieurs fois aussi considérable. Nous raconterons beaucoup de choses touchant les dons qui lui ont été offerts par des étrangers. Lorsque ses sujets furent accoutumés à lui voir tenir cette conduite, les marchands qui habitaient le Sind et l'Inde se mirent à donner en prêt à chaque individu se rendant à la cour du sultan des milliers de dînârs. Ils lui fournissaient ce qu'il voulait offrir au souverain, ou bien il employait cette somme comme il l'entendait pour son propre usage, en chevaux de selle, en chameaux et en effets. Ces marchands le servaient de leur argent et de p326 leurs personnes, et se tenaient debout devant lui comme des domestiques. Quand il arrivait près du sultan, celui-ci lui faisait un présent considérable. Alors il payait les sommes qu'il devait aux marchands, et s'acquittait envers eux. De la sorte, leur négoce était acha- 
landé et leurs profits étaient considérables. Aussi cette conduite estelle devenue pour eux une coutume constante.

Lorsque je fus arrivé dans le Sind, je suivis cette méthode, et j'achetai à des marchands des chevaux, des chameaux, des esclaves, etc. Précédemment, j'avais acquis à Ghaznah, d'un marchand de l'Irâk, originaire de Tecrît et nommé Mohammed Addoûry, environ trente chevaux et un chameau qui portait une charge de flèches, car cet article figure au nombre des présents que l'on offre au sultan, Le susdit marchand partit pour le Khorâçân, puis il revint dans l'Inde et y reçut de moi ce que je lui devais; par mon moyen il fit un profit considérable, et devint un des plus riches marchands. Après de nombreuses années, je le rencontrai dans la ville d'Alep, lorsque les infidèles m’eurent dépouillé de ce que je possédais ; mais je n'en obtins aucun bienfait.

\section{DESCRIPTION DU « CARCADDAN »}

Quand nous eûmes franchi le fleuve du Sind, connu sous le nom de Pendjâb, nous entrâmes dans un marais planté de roseaux, afin de suivre le chemin qui le traversait par le milieu. Un carcaddan en sortit sous nos yeux. Voici la description de cet animal : il est de couleur noire, a le corps grand, la tête grosse et d'un volume excessif ; c'est pourquoi on en fait le sujet d'un proverbe, et l'on dit: « Le rhinocéros, tête sans corps. » Il est plus petit que l'éléphant, mais sa tête est plusieurs fois aussi forte que celle de cet animal. Il a entre les yeux une seule corne, de la longueur d'environ trois coudées et de la largeur d'environ un empan. Lorsque l'animal dont il est ici question sortit du marais à notre vue, un cavalier voulut l'attaquer ; le carcaddan frappa ${ }_{p 327}$ de sa corne la monture de ce cavalier, lui traversa la cuisse et le renversa, après quoi il rentra parmi les roseaux et nous ne pûmes nous en emparer. J'ai vu un rhinocéros une seconde fois, pendant le même voyage, après la prière de l'asr ; il était occupé à se repaître de plantes. Lorsque nous nous dirigeâmes vers lui, il s'enfuit. J'en vis un encore une fois, tandis que je me trouvais avec le roi de l'Inde. Nous entrâmes dans un bosquet de roseaux; le sultan était monté sur un éléphant, et nous-mêmes avions pour montures plusieurs de ces animaux ; les piétons et les cavaliers pénétrèrent parmi les ro- 
seaux, firent lever le carcaddan, le tuèrent et poussèrent sa tête vers le camp.

Cependant, nous marchâmes pendant deux jours, après avoir passé le fleuve du Sind, et nous arrivâmes à la ville de Djénâny ${ }^{626}$, grande et belle place située sur le bord de ce même fleuve. Elle possède des marchés élégants, et sa population appartient à une peuplade appelée les Sâmirah ${ }^{627}$, qui l'habite depuis longtemps et dont, les ancêtres s'y sont établis lors de la conquête, du temps de Heddjâdj, fils de Yoûcef ${ }^{628}$, selon ce que racontent les chroniqueurs à propos de la conquête du Sind. Le cheïkh, l'imâm savant, pratiquant les bonnes œuvres, pieux et dévot, Rocn eddîn, fils du cheïkh, du vertueux docteur Chems eddîn, fils du cheïkh, de ${ }_{\mathrm{p} 328}$ l'imâm pieux et dévot, Béhâ eddîn Zacariâ ${ }^{629}$ le koreïchite (c'est un des trois personnages que le cheïkh, le saint et vertueux Borhân eddîn ala'radj m’avait prédit, dans la ville d'Alexandrie, que je rencontrerais dans le cours de mon voyage ${ }^{630}$, et, en effet, je les rencontrai ; Dieu en soit loué !) ; ce cheïkh, dis-je, m'a raconté que le premier de ses ancêtres s'appelait Mohammed, fils de Kâcim, le koreïchite ${ }^{631}$, qu'il assista à la conquête du Sind avec l'armée qu'envoya pour cet objet Heddjâdj, fils de Yoûcef, pendant qu'il était émir de l’Irâk ; qu'il y fixa son séjour et que sa postérité devint considérable.

${ }^{626}$ La ville n'existe plus et son site n’a pas été identifié.

${ }^{627}$ Il s’agit des Sumras, tribu ou dynastie qui paraît avoir établi son autorité dans le Sind après la défaite de Ma’sud, fils de Mahmut de Ghazna, par les Seldjukides en 1040. Hindous à l'origine, ils ont dû s'islamiser vers la fin. On sait que leur dernier souverain s’appelait Hamir Duda et qu'il ont été supplantés par la tribu des Sammas dont le premier souverain Djam Unar (djam est un titre porté par tous les souverains samma) a inauguré son règne en 1336. Il s’agirait donc de ce même personnage qu'Ibn Battûta nomme plus loin chef des Sumras, et l'histoire racontée ne doit pas être étrangère au changement de dynastie.

628 Voir t. I, chap. 4, n. 191.

${ }^{629}$ Baha al-din Zakariya (1183-1267) fut l'envoyé de Shihab al-din Abu Hafs Omar Suhrawardi en Inde ; il est le fondateur de la branche indienne de cet ordre. Son fils, Sadr al-din (et non Shams al-din), mort en 1285, et son petit-fils 630 Voir t. I, p. 100.

631 Imad al-din Muhammad bin Qasim, cousin de Hadjadj, conquit bien le Sind en 712, mais Baha al-din fut envoyé du Khorasan en Inde par Suhrawardi, selon ses biographes. 
Quant à cette peuplade connue sous le nom de Sâmirah, elle ne mange avec personne, et qui que ce soit ne doit regarder ses membres lorsqu'ils mangent; ils ne s'allient pas par mariage avec quelqu'un faisant partie d'une autre tribu et personne non plus ne s'allie avec eux. Ils avaient alors un émir nommé Ounâr ${ }^{632}$, dont nous raconterons l'histoire.

Après être partis de la ville de Djénâny, nous marchâmes jusqu'à ce que nous fussions arrivés à celle de Siwécitân ${ }^{633}$, grande cité, entourée d'un désert de sable où l'on ne trouve d'autre arbre que l'oumm ghaïlân ${ }^{634}$. On ne cultive rien sur le bord du fleuve qui l'arrose, si ce n'est des pastèques. La nourriture des habitants consiste en sorgho et en pois, que l'on y appelle mochonc ${ }^{635}$ et avec lesquels

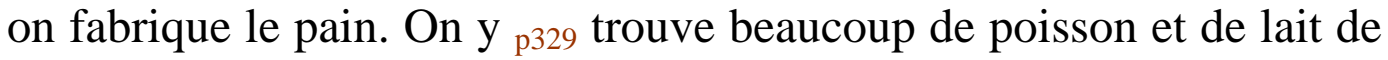
buffle. Les habitants mangent le scinque, qui est un petit animal semblable au caméléon, que les Maghrébins nomment petit serpent de jardin, sauf qu'il n'a pas de queue. Je les ais vus creuser le sable, en retirer cet animal lui fendre le ventre, jeter les intestins et le remplir de curcuma, qu'ils appellent zerd-choûbeh ${ }^{636}$, ce qui signifie le bois jaune. Cette plante remplace chez eux le safran. Lorsque je vis ce petit animal que mangeaient les Indous, je le regardai comme une chose impure et je n'en mangeai pas.

Nous entrâmes dans Siwécitân au fort de l'été, et la chaleur y était très grande ${ }^{637}$. Aussi mes compagnons s'asseyaient-ils tout nus; chacun plaçait à sa ceinture un pagne, et sur ses épaules un autre pagne trempé dans l'eau. Bien peu de temps s'écoulait avant que cette étoffe ne fût séchée, et alors on la mouillait de nouveau, et ainsi de suite. Je vis à Siwécitân son prédicateur, nommé Accheïbâny ; il me fit voir une lettre du prince des croyants, le khalife 'Omar, fils d'Abd Al'azîz, adressée au premier de ses ancêtres, pour l'investir des fonctions de

\footnotetext{
632 Voir ci-dessus n. 10.

633 Sehwan (voir chap. 4, n, 126).

634 Voir chap. 1, n. 109.

635 Du persan mushang, petit pois. Sorgho : millet.

636 Du persan zard tchuba.

${ }^{637}$ L'Indus étant atteint le 12 septembre, on n'était pas au fort de l'été.
} 
prédicateur en cette ville ${ }^{638}$. Sa famille se les est transmises par héritage, depuis cette époque jusqu’à présent.

Voici la teneur de cette lettre : «Ceci est l'ordre qu'a promulgué le serviteur de Dieu, le prince des croyants, 'Omar, fils d'Abd Al'azîz, en faveur d'un tel. » La date est l'année 99, Selon ce que m’a raconté le prédicateur susdit, sur ce diplôme est écrite, de la main du prince des croyants, 'Omar, fils d'Abd Al'azîz, la phrase suivante : «La louange appartient à Dieu seul. »

Je rencontrai aussi à Siwécitân le vénérable cheïkh Mohammed Albaghdâdy, qui habitait l'ermitage bâti ${ }_{\mathrm{p} 330}$ près du tombeau du vertueux cheïkh 'Othmân Almérendy. On raconte que l'âge de cet individu dépasse cent quarante années, et qu'il a été présent au meurtre d'Almosta'cim Billah, le dernier des khalifes abbâcides, lequel fut tué par le mécréant Holâoun, fils de Tenkîz, le Tartare ${ }^{639}$, Quant au cheïkh, malgré son grand âge, il était encore robuste et allait et venait à pied.

\section{ANECDOTE}

Dans cette ville habitaient l'émir Ounâr assâmiry ${ }^{640}$, dont il a été fait mention, et l'émir Kaïçar arroûmy, tous deux au service du sultan, et ayant avec eux environ mille huit cents cavaliers. Un Indien idolâtre, nommé Ratan, y demeurait aussi. C’était un homme habile dans le calcul et l'écriture ; il alla trouver le roi de l'Inde, en compagnie d'un émir ; le souverain le goûta, lui donna le titre de chef du Sind, l'établit gouverneur de cette contrée et lui accorda en fief la ville de Siwécitân et ses dépendances. Enfin, il le gratifia des honneurs, c'est-à-dire de timbales et de drapeaux, ainsi qu'il en donne aux principaux émirs. Lorsque Ratan fut de retour dans le Sind, Ounâr, Kaïçar, etc., virent avec peine la prééminence obtenue sur eux par un idolâtre. En conséquence, ils résolurent de l'assassiner, et, quelques jours s'étant écoulés

638 Il est très peu probable qu'un calife ait investi, en 717-720, d'un diplôme un prédicateur provincial.

639 Lire évidemment Hulagu, petit-fils de Gengis le Mongol.

640 Pour le nom et le récit, voir ci-dessus, n. 10. Ibn Battûta est la seule source de cette révolte. 
depuis son arrivée, ils lui conseillèrent de se transporter dans la banlieue de la ville, afin d'examiner la situation où elle se trouvait. Il sortit avec eux ; mais, lorsqu'il fit nuit, ils excitèrent du tumulte dans le camp, prétendant qu'un lion avait fait irruption. Ils se dirigèrent vers la tente de l'idolâtre, le tuèrent et revinrent en ville, où ils s'emparèrent de l'argent qui appartenait au sultan, et qui s'élevait à douze lacs. Le lac est une somme de cent mille ${ }_{\mathrm{p} 331}$ dînârs ${ }^{641}$ cette somme équivaut à dix mille dînârs d'or, monnaie de l'Inde, et le dînâr de l'Inde vaut deux dînârs et demi, en monnaie du Maghreb. Les insurgés mirent à leur tête le susdit Ounâr, qu'ils appelèrent Mélic Firoûz, et qui partagea l'argent entre les soldats. Mais ensuite il craignit pour sa sûreté, à cause de l'éloignement où il se trouvait de sa tribu. Il sortit de la ville, avec ceux de ses proches qui étaient près de lui, et se dirigea vers sa peuplade. Le reste de l'armée choisit alors pour chef Kaïçar arroûmy.

Ces nouvelles parvinrent à 'Imâd Almulc Sertîz, esclave du sultan, qui était alors émir des émirs du Sind et résidait à Moultân. Il rassembla des troupes, et se mit en marche, tant par terre que sur le fleuve du Sind. Entre Moultân et Siwécitân, il y a dix journées de marche. Kaïçar sortit à la rencontre de Sertîz, et un combat s'engagea. Kaïçar et ses compagnons furent mis en déroute de la manière la plus honteuse, et se fortifièrent dans la ville. Sertîz les assiégea et dressa contre eux des mangonneaux ou balistes ; le siège étant devenu très pénible pour eux, ils demandèrent à capituler au bout de quarante jours, à partir de celui où Sertîz avait campé vis-à-vis d'eux. Il leur accorda la vie sauve ; mais, lorsqu'ils furent venus le trouver, il usa de perfidie envers eux, prit leurs richesses et ordonna de les mettre à mort. Chaque jour, il en faisait décapiter plusieurs, en faisait fendre d'autres par le milieu du corps, écorcher d'autres ordonnait de remplir de paille la peau de ceux-ci et la pendait au-dessus de la muraille. La majeure partie de celle-ci était couverte de ces peaux, mises en croix, qui frappaient d'épouvante quiconque les regardait. Quant aux têtes, Sertîz les

${ }^{641}$ Le numéraire du royaume de Dihli était à l’époque composé principalement de deux monnaies appelées tanka, une en or pesant $9 \mathrm{~g}$ et une en argent de 9,3 g, la première valant officiellement dix fois la seconde. Ibn Battûta appelle la première tanga et la deuxième dinar. 
réunit au milieu de la ville, et elles y formèrent une sorte de monticule. p332

Ce fut après cette bataille que je m’arrêtai dans la ville de Siwécitân, où je me logeai dans un grand collège. Je dormais sur la terrasse de l'édifice, et, lorsque je me réveillais la nuit, je voyais ces peaux suspendues ; mon corps se contractait à ce spectacle, et mon âme ne fut pas satisfaite du séjour de ce collège. Aussi je l'abandonnai. Le docteur distingué et juste 'Alâ Almulc Alkhorâçâny, surnommé Facîh eddîn, anciennement kâdhi de Hérât, étant venu trouver le roi de l'Inde, celui-ci le nomma gouverneur de la ville de Lâhary et de ses dépendances, dans le Sind. Il assista à cette expédition, avec 'Imâd Almulc Sertîz, et en compagnie de ses troupes. Je résolus de me rendre avec lui dans la ville de Lâhary. Il avait quinze bateaux, en compagnie desquels il s'avança sur le fleuve Sind, et qui portaient ses bagages. Je partis donc dans sa société.

\section{RÉCIT DU VOYAGE SUR LE FLEUVE SIND}

\section{ET DES DISPOSITIONS QUI Y FURENT OBSERVÉES}

Le docteur 'Alâ Almulc avait, parmi ses navires, un bâtiment appelé alahhaourah, et qui était de l'espèce nommée chez nous tartane ${ }^{642}$, sauf qu'il était plus large et plus court. Il y avait au milieu de ce bâtiment une cabine de bois, à laquelle on arrivait par des degrés, et qui était surmontée d'un emplacement disposé pour que l'émir pût s'y asseoir. Les officiers de ce seigneur s'asseyaient vis-à-vis de lui, et ses esclaves se tenaient debout, à droite et à gauche. L'équipage, composé d'environ quarante individus, était occupé à ramer. Cette ahaourah était entourée, à sa droite et à sa gauche, par quatre navires, dont deux renfermaient les honneurs de l'émir, c'est-à-dire les drapeaux, les timbales, ${ }^{333}$ les trompettes, les clairons et les flûtes, que l'on appelle ghaïthah ${ }^{643}$, et les deux autres portaient les chanteurs. Les timbales et les trompettes se faisaient entendre d'abord, puis les chanteurs fai-

\footnotetext{
${ }^{642}$ Le texte arabe dit tarida, ce qui correspond à un vaisseau utilisé en Méditerranée pour le transport des chevaux et des marchandises lourdes, différent aussi bien de la tartane, qui est un petit navire de forme allongée, que de l'hindou 643 huri : bateau de pêche.

Cornemuses.
} 
saient leur partie, et ils ne cessaient d'agir ainsi depuis le commencement du jour jusqu'au moment du déjeuner. Lorsque cet instant arrivait, les bateaux se réunissaient et se serraient les uns contre les autres ; on plaçait entre eux des échelles, et les musiciens se rendaient sur l'ahaourah de l'émir. Ils chantaient jusqu'à ce qu'il eût fini de manger ; après quoi ils mangeaient, et lorsque le repas était terminé, ils retournaient à leur vaisseau. Alors on commençait à marcher, selon l'ordre accoutumé, jusqu'à la nuit, et, lorsqu'elle était arrivée, on plantait le camp sur la rive du fleuve, l'émir descendait dans ses tentes, la table était dressée, et la majeure partie de l'escorte assistait au festin. Quand on avait fait la dernière prière du soir, les sentinelles montaient la garde pendant la nuit, à tour de rôle et tout en conversant entre elles. Lorsque les gens d'une escouade avaient achevé leur faction, un d'entre eux criait à haute voix : «O seigneur roi, tant d'heures de la nuit sont écoulées. » Alors les gens d'une autre escouade veillaient ; et, quand ils avaient fini leur faction, leur hérault proclamait combien d'heures étaient passées. Lorsqu'arrivait le matin, on sonnait de la trompette et l'on battait les timbales, on récitait la prière de l'aurore et l'on apportait de la nourriture. Quand on avait cessé de manger, on commençait à marcher. Si l'émir veut voyager sur le fleuve, il s'embarque dans l'ordre que nous avons décrit ; mais, s'il veut marcher par terre, on fait résonner les timbales et les trompettes ; les chambellans s'avancent, suivis des fantassins qui précèdent l'émir. Les chambellans sont eux-mêmes devancés par six cavaliers, dont trois portent au cou des timbales, et les trois autres sont munis de flûtes. Lorsqu'ils approchent d'une bourgade ou d'un terrain élevé ces musiciens font retentir leurs timbales et leurs ${ }_{\mathrm{p} 334}$ flûtes ; puis les timbales et les trompettes du corps d'armée se font entendre. Les chambellans ont à leur droite et à leur gauche des musiciens qui chantent à tour de rôle. On campe lorsqu'arrive le moment du déjeuner.

Je voyageai pendant cinq jours en compagnie d'Alâ Almulc, et nous arrivâmes au siège de son gouvernement, c'est-à-dire à la ville de Lâhary ${ }^{644}$, belle place située sur le rivage de l'océan, et près de laquelle le fleuve du Sind se jette dans la mer. Deux mers ont donc

${ }^{644}$ Cette ville, connue sous le nom de Larry-Bender, se trouvait à une quarantaine de kilomètres au sud-est de Karachi. Au fur et à mesure de l'avancement des terres, elle fut supplantée vers 1800 par Shahbandar et ensuite par Karachi. 
leur confluent près d'elle ${ }^{645}$; elle possède un grand port, où abordent des gens du Yaman, du Fars, etc. Aussi ses contributions sont considérables et ses revenus importants. L'émir 'Alâ Almulc, dont il a été question, m'a raconté que le revenu de cette ville se montait à soixante lacs par an. Or nous avons dit combien valait le lac. L'émir prélève là-dessus la moitié de la dixième partie. C'est sur ce pied-là que le sultan confie les provinces à ses préposés ; ils en retirent pour eux-mêmes la moitié de la dîme, ou le vingtième du revenu.

\section{RÉCIT D’UNE CHOSE EXTRAORDINAIRE QUE J'AI VUE}

\section{À L’EXTÉRIEUR DE CETTE VILLE}

Je montai un jour à cheval, en compagnie d'Alâ Almulc, et nous arrivâmes dans une plaine située à la distance de sept milles de Lâhary, et que l'on appelait Târnâ ${ }^{646}$. Je vis là une quantité incalculable de pierres qui ressemblaient à des figures d'hommes et d'animaux; beaucoup avaient subi des altérations, et les p335 traits des objets qu'elles représentaient étaient effacés il n’y restait plus que la figure d'une tête ou d'un pied ou de quelque autre partie du corps. Parmi les pierres, il y en avait aussi qui représentaient des grains, tels que le blé, les pois chiches, les fèves, les lentilles. Il y avait là des traces d'un mur et des parois de maisons. Nous vîmes ensuite les vestiges d'une maison, où se trouvait une cellule construite en pierres de taille, au milieu de laquelle s'élevait une estrade, également en pierres taillées, avec une telle précision qu'elles paraissaient ne former qu'une seule pierre. Cette estrade supportait une figure d'homme, mais dont la tête était fort allongée, la bouche placée sur un des côtés du visage et les mains derrière le dos, comme celles d'un captif. On voyait là des flaques d'eau extrêmement puantes, et une des parois portait une inscription en caractères indiens. 'Alâ Almulc me raconta que les historiens prétendent qu'il y avait en cet endroit une ville considérable, dont les habitants, ayant commis beaucoup de désordres, furent changés en pierres, et que c'est leur roi qui figure sur l'estrade, dans la maison dont nous avons parlé ; aussi cette maison est-elle encore appelée la

\footnotetext{
645 Une référence coranique qu’Ibn Battûta affectionne (voir t. I, n. 4, et p. 375).

646 La seule identification possible est celle des ruines appelées Mora-Mari, à une douzaine de kilomètres au nord-est de Larry-Bender.
} 
demeure du roi. On assure que l'inscription indienne qui se voit sur une des murailles renferme la date de la destruction des habitants de cette ville : cela est arrivé il y a mille ans ou environ.

Je passai cinq jours à Lâhary, en compagnie d'Alâ Almulc ; après quoi il me fournit généreusement des provisions de route, et je le quittai pour me rendre à la ville de Bacâr ${ }^{647}$. On nomme ainsi une belle cité, que traverse un canal dérivé du fleuve Sind. Au milieu de ce canal se trouve un superbe ermitage, où l'on sert à manger aux voyageurs. Il a été construit par Cachloû Khân ${ }^{648}$, pendant qu'il était gouverneur du Sind. Or il ${ }_{\mathrm{p} 336}$ sera plus loin question de ce personnage. Je vis à Bacâr le jurisconsulte, l'imâm Sadr eddîn Alhanefy, ainsi que le kâdhi de la ville, nommé Abou Hanîfah. Je rencontrai à Bacâr le cheïkh pieux et dévot, Chems eddîn Mohammed acchîrâzy, qui était au nombre des hommes vénérables par leur grand âge : il me dit que son âge dépassait cent vingt ans. De cette ville, je me rendis à celle d'Oûdjah ${ }^{649}$, grande place située sur le fleuve Sind ; elle possède de beaux marchés et est très bien bâtie. Elle avait alors pour émir le roi distingué et noble Djélâl eddîn Alkîdjy, qui figurait parmi les hommes braves et généreux. Il mourut dans cette ville, des suites d'une chute de cheval.

\section{ACTE DE GÉNÉROSITÉ DE CET ÉMIR}

Une amitié se forma entre moi et ce noble roi, Djélâl eddîn, et notre intimité et notre affection furent affermies. Nous nous rencontrâmes dans la capitale, Dihly. Lorsque le sultan partit pour Daoulet Abâd, ainsi que nous le raconterons, et qu'il m’ordonna de rester dans la capitale, Djélâl eddîn me dit : "Tu as besoin, pour ton entretien, d'une somme considérable, et l'absence du sultan sera longue. Accepte donc ma bourgade, et perçois-en le produit jusqu'à mon re-

647 Bukkur, une île fortifiée sur l’Indus située entre les villes de Sukkur et Rohri à cent cinquante kilomètres de Sehwan.

648 Voir plus loin, n. 76.

${ }^{649}$ Uch, sur le chemin de Multan, à l'ouest de Bahawalpur. C'était à l'époque un centre religieux important abritant, entre autres, le cheïkh suhrawardi Djalal al-din Bukhari (1199-1291). 
tour. » C'est ce que je fis, et j'en perçus environ cinq mille dînârs. Que Dieu lui accorde sa plus belle récompense !

Je vis à Oûdjah le cheïkh dévot, pieux et noble, Kothb eddîn Haïder, l'alide, qui me fit revêtir le froc ${ }^{650}$. C'était un des plus grands hommes de bien, et je ne cessai de garder l'habit dont il me revêtit, jusqu’à ce que les Indiens idolâtres m’eussent dépouillé sur mer. p337

D’Oûdjah, je me rendis à la ville de Moultân ${ }^{651}$, qui est la capitale du Sind et la résidence de l'émir suprême de cette province. Sur le chemin qui y conduit, et à dix milles avant d'y arriver, se trouve le fleuve connu sous le nom de Khosrew Abâd ${ }^{652}$. Il est au nombre des grands fleuves, et on ne le passe qu'en bateau. On y examine de la manière la plus sévère les marchandises des passagers et l'on fouille leurs bagages. C'était la coutume, lors de notre arrivée à Moultân, que l'on prît le quart de tout ce qu'apportaient les marchands. On percevait, pour chaque cheval, un droit de sept dînârs ; mais deux années après notre arrivée dans l'Inde le sultan abolit ces taxes ${ }^{653}$ et ordonna que l'on n'exigeât plus des voyageurs que la dîme aumônière et l'impôt du dixième. Cela eut lieu à l'époque où il prêta serment au khalife Abou'l Abbâs, l'abbâcide.

Lorsque nous commençâmes à traverser la rivière et que les bagages furent examinés, la visite de mon bagage me parut une chose pénible à supporter, car il ne renfermait rien de précieux, et cependant il paraissait considérable aux yeux du public. Il me répugnait qu'on en prît connaissance. Ce fut par la grâce de Dieu que survint un des principaux officiers de la part de Kothb Almulc, prince de Moultân. Il donna l'ordre de ne pas me soumettre à un examen ni à des recherches. Il en fut ainsi, et je remerciai Dieu des grâces qu'il avait daigné

650 Le personnage n’étant pas connu par ailleurs, on ne sait pas de quelle confrérie il s’agit. Uch était toutefois un centre suhrawardi.

651 Multan, capturé dès la première campagne musulmane en 713, fut un des plus importants centres du Sind.

${ }^{652}$ La rivière Ravi, un des cinq affluents de l'Indus qui compose le Pendjab (les Cinq Rivières).

653 Cet événement date de 1341 et non de deux années après l’arrivée d’Ibn Battûta en Inde. Pour le calife, voir t. I, chap. 4., n. 228 et p. 324 et 327 où cette histoire est racontée. La dîme aumônière est de deux et demi pour cent (voir aussi chap. 3, n. 28). 
m'accorder. Nous passâmes la nuit sur le bord du fleuve, et le matin le roi du bérîd ou de la poste vint nous trouver. On l'appelait Dihkân, et il était originaire de Samarkand. C'était lui qui écrivait au sultan les nouvelles ${ }_{\text {p338 }}$ de la ville et de son district, lui annonçant ce qui y survenait et quels individus y arrivaient. Je fus questionné par lui et j'entrai en sa société chez l'émir de Moultân.

\section{DE L’ÉMIR DE MOULTÂN ET DÉTAILS SUR CE QUI LE CONCERNE}

Le prince de Moultân était Kothb Almulc, un des principaux chefs et des plus distingués. Lorsque j'entrai chez lui, il se leva, me prit la main et me fit asseoir à son côté. Je lui offris un esclave, un cheval, ainsi qu'une certaine quantité de raisins secs et d'amandes. C'est un des plus grands cadeaux qu'on puisse faire aux gens de ce pays, car il ne s'en trouve pas chez eux ; seulement on en importe du Khorâçân. L'émir était assis sur une grande estrade, recouverte de tapis ; près de lui se trouvait le kâdhi appelé Sâlâr, et le prédicateur, dont je ne me rappelle pas le nom. Il avait, à sa droite et à sa gauche, les chefs des troupes, et les guerriers se tenaient debout derrière lui ; les troupes passaient en revue devant lui ; il y avait là un grand nombre d'arcs. Lorsqu'arrive quelqu'un qui désire être enrôlé dans l'armée en qualité d'archer, on lui donne un de ces arcs, afin qu'il le tende. Ces arcs sont plus ou moins roides, et la solde de l'archer est proportionnée à la force qu'il montre à les tendre. Pour celui qui désire être inscrit comme cavalier, il y a là une cible ; il fait courir son cheval et frappe la cible de sa lance. Il y a également un anneau suspendu à un mur peu élevé ; le cavalier pousse sa monture jusqu'à ce qu'il arrive vis-à-vis de l'anneau, et, s’il l'enlève avec sa lance, il est considéré comme un excellent homme de cheval. Pour celui qui veut être enregistré à la fois comme archer et cavalier, on place sur la terre une boule. Cet individu fait courir son cheval et vise la boule ; sa solde est proportionnée à l'habileté qu'il montre à toucher le but.

Lorsque nous fûmes entrés chez l'émir et que nous l'eûmes salué, ainsi que nous l'avons dit, il ordonna de ${ }_{\mathrm{p} 339}$ nous loger dans une maison située hors de la ville, et appartenant aux disciples du pieux 
cheïkh Rocn eddîn dont il a été question ci-dessus ${ }^{654}$. C’est la coutume de ces gens-là de n'héberger personne, jusqu'à ce qu'ils en reçoivent l'ordre du sultan.

DES ÉTRANGERS ARRIVANT POUR SE RENDRE À LA COUR DU ROI DE L'INDE ET QUE JE RENCONTRAI DANS CETTE VILLE

Je citerai : Khodhâwend Zâdeh Kiwâm eddîn, kâdhi de Termedh ${ }^{655}$, qui arriva avec sa femme et ses enfants ; il fut ensuite rejoint à Moultân par ses frères, 'Imâd eddîn, Dhiâ eddîn et Borhân eddîn ; Mobârec châh, un des principaux personnages de Samarkand ; Aroun Boghâ, un des principaux habitants de Bokhâra ; Mélic Zâdeh, fils de la sœur de Khodhâwend Zâdeh ; Bedr eddîn alfassâl. Chacun de ces individus avait avec lui ses compagnons, ses serviteurs et ses adhérents.

Lorsqu'il se fut écoulé deux mois depuis notre arrivée à Moultân, un des chambellans du sultan, Chems eddîn alboûchendjy arriva, ainsi qu'Almélic Mohammed alherawy, le cotouâl ${ }^{656}$. Le sultan les envoyait à la rencontre de Khodhâwend Zâdeh. Ils étaient accompagnés de trois eunuques députés par Almakhdoûmah Djihân, mère du sultan, à la rencontre de la femme du susdit Khodhâwend Zâdeh. Ces gens-là apportaient des vêtements d'honneur pour les deux époux et pour leurs enfants. Ils avaient mission de fournir des provisions de route aux hôtes nouvellement arrivés. Ils vinrent me trouver tous ensemble et me demandèrent dans quel but j'étais venu. Je les informai que c'était pour me fixer au service du Seigneur du monde, c'est-à-dire le sultan, car on le désigne ainsi dans ses États. Ce prince avait ordonné qu'on ne laissât pénétrer dans l'Inde aucune personne venant ${ }_{\text {p340 }}$ du Khorâçân, à moins que ce ne fût pour y demeurer. Lorsque j'eus fait savoir à ces individus que j'arrivais dans l'intention de séjourner, ils mandèrent le kâdhi et les notaires, et firent écrire un engagement en mon nom et en celui de mes compagnons qui voulaient demeurer.

\footnotetext{
${ }^{654}$ Voir plus haut n. 12.

${ }^{655}$ Voir plus haut p. 297.

${ }^{656}$ Chef de la police.
} 
Quelques-uns de mes camarades refusèrent de prendre cet engagement.

Nous nous préparâmes à nous mettre en route pour la capitale. Il y a entre elle et Moultân une distance de quarante journées, où l'on traverse constamment un pays habité. Le chambellan et le camarade qui avait été envoyé avec lui expédièrent les choses nécessaires pour héberger Kiwâm eddîn, et emmenèrent de Moultân environ vingt cuisiniers. Le chambellan se transportait d'avance, durant la nuit, à chaque station et faisait préparer les aliments, etc. Khodhâwend Zâdeh n'arrivait que quand le repas était prêt. Chacun des hôtes que nous avons mentionnés campait séparément dans ses tentes et avec ses compagnons. Souvent ils assistaient au repas qui était préparé pour Khodâwend Zâdeh. Quant à moi, je n’y assistai qu'une seule fois. Voici l'ordre suivi dans ce repas : on sert d'abord le pain, qui est une espèce de gâteau et ressemble à des galettes ; on coupe la viande rôtie en grands morceaux, de sorte qu'une brebis forme quatre ou six morceaux, et l'on en place un devant chaque convive. On sert aussi des pains ronds, préparés avec du beurre et qui ressemblent au pain commun de notre pays. On met au milieu de ces pains la friandise que l'on appelle sâboûniah ${ }^{657}$, et l'on couvre chacun d'eux avec un gâteau sucré que l'on appelle khichty, mot qui signifie briqueté. Ce dernier est fait de farine, de sucre, de beurre. On sert ensuite, dans des écuelles de porcelaine, la viande accommodée au beurre, aux oignons et au gingembre vert ; puis un mets que ${ }_{\mathrm{p} 341}$ l'on nomme samoûcec ${ }^{658}$, et qui consiste en viande hachée, cuite avec des amandes, des noix, des pistaches, des oignons et des épices, et que l'on place dans l'intérieur d'un gâteau frit dans le beurre. On met devant chaque personne quatre ou cinq morceaux de cela. Puis on sert le riz cuit au beurre et surmonté de poulets ; puis les petites bouchées du kâdhi, que ces gens-là appellent alhâchimy; enfin, les kâhiriyah. Le chambellan se tient debout près de la table, avant de manger ; il s'incline, en signe d'hommage, vers le côté où se trouve le sultan, et tous ceux qui sont présents pour le même objet en font autant. L'hommage, chez les Indiens, consiste à incliner la tête en avant comme pendant la prière. Lorsqu'ils ont fait

${ }^{657}$ Friandise égyptienne fabriquée à partir d'amandes, d'amidon, de miel et de sésame. 658 Du persan sanbusa, triangulaire. 
cela, ils s'asseyent pour manger ; on apporte des coupes d'or, d'argent et de verre, remplies de l'eau du sucre candi, c'est-à-dire de sirop délayé dans de l'eau. On appelle cette liqueur du sorbet et on la boit avant de manger. Ensuite, le chambellan prononce ces mots : «Au nom de Dieu. " Alors on commence à manger et, lorsqu'on a fini, des cruches de bière sont apportées. Quand elles sont bues, on apporte le bétel et la noix d'arec, dont il a été question précédemment. Après qu'on a pris le bétel et la noix d'arec, le chambellan prononce les mots : « Au nom de Dieu. » On se lève, on fait une salutation semblable à la première et on s'en retourne.

Nous voyageâmes, après être partis de la ville de Moultân, notre cortège observant ce même ordre que nous venons de décrire, jusqu'à ce que nous fussions arrivés dans l'Inde proprement dite. La première ville dans laquelle nous entrâmes était celle d'Aboûher ${ }^{659}$, où commencent les provinces indiennes. Elle est petite ; mais belle, et bien peuplée et pourvue de rivières et d'arbres. On ne trouve là aucun arbre de notre pays, p342 excepté le nebek ${ }^{660}$; mais, dans l'Inde, il est d'un volume considérable et chacun de ses fruits est aussi gros qu'une noix de galle et fort doux. Les Indiens ont beaucoup d'arbres dont aucun n'existe dans notre pays ni dans quelque autre.

\section{DES ARBRES ET DES FRUITS DE L’INDE}

\section{Nous citerons :}

Le manguier, arbre qui ressemble aux orangers, si ce n'est qu'il est plus grand et plus feuillu; aucun autre arbre ne donne autant d'ombrage ; mais cet ombrage est malsain et quiconque dort sous son abri est pris de fièvre. Le fruit du manguier a la grosseur d'une grosse poire. Lorsqu'il est encore vert, avant sa parfaite maturité, on prend les fruits tombés de l'arbre, on les saupoudre de sel et on les fait confire, comme le citron doux et le limon dans notre pays. Les Indiens confisent de même le gingembre vert et le poivre en grappes; ils mangent ces conserves avec leurs aliments, prenant après chaque bou-

659 Abohar, près de la frontière indo-pakistanaise.

${ }^{660}$ Le jujubier. 
chée un peu des ces objets salés. Lorsque la mangue est mûre, en automne, elle devient très jaune et on la mange comme une pomme. Quelques-uns la coupent avec un couteau et d'autres la sucent lentement. Ce fruit est doux, mais un peu d'acidité se mêle à sa douceur. Il a un gros noyau, que l'on sème à l'instar des pépins de l'oranger, ou d'autres fruits, et d'où proviennent les arbres.

Le checky et le berky ${ }^{661}$. On donne ce nom à des arbres qui durent fort longtemps ; leurs feuilles ressemblent à celles du noyer et leurs fruits sortent du tronc même de l'arbre. Ceux des fruits qui sont voisins de la terre forment le berky ; leur douceur est plus grande et leur goût plus agréable que ceux du cheky. Ce qui se trouve plus p343 haut est la portion appelée cheky, dont le fruit est pareil à de grandes courges et l'écorce à une peau de bœuf. Lorsqu'il est devenu jaune, en automne, on le cueille, on le fend et l'on trouve dans chaque fruit de cent à deux cents grains ressemblant à des cornichons. Entre chaque grain, il y a une pellicule de couleur jaunâtre ; chacun a un noyau à l'instar d'une grande fève. Lorsque ce noyau est rôti ou bouilli, son goût est analogue à celui de la fève, laquelle n'existe pas dans l'Inde. On conserve ces noyaux dans une terre rougeâtre et ils durent jusqu'à l'année suivante. Le cheky et le berky sont les meilleurs fruits de l'Inde.

Le tendoû, qui est le fruit de l'ébénier ; chacun de ces fruits est aussi gros qu'un abricot, dont ils ont aussi la couleur. Ils sont extrêmement doux.

Le tchoumoûn ${ }^{662}$. Les arbres de cette espèce vivent fort longtemps et leur fruit ressemble à l'olive. Il est de couleur noire et n'a qu'un noyau comme l'olive.

L'orange douce, qui est très abondante chez les Indiens. Quant à l'orange acide, elle est rare. Il y a une troisième espèce d'orange, qui tient le milieu entre la douce et l'acide. Son fruit est de la grosseur du citron doux ; il est fort agréable, et je me plaisais à en manger.

${ }^{661}$ Le jacquier ou arbre à pain (voir aussi t. III, chap. 3, n. 5).
${ }^{662}$ Le djambou (voir aussi t. III, chap. 3, n. 6). 
Le mehwâ ${ }^{663}$, arbre qui dure fort longtemps et dont les feuilles ressemblent à celles du noyer, sauf qu'elles sont mélangées de rouge et de jaune. Son fruit a la forme d'une petite poire et est fort doux. A la partie supérieure de chaque fruit se trouve un petit grain, de la grosseur d'un grain de raisin et creux ; son goût ressemble à celui du raisin, mais en manger beaucoup cause un mal de tête. Ce qu'il y a d'étonnant, c'est que ces grains, lorsqu'ils sont séchés au soleil, ont le goût de la figue. J'en mangeais en place de ce fruit, qui ne se rencontre ${ }_{\mathrm{p} 344}$ pas dans l'Inde. Les Indiens appellent ces grains angoûr, mot qui, dans leur langue, a le sens de raisin ${ }^{664}$. Ce dernier fruit est très rare dans l'Inde, et on ne l'y trouve que dans quelques endroits de Dihly, et dans d'autres localités. Le mewhâ porte des fruits deux fois dans une année, et avec ses noyaux on fabrique de l'huile dont on se sert pour l'éclairage.

Parmi les fruits des Indiens, on en distingue encore un qu'ils appellent cacîra. On l'extrait de la terre ; il est très doux et ressemble à la châtaigne.

On trouve dans l'Inde, parmi les fruits qui croissent dans notre pays, le grenadier, qui porte des fruits deux fois l'an. J'en ai vu, dans les îles Maldives, qui ne cessaient de produire. Les Indiens l'appellent anâr, mot qui, je pense, a donné naissance à la dénomination de djulnâr, car djul, en persan, signifie une fleur ${ }^{665}$ et anâr la grenade.

\section{DES GRAINS QUE SÈMENT LES HABITANTS DE L’INDE ET DONT ILS SE NOURRISSENT}

Les Indiens ensemencent la terre deux fois chaque année. Quand la pluie tombe, dans l'été, ils sèment les grains d'automne, qu'ils récoltent au bout de soixante jours. Parmi ces grains d'automne, on remarque le kudhroû, qui est une espèce de millet ${ }^{666}$. C'est de tous les grains celui qui se trouve chez eux le plus abondamment. Le kâl, qui

\footnotetext{
${ }^{663}$ Bassia latifolia, également utilisé pour fabriquer des boissons alcoolisées.

${ }^{664}$ Angur est un mot persan.

$665 \mathrm{Gul}$, en persan, signifie la rose.

${ }^{666}$ Paspalum scrobiculatum : le millet commun.
} 
ressemble à l'anly ${ }^{667}$. Le châmâkh ${ }^{668}$, dont les grains sont plus petits que ceux du kâl. Souvent ce châmâkh croît sans culture. C'est la nourriture des dévots, de ceux qui font profession d'abstinence, des pauvres et des malheureux, lesquels sortent pour recueillir ${ }_{\mathrm{p} 345}$ ceux de ces grains qui ont poussé sans culture. Chacun d'eux tient dans sa main gauche un grand panier, et dans sa droite un fouet, avec lequel il frappe les grains, qui tombent dans le panier. Ils ramassent ainsi de quoi se nourrir toute l'année. Le grain du châmâkh est fort petit. Lorsqu'on l'a recueilli, on le place au soleil, puis on le broie dans des mortiers de bois ; son écorce s'envole, et il ne reste qu'une farine blanche, avec laquelle on prépare une épaisse bouillie que l'on mélange avec du lait de buffle. Cette bouillie est plus agréable que le pain fabriqué avec la même farine ; j'en mangeais souvent, dans l'Inde, et elle me plaisait. Le mâch ${ }^{669}$, qui est une espèce de pois. Le mondj ${ }^{670}$. C'est une espèce de mâch ; mais ses grains sont allongés et sa couleur est d'un vert clair. On fait cuire le mondj avec du riz et on le mange assaisonné de beurre. C'est ce que l'on appelle kichry ${ }^{671}$, et c'est avec ces mets que l'on déjeune chaque jour. Il est, pour les Indiens, ce qu'est dans le Maghreb la harîrah ${ }^{672}$. Le loûbia ${ }^{673}$, qui est une espèce de fève. Le moût ${ }^{674}$, qui ressemble au kudhroû sauf que ses grains sont plus petits. Il fait partie, chez les Indiens, de la provende des animaux, et ceux-ci deviennent gras en le mangeant. L'orge n'a pas, chez ce peuple, de propriétés fortifiantes ; aussi la provende des bestiaux se compose-t-elle seulement de ce moût ou de pois chiches, qu'on leur fait manger, après les avoir concassés et humectés avec de l'eau. On donne aux animaux, en place de fourrage vert, des feuilles de mâch, après que l'on a fait boire du beurre fondu à la bête durant dix jours, sur le pied de trois ou quatre rathls ${ }^{675}$ par jour. Durant ce temps on ne monte pas sur elle. On p346 lui donne ensuite à manger,

\footnotetext{
${ }^{667}$ Voir chap. 3, n. 14.

${ }^{668}$ Le panic, dit aussi millet des oiseaux.

669 Phaseolus radiatus : haricot.

${ }^{670}$ Phaseolus mungo : une autre sorte de haricot.

671 Aujourd'hui connu sous le nom de kedjéré.

672 Farine cuite avec du lait ou de la graisse.

673 Vigna cattiang : nom persan pour les petits haricots.

674 Cyperus rotundus.

675 Livres.
} 
ainsi que nous l'avons dit, des feuilles de mâch durant un mois environ.

Les grains dont nous avons fait mention sont ceux d'automne. Lorsqu'on les a moissonnés, soixante jours après les avoir semés, on fait les semailles pour le printemps. Les grains que l'on recueille en cette saison sont : le froment, l'orge, les pois chiches, les lentilles. On les sème dans la même terre où ont lieu les semailles de l'automne, car l'Inde est douée d'un sol généreux et excellent.

Quant au riz, les Indiens le sèment trois fois chaque année, et c'est un de leurs principaux grains. Ils cultivent encore le sésame et la canne à sucre, en même temps que les plantes automnales dont nous avons fait mention.

Mais revenons à notre propos. Je dirai que nous marchâmes, après être partis d'Abouher, dans une plaine d'une vaste étendue, aux extrémités de laquelle se trouvent des montagnes inaccessibles, habitées par les Indiens idolâtres, qui souvent commettent des brigandages. Les habitants de l'Inde sont pour la plupart idolâtres ; parmi eux, il y en a qui se sont soumis à payer tribut aux musulmans et demeurent dans des bourgades. Ils ont à leur tête un magistrat musulman, placé par le percepteur ou l'eunuque ${ }^{676}$ dans le fief duquel la bourgade se trouve comprise. D’autres sont rebelles et résistent, retranchés dans les montagnes et exerçant le brigandage.

\section{RÉCIT D'UN COMBAT QUE NOUS EÛMES À LIVRER SUR CE CHEMIN, ET QUI FUT LE PREMIER AUQUEL J'ASSISTAI DANS L'INDE}

Lorsque nous voulûmes partir de la ville d'Abouher, le gros de la troupe en sortit au commencement du jour, p347 et j'y restai jusqu'à midi avec quelques-uns de mes compagnons; puis nous partîmes, au nombre de vingt-deux cavaliers, les uns arabes, les autres étrangers. Quatre-vingts idolâtres à pied, plus deux cavaliers, nous assaillirent dans la plaine. Mes camarades étaient doués de courage et de fermeté ; nous résistâmes donc très vigoureusement aux assaillants, nous

${ }^{676}$ Gibb indique que le mot khadim n’a pas ici le sens d'eunuque mais de «subordonné ». 
tuâmes un de leurs cavaliers et prîmes son cheval. Quant aux gens de pied, nous en tuâmes environ douze. Une flèche m'atteignit et une seconde atteignit mon cheval. Dieu daigna me préserver de tout mal ; car les traits lancés par les Indiens n’ont pas de force. Cependant, un de nos compagnons eut un cheval blessé ; nous l'indemnisâmes au moyen du cheval pris à l'idolâtre, et nous égorgeâmes ainsi l'animal blessé, qui fut mangé par les Turcs de notre troupe.

Nous portâmes les têtes des morts au château fort d'Abou Baqhar, et nous les y suspendîmes à la muraille. Ce fut au milieu de la nuit que nous arrivâmes au susdit château d'Abou Baqhar ${ }^{677}$.

Deux jours après en être partis, nous parvînmes à la ville d'Adjoûdéhen ${ }^{678}$, petite place appartenant au pieux cheïkh Férîd eddîn albedhâoûny ${ }^{679}$, celui-là même que le ${ }_{\mathrm{p} 348}$ cheïkh pieux, le saint Borhân eddîn alar'adj m’avait prédit, à Alexandrie, que je rencontrerais. Cela arriva : Dieu en soit loué ! Férîd eddîn a été le précepteur du roi de l'Inde, qui lui a fait cadeau de cette ville. Ce cheïkh est affligé de folie ; Dieu nous en préserve! Il ne prend la main de personne, et n'approche même de qui que ce soit. Lorsque son vêtement a touché celui de quelqu'un, il le lave. J'entrai dans son ermitage, je le vis et je lui offris les salutations du cheïkh Borhân eddîn ; il fut étonné et me dit : " Je ne suis pas digne de cela. » Je rencontrai ses deux excellents fils, savoir : Mo'izz eddîn ${ }^{680}$, qui était l'aîné, et qui, après la mort de

Le nom n'existe plus, mais il est cité dans une source comme un petit bourg avec un hospice à vingt miles d'Adjodhan (voir note suivante).

${ }^{678}$ Ibn Battûta inverse ici son itinéraire. Adjodhan se trouve entre Multan et Abohar. Lieu de traversée de la rivière Sutledj, la plus orientale du Pendjab, la ville fut nommée par l'empereur Akbar Pakpattan (le Bac sacré) en honneur du cheïkh Farid al-din (voir note suivante).

${ }^{679}$ Farid al-din Mas'ud, mort en 1271, était disciple du Qutb al-din Bakhtiyar Kaki (voir n. 103 ci-dessous) et fondateur de la lignée des cheïkhs tchishti d'Adjodhan. Son fils Badr al-din Sulaiman, mort en 1281, lui succéda et à celui-ci son fils Alam al-din Sulaiman, mort en 1334. C'est ce dernier qu'Ibn Battûta aurait pu rencontrer, à condition de retenir la date de 1333 pour son arrivée en Inde. C'est celui-ci qui était d'ailleurs précepteur spirituel du sultan Muhammad bin Tughluk. Il y aurait également confusion sur le nom d'origine de Farid al-din, qui ne serait pas né à Budaun, à l'est de Dihli, mais à Ghutaval près de Multan. Enfin, pour les prédictions de Burhan al-din al-Ar'adj, voir t. I, p. 100. 
son père, lui succéda dans la dignité du cheïkh ; et 'Alem eddîn ${ }^{681}$. Je visitai le tombeau de son aïeul, le pôle, le vertueux Férîd eddîn albédhâoûny, qui tirait son surnom de la ville de Bédhâoûn, capitale du pays de Sanbal ${ }^{682}$. Lorsque je voulus quitter Adjoûdehen, 'Alem eddîn me dit : " Il faut absolument que tu voies mon père. " Je le vis donc, dans un moment où il se trouvait sur sa terrasse. Il portait des vêtements blancs, et un gros turban garni d'un appendice qui retombait sur le côté. Il fit des vœux en ma faveur, et m’envoya du sucre ordinaire et du sucre candi.

\section{DE CEUX DES HABITANTS DE L’INDE QUI SE BRÛLENT VOLONTAIREMENT}

Au moment où je revenais de voir ce cheïkh, j’aperçus des gens qui couraient en toute hâte hors de notre campement, accompagnés de quelques-uns de mes ${ }_{\text {p349 }}$ camarades. Je leur demandai ce qui était arrivé ; ils m’annoncèrent qu'un Indien idolâtre était mort, qu'un brasier avait été allumé pour consumer son cadavre, et que sa femme se brûlerait en même temps que lui. Lorsque tous deux furent brûlés, mes compagnons revinrent et me racontèrent que la femme avait tenu le mort embrassé, jusqu'à ce qu'elle fût consumée avec lui. Par la suite, je voyais dans l'Inde des femmes idolâtres, toutes parées et montées sur un cheval ; la population, tant musulmane qu'idolâtre, les suivait ; les timbales et les trompettes résonnaient devant elles. Elles étaient accompagnées des brahmanes, qui sont les chefs des Indous. Lorsque cela se passe dans les États du sultan, ils demandent à ce prince la permission de brûler la femme du mort. Il leur accorde cette autorisation, et alors ils procèdent au brûlement de la veuve ${ }^{683}$.

Au bout d'un certain temps, il arriva que je me trouvai dans une ville dont la plupart des habitants étaient des idolâtres. Cette ville est nommée Amdjery ${ }^{684}$ et son prince était un musulman de la tribu des Sâmirah du Sind. Dans son voisinage habitaient les idolâtres rebelles.

\footnotetext{
681 Nommé cheïkh al-islam (chef mufti) à Delhi.

${ }^{682}$ District de Sambhal dans la région d’Uttar Pradesh, à l'est de Dihli (voir n. 61 ci-dessus).

683 Cette coutume célèbre est également signalée par Marco Polo.

${ }^{684}$ Amjhera, à douze miles à l'ouest de Dhar, dans le sud-ouest de la région de Madhya-Pradesh.
} 
Un certain jour, ils commirent des brigandages, et l'émir musulman se mit en marche pour les combattre. Ses sujets, tant musulmans qu'infidèles, marchèrent avec lui, et un combat acharné s'engagea, dans lequel périrent sept des derniers, dont trois étaient mariés ; leurs femmes convinrent entre elles de se brûler. Le brûlement de la femme, après la mort de son mari, est, chez les Indiens, un acte recommandé, mais non obligatoire. Si une veuve se brûle, les personnes de sa famille en retirent de la gloire, et sont célébrées pour leur fidélité à remplir leurs engagements. Quant à celle qui ne se livre pas aux flammes, elle revêt des habits grossiers et demeure chez ses parents, en proie à la misère et à ${ }_{\mathrm{p} 350}$ l'abjection, à cause de son manque de fidélité ; mais on ne la force pas à se brûler.

Or donc, quand les trois femmes que nous avons mentionnées furent convenues de se brûler, elles passèrent les trois jours qui devaient précéder ce sacrifice dans les chansons, les réjouissances et les festins, comme si elles avaient voulu faire leurs adieux à ce monde. De toutes parts les autres femmes venaient les trouver. Le matin du quatrième jour, on amena à chacune de ces trois femmes un cheval, sur lequel chacune monta, toute parée et parfumée. Dans la main droite elles tenaient une noix de cocotier, avec laquelle elles jouaient; et dans la gauche, un miroir, où elles regardaient leur figure. Les brahmanes les entouraient, et elles étaient accompagnées de leurs proches. Devant elles, on battait des timbales et l'on sonnait de la trompette et du clairon. Chacun des infidèles leur disait : «Transmettez mes salutations à mon père, ou à mon frère, ou à ma mère, ou à mon ami. » A quoi elles répondaient, en leur souriant : «Très bien. »

Je montai à cheval, avec mes compagnons, afin de voir de quelle manière ces femmes se comporteraient durant la cérémonie de leur brûlement. Nous marchâmes avec elles l'espace d'environ trois milles, et nous arrivâmes dans un endroit obscur, abondamment pourvu d'eau et d'arbres, et couvert d'un ombrage épais. Au milieu des arbres s'élevaient quatre pavillons, dans chacun desquels était une idole de pierre. Entre les pavillons se trouvait le bassin d'eau, au-dessus duquel l'ombre était extrêmement dense et les arbres fort pressés, de sorte que le soleil ne pouvait pénétrer au travers. On eût dit que ce lieu était une des vallées de l’enfer ; que Dieu nous en préserve ! 
Quand j'arrivai à ces tentes, les trois femmes mirent pied à terre près du bassin, s'y plongèrent, dépouillèrent les habits et les bijoux qu'elles portaient, et en firent des aumônes. On apporta à chacune d'elles une grossière étoffe de coton non façonnée, dont elles lièrent une partie sur leurs hanches et le reste sur leur tête et leurs ${ }_{\mathrm{p} 351}$ épaules. Cependant, des feux avaient été allumés, près de ce bassin, dans un endroit déprimé, et l'on y avait répandu de l'huile de cundjut ${ }^{685}$, c'est-à-dire de sésame qui accrut l'intensité des flammes. Il y avait là environ quinze hommes, tenant dans leurs mains des fagots de bois mince. Avec eux s'en trouvaient dix autres, portant dans leurs mains de grandes planches. Les joueurs de timbales et de trompettes se tenaient debout, attendant la venue de la femme. La vue du feu était cachée par une couverture que des hommes tenaient dans leurs mains, de peur que la malheureuse ne fût effrayée en l'apercevant. Je vis une de ces femmes qui, au moment où elle arriva près de cette couverture, l'arracha violemment des mains des gens qui la soutenaient, et leur dit, en souriant, des paroles persanes dont le sens était : « Est-ce que vous m'effrayerez avec le feu ? Je sais bien que c'est du feu ; laissezmoi. » Puis elle réunit ses mains au-dessus de sa tête, comme pour saluer le feu, et elle s'y jeta elle-même. Au même instant, les timbales, les clairons et les trompettes retentirent, et les hommes lancèrent sur elle le bois qu'ils portaient dans leurs mains. D'autres placèrent des planches par-dessus la victime, de crainte qu'elle ne se remuât. Des cris s'élevèrent, et la clameur devint considérable. Lorsque je vis ce spectacle, je fus sur le point de tomber de cheval. Heureusement, mes compagnons vinrent à moi avec de l'eau, ils me lavèrent le visage, et je m'en retournai.

Les habitants de l'Inde en usent de même en ce qui touche la submersion. Beaucoup d'entre eux se noient volontairement dans le Gange, où ils se rendent en pèlerinage. On y jette les cendres des personnes qui se sont brûlées. Les Indiens prétendent qu'il sort du Paradis. Lorsque l'un d'eux arrive sur ses bords avec le dessein de s'y noyer, il dit aux personnes présentes : « Ne vous imaginez pas que je me noie à cause de quelque chose qui me soit survenue ici-bas, ou faute d'argent. Mon ${ }_{\mathrm{p} 352}$ seul but est de m'approcher de Coçâî ${ }^{686}$. »

${ }_{685}^{685}$ Du persan kungud, sésame.

${ }^{686}$ Peut-être Krishna. 
Car tel est, dans leur langue, le nom de Dieu. Puis il se noie. Lorsqu'il est mort, les assistants le retirent de l'eau, le brûlent, et jettent ses cendres dans le même fleuve.

Mais revenons à notre premier propos. Or donc nous partîmes de la ville d'Adjoûdehen, et, après une marche de quatre jours, nous arrivâmes à la ville de Sarsaty ${ }^{687}$, qui est une place grande et fertile en riz. Ce riz est excellent, et on en exporte à la ville impériale de Dihly. Les revenus de Sarsaty sont très considérables. Le chambellan Chems eddîn Alboûchendjy m’en a appris le chiffre ; mais je l'ai oublié.

De Sarsaty, nous nous rendîmes à la ville de Hânsy ${ }^{688}$, qui est au nombre des cités les plus belles, les mieux construites et les plus peuplées. Elle est entourée d'une forte muraille dont le fondateur est, à ce que l'on prétend, un des principaux souverains idolâtres, appelé Toûrah, et touchant lequel les Indiens racontent des anecdotes et des histoires. C'est de cette ville que sont natifs Camâl eddîn Sadr Aldjihân ${ }^{689}$, grand kâdhi de l'Inde ; son frère Kothloû khân, précepteur du sultan, et leurs deux frères Nizhâm eddîn ${ }^{690}$ et Chems eddîn. Ce dernier s'est consacré au service de Dieu et a fixé son séjour à La Mecque, où il est mort.

Nous partîmes de Hânsy et arrivâmes, au bout de deux jours, à Maç'oûd Abâd ${ }^{691}$, à dix milles de la résidence impériale de Dihly. Nous y passâmes trois jours. Hânsy et Maç’oûd Abâd appartiennent à Almélic Almo’azzham, Hoûchendj, fils d’Almélic Camâl Gurg, p353 dont il sera fait mention ci-dessous. Or le mot gurg signifie, en persan, le loup.

Le sultan de l'Inde, vers la capitale duquel nous nous dirigions, était alors absent de Dihly, et se trouvait dans le canton de Canodje ${ }^{692}$, ville qui est séparée de la capitale par une distance de dix journées de marche. Mais il y avait alors à Dihly la sultane mère, ap-

687 Sarsati, abandonnée en 1726 et remplacée en 1837 par Sirsa dans la région de Haryana.

${ }^{688}$ Hansi fut conquise par les Ghaznavides en 1038.

689 Voir plus loin chap. 6, n. 1 ; pour Kutlu Khan, t. III, p. 82.

690 Voir plus loin t. III, p. 99.

691 Aujourd'hui en ruine, à proximité du bourg de Nadjafgarh.

692 Voir t. III, chap. 2, n. 28. 
pelée Almakhdoûmah Djihân. Le mot djihân, en persan, signifie la même chose que dounia en arabe ${ }^{693}$. Le vizir du sultan, Khodjah Djihân ${ }^{694}$, nommé aussi Ahmed, fils d'Ayâs, et qui était originaire de l'Asie Mineure, se trouvait également dans la capitale. Il envoya ses officiers au-devant de nous, et désigna, pour venir à la rencontre de chacun de nous en particulier, des personnages d'un rang analogue au nôtre. Parmi ceux qu'il choisit ainsi pour m'accueillir se trouvaient le cheïkh Albesthâmy, le chérîf Almâzenderâny, chambellan des étrangers, et le jurisconsulte 'Alâ eddîn Almoltâny, connu sous le nom de Konnarah. Cependant, il écrivit au sultan, pour lui annoncer notre arrivée, et expédia la lettre par l'addâouah, qui est la poste des courriers à pied, comme nous l'avons dit plus haut.

La lettre étant parvenue au sultan, le vizir reçut sa réponse durant les trois jours que nous passâmes à Maç'oûd Abâd. Au bout de ce temps, les kâdhis, les docteurs et les cheïkhs sortirent à notre rencontre, ainsi que plusieurs émirs. Les Indiens nomment ceux-ci mélics, rois ; et, dans tous les cas où les habitants de l'Égypte et d'autres contrées diraient l'émir, eux disent le roi. Le cheïkh Zhahîr eddîn azzendjâny, qui jouit d'un rang élevé auprès du sultan, sortit aussi à notre rencontre.

Nous partîmes ensuite de Ma'çoûd Abâd, et nous campâmes dans le voisinage d'une bourgade appelée ${ }_{\mathrm{p} 354}$ Pâlem ${ }^{695}$, qui appartient au seigneur, au chérif Nâcir eddîn Mothahher Alaouhéry ${ }^{696}$, un des commensaux du sultan, et une des personnes qui jouissent auprès de lui d'une entière faveur. Le lendemain, nous arrivâmes à la résidence impériale de Dihly, capitale de l'Inde, qui est une ville très illustre, considérable, réunissant la beauté et la force. Elle est entourée d'une muraille telle qu'on n'en connaît pas de semblable dans tout l'univers. C'est la plus grande ville de l'Inde, et même de toutes les contrées soumises à l'islamisme dans l’Orient.

-dire le monde.

${ }^{694}$ Il s’agirait en réalité d’un Hindou de la famille du radjah de Deogir, l'actuelle Dawlatabad, converti à l'islam.

695 A six miles au sud-est de la précédente étape.

696 Inconnu par ailleurs, mais déjà mentionné par Ibn Battûta, t. I, p. 365. 


\section{DESCRIPTION DE DIHLY}

Cette ville est d'une grande étendue, et possède une nombreuse population. Elle se compose actuellement de quatre villes voisines et contiguës, savoir :

Dihly proprement dite, qui est la vieille cité, construite par les idolâtres, et dont la conquête eut lieu l'année $584{ }^{697}$.

Sîry, aussi nommée le séjour du khalifat ${ }^{698}$ : c'est celle que le sultan donna à Ghiyâth eddîn, petit-fils du khalife abbâcide Almostancir, lorsqu'il vint le trouver. C'est là qu'habitaient le sultan 'Alâ eddîn et son fils Kothb eddîn, dont nous parlerons ci-après.

Toghlok Abâd ${ }^{699}$, ainsi appelée du nom de son fondateur, le sultan Toghlok, père du sultan de l'Inde, à la cour de qui nous nous rendions. Voici quel fut le motif ${ }_{\text {p35s }}$ pour lequel il la bâtit : un certain jour qu'il se tenait debout en présence du sultan Kothb eddîn, il lui dit: «O maître du monde, il conviendrait que tu élevasses ici une ville. » Le sultan lui répondit, par manière de plaisanterie : "Lorsque tu seras empereur, bâtis-la donc. » Il arriva, par la volonté de Dieu, que cet homme devint sultan; il construisit alors la ville en question et l'appela de son nom.

Djihân pénâh ${ }^{700}$, qui est destinée particulièrement à servir de demeure au sultan Mohammed châh, actuellement roi de l'Inde, et que nous venions trouver. C'est lui qui la bâtit; il avait eu l'intention de relier entre elles ces quatre villes par un seul et même mur ; il en édifia une partie, et renonça à élever le reste, à cause des grandes dépenses qu'aurait exigées sa construction.

${ }^{697}$ La citadelle du premier noyau de la ville, Laikot, fut construite vers 1052 par un chef Rajput. La ville fut conquise par Qutb al-din Aibak en 1192, et non en 584 (1188).

698 Quatre ou cinq kilomètres au nord-est de la vieille Dihli, fondée à l'origine comme camp militaire par Ala al-din Khaldji à partir de 1303.

699 A huit kilomètres au sud-est de la vieille ville, commencée par Ghiyath al-din Tughluk à partir de 1320.

700 Le Refuge du monde, construite par Muhammad bin Tughluk après 1325. Elle remplit l'espace entre la vieille Dihli et Sin. 


\section{DESCRIPTION DU MUR ET DES PORTES DE DIHLY}

Le mur qui entoure la ville de Dihly n'a pas son pareil. Il a onze coudées de largeur, et l'on y a pratiqué des chambres où demeurent des gardes de nuit et les personnes préposées à la surveillance des portes. Il se trouve aussi dans ces chambres des magasins de vivres que l'on appelle anbâr ${ }^{701}$, des magasins pour les munitions de guerre, et d'autres consacrés à la garde des mangonneaux et des ra'âdâh ${ }^{702}$. Les grains s'y conservent pendant longtemps sans altération et sans être exposés au moindre dégât. J'ai vu du riz que l'on retirait d'un de ces magasins ; la couleur en était devenue très noire ; mais il avait un goût agréable. J'ai vu aussi du millet que l'on retirait de cet endroit. Toutes ces provisions avaient été amassées par le sultan Balaban, p356 quatrevingt-dix ans auparavant. Les cavaliers et les fantassins peuvent marcher, à l'intérieur de ce mur, d'un bout de la ville à l'autre. On y a percé des fenêtres qui ouvrent du côté de la ville, et par lesquelles pénètre la lumière. La partie inférieure de cette muraille est construite en pierre, et la partie supérieure en briques. Les tours sont en grand nombre et très rapprochées l'une de l'autre.

La ville de Dihly à vingt-huit portes, ou comme les appellent les Indiens, derwâzehs. Parmi ces portes, on distingue: celle de Bedhâoun ${ }^{703}$, qui est la principale ; celle de Mindawy ${ }^{704}$, où se trouve le marché aux grains ; celle de Djoul ${ }^{705}$, près de laquelle sont situés les vergers ; celle de Châh, le Roi, ainsi appelée d'après un individu de ce nom ; celle de Pâlem ${ }^{706}$, nom par lequel on désigne une bourgade dont nous avons déjà parlé ; celle de Nedjîb, qui doit son nom à un personnage ainsi appelé ; celle de Camâl, qui se trouve dans le même cas ; celle de Ghaznah ${ }^{707}$, ainsi nommée d'après la ville de Ghaznah,

701 Terme persan : greniers.

702 Tonnantes : machines de siège, ballistes, plus légères que les mangonneaux.

703 A l'est, conduisant à Tughlukabad et au-delà à la ville de Badaun.

${ }^{704}$ Cf. le passage de l’historien Firishta : «Il nomma inspecteur du marché aux grains, que l’on appelle, dans la langue indienne, mandouy, le malic Kaboul. » Mandwi signifie à l'origine une espèce de grain.

${ }^{705}$ Du persan gul (rose), ouvrant donc apparemment vers les jardins.

706 Située au sud-ouest de la ville.

${ }^{707}$ Elle doit correspondre à la porte appelée aussi Randjit et fortifiée par Ala aldin Khaldji en même temps que la citadelle. 
située sur la frontière du Khorâçân : c'est en dehors de cette porte que sont situés le lieu où l'on célèbre la prière de la Rupture du jeûne, et plusieurs des cimetières; la porte d'Albedjâliçah ${ }^{708}$, l'extérieur de laquelle s'étendent les cimetières de Dihly. C'est là le nom d'un beau cimetière, où l'on construit des chapelles funéraires. Il y a inévitablement près de chaque tombeau un mihrâb, lors même que ce sépulcre est privé de chapelle funéraire. On plante dans ces cimetières des arbustes à ${ }_{\mathrm{p} 357}$ fleurs, tels que la tubéreuse, le reïboûl ${ }^{709}$, l'églantier, etc. Dans ce pays-là, il ne cesse pas d'y avoir des fleurs, dans quelque saison que ce soit.

\section{DESCRIPTION DE LA PRINCIPALE MOSQUÉE DE DIHLY}

La mosquée principale de Dihly est d'une grande étendue ${ }^{710}$ : ses murailles, son toit et son pavé sont en pierres blanches très admirablement taillées et très artistement reliées entre elles avec du plomb. Il n'entre pas dans sa construction une seule planche. Elle a treize dômes de pierre, et sa chaire est aussi bâtie en pierre ; elle a quatre cours. C'est au milieu de la mosquée que l'on voit une énorme colonne fabriquée avec un métal inconnu ${ }^{711}$. Un des savants indiens m'a dit qu'elle s'appelle Heft-djoûch, c'est-à-dire les Sept Métaux, et qu'elle est composée d'autant de métaux différents. On a poli cette colonne sur une étendue égale à la longueur de l'index, et cet endroit poli brille d'un grand éclat. Le fer ne laisse aucune trace sur cette colonne. Sa longueur est de trente coudées ; nous enroulâmes autour d'elle la toile d'un turban, et la portion de cette toile qui en fait le tour était de huit coudées.

\footnotetext{
${ }^{708}$ Ville située à l'est de Dihli dans le district de Kanauj.

709 Jasmin.

${ }^{710}$ Cette mosquée, appelée Quwwat al-Islam (la Force de l’islam), fut construite sur un temple hindou par Qutb al-din Aibak dès 1192. Elle fut agrandie au début du XIII ${ }^{\mathrm{e}}$ siècle par Iletmish et au début du XIV ${ }^{\mathrm{e}}$ par Ala al-din Khaldji. Son état actuel correspond aux constructions d'Iletmish.

${ }^{711}$ Cette colonne, datant du $\mathrm{IV}^{\mathrm{e}}$ siècle et ramenée d'un temple de Vishnu, a environ huit mètres de hauteur. Haft gush signifierait plutôt heptagonale ou de « sept tempéraments », par rapport à sa résistance à la rouille et aux intempéries.
} 
Près de la porte orientale de la mosquée, il y a deux très grandes idoles de cuivre, étendues à terre, et réunies ensemble par des pierres ${ }^{712}$. Tout individu qui entre dans ${ }_{\mathrm{p} 358}$ la mosquée ou qui en sort les foule aux pieds. L'emplacement de cette mosquée était un boudkhânah, c'est-à-dire un temple d'idoles ; mais, après la conquête de Dihly, il fut converti en mosquée. Dans la cour septentrionale de la mosquée se trouve le minaret ${ }^{713}$, qui n'a pas son pareil dans toutes les contrées musulmanes. Il est construit en pierres rouges, à la différence de celles qui composent le reste de l'édifice, lesquelles sont blanches ; de plus, les premières sont sculptées. Ce minaret est fort élevé ; la flèche qui le termine est en marbre blanc de lait, et ses pommes sont d'or pur ${ }^{714}$. L'entrée en est si large que les éléphants peuvent y monter. Quelqu'un en qui j'ai confiance m'a raconté avoir vu, à l'époque de la construction de ce minaret, un éléphant qui grimpait jusqu'en haut avec des pierres. C'est l'ouvrage du sultan Mo'izz eddîn, fils de Nâcir eddîn, fils du sultan Ghiyâth eddîn Balaban ${ }^{715}$. Le sultan Kothb eddîn voulut bâtir, dans la cour occidentale, un minaret encore plus grand $^{716}$; il en construisit environ le tiers, et mourut avant de l'avoir achevé. Le sultan Mohammed se proposa de le terminer ; mais il renonça à ce dessein, comme étant de mauvais augure. Le minaret en question est une des merveilles du monde, par sa grandeur et la largeur de son escalier, qui est telle que trois éléphants y montent de front. Le tiers qui en a été bâti égale en hauteur la totalité du minaret que nous avons dit être placé dans la cour du nord. J'y montai un $\mathrm{p}_{359}$ jour et j'aperçus la plupart des maisons de la ville, et je trouvai les murailles de celle-ci bien basses, malgré toute leur élévation. Les

712 Il s'agirait d'un lingam, image phallique de Vikramaditya rapportée d’Ujjain par Iletmish en 1234. Mais d'autres statues hindoues étaient périodiquement apportées pour être piétinées par les fidèles.

713 Le célèbre Qutb Minar, commencé par Qutb al-din Aibak, terminé sous Iletmish en 1229 et surélevé encore par Firuz Shah (1351-1388). Sa hauteur actuelle est de soixante-dix mètres.

714 Il s'agit d'ornements situés au sommet qui ont aujourd'hui disparu.

715 Il y a apparemment confusion entre Mu'izz al-din Kaiqubad, 1287-1290 (voir plus loin), et Mu'izz al-din Muhammad, sultan ghuride de Ghazna, mort en 1206 et suzerain d’Aibak. Ce dernier, qui a commencé le minaret, et y fit graver des éloges à son protecteur.

${ }^{716}$ La base de ce minaret, dont le diamètre est le double de celui de Qutb Minar, est toujours visible dans la cour nord, construite par Ala al-din Khaldji et non par son fils Qutb al-din Muhammad comme c’est indiqué ici. 
hommes placés au bas du minaret ne me paraissaient que des petits enfants. Il semble, à quiconque le considère d'en bas, que sa hauteur ne soit pas si considérable, à cause de la grandeur de sa masse et de sa largeur.

Le sultan Kothb eddîn avait formé aussi le projet de bâtir une mosquée cathédrale à Sîry, surnommé le séjour du khalifat ; mais il n’en termina que le mur faisant face à La Mecque et le mihrâb. Cette portion est construite en pierres blanches, noires, rouges et vertes ; et, si l'édifice avait été achevé, il n’aurait pas eu son pareil dans le monde. Le sultan Mohammed se proposa de le finir, et envoya des gens versés dans l'art de bâtir, afin qu'ils évaluassent à combien s'élèverait la dépense. Ils prétendirent qu'on dépenserait, pour son achèvement, trente-cinq lacs. Le sultan y renonça, trouvant cette dépense trop considérable. Un de ses familiers m’a raconté qu'il ne se désista pas de son projet pour ce motif-là, mais qu'il en regarda l'exécution comme de mauvais augure, vu que le sultan Kothb eddîn avait été tué avant de terminer cet édifice.

\section{DESCRIPTION DES DEUX GRANDS BASSINS QUI SE TROUVENT À L’EXTÉRIEUR DE DIHLY}

En dehors de cette ville se voit le grand bassin appelé du nom du sultan Chems eddîn Lalmich $^{717}$, et où les habitants de Dihly s'approvisionnent d'eau à boire. Il est situé dans le voisinage du lieu où se fait la prière des grandes fêtes. Il est alimenté par l'eau des pluies ; sa longueur est d'environ deux milles, et sa largeur moindre de moitié. Sa face occidentale, du côté du moçallâ, p360 est construite en pierres disposées en forme d'estrades, les unes plus hautes que les autres ; au-dessous de chacune sont des degrés, à l'aide desquels on descend jusqu'à l'eau. A côté de chaque estrade est un dôme de pierre, où se trouvent des sièges pour les gens qui veulent se divertir et s'amuser. Au milieu de l'étang s'élève un grand dôme en pierres sculptées et haut de deux étages. Lorsque l'eau est abondante dans le

717 C'est le bassin appelé Hawdh Shamsi, qui se trouve au sud-ouest de la vieille ville, à la limite du faubourg de Mihrawli. Il fut construit par Shams al-din Iletmish. 
bassin, on ne peut atteindre cet édifice, si ce n'est avec des barques. Quand, au contraire, il y a peu d'eau, les gens y entrent. A l'intérieur est une mosquée, et la plupart du temps on y trouve des fakîrs voués au service de Dieu et qui ne mettent leur confiance qu'en lui. Lorsque l'eau est tarie dans cet étang, on y cultive des cannes à sucre, des citrouilles, des concombres, des pastèques et des melons. Ces derniers sont extrêmement doux, mais d'un petit volume.

Entre Dihly et le séjour de khalifat se trouve le bassin impérial ${ }^{718}$, lequel est plus grand que celui du sultan Chems eddîn. Sur ses côtés s'élèvent environ quarante dômes ; les joueurs d'instruments habitent tout autour, et l'emplacement qu'ils occupent s'appelle Tharb-Abâd, le Séjour de l'allégresse. Ils ont là un marché qui est un des plus grands qui existent, une mosquée cathédrale et un grand nombre d'autres mosquées. On m'a raconté que, durant le mois de ramadhân, les chanteuses qui habitent en cet endroit récitent en commun, dans ces mosquées, la prière dite térâwîh. Des imâms président à cette prière, et elles y assistent en grand nombre. Les chanteurs en usent de même. J'ai vu les musiciens à la noce de l'émir Seïf eddîn Ghadâ, fils de Mohanna ${ }^{719}$; chacun d'eux avait sous ses genoux un tapis à prier, et quand il entendait l'appel à la prière, il se levait, faisait ses ablutions et priait. p361

\section{DESCRIPTION DE QUELQUES-UNS DES LIEUX DE PÈLERINAGE À DIHLY}

On remarque parmi ces endroits :

Le tombeau du pieux cheïkh Kothb eddîn Bakhtiâr Alca’ky ${ }^{720}$, Ce tombeau est l'objet de bénédictions manifestes, et jouit d'une grande vénération. Le motif pour lequel ce cheïkh fut surnommé Alca’ky, c'est que, quand des gens chargés de dettes venaient le trouver pour se plaindre de leur pauvreté ou de leur indigence, ou quand avaient re-

718 Le Hawdh a1-Khass, situé à deux kilomètres à l'est de Sin.

719 Pour Mohanna bin Isa, voir t. I, chap. 3, n. 143.

${ }^{720}$ Qutb al-din Bakhtiyar al kaki, mort en 1236, était le disciple de Mawdud alTchishti (voir chap. 4, n. 124) et son successeur à Dihli. Il fut également maître de Farid al-din Mas’ud, fondateur de la lignée tchishti d’Adjodhan (voir n. 62 ci-dessus). Son tombeau, situé dans le faubourg de Mihrawli, est toujours objet de vénération. 
cours à lui des individus ayant des filles et ne pouvant trouver de quoi leur fournir un trousseau au moment de les faire conduire près de leurs époux, le cheïkh donnait à ceux qui s'adressaient à lui un biscuit d'or ou d'argent : c'est pourquoi il fut connu par le surnom d'Alca'ky, ou l'Homme aux biscuits.

Le mausolée du vertueux docteur Noûr eddîn Alcorlâny.

Le sépulcre du docteur 'Al eddîn Alkermâny ${ }^{721}$, ainsi appelé d'après la province de Kermân. Ce tombeau jouit de bénédictions manifestes et brille de la plus vive lumière. L'endroit qu'il occupe indique la kiblah, ou la direction du lieu de la prière, et il s'y trouve un grand nombre de sépultures de saints personnages. Que Dieu nous fasse profiter de leurs mérites. p362

DE QUELQUES-UNS DES SAVANTS ET DES HOMMES DE BIEN DE DILHY

Nous citerons parmi eux :

Le cheïkh pieux et savant Mahmoûd Alcobbâ ${ }^{722}$ il est au nombre des principaux saints, et le vulgaire prétend qu'il dispose de richesses surnaturelles, car il n'en possède point d'apparentes, et cependant il donne à manger à tout-venant, et distribue de l'or, de l'argent et des habits. Il a accompli de nombreux miracles, et s'est ainsi rendu célèbre. Je l'ai vu à plusieurs reprises, et j'ai eu part à ses bénédictions.

Le cheïkh pieux et savant 'Alâ eddîn Annîly ${ }^{723}$. On dirait que ce surnom lui vient du nom du Nil, le fleuve de l'Égypte. Dieu sait le mieux ce qu'il en est. Il a été un des disciples du cheïkh savant et vertueux Nizhâm eddîn Albédhâoûny. Il prêche les fidèles tous les vendredis, et un grand nombre d'entre eux font pénitence en sa présence,

${ }^{721}$ La famille Kirmani, notables religieux, descendants de Husain fils d'Ali, était connue à Dihli. Il s’agit peut-être de Muhammad bin Mahmud, mort en 1311.

722 Il s’agirait de Nasir al-din Mahmud, connu sous le nom de Tciragh-i Dihli (la Lumière de Dihli), mort en 1356, successeur de Nizam al-din Awliya (voir chap. 6, n. 83). Kobba signifie bossu.

723 Natif d'Oudh il fut aussi un des disciples de Nizam al-din Awliya et mourut à Dihli en 1361. 
rasent leur tête, se lamentent à l'envi les uns des autres, et quelquesuns même s'évanouissent.

\section{ANECDOTE}

Je l'ai vu un certain jour pendant qu'il prêchait. Le lecteur du Coran lut, en sa présence, ces versets : " O hommes, craignez votre Seigneur. Certes, que le tremblement de terre, à l'heure de la résurrection, sera quelque chose de terrible ? Le jour où vous le verrez, chaque nourrice oubliera son nourrisson, et chaque femme enceinte avortera. On verra les hommes ivres. Non, ils ne seront pas ivres ; mais le châtiment infligé par Dieu ${ }_{\mathrm{p} 363}$ est terrible; il les étourdira ${ }^{724}$ " Le docteur 'Alâ eddîn répéta ces paroles, et un fakîr, placé dans un des coins de la mosquée, poussa un grand cri. Le cheïkh répéta le verset ; le fakîr cria une seconde fois et tomba mort. Je fus au nombre de ceux qui prièrent sur son corps et qui assistèrent à ses obsèques.

Le cheïkh pieux et savant Sadr eddîn Alcohrâny, qui jeûnait continuellement, et restait debout durant la nuit ; il avait renoncé à tous les biens de ce monde, et les avait repoussés loin de lui. Son vêtement consistait en un manteau court sans manches. Le sultan et les grands de l'État le visitaient, mais souvent il se dérobait à leurs visites. Le sultan désira lui constituer en fief des villages, avec le revenu desquels il pût donner à manger aux pauvres et aux étrangers ; mais il refusa. Dans une des visites qu'il lui fit, l'empereur lui apporta dix mille dînârs, qu'il n'accepta pas. On raconte qu'il ne rompt le jeûne qu'au bout de trois jours ; qu'on lui fit des représentations à ce sujet, et qu'il répondit : «Je ne romprai le jeûne que quand j’y serai forcé par une mort imminente. »

L'imâm pieux, savant et dévot, tempérant, humble, la perle de son époque, la merveille de son siècle, Camâl eddîn 'Abd Allah Alghâry, ainsi surnommé d'après une caverne qu'il habitait proche de Dihly, dans le voisinage de la zâouïah du cheïkh Nizhâm eddîn Albédhâouny. Je l'ai visité à trois différentes reprises dans cette caverne.

${ }^{724}$ Coran, XXII, I-2, sauf la dernière phrase : « Il les étourdira ». 


\section{MIRACLE DE CET IMÂM}

J'avais un jeune esclave qui s'enfuit et que je retrouvai en la possession d'un Turc. Je résolus de le retirer des mains de celui-ci ; mais le cheïkh me dit : "Cet esclave ne te convient point ; ne le reprends pas. » Or le p364 Turc était disposé à un accommodement. Je m’arrangeai avec lui, moyennant cent dînârs qu'il me paya, et je lui laissai l'esclave. Six mois s'étant écoulés, ce dernier tua son maître. On l'amena au sultan, qui prescrivit de le livrer aux enfants de la victime, lesquels le massacrèrent. Lorsque j'eus été témoin de ce miracle de la part du cheïkh, je me retirais près de lui, et me consacrai à son service, renonçant au monde, et donnant tout ce que je possédais aux pauvres et aux malheureux. Je séjournai près de lui un certain temps, et je le voyais jeûner dix et vingt jours de suite, et rester debout la plus grande partie de la nuit. Je ne cessai de demeurer avec lui, jusqu'à ce que le sultan m'envoyât chercher. Je me rattachai alors au monde ${ }^{725}$ (Puisse Dieu m'accorder une bonne fin !) Si Dieu le veut, je raconterai cela par la suite, ainsi que les détails de mon retour au siècle.

Retour à la Table des Matières

725 Voir t. III, p. 147. 


\section{L'histoire du sultanat de Dihli}

$\underline{\text { Retour à la Table des Matières }}$

RÉCIT DE LA CONQUÊTE DE DIHLY

ET NOTICE SUR LES ROIS QUI S’Y SUCCÉDÈRENT

Le jurisconsulte, l'imâm très savant, le grand kâdhi de l'Inde et du Sind, Camâl eddîn Mohammed, fils de Borhân eddîn, de Ghaznah ${ }^{726}$, surnommé Sadr Aldjihân, m'a raconté que la ville de Dihly fut conquise sur les infidèles dans l'année $5844^{727}$. J'ai lu cette même date écrite sur le mihrâb de la grande mosquée de cette ville.

Le personnage déjà nommé m’a appris aussi que Dihly fut prise par l'émir Kothb eddîn Aïbec ${ }^{728}$, qui était surnommé Sipâh Sâlâr, ce qui signifie général des armées. C’était un des esclaves du sultan vénéré Chihâb eddîn Mohammed, fils de Sâm le Ghouride, roi de Ghaznah et du Khorâçân ${ }^{729}$ et qui s'était emparé du ${ }_{\text {p366 }}$ royaume d’Ibrâhîm ${ }^{730}$, fils du sultan belliqueux Mahmoûd ibn Subuctekîn, lequel commença la conquête de l'Inde.

${ }^{726}$ Chef cadi des mameluks (esclaves) de l'armée de Dihli.

${ }^{727}$ La plus ancienne inscription de la mosquée est datée 587 (1191-1192), ce qui correspond à la date effective de la conquête de Dihli.

${ }^{728}$ Qutb al-din Aibak, esclave et ensuite lieutenant-général du souverain ghuride de Ghazna, accéda à une indépendance de fait après la mort de son protecteur, devenant ainsi le premier souverain du sultanat de Dihli (1206-1210).

Shihab al-din Muhammad fut nommé vice-roi à Ghazna en 1173 par son frère Ghiyath al-din Muhammad, souverain ghuride installé à Hérat (1163-1203). Il entreprit la conquête du nord de l'Inde et après la mort de son frère hérita de l'ensemble des possessions ghurides. A sa mort, en 1206, son empire se disloqua et les possessions indiennes restèrent aux mains d'Aibak.

730 Ibrahim, souverain ghaznavide (1059-1099), était petit-fils et neuvième successeur de Mahmud de Ghazna (voir chap. 4, n. 160). Ghazna fut conquise par les Ghurides au cours du règne de Bahram (1118-1152), et les derniers Ghaznavides ont survécu à Lahore jusqu'en 1186. 
Le susdit sultan Chihâb eddîn avait envoyé l'émir Kothb eddîn avec une armée considérable. Dieu lui ouvrit la ville de Lahaour ${ }^{731}$, où il fixa sa résidence. Son pouvoir devint considérable ; il fut calomnié près du sultan, et les familiers de ce prince lui inspirèrent l'idée qu'il voulait se déclarer souverain de l'Inde, et qu'il était déjà en pleine révolte. Cette nouvelle parvint à Kothb eddîn ; il partit en toute hâte, arriva de nuit à Ghaznah, et se présenta devant le sultan, à l'insu de ceux qui l'avaient dénoncé à ce monarque. Le lendemain, Chihâb eddîn s'assit sur son trône, et fit asseoir en dessous Aïbec, de sorte qu'il ne fut pas visible. Les commensaux et les courtisans qui l'avaient calomnié arrivèrent, et lorsqu'ils eurent tous pris place le sultan les questionna touchant Aïbec. Ils lui répétèrent que ce général s'était révolté, et dirent : « Nous savons avec certitude qu'il prétend à la royauté. » Alors le sultan frappa de son pied le trône, battit des mains et s'écria : «O Aïbec ! » « Me voici », répondit celui-ci, et il se montra à ses dénonciateurs. Ceux-ci furent confondus, et, dans leur effroi, ils s'empressèrent de baiser la terre. Le sultan leur dit : « Je vous pardonne cette faute ; mais prenez garde de recommencer à parler contre Aïbec ${ }^{732}$. » Puis il ordonna à celui-ci de retourner dans ${ }_{\mathrm{p} 367}$ l'Inde. Aïbec obéit, et prit la ville de Dihly et d'autres encore. La religion musulmane a été florissante dans ce pays-là jusqu’à présent. Quant à Kothb eddîn, il y séjourna jusqu'à ce qu'il mourût.

731 Lahore fut conquise par Ghiyath al-din Muhammad le Ghuride sur le dernier Ghaznavide, Khusrav Malik, en 1186. Il reste toutefois que Lahore fut le siège du pouvoir de l'Inde musulmane avant la prise de Dihli.

732

Cette anecdote ne se trouve pas dans les autres sources, mais Aibak, après un raid fructueux dans le Gudjarat en 1195 fut invité par Ghiyath al-din Muhammad à se rendre à Ghazna où il resta pendant près d'une année. Cette visite est toutefois postérieure à la prise de Dihli. 
HISTOIRE DU SULTAN CHEMS EDDÎN LALMICH ${ }^{733}$

Ce prince fut le premier qui régna dans la ville de Dihly avec un pouvoir indépendant. Avant son avènement au trône, il avait été l'esclave de l'émir Kothb eddîn Aïbec, le général de son armée et son lieutenant. Quand Kothb eddîn fut mort, il se rendit maître de l'autorité souveraine, et convoqua la population, afin qu'elle lui prêtât serment. Les jurisconsultes vinrent le trouver, ayant à leur tête le grand kâdhi alors en fonctions, Wedjîh eddîn Alcâçâny. Ils entrèrent dans la pièce où il était et s'assirent devant lui. Quant au kâdhi, il s'assit à son côté, selon la coutume. Le sultan comprit de quoi ils voulaient l'entretenir ; il souleva le coin du tapis sur lequel il était accroupi, et leur présenta un acte qui comprenait son affranchissement. Le kâdhi et les jurisconsultes le lurent et prêtèrent tous à Lalmich le serment d'obéissance ; il devint donc souverain absolu, et son règne dura vingt ans ${ }^{734}$. Il était juste, pieux et vertueux. Parmi ses actions mémorables, il convient de citer son zèle à redresser les torts et à rendre justice aux opprimés. Il ordonna que quiconque avait éprouvé une injustice revêtît un habit de couleur. Or tous les habitants de l'Inde portent des vêtements blancs. Toutes les fois qu'il donnait audience à ses sujets ou qu'il se promenait à cheval, s'il voyait quelqu'un vêtu d'un ${ }_{\mathrm{p} 368}$ habit de couleur, il examinait sa plainte, et s'occupait à lui rendre justice contre son oppresseur. Mais il se lassa d'agir ainsi, et se dit: «Quelques hommes souffrent des injustices pendant la nuit ; je veux en hâter le redressement. » En conséquence, il éleva à la porte de son palais deux lions de marbre, placés sur deux tours qui se trouvaient en cet endroit. Ces lions avaient au cou une chaîne de fer où pendait une grosse sonnette. L'homme opprimé venait de nuit et agitait la sonnette ; le sultan entendait le bruit, examinait l'affaire sur-le-champ et donnait satisfaction au plaignant ${ }^{735}$.

733 La véritable orthographe du nom serait Iletmish. A la mort à Lahore (d'une chute de cheval) d'Aibak en 1210, son entourage nomma comme souverain son fils, Aram Shah, tandis que les milieux de Dihli élisaient Shams al-din Iletmish, ancien esclave d'Aibak. Aram Shah, vaincu en 1211. disparut de la scène.

1211-29/4/1236.

${ }^{735}$ Les mêmes faits sont attribués à Anushirwan, dit le Juste, roi sassanide, et à d'autres souverains. 
A sa mort, le sultan Chems eddîn laissa trois fils : Rocn eddîn, qui lui succéda ; Mo’izz eddîn et Nâcir eddîn ; et une fille appelée Radhiyah, laquelle était sœur germaine de Mo’izz eddîn. Rocn eddîn régna après lui, ainsi que nous l'avons dit ${ }^{736}$.

\section{HISTOIRE DU SULTAN ROCN EDDÎN, FILS DU SULTAN CHEMS EDDÎN}

Lorsque Rocn eddîn eut été reconnu sultan, après la mort de son père, il inaugura son règne par un traitement injuste envers son frère Mo'izz eddîn, qu'il fit périr ${ }^{737}$. Radhiyah était sœur germaine de ce malheureux prince, et elle reprocha sa mort à Rocn eddîn. Celui-ci médita de l'assassiner. Un certain vendredi, il sortit du palais pour assister à la prière ${ }^{738}$. Radhiyah monta sur la ${ }_{\mathrm{p} 369}$ terrasse du vieux palais attenant à la grande mosquée, et que l'on appelait DaouletKhâneh, la Maison du bonheur ${ }^{739}$. Elle était revêtue des habits que portaient ceux qui avaient éprouvé des injustices.

Dans ce costume, elle se présenta au peuple, et lui parla de dessus la terrasse. "Mon frère, lui dit-elle, a tué son frère, et veut aussi me faire périr. » Puis elle rappela le règne de son père et les bienfaits qu'il avait prodigués au peuple. Là-dessus, les assistants se portèrent en tumulte vers le sultan Rocn eddîn, qui se trouvait alors dans la mosquée, se saisirent de lui, et l'amenèrent à Radhiyah. Celle-ci leur dit : «Le meurtrier sera tué »; et ils le massacrèrent, en représailles du meurtre de son frère. Le frère de ces deux princes, Nâcir eddîn, était

${ }^{736}$ Iletmish avait désigné comme successeur sa fille Raziya mais les émirs, ne pouvant se faire à l'idée d'élire une femme à la tête du royaume, préférèrent son fils Rukn al-din Firuz qui régna jusqu'au 9 novembre de la même année 1236.

${ }^{737}$ Rukn al-din n’a pas eu le temps de tuer aucun de ses frères. Mu’izz al-Din succédera à Raziya en 1240.

${ }^{738}$ Rukn al-din était sorti de Dihli pour marcher contre des gouverneurs révoltés quand, à la suite de rumeurs concernant l'assassinat imminent de Raziya par la reine mère, le peuple de la ville se révolta et la porta sur la trône. Rukn al-din, abandonné par ses troupes, fut saisi et tué.

La maison du pouvoir. 
encore dans l'enfance : aussi le peuple s'accorda-t-il à reconnaître comme souveraine Radhiyah.

\section{DE L’IMPÉRATRICE RADHIYA}

Lorsque Rocn eddîn eut été tué, les troupes convinrent de placer sur le trône sa sœur Radhiyah. Elles la proclamèrent souveraine ; et cette princesse régna avec une autorité absolue, durant quatre années. Elle montait à cheval à la manière des hommes, armée d'un arc et d'un carquois, entourée de courtisans, et elle ne voilait pas son visage. Dans la suite, elle fut soupçonnée d'avoir commerce avec un des ses esclaves, abyssin de naissance ${ }^{740}$, et le peuple décida de la déposer et de lui donner un époux. En conséquence, elle fut déposée et p370 mariée à un de ses proches, et son frère Nâcir eddîn devint maître de l'autorité ${ }^{741}$.

\section{HISTOIRE DU SULTAN NÂCIR EDDÎN, FILS DU SULTAN CHEMS EDDÎN}

Après la déposition de Radhiyah, son frère cadet Nâcir eddîn monta sur le trône et posséda quelque temps l'autorité souveraine ; ensuite, Radhiyah et son mari se révoltèrent contre lui ${ }^{742}$, montèrent à cheval, accompagnés de leurs esclaves et des malfaiteurs qui voulurent les suivre, et se préparèrent à le combattre. Nâcir eddîn sortit de Dihly avec son esclave et lieutenant Ghiyâth eddîn Balaban, celui-là même qui devint maître du royaume après lui. Le combat s’engagea, l’armée

740 La scène politique à Dihli était dominée à l’époque par les « quarante » familles des émirs turcs opposés depuis le début à l'avènement de Raziya. Celle-ci, pour contrebalancer leur pouvoir, favorisa l'accession du maître des écuries, l'Africain Djalal al-din Yaqut. D’où scandale supplémentaire qui mena à sa déposition.

741

Il faut lire Mu’izz al-din Bahram (1240-1242) ; lui succédera un fils de Rukn al-din, Ala al-din Mas'ud (1242-1246), et Nasir al-din Mahmud ne viendra qu’après (1246-1266).

${ }^{742}$ La révolte contre Raziya fut menée par un gouverneur, Ikhtiyar al-din Altuniya, qui devint par la suite geôlier de l'ex-souveraine. Or, par la suite, Ikhtiyar al-din, écarté du pouvoir instauré à Dihli, sortit Raziya de la prison, se maria avec elle pour acquérir une légitimité et marcha sur Dihli. Leur armée fut battue le 13 octobre 1240 et Raziya fut assassinée le lendemain par des Hindous. 
de Radhiyah fut mise en déroute, et elle-même prit la fuite ; elle fut surprise par la faim et accablée de fatigue ; en conséquence, elle se dirigea vers un laboureur qu'elle vit occupé à cultiver la terre, et lui demanda quelque chose à manger. Il lui donna un morceau de pain, qu'elle dévora, après quoi le sommeil s'empara d'elle. Or Radhiyah était revêtue d'un habit d'homme ; lorsqu'elle fut endormie, le laboureur la considéra, et vit, sous ses vêtements, une tunique brodée d'or et de perles ; il s'aperçut que c'était une femme, la tua, la dépouilla, chassa son cheval, et l'ensevelit dans le champ qui lui appartenait. Puis il prit une partie des vêtements de la princesse, et se rendit au marché, afin de les vendre. Les marchands conçurent des soupçons à p371 son égard, et l'amenèrent au chihneh ${ }^{743}$, c'est-à-dire au magistrat de police, qui lui fit infliger la bastonnade. Le misérable confessa qu'il avait tué Radhiyah et indiqua à ses gardiens le lieu où il l'avait ensevelie. Ils déterrèrent son corps, le lavèrent et l'enveloppèrent dans un linceul ; puis il fut remis en terre au même endroit, et l'on construisit une chapelle funéraire. Son tombeau est actuellement visité par des pèlerins, et regardé comme un lieu de sanctification. Il est situé sur le bord du grand fleuve appelé Djoûn ${ }^{744}$, une parasange de la ville de Dihly.

Après le meurtre de sa sœur, Nâcir eddîn resta seul maître du royaume, et régna paisiblement durant vingt ans. C’était un souverain pieux ; il copiait des exemplaires du Livre illustre, les vendait, et se nourrissait avec le prix qu'il en retirait ${ }^{745}$. Le kâdhi Camâl eddîn m’a fait voir un Coran copié de sa main, artistement et élégamment écrit. Dans la suite, son lieutenant Ghiyâth eddîn Balaban le tua et régna après lui ${ }^{746}$. Ce Balaban eut une aventure extraordinaire que nous raconterons.

743 Le mot désigne en général le gouverneur militaire de la ville, lequel se trouve aussi à la tête de la police.

744 La Yamouna.

745 Nasir al-din était un sage roi fainéant, de surcroît calligraphe, ce qui donna naissance à la légende, également mentionnée par d'autres sources.

746 Ghiyath al-din Balban, acheté en 1233 par Iletmish, fut chambellan de Nasir al-din depuis le début du règne de celui-ci en 1246 et vrai maître du royaume. Toutefois, Nasir al-din semble être mort de mort naturelle le 18 février 1266. Balban lui succéda et régna jusqu’à sa mort en 1287. 


\section{HISTOIRE DU SULTAN GHIYÂTH EDDÎN BALABAN}

Lorsque Balaban eut tué son maître, le sultan Nâcir eddîn, il régna, avec un pouvoir absolu, pendant vingt années, avant lesquelles il avait été le lieutenant de son prédécesseur durant un pareil espace de temps. Il fut au ${ }_{\mathrm{p} 372}$ nombre des meilleurs sultans, juste, doux ${ }^{747}$ et vertueux. Une de ses actions généreuses, c'est qu'il fit bâtir une maison à laquelle il donna le nom de Séjour de la sûreté. Tous les débiteurs qui y entraient voyaient acquitter leur dette, et quiconque s'y réfugiait par crainte y était en sûreté. Si quelqu'un s'y retirait après avoir tué une autre personne, le sultan désintéressait à sa place les amis du mort ; et si c'était quelque délinquant, il donnait satisfaction à ceux qui le poursuivaient. C'est dans cette maison qu'il fut enseveli, et j’y ai visité son tombeau $^{748}$.

\section{AVENTURE EXTRAORDINAIRE DE BALABAN}

On raconte qu'un fakir de Bokhâra y vit ce Balaban, qui était de petite taille et d'un extérieur chétif et méprisable. Il lui dit : «O petit Turc ! », ce qui était une expression indiquant du mépris. Balaban répondit : "Me voici, ô mon maître. » Cette parole plut au fakir. " Achète pour moi, reprit-il, de ces grenades », et il lui montrait des grenades qui étaient exposées en vente sur le marché. " Très bien », répliqua Balaban ; et tirant quelques oboles, qui étaient tout ce qu'il possédait, il acheta plusieurs de ces grenades. Lorsque le fakir les eut reçues, il lui dit: " Nous te donnerons le royaume de l'Inde. » Balaban baisa sa propre main (c'est là une manière de saluer) et répondit : « J'accepte et je suis content. » Cette parole se fixa dans son esprit. Cependant, il arriva que le sultan Chems eddîn Lalmich envoya un marchand, afin qu'il lui achetât des esclaves à Samarkand, à Bokhâra et à Termedh. Cet individu fit l'acquisition de cent esclaves, parmi lesquels se trouvait Balaban. Lorsqu'il se présenta avec eux devant le sultan, $\mathrm{p}_{373}$ tous plurent à ce prince, hormis Balaban, à cause de ce que nous avons dit de son extérieur méprisable. « Je n’accepte pas celui-

${ }^{747}$ La douceur de Balban est loin d'être confirmée par les sources, surtout en ce qui concerne la répression de la révolte du Bengale en 1280.

748

Il existe toujours, au sud-est de la vieille ville. 
ci », s'écria-t-il. L'esclave lui dit : «O maître du monde, pour qui astu acheté ces serviteurs ? » L'empereur se mit à rire et répondit : « Je les ai achetés pour moi-même. » Balaban reprit : "Achète-moi pour l'amour de Dieu. - Très bien ", répliqua le sultan ; il l'accepta, et le mit au nombre de ses esclaves.

Balaban fut traité avec mépris et placé parmi les porteurs d'eau. Les gens versés dans la connaissance de l'astrologie disaient au sultan Chems eddîn : " Un de tes esclaves enlèvera le royaume à ton fils et s'en emparera. » Ils ne cessaient de lui répéter cela ; mais il ne faisait pas attention à leurs discours, à cause de sa piété et de sa justice. Enfin on rapporta cette prédiction à la grande princesse, mère des enfants du sultan, et elle la lui répéta. Cela fit alors impression sur son esprit ; il manda les astrologues et leur dit: "Reconnaîtrez-vous, lorsque vous le verrez, l'esclave qui doit enlever le royaume à mon fils ? » Ils répondirent : "Oui, nous avons un indice qui nous le fera connaître." Le sultan ordonna de faire paraître ses esclaves, et s'assit pour les passer en revue. Ils parurent devant lui, classe par classe ; les astrologues les regardaient et disaient : " Nous ne le voyons pas encore. » Cependant, une heure de l'après-midi arriva, et les porteurs d'eau se dirent les uns aux autres : "Nous avons faim ; rassemblons quelques pièces de monnaie, et envoyons un de nous au marché afin qu'il nous achète de quoi manger. » Ils réunirent donc des drachmes, et firent partir avec elles Balaban ; car il n’y avait parmi eux personne qui fût méprisé plus que lui. Il ne trouva pas dans le marché ce que voulaient ses camarades ; en conséquence, il se dirigea vers un autre marché ; mais il tarda, et lorsque ce fut le tour des porteurs d'eau d'être passés en revue, il n'était pas encore revenu. Ses camarades prirent son outre et son pot à l'eau, les placèrent sur l'épaule d'un jeune garçon, et présentèrent celui-ci ${ }_{\mathrm{p} 374}$ comme si c'était Balaban. Lorsqu'on appela le nom de Balaban, le jeune garçon passa devant les astrologues, et la revue fut terminée sans qu'ils vissent la figure qu'ils cherchaient. Balaban arriva après l'achèvement de la revue, car Dieu voulait que son destin s’accomplît.

Par la suite, les nobles qualités de l'esclave se révélèrent, et il fut fait chef des porteurs d'eau ; puis il entra dans l'armée, et devint ensuite émir. Le sultan Nâcir eddîn, avant de parvenir au trône, épousa 
sa fille, et lorsqu'il fut devenu maître du royaume, il le fit son lieutenant ${ }^{749}$. Balaban remplit les fonctions de cette charge pendant vingt années ; après quoi, il tua son souverain et demeura maître de l'empire durant vingt autres années, ainsi qu'il a été dit plus haut. Il eut deux fils, dont l'un était le khân martyr, son successeur désigné et vice-roi dans le Sind, où il résidait dans la ville de Moultân. Il fut tué dans une guerre qu'il eut à soutenir contre les Tatars ${ }^{750}$, et laissa deux fils, Keï Kobâd et Keï Khosrew ${ }^{751}$. Le second fils du sultan Balaban était appelé Nâcir eddîn et était vice-roi pour son père dans les provinces de Lacnaouty ${ }^{752}$ et de Bengale.

Lorsque le khân martyr eut succombé pour la foi, le sultan Balaban déclara héritier du trône le fils du défunt, Keï Khosrew, et le préféra à son propre fils Nâcir eddîn. Celui-ci avait lui-même un fils qui habitait à Dihly, près de son aïeul, et qui était appelé Mo'izz eddîn. C'est ce dernier qui, après la mort de son aïeul, p375 et, du vivant même de son père, devint maître du trône, avec des circonstances extraordinaires, que nous raconterons.

HISTOIRE DU SULTAN Mo’'IZZ EDDÎN, FILS DE NÂCIR EDDÎN, FILS DU SULTAN GHIYÂTH EDDÎN BALABAN

Le sultan Ghiyâth eddîn mourut durant la nuit, tandis que son fils Nâcir eddîn se trouvait dans la province de Lacnaouty, et après avoir déclaré pour son successeur son petit-fils Keï Khosrew, ainsi que nous l'avons raconté. Or le chef des émirs, lieutenant du sultan Ghiyâth eddîn ${ }^{753}$, était l'ennemi du jeune prince, et il machina contre celui-ci une ruse qui lui réussit. En effet, il écrivit un acte dans lequel il contrefit l'écriture des principaux émirs, leur faisant attester qu'ils

749 Cette phrase est apparemment la seule véridique de tout ce récit.

750 Ce fils, appelé Muhammad et décrit comme un mécène, fut tué lors d’un raid mongol le 9 mars 1285 ; son tombeau se trouve à côté de celui de son père.

${ }^{751}$ Kaihusrav seul était fils de Muhammad. Mu’izz al-din Kaiqubad était le fils de Nasir al-din, second fils de Balban et succéda à ce dernier.

752 Lakhnawti, la capitale du Bengale, à l’époque. Elle correspond au site ruiné de Gaur dans la région de Rajshahi près de la frontière occidentale de l'Inde avec le Bangladesh. Nasir al-din fut nommé gouverneur par son père après la sup753 pression de la révolte du Bengale en 1280.

28. Il s’agit de Fakhr al-Din, kotwal (chef de police) de Dihli. 
avaient prêté serment d'obéissance à Mo’izz eddîn, petit-fils du sultan Balaban ; puis il se présenta devant Keï Khosrew, comme s’il avait été plein de sincérité envers lui, et lui dit : « Les émirs ont prêté serment à ton cousin, et je crains pour toi leurs mauvais desseins. » Keï Khosrew lui répondit : " Quel remède y a-t-il ? - Sauver ta vie en fuyant dans le Sind », reprit le chef des émirs. "Mais comment sortir de la ville, repartit le jeune prince, puisque les portes sont fermées ? - Les clefs sont entre mes mains, répliqua l'émir, et je t'ouvrirai. » Keï Khosrew le remercia de cette promesse et lui baisa la main. " A présent, monte à cheval », lui dit l'émir. En conséquence, le jeune prince monta à cheval, accompagné de ses familiers et de ses esclaves ; le grand émir lui ouvrit la porte, le fit sortir, et la ferma aussitôt après qu'il eût quitté Dihly ${ }^{754}$.

Alors il demanda à être admis près de Mo'izz eddîn et lui prêta serment. Mo’izz lui dit: "Comment pourrais-je p376 être le sultan, puisque le titre d'héritier présomptif appartient à mon cousin ? " Le chef des émirs lui fit connaître la ruse qu'il avait machinée contre celui-ci, et le moyen par lequel il l'avait fait sortir de la ville. Mo'izz eddîn le remercia de sa conduite, se rendit avec lui au palais du roi, et manda les émirs et les courtisans, qui lui prêtèrent serment durant la nuit. Le matin étant arrivé, le reste de la population fit de même, et le pouvoir de Mo'izz eddîn fut parfaitement affermi. Son père était encore en vie, et se trouvait dans le pays de Bengale et de Lacnaouty. La nouvelle de ce qui s'était passé lui étant parvenue, il dit : «Je suis l'héritier du royaume ; comment donc mon fils en deviendrait-il maître et le posséderait-il avec une autorité absolue, tandis que je suis encore vivant ? » Il se mit en marche avec ses troupes, se dirigeant vers la capitale de Dihly; son fils se mit aussi en campagne, à la tête de son armée, dans le dessein de le repousser de cette ville. Ils se rencontrèrent près de la ville de Carâ, située sur le rivage du fleuve Gange ${ }^{755}$, celui-là même où les Indiens vont en pèlerinage. Nâcir eddîn campa sur la rive, du côté qui touche Carâ, et son fils, le sultan

${ }^{754}$ Kaihusrav avait déjà quitté Dihli pour remplacer son père, et à la mort de Balban il se trouvait à Multan dans le Sind.

755 Nasir al-din ne paraît pas avoir jamais été tenté par la royauté mais, devant les désordres survenus à Dehli suite à l'avènement de Mu'izz al-din Kaiqubad se crut obligé d'intervenir. La rencontre eut lieu au milieu du mois de mars 1288 sur les bords de la Gaghra, affluent du Gange. 
Mo’izz eddîn, campa sur le côté opposé, de sorte que le fleuve se trouvait entre eux. Ils résolurent de combattre l'un contre l'autre ; mais Dieu voulut épargner le sang des musulmans et répandit dans le cour de Nâcir eddîn des sentiments de miséricorde envers son fils. En conséquence, il se dit en lui-même : "Lorsque mon fils régnera, ce sera un honneur pour moi ; il est donc plus juste que je désire cela. » En même temps, Dieu jeta dans le cœur du sultan Mo’izz eddîn des sentiments de soumission envers son père. Chacun des deux princes monta sur un bateau, sans être accompagné de ses troupes, et ils se p377 rencontrèrent au milieu du fleuve. Le sultan baisa le pied de son père, et lui fit des excuses. Celui-ci lui dit : « Je te donne mon royaume et je t'en confie le gouvernement. » Là-dessus il lui prêta serment de fidélité, et voulut s'en retourner dans les provinces qu'il possédait; mais son fils lui dit : "Il faut absolument que tu viennes dans mes États. » Le père et le fils se dirigèrent ensemble vers Dihly ${ }^{756}$ et entrèrent dans le palais ; le premier fit asseoir Mo'izz eddîn sur le trône et se tint debout devant lui. L'entrevue qui avait eu lieu entre eux sur le fleuve fut appelée la rencontre des deux astres heureux, à cause des résultats qu'elle eut, en épargnant le sang, en faisant que le père et le fils s'offrissent l'un à l'autre le royaume et qu'ils s'abstinssent de combattre. Les poètes célébrèrent en foule cet événement.

Nâcir eddîn retourna dans ses États et y mourut, au bout de quelques années, y laissant plusieurs enfants, parmi lesquels Ghiyâth eddîn Behâdoûr ${ }^{757}$, le même que le sultan Toghlok fit prisonnier, et que son fils Mohammed relâcha après sa mort. Cependant, la royauté resta encore en la possession paisible de Mo'izz eddîn durant quatre années, qui furent semblables à des jours de fête ${ }^{758}$. J'ai entendu une personne qui avait vécu de ce temps-là en décrire les félicités, le bon marché des denrées à cette époque, la libéralité et la munificence de Mo’izz eddîn. Ce fut ce prince qui construisit le minaret de la cour septentrionale de la grande mosquée de Dihly ${ }^{759}$, lequel n'a pas son

\footnotetext{
${ }^{756}$ La rencontre fut effectivement pacifique, mais sans plus. Nasir al-din ne visita 757 pas Dihli.

Il régna sous le nom de Nasir al-din Mahmud Shah Bughra, pratiquement indépendant jusqu'en 1291, et ses fils lui succédèrent. Ghiyath al-din Bahadur, dont l’histoire sera contée plus loin, était son petit-fils.

758 Les historiens parlent d'orgies et de débauches.

${ }^{759}$ Voir chap. 6, n. 98.
} 
pareil dans tout l'univers. Un habitant de l'Inde m'a raconté que Mo'izz eddîn était fort adonné au commerce des femmes et à la boisson ; qu'il lui survint une maladie dont la guérison défia ${ }_{\mathrm{p} 378}$ les efforts des médecins, et qu'un de ses côtés fut desséché (paralysé). Alors se souleva contre lui son lieutenant Djélâl eddîn Fîroûz chah Alkhaldjy ${ }^{760}$.

\section{HISTOIRE DU SULTAN DJÉLÂL EDDÎN}

Lorsque le sultan Mo'izz eddîn eut été atteint d'hémiplégie, ainsi que nous l'avons raconté, son lieutenant Djélâl eddîn se révolta contre lui, se transporta hors de la ville et campa sur une colline qui se trouvait en cet endroit, à côté d'une chapelle funéraire appelée la chapelle d'Aldjeïchâny. Mo'izz eddîn envoya des émirs pour le combattre ; mais tous ceux qu'il expédiait dans ce but prêtaient serment de fidélité à Djélâl eddîn et s'enrôlaient dans son armée. Le chef rebelle entra ensuite dans la ville et assiégea le sultan dans son palais durant trois jours. Quelqu'un qui a été témoin de ce fait m’a raconté que le sultan Mo'izz eddîn souffrit alors de la faim, et ne trouva rien à manger. Un chérîf, d'entre ses voisins, lui envoya de quoi apaiser sa faim ; mais l'émir rebelle entra à l'improviste dans le palais, et Mo'izz eddîn fut tué.

Djélâl eddîn lui succéda ; c'était un homme doux et vertueux, et sa douceur le fit périr victime d'un assassinat, ainsi que nous le raconterons. Il resta paisiblement maître de la royauté durant plusieurs années ${ }^{761}$ et construisit le palais qui porte son nom ${ }^{762}$. C'est ce même édifice ${ }_{\text {p379 }}$ que le sultan Mohammed donna à son beau-frère, l'émir

760 Djalal al-din Firuz appartenait à la tribu des Khaldjis, d'origine turque, mais plus ou moins afghanisée par son long séjour dans la région de Ghazna. Pour cette raison, l'arrivée de Djalal al-din au pouvoir fut mal vue aussi bien par l'aristocratie turque que par la population de Dihli.

761 1290-1296.

${ }^{762}$ Ce palais sera identifié plus loin par Ibn Battûta (p. 437) au Palais Rouge (Kushk i-La’l) situé dans la vieille ville de Dihli. Or ce palais fut bâti par Balban. Quant au palais bâti par Djalal al-din Firuz, il s’appelait Palais Vert et constituait l'extension de celui construit par Mu'izz al-din Kaiqubad à Kilokhri, à une dizaine de kilomètres au nord-est de la vieille ville au bord de la Yamuna. 
Ghadâ, fils de Mohannâ, lorsqu'il lui fit épouser sa sœur, événement qui sera raconté ci-après.

Le sultan Djélâl eddîn avait un fils nommé Rocn eddîn et un neveu appelé 'Alâ eddîn, qu'il maria à sa fille, et à qui il donna le gouvernement de la ville de Carâ et celui de Mânichoûr, avec son territoire ${ }^{763}$, Ce dernier est un des plus fertiles de l'Inde, il abonde en froment, en riz et en sucre, et l'on y fabrique des étoffes très fines, que l'on exporte à Dihly, dont Mânichoûr est éloignée de dix-huit journées. La femme d'Alâ eddîn le tourmentait et il ne cessait de s'en plaindre à son oncle (et beau-père), le sultan Djélâl eddîn ; si bien que la discorde s'éleva entre eux à ce sujet. Alâ eddîn était un homme perspicace, brave et souvent victorieux, et le désir de la royauté s'était fixé dans son âme ; mais il n'avait d'autres richesses que celles qu'il gagnait à la pointe de son épée, et au moyen des dépouilles des infidèles. Il lui arriva un jour de partir pour faire la guerre sainte, dans le pays de Doueïghîr ${ }^{j 64}$, que l'on appelle aussi le pays de Catacah, et dont nous ferons mention ci-après. Doueïghîr est la capitale des pays de Malwa et de Marhata ${ }^{765}$ et son souverain était le plus puissant des souverains infidèles. Dans cette expédition, la monture d’Alâ eddîn fit un faux pas contre une pierre et s'abattit avec son cavalier. Celui-ci entendit une sorte de tintement produit par la pierre; il ordonna de creuser en cet ${ }_{\mathrm{p} 380}$ endroit et trouva sous la pierre un trésor considérable ${ }^{766}$ qu'il partagea entre ses camarades. Puis il arriva à Doueïghîr,

${ }^{763}$ On trouve le plus souvent le nom de ces deux villes, situées au nord-ouest d'Allahabad, sur le Gange, réuni pour désigner le fief de Kara-Manikpur. A l'avènement de Djalal al-din Firuz, le détenteur de ce fief était Tchadju Khan, neveu de Balban, lequel le conserva jusqu'à sa révolte l'année suivante. Alors il lui fut confisqué et donné à Ala al-din, le neveu et futur successeur de Djalal al-din.

${ }^{764}$ Deoghir, rebaptisée Dawlatabad par Muhammad bin Tughluk, au nord-ouest de l'actuelle Aurangabad, dans le Deccan. Voir aussi t. III, p. 177, la description de la ville où Catacah (Camp royal en sanskrit) est donné comme le nom d'une partie de celle-ci.

${ }^{765}$ Maharashtra ou pays des Mahrates. La région de Malwa est située plus au nord, à l'est du Gudjarat.

${ }^{766}$ Ala al-din entreprit la campagne audacieuse de Deoghir en secret et avec ses propres troupes. Le souverain hindou Ramachandra d'abord seul, puis avec les forces de son fils, combattit l'envahisseur mais dut se rendre. Si l'histoire du trésor enfoui relève de la légende, le butin de l'expédition fut fabuleux et permit à Ala al-din d'accéder au trône. 
dont le sultan se soumit, lui rendit la ville sans combat et lui fit de grands présents. Il retourna à la ville de Carâ, et n'envoya à son oncle aucune portion des dépouilles. Des individus excitèrent son oncle contre lui, et le sultan le manda ; mais il refusa de se rendre à sa cour. Le sultan Djélâl eddîn dit alors : " J'irai le trouver et je l'amènerai, car il me tient lieu de fils. » En conséquence, il se mit en marche avec son armée, et franchit les étapes jusqu'à ce qu'il campât sur la rive voisine de la ville de Carâ, à l'endroit même où dressa son camp le sultan Mo'izz eddîn, lorsqu'il marcha à la rencontre de son père Nâcir eddîn. Il s'embarqua sur le fleuve, afin de se rendre près de son neveu. Celuici monta aussi sur un navire, dans le dessein de faire périr le sultan, et il dit à ses compagnons : " Lorsque je l'embrasserai, tuez-le. » Quand les deux princes se rencontrèrent au milieu du fleuve, le neveu embrassa son oncle, et ses camarades tuèrent celui-ci, ainsi qu'Alâ eddîn le leur avait recommandé. Le meurtrier s'empara du royaume et disposa des troupes de sa victime ${ }^{767}$.

\section{HISTOIRE DU SULTAN ’ALA EDDÎN MOHAMMED CHÂH ALKHALDJY}

Lorsqu'il eut tué son oncle, il devint maître du royaume, et la majeure partie des troupes de Djélâl eddîn passèrent de son côté. Le reste retourna à Dihly, $\mathrm{p} 381$ et se réunit auprès de Rocn eddîn ${ }^{768}$. Celui-ci sortit pour repousser le meurtrier ; mais, tous ses soldats s'étant retirés près du sultan 'Alâ eddîn, il s'enfuit dans le Sind. 'Alâ eddîn entra dans le palais royal, et jouit paisiblement du pouvoir durant vingt années. Il fut au nombre des meilleurs sultans, et les habitants de l'Inde le vantent beaucoup. Il examinait en personne les affaires de ses sujets, s’enquérait du prix des denrées et faisait venir chaque jour pour cela le mohtecib, ou inspecteur des marchés que les Indiens appellent

${ }^{767}$ Le récit d’Ibn Battûta correspond exactement à celui des autres sources. L’assassinat de Djalal al-din Firuz a eu lieu le 19 juillet 1326.

${ }^{768}$ L’héritier désigné de Djalal al-din était son fils Arkali Khan qui se trouvait à Multan comme gouverneur pendant ces événements. Alors la veuve de Djalal al-din proclama comme souverain son fils cadet Qadr Khan sous le nom de Rukn al-din Ibrahim. Ce dernier s'enfuit à l'approche d'Ala al-din qui entra à Dihli le 22 octobre. 
réîs, ou chef ${ }^{769}$. On raconte qu'il l'interrogea un jour touchant le motif de la cherté de la viande. L'inspecteur l'informa que cela provenait du taux élevé de l'impôt établi sur les bœufs. Il ordonna d'abolir cette taxe et d'amener devant lui les marchands; puis il leur donna de l'argent et leur dit: «Achetez avec cela des bœufs et des brebis et vendez-les ; le prix qu'ils produiront reviendra au fisc, et vous recevrez un salaire pour la vente. » Cela fut exécuté, et le sultan fit de même pour les étoffes que l'on apportait de Daoulet Abâd. Lorsque les grains atteignaient un prix élevé, il ouvrait les magasins de l'État et en vendait le contenu, jusqu'à ce que cette denrée fût à bon marché. On raconte que la valeur des grains s'éleva une certaine fois, et qu'il ordonna de les vendre à un prix qu'il fixa ; les gens refusèrent de les livrer pour ce prix-là. Il prescrivit alors que personne n'achetât d'autres grains que ceux du magasin du gouvernement, et il en vendit au peuple durant six mois. Les accapareurs craignirent alors que leurs provisions ne fussent infestées par les calandres, et ils demandèrent qu'il leur fût permis de vendre. Le sultan le leur permit, à condition qu'ils vendraient ${ }_{\mathrm{p} 382}$ à un prix moindre que celui qu'ils avaient auparavant refusé ${ }^{770}$.

'Alâ eddîn ne montait pas à cheval pour se rendre à la prière du vendredi, ni dans une fête solennelle, ni dans aucune autre occasion ; voici quel était le motif de cette abstention. Il avait un neveu appelé Soleïmân châh ${ }^{771}$, qu'il aimait et à qui il montrait des égards. Il monta un jour à cheval pour aller à la chasse, accompagné de ce neveu. Celui-ci conçut le dessein de traiter son oncle comme ce dernier avait lui-même traité son oncle Djélâl eddîn, c’est-à-dire de l’assassiner. En

769 Muhtesib est le nom arabe de l'inspecteur des marchés. A l'est, le nom de rais était le plus souvent appliqué aux officiers en charge de la police.

${ }^{770}$ Après les raids successifs des Mongols dans les premières années du XIV siècle, Ala al-din sentit le besoin d'une armée forte, et pour cela bien payée. Alors, au lieu d'augmenter la solde, il préféra faire baisser le prix des denrées, anormalement élevé par l'inflation résultant de l'abondance de l'or ramené par les campagnes du Sud. Pour cela, il institua un monopole d'achat à des prix fixes et enregistra les marchands en leur fixant aussi un taux de bénéfice. Les paysans étaient aussi obligés de vendre leurs produits aux marchands désignés à des prix fixes. Avec ces achats, le gouvernement constitua également de grands stocks de denrées qu'Ibn Battûta trouvera trente ans plus tard (voir p. 356).

\footnotetext{
Ce neveu est appelé Akat Khan dans les autres sources.
} 
conséquence, lorsque le sultan mit pied à terre pour déjeuner, il lui lança une flèche et le renversa ; mais un de ses esclaves le couvrit d'un bouclier. Son neveu s'approcha, afin de l'achever ; mais, les esclaves lui ayant dit que le prince était mort, il les crut et remonta à cheval et entra dans la partie du palais où se trouvaient les femmes. Cependant le sultan 'Alâ eddîn revint de son évanouissement, il monta à cheval, et ses troupes se rassemblèrent auprès de lui. Son neveu s'enfuit ; mais il fut atteint, et amené devant lui ; il le tua, et depuis lors il cessa de monter à cheval.

'Alâ eddîn avait des fils dont les noms suivent : Khidhr khân, Châdy khân, Abou Becr khân, Mobârec khân, appelé aussi Kothb eddîn, qui devint roi, et Chihâb eddîn. Kothb eddîn était mal traité de son père, et jouissait près de lui de très peu de considération. Le sultan avait donné à tous ses frères les honneurs, c'est-à-dire ${ }_{\text {p383 }}$ des étendards et des timbales, et ne lui avait rien accordé. Cependant, il lui dit un jour : " Il faut absolument que je te donne la même chose qu'à tes frères. » Kothb eddîn lui répondit : « C'est Dieu qui me l'accordera. » Cette parole effraya son père, qui le redouta. Le sultan fut ensuite atteint de la maladie dont il mourut. Or la femme dont il avait eu son fils Khidhr khân s’appelait Mâh Hakk (le mot mâh, dans la langue de ces peuples, signifie la lune), avait un frère nommé Sindjar, avec lequel elle convint d'élever au trône Khidhr khân ${ }^{772}$. Mélic Nâïb, le principal des émirs du sultan, et que l'on appelait Alalfy ${ }^{773}$, parce que ce souverain l'avait acheté pour mille (alf) tangahs, c'est-à-dire pour deux mille cinq cents dînârs du Maghreb ${ }^{774}$, Mélic Nâîb, dis-je, eut connaissance de cet accord, et le dénonça au sultan. Celui-ci dit à ses

772 Le nom de la reine était Mahru et son titre Malika-i Djahan. Elle était sœur de Malik Sandjar, lequel, pour avoir tué Djalal al-din Firuz de sa propre main, avait reçu le titre d'Alp Khan et était devenu un des principaux compagnons d’Ala al-din. Sa fille fut mariée en 1312 avec Khidhr Khan, et la famille préparait effectivement l'ascension au trône de celui-ci.

773 48. Malik Naib, c’est-à-dire vice-roi, est ici Kâfur, un Hindou acheté en 1297, lors du sac du port de Cambay dans le Gudjarat pour mille dinars, et connu ainsi sous le sobriquet persan Hezardinari qu'Ibn Battûta traduit en arabe par al-Alfi. Ce personnage, devenu tout-puissant vers la fin du règne d'Ala al-din, aurait conçu le projet d'éliminer toute la famille royale en commençant par la 774 coterie d'Alp Khan, mais cela sans le consentement d'Ala al-din.

Le tanka d'or (voir aussi chap. 5, n, 243) valait 9,010 g et le dinar du Maghreb 4,722 g. Il s’agirait donc d'un peu moins de 2000 dinars. 
familiers : "Quand Sindjar entrera dans la chambre où je me trouve, je lui donnerai un habit ; et lorsqu'il s'en revêtira, saisissez-le par les manches, renversez-le contre terre et égorgez-le. » Cela fut exécuté de point en point.

Khidhr khân était alors absent, et se trouvait dans un endroit appelé Sandabat ${ }^{775}$, à la distance d'une journée de Dihly, où il s'était rendu pour un pèlerinage aux tombeaux de plusieurs martyrs ensevelis en cet endroit ${ }_{\mathrm{p} 384}$ car il s'était engagé par un vœu à parcourir cette distance à pied et à prier pour la santé de son père. Lorsqu'il apprit que celui-ci avait tué son oncle maternel, il en conçut un très vif chagrin, déchira le collet de son habit, ainsi que les Indiens ont coutume de le faire lorsqu'il leur est mort quelqu'un qui leur est cher. Son père, ayant eu connaissance de sa conduite, en fut mécontent, et, lorsque Khidhr khân parut en sa présence, il le réprimanda, le blâma, ordonna de lui mettre les fers aux mains et aux pieds, et le livra à Mélic Nâïb, dont il a été question ci-dessus, avec l'ordre de le conduire à la forteresse de Gâlyoûr, appelée aussi Gouyâlior ${ }^{776}$. C'est une forteresse isolée, au milieu des idolâtres indous ; elle est inexpugnable et se trouve éloignée de dix journées de Dihly ; j’y ai demeuré quelque temps. Quand Mélic Nâïb eut mené le prince dans ce château fort, il le remit au cotouâl, c'est-à-dire au commandant, et aux mofreds ${ }^{777}$, qui sont les mêmes que les zimâmys ${ }^{778}$ et leur dit : "Ne vous dites pas que cet individu est le fils du sultan, et qu'il faut le traiter avec honneur ; c'est l'ennemi le plus acharné qu'ait l'empereur : gardez-le donc comme on garde un ennemi. »

Dans la suite, la maladie du sultan ayant redoublé, il dit à Mélic Nâib : « Envoie quelqu'un pour ramener mon fils Khidhr khân, afin que je le déclare mon successeur. " Mélic Nâib répondit: "Très bien », mais il remit de jour en jour l'exécution de cet ordre, et, toutes les fois que son maître l'interrogeait à ce sujet, il répondait : "Voici qu'il arrive. » Il continua d'agir ainsi jusqu'à ce que le sultan mourût.

775 L'actuelle Sonipat, au nord de Dihli.

${ }^{776}$ Gwalior, au sud d'Ara, qui deviendra par la suite une prison d’État. Elle sera visitée par Ibn Battûta (voir t. III, p. 169).

${ }^{777}$ Le terme semble indiquer un corps spécial, sans que sa fonction soit indiquée.

778 Soldats inscrits sur la liste, zimam, de l’armée. 


\section{HISTOIRE DU FILS D’ALÂ EDDÎN, LE SULTAN CHIHÂB EDDÎN}

Lorsque le sultan 'Alâ eddîn fut mort, Mélic Nâïb fit asseoir sur le trône du royaume son fils cadet Chihâb eddîn ${ }^{779}$. Le peuple prêta serment d'obéissance à ce prince ; mais Mélic Nâîb le tint sous sa tutelle, priva de la vue Abou Becr khân et Châdy khân, et les envoya à Gâlyoûr. Il ordonna d'aveugler leur frère Khidhr khân, qui était emprisonné dans le même endroit. Ils furent mis en prison, ainsi que Kothb eddîn ; mais le ministre épargna la vue de ce dernier. Le sultan 'Alâ eddîn avait deux esclaves, qui étaient au nombre de ses plus familiers courtisans ; l'un s'appelait Béchîr et l'autre Mobacchir (ces noms signifient tous deux Messagers de bonheur). La grande princesse, veuve d'Alâ eddîn et fille du sultan Mo'izz eddîn ${ }^{780}$, les manda, leur rappela les bienfaits qu'ils avaient reçus de leur ancien maître, et dit : "Cet eunuque, Nâib Mélic, a fait à mes enfants ce que vous savez, et il veut encore tuer Kothb eddîn. » Ils lui répondirent « Tu verras ce que nous ferons. » Or c'était leur coutume de passer la nuit près de Nâib Mélic et d'entrer chez lui tout armés. Ils vinrent le trouver la nuit suivante, au moment où il se tenait dans une chambre construite en planches et tendue de drap. Les Indiens appellent un appartement de cette espèce alkhoremkah ${ }^{781}$; le vizir y dormait, sur la terrasse du palais, pendant la saison des pluies. Il advint, par hasard, qu'il prit l'épée que portait un des deux conjurés, la brandit et la lui

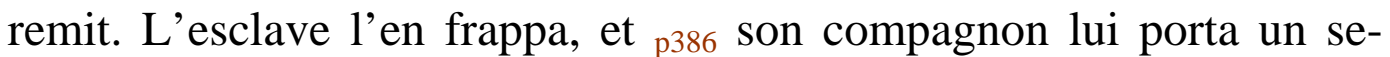
cond coup ; puis ils lui coupèrent la tête, la portèrent à la prison de Kothb eddîn, la jetèrent aux pieds de celui-ci et le délivrèrent de captivité. Le prince alla trouver son frère Chihâb eddîn, et resta près de

${ }^{779}$ Ala al-din mourut le 5 janvier 1316 et Kâfur nomma à la place du souverain défunt son plus jeune fils, âgé de cinq ou six ans, sous le nom de Shihab al-din Umar.

780

La veuve d'Ala al-din, qui eut à souffrir pendant cette période des visées de Kâfur, était la mère de Shihab al-din Umar et fille de Ramachandra de Deogir. Également d'après les autres sources, ce fut Qutb al-din Mubarak lui-même qui persuada Bashir et Mubshir venus le tuer de se retourner contre Kâfur. Ce dernier fut assassiné le 4 février 1316.

781

Khurramgâh : chambre de plaisir. 
lui plusieurs jours, comme s'il eût été son lieutenant. Ensuite, il se décida à le déposer, et mit son dessein à exécution ${ }^{782}$.

\section{HISTOIRE DU SULTAN KOTHB EDDÎN, FILS DU SULTAN ’ALÂ EDDÎN}

Ce prince déposa son frère Chihâb eddîn, lui coupa un doigt et l'envoya à Gâlyoûr, où il fut emprisonné avec ses frères. Le royaume appartint en paix à Kothb eddîn, qui sortit alors de la capitale, Dihly, pour se rendre à Daoulet Abâd, à quarante journées de là. Le chemin entre ces deux villes est bordé d'arbres, tels que le saule et autres, de sorte que celui qui y marche peut se croire dans un jardin. Pour chaque mille de distance, il y a trois dâouahs, c'est-à-dire maisons de poste, dont nous avons décrit l'organisation ${ }^{783}$, et dans chacune de ces stations on trouve tout ce dont le voyageur a besoin, de la même manière que s'il parcourait un marché pendant une distance de quarante journées. C'est ainsi que le chemin se continue durant six mois de marche, jusqu'à ce qu'il atteigne les pays de Tiling ${ }^{784}$ et de Ma'bar ${ }^{785}$. A chaque station se trouve un palais pour le sultan et un ermitage pour les voyageurs, et le pauvre n'a pas besoin d'emporter sur ce chemin des provisions de route.

Lorsque le sultan Kothb eddîn fut parti pour cette ${ }_{\text {p387 }}$ expédition ${ }^{786}$, quelques émirs convinrent entre eux de se révolter contre lui, et de mettre sur le trône un fils de son frère Khidhr khân, le prisonnier ${ }^{787}$. Cet enfant était âgé d'environ dix années, et il se trouvait près du sultan. Celui-ci, ayant appris le projet des émirs, prit son neveu, le saisit par les pieds et lui frappa la tête contre des pierres jusqu'à ce que sa cervelle fût dispersée ; puis il envoya un émir, appelé Mélic

782 Shihab al-din fut déposé et aveuglé par son frère qui le remplaça le 19 avril 1316.

${ }^{783}$ Voir plus haut, p. 324.

784 Telingana, dans le centre-est de la péninsule, au nord de la région actuelle d'Andhra Pradesh.

785 Nom arabe de la côte de Coromandel, côte est de l'extrémité de la péninsule.

786 Contre Harapaladeva, gendre de Ramachandra (voir ci-dessus n. 40) qui décla787 ra son indépendance à la mort d'Ala al-din. L'expédition date de 1318 .

Cet événement n’est pas connu par ailleurs, mais des monnaies frappées à Dehli en 718 (1318-1319) au nom d'un certain Shams al-din Mahmud Shah, inconnu par ailleurs, ont été retrouvées. 
châh, à Gâlyoûr, où se trouvaient le père et les oncles de cet enfant, et lui ordonna de les tuer tous. Le kâdhi Zeïn eddîn Mobârec, kâdhi de ce château fort, m’a fait le récit suivant : "Mélic châh arriva près de nous un matin, pendant que je me trouvais près de Khidhr khân, dans sa prison. Lorsque le captif apprit son arrivée, il eut peur et changea de couleur. L’émir étant entré : “Pourquoi es-tu venu ?” Il répondit : "Pour une affaire qui intéresse le seigneur du monde.- Ma vie estelle en sûreté ? demanda le prince.- Oui”, répliqua l'émir. Là-dessus il sortit, manda le cotouâl ou chef de la forteresse, et les mofreds, c'est-à-dire les zimâmys, qui étaient au nombre de trois cents, m'envoya chercher, ainsi que les notaires, et produisit l'ordre du sultan. Les hommes de la garnison le lurent, se rendirent près de Chihâb eddîn, le sultan déposé, et lui coupèrent le cou. Il fut plein de fermeté et ne montra pas de frayeur. Ensuite on décapita Abou Becr et Châdy khân. Lorsqu'on se présenta pour décoller Khidhr khân, il fut frappé de crainte et de stupeur. Sa mère se trouvait avec lui ; mais les exécuteurs fermèrent la porte sur elle et le tuèrent ; puis ils traînèrent les quatre cadavres dans une fosse, sans les envelopper dans des linceuls ni les laver. On les en retira au bout de plusieurs années, et on les ensevelit dans les sépulcres de leurs ancêtres. » La mère de Khidhr khân p388 vécut encore quelque temps, et je l'ai vue à La Mecque, dans l'année $728{ }^{788}$.

Le château de Gâlyoûr, dont il vient d'être question, est situé sur la cime d'une haute montagne et paraît, pour ainsi dire, taillé dans le roc même ; il n'a vis-à-vis de lui aucune autre montagne ; il renferme des citernes, et environ vingt puits entourés de murs lui sont annexés. Sur ces murs sont dressés des mangonneaux et des ra'adahs ${ }^{789}$. On monte à la forteresse par un chemin spacieux, que gravissent les éléphants et les chevaux. Près de la porte du château se trouve la figure d'un éléphant, sculpté en pierre et surmonté de la figure d'un cornac. Lorsqu'on l'aperçoit de loin, on ne doute pas que ce ne soit un éléphant véritable. Au bas de la forteresse est une belle ville, bâtie entièrement en pierres de taille blanches, les mosquées comme les maisons ; on n'y voit pas de bois, à l'exception des portes. Il en est de même du palais du roi, des dômes et des salons. La plupart des trafiquants de 
cette ville sont des idolâtres, et il s'y trouve six cents cavaliers de l'armée du sultan, qui ne cessent de combattre les infidèles, car cette place en est entourée.

Lorsque Kothb eddîn eut assassiné ses frères, qu'il fut devenu seul maître du pouvoir, et qu'il ne resta personne qui le combattît ou se révoltât contre lui, Dieu suscita contre lui son serviteur favori, le plus puissant de ses émirs, le plus élevé en dignité, Nâcir eddîn Khosrew khân. Cet homme l'attaqua à l'improviste, le tua, et demeura maître absolu de son royaume ; mais ce ne fut pas pour longtemps. Dieu suscita aussi contre lui quelqu'un qui le tua après l'avoir détrôné, et cette personne fut le sultan Toghlok, ainsi qu'il sera ci-après raconté et retracé en détail, si Dieu le veut. p389

\section{HISTOIRE DU SULTAN KHOSREW KHÂN NÂCIR EDDÎN}

Khosrew khân était un des principaux émirs de Kothb eddîn ${ }^{790}$, il était brave et avait une belle figure. Il avait conquis le pays de Djandîry ${ }^{791}$ et celui d'Alma'bar, qui sont au nombre des régions les plus fertiles de l'Inde, et sont éloignés de Dihly d'une distance de six mois de marche. Kothb eddîn l'aimait beaucoup et lui avait accordé sa prédilection ; cette conduite fut cause qu'il reçut la mort des mains de cet homme. Kothb eddîn avait eu pour précepteur un nommé Kâdhi khân Sadr Aldjihân ${ }^{792}$, qui était le principal de ses émirs et avait le titre de kélîd dâr, c'est-à-dire de gardien des clefs du palais. Cet officier avait coutume de passer toutes les nuits à la porte du sultan, avec les hommes de la garde ; ceux-ci sont au nombre de mille, qui veillent à tour de rôle toutes les quatre nuits. Ils sont rangés sur deux files, dans l'intervalle compris entre les portes du palais, et chacun a devant soi ses armes. Personne n'entre qu'en passant entre ces deux files. Quand

${ }^{790}$ Hindou de naissance, il fut fait prisonnier lors de l'invasion de Malwa, à l'est de Gudjarat, en 1305. Converti à l'islam sous le nom de Hasan, il fut nommé vizir par Qutb al-din Mubarak à son ascension.

791 Tchanderi était une forteresse de Malwa appartenant à l'époque au royaume de Dihli. L'expédition de Khusraw fut menée contre Warangal, la capitale de Telingana, et contre les souverains Pandya du Coromandel. Si la première partie de l'expédition fut heureuse, la seconde le fut moins et Khusraw fut rappelé 792 Dihli.

2 D'autres sources l'appellent Ziya al-din. 
la nuit est achevée, les gens de la garde du jour arrivent. Les soldats de ce corps ont des chefs et des écrivains, qui font des rondes parmi eux et notent ceux qui sont absents ou présents.

Or le précepteur du sultan, Kâdhi khân, haïssait la conduite de Khosrew khân et était mécontent de ce qu'il voyait, savoir sa prédilection pour les Indiens idolâtres, son penchant pour eux et son origine semblable à la leur. Il ne cessait de rappeler cela au sultan, qui ne ${ }_{p 390}$ l'écoutait pas, lui répondait : "Laisse-le », et ne voulait pas agir, à cause du dessein que Dieu avait formé de le faire périr par les mains de cet homme. Un certain jour Khosrew khân dit au sultan : " Plusieurs Indiens désirent embrasser l'islamisme. » Or c'est une des coutumes en vigueur dans ce pays, quand un individu veut se faire musulman, qu'on l'introduise près du sultan, qui le revêt d'un bel habit et lui donne un collier et des bracelets d'or, d'une valeur proportionnée à son rang. Le sultan dit à Khosrew : " Amène-les-moi. — Ces gens-là, répondit l'émir, seraient honteux d'entrer chez toi en plein jour, à cause de leurs proches et de leurs coreligionnaires.- Amène-les-moi donc de nuit », reprit le sultan.

Khosrew khân rassembla une troupe d'Indiens choisis parmi les plus braves et les plus considérables, et au nombre desquels était son frère Khân khânân ${ }^{793}$. On se trouvait alors au temps des chaleurs, et le sultan dormait sur la terrasse du palais, n'ayant auprès de lui que plusieurs eunuques. Lorsque les Indiens, armés de toutes pièces, eurent franchi les quatre portes du palais, et qu'ils arrivèrent à la cinquième, où se trouvait Kâdhi khân, cet officier suspecta leur conduite et soupçonna quelque mauvais dessein. En conséquence, il les empêcha d'entrer et dit : " Il faut absolument que j'entende de la bouche du souverain du monde la permission de les introduire; alors ils seront admis. " Ces hommes, se voyant ainsi arrêtés, se jetèrent sur lui et le tuèrent. Le bruit que cette dispute excita près de la porte devint considérable, et le sultan s’écria : "Qu’est-ce que cela ? » Khosrew khân répondit : «Ce sont les Indiens qui viennent pour se convertir. Kâdhi khân les a empêchés d'entrer, et le tumulte a augmenté. » Le sultan

${ }^{793}$ Khusraw aurait amené du Gudjarat quarante mille personnes appartenant à son propre clan, les Barwar, qui étaient des Hindous, pour former une armée personnelle. Khan khanan est un titre ; le frère de Khusraw s’appelait Husam aldin et s’était déjà révolté dans le Gudjarat contre Qutb al-din Mubarak. 
eut ${ }_{\mathrm{p} 391}$ peur et se leva avec l'intention de se retirer dans l'intérieur du palais ; mais la porte était fermée et les eunuques se trouvaient près de là. Le prince frappa à la porte. Khosrew khân le saisit dans ses bras par derrière ; mais le monarque, étant plus fort que lui, le terrassa. Les Indiens survinrent alors, et Khosrew khân leur dit : " Le voici sur moi, ; tuez-le. » Ils le massacrèrent, coupèrent sa tête et la jetèrent de la terrasse du palais dans la cour ${ }^{794}$.

Khosrew khân manda aussitôt les émirs et les rois, qui ne savaient pas encore ce qui était survenu. Chaque fois qu'une troupe entrait, elle le trouvait assis sur le trône royal ; on lui prêta serment, et, lorsque le matin fut arrivé, il fit publier son avènement, expédia des rescrits ou ordres dans toutes les provinces, et envoya un habit d'honneur à chaque émir. Ils se soumirent tous à lui et lui obéirent, à l'exception de Toghlok châh, père du sultan Mohammed châh, qui était alors gouverneur de Dibâlboûr ${ }^{795}$, dans le Sind. Quand il reçut le vêtement d'honneur que lui octroyait Khosrew khân, il le jeta à terre et s'assit dessus. Khosrew fit marcher contre lui son frère Khân khânân, "le khan des khans ", mais Toghlok le mit en déroute, et finit ensuite par le tuer, ainsi que nous le raconterons dans l'histoire du règne de Toghlok.

Lorsque Khosrew khân fut devenu roi, il accorda sa prédilection aux Indiens ${ }^{796}$ et publia des ordres répréhensibles, tels qu'un édit par lequel il défendait d'égorger des bœufs conformément à la coutume des Indiens ${ }_{\mathrm{p} 392}$ idolâtres ; car ils ne permettent pas de les tuer. Le châtiment de quiconque en égorge un, chez ce peuple consiste à être cousu dans la peau de l'animal et brûlé. Ils honorent les bœufs et boivent leur urine, pour se sanctifier et obtenir leur guérison lorsqu'ils sont malades, et ils enduisent avec la fiente de ces animaux leurs maisons,

Dipalpur, dans le Pakistan actuel, au sud de Lahore, près de la frontière indienne.

${ }^{796}$ La plupart des historiens musulmans qui ont écrit sous les Tughluks portent cette accusation contre Khusraw, mais il ne semble pas que celui-ci manifestât l'intention de mettre en cause la prépondérance de l'islam. Tout au plus se montra-t-il plus libéral face à la pratique religieuse des Hindous qui composaient ses régiments. Mais il fut le premier souverain d'origine hindoue, et même non turque, du sultanat, et le slogan de la " religion en danger » servit à rallier l’opposition autour de Ghiyath al-din Tughluk. 
tant au-dedans qu'au-dehors. Une pareille conduite fut une des causes qui rendirent Khosrew khân odieux aux musulmans, et les firent pencher en faveur de Toghlok. Le règne du premier ne dura pas longtemps, et les jours de sa royauté ne se prolongèrent pas, ainsi que nous le raconterons.

\section{HISTOIRE DU SULTAN GHIYÂTH EDDÎN TOGHLOK CHÂH}

Le cheïkh et imâm pieux, savant, bienfaisant et dévot Rocn eddîn, fils du pieux cheïkh Chems eddîn Abou 'Abd Allah, fils du saint, de l'imâm savant et dévot Behâ eddîn Zacariâ alkorachy almoultâny, m'a fait le récit suivant, dans son ermitage de la ville de Moultân. Le sultan Toghlok était au nombre de ces Turcs connus sous le nom de Karaounah ${ }^{797}$ et qui habitent dans les montagnes situées entre le Sind et le pays des Turcs. Il était dans une situation misérable, et se rendit dans le Sind comme serviteur d'un certain marchand dont il était golwâny, c'est-à-dire palefrenier. Cela se passait sous le règne du sultan 'Alâ eddîn, et le gouverneur du Sind était alors son frère Oûloû khân ${ }^{798}$. Toghlok s'engagea à son service et fut attaché à sa personne, et Oûloû khân l'enrôla parmi les biâdehs ${ }^{799}$, c'est-à-dire les p393 gens de pied. Par la suite, sa bravoure se fit connaître, et il fut inscrit parmi les cavaliers ; puis il devint un des petits émirs, et Oûloû khân le fit chef de ses écuries. Enfin, il fut un des grands émirs et reçut le titre d'almélic alghâzy, le roi belliqueux ${ }^{800}$. J'ai vu l'inscription qui suit sur la tribune grillée de la grande mosquée de Moultân, dont il a ordonné la construction : " J'ai combattu es Tartares vingt-neuf fois, et

${ }^{797}$ Le Qaraunas — d'après Marco Polo, mais aussi selon la tradition indienne seraient issus de pères turcs ou mongols et de mères indiennes, mais il peut également s'agir d'une tribu d'origine turque. Le patronyme Tughluk est sans doute turc.

798 Il s’agit d’Almas Beg, intitulé Ulugh Khan après l'accession de son frère au pouvoir en 1296 et nommé aussitôt gouverneur du Sind. Après la reconquête de Ranthambor, dans le Radjastan, en 1301, il fut transféré dans cette ville et mourut l'année suivante.

800 Ghiyath al-din Tughluk se distingua pour la première fois pendant l'attaque des Mongols en 1304 et reçut le titre de ghazi (victorieux) après avoir repoussé une autre attaque mongole en 1306. 
je les ai mis en déroute. C’est alors que j’ai été surnommé le roi belliqueux. »

Lorsque Kothb eddîn fut devenu roi, il nomma Toghlok gouverneur de la ville de Dibâlboûr et de son district, et fit à son fils, celui-là même qui est à présent sultan de l’Inde, chef des écuries impériales. On le nommait Djaounah, le Soleil, et quand il fut roi, il se fit appeler Mohammed châh. Kothb eddîn ayant été tué et Khosrew khân lui ayant succédé, ce dernier confirma Djaounah dans le poste de chef des écuries. Lorsque Toghlok voulut se révolter, il avait trois cents camarades en qui il mettait sa confiance, les jours de bataille. Il écrivit à Cachloû khân ${ }^{801}$, qui se trouvait alors à Moultân, à trois journées de distance de Dibâlboûr, pour lui demander du secours, lui rappelant les bienfaits de Kothb eddîn et l'excitant à poursuivre la vengeance du meurtre de ce prince. Le fils de Cachloû khân résidait à Dihly. En conséquence, il répondit à Toghlok : " Si mon fils était près de moi, certes, je t'aiderais dans tes desseins. » Toghlok écrivit à son fils Mohammed châh, pour lui faire connaître ce qu'il avait résolu, et lui ordonner de s'enfuir et de revenir le trouver, en se faisant accompagner du fils de Cachloû khân. Le jeune émir machina une ruse contre Khosrew khân, et elle lui p394 réussit, ainsi qu'il désirait. Or il dit au sultan : « Les chevaux sont devenus gras et ont pris de l'embonpoint, ils ont besoin du yarâk ${ }^{802}$ ", c'est-à-dire du dégraissement. En conséquence, Khosrew khân lui permit de les entraîner. Le chef des écuries montait chaque jour à cheval, avec ses subordonnés, se promenait d'une à trois heures, avec les animaux confiés à ses soins ; il alla même jusqu'à rester sorti quatre heures, si bien qu'un jour il était encore absent à midi passé, ce qui est le moment où les Indiens prennent leur repas. Le sultan ordonna qu'on partît à cheval pour le chercher ; mais on n'en trouva aucune nouvelle, et il rejoignit son père, emmenant avec lui le fils de Cachloû khân.

Alors Toghlok, se déclarant ouvertement rebelle, rassembla des troupes, et Cachloû khân marcha avec lui, accompagné de ses soldats.

80

Ce personnage s'appelait à l'époque Bahram Aiba et était gouverneur d'Uch (voir chap. 5, n. 75). Le premier à se joindre à Tughluk, il reçut par la suite le nom de Kishlu Khan et le gouvernorat du Sind. Il conservera ce poste juqu'à 802 sa révolte en 1328 (voir t. III, p. 73).

Le mot est turc. 
Le sultan envoya pour les combattre son frère Khân khânân ; mais ils lui firent essuyer la déroute le plus complète, et son armée passa de leur côté. Khân khânân se retira près de son frère, ses officiers furent tués et ses trésors pris. Toghlok se dirigea vers Dihly. Khosrew khân sortit à sa rencontre avec son armée, et campa près de la capitale, dans un lieu appelé Acya Abâd ${ }^{803}$, c'est-à-dire le Moulin à vent. Il ordonna d'ouvrir ses trésors, et donna de l'argent par bourses et non au poids, ni par sommes déterminées. La bataille s'engagea entre lui et Toghlok, et les indiens combattirent avec la plus grande ardeur. Les troupes de Toghlok furent mises en déroute, son camp fut pillé, et il resta au milieu de ses trois cents compagnons les plus anciens. Il leur dit : " Où fuir ? Partout où nous serons atteints, nous serons tués. » Les soldats de Khosrew khân s'occupèrent à piller, et se dispersèrent, et il n'en demeura près de lui qu'un petit nombre. Toghlok et ses p395 camarades se dirigèrent vers l'endroit où il se trouvait. La présence du sultan dans ce pays-là est connue au moyen du parasol que l'on élève au-dessus de sa tête, et que l'on appelle en Égypte le dais et l'oiseau. Dans cette dernière contrée, on l'arbore dans les fêtes solennelles ; quant à l'Inde et à la Chine, il y accompagne toujours le sultan, soit en voyage, soit dans sa résidence habituelle.

Or, quand Toghlok et ses compagnons se furent dirigés vers Khosrew, le combat se ralluma entre eux et les Indous ; les soldats du sultan furent mis en déroute, et il ne resta personne près de lui. Il prit la fuite, descendit de cheval, jeta ses vêtements et ses armes, demeura en chemise, et laissa pendre ses cheveux entre ses épaules, ainsi que font les fakîrs de l'Inde ; puis il entra dans un verger situé près de là. Le peuple se réunit près de Toghlok, qui prit le chemin de la ville. Le gouverneur lui en apporta les clefs; il entra dans le palais et se logea dans une de ses ailes; puis il dit à Cachloû khân : "Sois sultan. Sois-le plutôt », répondit Cachloû khân. Tous deux se disputèrent ; enfin Cachloû khân dit à Toghlok : "Si tu refuses d'être sultan, ton fils deviendra maître du pouvoir. » Toghlok eut de la répugnance pour cette proposition; il accepta alors l'autorité et s'assit sur le trône royal. Les grands et les gens du commun lui prêtèrent serment.

803 Asyabad se trouverait dans la plaine de Lahwarat, à cinq kilomètres au nordnord-ouest de Sin (voir chap. 5, n. 81). Or la bataille se déroula à Indarpat, à six kilomètres au nord-est de Sin, le 6 septembre 1320. 
Au bout de trois jours, Khosrew khân, toujours caché dans le même verger, fut vivement pressé par la faim. Il sortit de cet asile et se mit à en faire le tour. Il rencontra le gardien de ce verger, et lui demanda quelque aliment. Cet homme n'en ayant aucun à sa disposition, Khosrew lui donna son anneau, en lui disant : « Va et mets-le en gage, pour te procurer de la nourriture. » Lorsque cet individu se fut rendu au marché avec l'anneau, les gens conçurent des soupçons à son égard et le conduisirent au chihneh, ou magistrat de police. Celui-ci l'introduisit près du sultan Toghlok, auquel il fit connaître qui lui avait remis la bague. Toghlok envoya son fils Mohammed, afin qu'il ramenât Khosrew. Mohammed se saisit de celui-ci et le conduisit près de son père, monté sur un ${ }_{\mathrm{p} 396}$ tatoû, c'est-à-dire un cheval de bât. Lorsque Khosrew fut en présence de Toghlok, il lui dit : « Je suis affamé, donne-moi à manger. » Le nouveau sultan ordonna qu'on lui servît du sorbet, puis des aliments, puis de la bière, et, enfin, du bétel. Quand il eut mangé, il se leva et dit : "Ô Toghlok, conduis-toi envers moi à la manière des rois et ne me déshonore pas ! — Cela t'est accordé », répondit Toghlok, et il ordonna de lui couper le cou, ce qui fut exécuté dans l'endroit même où Khosrew avait tué Kothb eddîn. Sa tête et son corps furent jetés du haut de la terrasse, ainsi qu'il avait fait de la tête de son prédécesseur. Toghlok commanda ensuite de laver le cadavre et de l'envelopper dans un linceul ; après quoi on l'ensevelit dans le mausolée qu'il s'était construit. La royauté appartint en paix pendant quatre ans à Toghlok, qui était un prince juste et vertueux.

\section{RÉCIT DE LA RÉBELLION QUE SON FILS MÉDITA CONTRE LUI, MAIS QUI NE RÉUSSIT PAS}

Lorsque Toghlok fut établi fermement dans la capitale, il envoya son fils Mohammed pour faire la conquête du pays de Tiling ${ }^{804}$ situé à trois mois de marche de Dihly. Il fit partir avec lui une armée considérable, dans laquelle se trouvaient les principaux émirs, tels que le roi Témoûr, le roi Tikîn, Mélic Câfoûr Almuhurdâr, le Gardien du

${ }^{804}$ L'expédition (1321-1322) fut dirigée contre les Kakatiyas de Telingana (voir ci-dessus n. 58) dont le roi Prataparudra, profitant des désordres de Dihli, refusait de payer le tribut. 
Sceau, Mélic Beïram, etc. ${ }^{805}$. Quand Mohammed fut arrivé dans la contrée de Tiling, il voulut se révolter. Or il avait pour commensal un homme, du nombre de jurisconsultes et des poètes, que l'on appelait 'Obaïd. Il lui ordonna de répandre le bruit que ${ }_{\text {p397 }}$ le sultan Toghlok était mort ; car il s'imaginait que les gens lui prêteraient en toute hâte le serment de fidélité, dès qu'ils entendraient cette nouvelle. Lorsque ce bruit eut été porté à la connaissance des soldats, les émirs n’y ajoutèrent pas foi ; chacun d'eux fit battre sa timbale et se révolta. Il ne demeura personne près de Mohammed, et les chefs voulurent le tuer. Mélic Témoûr les en empêcha et le protégea. Il s'enfuit près de son père, avec dix cavaliers, qu'il surnomma iârân mouâfik, c'est-à-dire les compagnons sincères. Son père lui donna des sommes d'argent et des troupes, et lui commanda de retourner dans le Tiling ${ }^{806}$, et il obéit. Mais le sultan connut quel avait été son dessein ; il tua le légiste 'Obaïd et ordonna de mettre à mort Mélic Câfoûr, le muhurdâr. On ficha en terre un pieu de tente, aiguisé à son extrémité supérieure, et on l'enfonça dans le cou de Câfoûr, jusqu'à ce que la pointe sortît par un des côtés de ce malheureux, qui avait la tête en bas, et fut laissé dans cet état. Les autres émirs s'enfuirent près du sultan Chems eddîn, fils du sultan Nâcir eddîn, fils du sultan Ghiyâth eddîn Balaban, et se fixèrent à sa cour.

Les traducteurs utilisent indistinctement l'arabe malik ou sa traduction roi. Dans les deux cas, il s'agit d'un titre honorifique et non d'une fonction.

${ }^{806}$ Les historiens indiens discutent la responsabilité de Muhammad Tughluk dans ces événements. Toutefois, il fut aussitôt renvoyé au Telingana, et cette deuxième expédition de 1323 aboutit à l'extinction du royaume Kakatiya. 
RÉCIT DE LA MARCHE DE TOGHLOK VERS LE PAYS DE LACNAOUTY ET DE CE QUI S’ENSUIVIT JUSQU’À SA MORT

Les émirs fugitifs séjournèrent près du sultan Chems eddîn ${ }^{807}$.

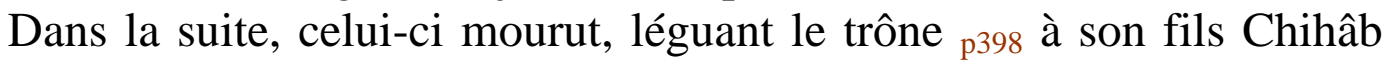
eddîn. Ce prince succéda à son père ; mais son frère cadet, Ghiyâth eddîn Behâdoûr Boûrah, le vainquit, s'empara du royaume, et tua son frère Kothloû khân, ainsi que la plupart de ses autres frères. Deux de ceux-ci, le sultan Chihâb eddîn et Nâcir eddîn, s'enfuirent près de Toghlok, qui se mit en marche avec eux, afin de combattre le fratricide. Il laissa dans son royaume son fils Mohammed en qualité de vice-roi, et s'avança en hâte vers le pays de Lacnaouty. Il s'en rendit maître, fit prisonnier son sultan Ghiyâth eddîn Behâdoûr et reprit avec ce captif le chemin de sa capitale ${ }^{808}$.

Il y avait alors à Dihly le saint Nizhâm eddîn Albedhâouny ${ }^{809}$, et Mohammed châh, fils du sultan, ne cessait de lui rendre des visites, de témoigner de la considération à ses serviteurs et d'implorer ses prières Or le cheïkh était sujet à des extases qui s’emparaient de tout son être. Le fils du sultan dit à ses serviteurs : "Quand le cheïkh sera dans cette extase qui se rend maîtresse de lui, faites-le-moi savoir. » Lorsque son accès le prit, on en prévint le prince, qui se rendit près de lui. Dès que le cheïkh le vit, il s’écria : « Nous lui donnons la royauté ! » Ensuite il mourut pendant l'absence du sultan, et le fils de ce prince, Moham-

${ }^{807}$ Nasir al-din Mahmud, fils de Balban et souverain du Bengale (voir ci-dessus, n. 31), avait abdiqué en 1291 au profit de son fils Rukn al-din Kaikaus, lequel régna jusqu'en 1302. Shams al-din Firuz lui succéda, qu’Ibn Battûta est le seul à le présenter comme fils de Nasir al-din. Shams al-din Firuz avait étendu sa souveraineté à l'est et au sud du Bengale, mais celle-ci fut très vite contestée par ses fils Ghiyath al-din Bahadur dit Bura (le Noir), qui s'installa à l'est, et Shihab al-din Bughra, qui supplanta pendant un moment son père à Lakhnawti en 1318. En 1322, à la mort de Shams al-din Firuz, Ghiyath al-din supprima tous ses frères à l'exception de Shihab al-din et de Nasir al-din, et ce sont plutôt les suppliques de ceux-ci qui donnèrent le prétexte à une intervention de Dihli, puisqu'Ibn Battûta est le seul à parler de la fuite des conspirateurs au Bengale.

L'expédition date de 1324. Nasir al-din fut nommé souverain du nord Bengale 809 et le reste fut annexé à l'Empire de Dihli.

Connu sous le nom de Nizam al-din Awila (le Saint), il fut un des plus célèbres représentants de l'ordre tchishti en Inde ; diciple de Farid al-din Mas'ud (voir chap. 5, n. 63). Certaines sources le mêlent à l'assassinat du roi et pour cela font repousser la date de sa mort après celle du roi. 
med, porta sa bière sur son épaule. Cette nouvelle parvint à son père, il se défia de lui et lui adressa des menaces. Différents actes avaient déjà inspiré des soupçons à Toghlok contre son fils il le voyait de mauvais œil acheter un grand nombre d'esclaves, donner des présents p399 magnifiques et se concilier les cœurs ; mais alors sa colère contre lui augmenta. On rapporta au sultan que les astrologues prétendaient qu'il n'entrerait pas dans la ville de Dihly ${ }^{810}$, au retour de ce voyage. Il se répandit contre eux en menaces.

Lorsqu'il fut revenu de son expédition et qu'il approcha de la capitale, il ordonna à son fils de lui bâtir un palais, ou, comme ce peuple l'appelle, un kiosque, près d'une rivière qui coule en cet endroit et que l'on nomme Afghân Poûr ${ }^{811}$. Mohammed l'édifia en trois jours, et le construisit pour la majeure partie en bois. Il était élevé au-dessus du sol et reposait sur des colonnes de bois. Mohammed le disposa avec art et dans des proportions que fut chargé de faire observer Almélic Zâdeh, connu dans la suite par le titre de Khodjah djihân ${ }^{812}$. Le vrai nom de cet individu était Ahmed fils d'Ayâs; il devint le principal vizir du sultan Mohammed, et il était alors inspecteur des bâtiments. L'invention qu'imaginèrent ces deux personnages en construisant le kiosque consista à le bâtir de telle sorte qu'il tombât et s'écroulât dès que les éléphants en approcheraient d'un certain côté. Le sultan s'arrêta dans cet édifice, et fit servir à manger au peuple, qui se dispersa ensuite. Son fils lui demanda la permission de faire passer devant lui les éléphants, couverts de leurs harnais de parade. Le sultan le lui permit.

Le cheïkh Rocn eddîn m’a raconté qu'il se trouvait alors près du sultan, et qu'ils avaient avec eux le fils de ce dernier, son enfant de prédilection, Mahmoûd. Sur ces entrefaites, Mohammed revint et dit au cheïkh : «O maître ! voici le moment de la prière de l'après-midi ; descends et prie. - Je descendis, continue le cheïkh, et ${ }_{\text {p } 400}$ l'on ame-

810 Ces prédictions sont attribuées à Nizam al-din Awliya, qui aurait répondu à l'ordre royal envoyé par Ghiyath al-din Tughluk au retour du Bengale le sommant de quitter Dihil avant l'arrivée du souverain : "Dihli est encore loin. »

${ }^{811}$ Afghanpur est le nom d'un village situé au sud-est de Tughtu-kabad (voir chap. 5, n. 82), mais on ne sait rien d'une rivière.

${ }^{812}$ Voir chap. 5, n. 77. Il avait été converti à l’islam par Nizam al-din Awliya. 
na les éléphants d'un même côté, ainsi que le prince et son confident avaient imaginé de le faire. Lorsque ces animaux marchèrent de ce côté, le kiosque s'écroula sur le sultan et son fils Mahmoûd. J'entendis le bruit, dit toujours le cheïkh, et je revins sur mes pas sans avoir fait ma prière. Je vis que le kiosque était renversé. Le fils du sultan, Mohammed, ordonna d'apporter des pioches et des pelles, afin de creuser la terre et de chercher après son père. Mais il fit signe qu'on tardât d'obéir, et on n'apporta les outils qu'après le coucher du soleil. On se mit alors à creuser et l'on découvrit le sultan, qui avait courbé le dos au-dessus de son fils, afin de le préserver de la mort. Quelquesuns prétendirent que Toghlok fut retiré mort, d'autres, au contraire, qu'il était encore en vie, qu'on l'acheva et qu'on le transporta de nuit dans le mausolée qu'il s'était construit près de la ville appelée, d'après lui, Toghlok Abâd, et où il fut enterré ${ }^{813}$ "

Nous avons raconté ${ }^{814}$ pour quel motif il avait bâti cette ville, où se trouvaient ses trésors et ses palais. C'est là qu'était le palais immense qu'il recouvrit de tuiles dorées. Au moment où le soleil se levait, ces tuiles resplendissaient d'une vive lumière, et d'un éclat qui empêchait l'œil de les regarder longtemps. Toghlok déposa dans cette ville de Toghlok Abâd des trésors considérables. On raconte qu'il construisit un bassin, où il versa de l'or fondu, de manière à en former un seul morceau. Son fils Mohammed châh dépensa tout cela lorsqu'il fut monté sur le trône.

Ce fut aux habiles mesures observées par le vizir Khodjah djihân, en construisant le kiosque qui s'écroula sur Toghlok, ainsi que nous l'avons rapporté, qu'il dut la considération dont il jouissait auprès de Mohammed et la prédilection que celui-ci lui témoignait. Personne, soit vizir ou autre, n'approchait de lui sous le rapport de l'estime où le tenait le sultan, et n’atteignait le rang dont il était en possession près de ce prince.

813 Son mausolée existe toujours au sud de Tughlukabad. Certaines sources indiennes racontent cet incident d'une manière plus allusive, mais la version d'Ibn Battûta semble prévaloir.

814 Voir p. 356. 


\section{Le bon et le mauvais gouvernement de Muhammad bin Tughluk}

$\underline{\text { Retour à la Table des Matières }}$

Histoire DU SUlTAN ABOUl'MODJÂHID MOHAMMED CHÂH, FILS DU SULTAN GHIYÂTH EDDÎN TOGHLOK CHÂH, ROI DE L'INDE ET DU SIND, À LA COUR DUQUEL NOUS NOUS RENDÎMES

Lorsque le sultan Toghlok fut mort, son fils Mohammed s'empara du royaume, sans rencontrer d'adversaire ni de rebelle. Nous avons dit ci-dessus que son nom était Djaounah ; mais, quand il fut devenu roi, il se fit appeler Mohammed et fut surnommé Abou'l Modjâhid ${ }^{815}$. Tout ce que j'ai rapporté touchant l'histoire des sultans de l'Inde, j'en ai été informé et je l'ai appris, au moins pour la plus grande partie, de la bouche du cheïkh Camâl eddîn, fils de Borhân eddîn, de Ghaznah ${ }^{816}$, kâdhi des kâdhis. Quant aux aventures de ce roi-ci, la plupart sont au nombre de ce que j’ai vu durant mon séjour dans ses États. p403

\section{PORTRAIT DE CE ROI}

Mohammed est de tous les hommes celui qui aime davantage à faire des cadeaux et aussi à répandre le sang. Sa porte voit toujours près d'elle quelque fakîr ${ }^{817}$ qui devient riche, ou quelque être vivant qui est mis à mort. Ses traits de générosité et de bravoure, et ses

${ }^{815}$ Le Père des guerriers contre les infidèles. Les sultans de Dihli avaient imité les titres royaux des Ghaznevides et des Ghurides. Iletmish, Balban et Ghiyath aldin Tughluk s'étaient fait appeler Abu'l Muzaffar (le Père des victorieux). Toutefois, sur les monnaies de Muhammad Tughluk on trouve la mention : 816 Voir chap. 6, n. 1.

${ }^{817}$ Ici dans le sens de pauvre. 
exemples de cruauté et de violence envers les coupables, ont obtenu de la célébrité parmi le peuple. Malgré cela, il est le plus humble des hommes et celui qui montre le plus d'équité ; les cérémonies de la religion sont observées à sa cour ; il est très sévère en ce qui regarde la prière et le châtiment qui suit son inexécution. Il est au nombre des rois dont la félicité est grande, et dont les heureux succès dépassent ce qui est ordinaire ; mais sa qualité dominante, c’est la générosité. Nous raconterons, parmi les traits de sa libéralité, des merveilles dont les semblables n’ont été rapportées d'aucun des princes qui l'ont précédé. J'atteste Dieu, ses anges et ses prophètes que tout ce que je dirai de sa munificence extraordinaire est la vérité sûre. Il me suffit de Dieu pour témoin. Je sais qu'une portion de ce que je raconterai en ce genre ne sera pas admise dans l'esprit de beaucoup d'individus, et qu'ils la comprendront parmi ce qui est impossible dans l'ordre habituel des choses. Mais, quand il s'agit d'un événement que j'ai vu de mes yeux, dont j'ai connu la réalité, dans lequel j'ai pris une grande part, je ne puis faire autrement que de dire la vérité ${ }^{818}$. D’ailleurs, la majeure partie de ces faits est rendue constante par la tradition orale dans les pays de l'Orient. p404

\section{DES PORTES DU PALAIS DE CE SULTAN, DE SA SALLE D'AUDIENCE ET DE L'ORDRE SUIVI EN CES LIEUX}

Le palais du sultan, à Dihly, est appelé Dâr Sérâ ${ }^{819}$ et a un grand nombre de portes. A la première se tiennent une troupe d'hommes préposés à sa garde ; les joueurs de clairon, de trompette et de fifre sont assis en cet endroit, et quand il arrive un émir ou un grand personnage ils jouent de leur instrument et disent, dans les intervalles de ce concert : « Un tel est venu, un tel est venu. » Il en est de même à la

${ }^{818}$ C’est cette partie du récit qui a été la plus contestée par ses contemporains de la cour de Fez, d'après les dires d'Ibn Khaldoun c'est pour cela que notre auteur prend ses précautions, en se référant à la tradition orale qui est la plus valable dans la société islamique.

${ }^{819}$ Ce palais est un des rares monuments de l'époque de Muhammad Tughluk dont des traces subsistent à l'emplacement de la quatrième ville de Dihli, appelée Djahanpenah (voir chap. 5, n. 83), près du village actuel de Begampur. Il s’appelle Bidjay Mandal et correspond aux restes du Kasr-i Hezar Situn (le Palais aux mille colonnes), qui serait la salle d'audience du palais citée par Ibn Battûta. 
seconde et à la troisième porte. En dehors de la première, il y a des estrades, sur lesquelles s'asseyent les bourreaux qui sont chargés de tuer les gens. C'est la coutume chez ce peuple, toutes les fois que le sultan a ordonné de tuer un homme, qu'il soit massacré à la porte de la salle d'audience ${ }^{820}$ et que son corps y reste trois jours. Entre les deux portes, la première et la seconde, il y a un grand vestibule, de chaque côté duquel sont des estrades en pierre de taille, où s'asseyent les hommes de faction parmi les gardiens des portes. Quant à la seconde de ces deux portes, les portiers chargés de sa garde y prennent place. Entre elle et la troisième, il y a une grande estrade où siège le nakîb en chef ${ }^{821}$; il a devant lui une massue d'or, qu'il prend dans sa main, et sur sa tête il porte une tiare d'or incrustée de pierreries et surmontée de plumes de paon ${ }^{822}$, Les nakîbs se tiennent devant lui, coiffés chacun d'une calotte dorée, les reins serrés par une riche ceinture, et ${ }_{\mathrm{p} 405}$ tenant dans la main un fouet, dont la poignée est d'or ou d'argent.

Cette seconde porte aboutit à une très grande salle d'audience ${ }^{823}$ où s'asseyent les sujets. Quant à la troisième porte, elle est pourvue d'estrades, où se placent les écrivains de la porte. Une des coutumes de ce peuple, c'est que personne n'entre par cette porte, à moins que le sultan ne l'ait désigné pour cela. Il fixe, pour chaque individu, un certain nombre de ses compagnons et de ses gens qui entrent avec lui. Toutes les fois que quelqu'un se présente à cette porte, les secrétaires écrivent : "Un tel est venu à la première heure ou à la seconde », et ainsi de suite, jusqu'à la fin du jour. Le sultan prend connaissance de ce rapport après la dernière prière du soir. Les écrivains tiennent note aussi de tout ce qui arrive à la porte ; des fils de rois ${ }^{824}$. Ont été désignés pour transmettre au sultan tout ce qu'ils écrivent.

Une autre coutume des Indiens, c'est que quiconque s'abstient de paraître au palais du sultan ${ }^{825}$ pendant trois jours et plus, soit qu'il ait

\footnotetext{
820 Le mot arabe mashwar ici utilisé indique probablement l'ensemble du palais.

821 Ici probablement le chef des huissiers.

822 Coiffure empruntée aux Hindous.

823 Ici le mot mashwar est réutilisé pour indiquer apparemment une antichambre.

${ }^{824}$ Le terme malik (roi) correspondait à l'époque à un titre honorifique accordé aux grands serviteurs de l'empire. Il n'implique ni l'exercice du pouvoir ni l'appartenance à la famille impériale.

825 Parmi les grands de l'empire bien entendu.
} 
une excuse ou non, ne passe pas cette porte par la suite, si ce n'est avec la permission du souverain. S'il a quelque excuse, telle qu'une maladie ou un autre empêchement, il fait offrir au souverain un cadeau choisi parmi les objets qu'il lui convient de présenter à ce monarque. C'est ainsi qu'en usent également ceux qui arrivent de voyage. Le légiste offre un Coran, des livres et des dons semblables ; le fakîr, un tapis à prier, un chapelet, un cure-dents ou des objets du même genre. Les émirs et leurs pareils présentent des chevaux, des chameaux et des armes.

Cette troisième porte aboutit à la salle d'audience, p406 vaste et immense, que l'on appelle Hezâr Ousthoûn ${ }^{826}$, ce qui veut dire les Mille Colonnes. Ces colonnes sont de bois vernissé, et elles supportent une toiture de planches, peintes de la manière la plus admirable. Les gens s'asseyent au-dessous, et c'est dans cette salle que le sultan donne ses audiences solennelles.

\section{DE L’ORDRE OBSERVÉ PAR LE SULTAN DANS SES AUDIENCES}

La plupart de ses audiences ont lieu après la prière de quatre heures du soir ; mais souvent il en donne au commencement de la journée. Il siège sur une estrade tendue d'étoffes de couleur blanche et surmontée d'un trône ; un grand coussin est placé derrière son dos; il a à sa droite un autre coussin et un troisième à sa gauche. Il s'assied à la manière de l'homme qui veut réciter le téchehhud, ou profession de foi musulmane, pendant la prière. C'est ainsi que s'asseyent tous les habitants de l'Inde. Quand le sultan est assis, le vizir se tient debout devant lui, les secrétaires se placent derrière le vizir, et les chambellans derrière les secrétaires. Le chef suprême des chambellans est Fîroûz Mélic, cousin germain du sultan et son lieutenant ${ }^{827}$. C'est celui des chambellans qui approche le plus près du sultan. Après lui vient le chambellan particulier, qui est lui-même suivi de son substitut, de l'intendant du palais et de son lieutenant, de deux dignitaires appelés l'un la gloire et l'autre le chef des chambellans, et des personnes placées sous leurs ordres.

\footnotetext{
${ }^{826}$ Hezar Situn (voir n. 10 ci-dessus).

${ }^{827}$ Et également son successeur (1351-1388).
} 
Les nakîbs, au nombre d'environ cent, viennent après les chambellans. Lorsque le sultan s'assied, les uns et les autres crient de leur voix la plus forte : «Au nom de Dieu. » Ensuite se place debout, derrière le sultan, le grand roi Kaboûlah ${ }^{828}$, tenant dans sa main un émouchoir p407 avec lequel il chasse les mouches. Cent silahdârs ${ }^{829}$ se tiennent debout à la droite du sultan, et un pareil nombre à sa gauche. Ils ont dans leurs mains des boucliers, des épées et des arcs. A droite et à gauche, sur toute la longueur de la salle d'audience, sont placés : le kâdhi des kâdhis ; le prédicateur en chef ; les autres kâdhis ; les principaux légistes; les principaux descendants de Mahomet; les cheïkhs ${ }^{830}$, les frères et beaux-frères du sultan ; les principaux émirs ; les chefs des illustres, c'est-à-dire des étrangers ${ }^{831}$; les généraux ${ }^{832}$.

On amène ensuite soixante chevaux, sellés et bridés avec les harnais impériaux ; parmi eux il y en a qui portent les insignes du khalifat ce sont ceux dont les brides et les sangles sont de soie noire et dorée ; il y en a qui ont les mêmes objets en soie blanche et dorée ; le sultan, seul, monte des chevaux ainsi équipés. On tient la moitié de ces chevaux à droite et l'autre moitié à gauche, de manière que le sultan puisse les voir. Puis on amène cinquante éléphants décorés d'étoffes de soie et d'or ; leurs défenses sont recouvertes de fer, afin qu'elles soient plus propres à tuer les coupables. Sur le cou de chaque éléphant se tient son cornac, ayant à la main une sorte de hache d'armes de fer, avec laquelle il châtie sa bête et la fait se diriger selon ce qu'on exige d'elle. Chaque éléphant a sur son dos une espèce de grande boîte, qui peut contenir vingt combattants, plus ou moins, d'après la grosseur de l'animal et la grandeur de son corps. Quatre étendards sont fixés aux angles de cette boîte. Ces éléphants sont dressés à saluer le sultan et à incliner leurs têtes, et, lorsqu'ils saluent, les chambellans disent à haute voix : " Au nom de Dieu ! » On les fait aussi se tenir, moitié à droite, moitié à gauche, derrière les personnes qui sont debout. p408

${ }^{828}$ Un certain Malik Qabul était gouverneur de Warangal, la capitale de Telingana, en 1335.

${ }_{820}^{829}$ Mot persan désignant un corps de garde.

830 Probablement les cheïkhs des corporations soufis, qui étaient très puissantes dans la capitale.

831 Voir plus haut p. 326.

${ }^{832}$ Le terme arabe ca'id utilisé englobe aussi probablement les hauts fonctionnaires non militaires. 
Tous ceux qui arrivent, d'entre les gens désignés pour rester debout, soit à droite, soit à gauche, font une salutation près du lieu où se tiennent les chambellans. Ceux-ci disent: "Au nom de Dieu ! " et l'élévation du ton de leur voix est proportionnée à la grandeur de la renommée de celui qui salue. Lorsqu'il a fléchi le genou, il retourne à sa place, à la droite ou à la gauche, et ne la dépasse jamais. Si c'est un Indien idolâtre qui salue, les chambellans et les nakîbs lui disent: «Que Dieu te guide! » Les esclaves du sultan se tiennent debout derrière tout le monde, ayant dans leurs mains des boucliers et des épées, et il n'est possible à personne de se mêler parmi eux, si ce n'est en passant devant les chambellans qui sont debout devant l'empereur.

\section{DE L’ADMISSION DES ÉTRANGERS ET DES PORTEURS DE CADEAUX EN PRÉSENCE DU SULTAN}

S'il se trouve à la porte quelqu'un qui vienne pour offrir au sultan un présent, les chambellans entrent chez ce prince dans l'ordre hiérarchique. L'émir chambellan les précède, son substitut marche derrière lui; puis viennent le chambellan particulier et son substitut, l'intendant du palais et son suppléant, le chef des chambellans et le principal chambellan. Ils font une salutation dans trois endroits différents, et annoncent au sultan quelle est la personne qui attend à la porte. Lorsqu'il leur a ordonné de l'amener, ils placent le présent qu'elle apporte dans les mains d'individus qui doivent se tenir debout avec le cadeau devant l'assistance, afin que le sultan puisse le voir. Le prince mande alors celui qui l'offre, et ce dernier salue trois fois avant d'arriver devant lui ; puis il fait une salutation près de l'endroit où se tiennent les chambellans. Si c'est un homme considérable, il se tient debout sur la même ligne que l'émir chambellan ; sinon, il se met derrière lui. Le sultan lui adresse lui-même la parole de la manière la plus gracieuse et lui souhaite la bienvenue. Si cet homme est du nombre de ceux qui méritent de la considération, le sultan ${ }_{\mathrm{p} 409}$ lui prend la main ou il l'embrasse et demande quelque portion de son présent. On l'expose devant lui et, s'il se compose d'armes ou d'étoffes, il les tourne dans tous les sens et témoigne son approbation, afin de raffermir l'esprit du donateur, de l'enhardir et de lui montrer de la sollicitude. Il lui accorde un vêtement d'honneur et lui assigne une somme 
d'argent pour se laver la tête, selon la coutume des Indiens en pareille circonstance, le tout en proportion de ce que mérite le donateur.

DE LA MANIÈRE DONT ON PRÉSENTE AU SULTAN LES CADEAUX DE SES AGENTS

Lorsque les agents arrivent portant les dons et les richesses amassées au moyen d'impôts des différentes provinces, ils font des vases d'or et d'argent, tels que des bassins, des aiguières et autres. Ils font aussi, en or et en argent, des morceaux qui ont la forme de briques et qu'on appelle khicht ${ }^{833}$. Les farrâchs ${ }^{834}$ ou valets, qui sont les esclaves du sultan, se tiennent debout en un seul rang, et ils ont à la main les présents, chacun d'eux portant une pièce séparée. Après cela, on fait avancer les éléphants, s'il s'en trouve dans le cadeau, puis les chevaux sellés et bridés, ensuite les mulets, et enfin les chameaux chargés des tributs.

Je vis une fois le vizir Khodjah Djihân offrir un présent au sultan, qui revenait de Daoulet Abâd. Il alla à sa rencontre jusqu'à l'extérieur de la ville de Biyânah ${ }^{835}$ et fit porter le cadeau devant le monarque dans l'ordre que nous avons décrit. Parmi les objets offerts dans cette circonstance, je remarquai un vase de porcelaine rempli ${ }_{\mathrm{p} 410}$ de rubis, un autre rempli d'émeraudes et un troisième plein de perles magnifiques. Cela se passait en présence de Hâdji Câoun ${ }^{836}$, cousin germain du sultan Aboû Sa'îd, roi de l'Irâk. Le souverain de l'Inde lui donna une partie de ce cadeau, comme nous le dirons plus tard en détail, s’il plaît au Dieu très haut.

\footnotetext{
833 Terme persan.

${ }^{834}$ Littéralement, les préposés au nettoyage, qui par ailleurs, n’étaient pas obligatoirement des esclaves.

835 Bayana, dans le district de Bharatpur, à cent vingt miles au sud de Dihli. Elle ${ }^{836}$ Voir plus loin n. 61.
} 
DE LA SORTIE DU SULTAN LORS DES DEUX PRINCIPALES FÊTES ET DE CE QUI SE RATTACHE À CE SUJET

Le soir qui précède la fête, le sultan fait cadeau de vêtements aux rois ou grands dignitaires, aux favoris, aux chefs du royaume, aux personnages illustres ou étrangers, aux secrétaires, aux chambellans, aux officiers, aux gouverneurs, de même qu'aux serviteurs et aux messagers. Au matin de la fête, on orne tous les éléphants avec de la soie, de l'or et des pierres précieuses. Seize de ces animaux ne sont montés par personne, et ils sont seulement réservés pour le sultan. On élève sur ceux-ci seize tchetrs ou parasols de soie, incrustés de pierres précieuses, et dont les manches sont en or pur. Chacun de ces éléphants porte, de plus, un coussin de soie, enrichi de pierres précieuses. Le souverain monte un de ces éléphants, et l'on porte devant lui la ghâchiyah ${ }^{837}$, c'est-à-dire la housse qui recouvre la selle du sultan ; elle est incrustée des pierres les plus précieuses.

Devant le monarque marchent à pied ses serviteurs et ses esclaves, chacun d'eux ayant sur la tête une calotte d'or ${ }^{838}$, et autour des hanches une ceinture également d'or, que quelques-uns enrichissent de pierres précieuses. Les officiers, au nombre d'environ trois cents, marchent ${ }_{\mathrm{p} 411}$ aussi à pied devant le sultan ; ils portent sur leur tête un bonnet haut en or, ont autour des reins une ceinture d'or, et à leur main un fouet, dont le manche est en or. On remarque, montés sur des éléphants : le grand juge Sadr Aldjihân Camâl eddîn Alghaznéouy, le grand juge Sadr Aldjihân Nâssir eddîn Alkhârezmy ${ }^{839}$, et tous les autres juges ; il en est ainsi des principaux personnages illustres, parmi les Khorâçâniens, les Irâkiens, les Syriens, les Égyptiens et les Barbaresques. Tous ceux-ci sont pareillement montés sur des éléphants. Il est à noter que tous les étrangers sont nommés Khorâçâniens par les peuples de l'Inde. Les muezzins montent aussi sur des éléphants, et ne cessent de crier : « Dieu est tout-puissant ! »

Telle est la disposition qu'on observe quand le sultan sort de la porte du château. Il est attendu par toutes les troupes, chaque com-

${ }^{837}$ Coutume introduite depuis les Seldjukides comme symbole de la royauté.

838 Le terme aqruf utilisé indique un haut chapeau de forme conique.

${ }^{839}$ Ces deux personnages - le premier est l'informateur historique d'Ibn Battûta sont cités plusieurs fois dans le texte, mais ils ne sont pas connus par ailleurs. 
mandant étant à la tête de son corps, séparé des autres, et ayant avec lui ses tambours et ses drapeaux. Le souverain s'avance, précédé par les gens à pied que nous avons mentionnés; devant ceux-ci marchent les juges et les muezzins, qui proclament les louanges de l'Être suprême. Derrière le sultan se voient ses mérâtibs ${ }^{840}$ : ce sont les drapeaux, les tambours, les cors, les trompettes et les hautbois. Viennent après cela toutes les personnes qui sont dans son intimité ; à leur suite, le frère du monarque Mobârec khân ${ }^{841}$, avec ses insignes et ses troupes ; puis le neveu du sultan, Behrâm khân ${ }^{842}$, avec ses insignes et ses troupes ; le cousin du sultan, le roi Fîroûz ${ }^{843}$, avec ses insignes et ses troupes ; le vizir, avec ses insignes et ses troupes ; le roi Modjîr, p412 fils de Dhoû'rrédja ${ }^{844}$, avec ses insignes et ses troupes le grand roi Kaboûlah ${ }^{845}$, avec ses insignes et ses troupes. Celui-ci est fort estimé du sultan ; il occupe un rang très élevé et possède d'immenses richesses. J'ai été informé par le personnage qui tient ses registres, ou son intendant, et qui est connu sous la dénomination de l'Homme de confiance du royaume, 'Alâ eddîn 'Aly almisry, appelé aussi Ibn Acchérâbichy ${ }^{846}$, ou le fils du marchand de bonnets que la dépense de Kaboûlah, de ses serviteurs, ainsi que le total de leurs salaires, s'élevait à trente-six lacs par an, c'est-à-dire trente-six fois cent mille dînârs d'argent, ou trois millions six cent mille pièces d'argent. Après Kaboûlah viennent dans le cortège le roi Nocbïah ${ }^{847}$, avec ses insignes et ses troupes; le roi Boghrah, avec ses insignes et ses troupes ; le roi Mokhliss, avec ses insignes et ses troupes, et le roi Kothb almoulc ${ }^{848}$ avec ses insignes et ses troupes. Tous les individus que nous

\footnotetext{
840 Insignes.

841 Inconnu par ailleurs.

${ }^{842}$ Connu comme fils adoptif de Ghiyath al-din Tughluk et nommé gouverneur de l'est du Bengale après l'expédition de 1324 (voir chap. 6, n. 82 et 83). Il mourut dans ce poste en 1338-1339.

843 Voir ci-dessus n. 13.

${ }^{844}$ Mudjir al-din bin Abi Radja, chargé de réprimer la révolte de Gushtashp en 1326 (voir t. III, p. 70).

845 Voir ci-dessus n. 14.

${ }^{846}$ Du persan serpush : bonnet.

${ }^{847}$ Malik Nikpay, chef du secrétariat qui sera chargé de l'expédition aux Himalayas (voir t. III, p. 75).

${ }^{848}$ Il s’agit peut-être du même personnage que le gouverneur de Multan cité plus haut p. 339.
} 
venons de nommer sont les principaux émirs, qui ne quittent jamais le sultan. Ils montent à cheval avec lui le jour de la fête, avec leurs insignes, tandis que les autres émirs en sont privés. Toutes les personnes qui montent à cheval dans cette solennité sont revêtues de leurs cuirasses, et leurs montures sont caparaçonnées. La plupart de ces gens sont des esclaves du monarque.

Lorsque le sultan est arrivé à la porte de l'oratoire, il s'arrête, et ordonne aux juges, aux principaux émirs et aux plus notables des personnages illustres d'entrer. Il descend après cela de sa monture, et l'imâm prie et prêche. S'il s'agit de la fête des Sacrifices, le sultan amène un chameau et l'égorge avec une lance courte, qu'on p413 appelle dans l'Inde nîzeh, il a soin de recouvrir ses habits d'une serviette de soie, pour se garantir du sang. Cette cérémonie accomplie, il remonte sur l'éléphant et retourne à son palais.

DE LA SÉANCE QUE TIENT LE SULTAN LE JOUR DE LA FÊTE, DU TRÔNE PRINCIPAL ET DE LA PLUS GRANDE CASSOLETTE

Le jour de la fête on recouvre tout le château de tapis et on l'orne de la manière la plus somptueuse. On élève, sur tout l'espace du lieu de l'audience, la bârgah ${ }^{849}$, qui ressemble à une immense tente. Elle est soutenue par de nombreuses et grosses colonnes, et est entourée de tous côtés par des coupoles ou pavillons. On forme des arbres artificiels avec de la soie de différentes couleurs, et où les fleurs sont aussi imitées. On les distribue en trois rangées dans toute la salle d'audience, et l'on place partout, entre ces arbres, des estrades d'or, surmontées d'un coussin recouvert de sa housse. Le trône magnifique est dressé sur le devant de la salle ; il est entièrement en or pur, et les pieds en sont incrustés de pierres précieuses ; il a de hauteur vingttrois empans, et de targur, moitié environ. Il est composé de plusieurs pièces, qui se joignent ensemble et forment un tout. Chacune de ces pièces est portée par plusieurs hommes, à cause de la pesanteur de l'or. On place sur le trône le coussin, et l'on élève sur la tête du sultan le parasol incrusté de pierres précieuses. Quand le monarque monte sur son trône, les chambellans et les officiers crient à haute voix : 
«Au nom de Dieu! » Alors les assistants s’avancent pour saluer le souverain, en commençant par les juges, les prédicateurs, les savants, les nobles et les cheïkhs ; puis viennent les frères du sultan, ses proches parents, ses beaux-frères ou alliés et les personnages illustres. Ensuite le vizir, les commandants des troupes, les cheïkhs des esclaves et les notables de l'armée. Ils p414 saluent tous séparément, l'un après l'autre, sans presse et sans foule.

C'est l'usage, au jour de la fête, que chaque personne qui a été gratifiée du revenu de quelque village apporte des pièces d'or, enveloppées dans un lambeau d'étoffe, sur lequel elle écrit son nom, et qu'elle jette dans un bassin d'or, préparé à cet effet. On amasse ainsi une somme considérable, que le sultan donne à qui lui plaît. Les salutations accomplies, on dispose les mets pour les assistants, suivant le rang de chacun de ceux-ci.

On monte dans ce jour la grande cassolette, qui ressemble à une tour ; elle est en or pur et composée de diverses pièces qu'on joint à volonté. Il faut plusieurs hommes pour transporter chacune de ses parties. Dans son intérieur se trouvent trois cellules où entrent les hommes chargés de répandre les parfums ; ils allument le bois appelé $k a$ mâry ${ }^{850}$ ainsi que le kâkouly ${ }^{851}$, l'ambre gris et le benjoin, de façon que la vapeur de ces matières remplit toute la salle d'audience. De jeunes garçons tiennent à la main des barils d'or et d'argent, remplis d'eau de roses, et d'eau de fleurs d'oranger, qu'ils répandent à profusion sur les assistants.

Le trône et la cassolette dont nous avons parlé ne sont tirés du trésor qu'à l'occasion des deux grandes fêtes seulement. Les jours des autres solennités, le sultan s'assied sur un trône d'or inférieur au premier. On dresse alors un salle d'audience éloignée ${ }^{852}$, pourvue de trois portes, et le sultan prend place à l'intérieur. A la première porte se tient debout 'Imâd almoulc Sertîz ${ }^{853}$, à la seconde le roi Nocbïah,

850 De Qamar, c’est-à-dire Khmer, le Cambodge.

851 De Qaqula, en Malaisie. Les deux seront décrits au t. III.

852 Gibb traduit « haute ».

853 Cité plus haut comme gouverneur du Sind. Il fut par ta suite gouverneur d'Elichpur dans le Deccan et se tua au cours de la grande révolte de cette région en 1347. 
et à la troisième Yoûçuf Boghrah. A droite et à gauche se tiennent debout les chefs des esclaves écuyers ou porte-épées; la foule se tient pareillement debout, suivant le rang de chacun. p415

L'inspecteur de cette salle d'audience est le roi Thaghal, qui porte à la main une baguette d'or: son substitut en porte une d'argent, et, tous les deux, ils placent les assistants et forment les files. Le vizir et les secrétaires sont debout, ainsi que les chambellans et les officiers.

Puis viennent les musiciennes et les danseuses, et d'abord les filles des rois indiens infidèles qu'on a fait captives dans cette année-là. Elles chantent et dansent, et le sultan les donne aux émirs et aux personnages illustres. Après elles, arrivent les autres filles des infidèles, qui chantent aussi et dansent, et que le sultan donne à ses frères, à ses proches parents, à ses beaux-frères et aux fils des rois. Cette séance se tient après la prière de l'après-midi. Le souverain tient une autre séance le lendemain de la fête, à la même heure, et en suivant les mêmes dispositions. Les chanteuses viennent, elles chantent et dansent, et il les donne aux chefs des esclaves. Le troisième jour, il marie ses proches parents, qui reçoivent ses bienfaits ; le quatrième, il affranchit des hommes esclaves; le cinquième, il affranchit des femmes esclaves ; le sixième, il marie ensemble des hommes et des femmes esclaves ; enfin le septième jour, il distribue de nombreuses aumônes.

\section{DE L'ORDRE QU'ON OBSERVE QUAND LE SULTAN ARRIVE DE VOYAGE}

Lorsque le souverain est de retour de ses voyages, on orne les éléphants, et l'on élève sur seize d'entre eux seize parasols, dont les uns sont brochés d'or, et les autres enrichis de pierres précieuses. On porte devant lui la ghâchiyah, qui est la housse servant à recouvrir la selle, et qui est incrustée des pierreries les plus fines. On construit des coupoles de bois partagées en plusieurs étages, et on les recouvre d'étoffes de soie. Dans chaque étage, on voit les jeunes esclaves chanteuses, revêtues de très beaux habillements et de parures fort jolies ; quelques-unes parmi elles dansent. Dans le centre de ${ }_{p 416}$ toutes ces coupoles, il y a un réservoir immense, fait avec des peaux, et rempli d'essence de roses ou de sirop dissous dans de l'eau. Tout le monde, sans exception, peut en boire, les nationaux comme les étrangers. Ceux qui en prennent reçoivent en même temps les feuilles de bétel et 
la noix d'arec. L'espace qui sépare les pavillons est recouvert d'étoffes de soie, que foule la monture du sultan. Les murailles des rues par lesquelles le souverain doit passer sont ornées aussi d'étoffes de soie, depuis la porte de la ville jusqu'à celle du château. Devant le monarque marchent ses esclaves, au nombre de plusieurs milliers ; la foule et les soldats sont par-derrière.

J’ai été présent quelquefois à son entrée dans la capitale, revenant de voyage. On avait dressé trois ou quatre petites balistes sur les éléphants. Elles lançaient sur les assistants des pièces d'argent et d'or ${ }^{854}$ que ceux-ci ramassaient. Cela commença au moment de l'entrée du sultan dans la ville, et dura jusqu’à son arrivée au château.

\section{DE LA DISPOSITION DU REPAS PRIVÉ}

Il y a deux sortes de repas dans le palais du sultan : celui des grands et celui du public. Quant au premier, c'est le repas où mange le souverain ; et il a l'habitude de faire cela dans la salle d'audience, en compagnie des personnes présentes. Ce sont : les émirs les plus intimes, l'émir chambellan, cousin du monarque ${ }^{855}$, Imâd almoulc Sertîz, et l'émir madjlis, ou chef d'assemblée. Outre ceux-ci, le sultan invite les individus qu'il veut anoblir ou honorer, parmi les personnages illustres ou les principaux émirs, qui mangent ainsi avec lui. Il arrive quelquefois qu'il veut aussi honorer une des personnes p417 qui se trouvent présentes. Alors il prend un plat avec sa main, il y place un pain et le passe à cette personne. Celle-ci le prend, le tient dans sa main gauche, et s'incline, en touchant la terre avec sa main droite. Souvent le souverain envoie quelque mets de ce repas à un individu absent de l'audience. Celui-ci, en le recevant fait sa révérence, à l'instar de l'individu présent, et mange ce mets avec les gens qui se trouvent en sa compagnie. J'ai assisté bien des fois à ce repas privé, et j'ai vu que le nombre de ceux qui y prenaient part était d'environ vingt hommes.

\footnotetext{
${ }^{854}$ Le texte dit «dinars et dirhams ». Ibn Battûta ayant défini le dinar indien comme une monnaie d'argent (chap. 5, n. 24) valant huit dirhams d'argent marocain, il s'agit donc de monnaies d'argent. 


\section{DE LA DISPOSITION DU REPAS COMMUN}

Les mets que l'on sert au public sont apportés des cuisines, et précédés par les principaux officiers, qui crient: " Au nom de Dieu !" Ceux-ci ont en tête leur chef, lequel tient dans sa main une massue d'or, et son substitut, qui en tient une d'argent. Lorsqu'ils ont franchi la quatrième porte, et que ceux qui se trouvent dans la salle d'audience ont ainsi entendu leurs voix, ils se lèvent tous ensemble, et personne, si ce n'est le sultan, ne reste assis. Quand les mets sont posés à terre, les officiers se placent sur une seule ligne, le commandant à leur tête, qui parle à l'éloge du sultan, et fait son panégyrique. Il s'incline profondément après cela, tous les officiers l'imitent, de même que tous les assistants, sans exception, grands et petits. L'usage est que, dès qu'un individu entend la voix du chef des officiers dans cette circonstance, il s'arrête debout, s'il marchait, et garde sa place, s’il était debout et arrêté. Personne ne bouge, ni ne quitte sa place, jusqu'à ce que ledit personnage ait fini son discours. Après cela, son substitut parle d'une façon analogue à la sienne ; puis il s'incline, et il est imité en ceci par les officiers et le public, qui saluent ainsi une seconde fois. Alors tout le monde s'assied.

Les secrétaires, placés à la porte, écrivent pour informer ${ }_{\mathrm{p} 418}$ le sultan de l'arrivée des aliments, bien que celui-ci le sache déjà. On donne le billet à un enfant choisi parmi les fils des rois, et qui est chargé spécialement de cette besogne ; il le remet au souverain, lequel, après l'avoir lu, nomme ceux des principaux commandants qu'il charge de présider à l'arrangement des assistants et à leur nourriture. Celle-ci consiste en pains, ressemblant plutôt à des gâteaux ; en viandes rôties ; en pains ronds, fendus et remplis de pâte douce ; en riz, en poulets, et en une sorte de hachis de viande. Nous avons parlé précédemment de toutes ces choses et expliqué leur distribution.

En tête du banquet se placent les juges, les prédicateurs, les jurisconsultes, les nobles et les cheïkhs. Viennent après eux les parents du sultan, les principaux commandants et tout le public. Personne ne s'assied qu'à l'endroit qui lui a été destiné ; de sorte qu'il n'y a parmi eux jamais de presse. Les assistants étant placés, arrivent les chorbdârs, qui sont les échansons ; ils tiennent à la main des vases d'or, 
d'argent, d'airain et de verre remplis de sucre candi dissous dans l'eau : on boit cela avant de manger, et ensuite les chambellans s’écrient : "Au nom de Dieu ! » On commence alors le repas. Devant chaque personne, on place de tous les mets dont se compose le festin ; chacun les mange séparément, et nul n'est servi dans le même plat avec un autre individu. Le repas fini, on apporte une espèce de bière dans des pots d'étain, et, le public l'ayant bue, les chambellans disent encore : «Au nom de Dieu ! » On introduit les plats contenant le bétel et la noix d'arec ; on donne à chacun une pincée de celle-ci concassée, ainsi que quinze feuilles de bétel réunies ensemble et liées avec un fil de soie rouge. Les assistants ayant pris le bétel, les chambellans disent de nouveau : «Au nom de Dieu ! " Tout le monde se lève à ce moment, le commandant qui a présidé au repas salue ; le public en fait autant, et se retire. Cette sorte de festin a lieu deux fois par jour : la première, avant midi, et la seconde, après la prière de l'après-midi. p419

\section{QUELQUES HISTOIRES SUR CE SULTAN MONTRANT SA BIENFAISANCE ET SA GÉNÉROSITÉ}

Je me propose de mentionner seulement les faits de ce genre auxquels j'ai été présent, dont j'ai été témoin, et que j’ai ainsi vus de mes propres yeux. Le Dieu très haut connaît la vérité des choses que je vais raconter, et l'on n'a pas besoin, outre cela, d'un autre témoignage. D'ailleurs, tout ce que je vais dire est bien divulgué et assez notoire. Les pays qui sont peu éloignés de l’Inde, tels que le Yaman, le Khorâçân et la Perse, sont remplis d'anecdotes sur ce prince, et leurs habitants les connaissent fort bien ; ils n'ignorent pas surtout sa bienfaisance envers les étrangers, qu'il préfère aux indigènes, qu'il honore, qu'il favorise largement, qu'il comble de bienfaits, auxquels il donne des emplois élevés et fait de riches présents. Un de ses bienfaits à l'égard des étrangers, c'est qu'il les nomme a'izzahs, ou gens illustres, et défend qu'on les appelle étrangers. Il prétend qu'appeler un individu du nom d'étranger c'est lui déchirer le cœur et troubler son esprit. Je vais maintenant citer, s'il plaît à Dieu, un petit nombre de ses largesses et de ses dons magnifiques. 
DU CADEAU QU'IL A FAIT AU MARCHAND CHIHÂB EDDÎN ALCÂZÉROÛNY ET HISTOIRE DE CELUI-CI

Ce Chihâb eddîn ${ }^{856}$ était un ami du roi des marchands Alcâzéroûny, surnommé Perouîz, auquel le sultan avait donné en fief la ville de Cambaie, et promis la charge de vizir. Alors Perouîz envoya dire à son ami Chihâb eddîn de venir le rejoindre, et celui-ci arrivé, avec un présent qu'il avait préparé pour le sultan, et qui était composé des objets suivants ; une petite maison en drap découpé enrichi de feuilles d'or, une grande tente analogue à la ${ }_{\mathrm{p} 420}$ maisonnette, une petite tente avec ses accessoires, et une tente de repos, le tout en drap orné, enfin beaucoup de mulets. A l'arrivée de Chihâb eddîn avec son cadeau, son ami le roi des marchands allait partir pour la capitale. Il apportait les sommes qu'il avait amassées au moyen des impôts du pays qu'il gouvernait, et un cadeau pour le souverain.

Le vizir Khodjah Djihân, ayant appris que le sultan avait promis à Perouîz le vizirat, en devint jaloux et en fut troublé. Les pays de Cambaie et du Guzarate étaient, avant ce temps-là, sous la dépendance du vizir ; leurs populations étaient attachées à celui-ci, dévouées entièrement à lui et promptes à le servir. La plupart de ces peuples étaient des infidèles, et une partie d'entre eux des rebelles qui se défendaient dans les montagnes. Le vizir leur suggéra de tomber sur le roi des marchands lorsqu'il se dirigerait vers la capitale. En effet, quand Perouîz sortit avec ses trésors et ses biens, Chihâb eddîn, portant son cadeau, l'accompagna, et ils campèrent un jour avant midi, suivant leur habitude. Les troupes qui les escortaient se dispersèrent, et le plus grand nombre se mit à dormir. Les infidèles tombèrent sur eux dans ce moment en force considérable, ils tuèrent le roi des marchands, pillèrent ses biens et ses trésors, ainsi que le présent de Chihâb eddîn. Celui-ci put seulement sauver sa propre personne.

Les rapporteurs de nouvelles écrivirent au sultan ce qui s'était passé, et celui-ci ordonna de gratifier Chihâb eddîn d'une somme de trente mille pièces d'or, à prendre sur les revenus du pays de Nehrouâ-

${ }^{856}$ Malik al-Tudjar. Chef de la corporation des marchands en quelque sorte. Pour Cambay, voir t. III. p. 182. 
lah ${ }^{857}$, et qu'il eût à retourner ensuite dans sa patrie. On lui présenta ce trésor ; mais il refusa de l'accepter, en disant que son seul but était de voir le sultan et de baiser la terre en sa présence. Le sultan en fut informé ; il approuva ce désir, et commanda que Chihâb eddîn se rendît à Dihly, avec toutes sortes d'honneurs. p421

Or il arriva qu'il fut introduit pour la première fois chez le souverain le jour même de notre introduction près de celui-ci, qui nous donna à tous des robes d'honneur, ordonna de nous loger, et fit un riche présent à Chihâb eddîn. Quelque temps après, le sultan donna ordre qu'on me payât six mille tengahs ou pièces d'or, ainsi que nous le raconterons ; et il demanda ce jour-là où était Chihâb eddîn. Alors Bêhâ eddîn, fils d’Alfalaky, lui répondit : « $O$ maître du monde, némîdânem »; ce qui veut dire : "Je ne sais pas. » Puis il ajouta : "Chunîdem zehmet dâred », dont le sens est : « J'ai entendu dire qu'il est malade. » Le sultan reprit : "Berev hemîn zémân der khazâneh iec leki tengahi zer biguiri ve pîch oû bebérî tâ dili oû khoûch chéved. " Le sens de ceci est: "Va à l'instant dans le trésor, prends-y cent mille pièces d'or, et porte-les à Chihâb eddîn, afin que son cœur soit satisfait. » Bêhâ eddîn exécuta cet ordre, et le sultan commanda que Chihâb eddîn achetât avec cette somme les marchandises de l'Inde qu'il préférait, et que personne n'eût à acheter la moindre chose, jusqu'au moment où celui-ci aurait fait toutes ses provisions. Il mit à sa disposition trois bâtiments fournis de tous leurs agrès, de la paye des matelots et de leurs vivres, pour s'en servir dans son voyage. Chihâb eddîn partit, et débarqua dans l'île de Hormouz, où il fit bâtir une maison magnifique. Je l'ai vue plus tard, mais j'ai vu aussi Chihâb eddîn, qui avait perdu toute sa fortune, et qui se trouvait à Chîrâz, sollicitant quelque chose de son souverain Aboû Ishak. Telle est la fin ordinaire des trésors acquis dans l'Inde. Il est rare qu'un individu quitte ce pays avec les biens qu'il a amassés ; si cela lui arrive, et s’il se rend dans une autre contrée, Dieu lui envoie un malheur qui engloutit tous ses biens. C'est ainsi que la chose se passa à l'égard de ce Chihâb eddîn ; il fut dépouillé de tout son avoir, dans la guerre civile qui éclata entre

857 Anhilwara, l'ancienne capitale de Gudjarat conquise par Ala al-din Khaldji en 1297. C'est l'actuelle Patan. 
le roi de Hormouz et ses deux neveux ${ }^{858}$; et ${ }_{\mathrm{p} 422}$ il quitta le pays après que toutes ses richesses eurent été pillées.

\section{DU CADEAU QU'IL A FAIT AU GRAND CHEÏKH ROCN EDDÎN}

Le sultan avait envoyé un présent au calife Aboû’l Abbâs qui se trouvait en Égypte, le priant de lui expédier une ordonnance qui reconnaîtrait son autorité sur les pays de l'Inde et du Sind ${ }^{859}$. C'était là l'effet de son profond attachement pour le califat. Aboû'l Abbâs fit partir ce que sollicitait le sultan, en compagnie du grand cheïkh de l'Égypte, Rocn eddîn ${ }^{860}$. Quand celui-ci arriva près du souverain de l'Inde, il en fut excessivement honoré, et reçut de lui un riche cadeau. Toutes les fois que Rocn eddîn entrait chez le sultan, ce dernier se levait et le comblait de marques de vénération ; puis il le congédia, en lui donnant des richesses considérables, parmi lesquelles il y avait un certain nombre de plaques pour les pieds des chevaux, ainsi que leurs clous, le tout en or pur et massif. Il lui dit : « Lorsque tu débarqueras, tu mettras ceci aux sabots de tes chevaux, en place de fers. » Rocn eddîn partit pour Cambaie, afin d'y prendre la mer, jusqu'au Yaman ; mais dans ce moment eurent lieu la révolte du juge Djélâl eddîn ${ }^{861}$ et la saisie qu'il opéra sur les biens du fils d'Alcaoulémy ${ }^{862}$; et on prit aussi ce qui appartenait au grand cheïkh. Celui-ci, et le fils d'Alcaoulémy, s'enfuirent tous les deux près du sultan, qui, voyant Rocn eddîn, lui dit (en langue persane) p423 en plaisantant : "Amédi kih zer béri bâ diguéri sanam khouri zer nébéri ve ser nihi »; ce qui signifie : «Tu es venu pour emporter de l'or et le dépenser avec les belles ; mais tu n'auras pas d'or, et tu laisseras ici ta tête. » Le prince

${ }_{858}^{858}$ Voir chap. 1, n. 131 et introduction.

${ }^{859}$ Muhammad bin Tughluk, ébranlé par les révoltes successives de ses gouverneurs et l'attitude hostile des ulémas, chercha à renforcer son autorité en demandant une investiture de la part des califes abbassides installés en Égypte par les mameluks. Il commença par frapper monnaie au nom du calife alMustakfi Billah entre 1340 et 1343, alors que ce calife était mort en février 1340. Par la suite, il reçut l'investiture de la part de son successeur al-Hakim Biamrillah II (1341-1352) en 1343.

${ }^{860}$ Voir t. I, p. 324, où une partie de cette histoire est racontée.

${ }^{861}$ Voir t. III, p. 97 et suiv.

${ }^{862}$ Pour l'histoire de ce personnage, voir également t. III, p. 98. 
lui dit cela pour s'amuser; puis il reprit : «Sois tranquille ; car je vais marcher contre les rebelles, et je te donnerai plusieurs fois autant que ce qu'ils t'ont enlevé. » Après mon départ de l'Inde, j'ai su que le sultan lui avait tenu parole, qu'il lui avait remplacé tout ce qu'il avait perdu, et que Rocn eddîn était arrivé en Égypte avec ses biens.

DU CADEAU QU'IL A FAIT AU PRÉDICATEUR DE TERMEDH, NÂSSIR EDDÎN

Ce jurisconsulte prédicateur était venu trouver le sultan, et il était resté près de lui une année, jouissant de ses faveurs ; puis il désira retourner dans sa patrie, et il en obtint la permission. Le sultan ne l'avait pas encore entendu parler ni prêcher ; mais, avant de partir pour un voyage qu'il allait entreprendre dans la contrée de Ma'bar ${ }^{863}$, il voulut l'entendre. Il ordonna, en conséquence, qu'on lui préparât une chaire de bois de sandal blanc, appelé almokâssiry ${ }^{864}$. On l'orna avec des plaques et des clous d'or, et l'on adapta à sa partie supérieure un rubis magnifique. On revêtit Nâssir eddîn d'une robe abbâcide, noire ${ }^{865}$, brodée d'or, enrichie de pierres précieuses, et on le coiffa d'un turban, analogue à la robe. La chaire fut placée dans l'intérieur de la sérâtcheh, ou petit palais, autrement dite afrâdj ${ }^{866}$, Le sultan s'assit sur son trône, ayant ses principaux favoris à droite et à gauche. Les juges, les jurisconsultes et les chefs prirent leurs places. Nâssir eddîn prononça un sermon éloquent ; ${ }^{4} 424$ il avertit, il exhorta ; mais il n'y avait aucun mérite extraordinaire dans ce qu'il fit ; seulement la fortune le servit. Quand il fut descendu de la chaire, le sultan se leva, alla vers lui, l'embrassa, et le fit monter sur un éléphant. Il ordonna à tous les assistants, et j'étais du nombre ${ }^{867}$, de marcher à pied devant Nâssir eddîn pour se rendre au petit palais qu'on avait élevé exprès pour lui, vis-à-vis celui du souverain. Ce petit palais était en soie de différentes couleurs ; la grande tente était aussi en soie, de même que

\footnotetext{
863 L'expédition contre Madura en 1335 (voir t. III, p. 77).

${ }^{864}$ De Makassar, l'île de Célèbes en Indonésie.

${ }^{865}$ Le noir était la couleur de la dynastie abbasside.

${ }^{866}$ Voir chap. 3. n. 22.

${ }^{867}$ Ce qui pose encore le problème de la date d'arrivée d'Ibn Battûta en Inde, Muhammad Tughluk avait quitté Dihli pour la campagne de Madura le 5 janvier 1335.
} 
la petite. Nous nous assîmes avec Nâssir eddîn, et vîmes dans un coin de la sérâtcheh les ustensiles en or que le sultan lui avait donnés. Il y avait : un grand poêle, dans l'intérieur duquel pouvait tenir un homme assis ; deux chaudières ; des plats en grand nombre ; plusieurs pots ; une cruche ; une témîcendeh; enfin, une table à manger, avec quatre pieds, et un support ou pupitre pour les livres. Tout cela était en or pur. Il arriva que 'Imâd eddîn assimnâny retira deux des pieux de la sérâtcheh, dont l'un était en cuivre, l'autre en étain ; on supposa alors qu'ils étaient en or et en argent ; mais, en réalité, ils étaient faits avec les métaux que nous avons mentionnés. Ajoutons que, lors de l'arrivée de Nâssir eddîn près du sultan, celui-ci lui donna cent mille dînârs d'argent, et des centaines d'esclaves, dont il affranchit une partie, et prit l'autre avec lui.

\section{DU CADEAU QU'IL A FAIT À ’ABDAL’AZÎZ ALARDOOUÎLY}

Cet 'Abdal'azîz était un jurisconsulte traditionnaire ${ }^{868}$, qui avait étudié à Damas, sous Taky eddîn, fils de Taïmiyyah ; sous Borhân eddîn, fils d'Albarcah ; Djémâl eddîn almizzy ${ }^{869}$; Chams eddîn ${ }_{p 425}$ addhahaby ${ }^{870}$, et autres encore. Il se rendit ensuite près du sultan de l'Inde, qui le combla de bienfaits, et l'honora beaucoup. Un jour, il arriva que le jurisconsulte exposa au souverain un certain nombre de traditions sur le mérite d'Abbâs et de son fils, ainsi que des récits concernant les vertus des califes, leurs descendants. Le sultan fut très satisfait de cela, à cause de son attachement pour la maison d'Abbâs. Il baisa les pieds du légiste, et ordonna qu'on apportât une soucoupe d'or, dans laquelle il y avait deux mille tengahs, qu'il versa sur lui de sa propre main, en lui disant : "Cette somme est à toi, de même que la soucoupe. » Mais nous avons déjà fait mention de cette anecdote dans le volume précédent.

\footnotetext{
868 La même anecdote sur ce personnage se retrouve au t. I, p. 418.

869 Voir t. I, chap. 3, n. 235 et 227.

${ }^{870}$ Historien célèbre mort en 1347.
} 


\section{DU CADEAU QU’IL FIT À CHAMS EDDÎN ALANDOCÂNY}

Le jurisconsulte Chams eddîn alandocâny était philosophe, et poète inné. Il loua le sultan dans un petit poème en langue persane, dont le nombre de vers était de vingt-sept distiques. Le souverain lui donna mille dinars d'argent pour chacun de ceux-ci. C'est beaucoup plus que ce qu'on raconte à ce sujet des anciens, qui donnaient, dit-on, mille drachmes pour chaque vers. Ceci ne fait que le dixième du prix qu'en a payé le sultan.

\section{DU CADEAU QU'IL FIT À ’ADHOUD EDDÎN ACCHÉOUANCÂRY}

'Adhoud eddîn était un jurisconsulte et un imâm distingué ; son mérite était grand, ainsi que sa renommée, laquelle était fort répandue dans les contrées qu'il habitait. Le sultan fut informé de ses actes et entendit parler de ses vertus. Or il lui envoya dans son pays, le ${ }_{p 426}$ Chéouancâreh ${ }^{871}$, dix mille dînârs d'argent ; mais il ne le vit jamais, et ce jurisconsulte n’alla pas le visiter.

\section{DU CADEAU QU’IL FIT AU JUGE MADJD EDDÎN}

Quand le sultan connut l'histoire de Madjd eddîn ${ }^{872}$, juge à Chîrâz, ce kâdhi savant, intègre, et auteur de miracles célèbres, il lui envoya à Chîrâzh dix mille dînârs en argent, portés par le cheïkh Zâdeh de Damas. Nous avons déjà retracé, dans la première partie de ces voyages, les aventures de Madjd eddîn, et nous en reparlerons de nouveau plus loin.

${ }^{871}$ Shabankara, petite région dans le sud-est du Fars, ainsi nommée d’après une tribu kurde qui s'y installa au XII ${ }^{\mathrm{e}}$ siècle.

${ }^{872}$ Voir t. I, p. 406 et suiv., chap. 5, n. 125. 
DU CADEAU QU'IL FIT À BORHÂN EDDÎN ASSÂGHARDJY

Borhân eddîn ${ }^{873}$ était un imam prédicateur d'une grande libéralité : il prodiguait son bien, de façon que souvent il faisait des dettes, pour être libéral envers les autres. Lorsque son histoire parvint au sultan, celui-ci lui expédia quarante mille dînârs, et le sollicita de se rendre dans sa capitale. L'imam accepta la somme d'argent, avec laquelle il paya ses dettes ; puis il se rendit dans le pays de Khatha ${ }^{874}$, et il refusa d'aller vers le souverain de l'Inde. Il dit à ce propos: " Je n'irai point chez un sultan devant lequel les savants se tiennent debout. ” p427

\section{DU CADEAU QU'IL FIT À HÂDJI CÂOUN, ET HISTOIRE DE CE DERNIER}

Hâdji Câoun ${ }^{875}$ était cousin germain du sultan Aboû Sa'îd, roi de l'Irak; et son frère Moûça était roi d'une petite partie de ce dernier pays. Ce Hâdji Câoun alla rendre une visite au souverain de l'Inde, qui le traita avec de grands honneurs, et lui fit des cadeaux magnifiques. Je le vis une fois au moment où le vizir Khodjah Djihân avait apporté un cadeau pour le sultan, dont faisaient partie trois soucoupes remplies, l'une de rubis, l'autre d'émeraudes, et la troisième, de perles. Hâdji Câoun, qui était présent, reçut du monarque une portion considérable de ce don ; et plus tard, des richesses énormes. Il partit ensuite, se dirigeant vers l'Irâk ; mais à son arrivée il trouva que son frère Moûça était mort, et que le khân Soleïmân ${ }^{876}$ régnait à sa place. Il réclama l'héritage de son frère, se déclara roi, et les troupes lui prêtèrent serment. Alors il se rendit dans le Farsistân, et fit halte près de la ville de Chéouancâreh ${ }^{877}$, où se trouvait l'imâm 'Adhoud eddîn,

873 Burhan al-din al Saghardji, de la ville de Saghardj située à vingt-cinq kilomètres au nord-ouest de Samarkande, il est mentionné par ailleurs comme un mystique résidant dans la cour de l'empereur de Chine.

${ }^{874}$ Voir chap. 4, n. 41.

${ }^{875}$ Musa, cousin au troisième degré d'Abu Said, l’Ilkhanide, fut nommé roi par les émirs entre 1336 et 1338 (voir t. I, chap. 5, n. 248 et introduction). Toutefois, on ne sait rien sur son frère Hadji Ke’ün. Ke'ün est un titre mongol équivalent au khan turc.

${ }^{876}$ Cousin au troisième degré aussi bien d’Abu Said que de Musa, il régna de 1339 à 1344 voir t. I, introduction et chap. 5, n. 51).

${ }^{877}$ Voir n. 57 ci-dessus. Il s'agit d'une région dont le centre était à l'époque Idj, située entre Fasa et Darab à l'est de Shiraz. 
dont nous avons parlé précédemment. Quand il fut campé à l'extérieur de la ville, les cheïkhs qui l'habitaient tardèrent environ une heure à se rendre auprès de lui. Il sortirent ensuite, et Câoun leur dit : " Qu'estce qui vous a empêchés de venir plus vite pour me prêter hommage ? » Ils s'excusèrent ; mais il n'admit point leurs justifications, et il dit (en turc) aux soldats qui l'accompagnaient: Kilidj tchikâr, c'està-dire : « Dégainez les sabres. » Ceux-ci obéirent, et ils coupèrent les cous des cheïkhs, qui étaient fort nombreux. p428

Les émirs qui se trouvaient dans le voisinage de cette ville, ayant été informés de cet événement, en furent indignés, et écrivirent à Chams eddîn assimnâny ${ }^{878}$, un des principaux émirs et jurisconsultes, pour lui faire savoir ce qui s'était passé contre les gens de Chéouancâreh. Ils imploraient de lui des secours pour combattre Câoun, et Chams eddîn sortit à la tête de ses troupes. Les habitants se réunirent, désireux de venger le meurtre des cheïkhs qui avaient été tués par Hâdji Câoun. Ils attaquèrent son armée pendant la nuit, et la mirent en fuite. Câoun se trouvait dans le château de la ville ${ }^{879}$, qu'ils entourèrent ; il s'était caché dans les lieux d'aisances ; mais ils le découvrirent et lui tranchèrent la tête. Ils envoyèrent celle-ci à Soleïmân Khân, et répandirent les membres dans plusieurs contrées, afin d'assouvir ainsi leur vengeance contre Hâdji Câoun.

DE L’ARRIVÉE DU FILS DU CALIFE CHEZ LE SULTAN DE L'INDE, ET DE SES AVENTURES

L'émir Ghiyâth eddîn Mohammed, fils d'Abd alkâlihr, fils de Yoûçuf, fils d'Abd al'azzîz, fils du calife Almostansir billâh, al'abbâçy, albaghdâdy ${ }^{880}$, avait été trouver le sultan 'Alâ eddîn Thermachîrîn, roi de la Transoxiane. Celui-ci le traita avec beaucoup d'honneur, et lui donna un ermitage construit sur le tombeau de Ko-

${ }^{878}$ Voir t. I, chap. 5, n. 166. Ce personnage est cité dans les luttes qui secouèrent le Fars à cette époque (cf. introduction du t. I), mais on ne retrouve pas le nom de Hadji Ke’ün.

${ }^{879}$ Probablement la citadelle de Idj.

${ }^{880}$ Ce personnage et une partie de son histoire sont déjà cités p. 296, ainsi que t. I, p. 326. Son arrivée en Inde en 1340-1341 coïnciderait avec le début de l’intérêt de Muhammad Tughluk pour une investiture califale. 
tham, fils d'Al'abbâs ${ }^{881}$, où Ghiyâth eddîn demeura plusieurs années. Lorsqu'il entendit parler, plus tard, de l'affection que le sultan de l'Inde avait pour la famille d'Abbâs, et de sa persistance à reconnaître p429 ses droits, il désira se rendre auprès de lui, et il lui expédia, à cet effet, deux envoyés. L'un d'eux était son ancien ami Mohammed, fils d'Aboû Accharafy alharbâouy ; l'autre était Mohammed alhamadâny assoûfy ; ils se rendirent près du sultan. Or il arriva que Nâssir eddîn attermedhy ${ }^{882}$, dont nous avons parlé plus haut, avait fait la rencontre de Ghiyâth eddîn à Bagdâd, et que les habitants de cette ville lui avaient certifié l'authenticité de la généalogie dudit Ghiyâth eddîn. A son tour, Nâssir eddîn porta témoignage, à ce sujet, chez le souverain de l'Inde. Quand les deux ambassadeurs furent arrivés, le sultan leur donna cinq mille dînârs ; en outre, il leur consigna trente mille dînârs, destinés à être remis à Ghiyâth eddîn, et à servir pour ses frais de route jusqu’à Dihly. De plus, il lui écrivit une lettre de sa propre main, où il lui témoignait du respect, et le sollicitait de venir le trouver. Il partit, en effet, dès qu'il reçut cette missive.

Lorsque Ghiyâth eddîn fut parvenu dans le Sind, et que les donneurs de nouvelles le firent savoir au sultan, celui-ci envoya des personnes chargées, selon l'habitude, d'aller à sa rencontre. Quand il fut arrivé à Sarsati, le sultan envoya, pour le recevoir, Sadr Aldjihân, le kâdhi en chef, nommé Camâl eddîn alghaznéouy, ainsi qu'une foule de jurisconsultes ; puis il fit partir, dans ce même but, les émirs ; et quand Ghiyâth eddîn fit halte à Maç’oûd Abâd, à l'extérieur de la capitale, il sortit en personne à sa rencontre. Alors Ghiyâth eddîn mit pied à terre, et le sultan en fit autant ; le premier s'inclina profondément, et le sultan lui rendit le salut de la même manière. Ghiyâth eddîn apportait un cadeau dont faisaient partie des habillements. Le sultan prit un de ceux-ci, le mit sur son épaule, et s'inclina de la même façon qu'on le pratique à son égard. On amena les chevaux, le sultan en prit un dans sa main, le conduisit à Ghiyâth eddîn, qu'il conjura de monter ; il tint lui-même l'étrier. Le souverain monta à cheval et chemina à côté de ${ }_{p 430}$ Ghiyâth eddîn ; un seul parasol les recouvrait tous les deux. Il prit dans sa main le bétel et l'offrit à Ghiyâth eddîn : ce fut là la marque la plus grande de considération qu'il lui donna ; car il ne

${ }^{881}$ Voir chap. 4, n. 87.
${ }^{\mathbf{8 8 2}}$ Voir p. 424. 
fait cela pour personne. Le monarque lui dit : «Si je n’avais pas déjà prêté serment au calife Aboû'l'abbâs ${ }^{883}$, je te le prêterais à toi, » Ghiyâth eddîn répondit : "Moi aussi j'ai prêté le même serment. » Puis il ajouta : "Mahomet a dit : "Celui qui vivifie une terre déserte et inculte en devient le maître.” Et c'est toi qui nous as fait revivre. » Le sultan répliqua de la manière la plus agréable et la plus bienveillante ; et, quand ils furent arrivés à la tente ou petit palais préparé pour le souverain, celui-ci y fit descendre Ghiyâth eddîn, et l'on en éleva un autre pour lui. Ils passèrent tous les deux une nuit à l'extérieur de la capitale.

Le lendemain, ils firent leur entrée dans celle-ci, et le sultan fit descendre Ghiyâth eddîn dans la ville nommée Sîri, et aussi le séjour du califat, dans le château bâti par 'Alâ eddîn alkhâldjy, et par son fils Kothb eddîn ${ }^{884}$, Il ordonna à tous les émirs de l'y accompagner ; et il avait fait préparer dans ce château tous les ustensiles d'or et d'argent dont son hôte pouvait avoir besoin. On y remarquait un grand vase tout en or, pour se laver. Le sultan envoya à Ghiyâth eddîn quatre cent mille dînârs, selon l'usage, pour la toilette de sa tête ; une foule de jeunes garçons, de serviteurs, et de femmes esclaves ; et il lui assigna, pour sa dépense journalière, la somme de trois cents dînârs. Il lui envoya en sus un certain nombre de tables, fournies d'aliments, provenant du repas privé. Il lui donna en fief toute la ville de Sîri et toutes ses maisons, ainsi que les jardins et les champs du p431 magasin, ou trésor, adjacents à la ville. Il lui donna encore cent villages, et lui conféra l'autorité sur les lieux qui sont placés près de Dihly, du côté du levant. Il lui fit cadeau de trente mules, avec leurs selles dorées, et commanda que leur fourrage fût fourni par le trésor. Le souverain ordonna à Ghiyâth eddîn de ne pas descendre de sa monture, lorsque celui-ci irait le visiter dans son palais ; si ce n'est pourtant dans un lieu réservé où personne, excepté le sultan, ne doit entrer à cheval. Enfin, il commanda à tous, grands et petit, de rendre hommage à Ghiyâth eddîn, comme ils le faisaient à sa propre personne. Quand

883 Abu'l Abbas est le calife abbasside du Caire al-Hakim Biamrillah II (voir n. 45 ci-dessus), dont Muhammad Tughluk n'a reçu l'investiture qu'en 1343. Mais il devait avoir déjà l'intention comme le montrent ses monnaies, encore qu'il ait dû se référer à son prédécesseur puisqu’il ne paraissait pas connaître à l'époque sa mort et l'avènement d'al-Hakim.

${ }^{884}$ Voir chap. 5, n. 81. 
Ghiyâth eddîn entrait chez le sultan, celui-ci descendait de son trône, et s'il était assis sur un fauteuil, il se levait. Ils se saluaient l'un l'autre, et s'asseyaient sur le même tapis. Lorsque Ghiyâth eddîn se levait, le sultan en faisait autant, et ils se saluaient ; s'il désirait de se rendre à l'extérieur de la salle d'audience, on y plaçait pour lui un tapis, où il s'asseyait le temps qu'il voulait, et il partait ensuite. Ghiyâth eddîn agissait ainsi deux fois dans la journée.

\section{ANECDOTE SUR LE RESPECT QUE LE SULTAN AVAIT POUR GHIYÂTH EDDÎN}

Pendant le temps où le fils du calife se trouvait à Dihly, le vizir arriva du Bengale; et le sultan donna ordre aux principaux commandants de sortir à sa rencontre. Il en fit autant lui-même, et honora excessivement son vizir. On éleva dans la ville plusieurs coupoles ou pavillons, comme on le pratique à l'arrivée du souverain. Le fils du calife, les jurisconsultes, les juges et les notables se rendirent tous à la rencontre du vizir. Quand le sultan retourna à son palais, il dit à celuici : "Va chez le makhdoûm zâdeh. » C'est ainsi qu'il appelait le fils du calife ; et le sens de ces mots est «le fils du maître ». Le vizir se rendit donc au palais de Ghiyâth eddîn ; il lui fit cadeau de deux mille tengahs ou pièces d'or, et de beaucoup de vêtements. L'émir Kaboûlah et p432 plusieurs autres des principaux commandants étaient présents. Moi-même je m’y trouvais.

\section{ANECDOTE ANALOGUE À LA PRÉCÉDENTE}

Le roi de Gaznah, appelé Behrâm ${ }^{885}$, s’était rendu auprès du sultan ; et il existait entre lui et le fils du calife une inimitié ancienne. Le souverain ordonna de loger Behrâm dans une des maisons de la ville de Sîri, qu'il avait donnée au fils du calife, et de lui bâtir un palais dans ladite ville. Quand le fils du calife sut cela, il se mit en colère, il se rendit au château du sultan, s'assit sur le tapis qui lui servait habituellement, et envoya chercher le vizir. Il lui parla en ces termes :

${ }^{885}$ Le personnage n’est pas identifié mais, Ghazna appartenant à l’époque au royaume de Hérat, il doit s’agir d’un gouverneur portant le titre de malik. 
« Salue de ma part le maître du monde, et dis-lui que tous les trésors qu'il m’a donnés se trouvent intacts dans mon hôtel, je n’ai disposé de rien ; au contraire, ils ont augmenté de beaucoup chez moi. Je ne resterai pas plus longtemps avec vous. » Il se leva et partit. Alors le vizir demanda à un des compagnons de Ghiyâth eddîn la cause d'un tel discours ; et il sut que c'était l'ordre que le sultan avait donné de construire un palais à Sîri, pour le roi de Gaznah.

Le vizir se rendit chez le souverain et l'informa de cet événement. Ce dernier monta à cheval sans perdre un instant, et se rendit chez le fils du calife, accompagné par dix de ses gens. Il se fit annoncer, descendit de cheval à l'extérieur du palais, dans le lieu où le public met pied à terre, vit Ghiyâth eddîn et lui fit ses excuses. Celui-ci les agréa ; mais le sultan lui dit : "Pour Dieu, je ne saurai point que tu es satisfait de moi qu'après que tu auras placé ton pied sur mon cou. » Ghiyâth eddîn lui répondit : " Je ne ferai pas une telle chose, quand bien même

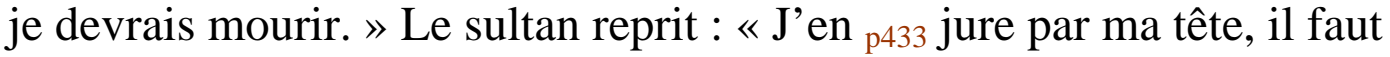
absolument que tu fasses cela. » Il posa sa tête sur le sol ; le grand roi Kaboûlah prit avec sa main le pied du fils du calife et le plaça sur le cou du souverain, qui se leva alors et dit : « Je sais maintenant que tu es satisfait de moi, et je suis tranquille. " Ceci est une histoire singulière, et l'on n'en connaît pas la pareille de la part d'un autre roi.

Je me trouvais un jour de fête avec ce Ghiyâth eddîn, au moment où le grand roi Kaboûlah lui apporta, au nom du sultan, trois vêtements d'honneur fort amples. En place des nœuds ou boutons en soie qui servent à les fermer, on y avait mis des boutons de perles, du volume d'une grosse noisette. Kaboûlah attendit à la porte du palais la sortie du fils du calife, et le revêtit desdits habillements. En somme, les dons que ce personnage a reçus du sultan de l'Inde ne peuvent être ni comptés ni déterminés. Malgré tout cela, le fils du calife est la plus avare des créatures de Dieu; et l'on connaît de lui, à ce sujet, des aventures étonnantes, qu'il peut être agréable d'entendre. On pourrait dire qu'il occupe, parmi les avares, le rang que le sultan tient parmi les généreux. Nous allons raconter quelques-unes de ces aventures. 


\section{DIVERSES ANECDOTES SUR L’AVARICE DU FILS DU CALIFE}

Des rapports d'amitié existaient entre moi et le fils du calife; j'allais souvent chez lui, et lorsque je partis, je lui laissai même un de mes fils, du nom d'Ahmed. Maintenant je ne sais pas ce qu'ils sont devenus l'un et l'autre. Je dis un jour au fils du calife : "Pourquoi manges-tu tout seul, et ne réunis-tu point tes compagnons pour le repas ? Il me répondit : "Le cœur me manque de les voir en si grand nombre, et tous manger mon pain ! » Ainsi, il se nourrissait isolément, il donnait à son ami Mohammed, fils d'Aboû Accharafy, une partie des aliments pour les personnes qu'il voulait, et s'emparait du reste.

J'allais et venais dans sa demeure, ainsi que je l'ai dit, p434 et je voyais au soir le vestibule du palais qu'il habitait, tout à fait obscur ; aucune lampe ne l'éclairait. Souvent j'ai aperçu Ghiyâth eddîn ramassant dans son jardin de petites branches de bois à brûler, dont il avait déjà rempli des magasins. Je lui fis quelques observations sur cela ; mais il me répondit: " On en a besoin. » il employait ses compagnons, ses mamloûcs, ainsi que les jeunes garçons, au service du jardin et de ses bâtisses ; il avait l'habitude de dire : " Je ne serais pas satisfait de les voir manger mes aliments sans servir à rien. » Une fois j'avais une dette, pour laquelle on me poursuivait ; il me dit plus tard : « J'en jure par Dieu, j'avais l'intention d'acquitter la dette en ta faveur ; mais mon âme ne me l'a pas permis, et ne m'a pas encouragé à cette action. »

\section{ANECDOTE}

Un jour, il me raconta ce qui suit : « Je sortis, dit-il, de Bagdad, en compagnie de trois autres individus (l'un de ceux-ci était son ami Mohammed, fils d'Aboû Accharafy); nous étions à pied et n'avions avec nous aucune provision. Nous nous arrêtâmes près d'une source d'eau, ou fontaine, dans un village, et l'un de nous trouva une drachme dans la source. Nous dîmes : "Que ferons-nous de cette petite pièce d'argent ? " Nous nous décidâmes à acheter du pain avec cela, et envoyâmes un de nous quatre pour faire cette emplette ; mais le boulanger du village se refusa de lui vendre du pain seulement ; il 
voulut débiter du pain pour la valeur d'un carat ${ }^{886}$ et de la paille pour le même prix. Il acheta donc le pain et la paille ; nous jetâmes celle-ci, puisque nous n'avions point de bête de somme qui pût la manger, et nous partageâmes le pain par bouchée. Tu vois ${ }_{p 435}$ aujourd'hui dans quelles conditions de fortune je me trouve ! » Je lui dis : " Il faut que tu loues Dieu pour les faveurs qu'il t'a prodiguées, que tu honores les fakîrs et les pauvres, et que tu fasses l'aumône. » Il répondit : "Ceci m'est impossible. » Je ne l'ai jamais vu user d'aucune libéralité, ni pratiquer le moindre bienfait. Que Dieu nous garde de l'avarice !

\section{ANECDOTE}

A mon retour de l'Inde, je me trouvais un jour à Bagdad et j'étais assis à la porte du collège, ou école, appelée Almostansiriyah, qui avait été fondée par l'aïeul de Ghiyâth eddîn, c'est-à-dire par le prince des croyants, Almostansir ${ }^{887}$. Je vis un malheureux jeune homme, courant derrière un individu qui sortait du collège, et l'un des étudiants me dit : «Ce jeune homme que tu vois, c'est le fils de l'émir Mohammed, lequel se trouve dans l'Inde, et qui est le petit-fils du calife Almostansir. » Alors je l'appelai et lui dis : « J'arrive de l'Inde, et je puis te donner des nouvelles de ton père. » Il me répondit : " J'en ai reçu ces jours-ci. » Il me quitta et continua de courir après l'individu. Je demandai qui était celui-ci, et l'on me dit que c'était l'inspecteur des legs pieux ; que le jeune homme était imâm ou directeur spirituel dans une mosquée ; qu'il recevait pour cela la récompense d'une seule drachme par jour, et qu'il réclamait de cet homme ses honoraires. Je fus très étonné de cet événement. Pour Dieu, si son père lui avait seulement envoyé une des perles qui se trouvent dans les robes d'honneurs qu'il a reçues du sultan de l'Inde, il aurait enrichi ce jeune garçon. Que Dieu nous garde d'un pareil état de choses ! p436

${ }^{886}$ Le carat vaut le huitième d'un dirham. La phrase signifie probablement que le 887 boulanger voulait donner autant de pain que de paille.

Le calife abbasside (1226-1242). 
DE CE QUE LE SULTAN A DONNÉ À L'ÉMIT SAÏF EDDÎN GHADA, FILS DE Hibet Allah, fils De Mohanna, Chef DEs ARABes De SyrIE ${ }^{888}$

Quand cet émir arriva chez le sultan, il fut très bien reçu, et fut logé dans le château du sultan défunt, Djélâl eddîn, à l'intérieur de Dihly. Ce château est appelé Cohc La'l, ce qui signifie le Château Rouge ${ }^{889}$. Il est très grand, avec une salle d'audience fort vaste, et un vestibule immense. Près de la porte se voit une coupole qui domine sur cette salle d'audience ${ }^{890}$, ainsi que sur une seconde, par laquelle on entre dans le palais. Le sultan Djélâl eddîn avait l'habitude de s'asseoir dans le pavillon, et l'on jouait au mail devant lui dans cette salle d'audience. J'entrai dans ce palais à l'arrivée de Saïf eddîn, et je le trouvai tout rempli de mobilier, de lits, de tapis, etc. ; mais tout cela était déchiré et ne pouvait plus servir. Il faut savoir que l'usage est, dans l'Inde, de laisser le château du sultan, à sa mort, avec tout ce qu'il contient ; on n'y touche pas. Son successeur fait bâtir pour lui un autre palais. En entrant dans ledit château, je le parcourus en tous sens, et montai sur le point le plus élevé. Ce fut là pour moi un enseignement qui fit couler mes larmes. Il y avait en ma compagnie le jurisconsulte, le médecin littérateur, Djémâl eddîn almaghréby, originaire de Grenade, né à Bougie, et fixé dans l'Inde, où il était arrivé avec son père, et où il avait plusieurs enfants. A la vue de ce château, il me récita ce distique :

Interroge la terre, si tu veux avoir des nouvelles de leurs sultans ; car les chefs sublimes ne sont plus que des os. p437

Ce fut dans ce château qu'eut lieu le festin du mariage de Saïf eddîn, comme nous le dirons ci-après. Le souverain de l'Inde aimait beaucoup les Arabes, il les honorait et reconnaissait leurs mérites. Lorsqu'il reçut la visite de cet émir, il lui prodigua les cadeaux et le combla de bienfaits. Une fois, en recevant les présents du grand roi Albâyazîdy, du pays de Mânicpoûr ${ }^{891}$, le sultan donna à Saïf eddîn

888 Pour Mohanna bin Isa, voir t. I, p. 194. Les notices bibliographiques citent neuf de ses fils, mais Hibat Allah ne figure pas parmi eux et Ghada est également inconnu.

${ }^{889}$ Voir chap. 6, n. 37.

890 Il s'agit donc apparemment d'une salle d'audience à ciel ouvert.

891 Ce personnage, qui sera aussi cité plus loin p. 100, est apparemment gouverneur de Manikpur (voir chap. 6, n. 38). 
onze chevaux de race ; une autre fois, dix chevaux, avec leurs selles dorées et les brides également dorées. Après cela, il le maria avec sa propre sœur, Fîroûz Khondah.

\section{DU MARIAGE DE L’ÉMIR SAÏF EDDÎN AVEC LA SEEUR DU SULTAN}

Quand le sultan eût ordonné de célébrer le mariage de sa sœur avec l'émir Ghada, il désigna, pour diriger tout ce qui regardait le festin et ses dépenses, le roi Fath Allah, nommé Cheounéouîs ${ }^{892}$; il me désigna pour assister l'émir Ghada, et passer avec lui les jours de la noce. Le roi Fath Allah fit apporter de grandes tentes, avec lesquelles il ombragea les deux salles d'audience, dans le Château Rouge ci-dessus mentionné. On éleva dans l'une et dans l'autre une coupole extrêmement vaste, dont le plancher fut recouvert de fort beaux tapis. Le chef des musiciens, Chams eddîn attibrîzy, arriva, accompagné de chanteurs des deux sexes, ainsi que de danseuses. Toutes les femmes étaient des esclaves du sultan. On vit arriver aussi les cuisiniers, les boulangers, les rôtisseurs, les pâtissiers, les échansons et les porteurs de bétel. On égorgea les bestiaux et les volailles, et l'on donna à manger au public durant quinze jours. Les chefs les plus distingués et les personnages illustres se trouvaient présents nuit et jour. Deux nuits avant celle $_{\text {p438 }}$ où devait avoir lieu la cérémonie de la conduite de la nouvelle mariée à la demeure de son époux, les princesses se rendirent du palais du sultan au Château Rouge. Elles l'ornèrent, le recouvrirent des plus jolis tapis et firent venir l'émir Saïf eddîn. Il était Arabe, étranger, sans parenté ; elles l'entourèrent et le firent asseoir sur un coussin destiné pour lui. Le sultan avait commandé que sa belle-mère, la mère de son frère Mobârec khân, tînt la place de la mère de l'émir Ghada ; qu'une autre dame, parmi les khâtoûns, tînt celle de sa sœur ; une troisième, celle de sa tante paternelle ; et une quatrième, la place de sa tante maternelle : de sorte qu'il pût se croire au milieu de sa famille. Quand ces dames eurent fait asseoir l'émir Ghada sur son coussin, elles teignirent ses mains et ses pieds en rouge avec de la poudre de hinnâ ${ }^{893}$. Quelques-unes d'entre elles restèrent debout en sa pré-

892 Shaw-nawis : scribe de mariage en persan.

${ }^{893}$ Cette pratique, générale en Orient pour les épouses, semble l'être moins pour les époux. 
sence ; elles chantèrent et dansèrent. Elles se retirèrent après cela, et se rendirent au château de la mariée. L’émir Ghada resta avec ses principaux compagnons.

Le sultan nomma une troupe d'émirs qui devaient tenir le parti de l'émir Ghada, et une autre, pour tenir celui de la nouvelle mariée. L'usage est, dans l'Inde, que ceux qui représentent la femme, se placent à la porte de l'appartement où doit se consommer le mariage. L'époux arrive avec sa suite ; mais ils n'entrent que s'ils remportent la victoire sur les autres. Dans le cas où ils ne réussissent point, il leur faut donner plusieurs milliers de pièces d'or à ceux qui sont du côté de la mariée. Au soir, on apporta à l'émir Ghada une robe de soie bleue, chamarrée d'or et de pierres précieuses ; celles-ci étaient en si grande quantité qu'elles ne permettaient pas de distinguer la couleur du vêtement. Il reçut aussi une calotte analogue à l'habit ; et je n'ai jamais connu un habillement plus beau que celui dont je parle. J'ai pourtant vu les robes que le sultan a $\mathrm{p}_{439}$ données à ses autres beaux-frères ou alliés, tels que le fils du roi des rois, 'Imâd eddîn assimnâny ; le fils du roi des savants ; le fils du cheïkh de l'islamisme, et le fils de Sadr Djihân albokhâry ${ }^{894}$. Parmi toutes ces robes, aucune ne pouvait soutenir le parallèle avec la robe donnée par le sultan à Ghada.

L'émir Saïf eddîn monta à cheval avec ses camarades et ses esclaves ; tous avaient dans la main un bâton, préparé d'avance. On avait fait une sorte de couronne avec des jasmins, des roses musquées et des reïboûls ${ }^{895}$. Elle était pourvue d'un voile, qui recouvrait la figure et la poitrine de celui qui la ceignait. On l'apporta à l'émir, afin qu'il la plaçât sur sa tête ; mais il refusa. Il était, en effet, un Arabe du désert, et ne connaissait rien aux habitudes des empires et des villes. Je le priai et le conjurai tant qu'il mit la couronne sur sa tête ${ }^{896}$. Il se rendit à bâb assarf, qu'on appelle aussi bâb alharam ${ }^{897}$, et où se trouvaient les champions de la mariée. Il les attaqua, à la tête de ses gens, à la vraie manière des Arabes, renversant tous ceux qui s'opposèrent à eux. Ils obtinrent une victoire complète ; car la troupe de la nouvelle

\footnotetext{
894 Voir p. 296.

895 Probablement des jasmins.

896 La couronne ainsi que le simulacre de combat sont des coutumes hindoues.

${ }^{897}$ La porte de l'interdit, menant aux appartements des femmes.
} 
mariée ne put point soutenir un pareil choc. Quand le sultan sut cela, il en fut très satisfait.

L'émir Ghada fit son entrée dans la salle d'audience, où la mariée se trouvait, assise sur une estrade élevée, ornée de brocart et incrustée de pierres précieuses. Tout ces vaste local était rempli de femmes ; les musiciennes avaient rapporté plusieurs sortes d'instruments de musique ; elles étaient toutes debout, par respect et par vénération pour le marié. Celui-ci entra à cheval, jusqu'à ce qu'il fût proche de l'estrade ; alors il mit pied à terre et salua profondément près du premier degré de cette estrade. L'épouse se leva et resta debout, jusqu'à ce ${ }_{p 440}$ qu'il fût monté ; elle lui offrit le bétel de sa propre main ; il le prit, et s’assit un degré au-dessous de celui où elle s'était levée. On répandit des pièces d'or parmi les compagnons de Ghada qui étaient présents, et les femmes les ramassèrent. Dans ce moment-là, les chanteuses chantaient, et l'on jouait des tambours, des cors et des trompettes à l'extérieur de la porte. L'émir se leva, prit la main de son épouse et descendit, suivi par elle. Il monta à cheval, foulant de la sorte les tapis et les nattes. On jeta des pièces d'or sur lui et sur ses camarades ${ }^{898}$ et on plaça la mariée dans un palanquin, que les esclaves portèrent sur leurs épaules jusqu'au château de l'émir. Les princesses allaient devant elle à cheval, et les autres dames à pied. Lorsque le cortège passait devant la demeure d'un chef ou d'un grand, celui-ci sortait à sa rencontre, et répandait parmi la foule des pièces d'or et d'argent, suivant sa volonté. Cela dura jusqu'à l'arrivée de la mariée au Château Rouge.

Le lendemain, l'épouse de Ghada envoya à tous les compagnons de son mari des vêtements, des dînârs et des drachmes. Le sultan leur donna à chacun un cheval sellé et bridé, ainsi qu'une bourse remplie d'argent, et contenant depuis deux cents dînârs jusqu'à mille dinars. Le roi Fath Allah fit cadeau aux princesses de vêtements de soie de différentes couleurs et de bourses remplies d'argent; il agit ainsi avec les musiciens des deux sexes et avec les danseuses. Il est d'usage, dans l'Inde, que personne, excepté le directeur de la noce, ne donne rien aux musiciens ni aux danseuses. On servit à manger au public ce jour-là, et la noce fut terminée. Le sultan ordonna de donner à l'émir 
Ghada les contrées de Mâlouah, Guzarate, Cambaie et Nehrouâlah ${ }^{899}$. Il nomma le susdit Fath Allah son substitut dans le gouvernement de ces pays, et honora excessivement son ${ }_{\mathrm{p} 441}$ beau-frère. Mais ce Ghada était un Arabe stupide, et ne méritait pas toutes ces distinctions; la grossièreté des gens du désert était son trait dominant, et elle l'entraîna dans l'adversité vingt jours après son mariage.

\section{DE L’EMPRISONNEMENT DE L’ÉMIR GHADA}

Vingt jours après ses noces, il arriva que Ghada se rendit au palais du sultan et désira entrer. Le chef des perdehdârs, qui sont les principaux huissiers, lui défendit l'entrée ; mais il ne l'écouta point et voulut s'introduire de force. Alors l'huissier le saisit par sa dabboûkah, c'est-à-dire sa tresse de cheveux, et le tira en arrière. L’émir, indigné, le frappa, avec un bâton qui se trouvait là, au point de le blesser et de faire couler son sang. Le personnage battu était un des principaux émirs ; son père était appelé « le kâdhi de Gaznah » ; il était de la postérité du sultan Mahmoûd, fils de Sebuctéguîn ${ }^{900}$, et le souverain de l'Inde, en lui adressant la parole, le nommait toujours « mon père ». Il nommait son fils, dont il est ici question, «mon frère ». Celui-ci entra tout ensanglanté chez le sultan, et l'informa de ce qu'avait fait l'émir Ghada. Le monarque réfléchit un instant, puis il dit : « Le juge décidera de la chose entre vous deux ; c'est là un crime que le sultan ne peut pardonner à aucun de ses sujets, et qui mérite la mort. Je consens pourtant à user de tolérance, à cause que le criminel est un étranger. » Le juge Camâl eddîn se trouvait présent dans la salle d'audience, et le sultan donna ordre au roi Tatar ${ }^{901}$ de se rendre, avec les deux parties, chez ce juge. Tatar avait fait le pèlerinage de La Mecque ; il était resté encore quelque temps dans cette ville, ainsi qu’à Médine, et parlait bien l'arabe. Se trouvant chez le juge avec les susdits personnages, il dit à l'émir Ghada : "Est-ce que tu as frappé le chambellan? ${ }_{\text {p442 }} \mathrm{Ou}$ bien dis : « Non. » Son but était de lui suggérer un argument de dé-

899 Malwa voir chap. 6, n, 40 ; Gudjarat : la péninsule de Kathiawar et son hinterland au nord-ouest de l'Inde Cambay : voir t. III, p. 182 ; Anhilwara : voir n. 43 ci-dessus.

900 Voir chap. 4, n. 160.

${ }^{901}$ Tatar Khan est un autre nom de Bahram Khan (voir ci-dessus n. 28). 
fense ; mais Saïf eddîn était un ignorant vulgaire, et il répondit : «Oui, je l’ai frappé. » Le père du personnage battu se présenta, et il voulait arranger l'affaire entre les deux parties ; mais Saïf eddîn ne s’y prêta point.

Le juge donna ordre qu'on le mît en prison cette nuit-là. Pour Dieu, son épouse ne lui envoya même pas un tapis pour dormir, et n'en demanda pas de nouvelles, par crainte du sultan. Ses camarades eurent peur aussi, et mirent en sûreté leurs biens. Je voulais l'aller visiter dans sa prison ; mais je rencontrai alors un émir qui me dit, en entendant cela : « Tu as donc oublié ce qui t'est arrivé ? » Il me rappela à la mémoire un événement qui me concernait, au sujet de ma visite au cheïkh Chihâb eddîn, fils du cheïkh d'Aldjâm, et comme quoi le sultan voulait me faire mourir, à cause de cette action. Nous en reparlerons plus tard. Je revins donc sur mes pas, et n'allai pas trouver l'émir Ghada. Celui-ci sortit de prison le lendemain vers midi ; le sultan le laissa dans l'abandon, le négligea, lui retira le gouvernement qu'il lui avait conféré, et voulut même le chasser.

Le souverain avait un beau-frère appelé Moghîth, fils du roi des rois ${ }^{902}$. La sœur du sultan se plaignit de lui à son frère jusqu'à ce qu'elle mourût. Ses femmes esclaves ont assuré que sa mort fut la suite de violences exercées sur elle par son mari. La généalogie de ce dernier laissait quelque chose à désirer, et le sultan écrivit de sa propre main ces mots : "Qu'on exile l'enfant trouvé. » Il faisait allusion à son beau-frère. Il écrivit après cela : "Qu'on exile aussi Moûch khor. " Ceci veut dire le Mangeur de rats; et il entendait parler de l'émir Ghada ; car les Arabes du désert mangent le yarboû, ${ }^{903}$, qui est une sorte de rat. Le monarque ordonna de leur faire quitter le pays à tous les deux ; en conséquence, les officiers se rendirent près de Ghada pour le faire partir. p443

Il voulut alors entrer dans sa demeure pour dire adieu à sa femme ; les officiers se mirent successivement à sa recherche, et il sortit tout en pleurs. Ce fut dans ce moment que je me rendis au palais du sultan, et que j'y passai la nuit. Un des chefs me demanda ce que je voulais, et je lui répondis que mon intention était de parler en faveur de l'émir

902 Il s'agit là encore probablement d'un titre honorifique.

${ }^{903}$ La gerboise. L'insulte est courante chez les Persans. 
Saïf eddîn, afin qu'il fût rappelé, et non chassé. Il me dit que c'était chose impossible ; mais je repris : «Pour Dieu, je ne quitterai pas le palais du souverain, quand bien même j'y devrais rester cent nuits, jusqu'à ce que Saïf eddîn soit rappelé. » Le sultan, ayant été informé de ces paroles, ordonna de le faire revenir, et il lui commanda de rester en quelque sorte au service de l'émir, nommé le roi Kaboûlah Allâhoûry. En effet, il resta attaché à lui pendant quatre années ; il montait à cheval avec Kaboûlah et voyageait avec lui. Il finit ainsi par devenir lettré et bien élevé. Alors le sultan le replaça dans le degré d'honneur où il était d'abord ; il lui donna en fief plusieurs contrées, le mit à la tête des troupes et le combla de dignités.

DU MARIAGE QUE LE SULTAN CONCLUT ENTRE LES DEUX FILLES DE SON VIZIR ET LES DEUX FILS DE KHODHÂOUEND ZÂDEH KIOUÂM EDDÎN, CELUI-LÀ MÊME QUI ARRIVA EN NOTRE COMPAGNIE CHEZ LE SOUVERAIN DE L'INDE

A l'arrivé de Khodhâouend zâdeh ${ }^{904}$, le sultan lui fit de nombreux cadeaux, le combla de bienfaits et l'honora excessivement. Plus tard, il maria ses deux fils avec deux filles du vizir Khodjah Djihân, qui se trouvait alors absent. Le souverain se rendit dans la maison de son vizir pendant la nuit ; il assista au contrat de mariage en qualité, pour ainsi dire, de substitut du vizir, et resta debout jusqu'à ce que le kâdhi en chef eût fait mention du don nuptial ${ }^{905}$. Les juges, les émirs et les p444 cheïkhs étaient assis. Le sultan prit avec ses mains les étoffes et les bourses d'argent, qu'il plaça devant le kâdhi et devant les deux fils de Khodhâouend zâdeh. En ce moment les émirs se levèrent, ne voulant pas que le monarque mît lui-même ces objets en leur présence ; mais il leur dit de rester assis ; il ordonna à l'un des principaux émirs de le remplacer, et se retira.

\footnotetext{
${ }^{904}$ Pour la famille de ce personnage, voir chap. 4, n. 82.

${ }^{905}$ La présentation de la dot et son acceptation par l'époux tiennent lieu de contrat de mariage. L’épouse se fait représenter dans cette cérémonie ; c’est le rôle joué ici par le souverain.
} 
ANECDOTE SUR L’HUMILITÉ DU SULTAN ET SUR SA JUSTICE

Un des grands parmi les Indiens prétendit que le souverain avait fait mourir son frère sans motif légitime, et le cita devant le juge. Le sultan se rendit à pied, sans armes, au tribunal ; il salua, s'inclina, monta au prétoire, et se tint debout devant le kâdhi. Il avait déjà prévenu celui-ci, bien avant ce temps, qu'il n'eût pas à se lever pour lui, ni à bouger de sa place, lorsqu'il lui arrivait de se rendre au lieu de ses audiences. Le juge décida que le souverain était tenu de satisfaire la partie adverse, pour le sang qu'il avait répandu, et la sentence fut exécutée.

\section{ANECDOTE ANALOGUE À LA PRÉCÉDENTE}

Une fois il arriva qu'un individu de religion musulmane prétendit avoir, sur le sultan, une certaine créance. Ils débattirent cette affaire en présence du juge, qui prononça un arrêt contre le souverain, portant qu'il devait payer la somme d'argent ; et il la paya.

\section{AutRe ANECDOTE DE CE GENRE}

Un enfant du nombre des fils de rois accusa le sultan de l'avoir frappé sans cause, et le cita devant le kâdhi.Celui-ci décida que le souverain était obligé d'indemniser le plaignant au moyen d'une somme d'argent, s'il ${ }_{\mathrm{p} 445}$ voulait bien s'en contenter ; sinon, qu'il pouvait lui infliger la peine du talion. Je vis alors le sultan qui revenait pour son audience ; il manda l'enfant, et lui dit, en lui présentant un bâton : "Par ma tête, il faut que tu me frappes, de même que j'ai fait envers toi. " L'enfant prit le bâton, et donna vingt et un coups, en sorte que je vis son bonnet lui tomber de la tête.

\section{DU ZĖLE DU SULTAN POUR L’ACCOMPLISSEMENT DE LA PRIÈRE}

Le sultan était très sévère pour l'exécution des prières ; il commandait de les célébrer en commun dans les temples, et punissait fortement ceux qui négligeaient de s'y rendre. Il fit mourir en un seul jour, pour cette faute, neuf individus, dont l'un était un chanteur. Il y 
avait des gens exprès, qu'il envoyait dans les marchés, et qui étaient chargés de punir ceux qui s'y trouvaient au moment de la prière. On alla même jusqu'à châtier les satâiriyoûns ${ }^{906}$ lorsqu'ils manquaient la prière. Ce sont ceux qui tiennent les montures des serviteurs à la porte de la salle d'audience. Le souverain ordonna qu'on exigeât du peuple la connaissance des préceptes sur les notions sacrées, sur la prière, ainsi que celle des statuts de l'islamisme. On les interrogeait sur ces points, et ceux qui ne les savaient pas bien étaient punis. Le peuple étudiait ces choses dans la salle d'audience, dans les marchés, et les mettait par écrit.

\section{DE SON ZÈLE POUR L’EXÉCUTION DES ORDONNANCES DE LA LOI}

Le sultan était rigoureux dans l'observation de la justice : parmi ses pratiques à ce sujet, il faut noter ce qui suit. Il chargea son frère Mobârec khân de siéger dans la salle d'audience, en compagnie du kâdhi en chef Camâl eddîn, sous une coupole élevée, garnie de tapis. ${ }^{446}$ Le juge avait une estrade toute recouverte de coussins, comme celle du sultan ; et le frère de celui-ci prenait place à la droite du kâdhi. Quand il arrivait qu'un des grands parmi les émirs avait une dette, et qu'il se refusait à la payer à son créancier, les suppôts du frère du sultan l'amenaient en présence du juge, qui le forçait d'agir avec justice.

\section{DE LA SUPPRESSION DES IMPÔTS ET DES ACTES D’ INJUSTICE ORDONNÉE}

PAR LE SULTAN ; DE LA SÉANCE DU SOUVERAIN POUR FAIRE RENDRE JUSTICE AUX OPPRIMÉS

L'année quarante et un ${ }^{907}$, le sultan ordonna d'abolir les droits pesant sur les marchandises dans tous ses pays ${ }^{908}$ et de se borner à percevoir du peuple la dîme aumônière et la taxe nommée le dixième ${ }^{909}$.

\footnotetext{
${ }^{906}$ Le mot serait dérivé de sitara : tapis de selle.

907741 (1340-1341).

908 L'ensemble de ces taxes ne correspondait pas au droit islamique mais au droit $\mathbf{9 0 9}$ coutumier de chaque pays.

${ }^{909}$ Le zakât et l'euchr prescrits par le droit islamique. Cette réforme qui paraît dater de la même année que la recherche de l'investiture califale vise à se
} 
Tous les lundis et jeudis, il siégeait en personne, pour examiner les actes d'oppression, dans une place située devant la salle d'audience ${ }^{910}$. A cette occasion, il n'était assisté que des personnages suivants : Émir Hâdjib ${ }^{911}$, Khâss Hâdjib ${ }^{912}$, Sayyid alhoddjâb et Cheref alhoddjâb ${ }^{913}$. On n’empêchait aucun individu, ayant une plainte à porter de se présenter devant le monarque. Celui-ci avait désigné quatre des principaux émirs pour s'asseoir à chacune ${ }_{\mathrm{p} 447}$ des quatre portes de la salle d'audience, et prendre les requêtes de la main des plaignants. Le quatrième était le fils de son oncle paternel, le roi Firoûz. Si le personnage assis à la première porte prenait le placet du plaignant, c'était bien ; sinon, il était pris par celui de la deuxième, ou de la troisième, ou de la quatrième porte. Dans le cas où aucun d'eux ne voulait le recevoir, le plaignant se rendait près de Sadr aldjihân, kâdhi des Mamloûcs ${ }^{914}$; si ce dernier ne voulait pas non plus prendre le placet, l'individu qui le portait allait se plaindre au sultan. Quand le souverain s'était bien assuré que le plaignant avait présenté sa requête à l'un desdits personnages, et qu'il n'avait pas consenti à s'en charger, il le réprimandait. Tous les placets qu'on recueillait les autres jours étaient soumis à l'examen du sultan après la dernière prière du soir.

concilier la population exténuée par sept années de famine et de révoltes, mais le mauvais choix des nouveaux fonctionnaires ne fit qu'aggraver les choses.

Il s’agit du tribunal royal chargé de redresser les abus commis par les fonctionnaires civils et militaires appliquant les décisions royales et ne tombant pas par conséquent sous le coup de la loi islamique ni de la juridiction du cadi.

911 Le chef des chambellans qui était Firuz Tughluk.

912 Le chambellan de la maison royale.

913 «La gloire des chambellans » et « la noblesse des chambellans » (voir plus haut, p. 407).

914 Probablement le même personnage que l'informateur historique d'Ibn Battûta (voir p. 366). 
DES VIVRES QUE LE SULTAN FIT DISTRIBUER À L'OCCASION DE LA DISETTE

Lorsque la sécheresse domina dans l'Inde et dans le Sind ${ }^{915}$, et que la pénurie fut telle que la mesure de blé appelée mann ${ }^{916}$ valait six pièces d'or, le souverain ordonna de distribuer à tous les habitants de Dihly la nourriture pour six mois, tirée du magasin de la couronne. On devait donner à chacun, grand ou petit, né libre ou esclave, la quantité d'un rithl et demi ${ }^{917}$ par jour, poids de Barbarie. Les jurisconsultes et les juges se ${ }_{\text {p448 }}$ mirent à enregistrer les populations des différentes rues; ils firent venir ces gens, et l'on donna à chaque personne les provisions de bouche qui devaient servir à sa nourriture pendant six mois.

\section{DES ACTES DE VIOLENCE COMMIS PAR CE SULTAN ET DE SES ACTIONS CRIMINELLES}

Le sultan de l'Inde, malgré ce que nous avons raconté sur son humilité, sa justice, sa bonté pour les pauvres et sa générosité extraordinaire, était très enclin à répandre le sang. Il arrivait rarement qu'à la porte de son palais il n'y eût pas quelqu'un de tué. J'ai vu bien souvent faire mourir des gens à sa porte, et y abandonner leur corps. Un jour, je me rendis à son château, et voilà que mon cheval eut peur ; je regardai devant moi et je vis sur le sol une masse blanchâtre. Je dis : «Qu'est-ce que cela ? » Un de mes compagnons répondit : "C'est le tronc d'un homme dont on a fait trois morceaux! » Ce souverain punissait les petites fautes, comme les grandes ; il n'épargnait ni savant, ni juste, ni noble. Tous les jours on amenait dans la salle d'audience des centaines d'individus enchaînés, les bras attachés au cou, et les pieds garrottés. Les uns étaient tués, les autres torturés, ou bien battus. Son habitude était de faire venir tous les jours dans la salle

${ }^{915}$ La famine dura sept ans à partir de 1336 ; elle correspond donc à la plus grande partie du séjour d'Ibn Battûta en Inde. Elle n’était pas seulement due à des causes naturelles mais aussi à la politique fiscale catastrophique de $\mathrm{Mu}-$ 916 hammad Tughluk.

${ }^{917}$ Le ratl de Dihli valait la moitié d’un mann ; le ratl marocain environ le vingtième du ratl indien. Il s’agit donc ici d'un peu moins de 600 g de blé par jour. 
d'audience, excepté le vendredi, tous ceux qui se trouvaient en prison. Ce dernier jour était pour eux une journée de répit ; ils l'employaient à se nettoyer, et se tenaient tranquilles. Que Dieu nous garde du malheur!

\section{DU MEURTRE COMMIS PAR LE SULTAN SUR SON PROPRE FRÈRE}

Le sultan avait un frère du nom de Maç'oûd khân ${ }^{918}$, dont la mère était fille du sultan 'Alâ eddîn. Ce ${ }_{\mathrm{p} 449}$ Maç'oûd était une des plus belles créatures que j'aie jamais vues dans ce monde. Le monarque le soupçonna de vouloir s'insurger contre lui ; il l'interrogea à ce propos, et Maç'oûd confessa, par crainte des tourments. En effet, toute personne qui nie les accusations de cette sorte, que le sultan formule contre elle, est de nécessité mise à la torture, et la plupart des gens préfèrent mourir que d'être torturés. Le souverain fit trancher la tête de son frère au milieu de la place, et le corps resta trois jours abandonné dans le même endroit, suivant l'usage. La mère de Maç'oûd avait été lapidée deux années auparavant, juste en ce lieu ; car elle avait avoué le crime de débauche ou d'adultère. Celui qui l'a condamnée à être lapidée ç’a été le juge Camâl eddîn.

\section{DE LA MORT QU'IL FIT DONNER À TROIS CENT CINQUANTE INDIVIDUS} DANS UN MÊME MOMENT

Une fois, le sultan avait destiné une portion de l'armée, commandée par le roi Yoûçuf Borghrah ${ }^{919}$, pour aller combattre les infidèles hindous sur des montagnes adjacentes au district de Dihly. Yoûçuf sortit, ainsi que la presque totalité de sa troupe ; mais une partie de ses soldats restèrent en arrière. Il écrivit au souverain, pour l'informer de cet événement, et celui-ci ordonna de parcourir la ville et de saisir tous les individus qu'on rencontrerait, parmi ceux qui étaient restés en arrière. On s'empara de trois cent cinquante de ceux-ci ; le monarque donna ordre de les tuer tous ; et il fut obéi.

918 Aussi bien l'histoire que le personnage sont inconnus par ailleurs.

919 Tué dans la révolte du Gudjarat en 1347. 
DES TOURMENTS QU'IL A FAIT SUBIR AU CHEÏKH CHIHÂB EDDÎN ET DE LA CONDAMNATION À MORT DE CE CHEÏKH

Le cheïkh Chihâb eddîn était fils du cheïkh Aldjâm alkhorâçâny, dont l'aïeul avait donné son nom à la ville ${ }_{\mathrm{p} 450}$ de Djâm, située dans le Khorâçân, comme nous l'avons déjà raconté ${ }^{920}$, Chihâb eddîn était un des principaux cheïkhs, un des plus probes et des plus vertueux; il avait l'habitude de jeûner quatorze jours de suite. Les deux sultans Kothb eddîn et Toghlok le vénéraient, le visitaient et imploraient sa bénédiction. Quand le sultan Mohammed fut investi du pouvoir, il voulut faire remplir au cheïkh quelque charge dans l'État ; mais celuici refusa. C'était l'usage chez ce souverain d'employer les jurisconsultes, les cheïkhs et les hommes pieux ; il se fondait sur ce que les premiers princes musulmans - que Dieu soit satisfait d'eux! - ne donnaient les places qu'aux savants et aux hommes probes. Il s'entretint à ce sujet avec Chihâb eddîn, à l'occasion d'une audience publique ; celui-ci refusa et résista ${ }^{921}$. Le sultan en fut indigné, et il commanda au jurisconsulte vénéré, le cheïkh Dhiyâ eddîn assimnâny d'arracher la barbe de Chihâb eddîn. Dhiyâ eddîn ne le voulut pas, et il dit: "Je ne ferais jamais cela." Alors le souverain donna l'ordre d'arracher à tous les deux les poils de leur barbe ; ce qui eut lieu.

Le sultan relégua Dhiyâ eddîn dans la province de Tiling ; et plus tard il le nomma juge à Ouarangal ${ }^{922}$ où il mourut. Il exila Chihâb eddîn à Daoulet Abâd, et l'y laissa pendant sept années ; puis il le fit revenir, il l'honora et le vénéra. Il le mit à la tête du Dîouân almostakhradj $^{923}$, c'est-à-dire celui des reliquats ou arriérés des agents, qu'on leur extorque par la bastonnade et par les tourments. Le souverain considéra de plus en plus Chihâb eddîn ; il ordonna aux émirs d'aller lui rendre hommage dans sa demeure, et de suivre ses ${ }_{\text {p451 }}$ conseils. Nul n’était au-dessus de lui dans le palais du sultan.

\footnotetext{
920 Voir chap. 4, n. 129.

921 Les rapports de Muhammad Tughluk avec les cheïkhs et mystiques qui avaient acquis un grand pouvoir en Inde étaient le plus souvent difficiles, ce qui amène les historiens contemporains à l'accuser d'irréligiosité.

922 Warangal, la capitale de Telingana (voir chap. 6. n. 59).

${ }^{923}$ Le Bureau du produit de l'extorsion.
} 
Lorsque le souverain se rendit à sa résidence située au bord du Gange, qu'il y bâtit le château appelé Sarg Douâr ${ }^{924}$, la Porte du Ciel, ce qui veut dire « semblable au Paradis ", et qu'il commanda au peuple de construire des demeures fixes en cet endroit, le cheïkh Chihâb eddîn sollicita de lui la permission de continuer à rester dans la capitale. Le sultan lui assigna pour séjour un lieu inculte et abandonné, à six milles de distance de Dihly. Chihâb eddîn y creusa une vaste grotte, dans l'intérieur de laquelle il construisit des cellules, des magasins, un four et un bain ; il fit venir l'eau du fleuve Djoumna ; il cultiva cette terre, et il amassa des sommes considérables au moyen de ses produits ; car, dans ces années-là, on souffrit de la sécheresse. Il demeura en cet endroit deux ans et demi, le temps que dura l'absence du sultan. Les esclaves de Chihâb eddîn labouraient le sol pendant le jour ; ils entraient la nuit dans la caverne, et la fermaient sur eux et sur les troupeaux, par crainte des voleurs hindous, qui habitaient sur une montagne voisine et inaccessible.

Quand le sultan retourna dans la capitale, le cheïkh alla à sa rencontre, et ils se virent à sept milles de Dihly. Le souverain l'honora, l'embrassa dès qu'il l'aperçut, et Chihâb eddîn retourna ensuite à sa grotte. Le monarque l'envoya quérir quelque temps après cela ; mais il refusa de se rendre près de lui. Alors le sultan lui expédia Mokhlis almolc, Annadharbâry ${ }^{925}$ qui était un des principaux rois. Il parla à Chihâb eddîn avec beaucoup de douceur, et lui dit de faire attention à la colère du monarque. Le cheïkh répondit : « Je ne servirai jamais un tyran. » Mokhlis almolc retourna auprès du ${ }_{\mathrm{p} 452}$ sultan et l'informa de ce qui s'était passé ; il reçut l'ordre d'amener le cheïkh, ce qu'il fit. Le sultan parla ainsi à Chihâb eddîn : "C'est toi qui as dit que je suis un tyran ? » Il répondit: «Oui, tu es un tyran; et parmi tes actes de tyrannie sont tels et tels faits. » Il en compta plusieurs au nombre desquels il y avait la dévastation de la ville de Dihly, et l'ordre d'en sortir intimé à tous les habitants.

${ }^{924}$ Pendant la grande famine, le souverain transporta sa cour en 1338 près de Kannaudj, à deux cents miles au sud-est de Dihli, afin de pouvoir se ravitailler 925 par la province fertile d'Oudh.

C'est-à-dire de Nadharbar, l'actuelle Nandurbar au sud du fleuve Tapti, dans le nord-ouest du Maharashtra (voir t. III, p. 181). 
Le sultan tira son sabre, il le passa à Sadr aldjihân, et dit: "Confirme ceci, que je suis un tyran, et coupe mon cou avec ce glaive. " Chihâb eddîn reprit : "Celui qui porterait témoignage sur cela serait sans doute tué ; mais tu as conscience toi-même de tes propres torts. » Le monarque ordonna de livrer le cheïkh au roi Nocbïah, chef des porte-encriers ou secrétaires, qui lui mit quatre liens aux pieds, et lui attacha les mains au cou. Il resta dans cette situation quatorze jours de suite, sans manger ni boire ; tous les jours on le conduisait dans la salle d'audience ; on réunissait les légistes et les cheïkhs, qui lui disaient : " Rétracte ton assertion. » Chihâb eddîn répondait : « Je ne la retirerai pas, et je désire d'être mis dans le chœur des martyrs. » Le quatorzième jour, le sultan lui envoya de la nourriture, au moyen de Mokhlis almolc; mais le cheïkh ne voulut pas manger, et dit : " Mes biens ne sont plus sur cette terre ; retourne près de lui [le sultan] avec tes aliments. " Celui-ci ayant été informé de ces paroles, ordonna immédiatement qu'on fît avaler au cheïkh cinq istârs ${ }^{926}$ de matière fécale, ce qui correspond à deux livres et demie, poids de Barbarie. Les individus chargés de ces sortes de choses, et ce sont des gens choisis parmi les Indiens infidèles, prirent cette ordure, qu'ils firent dissoudre dans l'eau ; il couchèrent le cheïkh sur son dos, lui ouvrirent la bouche avec des tenailles, et lui firent boire ce mélange. Le lendemain, on le conduisit à la maison du kâdhi Sadr aldjihân. On rassembla les jurisconsultes et les cheïkhs, ainsi que les notables

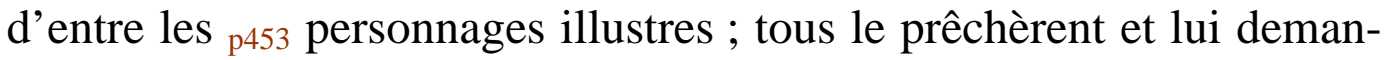
dèrent de revenir sur son propos. Il refusa de se rétracter, et on lui coupa le cou. Que Dieu ait pitié de lui !

DU MEURTRE COMMIS PAR LE SULTAN SUR LE JURISCONSULTE ET PROFESSEUR 'AFÎF EDDÎN ALCÂÇÂNY ${ }^{927}$ ET SUR DEUX AUTRES JURISCONSULTES, CONJOINTEMENT AVEC LUI

Dans les années de la disette, le sultan avait commandé de creuser des puits à l'extérieur de la capitale, et de semer des céréales dans ces

926 C'est le sir indien, qui vaut un peu moins de $400 \mathrm{~g}$.

927 De Kasan, l'actuelle Kasansaj, au nord de Siri Darya dans la république soviétique d'Uzbekistan. 
endroits ${ }^{928}$. Il fournit aux gens les grains, ainsi que tout l'argent nécessaire pour les semailles, et exigea que celles-ci fussent faites au profit des magasins du Trésor public. Le jurisconsulte 'Afîf eddîn, ayant entendu parler de cette chose, dit : « On n’obtiendra pas de cette semence l'effet qu'on désire. » Il fut dénoncé au souverain, qui le fit mettre en prison, et lui dit: "Pourquoi te mêles-tu des affaires de l’État? » Un peu plus tard, il le relâcha, et le légiste se rendit vers sa demeure.

Il rencontra par hasard, chemin faisant, deux jurisconsultes de ses amis, qui lui dirent : "Que Dieu soit loué, à cause de ta délivrance ! » Il répondit : « Louons l'Être suprême qui nous a sauvés des mains des méchants ${ }^{929}$. Ils se séparèrent ; mais ils n'étaient pas encore arrivés à leurs logements que le sultan était déjà instruit de leur discours. D'après son ordre, on les amena tous les trois en sa présence ; alors il dit [à ses suppôts] : "Partez avec celui-ci [en désignant 'Afîf eddîn], et coupez-lui le cou, à la manière des baudriers. » Cela veut dire qu'on tranche la tête avec un bras et une portion de la poitrine. Il ajouta: «Et coupez ${ }_{\text {p454 }}$ le cou aux deux autres. » Ceux-ci dirent au souverain : " Pour 'Afîf eddîn, il mérite d'être châtié à cause de son propos ; mais nous, pour quel crime nous fais-tu mourir ? " Le monarque répondit : " Vous avez entendu son discours et ne l'avez pas désapprouvé ; c'est donc comme si vous aviez été de son avis. » Ils furent tués tous les trois. Que Dieu ait pitié d'eux !

\section{DU MEURTRE COMMIS PAR LE SULTAN SUR DEUX JURISCONSULTES DU SIND QUI ÉTAIENT À SON SERVICE}

Le sultan ordonna à ces deux jurisconsultes du Sind de se rendre dans une certaine province, en compagnie d'un commandant qu'il avait désigné. Il leur dit : « Je mets entre vos mains les affaires de la province et des sujets ; cet émir sera avec vous uniquement pour agir suivant vos ordres. » Ils répondirent : «Il vaut mieux que nous soyons comme deux témoins à son égard, et que nous lui montrions le chemin

\footnotetext{
${ }^{928}$ Les gens étaient trop faibles pour pouvoir creuser et trop affamés pour pouvoir conserver les semences. Alors ils les mangèrent, ce qui entraîna une nouvelle 929 vague de répression.

Coran, XXIII, 28.
} 
de la justice, afin qu'il le suive. » Alors le souverain reprit : "Certes, votre but est de manger, de dissiper mes biens, et d'attribuer cela à ce Turc, qui n’a aucune connaissance. » Les deux légistes répliquèrent : «Que Dieu nous en garde! ô maître du monde; nous ne cherchons pas une telle chose.» Mais le sultan répéta: "Vous n’avez pas d'autre pensée. » Puis il dit à ses gens : « Emmenez-les chez le cheïkh Zâdeh annohâouendy. " Celui-ci est chargé d'administrer les châtiments.

Quand ils furent en sa présence, il leur dit : « Le sultan veut vous faire mourir ; or avouez ce dont il vous accuse, et ne vous faites pas torturer. » Ils répondirent : " Pour Dieu, nous n’avons jamais cherché que ce que nous avons exprimé. " Zâdeh reprit, en s'adressant à ses sbires ${ }^{930}$ : « Faites-leur goûter quelque chose. » Il voulait dire : « en fait de tourments ». En conséquence, on ${ }_{\mathrm{p} 455}$ les coucha sur leur dos, on plaça sur leur poitrine une plaque de fer rougie au feu, qu'on retira quelques instants après, et qui mit à nu ou détruisit leurs chairs. Alors on prit de l'urine et des cendres qu'on appliqua sur les plaies; et à ce moment les deux victimes confessèrent que leur but était celui qu'avait indiqué le sultan; qu'ils étaient deux criminels méritant la mort ; qu'ils n’avaient aucun droit à la vie, ni aucune réclamation à élever pour leur sang, dans ce monde pas plus que dans l'autre. Ils écrivirent cela de leur propre main, et reconnurent leur écrit devant le kâdhi. Celui-ci légalisa le procès-verbal, portant que leur confession avait eu lieu sans répugnance et sans coaction. S'ils avaient dit: " Nous avons été contraints ", ils auraient été infailliblement tourmentés de plus belle. Ils pensèrent donc qu'avoir le cou coupé sans délai valait mieux pour eux que mourir par une torture douloureuse ils furent tués. Que Dieu ait pitié d'eux !

\section{DU MEURTRE COMMIS PAR SON ORDRE SUR LE CHEÏKH HOÛD}

Le cheïkh Zâdeh, appelé Hoûd, était petit-fils du cheïkh pieux et saint Rocn eddîn, fils de Béhâ eddîn, fils d'Aboû Zacariyyâ almoltâny ${ }^{931}$, Son aïeul, le cheïkh Rocn eddîn, était vénéré du sultan ; et il en

930 En arabe zabaniya, les démons chargés d’infliger les châtiments en enfer.

931 Voir chap. 5, n. 12. 
était ainsi du frère de Rocn eddîn, nommé 'Imâd eddîn, qui ressemblait beaucoup au sultan, et qui fut tué le jour de la bataille contre Cachloû khân, comme nous le dirons plus bas. Lorsque 'Imâd eddîn fut mort, le souverain donna à son frère Rocn eddîn cent villages, pour qu'il tirât sa subsistance, et qu'il nourrît les passants dans son ermitage. A sa mort, le cheïkh Rocn eddîn nomma son successeur dans l'ermitage son petit-fils, le cheïkh Hoûd ; mais son neveu, le fils du frère de Rocn eddîn, s'y opposa, en disant qu'il avait plus de droits que l'autre à l'héritage de son oncle. Il se rendit avec Hoûd ${ }_{\mathrm{p} 456}$ chez le sultan, qui était à Daoulet Abâd; et entre cette ville et Moltân, il y a quatre-vingts jours de marche. Le souverain accorda à Hoûd la place de cheïkh, ou supérieur de l'ermitage, selon le testament de Rocn eddîn : Hoûd était alors d'un âge mûr, tandis que le neveu de Rocn eddîn était un jeune homme. Le sultan honora beaucoup le cheïkh Hoûd ; il ordonna de le recevoir comme un hôte, dans toutes les stations où il descendrait; il prescrivit aux habitants de sortir à sa rencontre dans toutes les villes par où il passerait, dans son voyage jusqu'à Moltân, et de lui préparer un festin.

Quand l'ordre parvint à la capitale, les jurisconsultes, les juges, les docteurs et les notables sortirent à la rencontre de Hoûd. J'étais du nombre ; nous le vîmes, assis dans un palanquin porté par des hommes, tandis que ses chevaux étaient conduits à la main. Nous le saluâmes ; mais, pour ma part, je désapprouvai son action de rester dans le palanquin, et dis : " Il aurait dû monter à cheval, et marcher parallèlement aux juges et aux docteurs, qui sont sortis pour le recevoir. » Ayant appris mon discours, Hoûd monta à cheval, et il s'excusa en alléguant qu'il ne l'avait point fait d'abord à cause d'une incommodité dont il souffrait. Il fit son entrée à Dihly, et on lui offrit un festin, pour lequel on dépensa des sommes considérables du trésor du sultan. Les kâdhis, les cheïkhs, les légistes et les personnages illustres s'y trouvaient ; on étendit les nappes, et l'on apporta les mets du banquet, suivant l'usage ${ }^{932}$. On distribua des sommes d'argent à tous les individus présents, en proportion du rang de chacun : le grand juge eut cinq cents dînârs, et moi j'en touchai deux cent cinquante. Telle est l'habitude, chez les Indiens, lors des festins impériaux. 
Le cheïkh Hoûd partit pour son pays, en compagnie du cheïkh Noûr eddîn acchîrâzy, que le sultan envoyait avec lui, pour le faire asseoir sur le tapis à prière de son ${ }_{\text {p457 }}$ aïeul dans la zâouïah ${ }^{933}$ et pour lui offrir un banquet en ce lieu aux frais du monarque. Il se fixa dans cet ermitage et y passa plusieurs années. Puis il arriva qu'Imâd almolc ${ }^{934}$, commandant du Sind, écrivit au sultan que le cheïkh Hoûd, ainsi que sa parenté, s'occupait à amasser des richesses, pour les dépenser ensuite dans les plaisirs de ce monde, et qu'ils ne donnaient à manger à personne dans l'ermitage. Le souverain ordonna d'exiger d'eux la restitution de ces biens. En conséquence, 'Imâd almolc en emprisonna quelques-uns, en fit frapper d'autres; il leur extorquait chaque jour vingt mille pièces d'or, et cela durant quelque temps ; il finit par prendre tout ce qu'ils possédaient. On leur trouva beaucoup d'argent et de choses précieuses ; on cite, entre autres, une paire de sandales incrustées de perles et de rubis, qui furent vendues pour sept mille pièces d'or. On dit qu'elles appartenaient à la fille du cheïkh Hoûd ; d'autres prétendent qu'elles étaient à une de ses concubines.

Lorsque le cheïkh fut fatigué de toutes ces vexations, il s'enfuit, et désira de se rendre dans le pays des Turcs ; mais il fut pris. 'Imâd almolc en informa le sultan, qui prescrivit de le lui envoyer, de même que celui qui l'avait arrêté, tous les deux comme des prisonniers. Quand ils furent arrivés près du souverain, il mit en liberté l'individu qui avait saisi le cheïkh Hoûd, et dit à celui-ci : «Où voulais-tu fuir ? » Le cheïkh s'excusa comme il put ; mais le sultan lui répondit : « Tu voulais aller chez les Turcs; tu voulais leur dire que tu es le fils du cheïkh Béhâ êddîn Zacariyyâ ; que le sultan de l'Inde t’a fait telle et telle chose ; et tu pensais venir ensuite me combattre en compagnie de ces Turcs. » Il ajouta en s'adressant à ses gardes : « Coupez-lui le cou. » Il fut tué. Que Dieu ait pitié de lui ! p458

933 C'est-à-dire prendre sa succession.

${ }^{934}$ Voir ci-dessus n. 39. 
DE L'EMPRISONNEMENT DU CHEÏKH FILS DE TÂDJ AL'ÂRIFÎN, ET DE LA CONDAMNATION À MORT DES FILS DE CE CHEÏKH, LE TOUT PAR L'ORDRE DU SULTAN

Le pieux cheïkh Chams eddîn, fils de Tâdj al'ârifîn, habitait la ville de Cowil ${ }^{935}$, s'occupant tout à fait d'actes de dévotion; et c'était un homme de grand mérite. Une fois le sultan entra dans cette cité, et l'envoya quérir ; mais il ne se rendit pas chez le souverain. Celui-ci se dirigea lui-même vers sa demeure ; puis, quand il en approcha, il rebroussa chemin, et ne vit pas le cheïkh.

Plus tard, il arriva qu'un émir se révolta contre le sultan dans une province, et que les peuples lui prêtèrent serment. On rapporta au souverain que, dans une réunion chez le cheïkh Chams eddîn, on avait parlé de cet émir, que le cheïkh avait fait son éloge, et dit qu'il méritait de régner. Le sultan envoya près du cheïkh un commandant, qui lui mit des liens aux pieds, et agit ainsi avec ses fils, avec le juge de Cowil et son inspecteur des marchés; car on avait su que ces deux derniers personnages se trouvaient présents dans l'assemblée où il avait été question de l'émir insurgé, et où son éloge avait été fait par le cheïkh Chams eddîn. Le souverain les fit mettre tous en prison, après avoir toutefois privé de la vue le juge et l'inspecteur des marchés. Quant au cheïkh, il mourut dans la prison ; le juge et l'inspecteur en sortaient tous les jours, accompagnés par un geôlier ; ils demandaient l'aumône aux passants, et étaient reconduits dans leur cachot.

Le sultan avait été averti que les fils du cheïkh avaient eu des rapports avec les Indiens infidèles, ainsi qu'avec les rebelles hindous, et avaient contracté amitié avec eux. A la mort de leur père, il les fit sortir de prison et leur dit: "Vous n'agirez plus comme vous l'avez fait. » Ils répondirent : « Et qu'avons-nous fait ? » Le sultan se mit en colère et ordonna de les tuer ; ce qui eut lieu. p459

Il fit venir après cela le juge susmentionné, et lui dit :« Fais-moi connaître ceux qui [dans Cowil] pensent comme les individus qui viennent d'être exécutés et agissent comme ils l'ont fait. " Le kâdhi dicta les noms d'un grand nombre de personnes, parmi les grands du pays. Lorsque le monarque vit cela, il dit: «Cet hommes désire la 
destruction de la ville. »Et, s'adressant à ses satellites, il ajouta «Coupez-lui le cou. » Ils le lui coupèrent. Que Dieu ait pitié de lui !

DE LA CONDAMNATION À MORT DU CHEÏKH ALHAÏDARY PAR LE SULTAN

Le cheïkh 'Aly alhaïdary habitait la ville de Cambaie, sur le littoral de l'Inde ; c'était un homme d'un grand mérite, d'une réputation immense, et il était célèbre dans les pays, même les plus éloignés. Les négociants qui voyageaient sur mer lui vouaient de nombreuses offrandes, et à leur arrivée ils s'empressaient d'aller saluer ce cheïkh, qui savait découvrir leur secrets, et leur disait la bonne aventure. Il arrivait souvent que l'un d'eux lui avait promis une offrande, et que depuis il avait regretté son vœu. Quand il se présentait devant le cheïkh pour le saluer, celui-ci lui rappelait sa promesse, et lui ordonnait d'y satisfaire. Pareille chose s'est passée un grand nombre de fois, et le cheïkh 'Aly est renommé sous ce rapport.

Lorsque le kâdhi Djélâl eddîn alafghâny et sa peuplade s'insurgèrent dans ces contrées ${ }^{936}$, on avertit le sultan que le cheïkh Alhaïdary avait prié pour le juge susnommé ; qu’il lui avait donné sa propre calotte, et on assurait même qu'il lui avait prêté serment. Le souverain ayant marché en personne contre les rebelles, Djélâl eddîn s'enfuit. Alors le sultan partit, et laissa en sa place, à Cambaie, Chéref almolc, émir bakht ${ }^{937}$, qui ${ }_{\mathrm{p} 460}$ est un de ceux qui arrivèrent avec nous chez le monarque de l'Inde. Il lui commanda d'ouvrir une enquête sur les gens qui s'étaient révoltés, et lui adjoignit des jurisconsultes pour l'aider dans les jugements à intervenir.

Émir bakht se fit amener le cheïkh 'Aly alhaïdary ; il fut établi que ce dernier avait fait cadeau de sa calotte au juge rebelle, et qu'il avait fait des vœux pour lui. En conséquence, il fut condamné à mourir ; mais, quand le bourreau voulut le frapper, il n’y réussit pas. Le peuple fut fort émerveillé de ce fait, et il pensa qu'on pardonnerait au condamné, à cause de cela ; mais l'émir ordonna à un autre bourreau de lui couper le cou, ce qui fut fait. Que Dieu ait pitié de ce cheïkh !

${ }_{936}$ Voir t. III, p. 97 et suiv.
${ }^{937}$ Voir t. III, p. 101. 
DU MEURTRE ORDONNÉ PAR LE SULTAN À L'ÉGARD

DE THOÛGHÂN ET DE SON FRÈRE

Thoûghân alferghâny et son frère étaient deux grands de la ville de Ferghânah ${ }^{938}$ qui étaient venus trouver le sultan de l'Inde. Il les accueillit fort bien, il leur fit de riches présents, et ils restèrent près de lui assez longtemps. Plus tard, ils désirèrent retourner dans leur pays, et voulurent prendre la fuite. Un de leurs compagnons les dénonça au souverain, qui ordonna de les fendre en deux par le milieu du corps ; ce qui fut exécuté. On donna à leur dénonciateur tout ce qu'ils possédaient ; car tel est l'usage dans ces pays de l'Inde. Quand un individu en accuse un autre, que sa déclaration est trouvée fondée et qu'on tue l'accusé, les biens de celui-ci sont livrés au délateur. p461

\section{DE LA CONDAMNATION À MORT PRONONCÉE PAR LE SULTAN} CONTRE LE FILS DU ROI DES MARCHANDS

Le fils du roi ou prévôt des marchands était un tout petit jeune homme, sans barbe. Lorsque arrivèrent l'hostilité de 'Aïn almolc, la révolte et sa guerre contre le souverain, comme nous le raconterons, le rebelle s'empara de ce fils du roi des marchands, qui se trouva ainsi par force au milieu de ses fauteurs. 'Aïn almolc ayant été mis en fuite, et puis saisi, de même que ses compagnons, on trouva parmi ceux-ci le fils du roi des marchands et son beau-frère ou allié, le fils de Kothb almolc ${ }^{939}$. Le sultan ordonna de les attacher tous les deux par leurs mains à une poutre, et les fils des rois leur lancèrent des flèches, jusqu'à ce qu'ils fussent morts.

Alors le chambellan Khodjah Émir 'Aly attibrîzy dit au grand juge Camâl eddîn : " Ce jeune homme ne méritait pas la mort. » Le sultan sut cela, et lui fit cette observation : "Pourquoi n'as-tu pas dit cette chose avant sa mort ? » Puis il le condamna à recevoir environ deux

\footnotetext{
938 Le nom de Ferghana correspondait â l'époque à une région située au sud de la haute vallée de Siri Darya, dans l'actuel Uzbekistan soviétique. Sa capitale 939 était Andigan, l’actuelle Andizan.

Voir ci-dessus n. 34.
} 
cents coups de fouet, il le fit mettre en prison, et donna tout ce qu'il possédait au chef des bourreaux. Le lendemain, je vis celui-ci, qui avait revêtu les habits d'Émir 'Aly, s'était coiffé de son bonnet, et était monté sur son cheval, de sorte que je le pris pour Émir 'Aly en personne. Ce dernier resta plusieurs mois dans le cachot ; il fut ensuite relâché, et le sultan lui rendit la place qu'il occupait avant sa disgrâce. Il se fâcha contre lui une seconde fois, et le relégua dans le Khorâçân. Émir 'Aly se fixa à Hérat, et écrivit au sultan, pour implorer ses faveurs. Le souverain lui répondit au dos de sa lettre, en termes [persans] : Eguer bâz âmédi bâz(âi) ; ce qui veut dire : "Si tu t'es repenti, reviens. » Il retourna en effet chez le souverain de l'Inde. p462

\section{DES COUPS QU'IL FIT DONNER AU PRÉDICATEUR EN CHEF JUSQU’À CE QU'IL EN MOURÛT}

Le sultan avait chargé le grand prédicateur de Dihly de surveiller pendant le voyage le trésor des pierres précieuses. Or il arriva que des voleurs hindous se jetèrent une nuit sur ce trésor et en emportèrent une partie. Pour cette cause, le souverain ordonna de frapper le prédicateur, de telle sorte qu'il en mourut. Que Dieu ait pitié de lui !

DE LA DESTRUCTION DE LA VILLE DE DIHLY ; DE L'EXIL DE SES HABITANTS ; DE LA MORT DONNÉE À UN AVEUGLE ET À UN INDIVIDU PERCLUS

Un des plus graves reproches qu'on fait à ce sultan, c'est d'avoir forcé tous les habitants de Dihly à quitter leurs demeures ${ }^{940}$. Le motif en fut que ceux-ci écrivaient des billets contenant des injures et des invectives contre le souverain ; ils les cachetaient, et traçaient sur ces billets les mots suivants : " Par la tête du maître du monde [le sultan],

940 La tentative de déplacement de la capitale de Dihli à Dawlatabad fut opérée en deux temps ; une première fois en 1327, après la révolte de Gushtasb (voir t. III. p. 70), quand Muhammad Tughluk, préférant une capitale ayant une position plus centrale, ordonna à la cour, aux hauts fonctionnaires et aux gouverneurs provinciaux de s'y transférer ou d'y installer leurs familles une seconde en 1330, quand le gouverneur, excédé par les plaintes de la population de Dihli, ordonna un exode massif. 
personne, excepté lui, ne doit lire cet écrit. » Ils jetaient ces papiers nuitamment dans la salle d'audience, et lorsque le monarque en brisait le cachet il y trouvait des injures et des invectives à son adresse. Il se décida à ruiner Dihly ; il acheta des habitants toutes leurs maisons et leurs auberges, il leur en paya le prix, et leur ordonna de se rendre à Daoulet Abâd. Ceux-ci ne voulurent d'abord pas obéir ; mais le crieur ou héraut ${ }_{\mathrm{p} 463}$ du monarque proclama qu'après trois jours nul n'eût à se trouver dans l'intérieur de Dihly.

La plupart des habitants partirent, et quelques-uns se cachèrent dans les maisons ; le souverain ordonna de rechercher minutieusement ceux qui étaient restés. Ses esclaves trouvèrent dans les rues de la ville deux hommes, dont l'un était paralytique et l'autre aveugle. Ils les amenèrent devant le souverain, qui fit lancer le perclus au moyen d'une baliste, et commanda que l'on traînât l'aveugle depuis Dihly jusqu'à Daoulet Abâd, c'est-à-dire l'espace de quarante jours de marche. Ce malheureux tomba en morceaux durant le voyage, et il ne parvint de lui à Daoulet Abâd qu'une seule jambe. Tous les habitants de Dihly sortirent, ils abandonnèrent leurs bagages, leurs marchandises, et la ville resta tout à fait déserte ${ }^{941}$.

Une personne qui m'inspire de la confiance m'a assuré que le sultan monta un soir sur la terrasse de son château, qu'il promena son regard sur la ville de Dihly, où il n'y avait ni feu, ni fumée, ni flambeau, et qu'il dit : " Maintenant, mon cœur est satisfait et mon esprit est tranquille. » Plus tard, il écrivit aux habitants de différentes pro-

« Sans aucune concertation et sans examiner attentivement les avantages et les inconvénients, il amena la ruine sur Dihli. [...] Tout a été détruit. La ruine fut si complète que même un chien ou un chat ne resta pas parmi les bâtiments de la cité, dans ses palais et ses faubourgs. Les habitants ont été forcés d'émigrer avec leur famille et leur entourage, femmes et enfants, domestiques et servantes. Le peuple, qui était né et avait vécu pendant des années et des générations dans le pays, eut le cour brisé. Plusieurs périrent en route des suites de ce long voyage et ceux qui arrivèrent à Deogir (Dawlatabad) ne purent endurer les malheurs de l'exil. Abattus, ils languirent à en mourir. Tout autour de Deogir, dans son pays infidèle se levèrent des cimetières musulmans. Le souverain était prodigue en faveurs et libéralités pour les migrants aussi bien pendant leur voyage qu’à leur arrivée ; mais ils étaient faibles et n’ont pu résister à l'exil et aux souffrances. Ils reposèrent leurs têtes dans cette terre païenne, et de la grande multitude des migrants très peu survécurent pour retourner à leurs maisons. Ainsi cette ville, enviée de toutes les villes du monde habité, fut réduite en ruine » (BARANI, Tarikh-i Firuz Shakhi). 
vinces de se rendre à Dihly pour la repeupler. p464 Ils ruinèrent leurs pays, mais ne peuplèrent point Dihly, tant cette ville est vaste, immense ; elle est, en effet, une des plus grandes cités de l'univers. A notre entrée dans cette capitale, nous la trouvâmes dans l'état auquel on vient de faire allusion ; elle était vide, abandonnée et sa population très clairsemée. 


\section{Bibliographie}

Retour à la Table des Matières

Sur l'ensemble de ce volume ont été utilisés :

Les volumes II et III de l'édition d'Ibn Battûta par H. A. R. Gibb parus dans la collection de la Hakluyt Society en 1962 et 1971 ;

Le long article d'Ivan HRBECK, "The Chronology of Ibn Battuta Travels », in Archiv Orientalni, $n^{\circ}$ 30, 1962 ;

Ainsi que l'Encyclopédie de l'Islam.

\section{L’océan indien et le golfe Persique}

Yémen

AL-KHAzRADJI : History of the Resuliyy Dynasty of Yemen, tr. anglaise Leyden et Londres, 1906-1908, 3 vol.

PIRES Tomé : The Suma Oriental, London Hakluyt Society, 1944, 2 vol.

Afrique de l'Est

The Cambridge History of Africa, t. III, 1050-1600, Cambridge, 1977.

Guillain M., Documents sur l'Afrique orientale, Paris, 1856, 3 vol.

DeviC L. M., Le Pays des Zendjs, Paris, 1883.

Mogadiscio

CERULli E., Somalia, t. I, Roma, 1957.

Kilwa

Strong, « The History of Kilwa », in Journal of the Royal Asiatic Society, 1895.

Zhafar et l'Arabie du Sud

Guest R., « Zufar in the Middle Ages », in Islamic Culture, n 9, 1935.

BENT Th., Southern Arabia, London, 1900. 


\section{Oman}

Ross E. C., "Annals of Oman », in Journal of the Asiatic Society of Bengal, 1874, vol. I.

VECCIA VAGLIERI L., « L’imamato Ibadita dell’Oman », in Istituto Universitario Orientale di Napoli. Annali, Nuova Serie, vol. III.

Golfe Persique

Wilson A. T., The Persian Gulf, Oxford, 1928.

Aubin J., "Les Princes d'Ormuz du XIII ${ }^{\mathrm{e}}$ au XV $\mathrm{XV}^{\mathrm{e}}$ siècle ", in Journal asiatique, Paris, 1953.

\section{L’Asie Mineure}

LEMERLE P., L'Emirat d'Aydin, Paris, 1957.

WITTEK P., Das Fürstentum Mentesche, Istanbul, 1934.

HEYD W., Histoire du commerce du Levant au Moyen Age, 2 vol.

\section{Russie méridionale}

BRATIANU G., Recherches sur le commerce génois dans la mer Noire au XIII siècle, Paris, 1929.

SPUlER B., Die Goldene Horde, Leipzig, 1943.

Grekov B., YAKOUBOvsKy A., La Horde d'Or et la Russie, Paris, 1961.

JANICSEK S., « Ibn Battuta's Journey to Bulghar : is it a fabrication ? », in Journal of the Royal Asiatic Society.

RUBRUCK Guillaume DE, The Journey of William of Rubruck to the Eastern Parts of the World, London, 1900.

\section{Constantinople}

IzZEDDIN M., "Ibn Battouta et la topographie byzantine », in Actes $d u V I^{e}$ Congrès international des Études byzantines, Paris, 1951, t. II.

\section{Asie centrale}

Le StRAnge G., Lands of the Eastern Caliphate, Cambridge, 1905. BARTHOLD W. W., Histoire des Turcs d'Asie centrale, Paris, 1945. The Cambridge History of Iran, vol. V, 1968. 
ELLIOT H. The History of India as told by its own historians, vol. III, London, 1871.

The Cambridge History of India, vol. III, Turks and Afghans, 1928.

The History and Culture of the Indian People, vol. V, The Struggle for the Empire, vol. VI, The Dihli Sultanate, Bombay, 1960.

PRASAD Ishwari, L'Inde du VII ${ }^{e}$ au XVI ${ }^{e}$ siècle, Paris, 1930.

HusaIN Mahdi, The Rise and Fall of Muhammad bin Tughluq, London, 1938.

Retour à la Table des Matières 